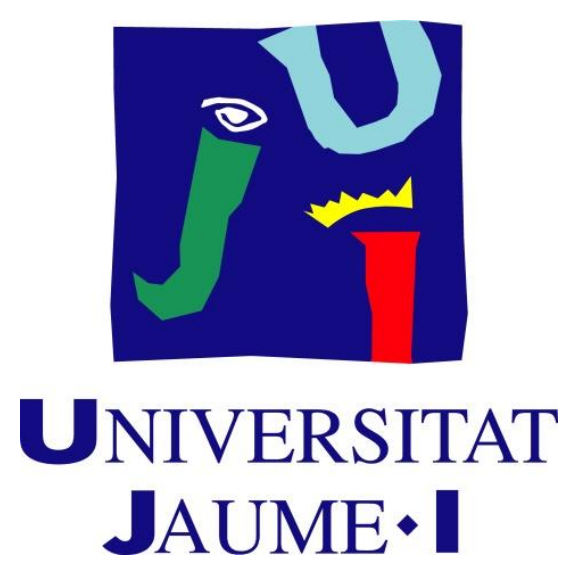

\title{
NECESIDADES FORMATIVAS DE LAS ENFERMERAS DE CUIDADOS INTENSIVOS EN ESPAÑA
}

\section{TESIS DOCTORAL}

Programa de Doctorado en Ciencias de la Enfermería

\author{
Autor: \\ D. Yeray Gabriel Santana Padilla \\ Directores de tesis: \\ Dra. Mạ Desamparados Bernat Adell \\ Dr. Luciano Santana Cabrera
}



Programa de Doctorado en Ciencias de la Enfermería

Escuela de Doctorado de la Universitat Jaume I
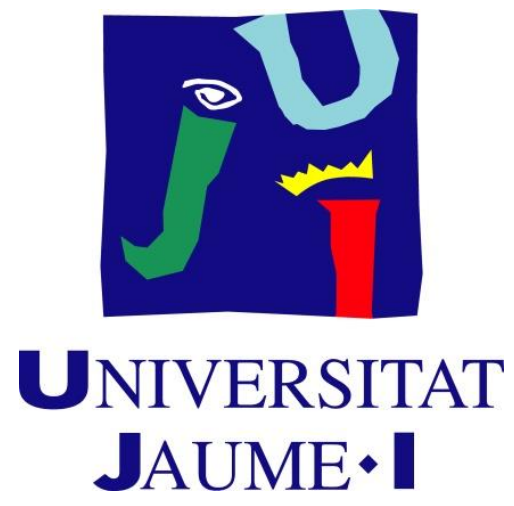

\title{
NECESIDADES FORMATIVAS DE LAS ENFERMERAS DE CUIDADOS INTENSIVOS EN ESPAÑA
}

\author{
Memoria Presentada por \\ D. Yeray Gabriel Santana Padilla \\ para optar al grado de doctor \\ por la Universitat Jaume I
}

Doctorando

D. Yeray Gabriel Santana Padilla

Yeray

Gabriel

Santana

Padilla
Directora

Dra. Ma Desamparados

Bernat Adell

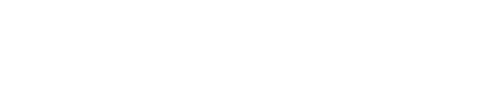

Director

Dr. Luciano

Santana Cabrera

\begin{tabular}{l|l} 
SANTANA & $\begin{array}{l}\text { Firmado digitalmente } \\
\text { por SANTANA CABRERA }\end{array}$ \\
CABRERA JOSE & JOSE LUCIANO - \\
LUCIANO - & $52841889 X$ \\
$52841889 X$ & Fecha: 2021.04 .13 \\
& $15: 01: 39+010^{\prime} 0^{\prime}$
\end{tabular}

Castellón de la Plana, Febrero de 2021 


Tesis Registrada con el ISBN: 978-84-09-26173-4

Yeray Gabriel Santana Padilla, Autor (c)

María Desamparados Bernat Adell, Directora de Tesis (C)

Luciano Santana Cabrera, Director de Tesis $\bigodot$

Universitat Jaume I 


\section{Agradecimientos}

La vida es un constante aprendizaje, y aunque puedas tener una idea de todo lo que se consigue a través del estudio, a fecha de hoy puedo considerar este trabajo como el mayor evento de aciertos y errores a los que me he enfrentado a lo largo de mi vida. $Y$ es por ello que debo agradecer, a todas aquellas personas que me han permitido llegar hasta aquí, con sus distintos tipos de enseñanzas:

Agradecer a mis padres, que me han enseñado que el esfuerzo, la constancia y perseverancia son las herramientas para conseguir todos los objetivos de la vida; y es que ser "coronel" no se regala.

Agradecer a Tamara y Paula, que me hayan dejado robar e invertir parte del tiempo en familia para ser dedicado a esta tesis; sin su colaboración, ánimo y ayuda nunca hubiera sido posible terminar este proceso. El confinamiento de marzo de 2020 y el cese de la actividad escolar provoco que esta tesis tenga una autora accidental en las horas de estudio matutino, que con 9 años miraba con especial interés esos números y letras que su padre escribía en el ordenador.

Agradecer a todos los profesores desde el colegio hasta la universidad, que hayan despertado en mí la avidez de conocimientos. Mención especial merecen los doctores María Desamparados Bernat Adell y Luciano Santana Cabrera por su incondicional apoyo, ayuda y estimulo durante estos años; además de haberme hecho participe de todos los conocimientos que atesoran para poder finalizar este proyecto, por lo cual les estoy eternamente agradecido.

Agradecer a todos mis compañeros sanitarios que han bregado turno a turno durante más de 20 años de experiencia profesional y que me han enseñado la importancia del trabajo en equipo y del esfuerzo constante. A la Unidad de Cuidados Intensivos del Hospital Universitario Insular de Gran Canaria, donde residen los principales elementos motivadores que me animaron a iniciar el camino del postgrado. A mis compañeros de $\mathrm{UCl}$, que me ayudaron en el inicio de esta tesis: ¡Gracias!.

Agradecer a los colaboradores de los centros que difundieron altruistamente, mi cuestionario a lo largo y ancho de todo el país. También agradecer a todos los centros hospitalarios involucrados en este estudio; a los gerentes, las direcciones de enfermería, las unidades de docencia e investigación y los comités de ética e investigación tanto su evaluación, sus propuestas de mejora del estudio como su autorización para poder reclutar profesionales. Y sin lugar a dudas, a aquellas enfermeras que dedicaron unos minutos a cumplimentar los datos expresados en este trabajo.

Sin lugar a dudas, no puedo sino también agradecer desde ya a los investigadores que en un futuro, espero que no muy lejano, sigan construyendo un conocimiento científico en el ámbito de los cuidados críticos.

Las Palmas de Gran Canaria, a 12 de noviembre de 2020. 



\section{Abreviaturas}

AACN: American Association of Critical-Care Nurses.

ACCCN: Australian College of Critical Care Nurses.

AFC: Análisis Factorial Confirmatorio.

AFE: Análisis Factorial Exploratorio.

CCAA: Comunidades Autónomas (España).

CC3N: Critical Care National Network-Nurse Leads Forum.

CFI: Índice de Ajuste Comparativo

CIE: Consejo Internacional de Enfermeras.

COVID-19: Coronavirus Disease 2019. Enfermedad por Coronavirus de 2019.

D.T: Desviación típica.

EA: Eventos Adversos.

ECTS: European Credit Transfer System.

EEES: Espacio Europeo de Enseñanza Superior.

EEUU: Estados Unidos de Norteamérica.

EfCCNa: European federation of Critical Care Nurse association.

EIR: Enfermero Interno Residente.

E/P: Enfermera/Paciente.

IQR: Rango Intercuartílico.

IRAS: Infecciones Relacionadas con la Asistencia Sanitaria.

ISBAR: Identification, Situation, Background, Assesment and Recomendation. Identificación, Situación, Antecedentes, Evaluación y Recomendaciones.

ISOBAR: Identification, Situation, Observation, Background, Assesment and Read-Back. Identificación, Situación, Antecedentes, Evaluación y Confirmar la eficacia de la transferencia.

KMO: Indice Kaiser-Meyer-Olkin

LTSV: Limitación Terapéutica del Soporte Vital.

NAS: Nursing Activities Scores.

NEMS: Nine Equivalents of nursing Manpower use Score.

OMS: Organización Mundial de la Salud.

Prueba S: Prueba Samples (Test Jonckheere-Terpstra)

RD: Real Decreto.

RMSEA: Root Mean Square Error of Aproximation. Raíz cuadrada media del error de aproximación. 
SARS-Cov-2: Severe Acute Respiratory Syndrome Coronavirus 2. Coronavirus 2 del Síndrome Respiratorio Agudo Grave.

SBAR: Situation, Background, Assesment, Recomendation. Situación, Antecedentes, Evaluación y Recomendaciones.

SEEIUC: Sociedad Española de Enfermería Intensiva y Unidades Coronarias.

SEMICYUC: Sociedad Española de Medicina Intensiva, Crítica y Unidades Coronarias.

SNS: Sistema Nacional de Salud.

SYREC: Seguridad y Riesgo en el Enfermo Crítico. Incidentes y eventos adversos en Medicina Intensiva.

TDEC: Terapias de Depuración Extrarenal Continuas.

Test J-T: Test Jonckheere-Terpstra.

TISS-76: Therapeutic Intervention Scoring System.

TLI: Índice de Tucker-Lewis.

UCI: Unidad de Cuidados Intensivos.

ULS: Mínimos Cuadrados no ponderados. 


\section{RESUMEN}

Introducción: Las enfermeras de las Unidades de Cuidados Intensivos (UCI) desarrollan los cuidados ante una población muy vulnerable como es el paciente crítico. Para llevar a cabo estos cuidados especiales, está más que reconocida en la literatura científica, la necesidad de poseer unos conocimientos, destrezas y habilidades específicas previas. Actualmente en nuestro país, no han sido desarrolladas mediante programas formativos específicos las competencias para garantizar un cuidado seguro y de calidad en el ámbito del paciente crítico.

Objetivos: Validar un cuestionario que permita identificar las necesidades formativas y competencias que desempeñan, en la actualidad, las enfermeras de $\mathrm{UCl}$.

Material y método: Estudio de metodología mixta y secuencial, a través de la creación de un cuestionario, partiendo de una entrevista semiestructurada (fase 1) sobre las experiencias y vivencias de las enfermeras de $\mathrm{UCl}$, con abordaje fenomenológico de las necesidades formativas que detectan en el día a día ( $n=15)$. En la fase 2, creación de un cuestionario, a través de técnica Delphi modificada, con las enfermeras de la fase 1 , de una UCl polivalente. Fase 3, estudio descriptivo y multicéntrico en enfermeras de $85 \mathrm{UCl}$. Tras aplicar los criterios de inclusión se contó con una muestra para el análisis de $n=583$. La fase 3 se completó con un análisis psicométrico del cuestionario mediante el paquete estadísticos SPSS v.20 para los análisis uni- bi- y multivariante, el análisis factorial exploratorio (AFE) se realizó con el programa Factor Analysis 10.9 .02 y el análisis factorial confirmatorio (AFC) mediante el programa IBM AMOS v.24.

Resultados: Las enfermeras entrevistadas reconocen que, para desempeñar su labor profesional en UCl, requieren de una formación específica más allá de la aportada por el grado. Su formación se ha basado en el autoaprendizaje y la consulta entre compañeros. A través de sus respuestas se creó, tras 3 rondas de consulta, un cuestionario de 66 ítems ( $\alpha$ Cronbach=0,908). A nivel nacional, encontramos diferencias estadísticas en la valoración de los ítems en función de la experiencia, laboral total y en $\mathrm{UCl}$, y de la formación académica; a pesar de que, casi todos resultaron con más del $70 \%$ de la puntuación. En el AFE, se identificaron 13 dimensiones, se hallaron diferencias significativas $(p \leq 0,005)$ a la hora de evaluar estas dimensiones, siendo las poblaciones jóvenes las más proclives a valorar más los aspectos técnicos, mientras las enfermeras con mayor experiencia dieron mayor importancia a la continuidad de cuidados, la comunicación y la seguridad clínica. El AFC valoró la relación entre 10 de los factores.

Conclusión: Las enfermeras de UCI reconocen la necesidad de una formación específica, aunque se han detectado diferencias en la valoración según las características de las profesionales. En general, valoran la necesidad urgente de cambiar el modelo de planes de acogida y el apoyo de una formación especializada en cuidados críticos.

Palabras claves: Cuidados críticos, educación basada en competencias, rol de la enfermera, enfermeras clínicas, enfermeras especialistas, educación continua, educación en enfermería. (Fuente: DeCS BIREME) 


\section{ABSTRACT}

Background: Nurses of the Intensive Care Unit (ICU) provide care for very vulnerable population such as the critical patients. To carry out with this special care, it is widely recognized in the scientific literature, the need to have prior specific knowledge, ability and skills to care for those patients. Currently in our country, the competencies to guarantee safe and quality care in the critical patient field have not been developed through specific training programs.

Aim: To validate a questionnaire in order to identify the training needs and the competencies currently performed by ICU nurses.

Methods: A mixed and sequential design study has been carried out, through the creation of a questionnaire based on a semi-structured interview (phase 1) on the experiences of ICU nurses, with phenomenological approach to the training needs they detect on a day-to-day as professionals $(n=15)$. In phase 2, a questionnaire was made through a modified Delphi technique, with phase 1 nurses, who worked in a polyvalent ICU. Phase 3 includes a descriptive and a multicentre study with nurses of $85 \mathrm{UCls}$. After applying the inclusion criteria, a sample of $n=583$ nurses was available for the analysis. Phase 3 has been completed with a psychometric analysis of the questionnaire using the SPSS v. 20 statistical package for uni- bi- and multivariate analyses, exploratory factorial analysis (EFA) has been performed through the factor analysis program v.10.9.02, and confirmatory factor analysis (CFA) with the IBM AMOS v.24.

Outcomes: The interviewed nurses recognized that, in order to carry out their professional work at ICU, they required a specific training beyond those granted by the university degree. Nowadays, their training has been based on self-learning and peer consultation. Through their answers, a questionnaire of 66 items was created after three-step of consultation ( $\alpha$ Cronbach=0,908). At national level, we found statistical differences in the valuation of items based on ICU work and total work, experience as nurses and postgraduate education; despite the fact that almost all items were scored with more than $70 \%$ of the punctuation. In EFA, 13 dimensions were identified, significant differences $(p \leq 0,005)$ were found in assessing these dimensions; the young populations are more likely to value technical aspects with higher scores, while more experienced nurses do so with continuity of care, communication and clinical safety. The AFC found the relationship between 10 of the factors.

Conclusion: ICU nurses recognize the need for specific training, although differences in assessment have been identified based on the own characteristics of professionals. In general, they value the urgent need to change the model of host plans and support for specialized critical care training.

Keywords: critical care, competency-based education, nurse's role, nurse clinicians, nurse specialist, continuing education, nursing education. (Source: MeSH NLM) 


\section{ÍNDICE}

INTRODUCCIÓN

2.1. HIPÓTESIS

2.2. OBJETIVOS

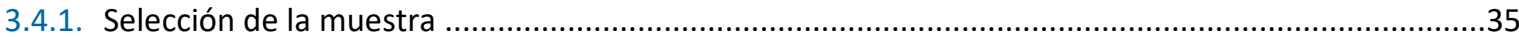

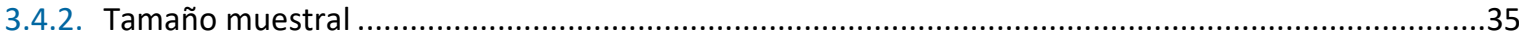

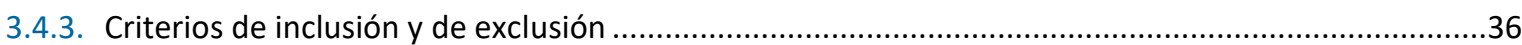

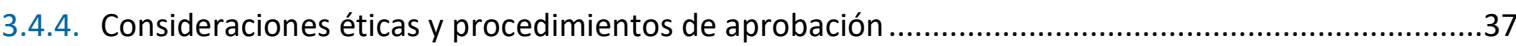

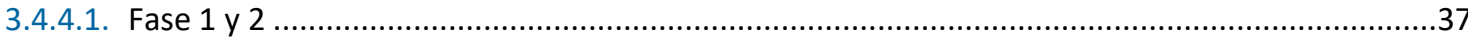

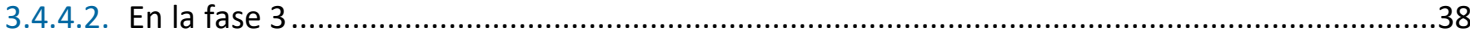

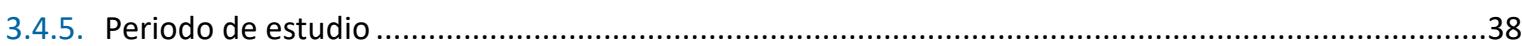

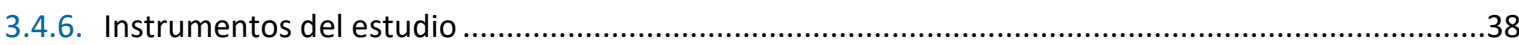

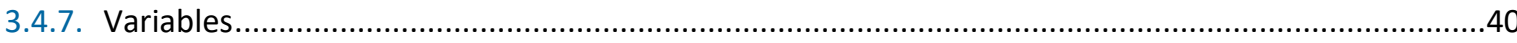

3.4.8. Registro y análisis de datos. (Análisis estadístico) ......................................................................41

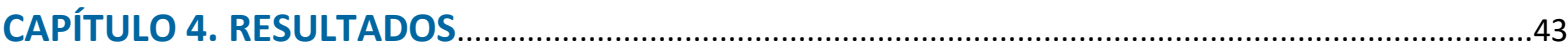

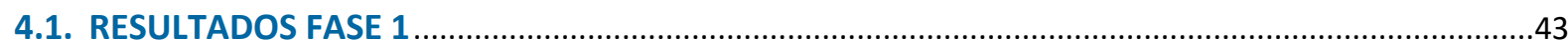

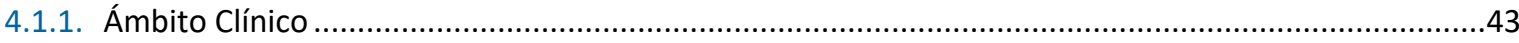

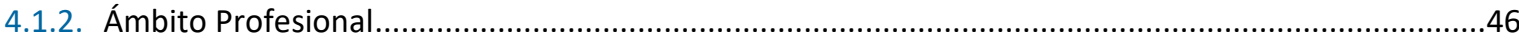

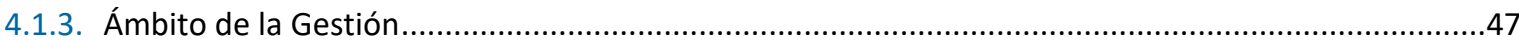

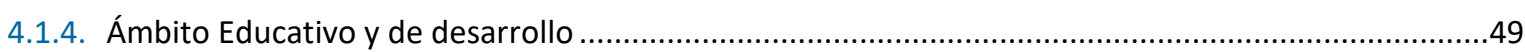

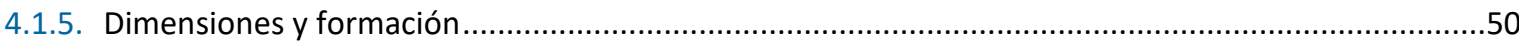




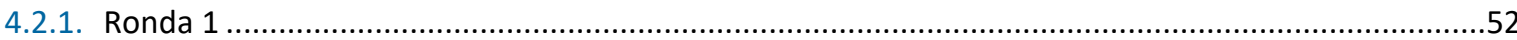

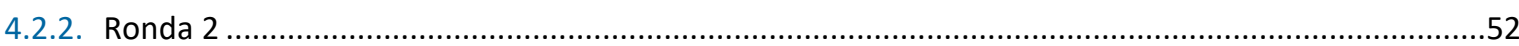

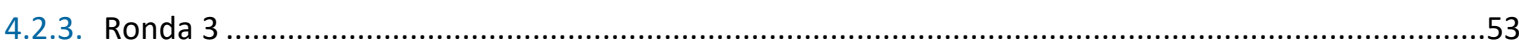

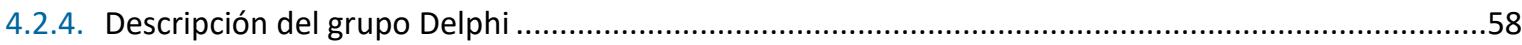

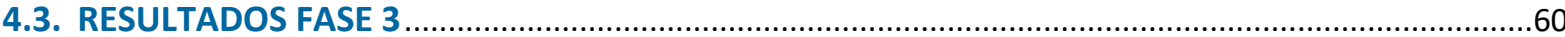

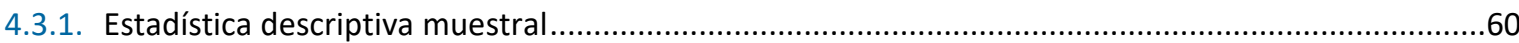

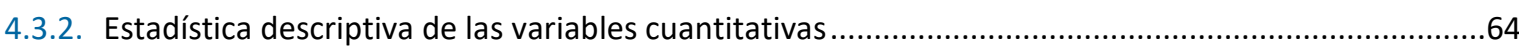

4.3.3. Analizar la existencia de diferencias en la puntuación de las necesidades formativas de las enfermedades de $\mathrm{UCl}$ en función de las características demográficas de las enfermeras ..................69

4.3.4. Analizar la existencia de diferencias en la puntuación de las necesidades formativas de las enfermedades de $\mathrm{UCl}$ en función de las características socio laborales de las enfermeras ................91

4.3.5. Analizar la valoración de las enfermeras ante requisitos previos a la hora de comenzar la labor profesional en $\mathrm{UCl}$

4.3.6. Analizar la valoración de las enfermeras sobre la necesidad de planes de acogida 116

4.3.7. Comparación entre las puntuaciones de los ámbitos de las necesidades formativas de las enfermeras de cuidados intensivos entre el grupo Delphi y el grupo nacional

4.3.8. Valorar los valores predictivos de las respuestas al cuestionario en función de las variables independientes

4.3.9. Análisis de las dimensiones presentes en la escala utilizada

4.3.10. Análisis de las dimensiones de las necesidades formativas en función de las características demográficas

4.3.11. Análisis de la valoración de las dimensiones detectadas en las necesidades formativas de las enfermeras en relación a las preguntas dicotómicas de la encuesta

4.3.12. Análisis de la valoración de las dimensiones detectadas en las necesidades formativas de las enfermeras en relación a las características de las enfermeras encuestadas

4.3.13. Análisis de la valoración de las dimensiones detectadas en las necesidades formativas de las enfermeras en relación a la experiencia laboral y formación previa necesaria según los encuestados

4.3.14. Comparación entre las puntuaciones de las dimensiones de las necesidades formativas de las enfermeras de cuidados intensivos entre el grupo Delphi y el grupo nacional

4.3.15. Análisis factorial confirmatorio del modelo generado

CAPÍTULO 5. DISCUSIÓN 


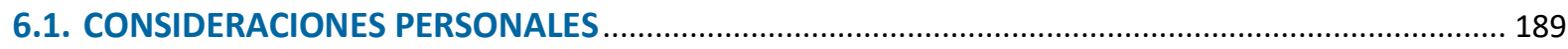

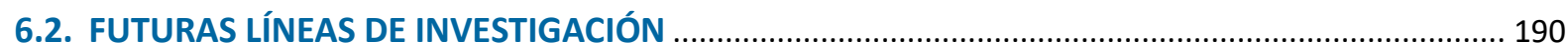

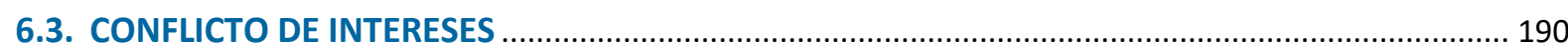

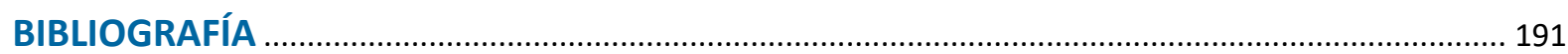

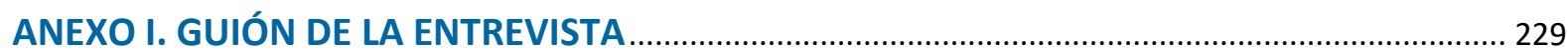

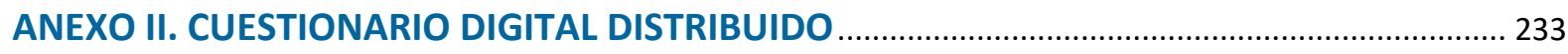

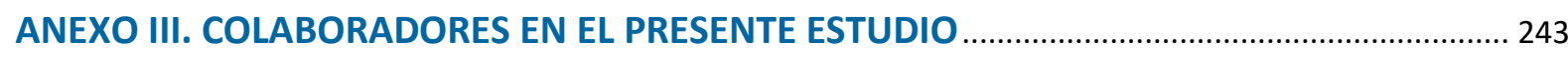

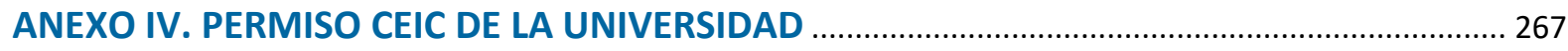

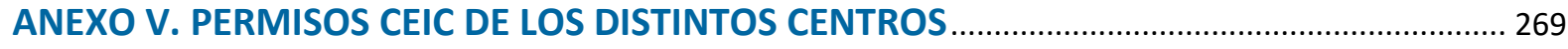




\section{ÍNDICE DE CUADROS}

\section{CAPÍTULO 1}

Cuadro 1. Clasificación de los niveles de asistencia hospitalaria.....

Cuadro 2. Niveles educativos de Kirkpatrick. Extraído de Vázquez ${ }^{(40)}$

\section{CAPÍTULO 3}

Cuadro 1. Técnica para asegurar la calidad de la investigación . .30

Cuadro 2. Momentos esenciales de la investigación cualitativa según Taylor-Bogdan ${ }^{(174)}$ . .30

\section{CAPÍTULO 4}

Cuadro 1. Carta explicativa participantes Delphi

Cuadro 2. Respuesta abierta “¿En qué consiste el plan de acogida?"

Cuadro 3. Respuesta abierta “¿En qué debería consistir un plan de acogida?”

\section{CAPÍTULO 5}

Cuadro 1. Requisitos de competencias en enfermería de cuidados críticos, extraído de Ääri et al. ${ }^{(366)}$ 177

Cuadro 2. Modelo de competencias básicas extraído de Lakanmaa et al. ${ }^{(56)}$ 


\section{ÍNDICE DE TABLAS}

\section{INTRODUCCIÓN}

Tabla 1. Subámbitos EfCCNa. Extraído de Waters et al. ${ }^{(47)}$

\section{CAPÍTULO 3}

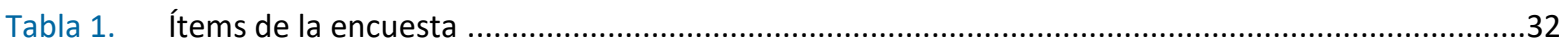

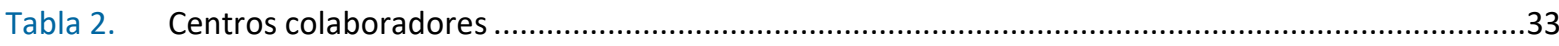

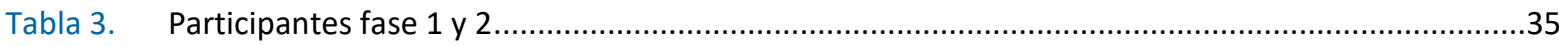

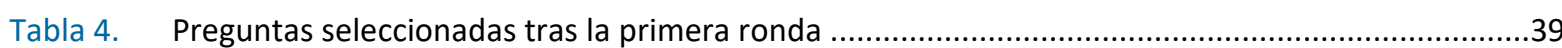

\section{CAPÍTULO 4}

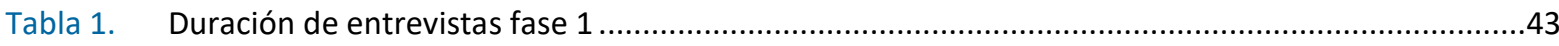

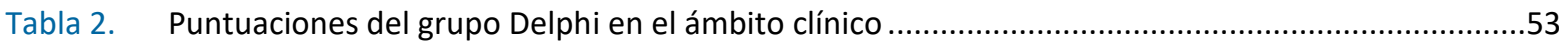

Tabla 3. Puntuaciones del grupo Delphi en el ámbito profesional .........................................................54

Tabla 4. Puntuaciones del grupo Delphi en el ámbito de la gestión ......................................................55

Tabla 5. Puntuaciones del grupo Delphi en el ámbito educativo y de desarrollo........................................56

Tabla 6. Puntuaciones del grupo Delphi al aparado de Formación .......................................................56

Tabla 7. Puntuaciones totales de las distintas secciones del cuestionario distribuido al grupo Delphi .........57

Tabla 8. Formación mínima aconsejable antes de comenzar a trabajar en UCl según grupo Delphi .............59

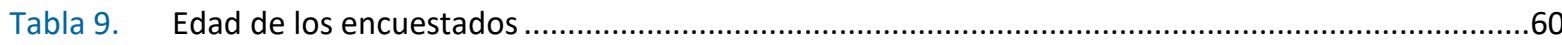

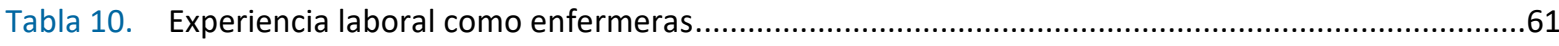

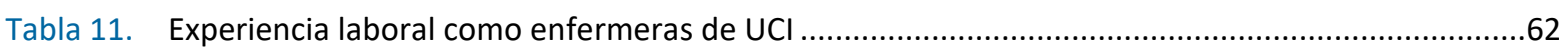

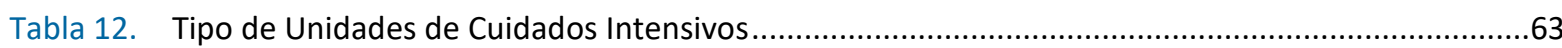

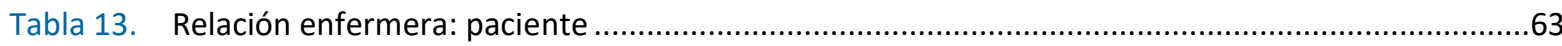

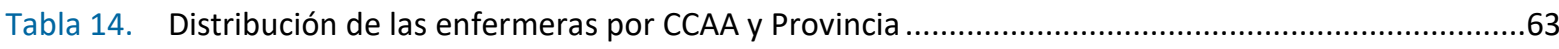

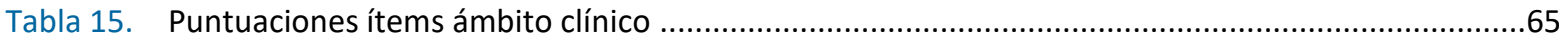

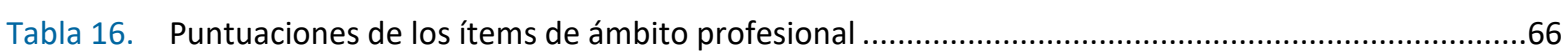

Tabla 17. Puntuaciones de los ítems de ámbito de la gestión ................................................................66

Tabla 18. Puntuaciones de los ítems de ámbito educativo y de desarrollo..............................................67

Tabla 19. Puntuaciones de los ítems de dimensiones y formación .............................................................68

Tabla 20. Puntuaciones por ámbito y totales. Test de Kolmogorov-Smirnov...............................................68

Tabla 21. Puntuaciones en el ámbito clínico en función del género ...........................................................69

Tabla 22. Puntuaciones en el ámbito profesional en función del género ................................................70

Tabla 23. Puntuaciones en el ámbito de la gestión en función del género ................................................71

Tabla 24. Puntuaciones en el ámbito educativo y de desarrollo en función del género ................................72

Tabla 25. Puntuaciones de cada ámbito de necesidad formativa en relación con el género..........................73

Tabla 26. Puntuaciones de los ítems de dimensiones y formación en función del género .............................73

Tabla 27. Puntuación total de dimensiones y formación en función del género y total del cuestionario.........74

Tabla 28. Puntuaciones de los ítems del ámbito clínico en función de la edad..............................................75 
Tabla 29. Puntuaciones de los ítems del ámbito profesional en función de la edad.....

Tabla 30. Puntuaciones de los ítems del ámbito de la gestión en función de la edad .................................77

Tabla 31. Puntuaciones de los ítems del ámbito educativo y de desarrollo en función de la edad .................78

Tabla 32. Puntuaciones de los ítems de dimensiones y formación ...........................................................79

Tabla 33. Puntuaciones totales de los 4 ámbitos y la total de la escala en función de la edad........................80

Tabla 34. Puntuación total parte $B$ y total de la escala en función de la edad .............................................80

Tabla 35. Prueba Post-Hoc de Scheffé entre diferencias de grupo de edad y resultados puntuaciones del cuestionario.

Tabla 36. Prueba Post-Hoc de Games-Howell entre diferencias de grupo de edad y resultados puntuaciones del cuestionario

Tabla 37. Máximo Nivel académico alcanzado .....

Tabla 38. Relación entre la formación universitaria y las puntuaciones dadas al cuestionario en las distintas secciones.

Tabla 39. Enfermeras agrupadas en función del tipo de gestión del centro donde trabajan..... .92

Tabla 40. Diferencias significativas de la valoración de los ítems en función del tipo de gestión del hospital.

Tabla 41. Valoración entre los ámbitos y las puntuaciones totales en función del tipo de gestión del hospital......

Tabla 42. Diferencias significativas en la valoración de los ítems de la encuesta en función de la relación de los centros hospitalarios con la universidad

Tabla 43. Valoración entre los ámbitos y las puntuaciones totales en función de la relación de los centros hospitalarios con la universidad

Tabla 44. Diferencias significativas en la valoración de los ítems de la encuesta en función del número de camas del hospital

Tabla 45. Valoración entre los ámbitos y las puntuaciones totales en función del número de camas del hospital......

Tabla 46. Diferencias significativas en la valoración de los ítems de la encuesta en función del tipo de $\mathrm{UCl}$.

Tabla 47. Valoración entre los ámbitos y las puntuaciones totales en función del tipo de unidad de $\mathrm{UCl}$.......97

Tabla 48. Diferencias significativas en la valoración de los ítems de la encuesta en función del tamaño de la $\mathrm{UCl}$

Tabla 49. Valoración entre los ámbitos y las puntuaciones totales en función del tamaño de la UCI .99

Tabla 50. Diferencias significativas de la puntuación de cada ítem del ámbito clínico en función de la experiencia laboral total como enfermera.....

Tabla 51. Diferencias significativas de la puntuación de cada ítem del ámbito profesional en función de la experiencia laboral total como enfermera.....

Tabla 52. Diferencias significativas de la puntuación de cada ítem del ámbito de la gestión en función de la experiencia laboral total como enfermera....

Tabla 53. Diferencias significativas de la puntuación de cada ítem del ámbito educativo y de desarrollo en función de la experiencia laboral total como enfermera

Tabla 54. Diferencias significativas de la puntuación de cada ítem de la parte B de la encuesta en función de la experiencia laboral total como enfermera.....

Tabla 55. Diferencias entre las puntuaciones de los distintos ámbitos y la experiencia laboral total como enfermera 
Tabla 56. Diferencias significativas de la puntuación de cada ítem del ámbito clínico en función de la experiencia laboral como enfermera de $\mathrm{UCl}$......

Tabla 57. Diferencias significativas de la puntuación de cada ítem del ámbito profesional en función de la experiencia laboral como enfermera de $\mathrm{UCl}$.

Tabla 58. Diferencias significativas de la puntuación de cada ítem del ámbito de la gestión en función de la experiencia laboral como enfermera de $\mathrm{UCl}$....

Tabla 59. Diferencias significativas de la puntuación de cada ítem del ámbito educativo y de desarrollo en función de la experiencia laboral como enfermera de $\mathrm{UCI}$.....

Tabla 60. Diferencias significativas de la puntuación de cada ítem de las dimensiones y formación en función de la experiencia laboral como enfermera de $\mathrm{UCl}$.

Tabla 61. Prueba de Jockheere-Terpstra de las distintas secciones y puntuaciones globales en función de la experiencia profesional como enfermera de $\mathrm{UCl}$

Tabla 62. Frecuencias de opinión frente a requisitos previos de experiencia laboral

Tabla 63. Formación previa aconsejable antes de comenzar a trabajar en $\mathrm{UCl}$

Tabla 64. Tabla de contingencia entre necesidad formación tipo EIR y máximo nivel académico alcanzado.

Tabla 65. Tabla de contingencia entre necesidad formación tipo EIR y experiencia o formación previa a comenzar a trabajar en $\mathrm{UCl}$

Tabla 66. Tabla de contingencia entre necesidad formación tipo EIR y formación mínima previa antes de comenzar a trabajar en $\mathrm{UCI}$

Tabla 67. Tabla de contingencia entre necesidad formación tipo EIR y experiencia laboral mínima en hospitalización.

Tabla 68. Análisis de las diferencias entre las puntuaciones de las distintas secciones del cuestionario entre el grupo Delphi y el grupo nacional

Tabla 69. Diferencias significativas en las afirmaciones de todos los ámbitos entre el grupo nacional y el grupo Delphi

Tabla 70. Análisis univariante de la puntuación total A

Tabla 71. Regresión lineal multivariante en función de la puntuación total A

Tabla 72. Mejor modelo de la regresión lineal multivariante para la puntuación total A.....

Tabla 73. Resultados del análisis factorial exploratorio (AFE)

Tabla 74. Resultados de la Matriz de Correlación Interfactores..... 131

Tabla 75. Análisis descriptivo de los factores de la escala de Necesidades Formativas de las Enfermeras de $\mathrm{UCl}$.

Tabla 76. Agrupación de factoriales a través de los dominios en los cuales se pueden incluir.....

Tabla 77. Análisis de las diferencias de las dimensiones detectadas en función del género

Tabla 78. Test de Jonckheere-Terpstra para las dimensiones detectadas en función de los 4 niveles de rango de edad de los encuestados.

Tabla 79. Test de Jonckheere-Terpstra para las dimensiones detectadas en función del máximo rango académico alcanzado por los encuestados

Tabla 80. Diferencias en la valoración de las dimensiones detectadas en función del tipo de gestión hospitalaria

Tabla 81. Diferencias en la valoración de las dimensiones detectadas en función de la relación con la universidad 
Tabla 82. Diferencias en la valoración de las dimensiones detectadas en función del tamaño del hospital.

Tabla 83. Diferencias en la valoración de las dimensiones detectadas en función del tipo de UCl

Tabla 84. Diferencias en la valoración de las dimensiones detectadas en función del tamaño de $\mathrm{UCI}$

Tabla 85. Diferencias en la valoración de las dimensiones detectadas en función de la experiencia laboral como enfermera.....

Tabla 86. Diferencias en la valoración de las dimensiones detectadas en función de la experiencia laboral como enfermera de $\mathrm{UCI}$

Tabla 87. Comparativa por parejas de años de experiencia como enfermera de UCl en relación a las dimensiones con resultado significativo

Tabla 88. Grupos de valoración de las dimensiones detectadas 146

Tabla 89. Diferencias significativas en la valoración de las dimensiones detectadas en función de la opinión de precisar experiencia o formación previa para trabajar en $\mathrm{UCl}$

Tabla 90. Diferencias significativas en la valoración de las dimensiones detectadas en función de la opinión de precisar una formación sanitaria especializada tipo EIR 148

Tabla 91. Diferencias significativas en la valoración de las dimensiones detectadas en función de la opinión de precisar un plan de acogida al personal de nueva incorporación

Tabla 92. Diferencias significativas en la valoración de las dimensiones detectadas en función del género

Tabla 93. Diferencias significativas en la valoración de las dimensiones detectadas en función del grupo de edad de las enfermeras consultadas

Tabla 94. Diferencias significativas en la valoración de las dimensiones detectadas en función del grupo de edad de las enfermeras consultadas

Tabla 95. Diferencias significativas en la valoración de las dimensiones detectadas en función de la pertenencia a centros universitarios o no universitarios.

Tabla 96. Diferencias significativas en la valoración de las dimensiones detectadas en función del número de camas del centro hospitalario

Tabla 97. Diferencias significativas en la valoración de las dimensiones detectadas en función del tamaño de la UCI

Tabla 98. Diferencias significativas en la valoración de las dimensiones detectadas en función de la experiencia laboral total como enfermera.

Tabla 99. Diferencias significativas en la valoración de las dimensiones detectadas en función de la experiencia laboral como enfermera de $\mathrm{UCl}$

Tabla 100. Diferencias significativas en la valoración de las dimensiones detectadas en función de los requisitos laborales previos en hospitalización.

Tabla 101. Diferencias significativas en la valoración de las dimensiones detectadas en función de los requisitos laborales previos en urgencias y/o quirófano

Tabla 102. Estadísticos descriptivos de las puntuaciones de las dimensiones de las necesidades formativas de las enfermeras de $\mathrm{UCl}$ tanto del grupo nacional como del grupo Delphi

Tabla 103. Comparación de las puntuaciones de las dimensiones de las necesidades formativas de las enfermeras entre el grupo nacional y el grupo Delphi.....

Tabla 104. Covarianzas en el modelo estudiado 158

Tabla 105. Relación de las variables incluidas en el AFC y sus variables latentes 159 


\section{ÍNDICE DE FIGURAS}

\section{CAPÍTULO 4}

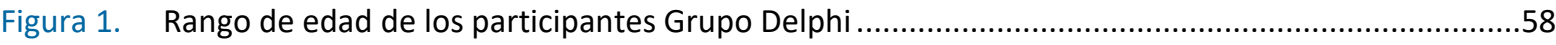

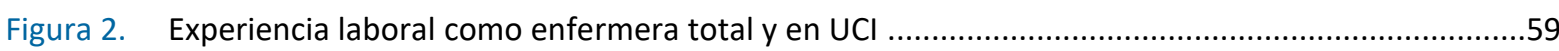

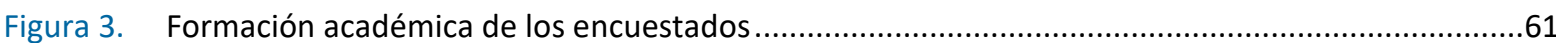

Figura 4. Distribución de participantes en relación al número de camas del hospital ................................62

Figura 5. Análisis por parejas de la puntuación de ámbito clínico y la máxima formación académica ...........90

Figura 6. Análisis por parejas de la puntuación de ámbito de la gestión y la máxima formación académica

Figura 7. Análisis por parejas de la puntuación del ámbito educativo y de desarrollo y la máxima formación académica

Figura 8. Diagrama de cajas de la prueba Samples Jonckheere-Terpstra entre la puntuación total parte A y el máximo nivel académico

Figura 9. Análisis por parejas de la puntuación total parte A y la máxima formación académica..................91

Figura 10. Análisis por parejas de la puntuación de la parte B y la máxima formación académica..................91

Figura 11. Análisis puntuación total de la encuesta y la máxima formación académica ................................91

Figura 12. Análisis de comparación por parejas entre ámbito clínico y experiencia profesional total........... 104

Figura 13. Análisis de comparación por parejas entre ámbito profesional y experiencia profesional total... 104

Figura 14. Análisis de comparación por parejas entre el ámbito de la gestión y experiencia profesional total 104

Figura 15. Diagrama de caja de la puntuación total parte $\mathrm{A}$ y años de experiencia laboral total. 105

Figura 16. Análisis de comparación por parejas entre puntuación total parte A y experiencia laboral total

Figura 17. Análisis de comparación por parejas entre puntuación total parte B y experiencia laboral total

Figura 18. Análisis de comparación por parejas entre la puntuación total del cuestionario y la experiencia profesional total......

Figura 19. Análisis de comparación por parejas del ámbito profesional en función de la experiencia laboral en $\mathrm{UCl}$

Figura 20. Análisis de comparación por parejas del ámbito de la gestión en función de la experiencia laboral en $\mathrm{UCl}$

Figura 21. Diagrama de caja de la prueba Samples de Jonckheere-Terpstra del ámbito de la gestión en función de la experiencia laboral en $\mathrm{UCl}$.

Figura 22. Análisis de comparación por parejas de la puntuación

Figura 23. Diagrama de caja de la prueba Samples de Jockheere-Terpstra de la puntuación total del cuestionario en función de la experiencia laboral en $\mathrm{UCI}$

Figura 24. Análisis de comparación por parejas de la puntuación total del cuestionario en función de la experiencia laboral en $\mathrm{UCl}$

Figura 25. Necesidad de formación especializada tipo EIR para las enfermeras de UCI............................. 113

Figura 26. Existencia de planes de acogida para el personal de nueva incorporación ................................. 116

Figura 27. Necesidad de plan de acogida al personal de nueva incorporación ......................................... 117

Figura 28. Histograma de residuos del modelo creado para la puntuación total A................................... 123 
Figura 29. Gráfico de residuos tipificados del modelo creado para la puntuación total A

Figura 30. Comparación por parejas de los grupos de edad de los encuestados y la dimensión habilidades en el cuidado del paciente crítico

Figura 31. Comparación por parejas de los grupos de edad de los encuestados y la dimensión comunicación y seguridad clínica.....

Figura 32. Comparación por parejas de los grupos de edad de los encuestados y la dimensión evaluación del paciente crítico, herramientas y tecnología

Figura 33. Comparación por parejas de los grupos de edad de los encuestados y la dimensión gestión sanitaria

Figura 34. Comparación por parejas de los grupos de edad de los encuestados y la dimensión toma de decisiones y afrontamiento al final de la vida

Figura 35. Comparación por parejas del nivel académico de las enfermeras encuestadas y la dimensión formación específica y continuada de las enfermeras de plantilla (staff)

Figura 36. Comparación por parejas del nivel académico de las enfermeras encuestadas y la dimensión toma de decisiones y afrontamiento al final de la vida

Figura 37. Comparación por parejas del nivel académico de las enfermeras encuestadas y la dimensión motivación para continuar con la formación

Figura 38. Comparación por parejas del nivel académico de las enfermeras encuestadas y la dimensión repercusión de la formación

Figura 39. Comparación por parejas de la experiencia laboral total como enfermera y la dimensión habilidades en el cuidado del paciente crítico

Figura 40. Comparación por parejas de la experiencia laboral total como enfermera y la dimensión formación específica y continuada de las enfermeras de plantilla

Figura 41. Comparación por parejas de la experiencia laboral total como enfermera y la dimensión evaluación del paciente crítico, herramientas y tecnología

Figura 42. Comparación por parejas de la experiencia laboral total como enfermera y la dimensión gestión sanitaria

Figura 43. Comparación por parejas de la experiencia laboral como enfermera de $\mathrm{UCl}$ y la dimensión Toma de decisiones y afrontamiento al final de la vida

Figura 44. Análisis Factorial Confirmatorio 158 


\section{INTRODUCCIÓN}





\section{Introducción}

La enfermera, según las leyes vigentes en el país, desde el momento que finaliza la formación de grado es habilitada en cualquiera de los ámbitos de su profesión: asistencial, docente, investigadora o gestora, y puede incorporarse al mercado laboral. La Ley Orgánica $4 / 2007^{(1)}$ y el Real Decreto $1393 / 2007^{(2)}$, por los que se establece la ordenación de las enseñanzas universitarias oficiales, siguen desarrollando la profesión enfermera, haciendo frente a las nuevas realidades educativas y sociales, las cuales se están adaptando en España en los últimos 30 años ${ }^{(3)}$.

El marco legal español sigue las directrices de la normativa europea, avaladas según determinaciones de las entidades colegiales internacionales enfermeras, como es el caso del Consejo Internacional de Enfermeras (CIE) que, en 2003, publicó un documento de referencia sobre el marco de competencias de las enfermeras generalistas ${ }^{(4)}$. Este hecho es relevante, pues surge de la legislación de los estados y de las necesidades que las propias enfermeras determinan para el ejercicio efectivo de su profesión. Este constructo es necesario sobre todo a la hora de asegurar una empleabilidad y un perfeccionamiento de los profesionales en áreas tan críticas para la sociedad como es el sector salud ${ }^{(5,6)}$. Por lo que es necesario definir las cualidades, capacidades y competencias profesionales de los títulos en el Espacio Europeo de Enseñanza Superior (EEES) en el cual se incluyen todos los titulados universitarios. Este hecho es fundamental, pues como mencionan García-Manjón y PérezLópez tiene una relación muy estrecha con la empleabilidad de los egresados universitarios ${ }^{(5)}$.

En los últimos años, se ha producido un avance importante con la creación de nuevas especialidades en enfermería con formación específica de postgrado, que se desarrolla bajo la supervisión de las unidades docentes acreditadas en los centros sanitarios. Este modelo de formación sanitaria especializada, identifica y dota de competencias al Enfermero Interno Residente (EIR) regulado por la Ley $44 / 2003$, de 21 de noviembre, de ordenación de las profesiones sanitarias ${ }^{(7)}$ y por el Real Decreto $450 / 2005$, de 22 de abril, sobre especialidades de enfermería ${ }^{(8)}$. Paulatinamente, se han ido creando categorías sanitarias de una manera desigual en distintas comunidades autónomas como paso previo a la creación de plazas propias que se ajusten a los criterios y competencias de las especialidades legalmente reconocidas. Aunque en el ámbito laboral se vislumbra un camino lento, ya que no todas las especialidades tienen definidos puestos de trabajo y reconocimiento profesional adecuado. Este hecho es fundamental, ya que, actualmente, no se reconoce una formación oficial específica y habilitante para el ejercicio de la profesión enfermera en cuidados intensivos. La inferencia más arriesgada que se puede hacer es que esta formación se incluya dentro de la especialidad de enfermería de cuidados médico-quirúrgicos, publicada en la ley anteriormente mencionada $450 / 2005$, artículo 2 , subapartado $e^{(8)}$ y todavía pendiente de desarrollar, presupuestar y poner en activo.

Desde el ámbito universitario, se ha incrementado la oferta de formación de segundo ciclo mediante másteres dirigidos a enfermeros graduados, con distintos programas que ofrecen una formación académica necesaria para el desempeño de competencias clínicas avanzadas y que, además, facilita el acceso a programas de doctorado ${ }^{(9)}$. Estos programas académicos de segundo ciclo oscilan entre los 60 y 120 créditos ECTS (European Credit Transfer System). Pero sucede algo similar a la formación EIR, ya que en el ámbito clínico no hay una respuesta positiva que refleje de forma real el currículo de un enfermero en función del puesto que ocupe o del puesto para el que es contratado. 
Los requisitos que actualmente rigen el acceso al campo laboral son asimétricos, no reglados y fundamentados únicamente en la posesión de la titulación de grado en Enfermería y en el tiempo trabajado previamente en un área o servicio determinado. En este contexto, la especialización de enfermería en cuidados intensivos actualmente no está ni siquiera planteada ni a medio ni a largo plazo en España, a pesar de que existen modelos en otros países como Estados Unidos ${ }^{(10,11)}$ o Australia ${ }^{(12,13)}$. En un entorno como el de cuidados intensivos, que requiere habilidades muy específicas y competencias profesionales adaptadas a unos elevados requerimientos en cuidados complejos, los cuidados continúan siendo realizados por enfermeras sin una especialización requerida previa incorporación laboral ni durante el ejercicio profesional. Tomando los ejemplos de los dos países citados anteriormente, la formación está destinada a dar una homogeneidad a la formación enfermera. Estos modelos están dirigidos a dotar al profesional de unos conocimientos, habilidades y destrezas mínimas para afrontar el cuidado con seguridad y eficiencia.

Teniendo en cuenta que las unidades de cuidados intensivos ( $\mathrm{UCl}$ ), son unidades muy exigentes en cuanto al manejo del paciente crítico, no es fácil de explicar por qué se encuentran en estas áreas enfermeros noveles, que pueden requerir de múltiples actividades formativas para poder alcanzar un nivel de competencia experto ${ }^{(14)}$. Este hecho se contrapone con la ausencia de una formación homogénea y excelente en relación con los cuidados a los que tienen que hacer frente en las $\mathrm{UCl}$. Siendo un hecho de gran importancia para el sistema sanitario, pues como se menciona en Martín et al. ${ }^{(15)}$, las unidades de cuidados intensivos están mayoritariamente estructuradas como unidades polivalentes y se encuentran en todas las comunidades autónomas (CCAA). El $71 \%$ de las UCl están dirigidas a la atención de pacientes adultos graves médico-quirúrgicos con una distribución de camas de aproximadamente 3363, según datos de 2013, y que seguramente se han incrementado sustancialmente en los últimos años. Por tanto, el Sistema Nacional de Salud (SNS) destina una gran cantidad de recursos materiales a la atención del paciente crítico, y estos deben ir en paralelo a unos recursos humanos adecuados en lo que afecta a los profesionales de enfermería. Parece lógico que estos profesionales deben estar preparados y formados para administrar cuidados específicos. Sin embargo, como se ha comentado previamente, el SNS no tiene una especialidad reconocida para este menester. Aun así, las necesidades de las especiales características de las enfermeras de estos servicios y/o unidades son reconocidas administrativamente por las propias gerencias de los servicios de salud con la creación de listas de empleo especiales para distintos servicios, entre ellos las $\mathrm{UCl}$. Con lo cual, las áreas de salud disponen de un instrumento administrativo para la contratación de personal con unas condiciones distintas a las que legislan en la contratación de listas generales. Por ejemplo:

- Canarias mediante resolución publicada en el Boletín Oficial de Canarias el 19 de noviembre 1999, determinaba en su base cuarta las listas de servicios especiales que se creaban para toda la comunidad autónoma donde ya se encontraban las que a continuación se detallan: medicina intensiva-reanimación, quirófano, salud mental, neonatología, urgencias y esterilización. En su base séptima se determinaban los requisitos de los aspirantes y en la decimocuarta el baremo de méritos para este tipo de listas de servicios especiales específicamente ${ }^{(16)}$.

- Otro caso similar es el de Andalucía; en el Boletín Oficial de Andalucía en 2010, se crea dentro de la categoría de enfermero determinada en su base 4, punto 10; áreas específicas de conformidad con las necesidades asistenciales. En el punto 2 subapartados $c$ y d, se 
especifican áreas de cuidados críticos. En el punto c, se hace referencia a los cuidados críticos neonatales y pediátricos y en el punto $d$, se hace referencia a cuidados críticos y urgencias $^{(17)}$. Incluso presenta un documento de acreditación profesional específica ${ }^{(18)}$.

- Por último, tenemos el ejemplo de Castilla y León en su artículo 20, apartado B, "Cuando sea necesaria la cobertura con carácter temporal de plazas o efectuar nombramientos temporales de la categoría de Enfermero/a se considerarán preferentes, en el orden de llamamiento, las personas que cuenten con la experiencia mínima acreditada en su desempeño de dos meses en los últimos dos años o de cinco meses en los últimos cinco años, para ocupar los puestos que a continuación se indican: Cuidados Intensivos y/o Reanimación, Quirófanos, Hemodiálisis, Urgencias Hospitalarias y Emergencias, Farmacia, Oncohematología, y Cuidados Paliativos" ${ }^{\prime 19)}$.

Por tanto, se observa como las propias gerencias y consejerías de salud se han visto obligadas a establecer unos requisitos que priman una formación y experiencia específica en distintas áreas, hecho a reseñar es que han contado con el apoyo de las entidades sindicales. Además, debe llamar la atención el amplio consenso que estas necesidades específicas de formación tienen en los propios ambientes sanitarios ${ }^{(20)}$. Países de nuestro entorno, como Alemania, ante la falta de profesionales enfermeras cualificadas en cuidados intensivos se ven obligados a realizar llamamientos a través de la prensa ofertando, como incentivo, unas condiciones económicas superiores al resto de enfermeras para atraerlas a su mercado laboral ${ }^{(21)}$.

Observamos anteriormente como los empleadores han tenido y tienen que buscar unos requisitos que resuelvan sus necesidades asistenciales en determinados puestos, ya que la ausencia de formación puede afectar a muchos ítems de la atención sanitaria, pero cabe centrarse en dos de ellos: la mortalidad y los eventos adversos de la asistencia sanitaria.

a) En referencia a la mortalidad, existe evidencia científica para valorar, de manera cuantitativa, que el número de enfermeras influye en la mortalidad, como publica Linda H. Aiken ${ }^{(22)}$ en su estudio con pacientes ingresados en plantas quirúrgicas, apreciando un incremento en la mortalidad a 30 días por una dotación insuficiente de enfermeras. Los estudios realizados en $\mathrm{UCl}$ referidos a resultados y mortalidad se encuentran discrepancias en los resultados midiendo términos cuantitativos. La revisión bibliográfica de Penoyer ${ }^{(23)}$ encuentra asociación entre obtener mejores resultados en la atención sanitaria en relación con un menor ratio enfermera/paciente (E/P); sin embargo, McMagan et al. ${ }^{(24)}$ no encontraron asociación entre incrementar el número de enfermeras y disminuir la mortalidad. En las $\mathrm{UCl}$, los ratios enfermera/paciente son menores que en otras unidades hospitalarias por las propias características de los pacientes atendidos. Pero no se debe pensar únicamente en números absolutos sino también en las cualidades y capacitaciones que tienen las enfermeras para poder cuidar a estos pacientes y que influirían, sin lugar a dudas, en los resultados de la atención sanitaria. Como comenta Lindberg ${ }^{(25)}$, el conocimiento del personal de cuidados críticos se desarrolla a través de su formación científica, pero también por las experiencias de éxito vividas. Asimismo, la experiencia profesional con pacientes y patologías favorece el desarrollo de su intuición a la hora de abordar nuevos casos. La relación formación y 
experiencia profesional es sólidamente apoyada por muchos autores a la hora de asegurar unos cuidados eficaces.

b) En referencia a los eventos adversos (EA), la evidencia científica avala que las $\mathrm{UCI}$ son áreas donde el riesgo de EA es muy elevado, pudiendo llegar a cifras del $40 \%$, según el estudio SYREC. Este estudio observa como se produjeron 1,22 incidentes por cada paciente ingresado, lo que implica una probabilidad de sufrir, al menos, un evento adverso durante el ingreso y, lo que pudiera ser más preocupante, la concatenación de distintos EA en un mismo usuario, hecho este que puede lastrar la recuperación de un paciente con unas características tan especiales como es el paciente crítico $^{(26)}$. Como ya se demuestra en distintos estudios, los EA no son unicausales sino que tienen una generación multicausal, estando todo el equipo multidisciplinar implicado. Según el modelo de Reason, no hay que olvidar que el $8 \%$ de los EA está relacionado con el cuidado ${ }^{(26)}$. Muchos EA están centrados en características propias de: el profesional, las habilidades, la formación y el entrenamiento, así como, del equipo y de la comunicación. La formación de las enfermeras adquiere una relevancia mayúscula, cuando se plantea que muchas de las actuaciones sobre el paciente están bajo su control. Por tanto, los elementos para garantizar la seguridad se observan y se relacionan con la formación previa y continua de los profesionales. Entendiendo que los cuidados en UCI los valoran, aplican y modifican las enfermeras, hay que poner en valor las competencias que estas deben desarrollar para garantizar la seguridad.

En esta línea, el trabajo de González Nahuelquin ${ }^{(27)}$ identificó en las enfermeras chilenas distintas competencias, divididas en transversales, genéricas y críticas. Aunque todas las competencias son importantes, es de señalar que dentro de las críticas o claves como las denomina esta autora, se encuentran algunas de vital importancia para la seguridad como son: el pensamiento crítico, juicio crítico y el pensamiento analítico, además de la resolutividad y un hecho muy remarcado en todas las teorías de estudio de EA como son la autocrítica/comportamiento ante los fracasos/comportamiento ante el error.

Autores como Roselló-Hervás y Valls-Andrés ${ }^{(28)}$ consideran que se deben adquirir conocimientos, habilidades y actitudes para cumplir las competencias propias de las UCl cardiológicas. Este elemento es susceptible de debate en la literatura científica, ya que muchos autores consideran que la formación debe ir centrada a la realidad asistencial; motivo por el cual muchas unidades han desarrollado formación específica para afrontar sus retos diarios ${ }^{(29-31)}$. Algunas unidades han realizado formación propia y otras han desarrollado programas de master en cuidados críticos. La necesidad de contar con programas específicos es un hecho que redunda en la seguridad clínica de una manera incuestionable, aun así el debate sigue abierto ${ }^{(32-34)}$.

Si se da por hecho que profesionales más formados cometen menos errores; la formación específica debería ser fundamental. Este hecho lo destaca Navarro Arnedo et al. ${ }^{(35)}$, quienes ponen especial interés en que el personal de nueva incorporación que se enfrenta al cuidado de enfermos graves se da cuenta rápidamente de que las destrezas, celeridad y observación que requieren este tipo de pacientes, no están desarrolladas en las competencias que aporta el Grado y tienen déficit en determinadas técnicas invasivas. Por este hecho, crearon una guía práctica para el aprendizaje del personal novel que comenzaba a trabajar en unidades de cuidados críticos. Como enuncia Henriques 
Camelo ${ }^{(36)}$, desde un punto de vista constructivista en Brasil, la generación de las competencias profesionales debe surgir de un período reflexivo de las propias enfermeras; ya que no es solo aplicar cuidados de enfermería sino también cuidados de mayor complejidad, liderazgo, toma de decisiones, comunicación y la administración de recursos humanos y materiales sin olvidar que todo este constructo de competencias requiere de una educación continuada y permanente. Así como mencionan Gill et al. ${ }^{(12)}$, las competencias no son un estático sino que evolucionan con la adquisición de nuevos roles y cuidados. Cuando estas se plantearon hace 20 años tenían un contexto distinto al actual; pasando de un contexto más técnico a uno más humanista, aumentando las necesidades de formación en comunicación y centrar el cuidado en el paciente y la familia, siendo el núcleo familiar un elemento fundamental.

Por tanto, la mortalidad y los EA pueden ser disminuidos con una adecuada formación y unas competencias dirigidas a la atención del paciente crítico. Distintos estudios se han desarrollado en el marco de adquirir competencias de las enfermeras de UCI para poder desarrollar en términos de calidad, eficacia y eficiencia su actividad profesional en UCl. Algunos autores abogan por la incorporación de la simulación clínica, la cual las acerca progresivamente ante las realidades propias de su labor profesional con el fin de que las enfermeras adquieran las destrezas necesarias antes de tener contacto con los pacientes, dotándolas de herramientas para abordar y desarrollar competencias $^{(37-42)}$.

Para realizar una adecuada aproximación al tema "competencias" hay que centrarse en su significado. Las competencias son un objetivo marcado dentro del EEES destinado a mejorar la empleabilidad de los egresados universitarios ${ }^{(5)}$; y son además, el elemento central de multitud de estudios para evaluar la formación asistencial de las enfermeras en todos los ámbitos y también en UCI. Por definición las competencias son:

“los conocimientos, destrezas y actitudes necesarias para ejercer una profesión, la persona que las posee puede resolver problemas profesionales de forma autónoma y flexible y está capacitada para colaborar en su entorno profesional y en la organización del trabajo"(6).

Las competencias no son una probabilidad de éxito, sino una capacidad real y demostrada de saber hacer las cosas ${ }^{(43)}$. Además, permiten el desarrollo de un tipo de aprendizaje con objetivos propios, manteniendo la responsabilidad personal del alumno y social de las instituciones. Tal y como mencionan Villa y Poblete ${ }^{(44)}$ en el ámbito universitario, las competencias se pueden agrupar de distintas maneras, pero estos autores recomiendan incluir las competencias genéricas o generales dentro de los siguientes conceptos: competencias genéricas instrumentales, interpersonales y sistémicas. Estas clasificaciones deben ir dirigidas a mejorar el desempeño y las destrezas que deben mejorar los análisis previos de dos hechos fundamentales, analizando el desempeño de los profesionales en la institución para reconocer qué tipo de profesionales se precisa y de qué tipo de profesionales se dispone. La mayoría de los desarrollos curriculares del pregrado dividen estas competencias en dos grandes bloques: competencias generales y competencias específicas. Las competencias generales son aquellas que son válidas para gran multitud de funciones y tareas en cuidados generales. Las competencias específicas aquellas relacionadas con una ocupación concreta. Por tanto, para la presente tesis nos interesan las competencias específicas en el ámbito de la enfermería de cuidados intensivos. Según la bibliografía consultada, los elementos básicos para el 
desarrollo de estas competencias han sido definidas por la $\operatorname{EfCCNa}^{(45)}$, la $\operatorname{AACN}^{(10)}$ y el proyecto CC $3 N^{(46)}$, las dos primeras sociedades científicas de cuidados intensivos son europea y estadounidense, respectivamente. El proyecto $\mathrm{CC} 3 \mathrm{~N}$ es un trabajo colaborativo liderado por enfermeras para la modernización del sistema sanitario inglés en el ámbito de los cuidados críticos y centrado en la homogeneización de las competencias.

La EfCCNa divide las competencias en ámbitos de desarrollo que engloban distintos tipos de actividades según el objetivo final de la acción; estos ámbitos son: clínico, profesional, gestión, y educativo y de desarrollo.

- El ámbito clínico se dirige a fomentar unos cuidados enfermeros que sean seguros y efectivos para el paciente crítico y sus familiares.

- El ámbito profesional pretende fomentar y potenciar la práctica profesional en cuidados intensivos.

- El ámbito de la gestión se centra en el desarrollo de conocimientos y habilidades en el campo de la gestión y organización relacionada con las enfermeras.

- El ámbito educativo y de desarrollo se dirige en facilitar la educación y el desarrollo de las enfermeras de cuidados intensivos.

Esta organización de las competencias incluye una serie de subámbitos que se muestran en la siguiente imagen, que surge del trabajo de Waters et al., y que fue traducido por la Sociedad Española de Enfermería Intensiva y Unidades Coronarias (SEEIUC) ${ }^{(45,47,48)}$.

Tabla 1. Subámbitos EfCCNa. Extraído de Waters et al. ${ }^{(47)}$

\begin{tabular}{llll}
\hline \multicolumn{1}{|c}{ Ámbito clínico } & Ámbito profesional & Ámbito de gestión & $\begin{array}{c}\text { Ámbito educativo y } \\
\text { desarrollo }\end{array}$ \\
\hline $\begin{array}{l}\text { Evaluación y diagnóstico } \\
\text { enfermero }\end{array}$ & $\begin{array}{l}\text { Toma de decisiones } \\
\text { complejas }\end{array}$ & Gestión de la unidad & Desarrollo personal \\
\hline Planificación & Ético y legal & Gestión de equipos & Desarrollo de los demás \\
Implementación & Comunicación & Salud y seguridad & $\begin{array}{l}\text { Práctica basada en la } \\
\text { evidencia }\end{array}$ \\
\hline Evaluación & & Garantía de calidad & \\
\hline
\end{tabular}

Por otro lado, cabe observar la distribución de competencias realizadas por la American Association of Critical-Care Nurses $(\mathrm{AACN})^{(10,49)}$ y clasificadas en 5 niveles, desde el nivel 1 competente hasta el nivel 5 experto, afectando a las siguientes acciones:

- Juicio clínico. El razonamiento clínico, el cual incluye la toma de decisiones clínicas, el pensamiento crítico y la comprensión de la situación global manejando destrezas enfermeras adquiridas a través de experiencias integrativas de conocimiento tanto formal como informal y de guías basadas en la evidencia. 
- Apoyo y soporte moral. Trabajar como representante de otro y siendo interlocutor de las preocupaciones del paciente/familia y del personal de enfermería. Identificando y resolviendo problemas éticos en el ámbito clínico.

- Prácticas del cuidado. Actividades de enfermería que crean un ambiente de apoyo para los pacientes con el objetivo de promover el confort, la curación y evitando el sufrimiento innecesario.

- Colaboración. Trabajando con pacientes, familiares y otros profesionales sanitarios de una manera que se promueve la contribución de cada persona hacia un logro realista y óptimo para el paciente y familiares. Implica el trabajo inter e intradisciplinar.

- Pensamiento en el sistema. Cuerpo de conocimientos y herramientas que permite a la enfermera gestionar cualquier entorno y sistema. Utilizando recursos del propio sistema sanitario o institución en el que se encuentren.

- Respuesta a la diversidad. La sensibilidad para apreciar, reconocer e incorporar diferencias en la prestación de cuidados. Se incluyen las diferencias culturales, creencias espirituales, género, raza, etnicidad, estilo de vida, estado socioeconómico, edad y valores.

- Facilitar el aprendizaje. La capacidad de facilitar el aprendizaje de pacientes /familias, personal de enfermería y otros miembros del equipo de salud, y la comunidad. Incluye tanto la formación formal como informal.

- Evaluación Clínica (Innovación). El proceso continuo de cuestionar, evaluar y promover la práctica clínica. Creando cambios en la práctica a través de la investigación y el aprendizaje experimental. ${ }^{(49)}$

La AACN utiliza para los cuidados críticos 5 etapas de desarrollo; tal y como Patricia Benner ${ }^{(14,50)}$ recomendaba para las enfermeras en general. Actualmente, se han ido poniendo en marcha distintas actividades formativas para adquirir una formación estándar de las distintas enfermeras de cuidados críticos. Por tanto, surge la necesidad de conocer qué enfermeras necesitamos, sus competencias y cómo medir su logro.

Los estudios de Lakanmaa et al., ${ }^{(51)}$ dividen los requisitos competenciales de las enfermeras en 5 dominios principales: conocimientos básicos, destrezas básicas, actitudes y valores básicos, experiencia básica en enfermería y características personales. Todos los autores hacen referencia a la importancia de la experiencia en el cuidado del paciente crítico y a las necesidades de una transición formativa adecuada ${ }^{(51-53)}$. Esta transición se puede llevar a cabo desde el pregrado de enfermería, aunque algunos autores y sociedades científicas reconocen que sería adecuado para estas áreas tan específicas que todas las enfermeras contaran con un nivel formativo de segundo ciclo (Master) $)^{(32,54)}$. La vía académica delega la formación a las entidades universitarias con la colaboración de las instituciones sanitarias en el período de práctica, por lo cual los gastos de esta formación los debe asumir la enfermera interesada. Poder simultanear la vía de formación EIR con la vía académica y con las alternativas ya generadas, y anteriormente mencionadas, como las soluciones aportadas por 
algunas comunidades autónomas de España ${ }^{(16,17,19)}$, no deberían entrar en conflicto sino ser un reto real para lograr una formación óptima.

Otros autores han optado por programas de mentoría para la acogida progresiva de las nuevas enfermeras; estos programas están centrados en la tutorización de conocimientos propios de las $\mathrm{UCl}$, e indican unos requisitos mínimos de aprendizaje con el fin de dar unos cuidados adecuados y evitar eventos adversos ${ }^{(29,34,55,56)}$. Estos programas se basan en el acompañamiento del personal de nueva incorporación durante un tiempo determinado con un período de aprendizaje teórico y otro práctico, la tutela de los profesionales experimentados va disminuyendo a lo largo de todo el proceso a través del cumplimiento de las competencias alcanzadas por el personal novel. Como menciona Lindberg ${ }^{(25)}$, la adquisición de competencias está centrada en realizar tareas prácticas, pero se deja de lado el estudio de cómo deberían hacerse los procesos y las respuestas que se debieran encontrar para ser llevados a la práctica. La aproximación de las necesidades del personal de cuidados críticos es compartida por distintos autores, que desarrollan diferentes programas, pero siempre reconociendo áreas de debilidad para poder centrar el aprendizaje en ellas y conseguir una provisión de cuidados óptimos al paciente crítico ${ }^{(57)}$.

\section{Proyecto CC3N}

Deacon et al., ${ }^{(58)}$ han aplicado un modelo de fases para la adquisición de competencias en cuidados críticos en Reino Unido, desarrollado a través de la línea estratégica del National Health System (NHS) de Reino Unido para modernizar el sistema sanitario, adoptando el nombre del proyecto CC3N ${ }^{(46,59-62)}$. Las fases desarrolladas parten del consenso de que los trabajadores sanitarios deben estar adecuadamente entrenados para las labores que el sistema sanitario les requiere. Por ello, se trabajó en un consenso para desarrollar un marco nacional homogéneo dentro del sistema para adquirir las competencias que los grupos de expertos consideraron necesarias desarrollar en todas las enfermeras de cuidados críticos. Estas competencias fueron divididas en distintas fases denominadas "step". El "step 1" donde se lleva a cabo una acogida de las enfermeras cuando comienzan a trabajar y los "step 2, 3, 4" que son para profundizar en el desarrollo de todas las competencias cuando el profesional ya cumple con los mínimos requeridos en el "step 1", y que se prolongan a lo largo de toda la vida laboral para mantener una competencia continua, y apoyándose en la figura del mentor ${ }^{(59-62)}$. Desarrolla las competencias para la enfermera asistencial, identificando en todo momento prácticas que requieran de unas destrezas específicas y que son evaluadas con unos criterios homogéneos y vinculados a la evidencia científica disponible actualmente en Reino Unido. Este proyecto se mantiene en constante evolución y ha ampliado las competencias generales de los cuidados intensivos a otras áreas más específicas, como son: la atención al politrauma, quemados, obstétrico-ginecológicas o pacientes hepáticos ${ }^{(46)}$. La implementación de esta metodología de trabajo ha recibido una reacción positiva de las propias enfermeras, de los grupos de trabajo y de los empleadores por lo que se ha tenido interés de exportar este modelo de éxito a otros países como Canadá, Finlandia, Oriente Medio, Nepal o India ${ }^{(58)}$. Incluso sugieren en algunos estudios que se debe buscar este tipo de formación como el "Gold Standard"(12). Las enfermeras en las que ha sido aplicado este modelo son las incluidas en el Band 5, 6 y 7 de organización de enfermeras en Reino Unido. Esta clasificación tiene niveles desde el 1 hasta el 9, donde cada nivel posee distintos salarios y responsabilidades. El nivel 5 y superiores corresponden a enfermeras con 
formación universitaria ${ }^{(63,64)}$ que son las que se pueden comparar con el tipo de formación que se exige en España.

Uno de los hechos que menciona este modelo inglés es la mayor satisfacción de los propios profesionales de enfermería a la hora de adquirir y obtener una mejor preparación para desenvolverse en el ámbito asistencial. Esta formación surge desde el primer día, y se constituye en una necesidad a lo largo de todo el tiempo de ejercicio profesional.

\section{Formación continuada}

La formación continuada se entiende como:

"un proceso de enseñanza-aprendizaje activo y permanente al que tienen derecho y obligación los profesionales sanitarios, que se inicia al finalizar los estudios de pregrado o de especialización y que está destinado a actualizar y mejorar los conocimientos, habilidades y actitudes de los profesionales sanitarios ante la evolución científica y tecnológica y las demandas y necesidades, tanto sociales como del propio sistema sanitario"${ }^{\prime(65,66)}$.

Esta formación es, por tanto, un derecho y un deber tanto de los profesionales sanitarios como de las instituciones sanitarias, constituyéndose como una responsabilidad común de cara a los ciudadanos. Las distintas formas de garantizar esta formación tienen un marco preestablecido $\mathrm{y}$, al tratar de las $\mathrm{UCl}$, se convierte en un hecho fundamental debido a que es un entorno sumamente dinámico y cambiante, con una permanente actualización de medios tecnológicos ${ }^{(40)}$. Si este hecho no se mantiene de manera constante a lo largo del tiempo, se podría caer en la incompetencia laboral por muchos años de experiencia que avalen al profesional; de hecho, en una encuesta realizada en 2007, más del $50 \%$ de enfermeras consultadas afirmaron haber sido testigos de la ruptura de reglas, errores o actuaciones incompetentes de sus compañeros ${ }^{(57)}$. Con el fin de mantener unos niveles óptimos y seguros de la asistencia sanitaria, se han desarrollado múltiples propuestas, tales como son los programas de acreditación de competencias de la Joint Commission para mantener y asesorar en el adecuado desarrollo y control de la formación de los profesionales sanitarios ${ }^{(67)}$.

Además, no todos los/as enfermeros/as se encuentran en el mismo momento profesional, por lo que es necesario distinguir entre los propios conocimientos, destrezas y habilidades de los profesionales a formar en cada una de las etapas de su continuum profesional y área de trabajo. Es importante contar con los profesionales de cada unidad a la hora de planificar esta formación, con el objetivo de buscar la excelencia en aspectos tanto cuantitativos como cualitativos; entre los cualitativos, el estudio de Tomes ${ }^{(33)}$ detectó 7 cualidades a desarrollar: dignidad, integridad, conocimientos, comunicación, asociación, compasión y pertenencia. Tanto para los aspectos cuantitativos como cualitativos es necesario instaurar un modelo de desarrollo que busque cómo poder desarrollar, de una manera homogénea y reglada, las competencias detectadas ${ }^{(12,25,68,69)}$.

\section{Modelo de Proulx y Bourcier}

Este modelo se creó a partir de las áreas de mayor dificultad detectadas en la bibliografía, con ellos trabajaron un equipo de mentores para desarrollar un modelo de orientación a las nuevas enfermeras con una duración de 11 semanas $^{(70)}$. Este programa se dividía en un primer día de 
acompañamiento y acogida de la unidad, y tres fases donde se iban adquiriendo responsabilidades progresivas acompañados continuamente por dos tipos de profesionales: un educador de cuidados críticos y preceptores. Los preceptores son enfermeras experimentadas en cuidados intensivos y empleadas en la propia unidad que proporcionan supervisión durante la práctica clínica y facilitan la aplicación de la teoría a la práctica para los profesionales noveles. Los educadores de cuidados críticos son preceptores que además se encargan de la organización de la docencia y de la formación en aspectos teóricos y guías de actuación. La formación se extiende a lo largo de todos los turnos de trabajo. Las enfermeras noveles se inician cuidando un único paciente acompañadas por dos enfermeras formadas, hasta que al final del proceso de formación son capaces de asumir dos pacientes críticos, acompañadas por los preceptores; otros autores utilizan el concepto de "mentor" ${ }^{(29,34)}$. Para el éxito de estos programas, se debe no solo elegir adecuadamente a los mentores y/o preceptores sino clarificar qué se espera de ellos; puesto que tal y como afirman Kaihlanen et al. ${ }^{(34)}$, el mentor tiene un efecto favorable o desfavorable en el interés de las enfermeras noveles. El mentor debe incorporar tres facetas fundamentales: guiar en el trabajo, dar feedback sobre sus actuaciones y consejo en la experiencia sobre los distintos roles. Estas facetas lo convierten, según los propios estudiantes, en un elemento facilitador para reflexionar sobre las prácticas del cuidado, y que se incrementa constantemente debido a los éxitos que va demostrando para la propia institución. La figura del mentor no es un coste añadido sino una inversión de los gestores, ya que mejora el ambiente laboral y la permanencia en las instituciones que ofertan estos procesos educativos a los profesionales enfermeros y también un descenso del tiempo necesario para obtener una enfermera competente para un puesto determinado ${ }^{(71-76)}$

Además, con estos programas de acogida o de residencia en distintos ámbitos mejoran también los aspectos individuales de las enfermeras como profesionales, disminuyendo la ansiedad y mejorando la satisfacción personal y el autoconcepto como profesionales capacitados ${ }^{(77)}$. Este hecho de mejorar la autopercepción redunda en una menor fatiga profesional y, como distintos autores han reseñado, mejora la cultura de seguridad ${ }^{(78-80)}$ y el trabajo en equipo ${ }^{(81)}$ y evita EA ${ }^{(82)}$. Anderson et al. ${ }^{(77)}$ mencionan que la existencia de estos programas de residencia, a la hora de acoger a nuevos profesionales, facilitan un ambiente positivo para el aprendizaje y el incremento de la colaboración interprofesional. No se puede obviar que estos programas deben ser evaluados en su conjunto para conocer los resultados obtenidos, y también potenciar el trabajo en equipo como un elemento vinculado ${ }^{(30,31)}$. Sería un error no incluir al equipo sanitario en la formación de las enfermeras, ya que cualquier elemento del equipo con una formación subóptima puede disminuir los resultados en salud, esto provoca que la coordinación y la mutua colaboración sean elementos siempre a medir en nuestros propios equipos como Weller et al. ${ }^{(83)}$ mencionan en su estudio. El trabajo en equipo, la colaboración y el liderazgo resultan necesarios para el éxito del equipo sanitario. El saber clínico se apoya en que ningún profesional es capaz de llevar a cabo todas las atenciones, es la colaboración de expertos o del propio grupo, lo que constituye desde un grupo de etiología "emic" son el grupo de trabajadores en cuidados intensivos quienes atesoran el saber a concretar y desarrollar ${ }^{(84-86)}$. Esta visión de generar conocimiento inductivo desde el grupo a la generalidad de las enfermeras de cuidados intensivos es el hecho en que se ha fundamentado la utilización de los grupos de expertos y la técnica Delphi para desarrollar estas necesidades de formación enfermera ${ }^{(51,80,84,87)}$.

Como ya menciona Navarro Arnedo et al. ${ }^{(35)}$, las enfermeras que se incorporan a las UCI pueden sentir miedo o ansiedad por la falta de destrezas y habilidades que son necesarias para cuidar a un 
paciente crítico cuya gravedad e inestabilidad son elementos constantes a valorar en la aplicación de cuidados. Estos mismos autores encontraron que existían procedimientos que planteaban más problemas que otros, entre ellos mencionaban: el respirador, el catéter de Swan-Ganz, el desfibrilador, el conocimiento de las arritmias cardíacas y la inserción de marcapasos temporal. Probablemente, procedimientos que únicamente se llevan a cabo en UCl son los que ocasionan mayor incertidumbre en los profesionales ${ }^{(34,41,70,88)}$.

Resulta interesante que Navarro Arnedo et al. ${ }^{(35)}$, no mencionen las técnicas de depuración extrarrenal continuas (TDEC) ya que numerosos estudios valoran la necesidad de la formación de las enfermeras para la adecuada aplicación de las técnicas de depuración extracorpórea ${ }^{(89-92)}$. Probablemente, este hecho pueda estar vinculado con el desarrollo exponencial de la utilización de esta terapia en los últimos años. Como mencionan Kee et al. ${ }^{(92)}$, para las TDEC la formación de las enfermeras en este aspecto mejora la utilización de estas técnicas disminuyendo las complicaciones, mejorando la tasa de ultrafiltración y disminuyendo la estancia en $\mathrm{UCl}$. Para distintos autores, la ventilación mecánica es el procedimiento más problemático, y en este caso la formación también mejora los resultados. El estudio de Bloos et al. ${ }^{(93)}$ aplicó un audit previo y posterior a una formación del equipo sanitario de una $\mathrm{UCl}$ y observó como la formación mejoraba la aplicación de los cuidados y las evidencias más relacionados con la ventilación mecánica; mejorando la adherencia a las recomendaciones aunque reconocieron que no completamente, aun así disminuyeron los días de ventilación mecánica de los pacientes ingresados.

Otros aspectos en los que la formación específica y la aplicación de las recomendaciones logran mejoras son: la gestión del dolor ${ }^{(94,95)}$ y el manejo del delirio ${ }^{(95,96)}$. Rowly-Conwy ${ }^{(96)}$ observó la existencia de correlación entre la formación sobre el delirio y unos mayores niveles de conocimiento y habilidad para usar escalas relacionadas; al mismo tiempo determinó que las enfermeras de mayor formación poseían mayores conocimientos y experiencias.

Como es lógico, en un equipo la contribución de todos los profesionales incluidos en la atención sanitaria es indispensable, por lo que los elementos de trabajo en equipo y comunicación son retos para potenciar constantemente. En este contexto, las oportunidades de formación a través de simulación clínica generan la posibilidad de adquirir competencias y sinergias entre profesionales, pues es cada vez mayor el grado de realismo de este tipo de actividades, ya que permiten reconducir errores detectados para modificar conductas en la atención real a los usuarios y entrenar nuevos protocolos de actuación ${ }^{(83,97)}$. Además, posibilitan generar un espacio de discusión durante las reuniones informativas para evaluar y dar a conocer elementos a mejorar. La simulación se constituye como una metodología docente que permite la evaluación de conocimientos y formación continuada de todo el personal de $\mathrm{UCl}$ mediante la utilización de escenarios acompañados de objetivos realistas y alcanzables por la enfermera ${ }^{(98)}$. Esta forma de aprendizaje potencia la comunicación entre profesionales provocando que las intervenciones educativas multiprofesionales sean más efectivas ${ }^{(99)}$. Elementos habituales son las reuniones "briefing" y "debriefing", para evaluar cambios en las circunstancias clínicas o para reconocer los cambios necesarios tras un escenario de simulación o ante reuniones con familiares de pacientes ${ }^{(98-103)}$. Informar y comunicar son procesos sumamente complejos y como menciona Jensen et al. ${ }^{(100)}$, la simulación facilita su aprendizaje y permite evaluar la propia asistencia sanitaria con cuatro indicadores: comunicación, gestión de síntomas, empatía y toma de decisiones. Los citados indicadores valoran positivamente recibir 
información entendible, la honestidad de la información, la calidad general de la información de las enfermeras, el apoyo emocional de las familias y la toma en consideración de las decisiones familiares. Beltrán-Salazar ${ }^{(104)}$ afirma que la comunicación es un elemento fundamental para una adecuada relación enfermero-paciente y esta debe ser entrenada para poder hacer frente a las distintas respuestas que los pacientes atribuyen a la enfermedad y a las respuestas de sufrimiento que se pueden llegar a producir, y como bien expone este autor, la dificultad de los pacientes sometidos a ventilación mecánica es un elemento a gestionar, pues el lenguaje simbólico y no verbal se constituye en su único elemento de interrelación con el entorno. Una mala interpretación de los mensajes puede minar la relación enfermero paciente, además de los distintos errores que se pueden llevar a cabo con una comunicación deficiente, ejemplos de esto son: no tratar al paciente como un ser único con experiencias únicas, no captar el sentido real del mensaje, minimizar la importancia de las situaciones vividas y la no comprensión del mensaje.

Las relaciones de ayuda entre las enfermeras y los usuarios fundamentadas en la comunicación tienen un componente de formación muy importante. Esta necesidad de formación es estudiada también por Radtke et al.., ${ }^{(105)}$ y Song et al., ${ }^{(106)}$, quienes objetivan que la formación es necesaria para una asistencia sanitaria efectiva, mejorando las conductas del equipo profesional. Además, Song et al. ${ }^{(106)}$ observan que la capacidad de comunicación aumenta si se tiene mayor formación y experiencia, por lo que esta competencia desarrollada influye en una práctica asistencial más efectiva. Las características del ámbito de cuidados intensivos hacen que la comunicación entre los miembros del equipo sea extremadamente necesaria en el contexto de la toma de decisiones, la gestión de conflictos y la incorporación de la familia como un miembro más del equipo asistencial, tal y como menciona Ervin et al. ${ }^{(107)}$. Actualmente, hay que tener en cuenta otro aspecto de la comunicación, el relacionado con las crisis migratorias. La competencia cultural está involucrada en el proceso de comunicación y en la necesidad del desarrollo de destrezas por parte de las enfermeras para adaptar los cuidados a las distintas realidades culturales y creencias $^{(108,109)}$.

La comunicación y el trabajo en equipo han despertado el interés de otras ciencias como es la psicología. Rosen et al. ${ }^{(110)}$ valoran como una oportunidad única el estudio de los equipos sanitarios a la hora de trabajar sobre ambientes sanitarios seguros y de alta calidad; centrándose en el trabajo en equipo, estos autores encuentran en su revisión bibliográfica una alta evidencia en los siguientes aspectos:

1. La relación entre el trabajo en equipo y los resultados sanitarios.

2. Comportamientos efectivos del equipo de trabajo.

3. Competencias efectivas en equipos sanitarios (conocimientos, destrezas y actitudes).

4. Intervenciones de trabajo en equipo.

5. Estrategias mensurables del trabajo en equipo.

6. El papel fundamental que juega la práctica colaborativa en el ambiente clínico.

Aunque analizan todos estos aspectos, son de especial interés para esta tesis los aspectos que se relacionan con la estructura de los componentes del equipo y, más concretamente, de las enfermeras. Y es que la práctica colaborativa es identificada como uno de los mejores elementos para solucionar los problemas que surgen a pie de cama, vinculando las reuniones y las rondas multidisciplinares como un elemento facilitador. Este elemento debe ser trabajado, ya que puede 
generar conflictos en equipos no entrenados en estas dinámicas o con baja capacidad de trabajo colaborativo. El trabajo en equipo tiene que potenciar las capacidades de colaborar de los miembros del equipo y sus responsabilidades, y esto se consigue, sin lugar a duda, mediante formación específica en el entorno en el cual sea necesario. El trabajo en equipo no se ciñe únicamente al trabajo interdisciplinar de colaboración, comunicación y coordinación entre disciplinas con distinta formación, entrenamiento, normas profesionales y lenguajes propios, sino también al trabajo asincrónico o secuenciado de distintos profesionales en un mismo proceso. Para ello, como mencionan Salas y Rosen ${ }^{(111)}$, lograr la capacidad de los miembros del equipo sanitario de adaptarse, llegar a una coordinación implícita y explicita, compartir el liderazgo y resolver los problemas en un entorno tan dinámico como el sector sanitario debe ser potenciado por las propias instituciones. Recibir formación en trabajo en equipo es un elemento facilitador para adoptar actitudes y sinergias positivas con otros profesionales ${ }^{(110)}$.

Por otra parte, la comunicación ha tenido mucho desarrollo desde las vertientes intraequipo y comunicación con las familias, sobre todo para incorporar a estas últimas en los cuidados. Tal y como menciona Hetland et al. ${ }^{(112)}$, existen para esta implicación factores facilitadores y barreras en los 5 elementos relacionados con el cuidado del paciente crítico: la propia familia, el paciente, las enfermeras, el entorno de práctica profesional y la organización de la propia unidad. Según los autores, la incorporación de las familias en los cuidados requiere tanto cambios organizativos como formación de las enfermeras, ya que estas han de ser capaces de evaluar las barreras detectadas en el entorno para eliminarlas y potenciar los elementos facilitadores; esta forma de trabajar requiere la adquisición de competencias específicas y un cambio de visión del equipo asistencial. Algunas de las barreras más comúnmente mencionadas son el desconocimiento y la alta carga de trabajo, y uno de los elementos facilitadores es la educación tanto del equipo como de los familiares. En este contexto, es necesario disponer de destrezas para llevar a cabo las intervenciones oportunas. Uno de los objetivos, como menciona Gutierréz et al., ${ }^{(113)}$ es combatir la soledad, la incertidumbre y el aislamiento que se acentúan una vez pasado el momento del ingreso, puesto que la estancia se hace tediosa, fundamentalmente, para el paciente; y la familia es un elemento clave para darle soporte emocional. Por ello, la familia se convierte en un instrumento del cuidado, pero también en un elemento a cuidar por parte de las enfermeras, pues los familiares son parte sensible del proceso.

\section{La investigación en enfermería en cuidados críticos}

Cuidar es un concepto holístico, y más en el caso de los pacientes críticos; por tanto, es necesario crear y mantener un cuerpo de conocimientos en continuo desarrollo. En este sentido, Blackwood et al. describieron 51 categorías de conocimientos, incluidos en 12 ítems que englobaban las prioridades de la investigación de las enfermeras de cuidados intensivos de adultos en 20 países ${ }^{(87)}$. Al evaluar la importancia de cada área se observó como cinco de ellas eran prioritarias para las enfermeras:

1. Seguridad clínica.

2. El impacto de la evidencia científica en los resultados de la atención sanitaria.

3. Impacto de la fuerza de trabajo de las enfermeras en los resultados (número y cualificación).

4. Bienestar del paciente y las familias.

5. Impacto de los cuidados al final de la vida en el personal. 
Para poder afrontar estas prioridades es necesario potenciar la formación en investigación. MorenoCasbas et al. ${ }^{(114)}$ mencionan que la mayor barrera para las enfermeras clínicas en el desarrollo de la investigación es la falta de confianza y de destrezas, asociadas ambas a una falta de tiempo. Todo ello unido a los factores culturales de los sistemas sanitarios y de la propia profesión. En general, los hospitales no consideran la investigación como algo prioritario; Gehrke et al. ${ }^{(115)}$ indican que los hospitales tienen una visión única de las necesidades de los pacientes y modificar esta actitud institucional puede mejorar los resultados asistenciales. Por tanto, es necesario fomentar la investigación con medidas destinadas a evitar las barreras, concienciar a las instituciones y buscar fondos económicos centrados en la investigación clínica ${ }^{(115)}$. Ya lo mencionaban Goldhamer et al. ${ }^{(116)}$ en referencia a los médicos clínicos investigadores, afirmando que era necesaria la creación de programas para potenciar la investigación; estos autores encontraron una mejora en la producción científica tras aplicar medidas educativas. Lo mismo sucedía en enfermeras de cuidados intensivos, según datos aportados por el programa de apoyo a la investigación de Swenson-Britt et al. ${ }^{(117)}$. El citado programa mostró que la formación a través de un mentor potenciaba las competencias de investigación de las enfermeras involucradas en esta formación; además, potenciaba las propias destrezas, mejoraba la búsqueda de la evidencia científica más reciente y la creación de nuevos topics de investigación. Este hecho es relevante pues las enfermeras de $\mathrm{UCl}$ investigan elementos propios de los cuidados críticos $^{(118)}$. Aprovechar las posibilidades que actualmente abren los nuevos postgrados en enfermería puede ser una magnífica oportunidad de promocionar la investigación ${ }^{(9)}$, siempre teniendo en cuenta que "las enfermeras investigan situaciones clínicas que difícilmente van a ser investigadas por profesionales sanitarios distintos a las enfermeras" como mencionan RamosMorcillo y Ruzafa-Martínez ${ }^{(119)}$. Un elemento válido para todas las áreas de la investigación enfermera es la necesidad de evitar las barreras y de generar un cambio cultural. Como menciona Ortuño-Soriano et al. ${ }^{(120)}$, existen barreras formativas, laborales y familiares para el desarrollo de investigación aunque también se reconoce la importancia que tiene la investigación en la práctica profesional. Es importante fomentar el compromiso entre la institución y las enfermeras; puesto que el beneficio de la investigación es mutuo y redunda directamente en la calidad asistencial. En este sentido, las enfermeras de cuidados intensivos atesoran mayores méritos investigadores que deben ser aprovechados como una oportunidad por aquellas instituciones cuya realidad sea simétrica a las del estudio de Santana-Padilla et al. ${ }^{(121)}$.

Los cuidados al final de la vida

Las $\mathrm{UCl}$ son las unidades donde ingresan los pacientes más graves, pero al contrario de lo que se puede pensar la mortalidad oscila entre el 15 y el $20 \%$, y la supervivencia al año del ingreso entre los grupos de mayores de 70 años con una estancia en $\mathrm{UCl}$ mayor y menor a 30 días no presenta diferencias significativas ${ }^{(122,123)}$. Aun así, la mortalidad en UCl continua siendo objeto de estudio. Gálvez et al. ${ }^{(124)}$ objetivan que la muerte en UCI necesita un enfoque multiprofesional, protocolizando las actuaciones de cada uno de los miembros del equipo. Monzón Martín et al. ${ }^{(125)}$ admiten que las decisiones de limitación del tratamiento del soporte vital (LTSV) continúan generando discrepancias entre médicos y enfermeras; por tanto, se precisan propuestas de mejora y formación tanto desde las instituciones como por parte de los profesionales. La decisión de LTSV debe ser tomada en consenso entre médicos y enfermeras, hecho este apoyado por las recomendaciones de la propia Sociedad Española de Medicina Intensiva, Crítica y Unidades Coronarias (SEMICYUC) en $2018^{(126)}$. En este sentido, White et al. ${ }^{(127)}$ identifican 12 competencias y ponen de manifiesto un déficit de 
formación de las enfermeras a la hora de comprender, reconocer y actuar a través de los cuidados paliativos. Las enfermeras formadas en este campo y con más experiencia son más capaces de controlar los síntomas y el dolor, además de hablar sobre la muerte con pacientes y apoyar a los familiares en el proceso del duelo. Como menciona Lomero et al. ${ }^{(128)}$, son las enfermeras las que apoyan mayoritariamente que los familiares se incorporen a la toma de decisiones de la LTSV, y también consideran que las enfermeras deben tener un papel más activo en el proceso, los autores muestran que a mayor nivel formativo se logra una mayor colaboración de los familiares. Hansen et al. ${ }^{(129)}$ también mencionan que una mayor formación de las enfermeras las posibilita a la hora de cuidar más eficientemente al final de la vida e incluso desarrollar la competencia de apoyo espiritual. En el ámbito nacional existe la percepción de que las enfermeras no son incorporadas a las decisiones del final de la vida lo que les genera dilemas éticos, para afrontar estas situaciones ${ }^{(130)}$.

\section{Seguridad en cuidados intensivos}

Desde hace años, aplicar cuidados y tratamientos con la mayor seguridad clínica ha sido desarrollado desde varios puntos de vista. Desde la SEMICYUC, se han adoptado distintas medidas para evitar eventos adversos, ya que identificaron, en 2008, la probabilidad de sufrir un incidente relacionado con la seguridad del $62 \%$ solo por ingresar en una $\mathrm{UCl}$, probabilidad que se mantiene a lo largo del ingreso y aumenta con la aplicación de medidas terapéuticas ${ }^{(131)}$. Muchos de ellos se relacionan con un déficit de formación y/o conocimiento y podrían ser evitables. Bloos et al. ${ }^{(93)}$ encontraron mejoría en el manejo de la ventilación mecánica y de las recomendaciones para prevenir la neumonía asociada a ventilación mecánica tras formación específica. Por otro lado, Kim y Kim ${ }^{(132)}$ encontraron bajos conocimientos a la hora de llevar a cabo actuaciones sobre circuitos respiratorios invasivos y baja adherencia al lavado de manos antes de ponerse guantes; lo que pone de manifiesto la necesidad de desarrollar actividades educativas dirigidas a mejorar las conductas y fomentar la adherencia a las recomendaciones para minimizar las infecciones nosocomiales. Este elemento es fundamental pues muchos dispositivos utilizados en las unidades de cuidados intensivos son invasivos y pueden convertirse en elementos causantes de infecciones relacionadas con la asistencia sanitaria (IRAS). Actualmente no hay ningún procedimiento que tenga riesgo "cero"; por tanto, la seguridad debe ser entrenada. Jarzemsky et al. ${ }^{(37)}$ incorporan la seguridad como un elemento a evaluar en todos los escenarios de simulación aplicados a pre y post graduados de enfermería. La reflexión de los intervinientes es fundamental y deben demostrar:

- El uso efectivo de la tecnología y las prácticas estándar que apoyan la seguridad y la calidad.

- La comunicación de observaciones o preocupaciones relacionadas con peligros o errores de pacientes, familiares o equipos.

- El conocimiento y manejo de los sistemas organizativos para informar sobre casi incidentes y errores.

Actualmente, se han extendido las prácticas asistenciales multimodales en la seguridad clínica desde los modelos de Pronovost et al. ${ }^{(133)}$ que consiguieron el descenso del $66 \%$ de las bacteriemias relacionadas con catéter en el estado norteamericano de Michigan; se han extendido a todo tipo de actuaciones en los cuidados intensivos, ejemplos en España son los cambios en las guías y 
recomendaciones para evitar las IRAS entre las que se incluyen los programas de Bacteriemia Zero, Neumonía Zero, Resistencia Zero o Infección Urinaria ZERO también denominada esta última como ITU-ZERO ${ }^{(126,134-138)}$. Los hechos son irrefutables: aplicar formación y la última evidencia científica, apoyados por listas de verificación y/o elementos de cuidados secuenciales ha disminuido las complicaciones de los pacientes ingresados en $\mathrm{UCl}$. El hecho de haber incorporado al $83 \%$ del equipo sanitario español de cuidados intensivos en un cambio de forma de trabajar mediante la formación ha provocado una reducción del 50 \% de las neumonías asociadas a ventilación mecánica, teniendo en cuenta que según Álvarez-Lerma et al. ${ }^{(137)}$ la adherencia a todas las recomendaciones no es total, ya que de las 14 recomendaciones solo 7 superaban el $80 \%$. Las razones pueden ser organizativas y/o de disponibilidad de materiales, pero no cabe duda de que la formación es la piedra angular del éxito.

Sherwood y Nickel ${ }^{(101)}$ también observaron como adoptar políticas de seguridad y calidad con el desarrollo de competencias de las enfermeras reducía las complicaciones de las terapias intravenosas. Kane et al. ${ }^{(139)}$ encontraron que la transición de distintos puestos asistenciales debía ir acompañada por una formación para garantizar la seguridad que puede llegar a extenderse durante 3 años. Enfermeras filipinas, con experiencia laboral en Nueva Zelanda y formación transicional, presentaron una diferencia positiva en los modelos de evaluación de competencias para cuidar con seguridad. En el contexto nacional de Filipinas, este hecho no se desarrolla sobre todo por las fuertes relaciones jerárquicas que imposibilitan a las enfermeras adoptar un papel más activo en cuidar con seguridad. Por tanto, la estructura es un elemento esencial a la hora de adoptar formación enfermera en algunos campos.

Es importante no solo tener una actitud positiva hacia la seguridad clínica sino aplicarla y transferir la información de una manera segura. En los contextos complejos con multitud de datos hay que centrarse en datos concretos e indispensables, así es como surgen los distintos modelos de transferencia de información con distintos acrónimos en uso SBAR, ISBAR, ISOBAR, iSoBAR, SHARED, actualmente no existe evidencia de cual es mejor, pero si se ha observado que seguir un modelo nemotécnico ayuda a no olvidar información esencial y en múltiples ámbitos se recomienda su implementación ${ }^{(140)}$. La pérdida de información provoca riesgos, redundancias y pérdida de la continuidad de la atención sanitaria.

\section{Pensamiento crítico-analítico y habilidades emocionales en enfermería}

En la educación de las competencias se observa una serie de áreas transversales a desarrollar en todos los ámbitos en los que se dividen las necesidades formativas enfermeras. Estas áreas transversales son: la comunicación, el trabajo en equipo, el pensamiento crítico-analítico y las habilidades emocionales. Las dos primeras han sido tratadas en párrafos anteriores.

a) Pensamiento crítico-analítico: varios estudios valoran la necesidad de que las enfermeras desarrollen una reflexión profesional sobre los elementos que el entorno asistencial les proporcionan. Paul ${ }^{(141)}$ menciona que la evaluación del pensamiento crítico de las enfermeras es algo esencial en todos los campos del cuidado y es importante incorporar su evaluación en todos los períodos formativos a los que las enfermeras se enfrenten. Las necesidades de la resolución de problemas asistenciales y la interpretación de los datos detectados en la 
educación de las enfermeras es avalada por múltiples autores ${ }^{(25,34,39,40,58,70,117,141-143)}$. Es objetivo de toda educación de competencias que las enfermeras observen, valoren, evalúen, realicen un proceso reflexivo y actúen según su juicio profesional. Es por ello, por lo que para entender este proceso, en la formación hay que ir desde de un conocimiento cognitivo a un conocimiento procedimental. Este aspecto concreto es el que ha desarrollado en el ámbito de $\mathrm{UCl}$ dos modelos formativos distintos, pero a su vez complementarios, como son la simulación clínica y la mentoría. Un elemento concreto de la formación debe ser disminuir las barreras en el aprendizaje, generando una actitud proactiva y de aprendizaje secuencial; ya que apoyarse en este tipo de experiencias provoca mayor seguridad y la posibilidad de observar situaciones complejas con asesoría y control en todo momento. Phillips et al. ${ }^{(102)}$ mencionan una serie de pasos a seguir en este contexto siguiendo una secuencia iSoBAR adoptada por la Australian Commision on Safety and Quality in Healthcare ${ }^{(140)}$ para desarrollar el aprendizaje de las enfermeras que es de utilidad en los contextos formativos en los que el pensamiento crítico y la actuación deben ser analizados. Flott y Linden $^{(144)}$ lo mencionan a la hora de dar herramientas para estos entornos formativos, no solo en la formación clínica sino en clases o laboratorios, es importante que la enfermera se cuestione todas sus actuaciones con herramientas oportunas para reconocer y reflexionar sobre por qué y cómo actuó. El concepto de reflexionar de manera positiva sobre las actuaciones es un modelo educativo para las competencias muy poderoso para modificar conductas y lograr niveles de excelencia. Por eso, el mensaje de los profesores, mentores y tutores tiene que ser positivo, ya que la técnica más común utilizada para evaluar actuaciones es el interrogatorio, y esto puede generar una sensación de culpa que no es la que se busca en contextos de aprendizaje.

b) Las habilidades emocionales: no cabe duda de que la visión humanista de la enfermería y su cercanía provoca la generación de una serie de sentimientos que deben de ser estudiados en las propias enfermeras al enfrentarse al entorno laboral. Diversos autores mencionan que la ansiedad o la inseguridad son elementos comunes a la hora de comenzar a trabajar en ámbitos tan complejos como las unidades de cuidados intensivos ${ }^{(107,145,146)}$. Mejorar la capacidad de actuación y la autoconfianza de las enfermeras es un elemento indispensable para mejorar el propio entorno laboral ${ }^{(70,72,144,145,147)}$. El desarrollo de la inteligencia emocional definida como la capacidad que tienen las personas para gestionar, comprender y controlar las emociones es un elemento por desarrollar. Los aspectos emocionales han sido denostados como básicos en la formación de las enfermeras y el contexto del paciente crítico apoya cada vez más su introducción como habilidad profesional ${ }^{(27,124)}$.

Como se comentó anteriormente, las competencias enfermeras no son algo estático sino en continuo desarrollo, con el único objetivo de cuidar adecuadamente. Por ello, es necesario además de reconocer las competencias enfermeras y las necesidades formativas de los citados profesionales, conocer también la disponibilidad de herramientas educativas y cómo aplicarlas. Estar evaluando continuamente áreas de mejora debe ser un compromiso de todos: instituciones, educadores y profesionales. Las competencias detectadas actualmente, pueden no ser las mismas de hace 10 años ni serán, posiblemente, las de dentro de 10 años, y ello motiva la continua evaluación de las necesidades que presentan las enfermeras en cuidados críticos. A partir de esta reflexión surge la presente tesis. 



\section{CAPÍTULO 1}

\section{MARCO TEÓRICO}





\section{Capítulo 1. Marco Teórico}

El presente capítulo se centra en aquellos aspectos que influyen en la formación de las enfermeras de cuidados intensivos. Este hecho general está relacionado con diferentes subgrupos de conocimientos que están muy influenciadas por la organización del sistema sanitario y universitario. Es de destacar que además, se basa en diversos modelos teóricos como el de Patricia Benner ${ }^{(14)}$ para la adquisición de competencias y responsabilidades enfermeras; estudiando el desarrollo profesional desde enfermera novel a experta.

En general, y en relación con la población a la que atienden, las expectativas de los profesionales sanitarios son la promoción de la salud y el bienestar, la prevención de la enfermedad y, cuando esta surge, la administración del tratamiento y del cuidado más oportuno. La salud es definida por la Organización Mundial de la Salud (OMS) como "un estado de completo bienestar físico, mental y social, y no solamente la ausencia de afecciones o enfermedades" ${ }^{(148)}$. Los avances tecnológicos y farmacéuticos de la segunda mitad del siglo XIX han modificado ostensiblemente tanto la esperanza como las expectativas de vida, mejorando la salud y buscando el bienestar poblacional. Este hecho se ve influenciado por el entorno social, cultural y económico en el que se desenvuelve; así como por la disponibilidad de recursos sanitarios para poder hacer frente a las necesidades de salud.

Centrando el tema en el paciente crítico, motivo fundamental de esta tesis; resulta adecuado identificar qué se entiende por paciente crítico o gravemente enfermo y cuáles son sus características. En esta línea, se define paciente crítico a aquella persona que tiene afectado uno o varios órganos o funciones y que estas comprometen potencialmente su vida. Algunos autores han incorporado el término recuperable a las distintas definiciones ofrecidas. Esto provoca que exista cierta controversia entre lo que se entiende por "recuperable"; además, los criterios de ingreso en las $\mathrm{UCl}$ son dinámicos y cambiantes en función de los avances en el conocimiento científico y en los éxitos que este aporta a nivel asistencial.

Las unidades de cuidados intensivos se consideran como unidades de alta complejidad cuyo objetivo es la atención a los pacientes críticos con los medios humanos y tecnológicos necesarios ${ }^{(149)}$. Brilli et al. ${ }^{(150)}$, desarrollaron una definición donde la multidisciplinariedad era y es un elemento fundamental para abordar el cuidado en $\mathrm{UCl}$, e identificaron como imprescindibles las siguientes características:

- Directores médicos y de enfermería con autoridad y corresponsabilidad en la gestión de la $\mathrm{UCl}$.

- Colaboración entre el equipo de enfermería, de farmacia, de terapia respiratoria y de médicos con un enfoque de equipo.

- Uso de estándares, protocolos y guías de práctica clínica para asegurar un enfoque coherente de los problemas de la asistencia sanitaria.

- Coordinar y comunicar todos los aspectos de la gestión de la UCI.

- Dar énfasis a la certificación de los profesionales, investigación, educación cuestiones éticas y defensa de los usuarios. 
Como estos mismos autores argumentan es muy importante la visión de todos los miembros del equipo sanitario debido a la necesidad de proveer unos cuidados de calidad al paciente crítico, y que precisa en todo momento por parte de los miembros directivos colaborar en la educación, estructura, procesos y evaluación de las dinámicas del equipo sanitario ${ }^{(150)}$.

La clasificación de los niveles de asistencia hospitalaria, expresada en el cuadro 1, estructura las áreas en las que debe ingresar un paciente según sus necesidades y complejidad; tal y como recomienda el sistema nacional de salud inglés ${ }^{(151)}$ y posteriormente adopta el ministerio de sanidad de España ${ }^{(152)}$.

\section{Cuadro 1. Clasificación de los niveles de asistencia hospitalaria}

Nivel Descripción de ciudadanos

- Pacientes cuyas necesidades pueden ser atendidas en una unidad de hospitalización convencional de hospital de agudos.

Pacientes en riesgo de que su condición se deteriore, o que provienen de un nivel más alto de

1 cuidados, cuyas necesidades de cuidados pueden ser satisfechas en hospitalización convencional con asesoramiento y apoyo del equipo de cuidados críticos.

2 Pacientes que requieren observación más frecuente o intervención, incluido el soporte a un sistema orgánico, o cuidados postoperatorios o aquellos que provienen de niveles más altos de cuidados. Pacientes que requieren soporte respiratorio avanzado o soporte respiratorio básico junto con, al

3 menos, soporte a dos sistemas orgánicos. Este nivel incluye todos los pacientes complejos requiriendo soporte por fallo multiorgánico.

En España, los requisitos y la organización de los establecimientos hospitalarios está determinado por el RD $1277 / 2003^{(153)}$, que define específicamente las características de las distintas unidades de un hospital y específicamente define las UCl englobadas bajo el término Medicina intensiva:

"Medicina intensiva: es aquella unidad asistencial en la que un médico especialista en Medicina intensiva es responsable de que se preste la atención sanitaria precisa, continua e inmediata, a pacientes con alteraciones fisiopatológicas que han alcanzado un nivel de severidad tal que representan una amenaza actual o potencial para su vida y, al mismo tiempo, son susceptibles de recuperación".

Estas necesidades de atención, en el caso del paciente crítico, están vinculadas a la necesidad de unos cuidados que se establecen como de alto requerimiento, y que según muchos autores se consideran extremadamente dinámicos, además Brilli et al. ${ }^{(150)}$, consideran que todos los cuidados de enfermería deben ser proporcionados por enfermeras entrenadas en cuidados críticos. Los estudios de la vinculación entre las necesidades asistenciales y el área de ingreso hospitalario han sido y son ampliamente analizados en el contexto total hospitalario ${ }^{(22,154-156)}$. Van Oostveen et al. ${ }^{(157)}$, menciona la necesidad de definir en cada área una intensidad de cuidados adecuada para conseguir que las enfermeras puedan desarrollar sus potencialidades y su liderazgo de la mejor manera posible, marcando como horizonte el logro de mejores resultados en salud y maximizando la autonomía de los cuidados. En cuanto a la relación ratio profesional/paciente continúa apreciándose controversia según la literatura consultada. Ciertos estudios retrospectivos han vinculado las ratios de las enfermeras con la mortalidad de los pacientes ingresado en $\mathrm{UCl}$ y con la presencia de complicaciones durante su ingreso ${ }^{(158,159)}$. Sin embargo, otros estudios incluso con cambios legislativos, no han encontrado esta correlación estricta entre ratio enfermera/paciente y resultados asistenciales ${ }^{(23,24,160)}$. Esto último es lo que observaron Law et al. ${ }^{(160)}$, quienes en su estudio, tras una 
serie de cambios en la legislación del estado de Massachusetts (EEUU) que incrementó la cantidad de enfermeras a nivel cuantitativo, no objetivaron efectos positivos ni en relación a los resultados ni en relación a las complicaciones de los pacientes. Por lo tanto, surge la importancia de poner en valor los aspectos cualitativos y no sólo tener en cuenta los cuantitativos. Haciendo referencia a los estudios de Lee et al., ${ }^{(161)}$ y Margadant et al., ${ }^{(162)}$, es la carga de trabajo de las enfermeras lo que influye en la mortalidad y en las complicaciones de los pacientes; por tanto, hay que incorporar un nuevo concepto como es la intensidad de cuidados dinámica a lo largo de todo el ingreso. Así la mayor parte de los autores han evaluado las cargas de trabajo centrándose en estructuras rígidas que no facilitan el reajuste de profesionales según las necesidades reales de cuidados, cuando los aspectos cualitativos de la asistencia varían a lo largo del ingreso en UCI. Margadant et al., haciendo referencia a la escala NAS (Nursing Activities Score) para calcular las necesidades de cuidados por parte de las enfermeras, encontró relación significativa entre valores mayores a 61 puntos NAS con una mayor mortalidad de los pacientes en las $\mathrm{UCl}$ de Holanda ${ }^{(162)}$; pero sin hallar relación significativa en la misma muestra en los ratios: enfermera/paciente. El estudio de Lee et al. ${ }^{(161)}$, con un instrumento de medida distinto el TISS-76 (Therapeutic Intervention Scoring System), encontró resultados simétricos, relacionando un aumento de la mortalidad con puntuaciones de carga de trabajo igual o superiores a 52 puntos por enfermera de esta escala. Los estudios ponen de manifiesto el carácter multifactorial que condiciona el éxito de la asistencia sanitaria en el ámbito del paciente crítico; por una parte, destacar el aspecto cuantitativo, por otra la complejidad del paciente y las cargas de trabajo asociadas y finalmente el aspecto cualitativo que se relaciona directamente con el nivel de formación, habilidad y experiencia de los profesionales.

La realidad asistencial en el sistema nacional de salud español es que las enfermeras tienen como único requisito de acceso, estar en posesión del título de graduado en enfermería. Este hecho provoca que a la hora de contratar, la verificación de este requisito previo, sea el único a corroborar. Por tanto, tras egresar de las universidades e incorporarse al mercado laboral, son profesionales ampliamente válidos para cumplir aquellas atribuciones que la Ley de Ordenación de las profesiones sanitarias ${ }^{(7)}$ les faculta en el ámbito generalista. Aunque la incorporación laboral, y la asunción de las responsabilidades totales del cuidado de los pacientes se convierte en un reto estresante según lo demostrado por varios autores ${ }^{(71,73,75,77)}$. Por tanto, surgen diversos problemas a estudiar como son la necesidad de profesionales, relacionado este aspecto con el número bajo de profesionales desde un punto de vista cuantitativo y las cualidades de esas enfermeras a la hora de desarrollar la totalidad de las competencias profesionales necesarias en el ambiente asistencial.

Haciendo referencia al aspecto del pleno desarrollo de las capacidades de las enfermeras, aspecto que más se relaciona con la presente tesis, cabe citar el modelo de Patricia Benner ${ }^{(14)}$; quien desarrolla un recorrido desde la enfermera novel hasta la enfermera experta a la hora de asumir los cuidados necesarios en todos los ámbitos enfermeros. Siendo un modelo usado ampliamente en numerosos artículos científicos y en determinados servicios sanitarios ${ }^{(73,75,147)}$. Se observa como muchos campos se nutren de este modelo desde los resultados a la seguridad clínica ${ }^{(163-165)}$.

Para Patricia Benner ${ }^{(14)}$, las etapas de desarrollo constan de 5 niveles o categorías: novel, principiante avanzada, competente, eficiente y experta. Siendo este un desarrollo basado en el modelo de Dreyfus. Este modelo describe que los profesionales adquieren las habilidades de su trabajo mediante ciclos o etapas de mejoría en la profesión ${ }^{(166)}$. 
Primer nivel: Principiante.

Son aquellas enfermeras recién egresadas de los estudios universitarios o aquellas que hacen frente a un cambio de servicio o unidad desconocido previamente. El entorno y las situaciones que tienen que desarrollar son elementos fundamentales, además de las normas y guías de práctica clínica que llevan a cabo el resto del personal de la misma categoría profesional. Una de las características fundamentales es la inseguridad a la hora de aplicar cuidados relacionados con una valoración enfermera basada en criterios científicos, ya que surgen en el entorno elementos nuevos o desconocidos previamente. Si es verdad, que no es el mismo escenario el de las enfermeras recién egresadas que no poseen una experiencia en la adopción de cuidados complejos que en el caso de las enfermeras que ya cuentan con una experiencia previa que pudiera ser parcialmente válida para algunas circunstancias, pero no tienen experiencia para afrontar cuidados específicos en unidades de cuidados intensivos. En este primer nivel el profesional busca aprender a través de la experiencia específica.

Segundo Nivel: Principiante avanzada.

En este nivel se incorporan aquellas enfermeras que pueden acreditar una ejecución parcialmente adecuada, ya que han afrontado con experiencia algunas situaciones y son capaces de haber observado suficientes situaciones significativas y relacionadas con los escenarios prácticos que la mentora les ha proporcionado, o los han observado en el ámbito clínico. Es un elemento identificador de esta fase que hayan podido reconocer, identificar y comprender situaciones globales que sólo pueden ser aprendidas mediante la interacción en el contexto clínico. En este nivel, todavía las enfermeras no son capaces de distinguir las necesidades más importantes en un contexto clínico específico; y por tanto, requieren de la guía o consejo de enfermeras con experiencia suficiente para establecer prioridades y un orden de acción. Para aquellas enfermeras tutorizadas, sus mentores deben indicar pautas de actuación para cada escenario asistencial, centrando la formación en una actuación con un pensamiento analítico, con las normas y protocolos de la propia unidad. Siguen siendo en este nivel, enfermeras no competentes para hacerse cargo de la situación clínica y tienen que hacer esfuerzos para categorizar la situación y saber desenvolverse ante un escenario novedoso y recordar las pautas de actuación.

\section{Tercer nivel: Competente.}

En este nivel se incorporan enfermeras con una experiencia contrastable y que pueden hacerse cargo de las situaciones asistenciales pues llevan un tiempo haciendo frente a situaciones similares. Se suele incluir un período temporal de práctica asistencial en la misma actividad entre dos y tres años. Son capaces de recabar información, y realizar una atención apriorística valorando su actuación mediante objetivos asumidos. Son capaces, en este nivel, de realizar una actividad profesional eficaz y tienen una atención organizada y ordenada; aunque les falta capacidad y flexibilidad. Se observa que tienen que seguir formándose para poder adquirir resolutividad que les lleve al siguiente nivel de desarrollo. 


\section{Cuarto Nivel: Eficiente}

En este nivel, el profesional se hace capaz de la situación incorporando el entorno clínico como un todo y no basándose en pequeños hallazgos. Toda su actividad se basa en las experiencias previas y tiene muy desarrollado la capacidad de percibir cambios en los usuarios a su cargo. Es capaz de evaluar episodios habituales y modificar sus actuaciones en relación a estos cambios. La capacidad de comprensión global identificando situaciones y la toma de decisiones están desarrolladas y se centra en un aspecto concreto de la atención. Desempeña su labor asistencial con pacientes con características clínicas similares en un período de tiempo entre tres y cinco años. Se pasa de ser un observador externo a tener una posición de implicación total. El método de aprendizaje de elección de este nivel es el estudio de casos o simulación clínica, mediante el cual las enfermeras ponen a prueba y aprenden a hacerse cargo de una situación.

\section{Quinto Nivel: Experta.}

En este nivel las enfermeras cuentan con una gran experiencia asistencial, incluyendo una gran habilidad para percibir y recolectar datos clínicos de manera que captan de forma casi intuitiva aquellas situaciones de relevancia clínica, sin caer en situaciones o determinaciones improcedentes. Tienen un gran conocimiento de las situaciones clínicas, saben actuar en una gran variedad de situaciones y además valoran los resultados de su situación. No todas las enfermeras pueden alcanzar este nivel ya que requiere de una formación extensa y además, se agrupan en este nivel siempre y cuando la misma enfermera se identifica como experta y tiene un tiempo trabajado de al menos 5 años atendiendo al mismo tipo de pacientes. Cuando se adquiere este nivel se es capaz de gestionar situaciones complejas de una manera resolutiva, con una evaluación favorable y con unos criterios comparables. Además, suele ser identificada por el resto del equipo multidisciplinar e incluso por los propios pacientes.

A pesar de ser un modelo enunciado en 1984, es plenamente válido ya que distintos autores lo toman como referencia a la hora de generar espacios de formación destinados a las enfermeras en distintos países del mundo ${ }^{(70,73,75,147,167)}$. Como mencionan Carrillo-Algarra et al. ${ }^{(166)}$, las habilidades que las enfermeras precisan para aplicar los cuidados de enfermería requieren de amplias aptitudes cognitivas, y la incorporación de destrezas mediante la observación y la repetición de aquellos elementos novedosos a los que se enfrenten. Esta misma autora menciona, que es el ámbito asistencial, donde las enfermeras tienen que desarrollar habilidades, destrezas e incluso la intuición, para poder afrontar cuidados excelentes centrados en los resultados, encontrando como un área de especial sensibilidad a la hora afrontar áreas de competencias las enfermeras que trabajan en cuidados intensivos, donde la enfermera novel debe adquirir una relación muy estrecha entre los conocimientos teóricos y prácticos hasta adquirir un área de expertise para que la calidad de la atención no se vea afectada.

Es por tanto que el modelo de Benner es aplicable al ambiente asistencial vinculando una teoría a poder seguir a la hora de evaluar los adecuados niveles formativos que las enfermeras deben adquirir $^{(50,146)}$. La incorporación de una propia identidad profesional debe iniciarse desde los estudios de pregrado, ya que como menciona Arreciado Marañón en sus conclusiones los estudiantes de enfermería enuncian que "la enfermera es representada como una profesional con más 
competencias a desarrollar y con más autonomía de la que imaginaban”(168). Este hecho genera una visión asimétrica entre lo que observan los estudiantes en el ámbito académico y lo que se van a encontrar en la realidad laboral. Lo que potencia la afirmación de que las enfermeras precisan desarrollar un grado de competencia suficiente a la hora de afrontar los cuidados que las instituciones requieren de ellas y que no tienen a la hora de egresar ${ }^{(146)}$. Esto afianza la necesidad de seguir un plan de formación y adquisición de competencias tal y como sugiere Benner ${ }^{(14,50)}$. Arreciado Marañón observa que la disciplina enfermera está en constante evolución y adaptación a los requerimientos que los cuidados requieren, por lo que la identidad enfermera, su formación y sus responsabilidades están en continuo cambio y desarrollo ${ }^{(168)}$.

Los planes de acogida son una demanda de muchos profesionales, tal y como los participantes de la tesis de Marrero González reclaman ${ }^{(146)}$. Múltiples modelos de mentoría han sido llevados a cabo, en el mundo anglosajón también se ha optado por la presencia de programas de residencia, los objetivos de ambos modelos han sido simétricos y destinados a conseguir la retención de enfermeras noveles, mejorar la seguridad clínica y mejorar la incorporación laboral asociándose esto con una mejor satisfacción laboral en muchos ámbitos asistenciales. Uno de los factores que ha sido estudiado en este contexto, es que si estos programas son un gasto o una inversión, así Pillai et al ${ }^{(74)}$. encontraron que era preciso la retención de las enfermeras formadas en estos ámbitos durante al menos dos años para que la inversión retornará a la propia institución. Kram y Wilson ${ }^{(147)}$ también observaron que estos programas en un ambiente de déficit de enfermeras mejoraban la permanencia en las instituciones y provocaban no tener mayores gastos para reemplazar a las enfermeras que dejaban esos puestos laborales, lo que contribuía a un ahorro por parte de los empleadores. En este mismo sentido la revisión bibliográfica de Ackerson et al. ${ }^{(167)}$, encontró que los programas de residencia de las enfermeras aplicados de una manera estructurada disminuían los costes de la organización. Uno de los valores que más se enfatiza en los estudios es medir el retorno de la inversión realizada en las enfermeras, siendo positivo para la institución Ackerson et al. ${ }^{(167)} y$, Van Camp y Chappy ${ }^{(73)}$. Por otro lado, también se valora la intención de permanecer en la institución; en este punto, el estudio de Medas et al. ${ }^{(169)}$ observa que la intención de abandonar la institución era mayor de 12 meses para las enfermeras incluidas en este proyecto, elemento que también es corroborado por Eckerson ${ }^{(170)}$. Estos programas dan una oportunidad única para el aprendizaje colaborativo entre profesionales, mejorando el ambiente laboral y transformando la organización ${ }^{(77)}$. Uno de los factores derivados es la seguridad clínica que se adquiere con este tipo de formación progresiva de las enfermeras, si se logra la ausencia o el descenso de eventos adversos es sin duda un ahorro para la institución, así Baid y Hargraves ${ }^{(41)}$ reflexionan en su artículo como la formación en cuidados críticos mejora la calidad de los cuidados y la seguridad clínica, además de adoptar una serie de recomendaciones para estas mejoras profesionales.

La simulación clínica es una herramienta utilizada que desarrolla una formación en un ambiente controlado de aquellas técnicas y procedimientos a los que una enfermera puede llegar a hacer frente sin la necesidad de contar con usuarios que pudieran sufrir eventos adversos. Todas las propuestas van dirigidas a la creación de un escenario estructurado centrado en una o varias competencias, que se desarrolla con una reunión y explicación anterior (briefing) y un estudio del escenario tras el trabajo del alumno (debriefing) donde es necesario que cuente con un método de evaluación acorde al aprendizaje al que está dirigido ${ }^{(98)}$. Así Linn et al. ${ }^{(103)}$ observan como es una herramienta muy adecuada para la adquisición de competencias técnicas, trabajo en equipo, 
comunicación y la confianza de los participantes. Para conseguir el objetivo planteado es necesario, seguir un método y algunas recomendaciones tales como las especificadas por Vázquez et al. ${ }^{(40)}$, para la consecución de una formación adecuada de las enfermeras de $\mathrm{UCl}$, teniendo como opciones útiles el entrenamiento en la simulación y el aprendizaje basado en problemas para que la enfermera pueda transitar de una manera lo más pedagógica posible por los 5 niveles de formación de Kirkpatrick.

Cuadro 2. Niveles educativos de Kirkpatrick. Extraído de Vázquez ${ }^{(40)}$

Niveles educativos de Kirkpatrick

- Nivel I: participación en la actividad educativa.

- Nivel II: apreciación personal de las características del curso.

- Nivel III: adquisición de los objetivos educativos prefijados.

- Nivel IV: cambios en el desempeño y conducta de los participantes.

- Nivel V: repercusión sobre los pacientes.

Distintos estudios demuestran la efectividad en el ambiente clínico de un aprendizaje dirigido a solventar la incorporación de nuevos procedimientos y guías clínicas ${ }^{(171-173)}$. Siendo efectivo en el cambio inmediato de la conducta y en la satisfacción de los profesionales, actualmente sigue siendo necesario como menciona Low et al. ${ }^{(172)}$, la realización de más estudios longitudinales para reconocer cuanto tiempo se mantiene estas habilidades en el profesional. Hecho este último que refuerza la necesidad de una formación continuada.

Para ello es necesario adquirir espacios formativos dedicados a estas simulaciones y un cambio de mentalidad de las instituciones para ser proactivos con estas necesidades, siendo la formación continuada en estas áreas de cuidados intensivos un fin de todos los trabajadores. Trabajar juntos entre distintos profesionales y según las necesidades de cada unidad sería el ideal de todo plan formativo de los equipos de $\mathrm{UCl}$. Para ello, se ha explorado en los siguientes epígrafes de esta tesis sobre las necesidades de las enfermeras en cuidados intensivos, valorando aquellos elementos que pudieran constituirse como elementos generales. 



\section{CAPÍTULO 2}

HIPÓTESIS Y OBJETIVOS 



\section{Capítulo 2. Hipótesis y Objetivos}

\subsection{Hipótesis}

La literatura nos ha impulsado a reconocer que las competencias son el elemento central a la hora de asegurar las cualidades profesionales de las enfermeras. Este hallazgo debe ser concretado dada la repercusión que pudiera provocar en la sociedad, que considera a los profesionales sanitarios elementos indispensables para asegurar su salud. Por tanto, debemos plantear la investigación en formato de pregunta, para poder confirmar o rechazar las percepciones subjetivas derivadas de la consulta de este tema tan complejo mediante las hipótesis de investigación:

¿Qué necesidades formativas tienen las enfermeras de cuidados intensivos en España?

Esta pregunta motiva las siguientes hipótesis que guiarán el planteamiento de la presente investigación.

- Las enfermeras de cuidados intensivos tienen unas competencias claramente definidas.

- Las enfermeras de cuidados intensivos reciben una formación académica que asegura la excelencia de los cuidados prestados.

- Las enfermeras de cuidados intensivos tienen las mismas necesidades y desempeñan las mismas competencias en todo el territorio nacional.

\subsection{Objetivos}

Se observa que la definición de las competencias específicas en cuidados intensivos, y sus distintas áreas concretas, son de interés para la formación enfermera. Se han revisado distintos programas destinados a adquirir las competencias necesarias para el cuidado del paciente crítico. Las capacidades y cualidades del profesional a la hora de desempeñar su labor en $\mathrm{UCl}$ influyen en los resultados de la asistencia sanitaria.

Si la formación en competencias es un elemento apoyado por la evidencia científica, es necesario extrapolar estos hallazgos a nuestro entorno más cercano. Entorno que se vincula con enfermeras que desempeñan su labor en las $\mathrm{UCl}$ a nivel nacional, y que son los elementos críticos más reseñables que pudiéramos encontrar en este ámbito ya que son ellas las que observan su entorno, aplican cuidados, observan que formación es o sería necesaria y además, son las que poseen intrínsecamente un concepto fundamental, una necesidad de formación.

La necesidad es un elemento intrínseco de la persona en este caso en su faceta como profesional; la necesidad surge de su valoración crítica y de sus reflexiones personales; "sensación de que precisa de 
algo", y es por ello por lo que debemos acercarnos al contexto más cercano para desarrollar coincidencias que puedan ser extrapolables a otros entornos más generales como pudiera ser el ámbito nacional. Estas necesidades no se adquieren en un momento concreto, sino que se desarrollarán en uno u otro sentido prospectivamente a lo largo de su cronología como profesional. Todo ello, y para responder a las hipótesis planteadas, se formulan los siguientes objetivos:

\section{Objetivo principal:}

Validar un cuestionario que permita identificar las necesidades formativas y las competencias que desempeñan en la actualidad los enfermeros de cuidados intensivos.

\section{Objetivos secundarios:}

1. Observar las diferencias en necesidades formativas y competencias en cuidados a paciente crítico entre comunidades autónomas.

2. Observar las carencias en formación en cuidados a paciente crítico entre comunidades autónomas.

3. Definir un perfil único para enfermeros de cuidados intensivos.

4. Definir las competencias profesionales concretas que se ajusten al perfil de enfermero en cuidados intensivos.

5. Observar si los factores sociodemográficos influyen en las necesidades y competencias de los enfermeros de cuidados intensivos.

6. Explorar las percepciones de las enfermeras del grupo experto sobre las necesidades formativas.

7. Identificar áreas de consenso entre las necesidades formativas de las enfermeras de cuidados intensivos a través de la experiencia. 


\section{CAPÍTULO 3}

MATERIAL Y MÉTODO 



\section{Capítulo 3. Material y Método}

La presente investigación se desarrolla en 3 fases diferenciadas, y destinadas a cumplir los objetivos planteados. Las fases se desarrollan secuencialmente para la creación de un instrumento de medición que nos permita valorar el constructo planteado de una manera global. El método utilizado es de metodología mixta, incluyendo fases de abordaje cualitativo y cuantitativo. Esta integración de ambos métodos tiene como objetivo obtener mayor veracidad y confianza en los resultados ${ }^{(174)}$.

\subsection{Método Fase 1}

La fase 1, tiene un enfoque metodológico cualitativo. Este tipo de investigación nos permite explorar sobre las percepciones y subjetividades que las personas le confieren a las distintas vivencias que observan en los entornos en los cuales desarrollan su vida. Es un elemento común que la subjetividad de las realidades vividas por un grupo poblacional suelen tener nexos de unión, por lo cual la característica de agrupación de las personas, los convierte en un elemento de estudio desde el cual interaccionan con cada elemento ${ }^{(175)}$.

En este caso, se interroga mediante enfoque cualitativo a enfermeras de $\mathrm{UCl}$, sobre un elemento que les afecta diariamente como es su formación. Esta interpretación de los datos expresados en sus discursos permite analizar una serie de manifestaciones que son elementos centrales de los interrogados, pero no debemos quedarnos meramente con el significado como tal, sino como enuncian Dunker y Parker ${ }^{(176)}$, llevarnos a un lenguaje latente que sea inequívoco y claro para el investigador y su tema de estudio. Este elemento de análisis "no sólo reduce la explicación social al nivel del individuo sino que invita a cada individuo a creer que las claves de los procesos sociales están en su propia experiencia”"(177). Por tanto, se debe partir de la idea de que "los participantes producen activamente las realidades por medio de los significados atribuidos a ciertos acontecimientos y objetos, y que la investigación social no puede escapar a estas atribuciones de significados" ${ }^{\prime 178)}$. Es por esta realidad, que se selecciona el constructivismo como marco cualitativo a la hora de analizar el objeto de esta primera fase de la tesis ya que son las personas las que le dan significado a sus realidades cotidianas generando un constructo humano que les es propio y es modificado por el entorno cercano de manera dinámica, estando asociado a los cambios continuos de los grupos humanos. Hay que hacer énfasis además, a la pertenencia a organizaciones complejas como las sanitarias que poseen significados propios $^{(178,179)}$.

Tras esta elección epistemológica es procedente seleccionar la estrategia metodológica de aproximación al elemento de estudio, centrada en interrogar sobre la construcción de los significados de la experiencia vivida por un grupo de profesionales en su interacción social como enfermeras de cuidados críticos. Esta aproximación nos guía hacia la elección de la fenomenología, ya que el núcleo central de investigación no es otro sino las propias necesidades formativas de este grupo de profesionales. Este fenómeno, por tanto, no puede ser entendido fuera de su contexto, por lo que los hallazgos no pueden ser generalizados a otros contextos distintos, esta interacción entre profesional y entorno de cuidados, les coloca en una posición de expertise difícil de alcanzar desde cualquier otro prisma ${ }^{(179)}$. Además, hay que valorar los elementos latentes inherentes a una realidad común de los sujetos ${ }^{(175)}$. Por tanto, hay que integrar en esta investigación los criterios postulados 
por Ruiz-Olabuénaga ${ }^{(175)}$ que se deben mantener en todo momento como criterios de calidad en la investigación cualitativa: la credibilidad, la transferibilidad, la dependencia y la confirmabilidad.

Cuadro 1. Técnica para asegurar la calidad de la investigación.

\begin{tabular}{|l|l|}
\hline Credibilidad & Técnicas de triangulación de la información. \\
\hline Transferibilidad & Muestreo intencional \\
\hline Dependencia & $\begin{array}{l}\text { El proceso de control seguido por el investigador examinado por un } \\
\text { investigador externo. }\end{array}$ \\
\hline Confirmabilidad & Se controla a través de un agente externo. \\
\hline
\end{tabular}

Así para entender un proceso de extracción de información como el cualitativo es necesario utilizar el enfoque aportado por Taylor-Bogdan ${ }^{(180)}$ con sus tres momentos esenciales: descubrimiento, codificación y relativización. $Y$ es que el conocimiento en profundidad requiere de un análisis pormenorizado de los datos esenciales del estudio.

Cuadro 2. Momentos esenciales de la investigación cualitativa según Taylor-Bogdan ${ }^{(174)}$

\begin{tabular}{|l|l|}
\hline Descubrimiento & $\begin{array}{l}\text { Entender el tema explorado examinando los datos de todos los modos } \\
\text { posibles. }\end{array}$ \\
\hline Codificación & $\begin{array}{l}\text { Reunión y análisis de todos los datos que se refieren a temas, ideas, } \\
\text { conceptos, interpretaciones y enunciados. }\end{array}$ \\
\hline Relativización & Interpretar los datos en el contexto en que fueron recogidos.
\end{tabular}

Por tanto, hay que desarrollar un modelo en el cual la información fluya a través de sus significados extrayendo aquellos nexos que le son comunes a la hora de poder identificar una realidad entrelazada entre los conceptos latentes que afectan a un mismo fenómeno vivido por las enfermeras de $\mathrm{UCl}$ y comunicado a través de sus contestaciones ${ }^{(181)}$. El elemento central de esta investigación está centrado en las necesidades formativas y es explorado a través de ítems competenciales extraídos de la bibliografía.

Como elemento central de esta realidad queda, por tanto, la necesidad de recoger los datos para cumplir el método propuesto en párrafos anteriores. Distintos autores afirman que la entrevista semiestructurada es un elemento adecuado a la hora de guiar discursos y extraer información dirigida a un entorno específico ${ }^{(175,178-180)}$. Nuestros participantes se integran en esta investigación no como sujetos únicos, sino como una representación de un grupo común con peculiaridades que les permiten emitir información relevante sobre su área de experto ${ }^{(178)}$. $Y$ es que como menciona Flick ${ }^{(178)}$, uno de los principales retos del investigador es determinar la información relacionada con el área de interés investigada. Es importante en estas entrevistas de expertos seguir un guion de entrevista, centrado este en el objeto de estudio, para evitar la pérdida en temas no relacionados. El guion permite al entrevistado responder libremente sobre la materia y además, genera un elemento de seguridad para el investigador al evitar presentarse ante el experto como un interlocutor incompetente ${ }^{(175,178)}$. 
Tras los elementos explorados en el apartado de introducción, la elección de la guía de "Competencias enfermeras según la EfCCNa para las enfermeras de cuidados intensivos en Europa" ${ }^{(45,182)}$ se convierte en un instrumento válido desde el cual extraer una serie de preguntas abiertas que respeten la estructura temática.

Estas preguntas se consensuaron por el equipo investigador formado por $\mathrm{M} \underline{a}$ Desamparados Bernat Adell, Luciano Santana Cabrera y Yeray Gabriel Santana Padilla; y debieron cumplir cuatro criterios fundamentales: ausencia de dirección, especificidad, amplitud y la profundidad ${ }^{(178)}$. Las preguntas interrogan sobre todas las vertientes que un mismo elemento pueda poseer, y debe posibilitar la comprensión del constructo a analizar. La elaboración del guion de entrevista posibilita la creación de un elemento común para todos y cada uno de los entrevistados. En la elaboración del guion se respetó la estructura del documento origen, y aquellos elementos extraídos, así como la adición de áreas transversales consideradas de clasificación compleja entre distintos ámbitos exploratorios. Este método permite reconocer las experiencias de los entrevistados, sus opiniones y vivencias sobre el tema explorado. Explorando su visión sobre áreas de conocimientos, habilidades y destrezas que son necesarias de ser abordadas mediante enseñanza a las enfermeras de UCI. La entrevista se realizó mediante consenso entre el investigador principal y los encuestados fijando fecha y hora, adaptándose a la disponibilidad de los encuestados. Las encuestas se realizaron en lugares apropiados elegidos por los encuestados y que no tuvieran elementos distorsionadores de la entrevista, así 7 entrevistados eligieron la realización de la encuesta en su domicilio particular, 7 en dependencias hospitalarias tipo despacho o sala de reuniones y 1 se realizó en una sala de estudio de una biblioteca pública. Todas las entrevistas fueron grabadas mediante dispositivo digital, comenzando con una breve explicación de los objetivos y temas de la entrevista, solicitando su consentimiento previo. Las entrevistas fueron dirigidas a través de un guion único para todos los entrevistados que se incluye en el Anexo 1.

\subsection{Método Fase 2}

En esta fase, tras la extracción de la información relevante por parte del equipo investigador, se generó un cuestionario que cohesionaba la información recogida en la primera fase. Estructurado este procedimiento como técnica Delphi, siendo esta técnica ampliamente utilizada en entornos científicos desde su creación hace más de 50 años. El elemento central de esta técnica es buscar un consenso fiable entre un grupo de expertos a través de una serie de cuestionarios respondidos de manera anónima y secuencial ${ }^{(183)}$. Según expone Landeta ${ }^{(184)}$, el método Delphi es una herramienta que ayuda a la investigación para obtener datos confiables de un grupo de expertos y en varias ocasiones puede proporcionar solución a problemas complejos; creando consensos tras los cuales explorar realidades diversas, siendo una técnica flexible y adaptable en áreas de incertidumbre $(185,186)$

Para desarrollar esta segunda fase nos apoyamos en los resultados de la primera; lo que constituye una modificación de la técnica Delphi, ya descrita por Keeney et al. ${ }^{(187)}$, debido a que el primer contacto es desarrollado por entrevistas presenciales a los expertos; por tanto, se trata de una técnica Delphi modificada. La selección de los expertos es fundamental para poder extraer la máxima información sobre el tema a explorar ${ }^{(184,187)}$. Esta técnica ya ha sido usada anteriormente por otros estudios de la ciencia enfermera ${ }^{(51,80,84,141,188-193)}$. Las características de los expertos para poder ser 
elegidos fueron: ser enfermeras con experiencia en cuidados intensivos de al menos tres años en la unidad de referencia elegida (UCI de adultos del Hospital Universitario Insular de Gran Canaria) y consentir participar en el estudio.

Se extrajo información de consenso, por parte del equipo investigador sobre los ámbitos explorados, y se les hicieron llegar a los participantes las conclusiones de los investigadores mediante correo electrónico. Posteriormente los participantes evaluaron las necesidades formativas detectadas, marcando sus respuestas mediante áreas de consenso y/o divergencia mediante puntuaciones en escala tipo Likert por grado de conformidad (muy de acuerdo hasta nada de acuerdo) e incluyendo texto libre para dar su opinión sobre el cuestionario generado. El equipo investigador estuvo compuesto por enfermeras con formación en investigación cualitativa. Se realizaron sucesivas rondas hasta lograr un consenso sobre las preguntas. Se precisaron de tres rondas para poder alcanzar un documento aceptado por todos los expertos. Para valorar este cuestionario definitivo se analizaron las respuestas por parte de los expertos, evaluando la validez interna del mismo.

\subsection{Método Fase 3}

Estudio descriptivo y transversal realizado mediante cuestionario electrónico de ámbito nacional. El cuestionario fue producido a través de la técnica Delphi, siendo un cuestionario estructurado y autoadministrado. El cuestionario fue pretestado, por varias enfermeras para detectar errores de comprensión siendo subsanados aquellos errores detectados. Al utilizar las tecnologías de la información para su difusión se garantizó el anonimato de los participantes a nivel nacional, lo que dio libertad al encuestado para expresar de manera libre sus opiniones sobre el tema de estudio. Al objeto de seguir modelos ya publicados, el equipo investigador consideró mantener la estructura que la EfCCNa desarrolló en $2004^{(45)}$.

Al tratarse de un cuestionario autoadministrado se incluyó en la primera parte, una breve explicación del estudio y de quien lo estaba llevando a cabo; además, de los permisos con los que contó. Recordando que era anónimo, y agradeciendo la colaboración en el mismo. El cuestionario se distribuyó mediante medios telemáticos por los colaboradores en sus respectivos centros laborales a las enfermeras de las $\mathrm{UCl}$. El cuestionario constaba de 66 ítems de respuesta tipo Likert, distribuidos de la siguiente manera según las áreas exploradas.

Tabla 1. Ítems de la encuesta

\begin{tabular}{|lcc|}
\hline \multicolumn{1}{|c|}{ Ámbitos } & Preguntas incluidas & Número de preguntas \\
\hline Ámbito Clínico & P1 hasta P18 & 18 \\
\hline Ámbito Profesional & P19 hasta P32 & 14 \\
\hline Ámbito de la Gestión & P33 hasta P48 & 16 \\
\hline Ámbito Educativo y de desarrollo & P49 hasta P54 & 6 \\
\hline Dimensiones y formación & P55 hasta P66 & 12 \\
\hline
\end{tabular}

Las preguntas redactadas tal y como las recibieron los participantes, se encuentran en el Anexo 2. El tiempo estimado para la cumplimentación de la encuesta era de 15 minutos aproximadamente. 


\section{4. Ámbito de Estudio}

El ámbito está diferenciado claramente entre las tres fases del estudio. En la fase 1 y fase 2, fue un estudio unicéntrico. La unidad de referencia fue la UCl de adultos del Hospital Universitario Insular de Gran Canaria (Canarias), constituida como unidad polivalente de 30 camas.

En la fase 3 del estudio, el cuestionario fue difundido a nivel nacional en los centros sanitarios que contaban con $\mathrm{UCl}$, que aceptaron participar y que dieron su visto bueno a los permisos correspondientes. Participaron en esta fase 70 centros sanitarios que contaban con un total de 85 $\mathrm{UCl}$, que se detallan ordenados por CCAA y provincia en la tabla siguiente.

Tabla 2. Centros colaboradores

\begin{tabular}{|c|c|c|}
\hline $\begin{array}{l}\text { Comunidad } \\
\text { Autónoma }\end{array}$ & Provincia & Hospital \\
\hline \multirow{7}{*}{ Andalucía } & Almería & $\begin{array}{l}\text { Hospital de Poniente. } \\
\text { Complejo Hospitalario Torrecárdenas de Almería. }\end{array}$ \\
\hline & Cádiz & Hospital Universitario Puerta del Mar. \\
\hline & Córdoba & $\begin{array}{l}\text { Hospital Infanta Margarita de Cabra. } \\
\text { Hospital Universitario Reina Sofía de Córdoba. }\end{array}$ \\
\hline & Granada & Hospital Clínico Universitario de Granada. \\
\hline & Jaén & Hospital Universitario de Jaén. \\
\hline & Málaga & $\begin{array}{l}\text { Hospital Universitario Virgen de la Victoria. } \\
\text { Hospital Regional Universitario de Málaga Carlos Haya. } \\
\text { Hospital Comarcal de la Axarquía. } \\
\text { Hospital General Serranía de Ronda. }\end{array}$ \\
\hline & Sevilla & $\begin{array}{l}\text { Hospital Universitario Virgen de la Macarena. } \\
\text { Hospital Universitario de Valme. }\end{array}$ \\
\hline \multirow{2}{*}{ Aragón } & Huesca & Hospital General San Jorge de Huesca. \\
\hline & Zaragoza & Hospital Universitario Miguel Servet. \\
\hline Asturias & Asturias & $\begin{array}{l}\text { Hospital Valle del Nalón. } \\
\text { Hospital Universitario de Cabueñes. }\end{array}$ \\
\hline \multirow[t]{2}{*}{ Canarias } & Las Palmas & $\begin{array}{l}\text { Hospital Universitario Insular de Gran Canaria- Complejo Hospitalario } \\
\text { Universitario Insular Materno-Infantil. } \\
\text { Hospital Universitario Materno-Infantil de Canarias- Complejo } \\
\text { Hospitalario Universitario Insular Materno-Infantil. } \\
\text { Hospital Universitario de Gran Canaria Dr. Negrín. } \\
\text { Hospital Insular de Fuerteventura. } \\
\text { Hospital San Roque Maspalomas. }\end{array}$ \\
\hline & Tenerife & $\begin{array}{l}\text { Hospital Universitario de Canarias. } \\
\text { Hospital Universitario Nuestra Señora de la Candelaria. }\end{array}$ \\
\hline Cantabria & Cantabria & Hospital Universitario Marqués de Valdecilla. \\
\hline \multirow{2}{*}{$\begin{array}{l}\text { Castilla-La } \\
\text { Mancha }\end{array}$} & Albacete & Hospital de Hellín. \\
\hline & Ciudad Real & Hospital General La Mancha Centro. \\
\hline
\end{tabular}




\begin{tabular}{|c|c|c|}
\hline $\begin{array}{l}\text { Comunidad } \\
\text { Autónoma }\end{array}$ & Provincia & Hospital \\
\hline & Cuenca & Hospital Virgen de la Luz de Cuenca. \\
\hline & Guadalajara & Hospital Universitario de Guadalajara. \\
\hline & Toledo & Hospital Nuestra Señora del Prado de Talavera. \\
\hline \multirow{5}{*}{ Castilla y León } & Burgos & Complejo Asistencial de Burgos. \\
\hline & León & Hospital del Bierzo-Ponferrada. \\
\hline & Salamanca & Complejo Asistencial Universitario de Salamanca (CAUSA). \\
\hline & Valladolid & Hospital Universitario de Valladolid. \\
\hline & Zamora & Hospital Virgen de la Concha de Zamora. \\
\hline \multirow{2}{*}{ Cataluña } & Barcelona & $\begin{array}{l}\text { Hospital de la Santa Creu y Sant Pau. } \\
\text { Hospital Universitari de BellVitge. }\end{array}$ \\
\hline & Tarragona & $\begin{array}{l}\text { Hospital Sant Pau y Santa Tecla. } \\
\text { Hospital Universitari Joan XXIII. }\end{array}$ \\
\hline \multirow{3}{*}{$\begin{array}{l}\text { Comunidad } \\
\text { Valenciana }\end{array}$} & Alicante & $\begin{array}{l}\text { Hospital de Dénia. } \\
\text { Hospital General Universitario de Elda Virgen de la Salud. } \\
\text { Hospital Comarcal Marina Baixa. }\end{array}$ \\
\hline & Castellón & $\begin{array}{l}\text { Hospital General Universitario de Castellón. } \\
\text { Hospital Comarcal de Vinaroz. }\end{array}$ \\
\hline & Valencia & $\begin{array}{l}\text { Hospital Universitario Dr. Peset. } \\
\text { Hospital Lluís de Alcanyis de Xàtiva. } \\
\text { Hospital Universitario y Politécnico La Fe. }\end{array}$ \\
\hline \multirow{2}{*}{ Extremadura } & Badajoz & $\begin{array}{l}\text { Hospital de Mérida. } \\
\text { Hospital Infanta Cristina. Complejo Hospitalario Universitario de Badajoz. }\end{array}$ \\
\hline & Cáceres & Hospital San Pedro de Alcántara de Cáceres. \\
\hline \multirow{2}{*}{ Galicia } & A Coruña & Complejo Hospitalario Arquitecto Marcide. \\
\hline & Pontevedra & $\begin{array}{l}\text { Hospital Álvaro Cunqueiro -Complejo Hospitalario Universitario de Vigo- } \\
\text { EOXI Vigo. }\end{array}$ \\
\hline Islas Baleares & $\begin{array}{l}\text { Islas } \\
\text { Baleares }\end{array}$ & $\begin{array}{l}\text { Hospital Universitario Son Espases. } \\
\text { Hospital Comarcal de Inca. } \\
\text { Hospital de Manacor. } \\
\text { Hospital Juaneda Miramar. } \\
\text { Hospital Can Misses. }\end{array}$ \\
\hline La Rioja & La Rioja & Hospital San Pedro de La Rioja. \\
\hline Madrid & Madrid & $\begin{array}{l}\text { Hospital Universitario Severo Ochoa. } \\
\text { Hospital General de Villalba. } \\
\text { Hospital Universitario de Móstoles. } \\
\text { Hospital Clínico San Carlos. } \\
\text { Hospital Universitario La Paz. } \\
\text { Hospital General Universitario Gregorio Marañón. } \\
\text { Hospital Universitario de Getafe. } \\
\text { Hospital Universitario Infanta Leonor. }\end{array}$ \\
\hline
\end{tabular}




\begin{tabular}{|l|l|l|}
\hline $\begin{array}{l}\text { Comunidad } \\
\text { Autónoma }\end{array}$ & Provincia & Hospital \\
\hline Murcia & Murcia & $\begin{array}{l}\text { Hospital General Universitario Morales Meseguer. } \\
\text { Hospital General Universitario Reina Sofía de Murcia. }\end{array}$ \\
\hline País Vasco & Bizkaia & $\begin{array}{l}\text { Hospital Universitario de Basurto - OSI Bilbao Basurto. } \\
\text { Hospital Galdakao-Usansolo - OSI Barrualde-Galdakao. }\end{array}$ \\
\hline
\end{tabular}

\subsubsection{Selección de la muestra}

Para las fases 1 y 2 , la muestra a estudio se seleccionó, siguiendo un muestreo por conveniencia a partir de una plantilla de 72 enfermeras. Como criterios de inclusión se aceptaron el tener una experiencia en $\mathrm{UCl}$ igual o superior a tres años y colaborar en el estudio de forma voluntaria y desinteresada. Se consideró alcanzada la muestra adecuada cuando se obtuvo la saturación de los datos determinado por el equipo investigador. La muestra fue de 15 participantes, cuya distribución se muestra en la tabla 3.

Tabla 3. Participantes 1 y 2

\begin{tabular}{|c|c|c|c|c|}
\hline Identificación & Sexo & Edad & Experiencia en UCI & $\begin{array}{c}\text { Experiencia total como } \\
\text { enfermera }\end{array}$ \\
\hline N1 & Hombre & 38 años & 14 años & 16 años \\
\hline N2 & Mujer & 39 años & 12 años & 16 años \\
\hline N3 & Mujer & 38 años & 8 años & 14 años \\
\hline N4 & Mujer & 31 años & 4 años & 8 años \\
\hline N5 & Mujer & 40 años & 16 años & 16 años \\
\hline N6 & Mujer & 37 años & 8 años & 16 años \\
\hline N7 & Hombre & 38 años & 13 años & 14 años \\
\hline N8 & Mujer & 37 años & 11 años & 15 años \\
\hline N9 & Mujer & 35 años & 13 años & 13 años \\
\hline N10 & Mujer & 37 años & 13 años & 15 años \\
\hline N11 & Hombre & 48 años & 14 años & 21 años \\
\hline N12 & Mujer & 37 años & 11 años & 16 años \\
\hline N13 & Mujer & 34 años & 10 años & 12 años \\
\hline N14 & Mujer & 39 años & 13 años & 14 años \\
\hline N15 & Mujer & 37 años & 11 años & 15 años \\
\hline
\end{tabular}

En la fase 3 del estudio, se realizó la difusión por parte de los colaboradores de los distintos centros a las enfermeras de $\mathrm{UCl}$ de los distintos centros. Los colaboradores de los distintos centros del estudio se encuentran nombrados en el anexo 3 y fueron los responsables de difundir la encuesta entre el personal de su centro, y de suministrar los datos descriptivos de sus unidades.

\subsubsection{Tamaño muestral}

Los datos para calcular el tamaño muestral de la tercera fase fueron suministrados por los colaboradores de los distintos centros participantes. Así el alcance del presente estudio, incluyó a 70 centros sanitarios con un global de camas hospitalarias de 38283. Las 85 unidades de UCl 
representaron un total de 1230 camas de $\mathrm{UCl}$, siendo la población total de las enfermeras de $\mathrm{UCl}$ en el período de estudio de $2965(\mathrm{~N}=2965)$.

El muestreo probabilístico determinó que para una significancia de los datos extraídos del $95 \%$ y con un margen de error del 4\%, para la población explorada de 2965 enfermeras, se precisaba la captación de 500 encuestas cumplimentadas $(n=500)$. Este fue el objetivo para obtener significación estadística con un valor $p \leq 0,05$.

Sin embargo, para poder cumplir el objetivo de validar el cuestionario debemos seguir las recomendaciones que tanto para el análisis factorial exploratorio (AFE) y los análisis factoriales confirmatorios (AFC) están vigentes actualmente. Los AFE y AFC son herramientas para establecer la validez del constructo planteado. Siendo posible su utilización cuando se usan variables ordinales y/o dicotómicas mediante matrices policóricas ${ }^{(194)}$. Estas matrices surgen del hecho de la existencia de variables latentes o factores comunes que explican las respuestas de un test ${ }^{(195)}$. Para la identificación del tamaño muestral, es importante seguir las recomendaciones actuales que defiende LLoret-Segura et al. ${ }^{(195)}$ en su revisión:

- Condición óptima: cuando las saturaciones son superiores a .70, y el número de variables por factor es adecuado -al menos 6 ítems por factor-, un tamaño muestral de 150 o 200 casos parece suficiente para obtener estimaciones precisas de los coeficientes en el AFE.

- Condición moderada: cuando disponemos de comunalidades entre .40 y .70, y el número de variables por factor es de 3-4 ítems, también se acepta un tamaño de 200 casos.

- Condición mínima: cuando las comunalidades son bajas, en torno a 0,30, y el número de variables por factor es de 3 ítems, se precisa una muestra mínima de 400 casos.

Al estar en una fase de planificación, y desconocer a priori los resultados a obtener, nos apoyamos en el tamaño muestral de 500 encuestas mencionado anteriormente. En este punto, se determinó necesario ajustar nuestra muestra al menos hasta este número de registros, ya que superaba los valores de la condición mínima que los autores requieren para la realización de este tipo de análisis estadísticos. El AFE realizado fue a través de matrices policóricas mediante rotación promin, siendo la rotación que daba una solución con una mayor consistencia interna ${ }^{(194,195)}$. Estos elementos han sido plenamente usados a la hora de la validar escalas y crear constructos propios ${ }^{(196-199)}$. Creando una serie de subescalas que fueron validadas mediante un análisis factorial confirmatorio que se realizó mediante programa IBM AMOS, y permitió contrastar el modelo construido anteriormente por el AFE.

El número de encuestas recibidas en la fase 3, fueron de 630 registros, a las cuales se les aplicaron los criterios de inclusión y exclusión.

\subsubsection{Criterios de inclusión y de exclusión}

En la fase 1 y 2 se aceptaron como criterios de inclusión el tener una experiencia en UCI igual o superior a tres años y colaborar en el estudio de forma voluntaria y desinteresada. Sólo se aceptaron aquellos participantes que además consintieron la grabación en audio digital de la entrevista en la fase 1. 
En la fase 3, sólo se aceptaron aquellos participantes que contestaran de forma afirmativa el consentimiento incluido en la encuesta digital. Y recordando en todas las encuestas digitales "el cuestionario es totalmente anónimo y la participación es voluntaria. Los datos obtenidos serán confidenciales (Ley 3/2018 de Protección de Datos Personales y garantía de los derechos digitales) ${ }^{(200)}$, los datos sólo serán usados con fines de carácter científico. Cumpliendo la ley de investigación biomédica 14/2007 y el reglamento UE 2016/679 de confidencialidad, pudiendo ejercer los derechos referidos (acceso, rectificación, cancelación, oposición, limitación del tratamiento de datos que sean incorrectos, solicitar una copia o que se trasladen a terceros) ante el doctorando en el correo al257600@uji.es".

En la fase 3, se excluyeron además aquellos registros que contestaron de manera errónea alguna de las dos respuestas control incluidas en el cuestionario digital para evitar respuestas automáticas. Las preguntas control fueron las siguientes:

Tras la pregunta 22:

Si esta rellenando, esta encuesta de manera concienzuda, marque en esta pregunta la respuesta cinco (pregunta control)

12345678910

Tras la pregunta 43:

Si esta rellenando, esta encuesta de manera concienzuda, marque en esta pregunta la respuesta tres (pregunta control)

Tras la aplicación de estas preguntas control para evitar respuestas automáticas, se observaron 62 registros que fallaron alguna de las preguntas control. De estos 62 registros, 49 (79,03\%) fallaron las dos preguntas y las 13 restantes (20,96\%) fallaron una de las preguntas. Quedando constituida la muestra final de la fase 3 en $n=568$.

\subsubsection{Consideraciones éticas y procedimientos de aprobación}

Tanto el proyecto como el estudio cumplió con la legislación vigente en materia de investigación biomédica.

\subsubsection{Fase 1 y 2 :}

- La investigación fue aprobada por la Comisión Deontológica de la Universitat Jaume I de Castellón con el número de referencia 13/2017 de fecha 15 de septiembre de 2017 (Anexo 4).

- El propósito de la investigación fue explicado a todos los participantes. Se solicitó el consentimiento verbal antes del inicio de las entrevistas.

- Se informó a los participantes que las entrevistas serían grabadas mediante audio formato digital. Y que los datos extraídos de la investigación serían datos de carácter confidencial y solo serían usados con fines de investigación en cumplimiento de la Declaración de Helsinki y de la Ley Orgánica 15/1999 de Protección de Datos de Carácter Personal y de su posterior actualización en la Ley Orgánica 3/2018. 
- Las grabaciones serían custodiadas durante 5 años que fue el período de producción científica estipulado.

\subsubsection{En la fase 3:}

- Debido al carácter multicéntrico de esta fase, se precisó de determinados permisos y autorizaciones según las normativas y procedimientos de cada Centro Sanitario.

- Todos los centros contaron con un investigador colaborador, para la difusión de la encuesta entre los profesionales. Se incluyen los colaboradores en el Anexo 3.

- Los Comités Éticos de Investigación Clínica (CEIC) que valoraron este estudio previa a la difusión de las encuestas fueron los siguientes: CEIC Provincial de Las Palmas (centro del investigador principal), CEIC del Departamento de Salud de Deniá, CEIC de Cantabria (IDIVAL), CEIC del Hospital Universitario Dr. Peset, CEIC Hospital General Universitario de Elda, CEIC del Hospital Universitari de Bellvitge, Comité Ética de Investigación con medicamentos (CEIm) área de salud de Valladolid, Comisión de investigación del Hospital Comarcal de Inca, CEIm de la Gerencia de Atención Integrada de Albacete, CElm del Hospital Universitario y Politécnico de la Fe, CEIm del Hospital Universitario Severo Ochoa, CEIC de Almería, Comisión de Investigación del Hospital Universitario Son Espases de Palma de Mallorca, CEIm del área de salud de Zamora, Comité ético de la investigación clínica de la Rioja (CEImCLAR), CEIC de la Provincia de Jaén, Comisión de Evaluación de Trabajos de Investigación (CETI) Área VI-Vega media del Segura del Servicio Murciano de Salud. Anexo 5.

- Además de los permisos de los citados comités, algunos centros solicitaron la autorización de otras figuras, como las que se detallan a continuación: Conformidad de la Gerencia del Complejo Hospitalario Universitario Insular Materno-Infantil (centro del investigador principal), Autorización Dirección de Enfermería del Hospital Universitario de Móstoles, Dirección de Enfermería de Atención Especializada del área de salud de Badajoz, Dirección de Enfermería del Hospital Universitari de Bellvitge, Conformidad del Director de Enfermería del Hospital Clínico Universitario de Valladolid, Autorización del Gerente de Asistencia Sanitaria del Complejo Asistencial de Zamora, Conformidad del Gerente del Hospital Universitario Marqués de Valdecilla, Conformidad de la directora de Enfermería del Hospital Universitario Marqués de Valdecilla. Anexo 5.

\subsubsection{Periodo de estudio}

El período de estudio fue de entre febrero y mayo de 2017 para la fase 1. Para la fase 2, el período de estudio fue entre junio y septiembre de 2017.

En la fase 3 debido a los requisitos de difusión de cada uno de los centros, el período de difusión fue entre el 31/10/2017 hasta el 31/10/2018. Logrando así un período de difusión de 3 meses en cada centro.

\subsubsection{Instrumentos del estudio}

En la fase 1, se realizó una guía para la realización de la entrevista. Realizada a través de una encuesta semiestructurada que fue confeccionada siguiendo los ámbitos evaluados por la EfCCNa, y de la cual se extrajeron preguntas concretas para cada uno de los ámbitos y subámbitos tratados en 
este documento ${ }^{(48)}$. Además, se incluyó un apartado 5 , donde se englobó aquella formación considerada como elemento transversal, para los anteriores 4 ámbitos. El equipo investigador consideró todos los ítems y la pertinencia de cada uno de ellos. Se incluyen las preguntas de la fase 1 en el Anexo 1. Los audios fueron analizados por enfermeras con formación cualitativa, siendo los componentes de estos análisis los siguientes: Tamara Linares Pérez, José Alemán González, Rogelio Fernando Acosta Rodríguez y Yeray Gabriel Santana Padilla.

En la fase 2, el instrumento de estudio fue elaborado inicialmente a través de las respuestas de los expertos participantes en la fase 1. Mediante la determinación por parte del equipo investigador de las áreas de mayor consenso entre los entrevistados. El equipo investigador de esta fase es el mismo que en la fase 1. Así se realizó una técnica Delphi modificada, donde se extrajeron distintas conclusiones de los discursos de los expertos. Esto fue aprovechado por los investigadores para la creación de un cuestionario ad Hoc, siendo este una fase preliminar. Cada uno de los investigadores identificó una serie de preguntas, que se distribuyeron de la siguiente forma, ver tabla 4:

Tabla 4. Preguntas seleccionadas tras la primera ronda

\begin{tabular}{|c|c|c|c|c|c|c|}
\hline Investigador & $\begin{array}{l}\text { Ámbito } \\
\text { clínico }\end{array}$ & $\begin{array}{c}\text { Ámbito } \\
\text { Profesional }\end{array}$ & $\begin{array}{l}\text { Ámbito de } \\
\text { Gestión }\end{array}$ & $\begin{array}{c}\text { Ámbito educativo } \\
\text { y de desarrollo }\end{array}$ & $\begin{array}{l}\text { Dimensiones y } \\
\text { formación }\end{array}$ & Total \\
\hline Investigador 1 & 19 & 12 & 22 & 4 & 10 & 67 \\
\hline Investigador 2 & 11 & 10 & 16 & 3 & 5 & 45 \\
\hline Investigador 3 & 7 & 8 & 18 & 3 & 10 & 46 \\
\hline Investigador 4 & 19 & 11 & 28 & 5 & 8 & 71 \\
\hline
\end{tabular}

A la hora de analizar el contenido de las preguntas generadas por los investigadores, se observaron preguntas coincidentes y otras divergentes, por lo que la primera ronda estaba compuesta por 92 preguntas, que se les hizo llegar a todos los participantes para que valoraran su contenido mediante puntuaciones (tipo Likert) y texto libre. En la segunda ronda, fueron retiradas las que consideraban redundantes y/o poco relevantes según el criterio de los expertos, esto provocó la retirada de 14 preguntas, quedando 78 preguntas analizando y evaluando las puntuaciones asignadas (media y mediana). En la tercera ronda, se enviaron las 78 preguntas elegidas para ser valoradas en escala tipo Likert de 10 puntos, analizando de cada ítem (media y mediana). Se consideró a priori consenso a partir de la segunda ronda una media igual o superior a 6,1 y una mediana igual o superior a 7. Este hecho provocó que en la tercera fase se retiraran 12 preguntas, quedando constituido el documento definitivo en 66 ítems. Este último documento de 66 ítems, se les reenvío a los expertos para que dieran sus puntuaciones sobre las necesidades formativas de las enfermeras, respuestas que identifican sus percepciones sobre las necesidades formativas de las enfermeras, y que servirán de utilidad en la fase 3 , para comparar este grupo con la muestra nacional.

En la fase 3, se envió el cuestionario mediante medios telemáticos a las distintas unidades colaboradoras, recogidas en el Anexo 2. La encuesta incluía los 66 ítems elegidos además de las variables sociodemográficas que definían las características de los encuestados. 


\subsubsection{Variables}

Las variables del cuestionario de la fase 3 estaban definidas en formato escala tipo Likert de (1 a 10 puntos). El valor 1 representaba "poco importante, o en desacuerdo con el enunciado expresado" y el valor 10 respondía a "muy importante o totalmente de acuerdo con el enunciado expresado". El cuestionario se estructuró en secciones que corresponden con los siguientes ámbitos y que estaban explicados en la parte superior de cada sección para el conocimiento de los participantes:

- Ámbito Clínico: Este ámbito busca conocer y fomentar unos cuidados enfermeros que sean seguros y efectivos para el paciente crítico y sus familiares.

- Ámbito Profesional: En este ámbito, se busca fomentar y potenciar la práctica profesional en cuidados intensivos.

- Ámbito de la Gestión: Este ámbito busca explorar el desarrollo de conocimientos y habilidades en el campo de la gestión y organización relacionada con las enfermeras de cuidados intensivos.

- Ámbito Educativo y de desarrollo: Este ámbito se centra en explorar las competencias que influyen en la educación y el desarrollo de las enfermeras de cuidados intensivos.

- Dimensiones y formación: En este apartado se busca explorar como se puede mejorar la excelencia de los cuidados tanto del personal novel como veterano, incluyendo elementos transversales de los anteriores ámbitos.

Las variables sociodemográficas estaban determinadas por la descripción de la muestra, por tanto, se incluyeron variables tanto del encuestado como del entorno laboral donde desarrollaba su labor como enfermera. Se incluyeron las características del hospital (clasificación del hospital, relación con la universidad, número de camas), las características de la $\mathrm{UCl}$ (tipo de $\mathrm{UCl}$, número de camas de $\mathrm{UCl}$, ratio enfermera: paciente, provincia en la que está la UCl). En cuanto a las características de los encuestados las variables fueron: sexo, edad (en rango de edades), experiencia laboral total y experiencia laboral en UCI (en rango de años), máximo nivel académico alcanzado. Además, se incluyeron preguntas dicotómicas para incluir las opiniones de los encuestados sobre la necesidad de experiencia laboral previa en otras unidades antes de trabajar en $\mathrm{UCl}$, la necesidad de un EIR (formación sanitaria especializada tipo enfermera interino residente) en cuidados críticos, la existencia de planes de acogida en sus unidades y la necesidad de planes de acogida previa. Estos dos últimos ítems contaban con apartados de texto libre para que pudieran explicar en qué consistían o debieran consistir los planes de acogida.

Para explicar las respuestas sobre la pregunta dicotómica "la necesidad de experiencia laboral previa en otras unidades antes de trabajar en $\mathrm{UCl}^{\prime \prime}$, se crearon dos preguntas condicionales para aquellas respuestas afirmativas, con 4 opciones para la experiencia laboral en hospitalización y/o experiencia laboral en urgencias-quirófano. 


\subsubsection{Registro y análisis de datos. (Análisis estadístico)}

Los datos de la fase 1 se analizaron mediante técnica cualitativa, por lo que fue un elemento central de esta fase el registro mediante la grabación digital de todas las entrevistas, en formato mp3. Este hecho es fundamental para que las enfermeras del equipo investigador, 4 enfermeras incluido el doctorando, pudieran valorar de la misma manera las respuestas de los entrevistados y se pudieran triangular los datos obtenidos ${ }^{(174,180,201)}$. El análisis de la información recogida se realizó siguiendo los datos propuestos por Cisterna-Cabrera, un procedimiento de triangulación hermenéutica, "seleccionar la información obtenida en el trabajo de campo; triangular la información por cada estamento; triangular la información con los datos mediante los otros instrumentos y; triangular la información con el marco teórico”(201). La triangulación se llevó a cabo unificando previamente la información recogida de las grabaciones y el cuaderno de campo entre los 4 investigadores, siendo esta una fase de preparación. Además, se identificaron los ámbitos temáticos en los que se había basado la entrevista, todos los investigadores tuvieron disponibles el guion utilizado en las entrevistas. Cada uno de los investigadores, escuchó de manera personal todas las grabaciones y generó sus conclusiones personales adaptadas a las áreas temáticas, codificando las respuestas ${ }^{(180)}$. Este hecho permitió crear categorías analíticas que, posteriormente, fueron analizadas mediante un procedimiento inferencial con conclusiones ascendentes, relacionado con áreas de consenso y divergencias entre los entrevistados. Se realizaron tres reuniones de consenso para validar las conclusiones de los investigadores, centrándose en mantener la validez descriptiva de los discursos expresados, con la verificación de los discursos iniciales y con las conclusiones de los investigadores. Indicando durante el desarrollo de las reuniones aquellos verbatims más pertinentes para valorar el consenso en las necesidades que detectan las enfermeras en su formación en UCI. Las estrategias de consenso fueron la de validar la información recogida, su adaptación a la categoría incluida y su relectura una vez reorganizados para valorar que tuviera el mismo sentido que el participante había expresado.

En la fase 2, la creación de las preguntas partió del análisis de las respuestas finales de la fase 1, tal y como se observa en el epígrafe anterior "instrumentos de estudio". Los análisis posteriores de descarte de preguntas se hicieron con registro tipo google docs a través del correo electrónico de los encuestados de la primera fase, generando las rondas necesarias. En la cuarta ronda, los expertos respondieron la versión definitiva.

En la fase 3, se realizó un análisis estadístico descriptivo uni-, bi- y multivariante. La muestra de análisis se realizó con $n=568$, para comparar resultados se utilizó en algunos ítems el grupo experto $(n=15)$ mediante sus respuestas en la cuarta ronda. Mediante paquete estadístico IBM ${ }^{\circledast}$ SPSS $^{\circledast}$ Statisticts versión 20. Mediante el análisis univariante se describieron las necesidades formativas que las enfermeras españolas detectaron a través de las puntuaciones asignadas a cada ítem del cuestionario. En las variables cuantitativas se calculó la media, desviación típica, mediana y percentiles 25 y 75, rangos mínimos y máximos. Las variables cualitativas se expresaron como frecuencias y porcentajes. Se aplicó el test de Normalidad Kolmogorov-Smirnov para analizar si los datos presentaban o no una distribución normal. Mediante el análisis bivariante, se comprobó la existencia o no de diferencias significativas en las respuestas de las enfermeras consultadas. Las pruebas usadas fueron la $\mathrm{t}$ de Student o la $\mathrm{U}$ de Mann-Whitney para comparar variables numéricas en función del tamaño muestral o la normalidad de los datos. Se calculó el índice KMO y el alfa de 
Cronbach para evaluar la consistencia interna en las subescalas. Se utilizó el test de JonckheereTerpstra para comprobar si había alguna tendencia entre una variable numérica y una ordinal. Se aplicó regresión lineal para predecir variables numéricas y se complementó este análisis mediante la técnica de Bootstrapping.

Para detectar la existencia de dimensiones subyacentes en el cuestionario se realizó un análisis factorial exploratorio (AFE). Este AFE se desarrolló mediante un análisis de matrices policóricas a través del programa Factor Analysis disponible de manera gratuita a través de la Universidad Rovira i Virgil ${ }^{(202)}$. El método de extracción utilizado fue el de mínimos cuadrados no ponderados (ULS) con rotación Promin ${ }^{(203)}$ (rotación oblicua) y la implementación de factores óptima se desarrolló a través del método de análisis paralelo ${ }^{(204)}$. El AFE fue realizado con una matriz seleccionada aleatoriamente con la mitad de la muestra valida $(n=284)$, asegurando los criterios que para este tipo de estudios defienden Conway y Huffcutt ${ }^{(205)}$. El análisis factorial confirmatorio se realizó a través del programa estadístico IBM AMOS con la otra mitad de la muestra $(n=284)$, mediante el método ULS para datos categóricos. La bondad de ajuste se determinó mediante los valores de Chi-Cuadrado respecto al factor experimental $\mathrm{X}^{2} / \mathrm{df}$, raíz cuadrada media del error de aproximación (RMSEA), índice de ajuste comparativo (CFI) y el índice de Tucker-Lewis (TLI), tal y como distintos autores sugieren ${ }^{(206,207)}$. 
CAPÍTULO 4

RESULTADOS 



\section{Capítulo 4. Resultados}

Los resultados se presentan estructurados según las fases descritas en el apartado metodología.

\subsection{Resultados Fase 1.}

En esta primera fase se presentan los resultados del análisis cualitativo, apoyándonos para ello en los verbatims generados por los entrevistados en cada uno de los ámbitos. La duración total de las entrevistas fue de 17 horas (h) 4 minutos (') y 16 segundos ("). Con un rango mínimo de 50':26" y un rango máximo de $1 \mathrm{~h}: 44^{\prime}: 25^{\prime \prime}$. Las entrevistas fueron realizadas entre 6 de febrero de 2017 y el 16 de abril de 2017, ver tabla 1.

Tabla 1. Duración de entrevistas fase 1

\begin{tabular}{cc}
\hline Participante & Duración de la entrevista \\
\hline N1 & $1 \mathrm{~h}: 1^{\prime}: 17^{\prime \prime}$ \\
N2 & $1 \mathrm{~h}: 9^{\prime}: 57^{\prime \prime}$ \\
N3 & $1 \mathrm{~h}: 5^{\prime}: 59^{\prime \prime}$ \\
N4 & $54^{\prime}: 15^{\prime \prime}$ \\
N5 & $1 \mathrm{~h}: 44^{\prime}: 24^{\prime \prime}$ \\
N6 & $1 \mathrm{~h}: 13^{\prime}: 56^{\prime \prime}$ \\
N7 & $52^{\prime}: 15^{\prime \prime}$ \\
N8 & $54^{\prime}: 36^{\prime \prime}$ \\
N9 & $1 \mathrm{~h}: 11^{\prime}: 11^{\prime \prime}$ \\
N10 & $55^{\prime}: 37^{\prime \prime}$ \\
N11 & $1 \mathrm{~h}: 16^{\prime}: 46^{\prime \prime}$ \\
N12 & $1 \mathrm{~h}: 23^{\prime}: 20^{\prime \prime}$ \\
N13 & $50^{\prime}: 26^{\prime \prime}$ \\
N14 & $57^{\prime}: 42^{\prime \prime}$ \\
N15 & $1 \mathrm{~h}: 32^{\prime}: 42^{\prime \prime}$ \\
\hline Nota: Tiempo expresado en horas (h): minutos ('): segundos (")
\end{tabular}

\subsection{1. Ámbito Clínico.}

Las preguntas de este ámbito estaban centradas en los conocimientos, habilidades y destrezas necesarias para determinar una realidad en la que los conocimientos son la base para desarrollar una práctica fundamentada. Las enfermeras entrevistadas reconocieron que en cuidados intensivos la formación y la experiencia eran elementos centrales. Los conocimientos adquiridos durante la formación universitaria son manifiestamente insuficientes $y$, además, se veían influenciados por el tipo de unidad y por las características del paciente crítico. Un elemento común al que han hecho referencia los entrevistados, ha sido la capacidad de observación e integración de los datos clínicos.

"Es importante saber que estás buscando, para interpretar que encuentras y tener habilidad para integrar conocimientos, para anticiparte a lo que puede pasar" (N9). 
"Además de los cuidados básicos que te dan en la carrera, precisas mucha experiencia y conocimientos pues se te pueden escapar datos que son muy importantes" (N14)

Se precisan conocimientos específicos en el "paciente crítico" ya que los cuidados se deben centrar en el factor riesgo-beneficio. Resulta fundamental la evaluación continua, el análisis de las respuestas a los cuidados y la capacidad para seguir aprendiendo a lo largo de toda la vida profesional.

"Un conocimiento de qué se va a hacer y qué se está buscando, para poder aplicar los cuidados de manera eficiente (...). Una enfermera no puede llevar a cabo cuidados sin saber exactamente si convienen o no, en ese momento del proceso. Para realizar buenos cuidados hay que saber qué es lo que pasa" (N5).

"Sobretodo en la UCl debes tener una visión que te permita saber conectar unos datos con otros. Precisas de un manejo muy exquisito de los elementos del cuidado, cuando llevas mucho tiempo parece sencillo, pero no lo es para nada" (N13).

"Se debe saber que estás buscando, para saber que encuentras y saber analizarlo, y para ello hay que tener tablas, experiencia y formación previa. Además, saber reevaluar, que para mí es lo más importante que tiene que estar haciendo una enfermera de UCI" (N9).

Otro elemento importante, es crear una relación enfermera-paciente que permita unos cuidados efectivos, y para ello hay que mantener en todo momento una actitud de respeto y de salvaguarda de la intimidad de todos los pacientes, sea cual fuere su situación a lo largo del proceso. Es necesario reconocer a la familia como parte de este binomio que posibilita mantener una adecuada relación terapéutica. Es fundamental mantener una comunicación efectiva que pueda trasmitir tranquilidad y certezas, ya que el ingreso en $\mathrm{UCl}$ es potencialmente estresante para el paciente y la familia.

"Se debe cuidar al paciente-familia como una unidad" (N3).

"Las enfermeras deben ser muy conscientes del desamparo o del miedo en que se encuentra el paciente, el cual puede estar violentado por el entorno. En críticos somos muy agresivos en muchos aspectos desde las movilizaciones hasta los abordajes de catéteres y sondas" (N5).

"Las enfermeras realizamos muchas actuaciones que vulneran la intimidad, por eso la comunicación es tan importante, puede ser violento para una persona ponerle una sonda e incluso el baño, un paciente destapado en esos boxes con cristaleras..., precisa cuidar su intimidad" (N12).

Otros entrevistados observaron que la necesidad de cuidados no sólo se centra en la patología en sí misma, sino también en la esfera emocional. Reconocen que los cuidados emocionales y psicológicos deben abarcar tanto a pacientes como a familiares. Un elemento destacado ha sido la habilidad de empatizar y relacionarse de una manera efectiva, así se demuestra en:

"Al principio se deja un poco de lado el aspecto psicológico, porque no lo tratamos como algo urgente, cuando el paciente ya está estable y, generalmente, es un paciente de larga estancia, entonces sí nos volcamos en ese cuidado, pero al principio se deja un poco de lado" (N12).

"Hay que ponerse en el lugar de los familiares que tienen un ser querido en situación crítica" (N8). 
"Quizás es un error por mi parte, pero priorizo estabilizar al paciente a conocer cuestiones emocionales" (N13).

A la hora de poder afrontar los cuidados intensivos, como profesionales, muchos de los entrevistados reconocieron no sentirse preparados al iniciar su labor profesional en UCI. Por ello, se manifiesta de manera reiterada la necesidad de una formación previa que posibilite a las enfermeras afrontar situaciones complejas, manejar emociones y poder trabajar bajo presión de una manera segura.

"Desde el minuto cero no tienes esas habilidades a no ser que hayas hecho unas buenas prácticas (...) y eso es una situación de estrés importante cuando se intenta una actividad laboral que muchas veces tiene que ser exquisita" (N3)

"Todo lo necesario para cuidar al paciente crítico no se adquiere, yendo a una UVI el primer día a trabajar sino teniendo una formación previa extensa (...) teniendo en cuenta que no todos los alumnos de enfermería pasan por la UVI y no todos desarrollan unas prácticas adecuadas para después enfrentarse al primer día. Desde contratación te sueltan a llevar pacientes críticos, hay episodios de inseguridad y ansiedad" (N8)

Los cuidados se plantean como un elemento central de la recuperación, no sólo el hecho de "hacer" intervenciones sino también que "no hacer" en cada momento. Elementos de vigilancia y de razonamiento clínico han sido englobados dentro de un proceso de observación, valoración y plan de cuidados. Se insiste en que las características de la unidad en la que trabajan influyen en las necesidades formativas. Los entrevistados mencionaban:

"La lista de cuidados de una enfermera de UCl es larga y complicada" (N4)

"La enfermera debe ser capaz de controlar todo lo derivado de los tratamientos de estabilización del paciente, un control técnico de unidades como estas de alto equipamiento tecnológico (...) todo influye en el cuidado del paciente, hoy en día la profesión ha evolucionado tanto que ya no sólo nos centramos en el paciente, sino que tenemos que mirar muchos elementos tecnológicos" (N7).

"Las habilidades técnicas son importantes, pero es fundamental la respuesta precoz ante complicaciones de las propias patologías, de los tratamientos y de los cuidados. Una enfermera de UCl debe ser muy reflexiva en lo que está pasando y en lo que puede pasar, realizando una adecuada correlación de todos los datos de los que dispone" (N6)

Se observó la exigencia de que para aplicar un razonamiento crítico es necesario conocer continuamente las medidas de soporte, farmacológicas o no, y la monitorización compleja, basándose en criterios clínicos que se apoyan en multitud de escalas de uso habitual en los cuidados críticos. Uno de los elementos centrales fue en el manejo de la ventilación mecánica como procedimiento de alta incidencia en las $\mathrm{UCI}$. Siendo conscientes que existe una dicotomía ¿qué hacer y qué no?, debiendo ser sus respuestas profesionales fundamentadas en todo momento.

"Todos los cuidados son importantes y se deben ir haciendo según el paciente vaya tolerando o admitiendo los distintos cuidados que se tienen que hacer" (N14)

"Para mí es muy importante que no desarrolle úlceras por presión, pero esto choca también con la estabilidad hemodinámica y respiratoria" (N11) 
"En el paciente crítico es importante priorizar (...) el enfermero debe adaptarse y, quizás, esta sea una de las características más importantes del enfermero de intensivos" (N1)

"Adecuar el plan terapéutico-plan de cuidados a la realidad actual del usuario, es un reto continuo para las enfermeras" (N6)

Los entrevistados indicaron que la formación adecuada capacitaba a la enfermera para priorizar y, mantener en todo momento, una capacidad de adaptación y de respuesta a las características del paciente crítico.

"La habilidad de detectar signos precoces de empeoramiento de las principales patologías (...) me parece una habilidad fundamental. Las habilidades técnicas son importantes, pero se aprenden, son más importantes en las enfermeras de UCl las habilidades de observación, análisis y razonamiento clínico" (N6)

"Una de las cosas que nos aportan los cuidados intensivos, es que nosotras las enfermeras, podemos hacer cuidados integrales" (N15)

\subsection{2. Ámbito Profesional.}

Este ámbito exploraba las medidas para potenciar una práctica profesional de las enfermeras en cuidados intensivos. Los entrevistados enunciaron la importancia de una formación continuada y la posibilidad de colaboración entre profesionales. La experiencia se identificó como eje fundamental a la hora de solucionar situaciones complejas.

"Consultar a compañeros o al farmacéutico, para cuestiones de administración de fármacos, siempre antes de provocar un error o evento adverso en el cuidado al paciente" (N2)

"Consultar a compañeros es la fuente fundamental, si después de esto, no me quedó conforme después iría a buscar a internet (...) pero generalmente las enfermeras experimentadas tienen la mayoría de las respuestas y suelen ser las más adecuadas, si no al médico de guardia. Además, alguna vez nos hemos visto buscando, entre todos, una solución" (N5).

Para trabajar con garantías, comentaban que era necesaria una especialización; aunque reconocían que, en los estudios de grado se aportan destrezas y habilidades, estas fueron etiquetadas como muy básicas. Se reafirmaban en lo comentado en el ámbito clínico, además, de añadir que:

"Todas las decisiones son complejas en cuidados intensivos y esta razón es en la que se debería basar el hecho de que hay que tener una formación adecuada antes de trabajar en UCI" (N8)

"Aquí las enfermeras toman decisiones, porque tenemos mucha autonomía" (N10).

En $\mathrm{UCl}$ se hace frente a situaciones profesionales que repercuten a nivel personal como son la muerte de un paciente o las decisiones de la limitación de terapias de soporte vital (LTSV). En la toma de decisiones al final de la vida las enfermeras continúan desempeñando un rol pasivo. En este caso, el cuidado se asoció a una relación muy personal, y la muerte de un paciente representaba una sobrecarga emocional. 
"Hablamos de un juicio médico (LET) en donde el enfermero no tiene otra opción de acatar la situación, aunque siempre se puede contrastar y verificar la información para que no haya ningún tipo de problema o información cruzada. Hay que asumirlo, acatarlo y reevaluar la situación adaptando el plan de cuidados" (N1)

"Personalmente, no es tan duro afrontar una limitación terapéutica que ves de manera clara y sí el ensañamiento que muchas veces se produce. Afronto peor la agonía del paciente" (N2)

La comunicación entre profesionales resulta una fuente de estrés. Recomendaban aprender comunicación mediante simulacros y solicitaban que esta fuera concisa y concreta, sin gritos y con datos objetivos. La comunicación había de centrarse en temas profesionales facilitando el feedback entre el equipo multidisciplinar; además debía ser bidireccional, fluida e integradora.

"Con voz pausada, y sin perder los papeles" (N13)

"Que quede siempre claro el mensaje que quieres dar y a quien, con el objetivo de solucionar la situación y no crear otro problema" (N4).

"No debemos olvidar que los enfermeros también tienen que informar y no sabemos informar sobre nuestro campo de actuación" (N15)

"Muchas veces y tras informarle el médico, los familiares salen corriendo, buscando alguien que les explique cómo está su familiar. Generalmente, es la enfermera la que soluciona esas dudas y por eso es importante, la comunicación dentro del equipo y dar a los familiares información veraz en todo momento" (N11).

\subsection{3. Ámbito de la Gestión.}

Este ámbito exploraba el desarrollo de conocimientos y habilidades en el campo de la gestión y organización en cuidados intensivos. Los participantes veían en la continuidad de cuidados una de las grandes fortalezas de la $\mathrm{UCl}$ y una obligación del profesional. Como eje fundamental para conseguir este objetivo asistencial se consideraron los registros de las actividades y las valoraciones de todos los profesionales incluidos en el cuidado. Otro elemento, que potenciaba y aseguraba esa continuidad era la sesión de enfermería.

"El saber cómo están los usuarios se debe basar en información tanto escrita como verbal, además de contar con todos los miembros del equipo otras enfermeras y/o auxiliares que ya conocen la situación en la que está el paciente o eventos que han pasado otros días" (N7)

"El seguimiento de los cuidados permite continuidad, la continuidad permite avance, el avance permite mejora y en última instancia permite evaluación. La evaluación permite mejorar o cambiar la dirección de los cuidados" (N6)

En cuanto a la importancia del liderazgo, las enfermeras creen que existe un liderazgo informal dentro del equipo sanitario. Tienen la capacidad de detectar muchos cambios en el estado del paciente al tener una posición cercana y continuada. Indicaron que la detección de los cambios era crucial para dar una pronta respuesta y adaptarse a la cambiante situación de un paciente crítico. 
"Las enfermeras no nos creemos la importancia que tenemos en una UCl y si nos lo creyéramos más, seríamos líderes en más cosas" (N13).

En lo referente a la calidad en la gestión, comentaban que se recogen indicadores de calidad, que consideran como un elemento no fundamental desaprovechando muchos otros datos e indicadores. Además, lo desvirtuaban, considerándolo como una cuestión externa a ellas como profesionales, recayendo tal responsabilidad, según los entrevistados, en el departamento de calidad.

"Se hace seguimiento de los indicadores de calidad cuando se puede y eso no suele pasar muy a menudo" (N5)

"Se desaprovechan muchos datos ya que vamos a la atención sanitaria inmediata y por eso dejamos estos datos de lado" (N1)

Afirmaban, además, que era necesario el trabajo en equipo, sobre todo a la hora de delegar actividades o emplear los recursos humanos y materiales, reconociendo que en la UCl se debe formar un equipo de trabajo cohesionado y responsable.

"Las auxiliares de UCl hacen bastantes cosas que en planta no harían y eso es un valor dentro del equipo sanitario, aunque la enfermera tenga que estar allí continuamente" (N3)

"La enfermera tiene que estar atenta en todo momento, para poder hacer frente a todo lo que pasa" (N12)

"La confianza y el ambiente de trabajo tienen mucho que ver con las personas con las que trabajas, con su personalidad, pero sobretodo con su experiencia y habilidades desde el médico hasta el celador" (N5)

"Las enfermeras nuevas muchas veces son ninguneadas por el equipo médico, porque piensan que no son dignas de compartir el plan de cuidados y eso se puede convertir en una debilidad en la atención sanitaria" (N6).

A la hora de buscar situaciones de mejora insistían en la necesidad de un aprendizaje gradual y reglado. La seguridad clínica es un elemento fundamental ya que las enfermeras son capaces de detectar múltiples errores. Los tratamientos y medidas de soporte requieren, en menor o mayor medida, de la intervención de las enfermeras, por lo que una adecuada formación en este campo evita eventos adversos.

"No se debe permitir que vengan 17 enfermeras, de golpe, sin experiencia a cubrir turnos, como ha pasado (...) mucha cantidad de personal nuevo provoca que el tema de la seguridad del paciente, sin gente con experiencia, sea un tema delicado" (N14)

"Las decisiones en la gestión nos han hecho formarnos y trabajar continuamente bajo estrés y no sólo somos capaces de trabajar bajo estrés sino también somos especialistas (...); además, hacerte cargo de otros compañeros nuevos, que con voluntad intentan sacar el trabajo adelante, requiere de un esfuerzo adicional por parte del veterano que les guía" (N6) 
"Asumir la carga asistencial, ser capaz de ayudar al compañero y concluir con éxito un turno de trabajo tiene mucho que ver mucho con la formación y, sobretodo, con la experiencia que te da tablas para afrontar, casi todo lo que te echen" (N9)

Asumir cuidados implica mantener un adecuado ambiente laboral, y es la comunicación junto con el respeto entre los profesionales una medida fundamental para garantizar el trabajo en equipo. $\mathrm{A}$ pesar de que muchos entrevistados reconocían que el rol de las enfermeras es importantísimo, por ser las que están "a pie de cama", se precisa mucha formación para poder trabajar en los equipos multidisciplinares de $\mathrm{UCl}$. En este sentido se observó que la multidisciplinariedad era considerada una fortaleza de los equipos de cuidados intensivos.

"Muchas veces la situación crítica no nos permite planificar sino hacer, y debemos tener una gestión de tiempo adecuada para afrontar estas situaciones (...) por eso debe haber alguien que controle nuestro trabajo y los estándares de calidad, no para fiscalizar, pero sí para controlar que todo se ha hecho bajo unos límites adecuados" (N6)

"Las sesiones clínicas nos dan confianza y permiten conocer el plan terapéutico, esto da cohesión al grupo y facilita ser reconocido como un miembro del equipo" (N8)

Las enfermeras entrevistadas identificaban carencias en el confort de los pacientes, relacionadas con el ruido y las luces, aunque no siempre eran conscientes. Desde el punto de vista material observaban una mala distribución de las luces y del ruido entre boxes, o ausencia de material como la disponibilidad de relojes en los boxes. Afirmaban realizar una gran actividad para orientar a los pacientes, mediante la reconducción verbal o mediante la conversación.

\subsection{4. Ámbito Educativo y de desarrollo.}

En este ámbito los entrevistados se centraron en explorar cómo la educación y formación en cuidados intensivos influía en las competencias enfermeras. En epígrafes anteriores se ha tratado la necesidad de que las enfermeras de $\mathrm{UCl}$ estén en un proceso de formación continua; aunque, la ausencia de requisitos previos, la ausencia de un plan de formación específico de UCl y la subjetividad de los intereses de cada enfermera se han mostrado como debilidades.

"Cada unidad debería tener su formación específica según las necesidades detectadas y contar con sesiones propias, impartidas por expertos tanto a los nuevos como a los viejos" (N14).

"Hay que tener mucha voluntad, y sacar tiempo del tuyo personal para autoformarse" (N6).

"La institución colabora bastante poco pues hace docencia muy general, mientras que la UCl es muy específica en las necesidades formativas que requieren las enfermeras y todos los profesionales, (...) aquí se usan mil cosas que no se utilizan en el resto del hospital" (N11)

Un elemento común, que llama la atención, es que las enfermeras reconocían que una adecuada formación mejora la calidad de cuidados; pero no observaban que en su entorno se aplicaran medidas para motivar al profesional a mejorar la práctica clínica. Esto provoca que haya una disparidad en los intereses y en la formación de las enfermeras, ser guiados por la subjetividad provoca que la obligatoriedad se convierta en el elemento de incentivación. 
"Mucha gente hace la formación a la que te obliga el hospital para cobrar los incentivos y muchas veces no tiene que ver con las necesidades de cuidados intensivos" (N9)

"Hay que cambiar el concepto de que cada vez que vamos a un curso, es un problema para el hospital. Si el curso es bueno, hay que cambiar la política en la dirección de enfermería, médica y en la gerencia; en otros hospitales de España y del mundo la formación es sagrada" (N12)

Si la formación es difícil en el contexto estudiado, la investigación se observó como algo secundario y nulamente valorado en el ámbito laboral, se deben incentivar las áreas de investigación mediante reconocimientos o becas.

"Quizás estamos perdiendo gente muy válida, por no apostar por los que investigan" (N12)

"La investigación de las enfermeras se ve como algo secundario y que no está incluido en su contrato con la empresa. Por tanto, sólo investigan aquellas enfermeras muy motivadas y en su tiempo libre y eso es una pérdida para el sistema" (N7)

\subsubsection{Dimensiones y formación.}

Este apartado busca explorar como se puede mejorar la excelencia de los cuidados tanto del personal novel como veterano.

Actualmente, los entrevistados asumen que los requisitos para el acceso a UCI son mínimos y distan mucho de las necesidades reales. La existencia de unas listas de servicios especiales se antoja como una solución parcial, pues el acceso se realiza con una mínima formación teórico-práctica. Comentaban que era necesario, al menos, una formación previa en conocimientos sobre ventilación mecánica, medidas de soporte vital, maniobras de Reanimación Cardiopulmonar (RCP) básica y avanzada. También hicieron hincapié en conocimientos fisiopatológicos y farmacológicos (incluyendo cálculos de dosificación), la gran variedad de enfermedades y de fármacos que se manejan así lo sugieren. Sobre cuándo adquirir esta formación, se observó que había un consenso en que debía ser antes de iniciar el periodo trabajo.

"La experiencia es lo que te forma, vivirlo, verlo y hacerlo" (N2)

"Si las contrataciones se hicieran bien en UCl a esa enfermera se le contrataría un tiempo antes de que tuviera que empezar a desempeñar su trabajo y se le formaría en materias específicas que sólo hay en UCl" (N4)

Muchos entrevistados recomendaban que una tutorización, o curso previo, fuera un elemento necesario para las enfermeras noveles en $\mathrm{UCl}$. Este hecho daría seguridad en la atención sanitaria y no provocaría una sobrecarga en los veteranos de la unidad. Las prácticas en las propias unidades han sido consideradas como elemento central de la formación. Se volvió a citar la necesidad de que todas las enfermeras sepan "cuándo hacer" y "cuándo no hacer".

"Cuidados intensivos no se aprende en dos semanas, pero sí se aprenden dinámicas y los errores más frecuentes" (N5) 
"En cuidados intensivos sería tremendamente productivo que cuando un enfermero ingresa en el servicio sin experiencia, aunque tuviera conocimientos teóricos previos, pueda estar supervisado por alguien para que se pueda ir enfrentando a la situación de manera tutorizada y que le dé seguridad para que en un futuro pueda hacerlo de manera eficiente" (N7)

"A parte de la formación de enfermera, puedes tener un curso o un máster, o un curso de intensivos (...); pero, se debe exigir un mínimo de experiencia, y esa experiencia sólo la puedes adquirir trabajando o estando de alumno en UCI" (N14)

Las exigencias no se ceñían únicamente al personal novel, sino que se incidió especialmente en los conceptos de reciclaje y actualización de los profesionales de $\mathrm{UCI}$. El aprendizaje sobre los tratamientos y nuevos dispositivos se debería mantener durante toda la vida laboral en UCI. Se señaló la necesidad de conocer y reconocer los nuevos dispositivos y actualizaciones de los ya disponibles. Un elemento que preocupaba, en cuanto a la formación de las enfermeras veteranas, era el reconocimiento de experiencias en el cuidado o la resolución de problemas asistenciales de los otros compañeros; compartir esas experiencias para mejorar, así como mantener el trabajo en equipo. Alcanzar la excelencia en los cuidados se logra con la práctica (hacer), la experiencia (haber vivido) y la formación.

"La formación nos la damos entre nosotros mismos" (N10)

"La formación nos da una mejor calidad de los cuidados y una mejor resolución" (N8)

Los entrevistados recordaron que había que mantener, en todo momento, una capacidad de observación, análisis, reacción y adaptación a todos los elementos asistenciales. Han observado que las mejores decisiones se toman a medida que se desarrolla e implementa la capacidad de razonamiento clínico. Las enfermeras observaron dos elementos que consideraban como un hándicap en su formación, y estos fueron las habilidades de comunicación y las emociones. La comunicación empática, respetuosa y asertiva es un elemento que precisa formación y práctica para tratar con las familias y pacientes.

"El saber adelantarse a lo que le puede pasar o estar pasándole al paciente, esto es razonamiento clínico" (N14)

"El manejo de las emociones en UCl es muy importante, primero para poder afrontar las situaciones que tienes delante y no llevártelos a tu casa y, segundo para poder tratar con la familia y los pacientes" (N3)

"No nos enseñan a afrontar la muerte, y estamos en un entorno sanitario donde esto tiene una especial relevancia" (N12)

\subsection{Resultados Fase 2.}

En esta fase se reclutó a los 15 participantes de la fase 1, se les explicó nuevamente el propósito del estudio, el $100 \%$ de los participantes finalizaron las rondas necesarias de esta segunda fase.

A través de los discursos expresados en la primera fase se extrajeron por parte del equipo investigador una serie de conclusiones y nexos comunes de las necesidades formativas detectadas 
por las enfermeras. Los 4 miembros del equipo hicieron sus propuestas tras análisis de todas y cada una de las entrevistas de los expertos, teniendo acceso al guion de la entrevista (Anexo 1). Se realizó una puesta en común de las propuestas valorando cada una de las preguntas y sus ámbitos temáticos. Al final de esta puesta en común, la ronda 1 quedó constituida por 92 preguntas. Las preguntas se incluyeron en cada uno de los subapartados sin seguir ningún orden ni jerarquía.

\subsubsection{Ronda 1.}

Esta ronda estaba constituida por 92 preguntas enviadas a los 15 participantes a través de e-mail. A pesar de que conocían el propósito del estudio de la fase 1, en esta ronda se les envió un pequeño recordatorio de los objetivos y del procedimiento, tal y como se menciona en el siguiente cuadro.

Cuadro 1. Carta explicativa participantes Delphi.

Estimado compañero:

Tras haber analizado los discursos de todas las enfermeras participantes a través de las grabaciones de la entrevista en la cual tan amablemente participaste. El equipo investigador ha extraído una serie de preguntas las cuales te solicitamos valores según tu opinión de experto.

Las preguntas van dirigidas a las necesidades formativas de las enfermeras de cuidados intensivos, por lo que nos interesa tanto tu opinión, como tu valoración de cómo están redactadas las preguntas mediante la contestación de este correo. Solicitamos además que valores cada ítem adjunto en la escala Likert de 1 a 10, donde 1 siempre es poco importante, o en desacuerdo con el enunciado expresado y 10 , es muy importante o totalmente de acuerdo con el enunciado expresado.

Una vez recibida todas las respuestas, se les hará llegar los resultados y las valoraciones de los otros participantes tal y como la técnica Delphi precisa.

Un saludo

Se recibió respuesta de todos los participantes en el plazo de 8 días. Tras analizarlas se observó que consideraban que había preguntas que eran repetitivas, expresando esto mediante texto libre. De esta manera 7 participantes eliminaron las mismas 6 preguntas, tres participantes eliminaron 5 preguntas y dos coincidieron en dos ítems distintos. Además, se analizaron las puntuaciones que habían dado a cada uno de los ítems, observando que el $80 \%$ tenían medias superiores a 6 . Al final de esta fase, el equipo investigador eliminó 14 ítems, quedando el documento original en 78 ítems. Esta Ronda 1, generó un nuevo cuestionario en el cual se mantuvieron agrupadas las preguntas según los ámbitos temáticos; ordenándose los ítems sin jerarquía para una siguiente ronda.

\subsubsection{Ronda 2 .}

El cuestionario generado con 78 ítems fue distribuido mediante formato electrónico, para ser evaluado con una escala tipo Likert, en las mismas condiciones que el resto del estudio. Además, se solicitó valoración de las preguntas en texto libre. Los resultados recibidos fueron analizados mediante media y mediana. Al objetivar en la ronda anterior que la mayoría de los ítems tenían una puntuación mayor de 6 , se consideró incluir sólo aquellos en los que los expertos hubieran otorgado una puntuación igual o superior a 6,1 y una mediana igual a 7 . Se recibió el $100 \%$ de las respuestas en el plazo de 15 días. 
En esta ronda no se recibieron respuestas al documento de texto libre, ni modificaciones a las preguntas incluidas por parte de la ronda anterior.

Este análisis de datos provocó la retirada de 12 ítems, quedando 66 ítems con puntuaciones medias superiores a 6,1 y mediana superior a 7. Al cuestionario de 66 ítems se incorporaron las preguntas demográficas oportunas para describir la muestra a nivel nacional en la tercera fase; se incluyeron también preguntas dicotómicas relacionadas con las necesidades formativas y texto libre sobre las opiniones de las necesidades de planes de acogida previo al ingreso en las unidades de cuidados intensivos.

\subsubsection{Ronda 3.}

Se envió el nuevo cuestionario, constituido por 66 ítems, a los participantes, para evaluar el cuestionario definitivo. En esta ronda buscábamos que todos los ítems cumplieran una fiabilidad en la escala utilizada. En esta ronda no se envió formato de texto libre, y tampoco se comunicó a los participantes que fuera una ronda definitiva. El cuestionario enviado corresponde con el incluido en el anexo 2. Se recibió contestación de los 15 participantes en el plazo de 15 días.

El análisis de los datos suministrados en este cuestionario fue utilizado como elemento comparativo para el resto del estudio en sus fases de nivel nacional. Para reconocer la fiabilidad de la escala, se valoró el coeficiente alfa de Cronbach de los 66 ítems y este fue de 0,908. En la tabla 2 se detallan las puntuaciones de cada ítem, ver tabla 2.

Tabla 2. Puntuaciones del grupo Delphi en el ámbito clínico.

\begin{tabular}{|c|c|c|c|c|}
\hline Afirmaciones & Media & Mediana & IQR & D.T \\
\hline $\begin{array}{l}\text { Las enfermeras de UCl deben tener conocimientos extensos de } \\
\text { enfermería básica }\end{array}$ & 9,53 & 10 & 1 & 0,516 \\
\hline $\begin{array}{l}\text { Las enfermeras de UCI deben desarrollar habilidades específicas para } \\
\text { la atención al paciente crítico }\end{array}$ & 9,80 & 10 & 0 & 0,561 \\
\hline $\begin{array}{l}\text { La observación es una herramienta necesaria, para obtener datos en la } \\
\text { valoración del paciente crítico }\end{array}$ & 9,60 & 10 & 1 & 0,632 \\
\hline $\begin{array}{l}\text { La monitorización es una herramienta fundamental, para obtener } \\
\text { datos en la valoración del paciente crítico }\end{array}$ & 9,13 & 9 & 2 & 0,834 \\
\hline El uso de escalas son necesarias para la valoración del paciente crítico & 8,60 & 9 & 2 & 1,242 \\
\hline $\begin{array}{l}\text { La empatía y el respeto a la intimidad son fundamentales para la } \\
\text { enfermera de } \mathrm{UCl}\end{array}$ & 9,60 & 10 & 1 & 0,632 \\
\hline $\begin{array}{l}\text { Hay que involucrar al paciente y a la familia en el proceso de } \\
\text { recuperación }\end{array}$ & 9,00 & 10 & 2 & 1,254 \\
\hline $\begin{array}{l}\text { Observar, analizar e interpretar situaciones y/o problemas en un } \\
\text { paciente crítico es necesario para realizar un examen físico. }\end{array}$ & 8,60 & 9 & 2 & 1,352 \\
\hline $\begin{array}{l}\text { La integración e interrelación de los datos es una habilidad muy } \\
\text { importante de las enfermeras de } \mathrm{UCl}\end{array}$ & 9,27 & 10 & 1 & 0,961 \\
\hline $\begin{array}{l}\text { Las principales patologías que debe conocer una enfermera de } \mathrm{UCl} \text {, } \\
\text { son la cardíaca, la respiratoria y la neurológica }\end{array}$ & 8,47 & 9 & 1 & 1,060 \\
\hline
\end{tabular}


Afirmaciones

Las medidas de soporte son el pilar fundamental de las actividades enfermeras

$\begin{array}{llll}8,47 & 9 & 1 & 1,187\end{array}$

Las enfermeras de $\mathrm{UCl}$ deben estar formadas en la atención de los distintos tipos de shock

$9,80 \quad 10 \quad 0 \quad 0,414$

El cálculo de fármacos y drogas, es una competencia imprescindible

El cuidado integral de un paciente crítico forma parte de la actuación principal del profesional de enfermería

Los cuidados respiratorios son los que de manera prioritaria deben ser desarrollados en las enfermeras de UCI

$9,87 \quad 10 \quad 0 \quad 0,516$

$9,80 \quad 10 \quad 0 \quad 0,414$

La reevaluación continua es la principal medida que debe implementar la enfermera para evaluar estrategias de mejora del plan de cuidados.

La capacidad de priorización es una habilidad imprescindible

El razonamiento clínico (que pasa, y que puede llegar a pasar) debe ser fomentado en las enfermeras de UCl

$8,53 \quad 9 \quad 1 \quad 1,187$

$\begin{array}{cccc}9,27 & 9 & 1 & 0,799 \\ 9,67 & 10 & 1 & 0,488 \\ 9,67 & 10 & 1 & 0,488\end{array}$

Nota: Media, Mediana y Desviación Típica (DT). Rango Intercuartílico (IQR)

Seguidamente, se presentan los resultados del análisis descriptico tras la ronda 2, englobando cada ítem en el ámbito correspondiente. Como se puede observar en el ámbito profesional se obtuvieron valores de acuerdo elevados, todos ellos superiores a 8 puntos como valor medio, ver tabla 3.

Tabla 3. Puntuaciones del grupo Delphi al ámbito profesional.

\begin{tabular}{|c|c|c|c|c|}
\hline Afirmaciones & Media & Mediana & IQR & D.T \\
\hline $\begin{array}{l}\text { Ante situaciones complejas, la ayuda y el apoyo de compañeros más } \\
\text { experimentados ayudan a resolver problemas }\end{array}$ & 9,73 & 10 & 1 & 0,458 \\
\hline $\begin{array}{l}\text { Las enfermeras pueden hacer frente a decisiones complejas gracias a } \\
\text { la experiencia laboral obtenida en } \mathrm{UCl}\end{array}$ & 8,80 & 9 & 2 & 1,146 \\
\hline $\begin{array}{l}\text { Las decisiones de cuidado son muy complejas y requieren de una } \\
\text { formación extensa }\end{array}$ & 8,67 & 9 & 2 & 1,047 \\
\hline $\begin{array}{l}\text { Las enfermeras de UCI tienen mucha autonomía, por lo que es } \\
\text { necesario una formación reglada y adecuada al puesto de trabajo }\end{array}$ & 8,73 & 9 & 2 & 1,438 \\
\hline $\begin{array}{l}\text { La enfermera de UCI suele afrontar bien la decisión de limitación de } \\
\text { soporte vital (esfuerzo terapéutico) }\end{array}$ & 8,13 & 8 & 3 & 1,642 \\
\hline $\begin{array}{l}\text { La enfermera debería participar en las decisiones de limitación de } \\
\text { soporte vital (esfuerzo terapéutico) }\end{array}$ & 8,73 & 9 & 2 & 1,163 \\
\hline La enfermera de $\mathrm{UCl}$ afronta peor el encarnizamiento terapéutico & 9,27 & 10 & 2 & 1,033 \\
\hline $\begin{array}{l}\text { El afrontamiento de la muerte de los usuarios dependerá de las } \\
\text { creencias, experiencias y valores del profesional de enfermería }\end{array}$ & 8,27 & 9 & 4 & 1,907 \\
\hline $\begin{array}{l}\text { El profesional de enfermería en } \mathrm{UCl} \text {, dentro de su competencia, busca } \\
\text { la excelencia a nivel clínico }\end{array}$ & 9,27 & 10 & 2 & 1,033 \\
\hline $\begin{array}{l}\text { El lenguaje verbal y no verbal son fundamentales en la comunicación } \\
\text { en UCI }\end{array}$ & 9,20 & 10 & 2 & 1,082 \\
\hline $\begin{array}{l}\text { En situaciones de estrés, las enfermeras se deben comunicar de } \\
\text { manera técnica, concisa y clara, ajustando la información a las } \\
\text { características del interlocutor }\end{array}$ & 9,13 & 10 & 2 & 1,060 \\
\hline
\end{tabular}


Las principales herramientas de comunicación son la asertividad, la empatía y la escucha activa tanto con usuarios y familia como con profesionales

$9,13 \quad 10 \quad 2 \quad 1,060$

Las tecnologías de la información y comunicación (TIC) son herramientas esenciales que permiten la formación, el aprendizaje y e desarrollo de la profesión

La comunicación escrita en $\mathrm{UCl}$ se debe fomentar siempre, pues es indispensable para la continuidad de cuidados

$9,60 \quad 10 \quad 1 \quad 0,737$

Nota: Media, Mediana y Desviación Típica (DT). Rango Intercuartílico (IQR)

En el ámbito de la gestión se observó que había dos ítems que no cumplían los requisitos de la mediana, pero sí de la media, a saber: "Se gestiona adecuadamente la carga de trabajo de las enfermeras en UCl" y "En UCl, se toman medidas que ayudan a prevenir o evitar el delirio o la desorientación", ver tabla 4.

Tabla 4. Puntuaciones del grupo Delphi en el ámbito de la gestión.

\begin{tabular}{|c|c|c|c|c|}
\hline Afirmaciones & Media & Mediana & IQR & D.T. \\
\hline $\begin{array}{l}\text { El seguimiento de los cuidados que prestan las enfermeras es } \\
\text { indispensable para la continuidad y evaluación de los cuidados }\end{array}$ & 9,47 & 10 & 1 & 0,834 \\
\hline $\begin{array}{l}\text { Registrar los cuidados prestados es la mejor medida posible para } \\
\text { garantizar la continuidad }\end{array}$ & 9,40 & 10 & 1 & 0,828 \\
\hline La enfermera de UCl actúa de nexo entre los distintos profesionales & 9,13 & 10 & 2 & 1,125 \\
\hline La coordinación del equipo sanitario es imprescindible & 9,87 & 10 & 0 & 0,352 \\
\hline $\begin{array}{l}\text { Las enfermeras son capaces de planificar actuaciones a lo largo del } \\
\text { turno de trabajo }\end{array}$ & 8,67 & 9 & 2 & 1,345 \\
\hline $\begin{array}{l}\text { Las enfermeras que trabajan en } \mathrm{UCl} \text { recogen datos relacionados con } \\
\text { los indicadores de calidad }\end{array}$ & 7,93 & 8 & 2 & 1,486 \\
\hline Se realiza un seguimiento de los indicadores de calidad & 7,07 & 7 & 3 & 1,668 \\
\hline $\begin{array}{l}\text { Es necesaria una correcta formación para garantizar la seguridad } \\
\text { clínica }\end{array}$ & 9,67 & 10 & 1 & 0,617 \\
\hline Las enfermeras de UCl están involucradas en la seguridad clínica & 7,93 & 8 & 2 & 1,335 \\
\hline $\begin{array}{l}\text { Las enfermeras de } \mathrm{UCl} \text { deben ser capaces de actuar rápidamente ante } \\
\text { el deterioro del usuario y ante eventos adversos }\end{array}$ & 9,47 & 10 & 1 & 0,834 \\
\hline $\begin{array}{l}\text { Los equipos asistenciales de UCI son capaces de realizar su trabajo en } \\
\text { un ambiente de presión y estrés }\end{array}$ & 9,33 & 10 & 1 & 1,113 \\
\hline $\begin{array}{l}\text { Se gestiona adecuadamente la carga de trabajo de las enfermeras en } \\
\mathrm{UCl}\end{array}$ & 6,53 & 6 & 3 & 2,356 \\
\hline $\begin{array}{l}\text { En una } \mathrm{UCl} \text { es fundamental la capacidad de adaptación de las } \\
\text { enfermeras en las situaciones urgentes y emergentes }\end{array}$ & 9,33 & 10 & 2 & 0,900 \\
\hline $\begin{array}{l}\text { Evitar ruidos innecesarios o bajar el volumen de luces y alarmas, son } \\
\text { acciones que fomentan el descanso del paciente crítico }\end{array}$ & 9,53 & 10 & 1 & 0,743 \\
\hline $\begin{array}{l}\text { Se fomentan acciones para el adecuado confort y descanso de los } \\
\text { pacientes }\end{array}$ & 6,80 & 7 & 3 & 1,971 \\
\hline
\end{tabular}


En $\mathrm{UCl}$, se toman medidas que ayudan a prevenir o evitar el delirio o la desorientación

Nota: Media, Mediana y Desviación Típica (DT). Rango Intercuartílico (IQR)

En la descripción de las puntuaciones observamos que en el ámbito educativo y de desarrollo se mostró un perfil más crítico y negativo que provocó que no se cumplieran ni la media ni la mediana en el ítem "La institución colabora en una formación específica de UCl”, ver tabla 5.

Tabla 5. Puntuaciones del grupo Delphi en el ámbito educativo y de desarrollo.

\begin{tabular}{|c|c|c|c|c|}
\hline Afirmaciones & Media & Mediana & IQR & D.T. \\
\hline $\begin{array}{l}\text { Las enfermeras realizan actividades formativas sobre los cuidados } \\
\text { intensivos }\end{array}$ & 7,33 & 8 & 2 & 1,234 \\
\hline $\begin{array}{l}\text { La realización de esta formación depende de la motivación de la } \\
\text { enfermera }\end{array}$ & 8,80 & 10 & 2 & 1,656 \\
\hline Las actividades formativas repercuten positivamente a nivel clínico & 9,73 & 10 & 0 & 0,594 \\
\hline La institución colabora en una formación específica de UCI & 4,40 & 4 & 3 & 1,805 \\
\hline $\begin{array}{l}\text { La acogida de personal de nueva incorporación debe ser realizada } \\
\text { lenta y progresivamente }\end{array}$ & 8,20 & 10 & 3 & 3,321 \\
\hline $\begin{array}{l}\text { La formación en } \mathrm{UCl} \text { se realiza sobre todo para el cobro de incentivos, } \\
\text { bolsas de empleo y oposiciones }\end{array}$ & 7,93 & 8 & 2 & 2,520 \\
\hline
\end{tabular}

Nota: Media, Mediana y Desviación Típica (DT). Rango Intercuartílico (IQR)

Si evaluamos la respuesta del grupo de expertos a la parte B de la encuesta, donde se observa la formación requerida antes y durante el trabajo en una $\mathrm{UCl}$, sí observamos que se cumplen los requisitos planteados en la técnica Delphi, en todos los ítems. El nivel de consenso y de acuerdo fue elevado, ver tabla 6.

Tabla 6. Puntuaciones del grupo Delphi al apartado de Formación.

\begin{tabular}{|c|c|c|c|c|}
\hline Afirmaciones & Media & Mediana & IQR & D.T. \\
\hline $\begin{array}{l}\text { La enfermera de nueva incorporación debería tener conocimientos } \\
\text { hemodinámicos, de ventilación mecánica, reanimación } \\
\text { cardiopulmonar básica y avanzada, además de monitorización }\end{array}$ & 8,73 & 8 & 2 & 1,163 \\
\hline $\begin{array}{l}\text { Debería existir la figura de un enfermero tutor en la unidad para } \\
\text { ayudar a las enfermeras de nueva incorporación }\end{array}$ & 9,47 & 10 & 1 & 0,743 \\
\hline $\begin{array}{l}\text { Es necesario una formación previa postgrado de UCI para las } \\
\text { enfermeras noveles }\end{array}$ & 8,40 & 9 & 3 & 1,639 \\
\hline $\begin{array}{l}\text { La primera semana, las enfermeras noveles deben estar supervisadas } \\
\text { en todo momento }\end{array}$ & 9,67 & 10 & 1 & 0,617 \\
\hline $\begin{array}{l}\text { El personal del staff (veterano), requiere de planes formativos } \\
\text { específicos de periodicidad anual }\end{array}$ & 8,60 & 9 & 2 & 1,183 \\
\hline $\begin{array}{l}\text { La formación amplia y específica en cuidados críticos, facilita que el } \\
\text { profesional alcance un nivel de excelencia }\end{array}$ & 9,53 & 10 & 1 & 1,014 \\
\hline
\end{tabular}


La formación se debe apoyar en eventos teórico-prácticos y en la simulación, antes de llevar esos conocimientos a la realidad

$9,20 \quad 10 \quad 2 \quad 1,014$

La formación debe terminar con una intervención real, siempre tutelado con un profesional experimentado

$9,40 \quad 10 \quad 1 \quad 0,910$

\begin{tabular}{|c|c|c|c|c|}
\hline $\begin{array}{l}\text { La empatía es una actitud indispensable a desarrollar dentro del } \\
\text { equipo sanitario }\end{array}$ & 9,07 & 9 & 2 & 0,961 \\
\hline $\begin{array}{l}\text { Las enfermeras necesitan formación específica para afrontar la muerte } \\
\text { de los usuarios }\end{array}$ & 8,87 & 9 & 2 & 1,246 \\
\hline $\begin{array}{l}\text { Son habilidades a desarrollar en las enfermeras de UCl, la calma, ser } \\
\text { metódico y resolutivas }\end{array}$ & 9,33 & 10 & 1 & 0,816 \\
\hline $\begin{array}{l}\text { La inteligencia emocional es necesaria de ser desarrollada en las } \\
\text { enfermeras de } \mathrm{UCl}\end{array}$ & 8,93 & 9 & 2 & 1,033 \\
\hline
\end{tabular}

Nota: Media, Mediana y Desviación Típica (DT). Rango Intercuartílico (IQR)

Podemos observar que, salvo los ítems mencionados, se han cumplido los requisitos planteados de este abordaje Delphi. De los 66 ítems planteados, entre la ronda 2 y la 3, sólo uno no cumplía ni la media ni la mediana, y dos no cumplían la mediana.

Si observamos la puntuación total de cada ámbito y cada parte del cuestionario, encontramos que el rango en el cual los participantes podían evaluar las afirmaciones fue:

- Ámbito Clínico: 18 ítems, puntuaciones posibles (18-180)

- Ámbito Profesional: 14 ítems, puntuaciones posibles (14-140)

- Ámbito de la gestión: 16 ítems, puntuaciones posibles (16-160)

- Ámbito Educativo y de desarrollo: 6 ítems, puntuaciones posibles (6-60)

- Puntuación total parte A: 54 ítems, puntuaciones posibles (54-540)

- Puntuación total parte B (Formación y dimensiones): 12 ítems, puntuaciones posibles (12120)

En relación con las puntuaciones máximas posibles de cada ámbito, la media de cada ámbito corresponde a los siguientes porcentajes del total: ámbito clínico $(92,5 \%)$, ámbito profesional (89,32\%), ámbito de la gestión (85,16\%), ámbito educativo y de desarrollo (77,33\%), puntuación total parte $A(87,85 \%)$ y la puntuación parte B $(91 \%)$. Esto implica un nivel de acuerdo superior al $75 \%$ en todos los ítems en relación con las afirmaciones expresadas, tal y como se refleja en la tabla 7.

Tabla 7. Puntuaciones totales de las distintas secciones del cuestionario distribuido al grupo Delphi.

\begin{tabular}{|l|cccccccc|}
\hline Puntuaciones totales & Media & D.T. & Min & P25 & P50 & P75 & IQR & Max \\
\hline Ámbito Clínico & 166,66 & 8,90 & 151 & 158 & 169 & 172 & 14 & 180 \\
\hline Ámbito Profesional & 125,06 & 8,89 & 108 & 121 & 125 & 133 & 12 & 140 \\
\hline Ámbito De la Gestión & 136,26 & 10,51 & 115 & 127 & 138 & 145 & 18 & 155 \\
\hline Ámbito Educativo y de Desarrollo & 46,40 & 6,33 & 33 & 43 & 47 & 53 & 10 & 56 \\
\hline Puntuación Parte A & 474,40 & 26,35 & 421 & 456 & 475 & 491 & 35 & 510 \\
\hline Puntuación Parte B & 109,20 & 7,41 & 96 & 103 & 110 & 114 & 11 & 120 \\
\hline
\end{tabular}

Nota: Media, Desviación Típica (DT), Percentiles: 25, 50 y 75. Rango Intercuartílico (IQR). Valor máximo y mínimo (MinMax). 


\subsubsection{Descripción del grupo Delphi.}

Las características del grupo Delphi deben ser definidas para poder evaluar su coincidencia o divergencia con el grupo nacional. Este grupo estaba constituido por un $80 \%$ de mujeres y un $20 \%$ de hombres, todas enfermeras de cuidados intensivos. De este grupo, 5 contaban con formación como expertos universitarios y 1 un máster como título propio; el resto de los miembros del grupo sólo reflejaron disponer de formación académica como diplomado/grado en enfermería. En cuanto a la edad observamos que el $73,3 \%$ se encontraba incluido en el rango de edad de $36-40$ años. Al tratarse de una fase desarrollada en un ámbito unicéntrico, es necesario recordar las características sociolaborales comunes de este grupo, puesto que todos sus miembros desarrollan su labor profesional en la isla de Gran Canaria, en el Hospital Universitario Insular de Gran Canaria centro de gestión pública dependiente del Servicio Canario de la Salud. Este hospital de tercer nivel y de 850 camas cuenta con una unidad de cuidados intensivos de adultos organizada como unidad polivalente. Dicha unidad de referencia cuenta con 32 camas.

Figura 1. Rango de edad de los participantes Grupo Delphi.

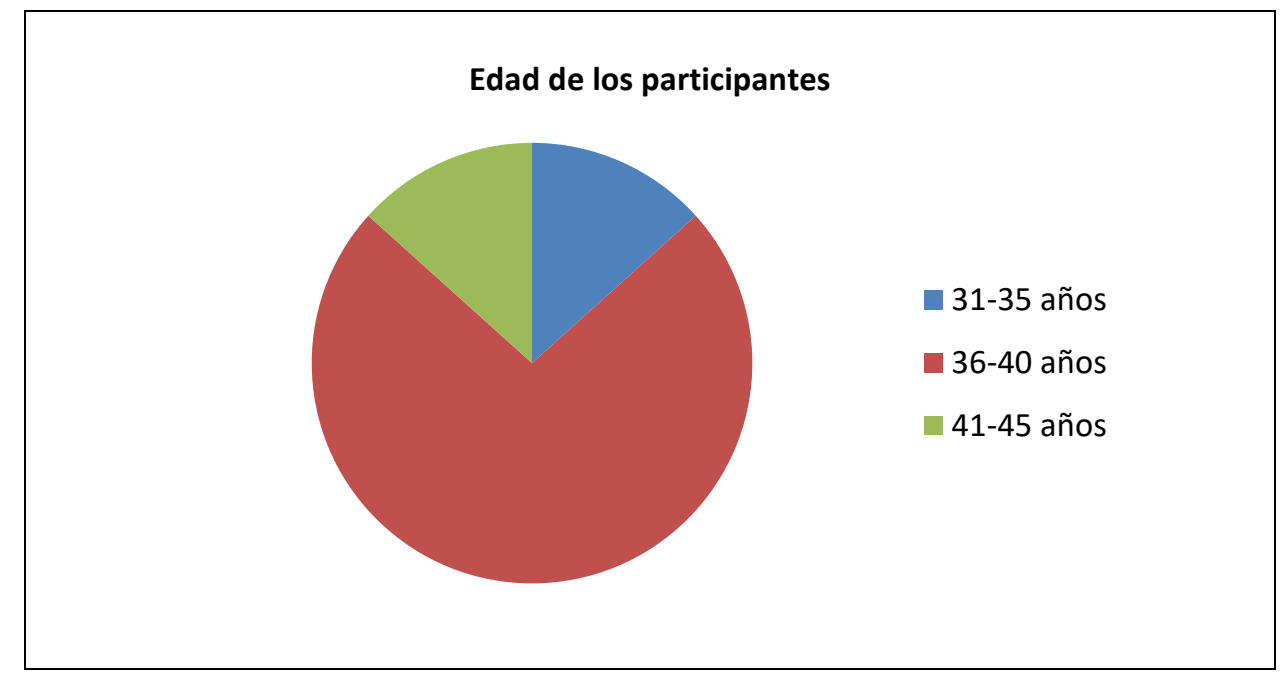

En lo que se refiere a la experiencia laboral de los participantes, decir que estos tenían una experiencia total previa como enfermeras que se muestra en la figura 2. El 53,3\% tenía una experiencia laboral como enfermera de 16 a 20 años y el 33,3\% de 11 a 15 años. Todas las enfermeras contaban con al menos 6 años de experiencia laboral.

Si nos centramos en la experiencia laboral en $\mathrm{UCl}$, observamos que, el $60 \%$ contaba con una experiencia de 11 a 15 años. En el rango de 6 a 10 años se halla $26,7 \%$ de la muestra.

Un dato por reseñar es que el 83,3\% de la muestra consideraba que sí era necesaria una formación o experiencia previa para empezar a trabajar en $\mathrm{UCl}$. De aquellos que contestaron afirmativamente a esta pregunta, el 61,5\% consideró que al menos se debía solicitar una experiencia mínima de 2 años como enfermera en planta de hospitalización, el resto $(38,5 \%)$ respondió que, con al menos 1 año de enfermera en hospitalización, sería suficiente. En el mismo sentido, pero con experiencia en urgencias y/o quirófano, el 93,2\% indicó que se debería exigir al menos 1 año de experiencia en estos servicios. 
Figura 2. Experiencia laboral como enfermera total y en UCI.

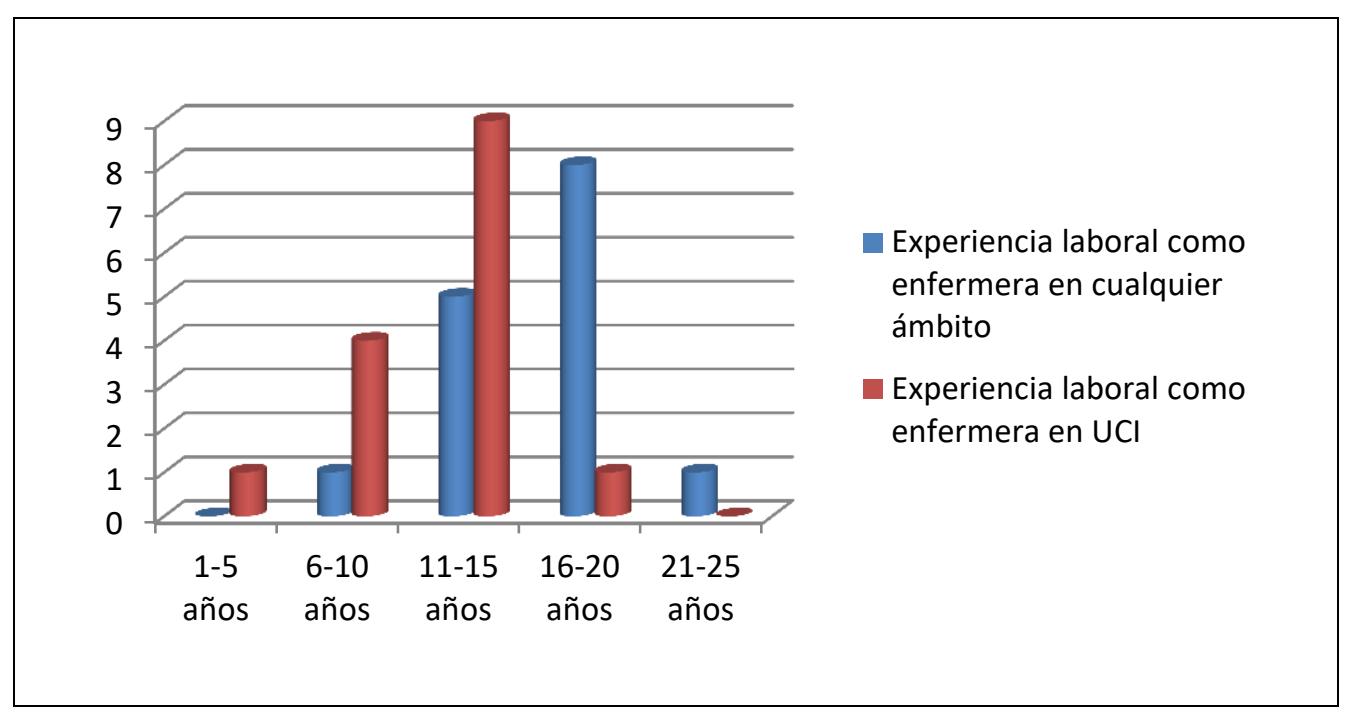

En cuanto a las necesidades de formación mínima que serían aconsejables antes de comenzar a trabajar en $\mathrm{UCl}$, encontramos la siguiente distribución de las respuestas, tal y como se observa en la tabla 8. El elemento más valorado son los planes de acogida de las unidades, seguido de expertos universitarios (con prácticas incluidas). Este hecho, se ve refrendado por la pregunta específica de los planes de acogida, donde se preguntaba "Según su experiencia personal, ¿Sería necesario un plan de acogida para el personal de nueva incorporación?”, el 100\% de los miembros del grupo Delphi respondió afirmativamente $(n=15)$. Además, esta respuesta se relacionó con la pregunta "¿Existe en su unidad, un plan de acogida del personal de nueva incorporación?", los 15 miembros del grupo Delphi respondieron negativamente.

Tabla 8. Formación mínima aconsejable antes de comenzar a trabajar en UCI según grupo Delphi.

\section{Ítems}

$(n=15)$

No es necesaria ninguna formación extra, salvo la proporcionada en los estudios de enfermería

7,9

Formación de postgrado mediante planes de acogida de las propias unidades 40,0

Formación de postgrado con créditos de formación continuada de las profesiones sanitarias

Formación de postgrado en forma de experto universitario (con prácticas incluidas) 25,4

Formación de postgrado en forma de máster universitario (con prácticas incluidas)

Nota: Resultados expresados en porcentajes (\%)

Es de destacar que a la pregunta: "Según su opinión, ¿sería aconsejable una formación sanitaria especializada tipo EIR (Enfermero Interino Residente), para trabajar en UCI?", la respuesta afirmativa aglutinó al $60 \%$ de los encuestados. El $40 \%$ restante se dividía en partes iguales, ante una respuesta negativa (20\%) y no tiene opinión al respecto el restante $20 \%$.

En lo referente a la respuesta cualitativa, sobre que debía contener el plan de acogida, se recibieron 12 respuestas válidas, diferenciándose tres grandes grupos: los que optaban por un sistema de 
tutorización inicial con un profesional experto $(50 \%)$, la formación teórico-práctica $(33,3 \%)$ y las prácticas remuneradas al inicio del contrato $(16,6 \%)$.

\subsection{Resultados Fase 3.}

A continuación, se detallan los resultados obtenidos en la última fase del presente estudio, los cuales se obtuvieron de los centros nacionales incluidos en el estudio. Para establecer una comparación, se valoraron las respuestas dadas en la última fase del grupo Delphi.

\subsubsection{Estadística descriptiva muestral.}

En esta fase se obtuvieron 630 registros, de los cuales $n=568$ fueron válidos para su análisis según los criterios de inclusión planteados. La muestra era de predominio femenino, 462 mujeres $(81,3 \%)$ frente a 106 hombres (18,7\%); la mayoría de más de 36 años de edad (70\%) (tabla 9).

Tabla 9. Edad de los encuestados.

\section{Rango de edad de los encuestados}

$(n=568)$

Frecuencia

22-25 años

26-30 años

31-35 años

36-40 años

41-45 años

Mayor de 45 años

Nota: Resultados expresados en porcentajes (\%)

Un elemento importante, a la hora de evaluar las opiniones sobre las necesidades formativas de las enfermeras, fue su nivel formativo. En este sentido, 296 de los encuestados $(52,11 \%)$ no disponían de formación posgrado. Los restantes 272 participantes (47,89\%) sí disponían de formación posgraduada tal y como se observa en la figura 3.
Porcentaje (\%)

3,35

8,80

15,85

25,70

20,60

25,70

\begin{tabular}{cc}
19 & 3,35 \\
50 & 8,80 \\
90 & 15,85 \\
146 & 25,70 \\
117 & 20,60 \\
146 & 25,70 \\
\hline
\end{tabular}


Figura 3. Formación académica de los encuestados.

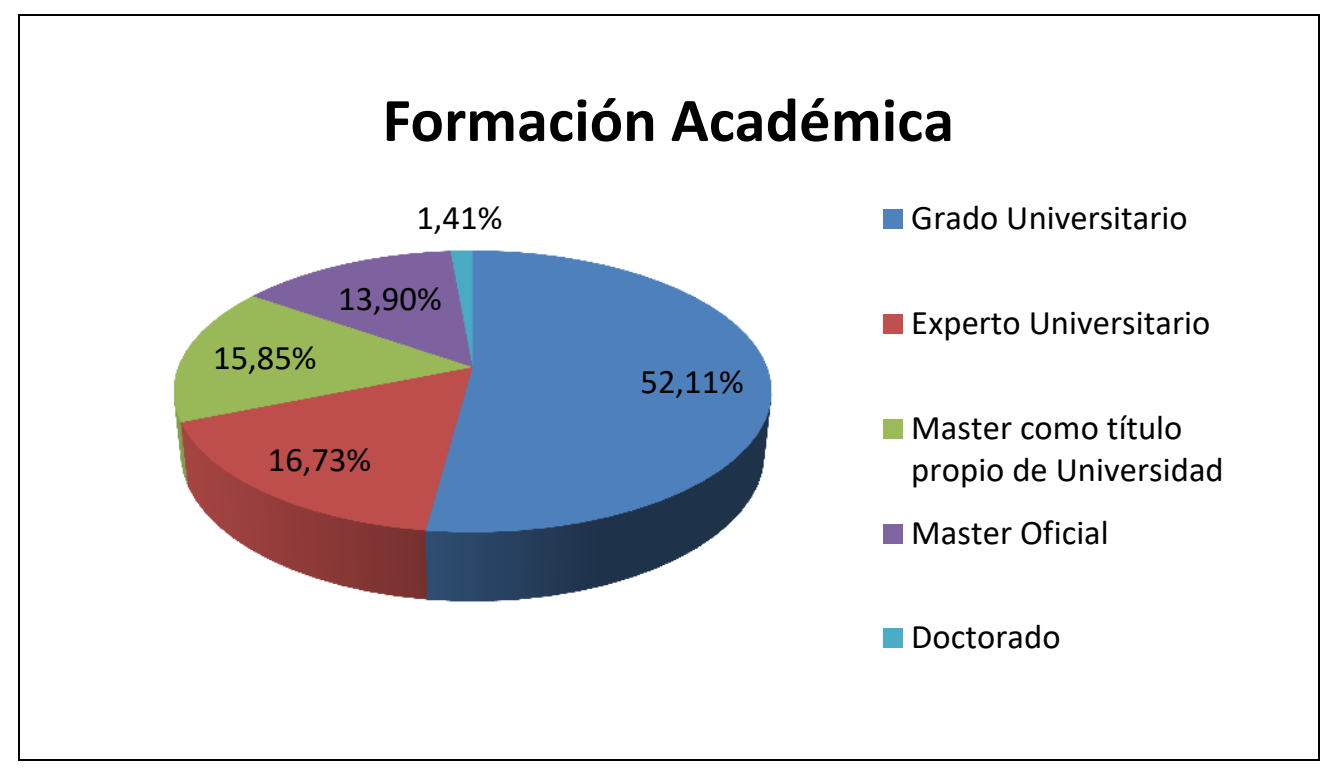

En lo que se refiere a la experiencia laboral en cualquier ámbito como enfermeras, se observó como el 76,05\% tenía más de 11 años de experiencia en el ámbito de la enfermería, lo que nos aporta una muestra de enfermeras con amplia experiencia en la realidad asistencial, ver tabla 10.

Tabla 10. Experiencia laboral como enfermeras.

\begin{tabular}{lcc|}
\hline $\begin{array}{l}\text { Años de experiencia laboral en el campo de la enfermería en } \\
\text { cualquier ámbito } \\
\text { (n=568) }\end{array}$ & Frecuencia & Porcentaje (\%) \\
\hline Menos de un año & 2 & 0,35 \\
\hline $1-5$ años & 50 & 8,80 \\
\hline -10 años & 84 & 14,79 \\
\hline $11-15$ años & 130 & 22,89 \\
\hline $16-20$ años & 124 & 21,83 \\
\hline $21-25$ años & 75 & 13,21 \\
\hline Más de 25 años & 103 & 18,13 \\
\hline
\end{tabular}

Nota: Resultados expresados en porcentajes (\%)

El presente trabajo se centra en el entorno de las unidades de cuidados intensivos, y la experiencia laboral de los participantes en el ámbito concreto de UCI. La tabla 11, muestra la experiencia laboral de la muestra a estudio en UCI. El (33,80\%) contaba con una experiencia menor o igual a 5 años, el $24,30 \%$ con una experiencia entre 6 y 10 años, el 16,90\% con experiencia entre 11 y 15 años y el 25\% contaba con una experiencia en UCl superior a 15 años. 
Tabla 11. Experiencia laboral como enfermeras de UCI.

\begin{tabular}{lcc|}
\hline $\begin{array}{l}\text { Años de experiencia como enfermera en cuidados intensivos } \\
(\mathbf{n = 5 6 8 )}\end{array}$ & Frecuencia & Porcentaje (\%) \\
\hline Menos de un año & 20 & 3,52 \\
\hline $1-5$ años & 172 & 30,28 \\
\hline 6-10 años & 138 & 24,30 \\
\hline $11-15$ años & 96 & 16,90 \\
\hline $16-20$ años & 61 & 10,74 \\
\hline $21-25$ años & 42 & 7,39 \\
\hline Más de 25 años & 39 & 6,87 \\
\hline
\end{tabular}

Nota: Resultados expresados en porcentajes (\%) y frecuencias

Estas enfermeras desempeñaban su labor profesional predominantemente en centros pertenecientes al ámbito de la gestión pública 91,55\% (520), sólo un 4,76\% (27) y un 3,69\% (21) a la gestión mixta y privada respectivamente. El 86,44\% (491) trabajaban en un centro hospitalario de carácter universitario. Respecto al tamaño de los centros hospitalarios se observó un predominio de los participantes que trabajaban en instituciones con mayor número de camas, como se observa en la figura 4:

Figura 4. Distribución de participantes en relación al número de camas del hospital.

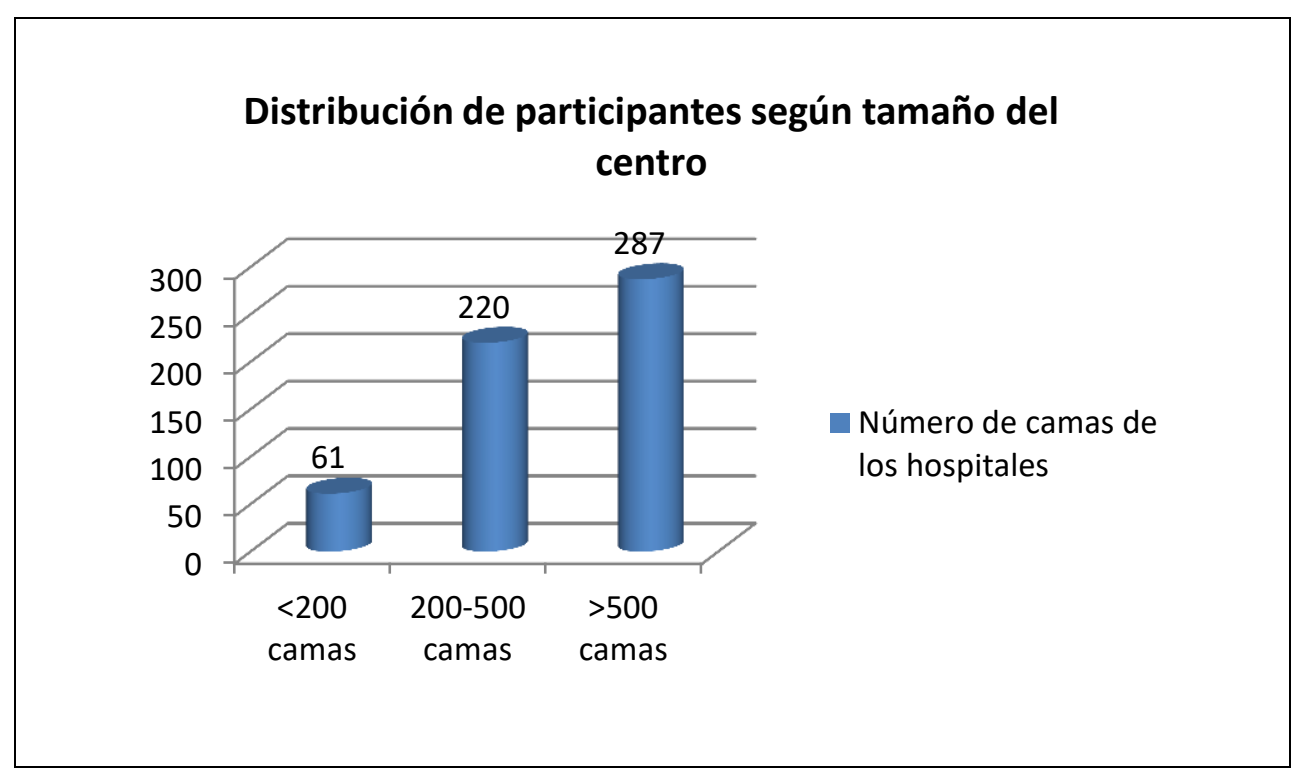

Por tanto, el 50,53\% de la muestra correspondió a centros con más de 500 camas hospitalarias, el $38,74 \%$ a centros de tamaño medio (200-500 camas) y el $10,73 \%$ restante a centros de menos de 200 camas. Según el tipo de organización de las UCl incluidas, observamos como existe un predominio de las unidades polivalentes, ver tabla 12 . 
Tabla 12. Tipo de Unidades de Cuidados Intensivos.

\begin{tabular}{lcc}
\hline $\begin{array}{l}\text { Tipo de Unidad de Cuidados Intensivos } \\
\text { (n=568) }\end{array}$ & Frecuencia & Porcentaje (\%) \\
\hline Cardiológica o Coronaria & 38 & 6,69 \\
\hline Intermedios & 5 & 0,88 \\
\hline Médica & 28 & 4,93 \\
\hline Pediátricos & 47 & 8,27 \\
\hline Polivalente & 405 & 71,30 \\
\hline Post-quirúrgica & 30 & 5,28 \\
\hline Quemados & 3 & 0,53 \\
\hline Respiratoria & 3 & 0,53 \\
\hline Trauma & 9 & 1,59 \\
\hline
\end{tabular}

Nota: Resultados expresados en porcentajes (\%) y frecuencias

Estas unidades contaban con un número de camas cuyo rango osciló entre 4 y 40 camas siendo la media 16,33 con una desviación típica de 7,930 y un valor de la moda de 12 camas. Se observó como la ratio enfermera: paciente más habitual fue de $1: 2$ en el $62,5 \%$ de los casos y del 1:3 en el $35,21 \%$, ver tabla 13.

Tabla 13.Relación enfermera: paciente.

\section{Ratio Enfermera: Paciente}

( $n=568)$

Frecuencia

1 enfermera:1 paciente

1 enfermera: 2 pacientes

1 enfermera: 3 pacientes

1 enfermera:4 pacientes

1 enfermera: $\geq 5$ pacientes

20,35

$355 \quad 62,5$

$200 \quad 35,21$

$11 \quad 1,94$

0

Nota: Resultados expresados en porcentajes (\%) y frecuencias

La tabla 14 presenta la distribución nacional de las enfermeras encuestadas tanto por provincia como por Comunidad Autónoma.

Tabla 14. Distribución de las enfermeras por CCAA y Provincia.

\begin{tabular}{|c|c|c|c|c|c|}
\hline $\begin{array}{l}\text { Comunidad } \\
\text { Autónoma }\end{array}$ & Frecuencia & Porcentaje (\%) & Provincia & Frecuencia & Porcentaje (\%) \\
\hline \multirow{7}{*}{ Andalucía } & \multirow{7}{*}{77} & \multirow{7}{*}{13,56} & Almería & 6 & 1,05 \\
\hline & & & Cádiz & 23 & 4,04 \\
\hline & & & Córdoba & 14 & 2,46 \\
\hline & & & Granada & 6 & 1,05 \\
\hline & & & Jaén & 3 & 0,52 \\
\hline & & & Málaga & 12 & 2,11 \\
\hline & & & Sevilla & 13 & 2,28 \\
\hline \multirow{2}{*}{ Aragón } & \multirow{2}{*}{31} & \multirow{2}{*}{5,46} & Huesca & 7 & 1,23 \\
\hline & & & Zaragoza & 24 & 4,22 \\
\hline Asturias & 7 & 1,23 & Asturias & 7 & 1,23 \\
\hline
\end{tabular}




\begin{tabular}{|c|c|c|c|c|c|}
\hline $\begin{array}{l}\text { Comunidad } \\
\text { Autónoma }\end{array}$ & Frecuencia & Porcentaje (\%) & Provincia & Frecuencia & Porcentaje (\%) \\
\hline \multirow{2}{*}{ Canarias } & \multirow{2}{*}{60} & \multirow{2}{*}{10,56} & Las Palmas & 37 & 6,51 \\
\hline & & & Tenerife & 23 & 4,04 \\
\hline Cantabria & 20 & 3,52 & Cantabria & 20 & 3,52 \\
\hline \multirow{5}{*}{ Castilla-La Mancha } & \multirow{5}{*}{26} & \multirow{5}{*}{4,58} & Albacete & 8 & 1,40 \\
\hline & & & Ciudad Real & 7 & 1,23 \\
\hline & & & Cuenca & 4 & 0,70 \\
\hline & & & Guadalajara & 4 & 0,70 \\
\hline & & & Toledo & 3 & 0,52 \\
\hline \multirow{5}{*}{ Castilla y León } & \multirow{5}{*}{32} & \multirow{5}{*}{5,63} & Burgos & 14 & 2,46 \\
\hline & & & León & 2 & 0,35 \\
\hline & & & Salamanca & 5 & 0,88 \\
\hline & & & Valladolid & 5 & 0,88 \\
\hline & & & Zamora & 6 & 1,05 \\
\hline \multirow{2}{*}{ Cataluña } & \multirow{2}{*}{68} & \multirow{2}{*}{11,97} & Barcelona & 52 & 9,15 \\
\hline & & & Tarragona & 16 & 2,81 \\
\hline \multirow{3}{*}{$\begin{array}{l}\text { Comunidad } \\
\text { Valenciana }\end{array}$} & \multirow{3}{*}{77} & \multirow{3}{*}{13,56} & Alicante & 37 & 6,51 \\
\hline & & & Castellón & 13 & 2,28 \\
\hline & & & Valencia & 27 & 4,75 \\
\hline \multirow{2}{*}{ Extremadura } & \multirow{2}{*}{15} & \multirow{2}{*}{2,64} & Badajoz & 12 & 2,11 \\
\hline & & & Cáceres & 3 & 0,52 \\
\hline \multirow{2}{*}{ Galicia } & \multirow{2}{*}{15} & \multirow{2}{*}{2,64} & A Coruña & 3 & 0,52 \\
\hline & & & Pontevedra & 12 & 2,11 \\
\hline Islas Baleares & 26 & 4,58 & Islas Baleares & 26 & 4,57 \\
\hline La Rioja & 16 & 2,82 & La Rioja & 16 & 2,81 \\
\hline Madrid & 83 & 14,61 & Madrid & 83 & 14,61 \\
\hline Murcia & 9 & 1,58 & Murcia & 9 & 1,58 \\
\hline País Vasco & 6 & 1,06 & Bizkaia & 6 & 1,05 \\
\hline
\end{tabular}

Nota: Resultados expresados en porcentajes (\%) y frecuencias

\subsubsection{Estadística descriptiva de las variables cuantitativas.}

A continuación, se detallan los resultados obtenidos en cada uno de los ítems, agrupados estos en los mismos 5 subgrupos: ámbito clínico, ámbito profesional, ámbito de la gestión, ámbito educativo y de desarrollo y finalmente el ámbito de formación. También se utilizó una escala tipo Likert de 1-10, donde los valores superiores corresponden a estar totalmente de acuerdo con la afirmación y los valores inferiores a no estar de acuerdo con la afirmación evaluada. Los resultados se expresan en valores medios y desviación típica, además de valores mínimos y máximos.

Se realizó la prueba de normalidad de Kolmogorov-Smirnov para evaluar la distribución de las respuestas. Es de destacar que, en todos los ítems estudiados, la prueba de Kolmogorov-Smirnov dio como resultado $p<0,05$; lo que indicó que la distribución de las respuestas no seguía una curva de normalidad. Con varianzas iguales se optó por aplicar test paramétricos debido a que el tamaño de la muestra era representativo y con un número elevado de respuestas, con varianzas diferentes se aplicaron test no paramétricos.

La tabla 15 presenta las respuestas relativas al ámbito clínico. Los encuestados valoraron la necesidad de incluir dentro de la formación de las enfermeras gran cantidad de competencias en el ámbito clínico. 
Tabla 15. Puntuaciones ítems ámbito clínico.

\begin{tabular}{|c|c|c|c|c|}
\hline $\begin{array}{l}\text { Afirmaciones } \\
(n=568)\end{array}$ & Media & D.T & Min. & Max. \\
\hline $\begin{array}{l}\text { Las enfermeras de UCI deben tener conocimientos extensos de } \\
\text { enfermería básica }\end{array}$ & 9,48 & 0,85 & 5 & 10 \\
\hline $\begin{array}{l}\text { Las enfermeras de UCI deben desarrollar habilidades específicas } \\
\text { para la atención al paciente crítico }\end{array}$ & 9,63 & 0,73 & 2 & 10 \\
\hline $\begin{array}{l}\text { La observación es una herramienta necesaria, para obtener datos en } \\
\text { la valoración del paciente crítico }\end{array}$ & 9,50 & 0,80 & 6 & 10 \\
\hline $\begin{array}{l}\text { La monitorización es una herramienta fundamental, para obtener } \\
\text { datos en la valoración del paciente crítico }\end{array}$ & 9,34 & 0,91 & 5 & 10 \\
\hline $\begin{array}{l}\text { El uso de escalas son necesarias para la valoración del paciente } \\
\text { crítico }\end{array}$ & 8,81 & 1,14 & 3 & 10 \\
\hline $\begin{array}{l}\text { La empatía y el respeto a la intimidad son fundamentales para la } \\
\text { enfermera de } \mathrm{UCl}\end{array}$ & 9,40 & 0,87 & 4 & 10 \\
\hline $\begin{array}{l}\text { Hay que involucrar al paciente y a la familia en el proceso de } \\
\text { recuperación }\end{array}$ & 8,83 & 1,22 & 4 & 10 \\
\hline $\begin{array}{l}\text { Observar, analizar e interpretar situaciones y/o problemas en un } \\
\text { paciente crítico es necesario para realizar un examen físico. }\end{array}$ & 9,06 & 1,05 & 3 & 10 \\
\hline $\begin{array}{l}\text { La integración e interrelación de los datos es una habilidad muy } \\
\text { importante de las enfermeras de } \mathrm{UCI}\end{array}$ & 9,19 & 0,99 & 5 & 10 \\
\hline $\begin{array}{l}\text { Las principales patologías que debe conocer una enfermera de } \mathrm{UCl} \text {, } \\
\text { son la cardíaca, la respiratoria y la neurológica }\end{array}$ & 8,06 & 1,64 & 1 & 10 \\
\hline $\begin{array}{l}\text { Las medidas de soporte son el pilar fundamental de las actividades } \\
\text { enfermeras }\end{array}$ & 8,36 & 1,75 & 1 & 10 \\
\hline $\begin{array}{l}\text { Las enfermeras de UCI deben estar formadas en la atención de los } \\
\text { distintos tipos de shock }\end{array}$ & 9,46 & 0,89 & 4 & 10 \\
\hline El cálculo de fármacos y drogas, es una competencia imprescindible & 9,33 & 1,33 & 1 & 10 \\
\hline $\begin{array}{l}\text { El cuidado integral de un paciente crítico forma parte de la actuación } \\
\text { principal del profesional de enfermería }\end{array}$ & 9,52 & 0,87 & 2 & 10 \\
\hline $\begin{array}{l}\text { Los cuidados respiratorios son los que de manera prioritaria deben } \\
\text { ser desarrollados en las enfermeras de } \mathrm{UCl}\end{array}$ & 7,92 & 1,58 & 1 & 10 \\
\hline $\begin{array}{l}\text { La reevaluación continua es la principal medida que debe } \\
\text { implementar la enfermera para evaluar estrategias de mejora del } \\
\text { plan de cuidados. }\end{array}$ & 9,03 & 1,01 & 5 & 10 \\
\hline La capacidad de priorización es una habilidad imprescindible & 9,52 & 0,77 & 6 & 10 \\
\hline $\begin{array}{l}\text { El razonamiento clínico (que pasa, y que puede llegar a pasar) debe } \\
\text { ser fomentado en las enfermeras de } \mathrm{UCl}\end{array}$ & 9,41 & 0,86 & 5 & 10 \\
\hline
\end{tabular}

Nota: Resultados expresados como media y desviación típica (DT). Mínimos y máximos (Min-Max)

En lo referente a las puntuaciones del ámbito profesional, cabe destacar que siguen una línea similar a las relacionadas con el ámbito clínico. Todos los ítems fueron puntuados con valores medios superiores a 7, lo que constituye una simetría muy interesante con el grupo generador del cuestionario, ver tabla 16. 
Tabla 16. Puntuaciones de los ítems de ámbito profesional.

\begin{tabular}{|c|c|c|c|c|}
\hline $\begin{array}{l}\text { Afirmaciones } \\
(n=568)\end{array}$ & Media & D.T. & Min. & Max. \\
\hline $\begin{array}{l}\text { Ante situaciones complejas, la ayuda y el apoyo de compañeros } \\
\text { más experimentados ayudan a resolver problemas }\end{array}$ & 9,42 & 0,90 & 1 & 10 \\
\hline $\begin{array}{l}\text { Las enfermeras pueden hacer frente a decisiones complejas gracias } \\
\text { a la experiencia laboral obtenida en } \mathrm{UCI}\end{array}$ & 9,12 & 0,98 & 5 & 10 \\
\hline $\begin{array}{l}\text { Las decisiones de cuidado son muy complejas y requieren de una } \\
\text { formación extensa }\end{array}$ & 8,93 & 1,06 & 5 & 10 \\
\hline $\begin{array}{l}\text { Las enfermeras de UCl tienen mucha autonomía, por lo que es } \\
\text { necesario una formación reglada y adecuada al puesto de trabajo }\end{array}$ & 8,93 & 1,28 & 1 & 10 \\
\hline $\begin{array}{l}\text { La enfermera de UCI suele afrontar bien la decisión de limitación } \\
\text { de soporte vital (esfuerzo terapéutico) }\end{array}$ & 8,12 & 1,57 & 1 & 10 \\
\hline $\begin{array}{l}\text { La enfermera debería participar en las decisiones de limitación de } \\
\text { soporte vital (esfuerzo terapéutico) }\end{array}$ & 8,41 & 1,81 & 1 & 10 \\
\hline La enfermera de $\mathrm{UCl}$ afronta peor el encarnizamiento terapéutico & 8,64 & 1,74 & 1 & 10 \\
\hline $\begin{array}{l}\text { El afrontamiento de la muerte de los usuarios dependerá de las } \\
\text { creencias, experiencias y valores del profesional de enfermería }\end{array}$ & 7,31 & 2,36 & 1 & 10 \\
\hline $\begin{array}{l}\text { El profesional de enfermería en } \mathrm{UCl} \text {, dentro de su competencia, } \\
\text { busca la excelencia a nivel clínico }\end{array}$ & 8,66 & 1,41 & 1 & 10 \\
\hline $\begin{array}{l}\text { El lenguaje verbal y no verbal son fundamentales en la } \\
\text { comunicación en } \mathrm{UCl}\end{array}$ & 9,05 & 1,09 & 5 & 10 \\
\hline $\begin{array}{l}\text { En situaciones de estrés, las enfermeras se deben comunicar de } \\
\text { manera técnica, concisa y clara, ajustando la información a las } \\
\text { características del interlocutor }\end{array}$ & 8,97 & 1,11 & 4 & 10 \\
\hline $\begin{array}{l}\text { La principales herramientas de comunicación son la asertividad, la } \\
\text { empatía y la escucha activa tanto con usuarios y familia como con } \\
\text { profesionales }\end{array}$ & 9,03 & 1,05 & 3 & 10 \\
\hline $\begin{array}{l}\text { Las tecnologías de la información y comunicación (TIC) son } \\
\text { herramientas esenciales que permiten la formación, el aprendizaje } \\
\text { y el desarrollo de la profesión }\end{array}$ & 8,41 & 1,32 & 1 & 10 \\
\hline $\begin{array}{l}\text { La comunicación escrita en } \mathrm{UCl} \text { se debe fomentar siempre, pues es } \\
\text { indispensable para la continuidad de cuidados }\end{array}$ & 8,98 & 1,18 & 2 & 10 \\
\hline
\end{tabular}

Nota: Resultados expresados como media y desviación típica (DT). Mínimos y máximos (Min-Max)

La tabla 17 presenta los resultados del ámbito de la gestión. Los ítems relacionados con gestión de la calidad asistencial y carga de trabajo fueron los que obtuvieron unas peores valoraciones. Observando que la gestión de la carga de trabajo es la única que se puntúa con un valor inferior a 6 puntos.

Tabla 17. Puntuaciones de los ítems de ámbito de la gestión.

El seguimiento de los cuidados que prestan las enfermeras es indispensable para la continuidad y evaluación de los cuidados

Registrar los cuidados prestados es la mejor medida posible para garantizar la continuidad

$9,24 \quad 1,00 \quad 1 \quad 10$




\begin{tabular}{|c|c|c|c|c|}
\hline $\begin{array}{l}\text { Afirmaciones } \\
(n=568)\end{array}$ & Media & D.T. & Min. & Max. \\
\hline La enfermera de UCl actúa de nexo entre los distintos profesionales & 8,66 & 1,53 & 1 & 10 \\
\hline La coordinación del equipo sanitario es imprescindible & 9,61 & 0,73 & 7 & 10 \\
\hline $\begin{array}{l}\text { Las enfermeras son capaces de planificar actuaciones a lo largo del } \\
\text { turno de trabajo }\end{array}$ & 9,04 & 1,18 & 2 & 10 \\
\hline $\begin{array}{l}\text { Las enfermeras que trabajan en } \mathrm{UCl} \text { recogen datos relacionados con } \\
\text { los indicadores de calidad }\end{array}$ & 7,48 & 1,98 & 1 & 10 \\
\hline Se realiza un seguimiento de los indicadores de calidad & 6,66 & 2,21 & 1 & 10 \\
\hline $\begin{array}{l}\text { Es necesaria una correcta formación para garantizar la seguridad } \\
\text { clínica }\end{array}$ & 9,34 & 0,94 & 6 & 10 \\
\hline Las enfermeras de UCl están involucradas en la seguridad clínica & 8,72 & 1,37 & 2 & 10 \\
\hline $\begin{array}{l}\text { Las enfermeras de UCI deben ser capaces de actuar rápidamente } \\
\text { ante el deterioro del usuario y ante eventos adversos }\end{array}$ & 9,48 & 0,87 & 5 & 10 \\
\hline $\begin{array}{l}\text { Los equipos asistenciales de UCI son capaces de realizar su trabajo } \\
\text { en un ambiente de presión y estrés }\end{array}$ & 8,93 & 1,17 & 3 & 10 \\
\hline $\begin{array}{l}\text { Se gestiona adecuadamente la carga de trabajo de las enfermeras } \\
\text { en } \mathrm{UCl}\end{array}$ & 5,78 & 2,13 & 1 & 10 \\
\hline $\begin{array}{l}\text { En una } \mathrm{UCl} \text { es fundamental la capacidad de adaptación de las } \\
\text { enfermeras en las situaciones urgentes y emergentes }\end{array}$ & 9,16 & 1,17 & 3 & 10 \\
\hline $\begin{array}{l}\text { Evitar ruidos innecesarios o bajar el volumen de luces y alarmas, son } \\
\text { acciones que fomentan el descanso del paciente crítico }\end{array}$ & 9,15 & 1,06 & 4 & 10 \\
\hline $\begin{array}{l}\text { Se fomentan acciones para el adecuado confort y descanso de los } \\
\text { pacientes }\end{array}$ & 7,83 & 1,73 & 1 & 10 \\
\hline $\begin{array}{l}\text { En UCl, se toman medidas que ayudan a prevenir o evitar el delirio o } \\
\text { la desorientación }\end{array}$ & 7,07 & 1,92 & 1 & 10 \\
\hline
\end{tabular}

Nota: Resultados expresados como media y desviación típica (DT). Mínimos y máximos (Min-Max)

En cuanto al ámbito educativo y de desarrollo, el ítem que relaciona la colaboración de la institución con la formación de las enfermeras en cuidados intensivos resultó el peor puntuado, ver tabla 18.

Tabla 18. Puntuaciones de los ítems de ámbito educativo y de desarrollo.

\begin{tabular}{|c|c|c|c|c|}
\hline $\begin{array}{l}\text { Afirmaciones } \\
(n=568)\end{array}$ & Media & D.T. & Min. & Max. \\
\hline $\begin{array}{l}\text { Las enfermeras realizan actividades formativas sobre los cuidados } \\
\text { intensivos }\end{array}$ & 7,72 & 1,66 & 1 & 10 \\
\hline $\begin{array}{l}\text { La realización de esta formación depende de la motivación de la } \\
\text { enfermera }\end{array}$ & 8,66 & 1,78 & 1 & 10 \\
\hline Las actividades formativas repercuten positivamente a nivel clínico & 9,32 & 1,01 & 1 & 10 \\
\hline La institución colabora en una formación específica de UCI & 5,56 & 2,33 & 1 & 10 \\
\hline $\begin{array}{l}\text { La acogida de personal de nueva incorporación debe ser realizada } \\
\text { lenta y progresivamente }\end{array}$ & 8,99 & 1,54 & 1 & 10 \\
\hline $\begin{array}{l}\text { La formación en } \mathrm{UCl} \text { se realiza sobre todo para el cobro de } \\
\text { incentivos, bolsas de empleo y oposiciones }\end{array}$ & 6,25 & 2,61 & 1 & 10 \\
\hline
\end{tabular}

Nota: Resultados expresados como media y desviación típica (DT). Mínimos y máximos (Min-Max) 
A continuación, se presentan los resultados descriptivos obtenidos por los ítems incluidos en la categoría de dimensiones y formación. La parte B de la encuesta nos muestra que existe un gran consenso en que son necesarias las afirmaciones expresadas; las enfermeras encuestadas dan a esta sección del cuestionario puntuaciones superiores al 80\% de la puntuación total, ver tabla 19.

Tabla 19. Puntuaciones de los ítems de dimensiones y Formación.

\begin{tabular}{|c|c|c|c|c|}
\hline $\begin{array}{l}\text { Afirmaciones } \\
(n=568)\end{array}$ & Media & D.T. & Min. & Max. \\
\hline $\begin{array}{l}\text { La enfermera de nueva incorporación debería tener conocimientos } \\
\text { hemodinámicos, de ventilación mecánica, reanimación } \\
\text { cardiopulmonar básica y avanzada, además de monitorización }\end{array}$ & 8,85 & 1,27 & 3 & 10 \\
\hline $\begin{array}{l}\text { Debería existir la figura de un enfermero tutor en la unidad para } \\
\text { ayudar a las enfermeras de nueva incorporación }\end{array}$ & 9,48 & 0,95 & 4 & 10 \\
\hline $\begin{array}{l}\text { Es necesario una formación previa postgrado de UCI para las } \\
\text { enfermeras noveles }\end{array}$ & 8,42 & 1,94 & 1 & 10 \\
\hline $\begin{array}{l}\text { La primera semana, las enfermeras noveles deben estar } \\
\text { supervisadas en todo momento }\end{array}$ & 9,19 & 1,30 & 3 & 10 \\
\hline $\begin{array}{l}\text { El personal del staff (veterano), requiere de planes formativos } \\
\text { específicos de periodicidad anual }\end{array}$ & 8,32 & 1,70 & 1 & 10 \\
\hline $\begin{array}{l}\text { La formación amplia y específica en cuidados críticos, facilita que el } \\
\text { profesional alcance un nivel de excelencia }\end{array}$ & 9,05 & 1,14 & 2 & 10 \\
\hline $\begin{array}{l}\text { La formación se debe apoyar en eventos teórico-prácticos y en la } \\
\text { simulación, antes de llevar esos conocimientos a la realidad }\end{array}$ & 8,98 & 1,15 & 2 & 10 \\
\hline $\begin{array}{l}\text { La formación debe terminar con una intervención real, siempre } \\
\text { tutelado con un profesional experimentado }\end{array}$ & 8,98 & 1,27 & 2 & 10 \\
\hline $\begin{array}{l}\text { La empatía es una actitud indispensable a desarrollar dentro del } \\
\text { equipo sanitario }\end{array}$ & 9,10 & 1,02 & 4 & 10 \\
\hline $\begin{array}{l}\text { Las enfermeras necesitan formación específica para afrontar la } \\
\text { muerte de los usuarios }\end{array}$ & 8,50 & 1,55 & 1 & 10 \\
\hline $\begin{array}{l}\text { Son habilidades a desarrollar en las enfermeras de } \mathrm{UCl} \text {, la calma, ser } \\
\text { metódico y resolutivas }\end{array}$ & 8,95 & 1,15 & 1 & 10 \\
\hline $\begin{array}{l}\text { La inteligencia emocional es necesaria de ser desarrollada en las } \\
\text { enfermeras de } \mathrm{UCl}\end{array}$ & 8,82 & 1,15 & 4 & 10 \\
\hline
\end{tabular}

Nota: Resultados expresados como media y desviación típica (DT). Mínimos y máximos (Min-Max)

En la Tabla 20 se agrupan las puntuaciones obtenidas por las preguntas incluidas en cada uno de los ámbitos, así como la puntuación total de todos los ámbitos. Como podemos observar, los resultados muestran valores inferiores a $p<0,05$ en el test de Kolmogorov-Smirnov.

Tabla 20. Puntuaciones por ámbito y totales. Test de Kolmogorov-Smirnov.

\begin{tabular}{|lcccccc}
\hline $\begin{array}{l}\text { Puntuaciones totales } \\
\text { (n=568) }\end{array}$ & Media & D.T. & Min. & Max & Test K-S \\
\hline Ámbito Clínico & 163,77 & 9,77 & 132 & 180 & $<0,001$ \\
\hline Ámbito Profesional & 121,89 & 9,79 & 91 & 140 & $<0,001$ \\
\hline Ámbito de la Gestión & 135,35 & 11,50 & 102 & 160 & 0,002 \\
\hline Ámbito educativo y de desarrollo & 46,50 & 5,88 & 17 & 60 & $<0,001$
\end{tabular}




\begin{tabular}{lcccccc}
\hline $\begin{array}{l}\text { Puntuaciones totales } \\
\text { (n=568) }\end{array}$ & Media & D.T. & Min. & Max & Test K-S \\
\hline Puntuación total parte A & 467,53 & 29,21 & 374 & 540 & 0,019 \\
\hline Puntuación total parte B & 106,57 & 9,25 & 74 & 120 & 0,004 \\
\hline Puntuación total cuestionario & 574,10 & 35,66 & 449 & 660 & 0,038 \\
\hline
\end{tabular}

Nota: Resultados expresados como media y desviación típica (DT). Mínimos y máximos (Min-Max)

\subsubsection{Analizar la existencia de diferencias en la puntuación de las necesidades formativas de las enfermeras de $\mathrm{UCl}$ en función de las características demográficas de las enfermeras.}

En este apartado se han analizado las diferencias entre las puntuaciones obtenidas en cada ítem, en cada una de las subescalas y el valor global del cuestionario (parte A) en función de las características demográficas (género, edad y formación universitaria).

\section{En función del Género.}

La muestra presentó una mayor proporción de mujeres siendo el $81,3 \%$ del total. Para analizar si existían diferencias, en función del género, en la valoración de las necesidades formativas de las enfermeras de $\mathrm{UCl}$ se realizó una prueba de diferencia de medias aplicando el estadístico $\mathrm{t}$ de Student (Tabla 21).

Tabla 21. Puntuaciones en el ámbito clínico en función del género.

\begin{tabular}{|c|c|c|c|c|c|c|c|c|}
\hline \multirow[t]{2}{*}{ Afirmaciones } & \multicolumn{2}{|c|}{$\begin{array}{c}\text { Hombres } \\
(n=106)\end{array}$} & \multicolumn{2}{|c|}{$\begin{array}{l}\text { Mujeres } \\
(n=462)\end{array}$} & \multicolumn{2}{|c|}{ Prueba Levene } & \multirow[t]{2}{*}{$t$} & \multirow[t]{2}{*}{$p$} \\
\hline & Media & D.T. & Media & D.T. & $\mathbf{F}$ & $p$ & & \\
\hline $\begin{array}{l}\text { Las enfermeras de } \mathrm{UCl} \text { deben tener } \\
\text { conocimientos extensos de } \\
\text { enfermería básica }\end{array}$ & 9,31 & 0,97 & 9,52 & 0,81 & 5,950 & 0,015 & 2,300 & 0,022 \\
\hline $\begin{array}{l}\text { Las enfermeras de UCI deben } \\
\text { desarrollar habilidades específicas } \\
\text { para la atención al paciente crítico }\end{array}$ & 9,53 & 0,83 & 9,65 & 0,71 & 6,284 & 0,012 & 1,581 & 0,114 \\
\hline $\begin{array}{l}\text { La observación es una herramienta } \\
\text { necesaria, para obtener datos en la } \\
\text { valoración del paciente crítico }\end{array}$ & 9,35 & 0,89 & 9,53 & 0,78 & 10,839 & 0,001 & 2,070 & 0,039 \\
\hline $\begin{array}{l}\text { La monitorización es una } \\
\text { herramienta fundamental, para } \\
\text { obtener datos en la valoración del } \\
\text { paciente crítico }\end{array}$ & 9,19 & 1,09 & 9,38 & 0,86 & 4,492 & 0,034 & 1,957 & 0,051 \\
\hline $\begin{array}{l}\text { El uso de escalas son necesarias para } \\
\text { la valoración del paciente crítico }\end{array}$ & 8,72 & 1,25 & 8,84 & 1,11 & 1,426 & 0,233 & 0,962 & 0,337 \\
\hline $\begin{array}{l}\text { La empatía y el respeto a la intimidad } \\
\text { son fundamentales para la } \\
\text { enfermera de } \mathrm{UCl}\end{array}$ & 9,30 & 0,89 & 9,42 & 0,86 & 2,302 & 0,130 & 1,208 & 0,228 \\
\hline $\begin{array}{l}\text { Hay que involucrar al paciente y a la } \\
\text { familia en el proceso de } \\
\text { recuperación }\end{array}$ & 8,75 & 1,19 & 8,85 & 1,23 & 0,667 & 0,414 & 0,693 & 0,488 \\
\hline $\begin{array}{l}\text { Observar, analizar e interpretar } \\
\text { situaciones y/o problemas en un } \\
\text { paciente crítico es necesario para } \\
\text { realizar un examen físico. }\end{array}$ & 8,94 & 1,11 & 9,10 & 1,04 & 0,003 & 0,959 & 1,373 & 0,170 \\
\hline $\begin{array}{l}\text { La integración e interrelación de los } \\
\text { datos es una habilidad muy } \\
\text { importante de las enfermeras de UCI }\end{array}$ & 9,13 & 1,04 & 9,20 & 0,98 & 0,335 & 0,563 & 0,645 & 0,519 \\
\hline
\end{tabular}




\begin{tabular}{|c|c|c|c|c|c|c|c|c|}
\hline \multirow[t]{2}{*}{ Afirmaciones } & \multicolumn{2}{|c|}{$\begin{array}{l}\text { Hombres } \\
(n=106)\end{array}$} & \multicolumn{2}{|c|}{$\begin{array}{l}\text { Mujeres } \\
(n=462)\end{array}$} & \multicolumn{2}{|c|}{ Prueba Levene } & \multirow[t]{2}{*}{$\boldsymbol{t}$} & \multirow[t]{2}{*}{$p$} \\
\hline & Media & D.T. & Media & D.T. & $\mathbf{F}$ & $p$ & & \\
\hline $\begin{array}{l}\text { Las principales patologías que debe } \\
\text { conocer una enfermera de } \mathrm{UCl} \text {, son } \\
\text { la cardíaca, la respiratoria y la } \\
\text { neurológica }\end{array}$ & 7,75 & 1,85 & 8,11 & 1,58 & 2,523 & 0,113 & 2,095 & 0,037 \\
\hline $\begin{array}{l}\text { Las medidas de soporte son el pilar } \\
\text { fundamental de las actividades } \\
\text { enfermeras }\end{array}$ & 7,86 & 1,99 & 8,48 & 1,67 & 1,618 & 0,204 & 3,298 & 0,001 \\
\hline $\begin{array}{l}\text { Las enfermeras de UCl deben estar } \\
\text { formadas en la atención de los } \\
\text { distintos tipos de shock }\end{array}$ & 9,42 & 0,85 & 9,46 & 0,90 & 0,000 & 0,990 & 0,335 & 0,738 \\
\hline $\begin{array}{l}\text { El cálculo de fármacos y drogas, es } \\
\text { una competencia imprescindible }\end{array}$ & 9,32 & 1,23 & 9,32 & 1,36 & 0,378 & 0,539 & 0,003 & 0,998 \\
\hline $\begin{array}{l}\text { El cuidado integral de un paciente } \\
\text { crítico forma parte de la actuación } \\
\text { principal del profesional de } \\
\text { enfermería }\end{array}$ & 9,42 & 0,79 & 9,53 & 0,89 & 0,235 & 0,628 & 1,149 & 0,251 \\
\hline $\begin{array}{l}\text { Los cuidados respiratorios son los } \\
\text { que de manera prioritaria deben ser } \\
\text { desarrollados en las enfermeras de } \\
\text { UCl }\end{array}$ & 7,67 & 1,54 & 7,96 & 1,58 & 0,268 & 0,605 & 1,713 & 0,087 \\
\hline $\begin{array}{l}\text { La reevaluación continua es la } \\
\text { principal medida que debe } \\
\text { implementar la enfermera para } \\
\text { evaluar estrategias de mejora del } \\
\text { plan de cuidados. }\end{array}$ & 8,89 & 1,03 & 9,05 & 1,00 & 0,016 & 0,899 & 1,500 & 0,134 \\
\hline $\begin{array}{l}\text { La capacidad de priorización es una } \\
\text { habilidad imprescindible }\end{array}$ & 9,34 & 0,95 & 9,55 & 0,71 & 19,179 & $\leq 0,001$ & 2,601 & 0,010 \\
\hline $\begin{array}{l}\text { El razonamiento clínico (que pasa, y } \\
\text { que puede llegar a pasar) debe ser } \\
\text { fomentado en las enfermeras de } \mathrm{UCl}\end{array}$ & 9,40 & 0,80 & 9,40 & 0,87 & 0,550 & 0,458 & 0,045 & 0,964 \\
\hline
\end{tabular}

Nota. Prueba t de Student (t). $\mathbf{p}$ valor: $p<0,05$

En la misma línea, la tabla 22 presenta los resultados relacionados con el ámbito profesional en función de variable independiente género. Se detecta que las enfermeras mujeres valoran más el apoyo interprofesional, una formación amplia y las habilidades de comunicación para para poder hacer frente al cuidado de una manera eficiente, ver tabla 22.

Tabla 22. Puntuaciones en el ámbito profesional en función del género.

\begin{tabular}{|c|c|c|c|c|c|c|c|c|}
\hline \multirow[t]{2}{*}{ Afirmaciones } & \multicolumn{2}{|c|}{$\begin{array}{c}\text { Hombres } \\
(n=106)\end{array}$} & \multicolumn{2}{|c|}{$\begin{array}{l}\text { Mujeres } \\
(n=462)\end{array}$} & \multicolumn{2}{|c|}{ Prueba Levene } & \multirow[t]{2}{*}{$t$} & \multirow[t]{2}{*}{$p$} \\
\hline & Media & D.T. & Media & D.T. & $F$ & $p$ & & \\
\hline $\begin{array}{l}\text { Ante situaciones complejas, la ayuda } \\
\text { y el apoyo de compañeros más } \\
\text { experimentados ayudan a resolver } \\
\text { problemas }\end{array}$ & 9,24 & 0,86 & 9,45 & 0,90 & 0,093 & 0,760 & 2,263 & 0,024 \\
\hline $\begin{array}{l}\text { Las enfermeras pueden hacer frente } \\
\text { a decisiones complejas gracias a la } \\
\text { experiencia laboral obtenida en } \mathrm{UCl}\end{array}$ & 9,02 & 1,01 & 9,15 & 0,98 & 0,567 & 0,452 & 1,246 & 0,213 \\
\hline $\begin{array}{l}\text { Las decisiones de cuidado son muy } \\
\text { complejas y requieren de una } \\
\text { formación extensa }\end{array}$ & 8,75 & 1,16 & 8,98 & 1,04 & 4,451 & 0,035 & 2,090 & 0,037 \\
\hline $\begin{array}{l}\text { Las enfermeras de UCl tienen mucha } \\
\text { autonomía, por lo que es necesario } \\
\text { una formación reglada y adecuada al }\end{array}$ & 8,77 & 1,55 & 8,97 & 1,22 & 6,573 & 0,011 & 1,429 & 0,153 \\
\hline
\end{tabular}




\begin{tabular}{|c|c|c|c|c|c|c|c|c|}
\hline \multirow[t]{2}{*}{ Afirmaciones } & \multicolumn{2}{|c|}{$\begin{array}{c}\text { Hombres } \\
(n=106)\end{array}$} & \multicolumn{2}{|c|}{$\begin{array}{l}\text { Mujeres } \\
(\mathrm{n}=462)\end{array}$} & \multicolumn{2}{|c|}{ Prueba Levene } & \multirow[t]{2}{*}{$t$} & \multirow[t]{2}{*}{$p$} \\
\hline & Media & D.T. & Media & D.T. & $\mathbf{F}$ & $p$ & & \\
\hline $\begin{array}{l}\text { La enfermera de UCl suele afrontar } \\
\text { bien la decisión de limitación de } \\
\text { soporte vital (esfuerzo terapéutico) }\end{array}$ & 7,86 & 1,73 & 8,18 & 1,53 & 3,734 & 0,054 & 1,919 & 0,056 \\
\hline $\begin{array}{l}\text { La enfermera debería participar en } \\
\text { las decisiones de limitación de } \\
\text { soporte vital (esfuerzo terapéutico) }\end{array}$ & 8,51 & 1,72 & 8,37 & 1,83 & 0,519 & 0,471 & 0,703 & 0,482 \\
\hline $\begin{array}{l}\text { La enfermera de } \mathrm{UCl} \text { afronta peor el } \\
\text { encarnizamiento terapéutico }\end{array}$ & 8,50 & 1,79 & 8,65 & 1,73 & 1,475 & 0,225 & 0,819 & 0,413 \\
\hline $\begin{array}{l}\text { El afrontamiento de la muerte de los } \\
\text { usuarios dependerá de las creencias, } \\
\text { experiencias y valores del profesional } \\
\text { de enfermería }\end{array}$ & 7,38 & 2,09 & 7,26 & 2,42 & 3,561 & 0,060 & 0,461 & 0,645 \\
\hline $\begin{array}{l}\text { El profesional de enfermería en } \mathrm{UCl} \\
\text { dentro de su competencia, busca la } \\
\text { excelencia a nivel clínico }\end{array}$ & 8,46 & 1,52 & 8,69 & 1,38 & 1,588 & 0,208 & 1,470 & 0,142 \\
\hline $\begin{array}{l}\text { El lenguaje verbal y no verbal son } \\
\text { fundamentales en la comunicación } \\
\text { en } \mathrm{UCl}\end{array}$ & 8,90 & 1,10 & 9,08 & 1,08 & 0,207 & 0,649 & 1,587 & 0,113 \\
\hline $\begin{array}{l}\text { En situaciones de estrés, las } \\
\text { enfermeras se deben comunicar de } \\
\text { manera técnica, concisa y clara, } \\
\text { ajustando la información a las } \\
\text { características del interlocutor }\end{array}$ & 8,99 & 0,98 & 8,96 & 1,14 & 2,794 & 0,095 & 0,228 & 0,820 \\
\hline $\begin{array}{l}\text { La principales herramientas de } \\
\text { comunicación son la asertividad, la } \\
\text { empatía y la escucha activa tanto con } \\
\text { usuarios y familia como con } \\
\text { profesionales }\end{array}$ & 8,81 & 1,05 & 9,07 & 1,05 & 0,404 & 0,525 & 2,295 & 0,022 \\
\hline $\begin{array}{l}\text { Las tecnologías de la información y } \\
\text { comunicación (TIC) son } \\
\text { herramientas esenciales que } \\
\text { permiten la formación, el } \\
\text { aprendizaje y el desarrollo de la } \\
\text { profesión }\end{array}$ & 8,29 & 1,42 & 8,44 & 1,29 & 0,408 & 0,523 & 1,002 & 0,317 \\
\hline $\begin{array}{l}\text { La comunicación escrita en UCI se } \\
\text { debe fomentar siempre, pues es } \\
\text { indispensable para la continuidad de } \\
\text { cuidados }\end{array}$ & 8,89 & 1,22 & 8,98 & 1,17 & 0,005 & 0,946 & 0,750 & 0,454 \\
\hline
\end{tabular}

Nota. Prueba t de Student (t). p valor: $p<0,05$

En cuanto a las diferencias en el ámbito de gestión, en función del género, cabe destacar que el ítem "se fomentan acciones para el adecuado confort y descanso de los pacientes" ha sido considerado como más importante por las mujeres. Los hombres son más críticos en relación con cómo se gestiona la carga de trabajo en UCl (tabla 23).

Tabla 23. Puntuaciones en el ámbito de la gestión en función del género.

\begin{tabular}{|c|c|c|c|c|c|c|c|c|}
\hline \multirow[t]{2}{*}{ Afirmaciones } & \multicolumn{2}{|c|}{$\begin{array}{c}\text { Hombres } \\
(n=106)\end{array}$} & \multicolumn{2}{|c|}{$\begin{array}{l}\text { Mujeres } \\
(n=462)\end{array}$} & \multicolumn{2}{|c|}{ Prueba Levene } & \multirow[t]{2}{*}{$t$} & \multirow[t]{2}{*}{$p$} \\
\hline & Media & D.T. & Media & D.T. & $\mathbf{F}$ & $p$ & & \\
\hline $\begin{array}{l}\text { El seguimiento de los cuidados que } \\
\text { prestan las enfermeras es } \\
\text { indispensable para la continuidad y } \\
\text { evaluación de los cuidados }\end{array}$ & 8,98 & 0,99 & 9,26 & 0,96 & 1,350 & 0,246 & 2,637 & 0,009 \\
\hline $\begin{array}{l}\text { Registrar los cuidados prestados es la } \\
\text { mejor medida posible para garantizar } \\
\text { la continuidad }\end{array}$ & 9,21 & 0,88 & 9,25 & 1,02 & 0,778 & 0,378 & 0,364 & 0,716 \\
\hline
\end{tabular}




\begin{tabular}{|c|c|c|c|c|c|c|c|c|}
\hline \multirow[t]{2}{*}{ Afirmaciones } & \multicolumn{2}{|c|}{$\begin{array}{c}\text { Hombres } \\
(n=106)\end{array}$} & \multicolumn{2}{|c|}{$\begin{array}{c}\text { Mujeres } \\
(n=462)\end{array}$} & \multicolumn{2}{|c|}{ Prueba Levene } & \multirow[t]{2}{*}{$t$} & \multirow[t]{2}{*}{$p$} \\
\hline & Media & D.T. & Media & D.T. & $\mathbf{F}$ & $p$ & & \\
\hline $\begin{array}{l}\text { La enfermera de } \mathrm{UCl} \text { actúa de nexo } \\
\text { entre los distintos profesionales }\end{array}$ & 8,60 & 1,67 & 8,66 & 1,50 & 0,717 & 0,397 & 0,327 & 0,744 \\
\hline $\begin{array}{l}\text { La coordinación del equipo sanitario } \\
\text { es imprescindible }\end{array}$ & 9,64 & 0,72 & 9,60 & 0,74 & 0,982 & 0,322 & 0,581 & 0,562 \\
\hline $\begin{array}{l}\text { Las enfermeras son capaces de } \\
\text { planificar actuaciones a lo largo del } \\
\text { turno de trabajo }\end{array}$ & 9,06 & 1,19 & 9,05 & 1,18 & 0,124 & 0,725 & 0,087 & 0,930 \\
\hline $\begin{array}{l}\text { Las enfermeras que trabajan en } \mathrm{UCl} \\
\text { recogen datos relacionados con los } \\
\text { indicadores de calidad }\end{array}$ & 7,36 & 2,08 & 7,49 & 1,95 & 0,357 & 0,550 & 0,602 & 0,547 \\
\hline $\begin{array}{l}\text { Se realiza un seguimiento de los } \\
\text { indicadores de calidad }\end{array}$ & 6,59 & 2,12 & 6,67 & 2,23 & 0,344 & 0,558 & 0303 & 0,762 \\
\hline $\begin{array}{l}\text { Es necesaria una correcta formación } \\
\text { para garantizar la seguridad clínica }\end{array}$ & 9,28 & 1,00 & 9,35 & 0,92 & 1,518 & 0,218 & 0,646 & 0,518 \\
\hline $\begin{array}{l}\text { Las enfermeras de UCl están } \\
\text { involucradas en la seguridad clínica }\end{array}$ & 8,61 & 1,39 & 8,77 & 1,36 & 1,652 & 0,199 & 1,093 & 0,275 \\
\hline $\begin{array}{l}\text { Las enfermeras de } \mathrm{UCI} \text { deben ser } \\
\text { capaces de actuar rápidamente ante } \\
\text { el deterioro del usuario y ante } \\
\text { eventos adversos }\end{array}$ & 9,47 & 0,83 & 9,49 & 0,82 & 0,124 & 0,724 & 0,172 & 0,864 \\
\hline $\begin{array}{l}\text { Los equipos asistenciales de } \mathrm{UCl} \text { son } \\
\text { capaces de realizar su trabajo en un } \\
\text { ambiente de presión y estrés }\end{array}$ & 8,80 & 1,24 & 8,94 & 1,16 & 1,173 & 0,279 & 1,102 & 0,271 \\
\hline $\begin{array}{l}\text { Se gestiona adecuadamente la carga } \\
\text { de trabajo de las enfermeras en UCl }\end{array}$ & 5,29 & 2,05 & 5,86 & 2,14 & 0,310 & 0,578 & 2,491 & 0,013 \\
\hline $\begin{array}{l}\text { En una UCl es fundamental la } \\
\text { capacidad de adaptación de las } \\
\text { enfermeras en las situaciones } \\
\text { urgentes y emergentes }\end{array}$ & 9,17 & 1,12 & 9,16 & 1,18 & 0,000 & 0,983 & 0,093 & 0,926 \\
\hline $\begin{array}{l}\text { Evitar ruidos innecesarios o bajar el } \\
\text { volumen de luces y alarmas, son } \\
\text { acciones que fomentan el descanso } \\
\text { del paciente crítico }\end{array}$ & 9,00 & 1,13 & 9,17 & 1,04 & 0,220 & 0,639 & 1,471 & 0,142 \\
\hline $\begin{array}{l}\text { Se fomentan acciones para el } \\
\text { adecuado confort y descanso de los } \\
\text { pacientes }\end{array}$ & 7,24 & 2,02 & 8,00 & 1,63 & 8,914 & 0,003 & 4,165 & $\leq 0,001$ \\
\hline $\begin{array}{l}\text { En } \mathrm{UCl} \text {, se toman medidas que } \\
\text { ayudan a prevenir o evitar el delirio o } \\
\text { la desorientación }\end{array}$ & 6,78 & 2,05 & 7,17 & 1,89 & 0,863 & 0,353 & 1,861 & 0,063 \\
\hline
\end{tabular}

Nota. Prueba t de Student (t). p valor: $p<0,05$

La tabla 24 muestra las diferencias en el ámbito educativo y de desarrollo en función del género. Las enfermeras son más proactivas para realizar actividades formativas.

Tabla 24. Puntuaciones en el ámbito educativo y de desarrollo en función del género.

\begin{tabular}{|c|c|c|c|c|c|c|c|c|}
\hline \multirow[t]{2}{*}{ Afirmaciones } & \multicolumn{2}{|c|}{$\begin{array}{c}\text { Hombres } \\
(n=106)\end{array}$} & \multicolumn{2}{|c|}{$\begin{array}{c}\text { Mujeres } \\
(n=462)\end{array}$} & \multicolumn{2}{|c|}{ Prueba Levene } & \multirow[t]{2}{*}{$t$} & \multirow[t]{2}{*}{$p$} \\
\hline & Media & D.T. & Media & D.T. & $\mathbf{F}$ & $p$ & & \\
\hline $\begin{array}{l}\text { Las enfermeras realizan actividades } \\
\text { formativas sobre los cuidados } \\
\text { intensivos }\end{array}$ & 7,39 & 1,71 & 7,81 & 1,64 & 0,825 & 0,364 & 2,388 & 0,017 \\
\hline $\begin{array}{l}\text { La realización de esta formación } \\
\text { depende de la motivación de la } \\
\text { enfermera }\end{array}$ & 8,60 & 1,66 & 8,67 & 1,80 & 0,085 & 0,770 & 0,350 & 0,726 \\
\hline $\begin{array}{l}\text { Las actividades formativas } \\
\text { repercuten positivamente a nivel } \\
\text { clínico }\end{array}$ & 9,24 & 1,06 & 9,32 & 0,99 & 2,024 & 0,155 & 0,816 & 0,415 \\
\hline
\end{tabular}




\begin{tabular}{|c|c|c|c|c|c|c|c|c|}
\hline \multirow[t]{2}{*}{ Afirmaciones } & \multicolumn{2}{|c|}{$\begin{array}{c}\text { Hombres } \\
(n=106)\end{array}$} & \multicolumn{2}{|c|}{$\begin{array}{c}\text { Mujeres } \\
(\mathrm{n}=462)\end{array}$} & \multicolumn{2}{|c|}{ Prueba Levene } & \multirow[t]{2}{*}{$t$} & \multirow[t]{2}{*}{$p$} \\
\hline & Media & D.T. & Media & D.T. & $\mathbf{F}$ & $p$ & & \\
\hline $\begin{array}{l}\text { La institución colabora en una } \\
\text { formación específica de } \mathrm{UCl}\end{array}$ & 5,41 & 2,47 & 5,63 & 2,30 & 1,432 & 0,232 & 0,891 & 0,373 \\
\hline $\begin{array}{l}\text { La acogida de personal de nueva } \\
\text { incorporación debe ser realizada } \\
\text { lenta y progresivamente }\end{array}$ & 8,87 & 1,91 & 9,04 & 1,44 & 4,172 & 0,042 & 1,041 & 0,298 \\
\hline $\begin{array}{l}\text { La formación en } \mathrm{UCl} \text { se realiza sobre } \\
\text { todo para el cobro de incentivos, } \\
\text { bolsas de empleo y oposiciones }\end{array}$ & 6,39 & 2,67 & 6,16 & 2,60 & 0,770 & 0,381 & 0,803 & 0,422 \\
\hline
\end{tabular}

Nota. Prueba t de Student (t). p valor: $p<0,05$

En la tabla 25, observamos las diferencias resultantes en las distintas secciones y en la puntuación total de la parte A del cuestionario. Podemos observar que las mujeres valoran con una mayor puntuación las necesidades formativas en los ámbitos clínico, de la gestión y en la puntuación total de la parte A. Las enfermeras mujeres valoran como más necesarias la formación en conocimientos y en determinadas destrezas. En el ámbito de la gestión, valoran que es necesaria una formación que garantice tanto la continuidad de cuidados como el descanso y las actividades de prevención, ver tabla 25.

Tabla 25. Puntuaciones de cada ámbito de necesidad formativa en relación con el género.

\begin{tabular}{|c|c|c|c|c|c|c|c|c|}
\hline \multirow[t]{2}{*}{ Puntuaciones } & \multicolumn{2}{|c|}{$\begin{array}{l}\text { Hombres } \\
(n=106)\end{array}$} & \multicolumn{2}{|c|}{$\begin{array}{l}\text { Mujeres } \\
(n=462)\end{array}$} & \multicolumn{2}{|c|}{ Prueba Levene } & \multirow[t]{2}{*}{$t$} & \multirow[t]{2}{*}{$p$} \\
\hline & Media & D.T. & Media & D.T. & $\boldsymbol{F}$ & $p$ & & \\
\hline Ámbito Clínico & 161,29 & 10,03 & 164,34 & 9,63 & 0,005 & 0,944 & 2,922 & 0,004 \\
\hline Ámbito Profesional & 120,35 & 9,96 & 122,25 & 9,73 & 0,084 & 0,772 & 1,800 & 0,072 \\
\hline Ámbito de la Gestión & 133,09 & 12,28 & 135,87 & 11,27 & 0,592 & 0,442 & 2,249 & 0,025 \\
\hline Ámbito educativo y de desarrollo & 45,88 & 6,38 & 46,64 & 5,76 & 1,376 & 0,241 & 1,190 & 0,235 \\
\hline Puntuación total parte $\mathrm{A}$ & 460,63 & 30,60 & 469,11 & 28,69 & 0,275 & 0,600 & 2,711 & 0,007 \\
\hline
\end{tabular}

Nota. Prueba t de Student (t). $\mathbf{p}$ valor: $p<0,05$

Para analizar si existían diferencias entre los ítems que exploraban dimensiones y formación (parte B del cuestionario) en función del género, se realizó una prueba de diferencia de medias, la tabla 26 presenta los resultados de cada ítem y la tabla 27 las diferencias entre puntuación global y género. No se observaron diferencias significativas en la parte B del cuestionario. Sí fue significativa la puntuación total del cuestionario en relación con el género.

Tabla 26. Puntuaciones de los ítems de dimensiones y formación en función del género.

\begin{tabular}{|c|c|c|c|c|c|c|c|c|}
\hline \multirow[t]{2}{*}{ Afirmaciones } & \multicolumn{2}{|c|}{$\begin{array}{c}\text { Hombres } \\
(n=106)\end{array}$} & \multicolumn{2}{|c|}{$\begin{array}{c}\text { Mujeres } \\
(n=462)\end{array}$} & \multicolumn{2}{|c|}{ Prueba Levene } & \multirow[t]{2}{*}{$\boldsymbol{t}$} & \multirow[t]{2}{*}{$p$} \\
\hline & Media & D.T. & Media & D.T. & $F$ & $p$ & & \\
\hline $\begin{array}{l}\text { La enfermera de nueva incorporación } \\
\text { debería tener conocimientos } \\
\text { hemodinámicos, de ventilación } \\
\text { mecánica, reanimación } \\
\text { cardiopulmonar básica y avanzada, } \\
\text { además de monitorización }\end{array}$ & 8,74 & 1,39 & 8,88 & 1,24 & 1,820 & 0,178 & 1,045 & 0,297 \\
\hline $\begin{array}{l}\text { Debería existir la figura de un } \\
\text { enfermero tutor en la unidad para } \\
\text { ayudar a las enfermeras de nueva }\end{array}$ & 9,32 & 0,99 & 9,51 & 0,94 & 2,579 & 0,109 & 1,858 & 0,064 \\
\hline
\end{tabular}

incorporación 


\begin{tabular}{|c|c|c|c|c|c|c|c|c|}
\hline $\begin{array}{l}\text { Es necesario una formación previa } \\
\text { postgrado de UCI para las enfermeras } \\
\text { noveles }\end{array}$ & 8,15 & 2,18 & 8,49 & 1,88 & 1,007 & 0,316 & 1,609 & 0,108 \\
\hline $\begin{array}{l}\text { La primera semana, las enfermeras } \\
\text { noveles deben estar supervisadas en } \\
\text { todo momento }\end{array}$ & 9,08 & 1,32 & 9,20 & 1,29 & 0,258 & 0,611 & 0,883 & 0,378 \\
\hline $\begin{array}{l}\text { El personal del staff (veterano), } \\
\text { requiere de planes formativos } \\
\text { específicos de periodicidad anual }\end{array}$ & 8,38 & 1,55 & 8,30 & 1,73 & 1,130 & 0,288 & 0,416 & 0,677 \\
\hline $\begin{array}{l}\text { La formación amplia y específica en } \\
\text { cuidados críticos, facilita que el } \\
\text { profesional alcance un nivel de } \\
\text { excelencia }\end{array}$ & 8,89 & 1,34 & 9,08 & 1,09 & 2,334 & 0,127 & 1,529 & 0,127 \\
\hline $\begin{array}{l}\text { La formación se debe apoyar en } \\
\text { eventos teórico-prácticos y en la } \\
\text { simulación, antes de llevar esos } \\
\text { conocimientos a la realidad }\end{array}$ & 8,85 & 1,22 & 9,00 & 1,13 & 2,924 & 0,088 & 1,236 & 0,217 \\
\hline $\begin{array}{l}\text { La formación debe terminar con una } \\
\text { intervención real, siempre tutelado } \\
\text { con un profesional experimentado }\end{array}$ & 8,86 & 1,45 & 8,99 & 1,23 & 2,604 & 0,107 & 0,965 & 0,335 \\
\hline $\begin{array}{l}\text { La empatía es una actitud } \\
\text { indispensable a desarrollar dentro del } \\
\text { equipo sanitario }\end{array}$ & 9,03 & 1,06 & 9,11 & 1,02 & 0,055 & 0,814 & 0,779 & 0,436 \\
\hline $\begin{array}{l}\text { Las enfermeras necesitan formación } \\
\text { específica para afrontar la muerte de } \\
\text { los usuarios }\end{array}$ & 8,58 & 1,60 & 8,48 & 1,53 & 0,547 & 0,460 & 0,594 & 0,552 \\
\hline $\begin{array}{l}\text { Son habilidades a desarrollar en las } \\
\text { enfermeras de } \mathrm{UCI} \text {, la calma, ser } \\
\text { metódico y resolutivas }\end{array}$ & 8,95 & 1,10 & 8,93 & 1,16 & 0,302 & 0,583 & 0,161 & 0,872 \\
\hline $\begin{array}{l}\text { La inteligencia emocional es necesaria } \\
\text { de ser desarrollada en las enfermeras } \\
\text { de UCl }\end{array}$ & 8,84 & 1,10 & 8,81 & 1,17 & 1,883 & 0,171 & 0,206 & 0,837 \\
\hline
\end{tabular}

Nota. Prueba t de Student (t). $\mathbf{p}$ valor: $p<0,05$

Tabla 27. Puntuación total de dimensiones y formación en función del género y total del cuestionario.

\begin{tabular}{|c|c|c|c|c|c|c|c|c|}
\hline \multirow[t]{2}{*}{ Puntuaciones } & \multicolumn{2}{|c|}{$\begin{array}{c}\text { Hombres } \\
(n=106)\end{array}$} & \multicolumn{2}{|c|}{$\begin{array}{l}\text { Mujeres } \\
(n=462)\end{array}$} & \multicolumn{2}{|c|}{ Prueba Levene } & \multirow[t]{2}{*}{$t$} & \multirow[t]{2}{*}{$p$} \\
\hline & Media & D.T. & Media & D.T. & $\mathbf{F}$ & $p$ & & \\
\hline Puntuación total parte $B$ & 105,65 & 10,13 & 106,78 & 9,03 & 1,492 & 0,222 & 1,137 & 0,256 \\
\hline Puntuación total cuestionario & 566,28 & 38,41 & 575,89 & 34,79 & 1,012 & 0,315 & 1,012 & 0,012 \\
\hline
\end{tabular}

Nota. Prueba t de Student (t). p valor: $p<0,05$

\section{En Función de la edad.}

Tal y como indica la tabla 9, inicialmente se definieron 6 rangos de edad. Debido al escaso tamaño muestral de algunos rangos se decidió reagrupar la variable "edad" en cuatro grupos. Los nuevos ítems agrupados fueron los siguientes: 22-35 años, 36-40 años, 41-45 años y mayores de 45 años, lo que corresponde con los siguientes porcentajes muestrales $28 \%, 25,7 \%, 20,6 \%$ y $25,7 \%$, respectivamente. Se aplicó la prueba de ANOVA para observar las diferencias en las puntuaciones de cada ítem y ámbito en función de la edad. La tabla 28 presenta los resultados del ámbito clínico. 
Tabla 28. Puntuaciones de los ítems del ámbito clínico en función de la edad.

\begin{tabular}{|c|c|c|c|c|c|c|c|c|c|c|}
\hline \multirow[t]{2}{*}{ Afirmaciones } & \multicolumn{2}{|c|}{$\begin{array}{c}\leq 35 \text { años } \\
(n=159)\end{array}$} & \multicolumn{2}{|c|}{$\begin{array}{c}\text { 36-40 años } \\
(n=146)\end{array}$} & \multicolumn{2}{|c|}{$\begin{array}{l}\text { 41-45 años } \\
\text { (n=117) }\end{array}$} & \multicolumn{2}{|c|}{$\begin{array}{c}>45 \text { años } \\
(n=146)\end{array}$} & \multirow[t]{2}{*}{$\boldsymbol{F}$} & \multirow[t]{2}{*}{$p$} \\
\hline & Media & D.T. & Media & D.T. & Media & D.T. & Media & D.T. & & \\
\hline $\begin{array}{l}\text { Las enfermeras de } \mathrm{UCl} \text { deben } \\
\text { tener conocimientos extensos } \\
\text { de enfermería básica }\end{array}$ & 9,49 & 0,86 & 9,36 & 0,93 & 9,50 & 0,79 & 9,58 & 0,78 & 1,569 & 0,196 \\
\hline $\begin{array}{l}\text { Las enfermeras de UCI deben } \\
\text { desarrollar habilidades } \\
\text { específicas para la atención al } \\
\text { paciente crítico }\end{array}$ & 9,59 & 0,89 & 9,52 & 0,72 & 9,74 & 0,55 & 9,69 & 0,67 & 2,505 & 0,058 \\
\hline
\end{tabular}

La observación es una

herramienta necesaria, para

obtener datos en la valoración

$9,52 \quad 0,77 \quad 9,23 \quad 0,91 \quad 9,59$

0,72

9,65

$0,73 \quad 7,843$

$<0,001$

del paciente crítico

La monitorización es una

herramienta fundamental,

para obtener datos en la

$9,31 \quad 0,98$

valoración del paciente crítico

El uso de escalas son

necesarias para la valoración

del paciente crítico

$8,72 \quad 1,17 \quad 8,63 \quad 1,13 \quad 9,02$

1,12

$8,94 \quad 1,10 \quad 3,487$

0,016

La empatía y el respeto a la

intimidad son fundamentales

$\begin{array}{lllll}9,36 & 0,89 & 9,17 & 0,98 & 9,47\end{array}$

para la enfermera de $\mathrm{UCI}$

Hay que involucrar al paciente

y a la familia en el proceso de

$8,80 \quad 1,23$

$8,62 \quad 1,23 \quad 8,97$

1,13

$8,95 \quad 1,26 \quad 2,459$

0,062

recuperación

Observar, analizar e

interpretar situaciones y/o

problemas en un paciente

$8,99 \quad 1,09 \quad 8,92 \quad 0,99 \quad 9,28$

0,93

$9,13 \quad 1,13 \quad 2,955$

0,032

crítico es necesario para

realizar un examen físico.

La integración e interrelación

de los datos es una habilidad

muy importante de las

$9,19 \quad 0,95$

9,19

0,97

9,38

0,90

9,03

1,11

2,570

0,053

enfermeras de UCI

Las principales patologías que debe conocer una enfermera de UCl, son la cardíaca, la respiratoria y la neurológica

Las medidas de soporte son el

pilar fundamental de las

$\begin{array}{llllll}8,20 & 1,91 & 8,68 & 1,50 & 8,42 & 1,802\end{array}$

$8,17 \quad 1,731 \quad 2,664$

0,047

actividades enfermeras

Las enfermeras de $\mathrm{UCl}$ deben

estar formadas en la atención

de los distintos tipos de shock

El cálculo de fármacos y

drogas, es una competencia

imprescindible

$\begin{array}{llllllllll}8,08 & 1,52 & 7,96 & 1,63 & 8,09 & 1,65 & 8,05 & 1,76 & 0,196 & 0,899\end{array}$

El cuidado integral de un paciente crítico forma parte de

la actuación principal del

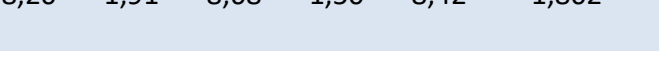

$\begin{array}{llllllllll}9,52 & 0,77 & 9,55 & 0,77 & 9,63 & 0,65 & 9,14 & 1,17 & 8,863 & <0,001\end{array}$

profesional de enfermería

Los cuidados respiratorios son

los que de manera prioritaria

deben ser desarrollados en las

$9,41 \quad 1,19 \quad 9,51 \quad 0,97 \quad 9,53 \quad 1,14$

$8,87 \quad 1,78 \quad 7,926$

$<0,001$

enfermeras de $\mathrm{UCl}$

$\begin{array}{llllllllll}9,38 & 1,07 & 9,45 & 0,82 & 9,62 & 0,71 & 9,63 & 0,77 & 2,996 & \mathbf{0 , 0 3 0}\end{array}$

$\begin{array}{llllllllll}7,62 & 1,82 & 8,14 & 1,19 & 8,03 & 1,61 & 7,90 & 1,57 & 3,074 & \mathbf{0 , 0 2 7}\end{array}$ 


\begin{tabular}{|c|c|c|c|c|c|c|c|c|c|}
\hline \multirow[t]{2}{*}{ Afirmaciones } & $\begin{array}{c}\leq 35 \text { años } \\
(n=159)\end{array}$ & $\begin{array}{r}36-40 \\
(n=1\end{array}$ & ถ̃ก์ & $\begin{array}{r}41-4 \\
(n=\end{array}$ & $\begin{array}{l}\text { ก̃os } \\
\text { 7) }\end{array}$ & $\begin{array}{l}>45 a \\
(n=1\end{array}$ & & \multirow[t]{2}{*}{$\boldsymbol{F}$} & \multirow[t]{2}{*}{$p$} \\
\hline & Media & Media & D.T. & Media & D.T. & Media & D.T. & & \\
\hline
\end{tabular}

La reevaluación continua es la principal medida que debe implementar la enfermera para evaluar estrategias de $\begin{array}{lllllllll}8,89 & 1,06 & 8,85 & 1,04 & 9,20 & 0,87 & 9,19 & 0,97 & 5,013\end{array}$ 0,002 mejora del plan de cuidados. La capacidad de priorización es una habilidad imprescindible $\begin{array}{llllllllll}9,53 & 0,74 & 9,48 & 0,83 & 9,47 & 0,76 & 9,57 & 0,74 & 0,486 & 0,692\end{array}$ El razonamiento clínico (que pasa, y que puede llegar a pasar) debe ser fomentado en

las enfermeras de UCl

Nota. Prueba ANOVA (F). p valor: $p<0,05$

La tabla 29 muestra las diferencias halladas en el ámbito profesional en función de la edad de los participantes. El grupo de mayor edad valora las afirmaciones con mayores puntuaciones, fundamentalmente las centradas con la toma de decisiones y cuidados al final de la vida. Este hallazgo se verá refrendado por los análisis posthoc posteriormente realizados.

Tabla 29. Puntuaciones de los ítems del ámbito profesional en función de la edad.

\begin{tabular}{|c|c|c|c|c|c|c|c|c|c|c|}
\hline \multirow[t]{2}{*}{ Afirmaciones } & \multicolumn{2}{|c|}{$\begin{array}{c}\leq 35 \text { años } \\
\text { (n=159) }\end{array}$} & \multicolumn{2}{|c|}{$\begin{array}{c}\text { 36-40 años } \\
(n=146)\end{array}$} & \multicolumn{2}{|c|}{$\begin{array}{c}\text { 41-45 años } \\
\text { ( } n=117)\end{array}$} & \multicolumn{2}{|c|}{$\begin{array}{c}>45 \text { años } \\
(n=146)\end{array}$} & \multirow[t]{2}{*}{$F$} & \multirow[t]{2}{*}{$p$} \\
\hline & Media & D.T. & Media & D.T. & Media & D.T. & Media & D.T. & & \\
\hline $\begin{array}{l}\text { Ante situaciones complejas, la } \\
\text { ayuda y el apoyo de } \\
\text { compañeros más } \\
\text { experimentados ayudan a } \\
\text { resolver problemas }\end{array}$ & 9,33 & 1,09 & 9,35 & 0,82 & 9,44 & 0,87 & 9,55 & 0,73 & 1,968 & 0,118 \\
\hline $\begin{array}{l}\text { Las enfermeras pueden hacer } \\
\text { frente a decisiones complejas } \\
\text { gracias a la experiencia laboral } \\
\text { obtenida en UCl }\end{array}$ & 9,01 & 1,07 & 8,99 & 0,98 & 9,26 & 0,90 & 9,29 & 0,93 & 3,683 & 0,012 \\
\hline $\begin{array}{l}\text { Las decisiones de cuidado son } \\
\text { muy complejas y requieren de } \\
\text { una formación extensa }\end{array}$ & 8,89 & 1,10 & 8,91 & 1,00 & 8,95 & 1,00 & 9,01 & 1,13 & 0,372 & 0,773 \\
\hline $\begin{array}{l}\text { Las enfermeras de UCI tienen } \\
\text { mucha autonomía, por lo que } \\
\text { es necesario una formación } \\
\text { reglada y adecuada al puesto } \\
\text { de trabajo }\end{array}$ & 9,04 & 1,11 & 8,97 & 1,07 & 8,91 & 1,35 & 8,82 & 1,58 & 0,804 & 0,492 \\
\hline $\begin{array}{l}\text { La enfermera de UCl suele } \\
\text { afrontar bien la decisión de } \\
\text { limitación de soporte vital } \\
\text { (esfuerzo terapéutico) }\end{array}$ & 7,91 & 1,61 & 7,99 & 1,55 & 8,21 & 1,50 & 8,42 & 1,58 & 3,113 & 0,026 \\
\hline $\begin{array}{l}\text { La enfermera debería } \\
\text { participar en las decisiones de } \\
\text { limitación de soporte vital } \\
\text { (esfuerzo terapéutico) }\end{array}$ & 8,35 & 1,80 & 8,10 & 1,73 & 8,42 & 1,83 & 8,73 & 1,83 & 3,072 & 0,029 \\
\hline $\begin{array}{l}\text { La enfermera de } \mathrm{UCl} \text { afronta } \\
\text { peor el encarnizamiento } \\
\text { terapéutico }\end{array}$ & 8,37 & 1,97 & 8,60 & 1,69 & 8,43 & 1,79 & 9,09 & 1,36 & 5,207 & 0,001 \\
\hline $\begin{array}{l}\text { El afrontamiento de la muerte } \\
\text { de los usuarios dependerá de } \\
\text { las creencias, experiencias y } \\
\text { valores del profesional de } \\
\text { enfermería }\end{array}$ & 7,15 & 2,39 & 7,34 & 2,01 & 7,64 & 2,21 & 7,08 & 2,74 & 1,433 & 0,232 \\
\hline
\end{tabular}




\begin{tabular}{|c|c|c|c|c|c|c|c|c|c|c|}
\hline \multirow[t]{2}{*}{ Afirmaciones } & \multicolumn{2}{|c|}{$\begin{array}{c}\leq 35 \text { años } \\
\text { ( } n=159)\end{array}$} & \multicolumn{2}{|c|}{$\begin{array}{c}\text { 36-40 años } \\
(n=146)\end{array}$} & \multicolumn{2}{|c|}{$\begin{array}{c}41-45 \text { años } \\
(n=117)\end{array}$} & \multicolumn{2}{|c|}{$\begin{array}{c}>45 \text { años } \\
(n=146)\end{array}$} & \multirow[t]{2}{*}{$F$} & \multirow[t]{2}{*}{$p$} \\
\hline & Media & D.T. & Media & D.T. & Media & D.T. & Media & D.T. & & \\
\hline $\begin{array}{l}\text { El profesional de enfermería en } \\
\text { UCl, dentro de su competencia, } \\
\text { busca la excelencia a nivel } \\
\text { clínico }\end{array}$ & 8,64 & 1,49 & 8,62 & 1,41 & 8,78 & 1,29 & 8,57 & 1,42 & 0,498 & 0,684 \\
\hline $\begin{array}{l}\text { El lenguaje verbal y no verbal } \\
\text { son fundamentales en la } \\
\text { comunicación en UCI }\end{array}$ & 9,01 & 1,12 & 8,76 & 1,15 & 9,15 & 1,03 & 9,30 & 0,96 & 6,598 & $<0,001$ \\
\hline $\begin{array}{l}\text { En situaciones de estrés, las } \\
\text { enfermeras se deben } \\
\text { comunicar de manera técnica, } \\
\text { concisa y clara, ajustando la } \\
\text { información a las } \\
\text { características del interlocutor }\end{array}$ & 8,97 & 1,17 & 8,79 & 1,11 & 9,01 & 1,01 & 9,12 & 1,11 & 2,199 & 0,087 \\
\hline $\begin{array}{l}\text { La principales herramientas de } \\
\text { comunicación son la } \\
\text { asertividad, la empatía y la } \\
\text { escucha activa tanto con } \\
\text { usuarios y familia como con } \\
\text { profesionales }\end{array}$ & 8,99 & 1,07 & 8,78 & 1,05 & 9,09 & 1,01 & 9,25 & 1,02 & 5,020 & 0,002 \\
\hline $\begin{array}{l}\text { Las tecnologías de la } \\
\text { información y comunicación } \\
\text { (TIC) son herramientas } \\
\text { esenciales que permiten la } \\
\text { formación, el aprendizaje y el } \\
\text { desarrollo de la profesión }\end{array}$ & 8,21 & 1,44 & 8,31 & 1,26 & 8,44 & 1,38 & 8,71 & 1,14 & 4,040 & 0,007 \\
\hline $\begin{array}{l}\text { La comunicación escrita en } \mathrm{UCl} \\
\text { se debe fomentar siempre, } \\
\text { pues es indispensable para la } \\
\text { continuidad de cuidados }\end{array}$ & 8,97 & 1,09 & 8,65 & 1,35 & 9,03 & 1,10 & 9,23 & 1,10 & 6,021 & $<0,001$ \\
\hline
\end{tabular}

Nota. Prueba ANOVA (F). p valor: $p<0,05$

En relación con el ámbito de la gestión se observan mayores puntuaciones en los dos grupos de mayor edad, con unas mayores necesidades formativas en el seguimiento de los cuidados, registros e indicadores de calidad, ver tabla 30.

Tabla 30. Puntuaciones de los ítems del ámbito de la gestión en función de la edad.

\begin{tabular}{|c|c|c|c|c|c|c|c|c|c|c|}
\hline \multirow[t]{2}{*}{ Afirmaciones } & \multicolumn{2}{|c|}{$\begin{array}{c}\leq 35 \text { años } \\
\text { ( } n=159)\end{array}$} & \multicolumn{2}{|c|}{$\begin{array}{l}\text { 36-40 años } \\
(n=146)\end{array}$} & \multicolumn{2}{|c|}{$\begin{array}{c}\text { 41-45 años } \\
(n=117)\end{array}$} & \multicolumn{2}{|c|}{$\begin{array}{l}>45 \text { años } \\
(n=146)\end{array}$} & \multirow[t]{2}{*}{$\boldsymbol{F}$} & \multirow[t]{2}{*}{$p$} \\
\hline & Media & D.T. & Media & D.T. & Media & D.T. & Media & D.T. & & \\
\hline $\begin{array}{l}\text { El seguimiento de los cuidados } \\
\text { que prestan las enfermeras es } \\
\text { indispensable para la } \\
\text { continuidad y evaluación de los } \\
\text { cuidados }\end{array}$ & 9,21 & 0,92 & 9,03 & 1,17 & 9,21 & 0,86 & 9,38 & 0,88 & 3,141 & 0,025 \\
\hline $\begin{array}{l}\text { Registrar los cuidados prestados } \\
\text { es la mejor medida posible para } \\
\text { garantizar la continuidad }\end{array}$ & 9,03 & 1,19 & 9,11 & 1,02 & 9,38 & 0,82 & 9,49 & 0,79 & 7,348 & $<0,001$ \\
\hline $\begin{array}{l}\text { La enfermera de UCl actúa de } \\
\text { nexo entre los distintos } \\
\text { profesionales }\end{array}$ & 8,48 & 1,69 & 8,77 & 1,42 & 8,73 & 1,46 & 8,65 & 1,53 & 1,041 & 0,374 \\
\hline $\begin{array}{l}\text { La coordinación del equipo } \\
\text { sanitario es imprescindible }\end{array}$ & 9,62 & 0,72 & 9,49 & 0,81 & 9,62 & 0,74 & 9,68 & 0,66 & 1,727 & 0,160 \\
\hline $\begin{array}{l}\text { Las enfermeras son capaces de } \\
\text { planificar actuaciones a lo largo } \\
\text { del turno de trabajo }\end{array}$ & 9,04 & 1,19 & 8,71 & 1,32 & 9,09 & 1,09 & 9,36 & 0,98 & 7,704 & $<0,001$ \\
\hline
\end{tabular}




\begin{tabular}{|c|c|c|c|c|c|c|c|c|c|c|}
\hline \multirow[t]{2}{*}{ Afirmaciones } & \multicolumn{2}{|c|}{$\begin{array}{c}\leq 35 \text { años } \\
(n=159)\end{array}$} & \multicolumn{2}{|c|}{$\begin{array}{c}\text { 36-40 años } \\
(n=146)\end{array}$} & \multicolumn{2}{|c|}{$\begin{array}{c}\text { 41-45 años } \\
\text { (n=117) }\end{array}$} & \multicolumn{2}{|c|}{$\begin{array}{l}>45 \text { años } \\
(n=146)\end{array}$} & \multirow[t]{2}{*}{$\boldsymbol{F}$} & \multirow[t]{2}{*}{$p$} \\
\hline & Media & D.T. & Media & D.T. & Media & D.T. & Media & D.T. & & \\
\hline $\begin{array}{l}\text { Las enfermeras que trabajan en } \\
\mathrm{UCI} \text { recogen datos relacionados } \\
\text { con los indicadores de calidad }\end{array}$ & 7,20 & 2,20 & 7,38 & 1,87 & 7,58 & 1,76 & 7,74 & 1,96 & 2,120 & 0,097 \\
\hline $\begin{array}{l}\text { Se realiza un seguimiento de los } \\
\text { indicadores de calidad }\end{array}$ & 6,47 & 2,26 & 6,26 & 2,37 & 6,65 & 1,91 & 7,25 & 2,12 & 5,507 & 0,001 \\
\hline $\begin{array}{l}\text { Es necesaria una correcta } \\
\text { formación para garantizar la } \\
\text { seguridad clínica }\end{array}$ & 9,27 & 0,99 & 9,23 & 1,00 & 9,41 & 0,86 & 9,46 & 0,86 & 2,011 & 0,111 \\
\hline $\begin{array}{l}\text { Las enfermeras de UCl están } \\
\text { involucradas en la seguridad } \\
\text { clínica }\end{array}$ & 8,74 & 1,39 & 8,63 & 1,31 & 8,74 & 1,35 & 8,87 & 1,42 & 0,744 & 0,526 \\
\hline $\begin{array}{l}\text { Las enfermeras de } \mathrm{UCl} \text { deben ser } \\
\text { capaces de actuar rápidamente } \\
\text { ante el deterioro del usuario y } \\
\text { ante eventos adversos }\end{array}$ & 9,55 & 0,78 & 9,32 & 0,97 & 9,44 & 0,79 & 9,62 & 0,70 & 3,911 & 0,009 \\
\hline $\begin{array}{l}\text { Los equipos asistenciales de UCI } \\
\text { son capaces de realizar su } \\
\text { trabajo en un ambiente de } \\
\text { presión y estrés }\end{array}$ & 8,86 & 1,18 & 8,77 & 1,12 & 8,91 & 1,10 & 9,12 & 1,25 & 2,418 & 0,065 \\
\hline $\begin{array}{l}\text { Se gestiona adecuadamente la } \\
\text { carga de trabajo de las } \\
\text { enfermeras en } \mathrm{UCl}\end{array}$ & 5,70 & 2,32 & 5,99 & 1,92 & 5,73 & 2,09 & 5,61 & 2,17 & 0,830 & 0,478 \\
\hline $\begin{array}{l}\text { En una } \mathrm{UCl} \text { es fundamental la } \\
\text { capacidad de adaptación de las } \\
\text { enfermeras en las situaciones } \\
\text { urgentes y emergentes }\end{array}$ & 9,06 & 1,31 & 8,99 & 1,26 & 9,26 & 1,04 & 9,36 & 0,98 & 3,170 & 0,024 \\
\hline $\begin{array}{l}\text { Evitar ruidos innecesarios o bajar } \\
\text { el volumen de luces y alarmas, } \\
\text { son acciones que fomentan el } \\
\text { descanso del paciente crítico }\end{array}$ & 9,06 & 1,10 & 8,81 & 1,11 & 9,26 & 0,95 & 9,45 & 0,96 & 9,951 & $<0,001$ \\
\hline $\begin{array}{l}\text { Se fomentan acciones para el } \\
\text { adecuado confort y descanso de } \\
\text { los pacientes }\end{array}$ & 7,82 & 1,66 & 7,69 & 1,78 & 7,86 & 1,63 & 8,07 & 1,83 & 1,181 & 0,316 \\
\hline $\begin{array}{l}\text { En UCI, se toman medidas que } \\
\text { ayudan a prevenir o evitar el } \\
\text { delirio o la desorientación }\end{array}$ & 7,04 & 0,93 & 6,92 & 1,91 & 7,21 & 2,00 & 7,25 & 1,88 & 0,905 & 0,438 \\
\hline
\end{tabular}

Nota. Prueba ANOVA (F). $\mathbf{p}$ valor: $p<0,05$

En la tabla 31, podemos observar que la única diferencia significativa detectada es la relacionada con la motivación a la hora de realizar formación.

Tabla 31. Puntuaciones de los ítems del ámbito educativo y de desarrollo en función de la edad.

\begin{tabular}{|c|c|c|c|c|c|c|c|c|c|c|}
\hline \multirow[t]{2}{*}{ Afirmaciones } & \multicolumn{2}{|c|}{$\begin{array}{l}\leq 35 \text { años } \\
(n=159)\end{array}$} & \multicolumn{2}{|c|}{$\begin{array}{c}\text { 36-40 años } \\
(n=146)\end{array}$} & \multicolumn{2}{|c|}{$\begin{array}{l}\text { 41-45 años } \\
(n=117)\end{array}$} & \multicolumn{2}{|c|}{$\begin{array}{c}>45 \text { años } \\
\text { (n=146) }\end{array}$} & \multirow[t]{2}{*}{$\boldsymbol{F}$} & \multirow[t]{2}{*}{$p$} \\
\hline & Media & D.T. & Media & D.T. & Media & D.T. & Media & D.T. & & \\
\hline $\begin{array}{l}\text { Las enfermeras realizan } \\
\text { actividades formativas sobre los } \\
\text { cuidados intensivos }\end{array}$ & 7,74 & 1,70 & 7,66 & 1,65 & 7,75 & 1,67 & 7,79 & 1,65 & 0,139 & 0,937 \\
\hline $\begin{array}{l}\text { La realización de esta } \\
\text { formación depende de la } \\
\text { motivación de la enfermera }\end{array}$ & 8,51 & 2,02 & 9,02 & 1,64 & 8,62 & 1,58 & 8,49 & 1,73 & 2,885 & 0,035 \\
\hline $\begin{array}{l}\text { Las actividades formativas } \\
\text { repercuten positivamente a } \\
\text { nivel clínico }\end{array}$ & 9,21 & 1,13 & 9,42 & 0,82 & 9,38 & 0,98 & 9,24 & 1,05 & 1,624 & 0,183 \\
\hline $\begin{array}{l}\text { La institución colabora en una } \\
\text { formación específica de } \mathrm{UCl}\end{array}$ & 5,46 & 2,42 & 5,42 & 2,23 & 5,88 & 2,31 & 5,66 & 2,35 & 1,082 & 0,356 \\
\hline
\end{tabular}




\begin{tabular}{|c|c|c|c|c|c|c|c|c|c|c|}
\hline \multirow[t]{2}{*}{ Afirmaciones } & \multicolumn{2}{|c|}{$\begin{array}{c}\leq 35 \text { años } \\
(n=159)\end{array}$} & \multicolumn{2}{|c|}{$\begin{array}{c}\text { 36-40 años } \\
(n=146)\end{array}$} & \multicolumn{2}{|c|}{$\begin{array}{c}\text { 41-45 años } \\
\text { ( } n=117)\end{array}$} & \multicolumn{2}{|c|}{$\begin{array}{c}>45 \text { años } \\
(n=146)\end{array}$} & \multirow[t]{2}{*}{$\boldsymbol{F}$} & \multirow[t]{2}{*}{$p$} \\
\hline & Media & D.T. & Media & D.T. & Media & D.T. & Media & D.T. & & \\
\hline $\begin{array}{l}\text { La acogida de personal de } \\
\text { nueva incorporación debe ser } \\
\text { realizada lenta y } \\
\text { progresivamente }\end{array}$ & 8,92 & 1,57 & 8,95 & 1,80 & 9,02 & 1,37 & 9,16 & 1,34 & 0,699 & 0,553 \\
\hline $\begin{array}{l}\text { La formación en UCl se realiza } \\
\text { sobre todo para el cobro de } \\
\text { incentivos, bolsas de empleo y } \\
\text { oposiciones }\end{array}$ & 6,33 & 2,68 & 6,29 & 2,55 & 6,29 & 2,72 & 5,90 & 2,51 & 0,885 & 0,464 \\
\hline
\end{tabular}

En los ítems englobados en la parte B del cuestionario, se observa que no existen diferencias significativas, salvo en el ítem relacionado con las habilidades personales para afrontar el cuidado en un área tan específica del paciente crítico, ver tabla 32.

Tabla 32. Puntuaciones de los ítems de dimensiones y formación.

\begin{tabular}{|c|c|c|c|c|c|c|c|c|c|c|}
\hline \multirow[t]{2}{*}{ Afirmaciones } & \multicolumn{2}{|c|}{$\begin{array}{c}\leq 35 \text { años } \\
(n=159)\end{array}$} & \multicolumn{2}{|c|}{$\begin{array}{c}36-40 \text { años } \\
(n=146)\end{array}$} & \multicolumn{2}{|c|}{$\begin{array}{c}\text { 41-45 años } \\
(n=117)\end{array}$} & \multicolumn{2}{|c|}{$\begin{array}{c}>45 \text { años } \\
(n=146)\end{array}$} & \multirow[t]{2}{*}{$\boldsymbol{F}$} & \multirow[t]{2}{*}{$p$} \\
\hline & Media & D.T. & Media & D.T. & Media & D.T. & Media & D.T. & & \\
\hline $\begin{array}{l}\text { La enfermera de nueva } \\
\text { incorporación debería tener } \\
\text { conocimientos hemodinámicos, de } \\
\text { ventilación mecánica, reanimación } \\
\text { cardiopulmonar básica y avanzada, } \\
\text { además de monitorización }\end{array}$ & 8,82 & 1,37 & 8,71 & 1,22 & 8,84 & 1,25 & 9,03 & 1,20 & 1,625 & 0,182 \\
\hline $\begin{array}{l}\text { Debería existir la figura de un } \\
\text { enfermero tutor en la unidad para } \\
\text { ayudar a las enfermeras de nueva } \\
\text { incorporación }\end{array}$ & 9,46 & 1,03 & 9,53 & 0,87 & 9,50 & 0,94 & 9,42 & 0,07 & 0,316 & 0,814 \\
\hline $\begin{array}{l}\text { Es necesario una formación previa } \\
\text { postgrado de UCI para las } \\
\text { enfermeras noveles }\end{array}$ & 8,35 & 2,14 & 8,50 & 1,56 & 8,42 & 1,84 & 8,43 & 2,13 & 0,147 & 0,931 \\
\hline $\begin{array}{l}\text { La primera semana, las } \\
\text { enfermeras noveles deben estar } \\
\text { supervisadas en todo momento }\end{array}$ & 9,08 & 1,43 & 9,27 & 1,01 & 9,18 & 1,29 & 9,19 & 1,40 & 0,562 & 0,640 \\
\hline $\begin{array}{l}\text { El personal del staff (veterano), } \\
\text { requiere de planes formativos } \\
\text { específicos de periodicidad anual }\end{array}$ & 8,29 & 1,55 & 8,08 & 1,78 & 8,44 & 1,62 & 8,47 & 1,82 & 1,566 & 0,196 \\
\hline $\begin{array}{l}\text { La formación amplia y específica } \\
\text { en cuidados críticos, facilita que el } \\
\text { profesional alcance un nivel de } \\
\text { excelencia }\end{array}$ & 9,06 & 1,10 & 8,89 & 1,09 & 9,13 & 1,12 & 9,10 & 1,25 & 1,213 & 0,304 \\
\hline $\begin{array}{l}\text { La formación se debe apoyar en } \\
\text { eventos teórico-prácticos y en la } \\
\text { simulación, antes de llevar esos } \\
\text { conocimientos a la realidad }\end{array}$ & 8,88 & 1,25 & 8,95 & 1,13 & 9,05 & 1,08 & 9,03 & 1,11 & 0,676 & 0,567 \\
\hline $\begin{array}{l}\text { La formación debe terminar con } \\
\text { una intervención real, siempre } \\
\text { tutelado con un profesional } \\
\text { experimentado }\end{array}$ & 8,95 & 1,37 & 8,99 & 1,24 & 9,01 & 1,18 & 8,93 & 1,28 & 0,099 & 0,961 \\
\hline $\begin{array}{l}\text { La empatía es una actitud } \\
\text { indispensable a desarrollar dentro } \\
\text { del equipo sanitario }\end{array}$ & 9,14 & 0,99 & 8,95 & 1,03 & 9,17 & 1,05 & 9,14 & 1,04 & 1,35 & 0,255 \\
\hline $\begin{array}{l}\text { Las enfermeras necesitan } \\
\text { formación específica para afrontar } \\
\text { la muerte de los usuarios }\end{array}$ & 8,51 & 1,57 & 8,64 & 1,49 & 8,62 & 1,32 & 8,23 & 1,71 & 2,087 & 0,101 \\
\hline
\end{tabular}




\begin{tabular}{|c|c|c|c|c|c|c|c|c|c|c|}
\hline \multirow[t]{2}{*}{ Afirmaciones } & \multicolumn{2}{|c|}{$\begin{array}{c}\leq 35 \text { años } \\
\text { (n=159) }\end{array}$} & \multicolumn{2}{|c|}{$\begin{array}{c}36-40 \text { años } \\
(n=146)\end{array}$} & \multicolumn{2}{|c|}{$\begin{array}{c}41-45 \text { años } \\
\text { ( } \mathrm{n}=117)\end{array}$} & \multicolumn{2}{|c|}{$\begin{array}{c}>45 \text { años } \\
(n=146)\end{array}$} & \multirow[t]{2}{*}{$F$} & \multirow[t]{2}{*}{$p$} \\
\hline & Media & D.T. & Media & D.T. & Media & D.T. & Media & D.T. & & \\
\hline $\begin{array}{l}\text { Son habilidades a desarrollar en } \\
\text { las enfermeras de } \mathrm{UCl} \text {, la calma, } \\
\text { ser metódico y resolutivas }\end{array}$ & 8,90 & 1,10 & 8,65 & 1,26 & 8,97 & 1,18 & 9,24 & 0,97 & 6,647 & $<0,001$ \\
\hline $\begin{array}{l}\text { La inteligencia emocional es } \\
\text { necesaria de ser desarrollada en } \\
\text { las enfermeras de UCl }\end{array}$ & 8,79 & 1,16 & 8,72 & 1,17 & 8,83 & 1,16 & 8,95 & 1,13 & 0,985 & 0,399 \\
\hline
\end{tabular}

Nota. Prueba ANOVA (F). $\mathrm{p}$ valor: $p<0,05$

En los análisis realizados en las distintas secciones, podemos observar en la tabla 33, la presencia de diferencias en el ámbito profesional, de la gestión y la parte A del cuestionario en función de los grupos de edad. En la tabla 34 se presentan las diferencias significativas en la puntuación total del cuestionario.

Tabla 33. Puntuaciones totales de los 4 ámbitos y la total de la escala en función de la edad.

\begin{tabular}{|c|c|c|c|c|c|c|c|c|c|c|}
\hline \multirow[t]{2}{*}{ Afirmaciones } & \multicolumn{2}{|c|}{$\begin{array}{c}\leq 35 \text { años } \\
(n=159)\end{array}$} & \multicolumn{2}{|c|}{$\begin{array}{c}\text { 36-40 años } \\
(n=146)\end{array}$} & \multicolumn{2}{|c|}{$\begin{array}{l}\text { 41-45 años } \\
\text { ( } \mathrm{n}=117)\end{array}$} & \multicolumn{2}{|c|}{$\begin{array}{l}>45 \text { años } \\
(n=146)\end{array}$} & \multirow[t]{2}{*}{$\boldsymbol{F}$} & \multirow[t]{2}{*}{$p$} \\
\hline & Media & D.T. & Media & D.T. & Media & D.T. & Media & D.T. & & \\
\hline $\begin{array}{l}\text { Puntuación total ámbito } \\
\text { clínico }\end{array}$ & 163,00 & 9,47 & 162,91 & 9,19 & 165,78 & 9,16 & 163,86 & 10,92 & 2,375 & 0,069 \\
\hline $\begin{array}{l}\text { Puntuación total ámbito } \\
\text { profesional }\end{array}$ & 120,82 & 8,76 & 120,15 & 9,14 & 122,71 & 9,73 & 124,15 & 11,05 & 5,146 & 0,002 \\
\hline $\begin{array}{l}\text { Puntuación total ámbito de } \\
\text { la gestión }\end{array}$ & 134,16 & 10,55 & 133,06 & 11,35 & 136,06 & 10,94 & 138,35 & 12,46 & 6,103 & $<0,001$ \\
\hline $\begin{array}{l}\text { Puntuación total ámbito } \\
\text { educativo y de desarrollo }\end{array}$ & 46,15 & 6,28 & 46,77 & 5,61 & 46,94 & 5,87 & 46,23 & 5,72 & 0,606 & 0,612 \\
\hline Puntuación total parte A & 464,15 & 26,81 & 462,91 & 26,77 & 471,52 & 27,35 & 472,62 & 34,15 & 4,195 & 0,006 \\
\hline
\end{tabular}

Nota. Prueba ANOVA (F). $\mathrm{p}$ valor: $p<0,05$

Tabla 34. Puntuación total parte B y total de la escala en función de la edad.

\begin{tabular}{|c|c|c|c|c|c|c|c|c|c|c|}
\hline \multirow[t]{2}{*}{ Afirmaciones } & \multicolumn{2}{|c|}{$\begin{array}{c}\leq 35 \text { años } \\
\text { (n=159) }\end{array}$} & \multicolumn{2}{|c|}{$\begin{array}{c}\text { 36-40 años } \\
(n=146)\end{array}$} & \multicolumn{2}{|c|}{$\begin{array}{c}\text { 41-45 años } \\
\text { (n=117) }\end{array}$} & \multicolumn{2}{|c|}{$\begin{array}{c}>45 \text { años } \\
(n=146)\end{array}$} & \multirow[t]{2}{*}{$\boldsymbol{F}$} & \multirow[t]{2}{*}{$p$} \\
\hline & Media & D.T. & Media & D.T. & Media & D.T. & Media & D.T. & & \\
\hline Puntuación total parte $B$ & 106,22 & 8,77 & 105,87 & 8,39 & 107,15 & 9,25 & 107,17 & 10,51 & 0,711 & 0,546 \\
\hline $\begin{array}{l}\text { Puntuación total } \\
\text { cuestionario }\end{array}$ & 570,38 & 32,73 & 568,79 & 32,30 & 578,67 & 33,61 & 579,80 & 42,01 & 3,587 & 0,014 \\
\hline
\end{tabular}

Nota. Prueba ANOVA ( $\boldsymbol{F}) . \mathbf{p}$ valor: $p<0,05$

Tras analizar las diferencias entre los grupos de edad y las afirmaciones de la encuesta, así como las puntuaciones de cada ámbito y las puntuaciones totales podemos valorar que existen diferencias significativas en función de la edad de los encuestados. Seguidamente, se realizó un análisis post-hoc en aquellos ítems que dieron diferencias significativas, se aplicó la prueba de Scheffé para los ítems con varianzas iguales y la prueba de Games-Howell para aquellos con varianzas no iguales. La tabla 35 presenta los resultados de la prueba de Scheffé para las variables significativas. 
Tabla 35.Prueba Post-Hoc de Scheffé entre diferencias de grupo de edad y resultados puntuaciones del cuestionario.

\begin{tabular}{|c|c|c|c|c|}
\hline Ítems & $\begin{array}{l}\text { Grupo de Edad } \\
\text { (I) }\end{array}$ & $\begin{array}{l}\text { Grupo de Edad } \\
\text { (J) }\end{array}$ & $\begin{array}{l}\text { Diferencia de } \\
\text { medias } \\
(\mathrm{I}-\mathrm{J})\end{array}$ & $p$ \\
\hline \multirow{12}{*}{$\begin{array}{l}\text { El uso de escalas es necesario para la valoración del } \\
\text { paciente crítico }\end{array}$} & $\leq 35$ años & 36-40 años & 0,087 & 0,910 \\
\hline & $\leq 35$ años & 41-45 años & $-0,300$ & 0,134 \\
\hline & $\leq 35$ años & $>45$ años & $-0,221$ & 0,325 \\
\hline & $36-40$ años & $\leq 35$ años & $-0,087$ & 0,910 \\
\hline & 36-40 años & 41-45 años & $-0,387$ & 0,032 \\
\hline & $36-40$ años & $>45$ años & $-0,308$ & 0,095 \\
\hline & 41-45 años & $\leq 35$ años & 0,300 & 0,134 \\
\hline & 41-45 años & $36-40$ años & 0,387 & 0,032 \\
\hline & 41-45 años & $>45$ años & 0,079 & 0,944 \\
\hline & $>45$ años & $\leq 35$ años & 0,221 & 0,325 \\
\hline & $>45$ años & 36-40 años & 0,308 & 0,095 \\
\hline & $>45$ años & 41-45 años & $-0,079$ & 0,944 \\
\hline \multirow{12}{*}{$\begin{array}{l}\text { Observar, analizar e interpretar situaciones y/o } \\
\text { problemas en un paciente crítico es necesario para } \\
\text { realizar un análisis físico }\end{array}$} & $\leq 35$ años & 36-40 años & 0,069 & 0,940 \\
\hline & $\leq 35$ años & 41-45 años & $-0,288$ & 0,111 \\
\hline & $\leq 35$ años & $>45$ años & $-0,136$ & 0,670 \\
\hline & 36-40 años & $\leq 35$ años & $-0,069$ & 0,940 \\
\hline & $36-40$ años & 41-45 años & $-0,357$ & 0,032 \\
\hline & 36-40 años & $>45$ años & $-0,205$ & 0,341 \\
\hline & 41-45 años & $\leq 35$ años & 0,288 & 0,111 \\
\hline & 41-45 años & 36-40 años & 0,357 & 0,032 \\
\hline & 41-45 años & $>45$ años & 0,152 & 0,650 \\
\hline & $>45$ años & $\leq 35$ años & 0,136 & 0,670 \\
\hline & $>45$ años & 36-40 años & 0,205 & 0,341 \\
\hline & $>45$ años & 41-45 años & $-0,152$ & 0,650 \\
\hline \multirow{12}{*}{$\begin{array}{l}\text { Las medidas de soporte son el pilar fundamental de } \\
\text { las actividades enfermeras }\end{array}$} & $\leq 35$ años & 36-40 años & $-0,477$ & 0,082 \\
\hline & $\leq 35$ años & 41-45 años & $-0,218$ & 0,736 \\
\hline & $\leq 35$ años & $>45$ años & 0,030 & 0,999 \\
\hline & 36-40 años & $\leq 35$ años & 0,477 & 0,082 \\
\hline & 36-40 años & 41-45 años & 0,259 & 0,629 \\
\hline & 36-40 años & $>45$ años & 0,507 & 0,046 \\
\hline & 41-45 años & $\leq 35$ años & 0,218 & 0,736 \\
\hline & 41-45 años & 36-40 años & $-0,259$ & 0,629 \\
\hline & 41-45 años & $>45$ años & 0,248 & 0,663 \\
\hline & $>45$ años & $\leq 35$ años & $-0,030$ & 0,999 \\
\hline & $>45$ años & 36-40 años & $-0,507$ & 0,046 \\
\hline & $>45$ años & 41-45 años & $-0,248$ & 0,629 \\
\hline \multirow{12}{*}{$\begin{array}{l}\text { La reevaluación continua es la principal medida que } \\
\text { debe implementar la enfermera para evaluar } \\
\text { estrategias de mejora del plan de cuidados }\end{array}$} & $\leq 35$ años & 36-40 años & 0,037 & 0,988 \\
\hline & $\leq 35$ años & 41-45 años & $-0,310$ & 0,054 \\
\hline & $\leq 35$ años & $>45$ años & $-0,305$ & 0,040 \\
\hline & $36-40$ años & $\leq 35$ años & $-0,037$ & 0,988 \\
\hline & 36-40 años & 41-45 años & $-0,347$ & 0,027 \\
\hline & 36-40 años & $>45$ años & $-0,342$ & 0,019 \\
\hline & 41-45 años & $\leq 35$ años & 0,310 & 0,054 \\
\hline & 41-45 años & $36-40$ años & 0,347 & 0,027 \\
\hline & 41-45 años & $>45$ años & 0,005 & 1,000 \\
\hline & $>45$ años & $\leq 35$ años & 0,305 & 0,040 \\
\hline & $>45$ años & $36-40$ años & 0,342 & 0,019 \\
\hline & $>45$ años & 41-45 años & $-0,005$ & 1,000 \\
\hline
\end{tabular}




\begin{tabular}{|c|c|c|c|c|}
\hline Ítems & $\begin{array}{l}\text { Grupo de Edad } \\
\text { (I) }\end{array}$ & $\begin{array}{l}\text { Grupo de Edad } \\
\text { (J) }\end{array}$ & $\begin{array}{l}\text { Diferencia de } \\
\text { medias } \\
(1-J)\end{array}$ & $p$ \\
\hline \multirow{12}{*}{$\begin{array}{l}\text { Las enfermeras pueden hacer frente a decisiones } \\
\text { complejas gracias a la experiencia obtenida en } \mathrm{UCl}\end{array}$} & $\leq 35$ años & 36-40 años & 0,013 & 0,999 \\
\hline & $\leq 35$ años & 41-45 años & $-0,250$ & 0,157 \\
\hline & $\leq 35$ años & $>45$ años & $-0,304$ & 0,041 \\
\hline & 36-40 años & $\leq 35$ años & $-0,013$ & 0,999 \\
\hline & 36-40 años & 41-45 años & $-0,263$ & 0,136 \\
\hline & 36-40 años & $>45$ años & $-0,295$ & 0,052 \\
\hline & 41-45 años & $\leq 35$ años & 0,250 & 0,157 \\
\hline & 41-45 años & 36-40 años & 0,263 & 0,136 \\
\hline & 41-45 años & >45 años & $-0,031$ & 0,994 \\
\hline & >45 años & $\leq 35$ años & 0,304 & 0,041 \\
\hline & $>45$ años & 36-40 años & 0,295 & 0,052 \\
\hline & $>45$ años & 41-45 años & 0,031 & 0,994 \\
\hline \multirow{12}{*}{$\begin{array}{l}\text { La enfermera debería participar en las decisiones de } \\
\text { limitación de soporte vital (esfuerzo terapéutico) }\end{array}$} & $\leq 35$ años & 36-40 años & 0,243 & 0,641 \\
\hline & $\leq 35$ años & 41-45 años & $-0,073$ & 0,987 \\
\hline & $\leq 35$ años & >45 años & $-0,387$ & 0,240 \\
\hline & 36-40 años & $\leq 35$ años & $-0,243$ & 0,641 \\
\hline & 36-40 años & 41-45 años & $-0,316$ & 0,491 \\
\hline & 36-40 años & >45 años & $-0,630$ & 0,015 \\
\hline & 41-45 años & $\leq 35$ años & 0,073 & 0,987 \\
\hline & 41-45 años & 36-40 años & 0,316 & 0,491 \\
\hline & 41-45 años & >45 años & $-0,314$ & 0,496 \\
\hline & >45 años & $\leq 35$ años & 0,387 & 0,240 \\
\hline & $>45$ años & 36-40 años & 0,630 & 0,015 \\
\hline & $>45$ años & 41-45 años & 0,314 & 0,496 \\
\hline \multirow{12}{*}{$\begin{array}{l}\text { Las principales herramientas de comunicación son la } \\
\text { asertividad, la empatía y la escucha activa tanto con } \\
\text { usuarios y familia como con profesionales }\end{array}$} & $\leq 35$ años & 36-40 años & 0,213 & 0,286 \\
\hline & $\leq 35$ años & 41-45 años & $-0,092$ & 0,889 \\
\hline & $\leq 35$ años & $>45$ años & $-0,253$ & 0,151 \\
\hline & 36-40 años & $\leq 35$ años & $-0,213$ & 0,286 \\
\hline & 36-40 años & 41-45 años & $-0,305$ & 0,088 \\
\hline & 36-40 años & $>45$ años & $-0,466$ & 0,001 \\
\hline & 41-45 años & $\leq 35$ años & 0,092 & 0,889 \\
\hline & 41-45 años & 36-40 años & 0,305 & 0,088 \\
\hline & 41-45 años & $>45$ años & $-0,161$ & 0,600 \\
\hline & $>45$ años & $\leq 35$ años & 0,253 & 0,151 \\
\hline & $>45$ años & 36-40 años & 0,466 & 0,001 \\
\hline & $>45$ años & 41-45 años & 0,161 & 0,600 \\
\hline \multirow{12}{*}{$\begin{array}{l}\text { Las tecnologías de la información y comunicación } \\
\text { (TIC) son herramientas esenciales que permiten la } \\
\text { formación, el aprendizaje y el desarrollo de la } \\
\text { profesión }\end{array}$} & $\leq 35$ años & 36-40 años & $-0,101$ & 0,909 \\
\hline & $\leq 35$ años & 41-45 años & $-0,228$ & 0,482 \\
\hline & $\leq 35$ años & >45 años & $-0,498$ & 0,005 \\
\hline & 36-40 años & $\leq 35$ años & 0,101 & 0,909 \\
\hline & 36-40 años & 41-45 años & $-0,128$ & 0,862 \\
\hline & 36-40 años & $>45$ años & $-0,397$ & 0,049 \\
\hline & 41-45 años & $\leq 35$ años & 0,228 & 0,482 \\
\hline & 41-45 años & 36-40 años & 0,128 & 0,862 \\
\hline & 41-45 años & >45 años & $-0,270$ & 0,348 \\
\hline & >45 años & $\leq 35$ años & 0,498 & 0,005 \\
\hline & $>45$ años & $36-40$ años & 0,397 & 0,049 \\
\hline & $>45$ años & 41-45 años & 0,270 & 0,348 \\
\hline
\end{tabular}




\begin{tabular}{|c|c|c|c|c|}
\hline Ítems & $\begin{array}{c}\text { Grupo de Edad } \\
\text { (I) }\end{array}$ & $\begin{array}{c}\text { Grupo de Edad } \\
\text { (J) }\end{array}$ & $\begin{array}{c}\text { Diferencia de } \\
\text { medias } \\
(\mathrm{I}-\mathrm{J})\end{array}$ & $p$ \\
\hline \multirow{12}{*}{ Puntuación total ámbito de la gestión } & $\leq 35$ años & $36-40$ años & 1,101 & 0,832 \\
\hline & $\leq 35$ años & $41-45$ años & $-1,898$ & 0,517 \\
\hline & $\leq 35$ años & $>45$ años & $-4,186$ & 0,007 \\
\hline & 36-40 años & $\leq 35$ años & $-1,101$ & 0,832 \\
\hline & 36-40 años & 41-45 años & $-2,999$ & 0,145 \\
\hline & 36-40 años & $>45$ años & $-5,287$ & $<0,001$ \\
\hline & $41-45$ años & $\leq 35$ años & 1,898 & 0,517 \\
\hline & 41-45 años & 36-40 años & 2,999 & 0,145 \\
\hline & $41-45$ años & $>45$ años & $-2,287$ & 0,366 \\
\hline & $>45$ años & $\leq 35$ años & 4,186 & 0,007 \\
\hline & $>45$ años & $36-40$ años & 5,287 & $<0,001$ \\
\hline & $>45$ años & 41-45 años & 2,287 & 0,366 \\
\hline
\end{tabular}

Nota. Prueba de Scheffé para varianzas iguales, diferencia de medias (I-J). $\mathbf{p}$ valor: $p<0,05$

Como podemos observar en la tabla anterior, las mayores diferencias se agrupan entre los dos grupos de mayor edad, siendo el grupo de mayores de 45 años aquellos que puntúan más positivamente los ítems significativos del cuestionario. Resulta interesante resaltar que las diferencias en puntuación son siempre positivas en la diferencia de medias a favor del grupo de $>45$ años. Los grupos con los cuales suele haber diferencias significativas son las de enfermeras entre 3640 años y las menores de 35 años.

A continuación, se detallan las pruebas post-hoc de los grupos, que no tienen varianzas iguales mediante la prueba de Games-Howell, ver tabla 36.

Tabla 36. Prueba Post-Hoc de Games-Howell entre diferencias de grupo de edad y resultados puntuaciones del cuestionario.

\begin{tabular}{|c|c|c|c|c|}
\hline Ítems & $\begin{array}{l}\text { Grupo de Edad } \\
\text { (I) }\end{array}$ & $\begin{array}{l}\text { Grupo de Edad } \\
\text { (J) }\end{array}$ & $\begin{array}{l}\text { Diferencia de } \\
\text { medias } \\
(\mathrm{I}-\mathrm{J})\end{array}$ & $p$ \\
\hline \multirow{12}{*}{$\begin{array}{l}\text { La observación es una herramienta necesaria, } \\
\text { para obtener datos en la valoración del paciente } \\
\text { crítico }\end{array}$} & $\leq 35$ años & 36-40 años & 0,289 & 0,017 \\
\hline & $\leq 35$ años & 41-45 años & $-0,068$ & 0,878 \\
\hline & $\leq 35$ años & $>45$ años & $-0,129$ & 0,445 \\
\hline & 36-40 años & $\leq 35$ años & $-0,289$ & 0,017 \\
\hline & $36-40$ años & 41-45 años & $-0,357$ & 0,003 \\
\hline & 36-40 años & $>45$ años & $-0,418$ & $<0,001$ \\
\hline & 41-45 años & $\leq 35$ años & 0,068 & 0,878 \\
\hline & 41-45 años & 36-40 años & 0,357 & 0,003 \\
\hline & $41-45$ años & $>45$ años & $-0,061$ & 0,906 \\
\hline & >45 años & $\leq 35$ años & 0,129 & 0,445 \\
\hline & $>45$ años & 36-40 años & 0,418 & $<0,001$ \\
\hline & $>45$ años & 41-45 años & 0,061 & 0,906 \\
\hline \multirow{12}{*}{$\begin{array}{l}\text { La empatía y el respeto a la intimidad son } \\
\text { fundamentales para la enfermera de } \mathrm{UCl}\end{array}$} & $\leq 35$ años & 36-40 años & 0,194 & 0,280 \\
\hline & $\leq 35$ años & 41-45 años & $-0,105$ & 0,744 \\
\hline & $\leq 35$ años & >45 años & $-0,224$ & 0,074 \\
\hline & 36-40 años & $\leq 35$ años & $-0,194$ & 0,280 \\
\hline & 36-40 años & 41-45 años & $-0,299$ & 0,039 \\
\hline & 36-40 años & >45 años & $-0,418$ & $<0,001$ \\
\hline & 41-45 años & $\leq 35$ años & 0,105 & 0,744 \\
\hline & 41-45 años & 36-40 años & 0,299 & 0,039 \\
\hline & 41-45 años & $>45$ años & $-0,119$ & 0,606 \\
\hline & $>45$ años & $\leq 35$ años & 0,224 & 0,074 \\
\hline & $>45$ años & 36-40 años & 0,418 & $<0,001$ \\
\hline & $>45$ años & 41-45 años & 0,119 & 0,606 \\
\hline
\end{tabular}




\begin{tabular}{|c|c|c|c|c|}
\hline Ítems & $\begin{array}{l}\text { Grupo de Edad } \\
\text { (I) }\end{array}$ & $\begin{array}{l}\text { Grupo de Edad } \\
\text { (J) }\end{array}$ & $\begin{array}{l}\text { Diferencia de } \\
\text { medias } \\
(\mathrm{I}-\mathrm{J})\end{array}$ & $p$ \\
\hline \multirow{12}{*}{$\begin{array}{l}\text { Las enfermeras de UCl deben estar formadas en } \\
\text { la atención de los distintos tipos de shock }\end{array}$} & $\leq 35$ años & 36-40 años & $-0,032$ & 0,983 \\
\hline & $\leq 35$ años & 41-45 años & $-0,117$ & 0,525 \\
\hline & $\leq 35$ años & $>45$ años & 0,379 & 0,006 \\
\hline & 36-40 años & $\leq 35$ años & 0,032 & 0,983 \\
\hline & 36-40 años & 41-45 años & $-0,085$ & 0,770 \\
\hline & 36-40 años & $>45$ años & 0,411 & 0,003 \\
\hline & 41-45 años & $\leq 35$ años & 0,117 & 0,525 \\
\hline & 41-45 años & 36-40 años & 0,085 & 0,770 \\
\hline & 41-45 años & $>45$ años & 0,495 & $<0,001$ \\
\hline & $>45$ años & $\leq 35$ años & $-0,379$ & 0,006 \\
\hline & $>45$ años & 36-40 años & $-0,411$ & 0,003 \\
\hline & $>45$ años & 41-45 años & $-0,495$ & $<0,001$ \\
\hline \multirow{12}{*}{$\begin{array}{l}\text { El cálculo de fármacos y drogas es una } \\
\text { competencia imprescindible }\end{array}$} & $\leq 35$ años & 36-40 años & $-0,098$ & 0,859 \\
\hline & $\leq 35$ años & 41-45 años & $-0,121$ & 0,830 \\
\hline & $\leq 35$ años & $>45$ años & 0,539 & 0,012 \\
\hline & 36-40 años & $\leq 35$ años & 0,098 & 0,859 \\
\hline & 36-40 años & 41-45 años & $-0,023$ & 0,998 \\
\hline & 36-40 años & $>45$ años & 0,637 & 0,001 \\
\hline & 41-45 años & $\leq 35$ años & 0,121 & 0,830 \\
\hline & 41-45 años & 36-40 años & 0,023 & 0,998 \\
\hline & 41-45 años & $>45$ años & 0,660 & 0,002 \\
\hline & $>45$ años & $\leq 35$ años & $-0,539$ & 0,012 \\
\hline & $>45$ años & $36-40$ años & $-0,637$ & 0,001 \\
\hline & $>45$ años & 41-45 años & $-0,660$ & 0,002 \\
\hline \multirow{12}{*}{$\begin{array}{l}\text { El cuidado integral de un paciente critico forma } \\
\text { parte de la actuación principal del profesional de } \\
\text { enfermería }\end{array}$} & $\leq 35$ años & 36-40 años & $-0,062$ & 0,942 \\
\hline & $\leq 35$ años & 41-45 años & $-0,240$ & 0,118 \\
\hline & $\leq 35$ años & $>45$ años & $-0,346$ & 0,046 \\
\hline & $36-40$ años & $\leq 35$ años & 0,062 & 0,942 \\
\hline & 36-40 años & 41-45 años & $-0,179$ & 0,238 \\
\hline & 36-40 años & $>45$ años & $-0,185$ & 0,197 \\
\hline & 41-45 años & $\leq 35$ años & 0,240 & 0,118 \\
\hline & 41-45 años & $36-40$ años & 0,179 & 0,238 \\
\hline & 41-45 años & $>45$ años & $-0,006$ & 1,000 \\
\hline & $>45$ años & $\leq 35$ años & 0,346 & 0,046 \\
\hline & $>45$ años & $36-40$ años & 0,185 & 0,197 \\
\hline & $>45$ años & 41-45 años & 0,006 & 1,000 \\
\hline \multirow{12}{*}{$\begin{array}{l}\text { Los cuidados respiratorios son los que de } \\
\text { manera prioritaria deben ser desarrollados en } \\
\text { las enfermeras de } \mathrm{UCl}\end{array}$} & $\leq 35$ años & 36-40 años & $-0,521$ & 0,017 \\
\hline & $\leq 35$ años & 41-45 años & $-0,409$ & 0,203 \\
\hline & $\leq 35$ años & $>45$ años & $-0,281$ & 0,474 \\
\hline & $36-40$ años & $\leq 35$ años & 0,521 & 0,017 \\
\hline & 36-40 años & 41-45 años & 0,111 & 0,925 \\
\hline & 36-40 años & $>45$ años & 0,240 & 0,460 \\
\hline & 41-45 años & $\leq 35$ años & 0,409 & 0,203 \\
\hline & 41-45 años & 36-40 años & $-0,111$ & 0,925 \\
\hline & 41-45 años & $>45$ años & 0,128 & 0,916 \\
\hline & $>45$ años & $\leq 35$ años & 0,281 & 0,474 \\
\hline & $>45$ años & $36-40$ años & $-0,240$ & 0,460 \\
\hline & $>45$ años & 41-45 años & 0,128 & 0,916 \\
\hline
\end{tabular}




\begin{tabular}{|c|c|c|c|c|}
\hline Ítems & $\begin{array}{l}\text { Grupo de Edad } \\
\text { (I) }\end{array}$ & $\begin{array}{l}\text { Grupo de Edad } \\
\text { (J) }\end{array}$ & $\begin{array}{l}\text { Diferencia de } \\
\text { medias } \\
(\mathrm{I}-\mathrm{J})\end{array}$ & $p$ \\
\hline \multirow{12}{*}{$\begin{array}{l}\text { La enfermera de UCl afronta peor el } \\
\text { encarnizamiento terapéutico }\end{array}$} & $\leq 35$ años & 36-40 años & $-0,225$ & 0,708 \\
\hline & $\leq 35$ años & 41-45 años & $-0,056$ & 0,995 \\
\hline & $\leq 35$ años & $>45$ años & $-0,718$ & 0,001 \\
\hline & 36-40 años & $\leq 35$ años & 0,225 & 0,708 \\
\hline & 36-40 años & 41-45 años & 0,169 & 0,865 \\
\hline & 36-40 años & $>45$ años & $-0,493$ & 0,034 \\
\hline & 41-45 años & $\leq 35$ años & 0,056 & 0,995 \\
\hline & 41-45 años & 36-40 años & $-0,169$ & 0,865 \\
\hline & 41-45 años & $>45$ años & $-0,662$ & 0,006 \\
\hline & $>45$ años & $\leq 35$ años & 0,718 & 0,001 \\
\hline & $>45$ años & 36-40 años & 0,493 & 0,034 \\
\hline & $>45$ años & 41-45 años & 0,662 & 0,006 \\
\hline \multirow{12}{*}{$\begin{array}{l}\text { El lenguaje verbal y no verbal son } \\
\text { fundamentales en la comunicación en } \mathrm{UCl}\end{array}$} & $\leq 35$ años & 36-40 años & 0,246 & 0,236 \\
\hline & $\leq 35$ años & 41-45 años & $-0,139$ & 0,712 \\
\hline & $\leq 35$ años & $>45$ años & $-0,295$ & 0,067 \\
\hline & $36-40$ años & $\leq 35$ años & $-0,246$ & 0,236 \\
\hline & $36-40$ años & 41-45 años & $-0,385$ & 0,024 \\
\hline & 36-40 años & $>45$ años & $-0,541$ & $<0,001$ \\
\hline & 41-45 años & $\leq 35$ años & 0,139 & 0,712 \\
\hline & 41-45 años & 36-40 años & 0,385 & 0,024 \\
\hline & 41-45 años & $>45$ años & $-0,156$ & 0,594 \\
\hline & $>45$ años & $\leq 35$ años & 0,295 & 0,067 \\
\hline & $>45$ años & 36-40 años & 0,541 & $<0,001$ \\
\hline & $>45$ años & 41-45 años & 0,156 & 0,594 \\
\hline \multirow{12}{*}{$\begin{array}{l}\text { La comunicación escrita en } \mathrm{UCl} \text { se debe } \\
\text { fomentar siempre, pues es indispensable para la } \\
\text { continuidad de cuidados }\end{array}$} & $\leq 35$ años & 36-40 años & 0,318 & 0,116 \\
\hline & $\leq 35$ años & 41-45 años & $-0,057$ & 0,974 \\
\hline & $\leq 35$ años & $>45$ años & $-0,257$ & 0,175 \\
\hline & 36-40 años & $\leq 35$ años & $-0,318$ & 0,116 \\
\hline & 36-40 años & 41-45 años & $-0,375$ & 0,067 \\
\hline & $36-40$ años & $>45$ años & $-0,575$ & 0,001 \\
\hline & 41-45 años & $\leq 35$ años & 0,057 & 0,974 \\
\hline & 41-45 años & 36-40 años & 0,375 & 0,067 \\
\hline & 41-45 años & $>45$ años & $-0,200$ & 0,459 \\
\hline & $>45$ años & $\leq 35$ años & 0,257 & 0,175 \\
\hline & $>45$ años & 36-40 años & 0,575 & 0,001 \\
\hline & $>45$ años & 41-45 años & 0,200 & 0,459 \\
\hline \multirow{12}{*}{$\begin{array}{l}\text { El seguimiento de los cuidados que prestan las } \\
\text { enfermeras es indispensable para la continuidad } \\
\text { y evaluación de los cuidados }\end{array}$} & $\leq 35$ años & 36-40 años & 0,186 & 0,420 \\
\hline & $\leq 35$ años & 41-45 años & 0,009 & 1,000 \\
\hline & $\leq 35$ años & $>45$ años & $-0,163$ & 0,393 \\
\hline & $36-40$ años & $\leq 35$ años & $-0,186$ & 0,420 \\
\hline & $36-40$ años & 41-45 años & $-0,178$ & 0,493 \\
\hline & $36-40$ años & $>45$ años & $-0,349$ & 0,022 \\
\hline & 41-45 años & $\leq 35$ años & $-0,009$ & 1,000 \\
\hline & 41-45 años & 36-40 años & 0,178 & 0,493 \\
\hline & 41-45 años & $>45$ años & $-0,172$ & 0,389 \\
\hline & >45 años & $\leq 35$ años & 0,163 & 0,393 \\
\hline & $>45$ años & 36-40 años & 0,349 & 0,022 \\
\hline & $>45$ años & 41-45 años & 0,172 & 0,389 \\
\hline
\end{tabular}




\begin{tabular}{|c|c|c|c|c|}
\hline Ítems & $\begin{array}{l}\text { Grupo de Edad } \\
\text { (I) }\end{array}$ & $\begin{array}{l}\text { Grupo de Edad } \\
\text { (J) }\end{array}$ & $\begin{array}{l}\text { Diferencia de } \\
\text { medias } \\
(\mathrm{I}-\mathrm{J})\end{array}$ & $p$ \\
\hline \multirow{12}{*}{$\begin{array}{l}\text { Registrar los cuidados prestados es la mejor } \\
\text { medida posible para garantizar la continuidad }\end{array}$} & $\leq 35$ años & 36-40 años & $-0,084$ & 0,910 \\
\hline & $\leq 35$ años & 41-45 años & $-0,351$ & 0,022 \\
\hline & $\leq 35$ años & $>45$ años & $-0,468$ & $<0,001$ \\
\hline & 36-40 años & $\leq 35$ años & 0,084 & 0,910 \\
\hline & 36-40 años & 41-45 años & $-0,266$ & 0,093 \\
\hline & 36-40 años & $>45$ años & $-0,384$ & 0,002 \\
\hline & 41-45 años & $\leq 35$ años & 0,351 & 0,022 \\
\hline & 41-45 años & 36-40 años & 0,266 & 0,093 \\
\hline & 41-45 años & $>45$ años & $-0,117$ & 0,651 \\
\hline & $>45$ años & $\leq 35$ años & 0,468 & $<0,001$ \\
\hline & $>45$ años & $36-40$ años & 0,384 & 0,002 \\
\hline & $>45$ años & 41-45 años & 0,117 & 0,651 \\
\hline \multirow{12}{*}{$\begin{array}{l}\text { Las enfermeras son capaces de planificar } \\
\text { actuaciones a lo largo del turno de trabajo }\end{array}$} & $\leq 35$ años & 36-40 años & 0,339 & 0,093 \\
\hline & $\leq 35$ años & 41-45 años & $-0,050$ & 0,984 \\
\hline & $\leq 35$ años & $>45$ años & $-0,312$ & 0,063 \\
\hline & 36-40 años & $\leq 35$ años & $-0,339$ & 0,093 \\
\hline & 36-40 años & 41-45 años & $-0,389$ & 0,048 \\
\hline & 36-40 años & $>45$ años & $-0,651$ & $<0,001$ \\
\hline & 41-45 años & $\leq 35$ años & $-0,050$ & 0,984 \\
\hline & 41-45 años & 36-40 años & 0,389 & 0,048 \\
\hline & 41-45 años & $>45$ años & $-0,262$ & 0,187 \\
\hline & $>45$ años & $\leq 35$ años & 0,312 & 0,063 \\
\hline & $>45$ años & 36-40 años & 0,651 & $<0,001$ \\
\hline & $>45$ años & 41-45 años & 0,262 & 0,187 \\
\hline \multirow{12}{*}{$\begin{array}{l}\text { Se realiza un seguimiento de los indicadores de } \\
\text { calidad }\end{array}$} & $\leq 35$ años & 36-40 años & 0,211 & 0,857 \\
\hline & $\leq 35$ años & 41-45 años & $-0,178$ & 0,895 \\
\hline & $\leq 35$ años & $>45$ años & $-0,755$ & 0,012 \\
\hline & 36-40 años & $\leq 35$ años & $-0,211$ & 0,857 \\
\hline & 36-40 años & 41-45 años & $-0,389$ & 0,456 \\
\hline & 36-40 años & $>45$ años & $-0,986$ & 0,001 \\
\hline & 41-45 años & $\leq 35$ años & 0,178 & 0,895 \\
\hline & 41-45 años & $36-40$ años & 0,389 & 0,456 \\
\hline & 41-45 años & $>45$ años & $-0,597$ & 0,081 \\
\hline & $>45$ años & $\leq 35$ años & 0,775 & 0,012 \\
\hline & $>45$ años & $36-40$ años & 0,986 & 0,001 \\
\hline & $>45$ años & 41-45 años & 0,597 & 0,081 \\
\hline \multirow{12}{*}{$\begin{array}{l}\text { Las enfermeras de } \mathrm{UCl} \text { deben ser capaces de } \\
\text { actuar rápidamente ante el deterioro del usuario } \\
\text { y ante eventos adversos }\end{array}$} & $\leq 35$ años & 36-40 años & 0,232 & 0,105 \\
\hline & $\leq 35$ años & 41-45 años & 0,111 & 0,654 \\
\hline & $\leq 35$ años & $>45$ años & $-0,076$ & 0,809 \\
\hline & $36-40$ años & $\leq 35$ años & $-0,232$ & 0,105 \\
\hline & 36-40 años & 41-45 años & $-0,121$ & 0,684 \\
\hline & 36-40 años & $>45$ años & $-0,308$ & 0,012 \\
\hline & 41-45 años & $\leq 35$ años & 0,111 & 0,654 \\
\hline & 41-45 años & 36-40 años & $-0,076$ & 0,809 \\
\hline & 41-45 años & $>45$ años & $-0,111$ & 0,654 \\
\hline & $>45$ años & $\leq 35$ años & 0,121 & 0,684 \\
\hline & $>45$ años & $36-40$ años & $-0,308$ & 0,012 \\
\hline & $>45$ años & 41-45 años & 0,187 & 0,191 \\
\hline
\end{tabular}




\begin{tabular}{|c|c|c|c|c|}
\hline Ítems & $\begin{array}{l}\text { Grupo de Edad } \\
\text { (I) }\end{array}$ & $\begin{array}{l}\text { Grupo de Edad } \\
\text { (J) }\end{array}$ & $\begin{array}{l}\text { Diferencia de } \\
\text { medias } \\
(\mathrm{I}-\mathrm{J})\end{array}$ & $p$ \\
\hline \multirow{12}{*}{$\begin{array}{l}\text { En la UCI es fundamental la capacidad de } \\
\text { adaptación de las enfermeras en las situaciones } \\
\text { urgentes y emergentes }\end{array}$} & $\leq 35$ años & 36-40 años & 0,077 & 0,955 \\
\hline & $\leq 35$ años & 41-45 años & $-0,194$ & 0,524 \\
\hline & $\leq 35$ años & $>45$ años & $-0,300$ & 0,108 \\
\hline & 36-40 años & $\leq 35$ años & $-0,077$ & 0,955 \\
\hline & 36-40 años & 41-45 años & $-0,270$ & 0,232 \\
\hline & 36-40 años & $>45$ años & $-0,377$ & 0,025 \\
\hline & 41-45 años & $\leq 35$ años & 0,194 & 0,524 \\
\hline & 41-45 años & 36-40 años & 0,270 & 0,232 \\
\hline & 41-45 años & $>45$ años & $-0,107$ & 0,833 \\
\hline & >45 años & $\leq 35$ años & 0,300 & 0,108 \\
\hline & $>45$ años & 36-40 años & 0,377 & 0,025 \\
\hline & $>45$ años & 41-45 años & 0,107 & 0,833 \\
\hline \multirow{12}{*}{$\begin{array}{l}\text { Evitar ruidos innecesarios o bajar el volumen de } \\
\text { luces y alarmas, son acciones que fomentan el } \\
\text { descanso del paciente crítico }\end{array}$} & $\leq 35$ años & 36-40 años & 0,255 & 0,191 \\
\hline & $\leq 35$ años & 41-45 años & $-0,202$ & 0,365 \\
\hline & $\leq 35$ años & $>45$ años & $-0,382$ & 0,008 \\
\hline & 36-40 años & $\leq 35$ años & $-0,255$ & 0,191 \\
\hline & $36-40$ años & 41-45 años & $-0,457$ & 0,002 \\
\hline & 36-40 años & $>45$ años & $-0,637$ & $<0,001$ \\
\hline & 41-45 años & $\leq 35$ años & 0,202 & 0,365 \\
\hline & 41-45 años & 36-40 años & 0,457 & 0,002 \\
\hline & 41-45 años & $>45$ años & $-0,180$ & 0,427 \\
\hline & $>45$ años & $\leq 35$ años & 0,382 & 0,008 \\
\hline & $>45$ años & 36-40 años & 0,637 & $<0,001$ \\
\hline & $>45$ años & 41-45 años & 0,180 & 0,427 \\
\hline \multirow{12}{*}{$\begin{array}{l}\text { La realización de esta formación depende de la } \\
\text { motivación de la enfermera }\end{array}$} & $\leq 35$ años & 36-40 años & $-0,511$ & 0,074 \\
\hline & $\leq 35$ años & 41-45 años & $-0,114$ & 0,953 \\
\hline & $\leq 35$ años & $>45$ años & 0,023 & 1,000 \\
\hline & $36-40$ años & $\leq 35$ años & 0,511 & 0,074 \\
\hline & $36-40$ años & 41-45 años & 0,397 & 0,197 \\
\hline & $36-40$ años & $>45$ años & 0,534 & 0,036 \\
\hline & 41-45 años & $\leq 35$ años & 0,114 & 0,953 \\
\hline & 41-45 años & 36-40 años & $-0,397$ & 0,197 \\
\hline & 41-45 años & $>45$ años & 0,138 & 0,908 \\
\hline & $>45$ años & $\leq 35$ años & $-0,023$ & 1,000 \\
\hline & $>45$ años & 36-40 años & $-0,534$ & 0,036 \\
\hline & $>45$ años & 41-45 años & $-0,138$ & 0,908 \\
\hline \multirow{12}{*}{$\begin{array}{l}\text { Son habilidades para desarrollar en las } \\
\text { enfermeras de } \mathrm{UCl} \text {, la calma, ser metódico y } \\
\text { resolutivas }\end{array}$} & $\leq 35$ años & 36-40 años & 0,249 & 0,266 \\
\hline & $\leq 35$ años & 41-45 años & $-0,066$ & 0,965 \\
\hline & $\leq 35$ años & $>45$ años & $-0,340$ & 0,024 \\
\hline & $36-40$ años & $\leq 35$ años & $-0,249$ & 0,266 \\
\hline & 36-40 años & 41-45 años & $-0,315$ & 0,162 \\
\hline & $36-40$ años & $>45$ años & $-0,589$ & $<0,001$ \\
\hline & 41-45 años & $\leq 35$ años & 0,066 & 0,965 \\
\hline & 41-45 años & 36-40 años & 0,315 & 0,162 \\
\hline & 41-45 años & $>45$ años & $-0,274$ & 0,185 \\
\hline & $>45$ años & $\leq 35$ años & 0,340 & 0,024 \\
\hline & $>45$ años & 36-40 años & 0,589 & $<0,001$ \\
\hline & $>45$ años & 41-45 años & 0,274 & 0,185 \\
\hline
\end{tabular}




\begin{tabular}{|c|c|c|c|c|}
\hline Ítems & $\begin{array}{c}\text { Grupo de Edad } \\
\text { (I) }\end{array}$ & $\begin{array}{c}\text { Grupo de Edad } \\
\text { (J) }\end{array}$ & $\begin{array}{c}\text { Diferencia de } \\
\text { medias } \\
(\mathrm{I}-\mathrm{J})\end{array}$ & $p$ \\
\hline \multirow{12}{*}{ Puntuación total ámbito profesional } & $\leq 35$ años & 36-40 años & 0,666 & 0,916 \\
\hline & $\leq 35$ años & 41-45 años & $-1,894$ & 0,344 \\
\hline & $\leq 35$ años & $>45$ años & $-3,333$ & 0,021 \\
\hline & $36-40$ años & $\leq 35$ años & $-0,666$ & 0,916 \\
\hline & $36-40$ años & 41-45 años & $-2,560$ & 0,132 \\
\hline & $36-40$ años & $>45$ años & $-4,000$ & 0,005 \\
\hline & 41-45 años & $\leq 35$ años & 1,894 & 0,344 \\
\hline & 41-45 años & 36-40 años & 2,560 & 0,132 \\
\hline & 41-45 años & $>45$ años & $-1,439$ & 0,676 \\
\hline & $>45$ años & $\leq 35$ años & 3,333 & 0,021 \\
\hline & $>45$ años & 36-40 años & 4,000 & 0,005 \\
\hline & $>45$ años & 41-45 años & 1,439 & 0,676 \\
\hline \multirow{12}{*}{ Puntuación total parte $\mathrm{A}$} & $\leq 35$ años & 36-40 años & 1,239 & 0,978 \\
\hline & $\leq 35$ años & 41-45 años & $-7,364$ & 0,118 \\
\hline & $\leq 35$ años & $>45$ años & $-8,466$ & 0,081 \\
\hline & $36-40$ años & $\leq 35$ años & $-1,239$ & 0,978 \\
\hline & 36-40 años & 41-45 años & $-8,603$ & 0,054 \\
\hline & 36-40 años & $>45$ años & $-9,705$ & 0,037 \\
\hline & 41-45 años & $\leq 35$ años & 7,364 & 0,118 \\
\hline & 41-45 años & $36-40$ años & 8,603 & 0,054 \\
\hline & 41-45 años & $>45$ años & $-1,101$ & 0,991 \\
\hline & $>45$ años & $\leq 35$ años & 8,466 & 0,081 \\
\hline & $>45$ años & $36-40$ años & 9,705 & 0,037 \\
\hline & $>45$ años & $41-45$ años & 1,101 & 0,991 \\
\hline \multirow{12}{*}{ Puntuación total cuestionario } & $\leq 35$ años & 36-40 años & 1,589 & 0,974 \\
\hline & $\leq 35$ años & 41-45 años & $-8,291$ & 0,174 \\
\hline & $\leq 35$ años & $>45$ años & $-9,417$ & 0,134 \\
\hline & $36-40$ años & $\leq 35$ años & $-1,589$ & 0,974 \\
\hline & 36-40 años & 41-45 años & $-9,880$ & 0,078 \\
\hline & $36-40$ años & $>45$ años & $-11,006$ & 0,041 \\
\hline & 41-45 años & $\leq 35$ años & 8,291 & 0,174 \\
\hline & 41-45 años & $36-40$ años & 9,880 & 0,078 \\
\hline & 41-45 años & $>45$ años & $-1,126$ & 0,995 \\
\hline & $>45$ años & $\leq 35$ años & 9,417 & 0,134 \\
\hline & $>45$ años & $36-40$ años & 11,006 & 0,041 \\
\hline & $>45$ años & 41-45 años & 1,126 & 0,995 \\
\hline
\end{tabular}

Nota. Prueba de Games-Howell para varianzas distintas, diferencia de medias (I-J). $\mathbf{p}$ valor: $p<0,05$.

En lo relacionado a la prueba post-hoc de Games-Howell, podemos observar que existen diferencias que siguen las mismas tendencias que la mayoría de las variables del análisis post-hoc reflejado en la tabla 35. Sí se observa, que las enfermeras más jóvenes puntúan más aquellas afirmaciones relacionadas con los conocimientos: tipos de shock, cálculo de drogas y cuidados respiratorios. En lo relacionado a los cuidados del entorno y de la gestión, las enfermeras más mayores puntúan más positivamente la necesidad de formación al respecto.

En función del máximo grado académico alcanzado.

A continuación, se analizan las respuestas en relación con el máximo nivel académico obtenido por los 568 participantes a nivel nacional. La distribución que queda reflejada en la tabla 37. 
Tabla 37.Máximo Nivel académico alcanzado.

\begin{tabular}{lcc|}
\hline $\begin{array}{l}\text { Máximo Nivel académico alcanzado } \\
\text { (n=568) }\end{array}$ & Frecuencia & Porcentaje (\%) \\
\hline Diplomatura Universitaria & 222 & 39,08 \\
\hline Grado Universitario & 74 & 13,03 \\
\hline Experto Universitario & 95 & 16,72 \\
\hline Master como título propio & 90 & 15,85 \\
\hline Master Universitario Oficial & 79 & 13,91 \\
\hline Doctorado & 8 & 1,41 \\
\hline
\end{tabular}

Nota. Resultados expresados en frecuencias y porcentajes (\%)

Para el tratamiento estadístico de los datos se reagrupó la variable "Máximo grado académico" en 4 grupos (Diplomatura Universitaria con Grado Universitario, Experto Universitario, Máster con título propio y Máster Universitario Oficial con Doctorado). En el grupo Graduados se identificaron 296 registros $(52,11 \%)$ y en el grupo de postgrados oficiales 87 encuestados $(15,32 \%)$. Para observar las diferencias en los valores totales en función del máximo grado académico se aplicó la prueba no paramétrica de Jonckheere-Terpstra.

Tabla 38. Relación entre la formación universitaria y las puntuaciones dadas al cuestionario en las distintas secciones.

\begin{tabular}{|c|c|c|c|c|c|c|c|c|c|c|}
\hline \multirow[t]{2}{*}{ Ámbito } & \multicolumn{2}{|c|}{$\begin{array}{c}\text { Grado } \\
(n=296)\end{array}$} & \multicolumn{2}{|c|}{$\begin{array}{c}\text { Experto } \\
(\mathrm{n}=95)\end{array}$} & \multicolumn{2}{|c|}{$\begin{array}{l}\text { Master título propio } \\
(\mathrm{n}=90)\end{array}$} & \multicolumn{2}{|c|}{$\begin{array}{l}\text { Postgrado oficial } \\
(n=87)\end{array}$} & \multirow[t]{2}{*}{ Prueba S } & \multirow[t]{2}{*}{$p$} \\
\hline & Media & D.T. & Media & D.T. & Media & D.T. & Media & D.T. & & \\
\hline Clínico & 163,62 & 10,77 & 162,23 & 8,69 & 163,83 & 8,30 & 165,94 & 8,39 & 2,380 & 0,017 \\
\hline Profesional & 122,84 & 10,14 & 120,04 & 8,97 & 119,37 & 9,65 & 123,33 & 8,92 & 0,811 & 0,418 \\
\hline Gestión & 136,07 & 11,39 & 132,51 & 11,50 & 133,72 & 10,76 & 137,67 & 12,00 & 2,128 & 0,033 \\
\hline $\begin{array}{l}\text { Educativo y de } \\
\text { desarrollo }\end{array}$ & 45,53 & 6,08 & 47,12 & 5,21 & 48,02 & 5,07 & 47,52 & 6,15 & 2,574 & 0,010 \\
\hline Parte A & 468,07 & 30,75 & 461,91 & 27,16 & 464,95 & 25,70 & 474,48 & 28,30 & 2,245 & 0,025 \\
\hline Formación & 106,07 & 9,92 & 104,62 & 8,34 & 106,78 & 7,94 & 110,17 & 8,15 & 3,980 & $<0,001$ \\
\hline Parte Total & 574,14 & 37,59 & 566,53 & 33,35 & 571,74 & 31,69 & 584,65 & 33,18 & 2,885 & 0,004 \\
\hline
\end{tabular}

Nota. Prueba de Jonckheere-Terpstra (Prueba S). p valor: $p<0,05$.

Podemos observar que todos los ítems analizados tienen relevación estadística excepto en el ámbito profesional. Para analizar los resultados significativos de la tabla anterior se aplicó un análisis gráfico post-hoc mediante comparación por parejas. Las diferencias significativas que se hallaron en relación con las parejas se muestran en las figuras siguientes mediante líneas amarillas. Debajo de cada ítem en los siguientes gráficos se encuentra reflejado el rango promedio analizado. Ver figuras 5, 6, 7, 8, 9 y 10.

Como podemos observar en la figura 5, al comparar la puntuación del ámbito clínico, existe diferencias significativas $(p=0,005)$ entre las enfermeras con postgrado oficial y las enfermeras con experto universitario ya que las primeras puntúan más las necesidades formativas que las enfermeras en el ámbito clínico. En la figura 6, se aprecian diferencias significativas, entre las siguientes parejas experto universitario-grado $(p=0,013)$, experto universitario-postgrado oficial $(p=0,003)$ y máster como título propio-postgrado oficial $(p=0,027)$. 
Figura 5. Análisis por parejas de la puntuación de ámbito clínico y la máxima formación académica.

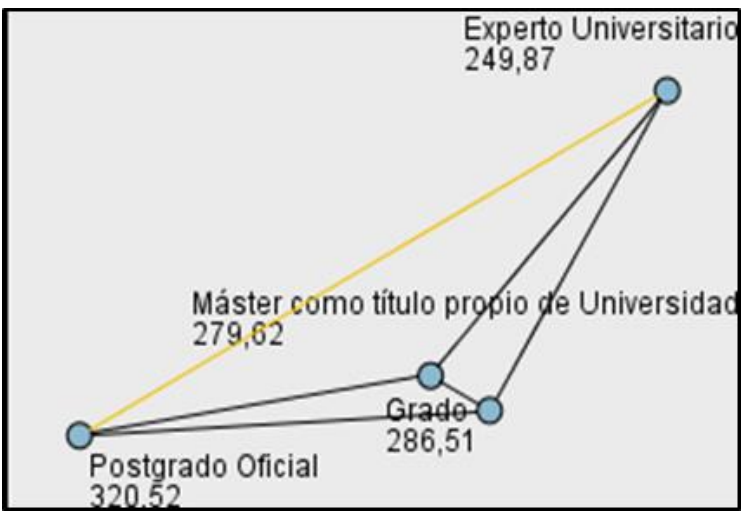

Figura 6. Análisis por parejas de la puntuación de ámbito de la gestión y la máxima formación académica.

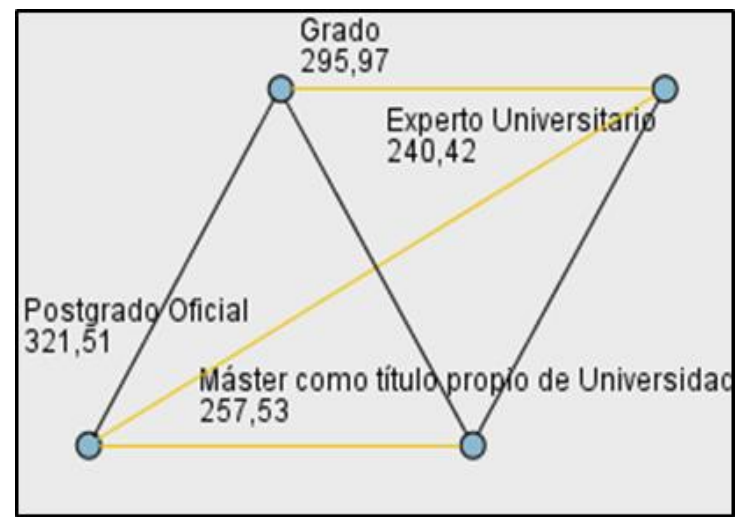

En la figura 7, observamos la existencia significativa de diferencias de puntuación entre la pareja grado-máster como título propio de Universidad con una significación de $p<0,001$ y también con la pareja grado-postgrado oficial con una relevancia estadística de $p=0,004$.

En la figura 8, la prueba de Jonckheere-Tersptra indicó diferencias significativas entre las parejas experto universitario-postgrado oficial $(p=0,002)$ y entre máster como título propio de universidadpostgrado oficial $(p=0,023)$.

Figura 7. Análisis por parejas de la puntuación del ámbito educativo y de desarrollo y la máxima formación académica.

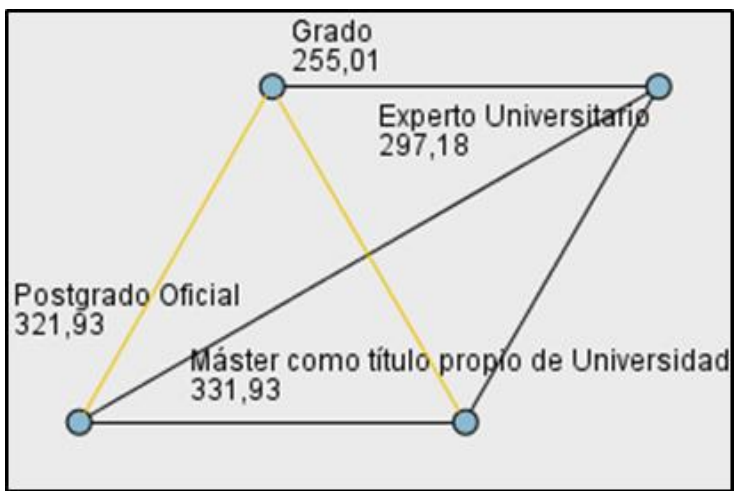

Figura 8. Diagrama de cajas de la prueba Samples Jonckheere-Terpstra entre la puntuación total parte A y el máximo nivel académico.

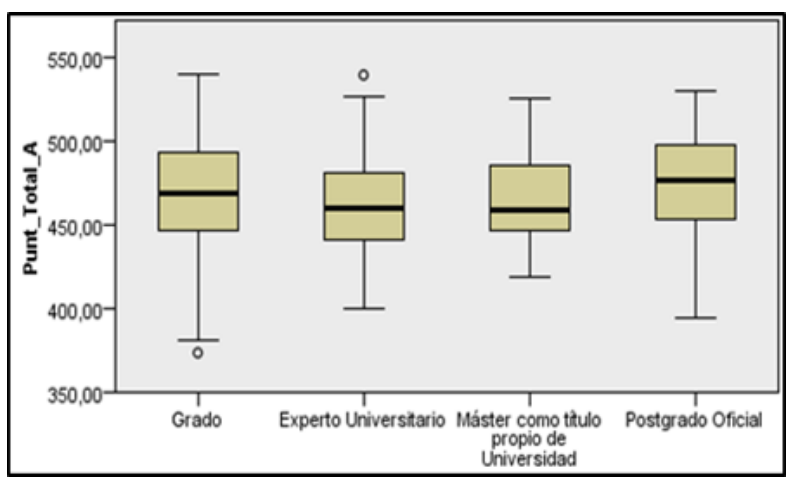

La figura 9 representa las diferencias de la puntuación total de la parte A, encontramos diferencias significativas entre las siguientes parejas de formación académica: experto universitario-postgrado oficial $(p<0,001)$ y máster como título propio de universidad-postgrado oficial $(p=0,008)$. La figura 9 presenta las diferencias significativas halladas al analizar la parte B del cuestionario, observamos como existen diferencias significativas entre las parejas experto universitario-postgrado oficial $(p<0,001)$ y máster como título propio de universidad-postgrado oficial $(p=0,012)$ y grado-postgrado oficial $(p=0,001)$. 
Figura 9. Análisis por parejas de la puntuación total parte A y la máxima formación académica.

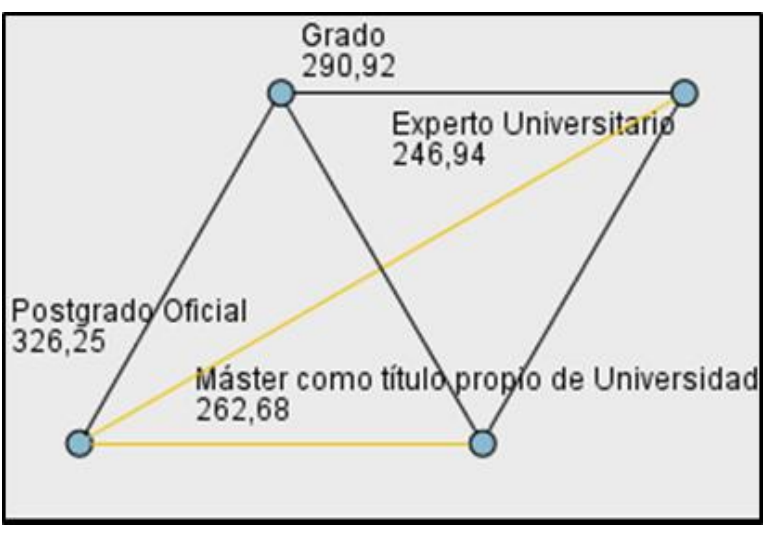

Figura 10. Análisis por parejas de la puntuación de la parte B y la máxima formación académica.

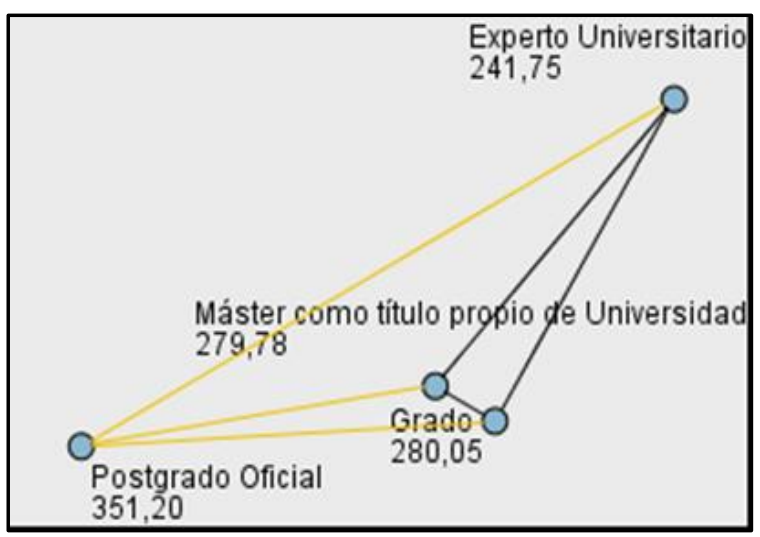

Para concluir este análisis post-hoc de la prueba $S$ de Jonckheere-Tersptra, se presentan los resultados de la puntuación total de los ítems del cuestionario. Como podemos observar en la figura 11, se presentan diferencias significativas entre el análisis por parejas de postgrado oficial-experto universitario $(p<0,001)$ y las parejas postgrado oficial-Master como título propio de universidad $(p=0,012)$

Figura 11. Análisis puntuación total de la encuesta y la máxima formación académica.

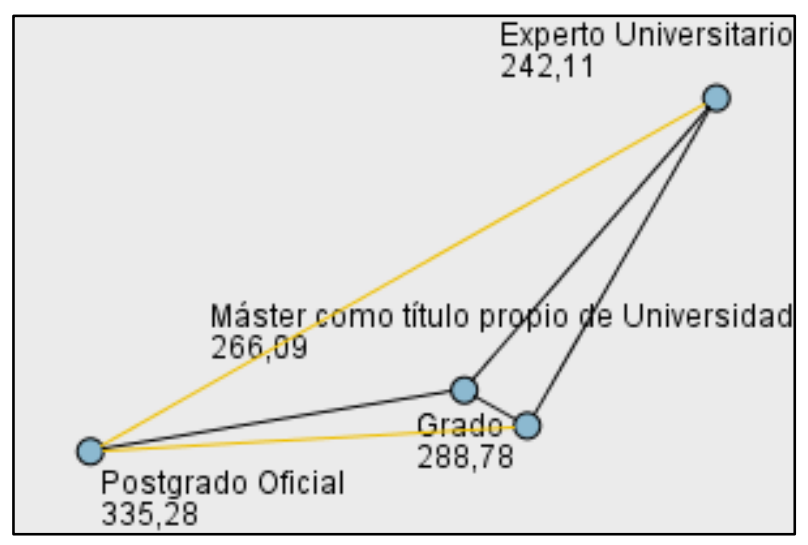

El postgrado oficial se constituye como el grupo que puntúa con valores más elevados las necesidades formativas. Por tanto, las enfermeras con doctorado y master universitario oficial valoran más positivamente la formación de las enfermeras en cuidados intensivos.

4.3.4. Analizar la existencia de diferencias en la puntuación de las necesidades formativas de las enfermeras de $\mathrm{UCl}$ en función de las características socio laborales de las enfermeras.

Este apartado evalúa si las características del ámbito laboral influyen en las respuestas de los encuestados. El ámbito laboral se ha definido mediante las siguientes variables: tipo de gestión del hospital, número de camas del hospital, tipo de unidad de cuidados intensivos, número de camas de la $\mathrm{UCl}$ donde trabajan y ratio enfermera paciente. Las características socio laborales propias de las 
enfermeras se han definido como: experiencia laboral total como enfermera y experiencia como enfermera de $\mathrm{UCI}$. A continuación, se presentan los resultados.

\section{En Función del tipo de gestión del Hospital.}

Del global de la muestra ( $n=568), 520$ enfermeras trabajaban en hospitales de gestión pública, 27 en hospitales de gestión mixta y 21 enfermeras en hospitales de gestión privada. A partir de estos datos se crearon dos grupos uno de gestión pública y otro que englobaba la gestión privada y mixta, tal y como se muestra en la tabla 39.

Tabla 39. Enfermeras agrupadas en función del tipo de gestión del centro donde trabajan.

\begin{tabular}{lcc}
\hline Tipo de Gestión Hospitalaria & Frecuencia & Porcentaje (\%) \\
\hline Gestión Pública & 520 & 91,54 \\
Gestión Mixta-Privada & 48 & 8,46 \\
\hline
\end{tabular}

Nota. Resultados expresados como frecuencias y porcentajes (\%).

La muestra se analizó mediante la prueba de t de Student. Únicamente se hallaron resultados significativos en 3 ítems del cuestionario y en la puntuación total del ámbito educativo. En gestión pública se consideró más importante el manejo de fármacos y drogas; en gestión privada se dio mayor importancia a la capacidad de planificación a largo tiempo y se mostró una mayor crítica en relación con la carga de trabajo, ver tabla 40.

Tabla 40. Diferencias significativas de la valoración de los ítems en función del tipo de gestión del hospital.

\begin{tabular}{|c|c|c|c|c|c|c|c|c|}
\hline \multirow[t]{2}{*}{ Afirmaciones } & \multicolumn{2}{|c|}{$\begin{array}{l}\text { Gestión Pública } \\
\qquad(n=520)\end{array}$} & \multicolumn{2}{|c|}{$\begin{array}{l}\text { Gestión Mixta-Privada } \\
(\mathrm{n}=48)\end{array}$} & \multicolumn{2}{|c|}{ Prueba Levene } & \multirow[t]{2}{*}{$t$} & \multirow[t]{2}{*}{$p$} \\
\hline & Media & D.T. & Media & D.T. & $\mathbf{F}$ & $p$ & & \\
\hline $\begin{array}{l}\text { El cálculo de fármacos y drogas es } \\
\text { una competencia imprescindible }\end{array}$ & 9,36 & 1,33 & 8,88 & 1,34 & 0,780 & 0,378 & 2,420 & 0,016 \\
\hline $\begin{array}{l}\text { Las enfermeras son capaces de } \\
\text { planificar actuaciones a lo largo del } \\
\text { turno de trabajo }\end{array}$ & 9,01 & 1,20 & 9,42 & 0,79 & 6,540 & 0,011 & 2,267 & 0,024 \\
\hline $\begin{array}{l}\text { Se gestiona adecuadamente la carga } \\
\text { de trabajo de las enfermeras en UCI }\end{array}$ & 5,82 & 2,10 & 5,10 & 2,37 & 1,467 & 0,226 & 2,218 & 0,027 \\
\hline
\end{tabular}

Nota. Prueba t de Student (t). p valor: $p<0,05$.

Al analizar las puntuaciones totales de cada ámbito en función del tipo de gestión sólo resultó significativo el ámbito educativo y de desarrollo, ver tabla 41.

Tabla 41. Valoración entre los ámbitos y las puntuaciones totales en función del tipo de gestión del hospital.

\begin{tabular}{|c|c|c|c|c|c|c|c|c|}
\hline \multirow[t]{2}{*}{ Afirmaciones } & \multicolumn{2}{|c|}{$\begin{array}{l}\text { Gestión Pública } \\
\qquad(n=520)\end{array}$} & \multicolumn{2}{|c|}{$\begin{array}{l}\text { Gestión Mixta-Privada } \\
\qquad(\mathrm{n}=48)\end{array}$} & \multicolumn{2}{|c|}{ Prueba Levene } & \multirow[t]{2}{*}{$\boldsymbol{t}$} & \multirow[t]{2}{*}{$p$} \\
\hline & Media & D.T. & Media & D.T. & $\mathbf{F}$ & $p$ & & \\
\hline Puntuación ámbito clínico & 163,80 & 9,72 & 163,52 & 10,36 & 0,174 & 0,677 & 0,190 & 0,849 \\
\hline Puntuación ámbito profesional & 121,84 & 9,77 & 122,50 & 10,13 & 0,099 & 0,754 & 0,443 & 0,658 \\
\hline Puntuación ámbito de la gestión & 135,21 & 11,64 & 136,81 & 9,94 & 2,704 & 0,101 & 0,918 & 0,359 \\
\hline $\begin{array}{l}\text { Puntuación ámbito educativo y de } \\
\text { desarrollo }\end{array}$ & 46,65 & 5,84 & 44,79 & 6,16 & 0,485 & 0,486 & 2,108 & 0,035 \\
\hline Puntuación total parte A & 467,52 & 29,30 & 467,62 & 28,55 & 0,055 & 0,814 & 0,023 & 0,982 \\
\hline
\end{tabular}




\begin{tabular}{|c|c|c|c|c|c|c|c|c|}
\hline \multirow[t]{2}{*}{ Afirmaciones } & \multicolumn{2}{|c|}{$\begin{array}{l}\text { Gestión Pública } \\
(n=520)\end{array}$} & \multicolumn{2}{|c|}{$\begin{array}{l}\text { Gestión Mixta-Privada } \\
\qquad(\mathrm{n}=48)\end{array}$} & \multicolumn{2}{|c|}{ Prueba Levene } & \multirow[t]{2}{*}{$t$} & \multirow[t]{2}{*}{$p$} \\
\hline & Media & D.T. & Media & D.T. & $\mathbf{F}$ & $p$ & & \\
\hline Puntuación total parte B & 106,58 & 9,31 & 106,41 & 8,60 & 0,461 & 0,497 & 0,122 & 0,903 \\
\hline Puntuación total encuesta & 574,10 & 35,77 & 574,04 & 34,74 & 0,336 & 0,563 & 0,013 & 0,990 \\
\hline
\end{tabular}

Nota. Prueba t de Student ( $\boldsymbol{t})$. $\mathbf{p}$ valor: $p<0,05$.

En función de la relación con la universidad.

Se analizaron las necesidades formativas de las enfermeras de UCl en función de si estas trabajaban en centros sanitarios con vinculación universitaria o no. En este caso también se aplicó la prueba t de Student. La mayoría de las enfermeras consultadas trabajaban en centros con vinculación universitaria, concretamente el $86,4 \%$ (491), el $13,6 \%$ (77) restante no trabajaban en centros sanitarios con vinculación a universidad. En la tabla 42 se presentan los resultados significativos.

Tabla 42. Diferencias significativas en la valoración de los ítems de la encuesta en función de la relación de los centros hospitalarios con la universidad.

\begin{tabular}{|c|c|c|c|c|c|c|c|c|}
\hline \multirow[t]{2}{*}{ Afirmaciones } & \multicolumn{2}{|c|}{$\begin{array}{l}\text { Centros Universitarios } \\
\qquad(\mathrm{n}=491)\end{array}$} & \multicolumn{2}{|c|}{$\begin{array}{l}\text { Centros No } \\
\text { Universitarios } \\
\quad(n=77)\end{array}$} & \multicolumn{2}{|c|}{ Prueba Levene } & \multirow[t]{2}{*}{$\boldsymbol{t}$} & \multirow[t]{2}{*}{$p$} \\
\hline & Media & D.T. & Media & D.T. & $\mathbf{F}$ & $p$ & & \\
\hline $\begin{array}{l}\text { La monitorización es una herramienta } \\
\text { fundamental para obtener datos en la } \\
\text { valoración del paciente crítico }\end{array}$ & 9,31 & 0,93 & 9,56 & 0,73 & 8,915 & 0,003 & 2,209 & 0,028 \\
\hline $\begin{array}{l}\text { Hay que involucrar al paciente y a la } \\
\text { familia en el proceso de recuperación }\end{array}$ & 8,78 & 1,16 & 9,04 & 0,95 & 1,956 & 0,163 & 2,424 & 0,016 \\
\hline $\begin{array}{l}\text { La reevaluación continua es la principal } \\
\text { medida que debe implementar la } \\
\text { enfermera para evaluar estrategias de } \\
\text { mejora en el plan de cuidados }\end{array}$ & 8,99 & 1,02 & 9,23 & 0,88 & 0,805 & 0,370 & 2,008 & 0,045 \\
\hline $\begin{array}{l}\text { Ante situaciones complejas, la ayuda y el } \\
\text { apoyo de compañeros más } \\
\text { experimentados ayudan a resolver } \\
\text { problemas }\end{array}$ & 9,37 & 0,93 & 9,71 & 0,58 & 24,721 & $<0,001$ & 3,175 & 0,002 \\
\hline $\begin{array}{l}\text { La enfermera de UCI suele afrontar bien } \\
\text { la decisión de limitación de soporte vital } \\
\text { (esfuerzo terapéutico) }\end{array}$ & 8,05 & 1,55 & 8,56 & 1,67 & 0,195 & 0,659 & 2,615 & 0,009 \\
\hline $\begin{array}{l}\text { La enfermera de UCI debería participar en } \\
\text { las decisiones de limitación de soporte } \\
\text { vital (esfuerzo terapéutico) }\end{array}$ & 8,33 & 1,84 & 8,82 & 1,48 & 4,761 & 0,030 & 2,199 & 0,028 \\
\hline $\begin{array}{l}\text { El afrontamiento de la muerte de los } \\
\text { usuarios dependerá de las creencias, } \\
\text { experiencias y valores del personal de } \\
\text { enfermería }\end{array}$ & 7,36 & 2,27 & 6,78 & 2,85 & 8,260 & 0,004 & 2,008 & 0,045 \\
\hline $\begin{array}{l}\text { La comunicación escrita en } \mathrm{UCl} \text { se debe } \\
\text { fomentar siempre, pues es indispensable } \\
\text { para la continuidad de cuidados }\end{array}$ & 8,92 & 1,20 & 9,26 & 1,04 & 3,269 & 0,071 & 2,354 & 0,019 \\
\hline $\begin{array}{l}\text { Registrar los cuidados prestados es la } \\
\text { mejor medida posible para garantizar la } \\
\text { continuidad }\end{array}$ & 9,20 & 1,02 & 9,52 & 0,73 & 6,611 & 0,010 & 2,656 & 0,009 \\
\hline $\begin{array}{l}\text { Las enfermeras son capaces de planificar } \\
\text { actuaciones a lo largo del turno de } \\
\text { trabajo }\end{array}$ & 9,00 & 1,21 & 9,34 & 0,94 & 3,277 & 0,071 & 2,323 & 0,021 \\
\hline $\begin{array}{l}\text { Es necesario una correcta formación para } \\
\text { garantizar la seguridad clínica }\end{array}$ & 9,30 & 0,96 & 9,60 & 0,73 & 13,383 & $<0,001$ & 2,636 & 0,009 \\
\hline
\end{tabular}




\begin{tabular}{|c|c|c|c|c|c|c|c|c|}
\hline \multirow[t]{2}{*}{ Afirmaciones } & \multicolumn{2}{|c|}{$\begin{array}{l}\text { Centros Universitarios } \\
\qquad(\mathrm{n}=491)\end{array}$} & \multicolumn{2}{|c|}{$\begin{array}{c}\text { Centros No } \\
\text { Universitarios } \\
(n=77)\end{array}$} & \multicolumn{2}{|c|}{ Prueba Levene } & \multirow[t]{2}{*}{$t$} & \multirow[t]{2}{*}{$p$} \\
\hline & Media & D.T. & Media & D.T. & $\mathbf{F}$ & $p$ & & \\
\hline $\begin{array}{l}\text { Los equipos asistenciales de } \mathrm{UCl} \text { son } \\
\text { capaces de realizar su trabajo en un } \\
\text { ambiente de presión y estrés }\end{array}$ & 8,86 & 1,20 & 9,25 & 0,93 & 3,983 & 0,046 & 2,670 & 0,008 \\
\hline $\begin{array}{l}\text { En una } \mathrm{UCl} \text { es fundamental la capacidad } \\
\text { de adaptación de las enfermeras en las } \\
\text { situaciones urgentes y emergentes }\end{array}$ & 9,12 & 1,17 & 9,42 & 1,14 & 2,018 & 0,156 & 2,055 & 0,040 \\
\hline $\begin{array}{l}\text { Evitar ruidos innecesarios o bajar el } \\
\text { volumen de luces y alarmas, son acciones } \\
\text { que fomentan el descanso del paciente } \\
\text { crítico }\end{array}$ & 9,07 & 1,09 & 9,55 & 0,75 & 16,575 & $<0,001$ & 3,650 & $<0,001$ \\
\hline $\begin{array}{l}\text { Se fomentan acciones para el adecuado } \\
\text { confort y descanso de los pacientes }\end{array}$ & 7,75 & 1,73 & 8,56 & 1,56 & 1,467 & 0,226 & 3,834 & $<0,001$ \\
\hline $\begin{array}{l}\text { En UCl, se toman medidas que ayudan a } \\
\text { prevenir o evitar el delirio o la } \\
\text { desorientación }\end{array}$ & 6,99 & 1,93 & 7,81 & 1,74 & 1,319 & 0,251 & 3,500 & 0,001 \\
\hline $\begin{array}{l}\text { La formación en } \mathrm{UCl} \text { se realiza sobre todo } \\
\text { para el cobro de incentivos, bolsa de } \\
\text { empleo y oposiciones }\end{array}$ & 6,29 & 2,55 & 5,62 & 2,94 & 6,364 & 0,012 & 2,093 & 0,037 \\
\hline $\begin{array}{l}\text { La enfermera de nueva incorporación } \\
\text { debería tener conocimientos } \\
\text { hemodinámicos, de ventilación mecánica, } \\
\text { reanimación cardiopulmonar básica y } \\
\text { avanzada, además de monitorización }\end{array}$ & 8,81 & 1,27 & 9,12 & 1,19 & 3,202 & 0,074 & 1,971 & 0,049 \\
\hline $\begin{array}{l}\text { La formación amplia y específica en } \\
\text { cuidados críticos, facilita que el } \\
\text { profesional alcance un nivel de excelencia }\end{array}$ & 8,99 & 1,18 & 9,38 & 0,85 & 4,179 & 0,041 & 2,778 & 0,006 \\
\hline $\begin{array}{l}\text { Son habilidades a desarrollar en las } \\
\text { enfermeras de } \mathrm{UCI} \text {, la calma ser metódico } \\
\text { y resolutivas }\end{array}$ & 8,89 & 1,16 & 9,23 & 0,98 & 1,773 & 0,184 & 2,446 & 0,015 \\
\hline
\end{tabular}

Nota. Prueba t de Student (t). p valor: $p<0,05$.

De los 66 ítems 20 mostraron diferencias significativas. Podemos observar como las enfermeras de $\mathrm{UCl}$ de centros hospitalarios sin relación con la universidad valoraron más positivamente 18 de los 20 ítems significativos. En centros no vinculados valoraron como más importante la formación; sin embargo, en los hospitales con vinculación a la universidad las enfermeras puntuaron de forma más elevada los ítems: "El afrontamiento de la muerte de los usuarios dependerá de las creencias, experiencias y valores del personal de enfermería" y "La formación en UCl se realiza sobre todo para el cobro de incentivos, bolsa de empleo y oposiciones".

A continuación, se detalla el análisis de diferencias mediante el test paramétrico de la t de Student para varianzas iguales en todos los ítems excepto en el del ámbito clínico que se utiliza el de varianzas desiguales. Como se puede observar el tipo de centro influye en las puntuaciones obtenidas en el cuestionario, en 5 de las 7 agrupaciones de ítems. Los centros no universitarios, puntúan las necesidades formativas de las enfermeras con puntuaciones mayores, ver tabla 43.

Tabla 43. Valoración entre los ámbitos y las puntuaciones totales en función de la relación de los centros hospitalarios con la universidad.

\begin{tabular}{|c|c|c|c|c|c|c|c|c|}
\hline \multirow{2}{*}{ Afirmaciones } & \multicolumn{2}{|c|}{$\begin{array}{c}\text { Centros Universitarios } \\
(\mathrm{n}=491)\end{array}$} & \multicolumn{2}{|c|}{$\begin{array}{l}\text { Centros No Universitarios } \\
\qquad(\mathrm{n}=77)\end{array}$} & \multicolumn{2}{|c|}{ Prueba Levene } & \multirow{2}{*}{$\mathbf{t}$} & \multirow[t]{2}{*}{$\mathbf{p}$} \\
\hline & Media & D.T. & Media & D.T. & $\mathbf{F}$ & $p$ & & \\
\hline Puntuación ámbito clínico & 163,46 & 10,03 & 165,75 & 7,69 & 5,520 & 0,019 & 2,315 & 0,022 \\
\hline
\end{tabular}




\begin{tabular}{|c|c|c|c|c|c|c|c|c|}
\hline \multirow[t]{2}{*}{ Afirmaciones } & \multicolumn{2}{|c|}{$\begin{array}{c}\text { Centros Universitarios } \\
\text { ( } n=491)\end{array}$} & \multicolumn{2}{|c|}{$\begin{array}{l}\text { Centros No Universitarios } \\
\qquad(\mathrm{n}=77)\end{array}$} & \multicolumn{2}{|c|}{ Prueba Levene } & \multirow[t]{2}{*}{$\mathbf{t}$} & \multirow[t]{2}{*}{$\mathbf{p}$} \\
\hline & Media & D.T. & Media & D.T. & $\mathbf{F}$ & $p$ & & \\
\hline Puntuación ámbito profesional & 121,52 & 9,92 & 124,31 & 8,62 & 2,276 & 0,132 & 2,333 & 0,020 \\
\hline Puntuación ámbito de la gestión & 134,77 & 11,55 & 139,05 & 10,53 & 1,464 & 0,227 & 3,055 & 0,002 \\
\hline $\begin{array}{l}\text { Puntuación ámbito educativo y } \\
\text { de desarrollo }\end{array}$ & 46,47 & 5,92 & 46,66 & 5,66 & 2,385 & 0,123 & 0,260 & 0,795 \\
\hline Puntuación total parte A & 466,23 & 29,64 & 475,77 & 24,95 & 1,476 & 0,225 & 2,679 & 0,008 \\
\hline Puntuación total parte B & 106,36 & 9,34 & 107,88 & 8,54 & 0,799 & 0,372 & 1,338 & 0,181 \\
\hline Puntuación total encuesta & 572,60 & 36,23 & 583,66 & 30,29 & 1,351 & 0,246 & 2,542 & 0,011 \\
\hline
\end{tabular}

Nota. Prueba t de Student (t). $\mathbf{p}$ valor: $p<0,05$.

\section{En función del número de camas del hospital.}

Como observamos en la figura 3 , el 50,53\% de los encuestados trabajaban en centros hospitalarios de más de 500 camas. A la hora de analizar las valoraciones de las enfermeras de UCl, se recodificó la variable en "hospitales de más de 500 camas y hospitales de igual o menos de 500 camas". Los datos se procesaron mediante la prueba $t$ de Student; destacar que en los centros más pequeños $(\leq 500$ camas), las enfermeras de UCl puntuaron más positivamente las necesidades formativas, ver tabla 44.

Tabla 44. Diferencias significativas en la valoración de los ítems de la encuesta en función del número de camas del hospital

\begin{tabular}{|c|c|c|c|c|c|c|c|c|}
\hline \multirow[t]{2}{*}{ Afirmaciones } & \multicolumn{2}{|c|}{$\begin{array}{l}\text { Hospitales } \\
>500 \text { camas } \\
(n=287) \\
\end{array}$} & \multicolumn{2}{|c|}{$\begin{array}{l}\text { Hospitales } \\
\leq 500 \text { camas } \\
(n=281)\end{array}$} & \multicolumn{2}{|c|}{ Prueba Levene } & \multirow[t]{2}{*}{$t$} & \multirow[t]{2}{*}{$p$} \\
\hline & Media & D.T. & Media & D.T. & $F$ & $p$ & & \\
\hline $\begin{array}{l}\text { La observación es una herramienta } \\
\text { necesaria para obtener datos en la } \\
\text { valoración del paciente crítico }\end{array}$ & 9,43 & 0,87 & 9,57 & 0,72 & 15,749 & $<0,001$ & 2,088 & 0,037 \\
\hline $\begin{array}{l}\text { Las principales patologías que debe } \\
\text { conocer una enfermera de } \mathrm{UCl} \text { son la } \\
\text { cardíaca, la respiratoria y la } \\
\text { neurológica }\end{array}$ & 7,90 & 1,67 & 8,19 & 1,59 & 1,123 & 0,290 & 2,109 & 0,035 \\
\hline $\begin{array}{l}\text { El cuidado integral de un paciente } \\
\text { crítico forma parte de la actuación } \\
\text { principal del profesional de } \\
\text { enfermería }\end{array}$ & 9,44 & 0,96 & 9,59 & 0,77 & 9,506 & 0,002 & 2,126 & 0,034 \\
\hline $\begin{array}{l}\text { La reevaluación continua es la } \\
\text { principal medida que debe } \\
\text { implementar la enfermera para } \\
\text { evaluar estrategias de mejora del plan } \\
\text { de cuidados }\end{array}$ & 8,92 & 1,06 & 9,12 & 0,95 & 0,599 & 0,439 & 2,382 & 0,018 \\
\hline $\begin{array}{l}\text { La capacidad de priorización es una } \\
\text { habilidad imprescindible }\end{array}$ & 9,43 & 0,81 & 9,60 & 0,72 & 12,776 & $<0,001$ & 2,691 & 0,007 \\
\hline $\begin{array}{l}\text { Ante situaciones complejas, la ayuda } \\
\text { y el apoyo de compañeros más } \\
\text { experimentados ayudan a resolver } \\
\text { problemas }\end{array}$ & 9,34 & 0,99 & 9,49 & 0,80 & 7,872 & 0,005 & 2,032 & 0,043 \\
\hline $\begin{array}{l}\text { La enfermera debería participar en las } \\
\text { decisiones de limitación de soporte } \\
\text { vital (esfuerzo terapéutico) }\end{array}$ & 8,17 & 2,06 & 8,63 & 1,47 & 22,958 & $<0,001$ & 3,044 & 0,002 \\
\hline $\begin{array}{l}\text { El profesional de enfermería en } \mathrm{UCl} \text {, } \\
\text { dentro de su competencia, busca la }\end{array}$ & 8,53 & 1,44 & 8,77 & 1,38 & 1,820 & 0,178 & 2,017 & 0,044 \\
\hline
\end{tabular}




\begin{tabular}{|c|c|c|c|c|c|c|c|c|}
\hline \multirow[t]{2}{*}{ Afirmaciones } & \multicolumn{2}{|c|}{$\begin{array}{l}\text { Hospitales } \\
>\mathbf{5 0 0} \text { camas } \\
(\mathrm{n}=\mathbf{2 8 7})\end{array}$} & \multicolumn{2}{|c|}{$\begin{array}{l}\text { Hospitales } \\
\leq 500 \text { camas } \\
(n=281)\end{array}$} & \multicolumn{2}{|c|}{ Prueba Levene } & \multirow[t]{2}{*}{$t$} & \multirow[t]{2}{*}{$p$} \\
\hline & Media & D.T. & Media & D.T. & $F$ & $p$ & & \\
\hline $\begin{array}{l}\text { Las principales herramientas de } \\
\text { comunicación son la asertividad, la } \\
\text { empatía y la escucha activa tanto con } \\
\text { usuarios y familia como con } \\
\text { profesionales }\end{array}$ & 8,90 & 1,07 & 9,15 & 1,03 & 2,651 & 0,104 & 2,843 & 0,005 \\
\hline $\begin{array}{l}\text { El seguimiento de los cuidados que } \\
\text { prestan las enfermeras es } \\
\text { indispensable para la continuidad y } \\
\text { evaluación de los cuidados }\end{array}$ & 9,13 & 0,95 & 9,29 & 1,00 & 0,446 & 0,505 & 1,988 & 0,047 \\
\hline $\begin{array}{l}\text { Registrar los cuidados prestados es la } \\
\text { mejor medida posible para garantizar } \\
\text { la continuidad }\end{array}$ & 9,13 & 1,08 & 9,35 & 0,89 & 4,345 & 0,038 & 2,675 & 0,008 \\
\hline $\begin{array}{l}\text { Las enfermeras son capaces de } \\
\text { planificar actuaciones a lo largo del } \\
\text { turno de trabajo }\end{array}$ & 8,91 & 1,28 & 9,19 & 1,06 & 6,033 & 0,014 & 2,902 & 0,004 \\
\hline $\begin{array}{l}\text { Se realiza un seguimiento de los } \\
\text { indicadores de calidad }\end{array}$ & 6,42 & 2,23 & 6,89 & 2,17 & 2,364 & 0,125 & 2,568 & 0,010 \\
\hline $\begin{array}{l}\text { Es necesaria una correcta formación } \\
\text { para garantizar la seguridad clínica }\end{array}$ & 9,23 & 1,00 & 9,45 & 0,86 & 9,668 & 0,002 & 2,831 & 0,005 \\
\hline $\begin{array}{l}\text { Las enfermeras de UCI deben ser } \\
\text { capaces de actuar rápidamente ante } \\
\text { el deterioro del usuario y ante } \\
\text { eventos adversos }\end{array}$ & 9,41 & 0,87 & 9,56 & 0,78 & 11,261 & 0,001 & 2,133 & 0,033 \\
\hline $\begin{array}{l}\text { Los equipos asistenciales de UCI son } \\
\text { capaces de realizar su trabajo en un } \\
\text { ambiente de presión y estrés }\end{array}$ & 8,81 & 1,21 & 9,02 & 1,13 & 3,518 & 0,061 & 2,199 & 0,028 \\
\hline $\begin{array}{l}\text { Evitar ruidos innecesarios o bajar el } \\
\text { volumen de luces y alarmas, son } \\
\text { acciones que fomentan el descanso } \\
\text { del paciente crítico }\end{array}$ & 8,99 & 1,13 & 9,29 & 0,98 & 8,897 & 0,003 & 3,367 & 0,001 \\
\hline $\begin{array}{l}\text { En UCl, se toman medidas que } \\
\text { ayudan a prevenir o evitar el delirio o } \\
\text { la desorientación }\end{array}$ & 6,86 & 2,01 & 7,33 & 1,81 & 5,656 & 0,018 & 2,925 & 0,004 \\
\hline $\begin{array}{l}\text { La acogida del personal de nueva } \\
\text { incorporación debe ser realizada } \\
\text { lenta y progresivamente }\end{array}$ & 8,88 & 1,62 & 9,14 & 1,46 & 3,219 & 0,073 & 1,990 & 0,047 \\
\hline $\begin{array}{l}\text { La formación amplia y específica en } \\
\text { cuidados críticos, facilita que el } \\
\text { profesional alcance un nivel de } \\
\text { excelencia }\end{array}$ & 8,92 & 1,28 & 9,16 & 0,98 & 6,712 & 0,010 & 2,468 & 0,014 \\
\hline $\begin{array}{l}\text { Son habilidades a desarrollar en las } \\
\text { enfermeras de UCI, la calma, ser } \\
\text { metódico y resolutivas }\end{array}$ & 8,82 & 1,21 & 9,05 & 1,08 & 4,017 & 0,046 & 2,401 & 0,017 \\
\hline
\end{tabular}

Nota. Prueba t de Student (t). p valor: $p<0,05$.

Las puntuaciones totales también se ven influenciadas por el tamaño del hospital, excepto en el ámbito educativo y de desarrollo y, en la puntuación total de la parte B del cuestionario, ver tabla 45.

Tabla 45. Valoración entre los ámbitos y las puntuaciones totales en función del número de camas del hospital.

\begin{tabular}{|c|c|c|c|c|c|c|c|c|}
\hline \multirow[t]{2}{*}{ Afirmaciones } & \multicolumn{2}{|c|}{$\begin{array}{l}\text { Hospitales } \\
>500 \text { camas } \\
(n=287)\end{array}$} & \multicolumn{2}{|c|}{$\begin{array}{l}\text { Hospitales } \\
\leq \mathbf{5 0 0} \text { camas } \\
(\mathrm{n}=\mathbf{2 8 1})\end{array}$} & \multicolumn{2}{|c|}{ Prueba Levene } & \multirow[t]{2}{*}{$\boldsymbol{t}$} & \multirow[t]{2}{*}{$p$} \\
\hline & Media & D.T. & Media & D.T. & $\mathbf{F}$ & $p$ & & \\
\hline Puntuación ámbito clínico & 162,82 & 10,13 & 164,75 & 9,31 & 2,366 & 0,125 & 2,356 & 0,019 \\
\hline Puntuación ámbito profesional & 120,82 & 9,95 & 122,99 & 9,52 & 1,003 & 0,317 & 2,646 & 0,008 \\
\hline
\end{tabular}




\begin{tabular}{|c|c|c|c|c|c|c|c|c|}
\hline \multirow[t]{2}{*}{ Afirmaciones } & \multicolumn{2}{|c|}{$\begin{array}{l}\text { Hospitales } \\
>500 \text { camas } \\
(n=287)\end{array}$} & \multicolumn{2}{|c|}{$\begin{array}{l}\text { Hospitales } \\
\leq 500 \text { camas } \\
(n=281)\end{array}$} & \multicolumn{2}{|c|}{ Prueba Levene } & \multirow[t]{2}{*}{$\boldsymbol{t}$} & \multirow[t]{2}{*}{$p$} \\
\hline & Media & D.T. & Media & D.T. & $\mathbf{F}$ & $p$ & & \\
\hline Puntuación ámbito de la gestión & 133,67 & 11,82 & 137,06 & 10,94 & 3,931 & 0,048 & 3,540 & $<0,001$ \\
\hline $\begin{array}{l}\text { Puntuación ámbito educativo y de } \\
\text { desarrollo }\end{array}$ & 46,34 & 5,81 & 46,66 & 5,97 & 0,062 & 0,804 & 0,663 & 0,508 \\
\hline Puntuación total parte A & 463,67 & 29,64 & 471,47 & 28,29 & 0,201 & 0,654 & 3,207 & 0,001 \\
\hline Puntuación total parte B & 105,90 & 9,39 & 107,25 & 9,07 & 1,081 & 0,299 & 1,738 & 0,083 \\
\hline Puntuación total encuesta & 569,58 & 36,30 & 578,73 & 34,46 & 0,171 & 0,679 & 3,079 & 0,002 \\
\hline
\end{tabular}

Nota. Prueba t de Student (t). p valor: $p<0,05$.

\section{En función del tipo de UCI.}

La organización de las $\mathrm{UCl}$ es un elemento fundamental a la hora de atender a los distintos tipos de pacientes críticos, como se pudo observar en la tabla 12, el 71,04\% (405) de los participantes formaban parte de unidades polivalentes. Para poder analizar las diferencias significativas, agrupamos las unidades no polivalentes quedando un grupo de 163 participantes para comparar la puntuación de los ítems en función de la organización de las unidades.

Se utilizó el test de la t de Student para varianzas iguales. Sólo se encontraron diferencias en 4 de los 66 ítems comparados. En todos ellos, las enfermeras que trabajan en unidades polivalentes puntuaron con valores superiores las cuatro afirmaciones. La tabla 46 presenta los resultados significativos.

Tabla 46. Diferencias significativas en la valoración de los ítems de la encuesta en función del tipo de UCl.

\begin{tabular}{|c|c|c|c|c|c|c|c|c|}
\hline \multirow[t]{2}{*}{ Afirmaciones } & \multicolumn{2}{|c|}{$\begin{array}{c}\text { Unidades } \\
\text { Polivalentes } \\
(n=405)\end{array}$} & \multicolumn{2}{|c|}{$\begin{array}{l}\text { Unidades } \\
\text { Específicas } \\
(n=163)\end{array}$} & \multicolumn{2}{|c|}{ Prueba Levene } & \multirow[t]{2}{*}{$\boldsymbol{t}$} & \multirow[t]{2}{*}{$p$} \\
\hline & Media & D.T. & Media & D.T. & $F$ & $p$ & & \\
\hline $\begin{array}{l}\text { El uso de escalas son necesarias para la } \\
\text { valoración del paciente crítico }\end{array}$ & 8,90 & 1,11 & 8,60 & 1,20 & 2,052 & 0,153 & 2,904 & 0,004 \\
\hline $\begin{array}{l}\text { La integración e interrelación de los datos es } \\
\text { una habilidad muy importante de las } \\
\text { enfermeras de UCl }\end{array}$ & 9,26 & 0,89 & 9,02 & 1,21 & 12,910 & $<0,001$ & 2,592 & 0,010 \\
\hline $\begin{array}{l}\text { La enfermera de } \mathrm{UCl} \text { afronta peor el } \\
\text { encarnizamiento terapéutico }\end{array}$ & 8,72 & 1,69 & 8,40 & 1,85 & 3,802 & 0,052 & 1,968 & 0,050 \\
\hline $\begin{array}{l}\text { Las tecnologías de la información y } \\
\text { comunicación (TIC) son herramientas } \\
\text { esenciales que permiten la formación, el } \\
\text { aprendizaje y el desarrollo de la profesión }\end{array}$ & 8,50 & 1,31 & 8,19 & 1,34 & 1,516 & 0,219 & 2,508 & 0,012 \\
\hline
\end{tabular}

Nota. Prueba t de Student (t). p valor: $p<0,05$.

Al analizar si cada uno de los ámbitos y las puntuaciones totales presentaban diferencias en función del tipo de unidad no observamos relación significativa alguna, ver tabla 49.

Tabla 47. Valoración entre los ámbitos y las puntuaciones totales en función del tipo de unidad de UCI.

\begin{tabular}{|c|c|c|c|c|c|c|c|c|}
\hline \multirow[t]{2}{*}{ Afirmaciones } & \multicolumn{2}{|c|}{$\begin{array}{c}\text { Unidades } \\
\text { Polivalentes } \\
(n=405)\end{array}$} & \multicolumn{2}{|c|}{$\begin{array}{c}\text { Unidades } \\
\text { Específicas } \\
\text { (n=163) }\end{array}$} & \multicolumn{2}{|c|}{ Prueba Levene } & \multirow[t]{2}{*}{$\boldsymbol{t}$} & \multirow[t]{2}{*}{$p$} \\
\hline & Media & D.T. & Media & D.T. & $F$ & $p$ & & \\
\hline Puntuación ámbito clínico & 164,01 & 9,40 & 163,20 & 10,65 & 1,865 & 0,173 & 0,900 & 0,369 \\
\hline
\end{tabular}




\begin{tabular}{|c|c|c|c|c|c|c|c|c|}
\hline \multirow[t]{2}{*}{ Afirmaciones } & \multicolumn{2}{|c|}{$\begin{array}{c}\text { Unidades } \\
\text { Polivalentes } \\
(n=405)\end{array}$} & \multicolumn{2}{|c|}{$\begin{array}{l}\text { Unidades } \\
\text { Específicas } \\
(n=163)\end{array}$} & \multicolumn{2}{|c|}{ Prueba Levene } & \multirow[t]{2}{*}{$t$} & \multirow[t]{2}{*}{$p$} \\
\hline & Media & D.T. & Media & D.T. & $\boldsymbol{F}$ & $p$ & & \\
\hline Puntuación ámbito profesional & 122,03 & 9,78 & 121,56 & 9,84 & 0,237 & 0,626 & 0,517 & 0,605 \\
\hline Puntuación ámbito de la gestión & 135,32 & 11,61 & 135,42 & 11,28 & 0,391 & 0,532 & 0,091 & 0,927 \\
\hline $\begin{array}{l}\text { Puntuación ámbito educativo y de } \\
\text { desarrollo }\end{array}$ & 46,65 & 5,73 & 46,13 & 6,25 & 4,909 & 0,027 & 0,937 & 0,349 \\
\hline Puntuación total parte A & 468,02 & 28,86 & 466,32 & 30,15 & 0,001 & 0,973 & 0,627 & 0,531 \\
\hline Puntuación total parte B & 106,86 & 8,80 & 105,85 & 10,29 & 2,190 & 0,139 & 1,166 & 0,244 \\
\hline Puntuación total encuesta & 574,87 & 34,82 & 572,18 & 37,70 & 0,452 & 0,502 & 0,816 & 0,415 \\
\hline
\end{tabular}

Nota. Prueba t de Student (t). p valor: $p<0,05$.

En función del número de camas de UCl de la unidad en la que las enfermeras trabajan.

Este apartado presenta los resultados de las percepciones de las enfermeras en función del tamaño de cada UCI. Las 568 enfermeras encuestadas trabajaban en unidades de tamaño muy dispares, así la unidad más pequeña incluida tenía 4 camas y la más grande 40 camas. El valor medio de camas de UCI fue de 16,33 camas con una desviación típica de 7,93. Utilizando el valor medio, creamos unidades de pequeño tamaño y de gran tamaño a partir. Así podemos observar que el $62 \%$ (352) de las enfermeras desarrollan su labor profesional en unidades pequeñas (rango 4-16 camas), el restante 38\% (216), trabajan en unidades grandes (rango 17-40). Las unidades con menos camas puntúan con valores superiores las medidas de soporte y la prevención ante eventos como el delirio y la desorientación. En la tabla 48 se presentan los resultados significativos tras aplicar la prueba t de Student.

Tabla 48. Diferencias significativas en la valoración de los ítems de la encuesta en función del tamaño de la $\mathrm{UCl}$.

\begin{tabular}{|c|c|c|c|c|c|c|c|c|}
\hline \multirow[t]{2}{*}{ Afirmaciones } & \multicolumn{2}{|c|}{$\begin{array}{l}\text { Unidades } \\
\text { pequeñas } \\
(\mathrm{n}=352)\end{array}$} & \multicolumn{2}{|c|}{$\begin{array}{l}\text { Unidades } \\
\text { grandes } \\
(\mathbf{n}=\mathbf{2 1 6})\end{array}$} & \multicolumn{2}{|c|}{ Prueba Levene } & \multirow[t]{2}{*}{$t$} & \multirow[t]{2}{*}{$p$} \\
\hline & Media & D.T. & Media & D.T. & $F$ & $p$ & & \\
\hline $\begin{array}{l}\text { Las medidas de soporte son el pilar } \\
\text { fundamental de las actividades enfermeras }\end{array}$ & 8,52 & 1,58 & 8,10 & 2,02 & 8,746 & 0,003 & 2,823 & 0,005 \\
\hline $\begin{array}{l}\text { La enfermera de } \mathrm{UCl} \text { afronta peor el } \\
\text { encarnizamiento terapéutico }\end{array}$ & 8,51 & 1,78 & 8,81 & 1,66 & 3,049 & 0,081 & 2,040 & 0,042 \\
\hline $\begin{array}{l}\text { En UCl, se toman medidas que ayudan a } \\
\text { prevenir o evitar el delirio o la desorientación }\end{array}$ & 7,23 & 1,88 & 6,88 & 1,99 & 0,558 & 0,455 & 2,154 & 0,032 \\
\hline $\begin{array}{l}\text { Debería existir la figura de un enfermero } \\
\text { tutor en la unidad para ayudar a las } \\
\text { enfermeras de nueva incorporación }\end{array}$ & 9,40 & 0,99 & 9,60 & 0,89 & 7,587 & 0,006 & 2,493 & 0,013 \\
\hline $\begin{array}{l}\text { La formación amplia y específica en cuidados } \\
\text { críticos, facilita que el profesional alcance un } \\
\text { nivel de excelencia }\end{array}$ & 8,95 & 1,16 & 9,19 & 1,11 & 1,788 & 0,182 & 2,514 & 0,012 \\
\hline $\begin{array}{l}\text { La formación se debe apoyar en eventos } \\
\text { teórico-prácticos y en la simulación antes de } \\
\text { Ilevar esos conocimientos a la realidad }\end{array}$ & 8,87 & 1,19 & 9,14 & 1,06 & 2,034 & 0,154 & 2,773 & 0,006 \\
\hline $\begin{array}{l}\text { La formación debe terminar con una } \\
\text { intervención real, siempre tutelado con un } \\
\text { profesional experimentado }\end{array}$ & 8,85 & 1,34 & 9,16 & 1,15 & 4,943 & 0,027 & 2,804 & 0,005 \\
\hline $\begin{array}{l}\text { La empatía es una actitud indispensable para } \\
\text { desarrollar dentro del equipo sanitario }\end{array}$ & 9,03 & 1,03 & 9,21 & 1,01 & 0,315 & 0,575 & 2,081 & 0,038 \\
\hline
\end{tabular}




\begin{tabular}{|c|c|c|c|c|c|c|c|c|}
\hline \multirow[t]{2}{*}{ Afirmaciones } & \multicolumn{2}{|c|}{$\begin{array}{l}\text { Unidades } \\
\text { pequeñas } \\
(n=352)\end{array}$} & \multicolumn{2}{|c|}{$\begin{array}{l}\text { Unidades } \\
\text { grandes } \\
(n=216)\end{array}$} & \multicolumn{2}{|c|}{ Prueba Levene } & \multirow[t]{2}{*}{$t$} & \multirow[t]{2}{*}{$p$} \\
\hline & Media & D.T. & Media & D.T. & $F$ & $p$ & & \\
\hline $\begin{array}{l}\text { La inteligencia emocional es necesaria ser } \\
\text { desarrollada en las enfermeras de UCI }\end{array}$ & 8,73 & 1,17 & 8,96 & 1,12 & 1,995 & 0,158 & 2,260 & 0,024 \\
\hline
\end{tabular}

Nota. Prueba t de Student (t). p valor: $p<0,05$.

A continuación, se detallan las puntuaciones totales de cada uno de los ámbitos, la total de cada sección y la total del cuestionario en función del tamaño de la UCl. En dos secciones, se encuentran diferencias significativas, siendo ambas en el mismo sentido. Las enfermeras de unidades grandes puntúan más el ámbito profesional y la puntuación de la parte B de la encuesta; este último hallazgo se podría esperar tras los datos de la tabla 48 (últimos 6 ítems). Observamos que las unidades grandes requieren de figuras docentes para la transmisión de habilidades, destrezas y conocimientos entre las distintas enfermeras, ver tabla 49.

Tabla 49. Valoración entre los ámbitos y las puntuaciones totales en función del tamaño de la UCI.

\begin{tabular}{|c|c|c|c|c|c|c|c|c|}
\hline \multirow[t]{2}{*}{ Afirmaciones } & \multicolumn{2}{|c|}{$\begin{array}{c}\text { Unidades } \\
\text { pequeñas } \\
(n=352)\end{array}$} & \multicolumn{2}{|c|}{$\begin{array}{l}\text { Unidades } \\
\text { grandes } \\
(n=216)\end{array}$} & \multicolumn{2}{|c|}{ Prueba Levene } & \multirow[t]{2}{*}{$\boldsymbol{t}$} & \multirow[t]{2}{*}{$p$} \\
\hline & Media & D.T. & Media & D.T. & $F$ & $p$ & & \\
\hline Puntuación ámbito clínico & 163,85 & 9,69 & 163,67 & 9,94 & 0,057 & 0,811 & 0,213 & 0,832 \\
\hline Puntuación ámbito profesional & 121,24 & 9,62 & 122,97 & 10,00 & 0,659 & 0,417 & 2,050 & 0,041 \\
\hline Puntuación ámbito de la gestión & 135,26 & 11,39 & 135,49 & 11,72 & 0,267 & 0,605 & 0,229 & 0,819 \\
\hline $\begin{array}{l}\text { Puntuación ámbito educativo y de } \\
\text { desarrollo }\end{array}$ & 46,44 & 5,78 & 46,58 & 6,07 & 2,297 & 0,130 & 0,264 & 0,792 \\
\hline Puntuación total parte $\mathrm{A}$ & 466,80 & 28,66 & 468,72 & 30,13 & 1,256 & 0,263 & 0,757 & 0,449 \\
\hline Puntuación total parte B & 105,63 & 9,31 & 108,11 & 8,96 & 0,038 & 0,846 & 3,129 & 0,002 \\
\hline Puntuación total encuesta & 572,43 & 35,32 & 576,83 & 36,13 & 0,313 & 0,576 & 1,428 & 0,154 \\
\hline
\end{tabular}

Nota. Prueba t de Student (t). $\mathbf{p}$ valor: $p<0,05$.

En función de la experiencia laboral de las enfermeras.

En este punto cabe evaluar las necesidades formativas de las enfermeras según su experiencia laboral como enfermera de forma total. En un inicio se identificaron 7 grupos edatarios (tabla 10), para el presente análisis se fusionaron en 4 grupos ( $\leq 10$ años, 11-15 años, 16-20 años y >20 años), que representan el $23,9 \%$ (136), $22,9 \%(130), 21,8 \%$ (124) y $31,4 \%$ (178), respectivamente de la muestra nacional.

El análisis fue realizado mediante la prueba no paramétrica de Jonckeheere-Tepstra, de los 66 ítems del cuestionario 39 presentaban significación estadística. En el ámbito clínico se sigue el mismo paralelismo que observamos en los grupos de edad, ya que las enfermeras con menos experiencia están más interesadas en aspectos técnicos y tecnológicos; sin embargo, las enfermeras de mayor experiencia laboral total se centran más en el cuidado y en la continuidad asistencial, ver tabla 50. 
Tabla 50. Diferencias significativas de la puntuación de cada ítem del ámbito clínico en función de la experiencia laboral total como enfermera.

\begin{tabular}{|c|c|c|c|c|}
\hline Ámbito clínico & $\begin{array}{l}\text { Estadístico } \\
\text { J-T }\end{array}$ & $\begin{array}{l}\text { Error } \\
\text { Típico }\end{array}$ & Prueba S & $p$ \\
\hline $\begin{array}{l}\text { Las enfermeras de } \mathrm{UCl} \text { deben desarrollar } \\
\text { habilidades específicas para la atención al paciente } \\
\text { crítico }\end{array}$ & 64358 & 1686,38 & 2,559 & 0,010 \\
\hline $\begin{array}{l}\text { La observación es una herramienta necesaria para } \\
\text { obtener datos en la valoración del paciente crítico }\end{array}$ & 66399 & 1812,33 & 3,508 & $<0,001$ \\
\hline $\begin{array}{l}\text { La monitorización es una herramienta fundamental } \\
\text { para obtener datos para la valoración del paciente } \\
\text { crítico }\end{array}$ & 66211 & 1929,66 & 3,197 & 0,001 \\
\hline $\begin{array}{l}\text { El uso de escalas es necesarias para la valoración } \\
\text { del paciente crítico }\end{array}$ & 66009 & 2085,93 & 2,861 & 0,004 \\
\hline $\begin{array}{l}\text { La empatía y el respeto a la intimidad son } \\
\text { fundamentales para la enfermera de } \mathrm{UCl}\end{array}$ & 68149 & 1896,54 & 4,275 & $<0,001$ \\
\hline $\begin{array}{l}\text { Hay que involucrar al paciente y a la familia en el } \\
\text { proceso de recuperación }\end{array}$ & 65968,5 & 2078,33 & 2,852 & 0,004 \\
\hline $\begin{array}{l}\text { Observar, analizar e interpretar situaciones y/o } \\
\text { problemas en un paciente crítico es necesario para } \\
\text { realizar un examen físico }\end{array}$ & 65810 & 2048,87 & 2,815 & 0,050 \\
\hline $\begin{array}{l}\text { Las medidas de soporte son el pilar fundamental } \\
\text { de las actividades enfermeras }\end{array}$ & 55715 & 2111,24 & $-2,050$ & 0,040 \\
\hline $\begin{array}{l}\text { Las enfermeras de UCI deben estar formadas en la } \\
\text { atención de los distintos tipos de shock }\end{array}$ & 56269 & 1841,16 & $-2,049$ & 0,040 \\
\hline $\begin{array}{l}\text { El cálculo de fármacos y drogas es una } \\
\text { competencia imprescindible }\end{array}$ & 55549,5 & 1801,28 & $-2,494$ & 0,013 \\
\hline $\begin{array}{l}\text { El cuidado integral de un paciente crítico forma } \\
\text { parte de la actuación principal del profesional de } \\
\text { enfermería }\end{array}$ & 66158,5 & 1775,33 & 3,445 & 0,001 \\
\hline $\begin{array}{l}\text { La reevaluación continua es la principal medida } \\
\text { que debe implementar la enfermera para evaluar } \\
\text { estrategias de mejora en el plan de cuidados }\end{array}$ & 67962 & 2060,86 & 3,843 & $<0,001$ \\
\hline
\end{tabular}

Nota. Prueba de Jonckheere-Terpstra (Prueba S). p valor: $p<0,05$.

Las enfermeras con mayor experiencia laboral total puntúan el ámbito profesional, con mayores puntuaciones que los grupos constituidos por enfermeras con menor experiencia, siendo estadísticamente significativos 10 de los 14 ítems. Resulta llamativo, que las enfermeras con experiencia laboral total entre los rangos de experiencia laboral 16-20 años y 11-15 años, no tuvieron diferencias significativas al analizar cada ítem en las representaciones gráficas por parejas, ver tabla 51.

Tabla 51. Diferencias significativas de la puntuación de cada ítem del ámbito profesional en función de la experiencia laboral total como enfermera.

\begin{tabular}{|c|c|c|c|c|}
\hline Ámbito profesional & $\begin{array}{l}\text { Estadístico } \\
\qquad \text { J-T }\end{array}$ & $\begin{array}{l}\text { Error } \\
\text { Típico }\end{array}$ & Prueba S & $p$ \\
\hline $\begin{array}{l}\text { Ante situaciones complejas, la ayuda y el apoyo de } \\
\text { compañeros más experimentados ayudan a } \\
\text { resolver problemas }\end{array}$ & 65821,5 & 1882,00 & 3,071 & 0,002 \\
\hline $\begin{array}{l}\text { Las enfermeras pueden hacer frente a decisiones } \\
\text { complejas gracias a la experiencia laboral obtenida }\end{array}$ & 67520 & 2033,95 & 3,677 & $<0,001$ \\
\hline
\end{tabular}
en $\mathrm{UCl}$ 


\begin{tabular}{|c|c|c|c|c|}
\hline Ámbito profesional & $\begin{array}{l}\text { Estadístico } \\
\qquad \mathrm{J}-\mathrm{T}\end{array}$ & $\begin{array}{l}\text { Error } \\
\text { Típico }\end{array}$ & Prueba S & $p$ \\
\hline $\begin{array}{l}\text { La enfermera de UCl suele afrontar bien la decisión } \\
\text { de limitación de soporte vital (esfuerzo } \\
\text { terapéutico) }\end{array}$ & 67366 & 2126,26 & 3,445 & 0,001 \\
\hline $\begin{array}{l}\text { La enfermera debería participar en las decisiones } \\
\text { de limitación del soporte vital (esfuerzo } \\
\text { terapéutico) }\end{array}$ & 67964 & 2106,90 & 3,760 & $<0,001$ \\
\hline $\begin{array}{l}\text { La enfermera de UCl afronta peor el } \\
\text { encarnizamiento terapéutico }\end{array}$ & 67454,5 & 2062,35 & 3,594 & $<0,001$ \\
\hline $\begin{array}{l}\text { El lenguaje verbal y no verbal son fundamentales } \\
\text { en la comunicación en } \mathrm{UCl}\end{array}$ & 68718 & 2033,07 & 4,267 & $<0,001$ \\
\hline $\begin{array}{l}\text { En situaciones de estrés, las enfermeras se deben } \\
\text { comunicar de manera técnica, concisa y clara, } \\
\text { ajustando la información a las características del } \\
\text { interlocutor }\end{array}$ & 65655,5 & 2060,57 & 2,754 & 0,006 \\
\hline $\begin{array}{l}\text { Las principales herramientas de comunicación son } \\
\text { la asertividad, la empatía y la escucha activa tanto } \\
\text { con usuarios y familia como con profesionales }\end{array}$ & 67115,5 & 2048,03 & 3,454 & 0,001 \\
\hline $\begin{array}{l}\text { Las tecnologías de la información y comunicación } \\
\text { (TIC) son herramientas esenciales que permiten la } \\
\text { formación, el aprendizaje y el desarrollo de la } \\
\text { profesión }\end{array}$ & 67758,5 & 2102,99 & 3,669 & $<0,001$ \\
\hline $\begin{array}{l}\text { La comunicación escrita en } \mathrm{UCl} \text { se debe fomentar } \\
\text { siempre, pues es indispensable para la continuidad } \\
\text { de cuidados }\end{array}$ & 67061 & 2049,51 & 3,425 & 0,001 \\
\hline
\end{tabular}

Nota. Prueba de Jonckheere-Terpstra (Prueba S). p valor: $p<0,05$.

El ámbito de la gestión sigue la misma tendencia, ya que las enfermeras con mayor experiencia laboral total presentan diferencias significativas en comparación con los dos grupos de menor experiencia laboral. Este hecho implica que, las enfermeras con más experiencia valoran que las enfermeras de $\mathrm{UCl}$ deben tener más conocimientos, habilidades y destrezas en los distintos componentes de la gestión sanitaria, ver tabla 52.

Tabla 52. Diferencias significativas de la puntuación de cada ítem del ámbito de la gestión en función de la experiencia laboral total como enfermera.

\begin{tabular}{|c|c|c|c|c|}
\hline Ámbito de la gestión & $\begin{array}{l}\text { Estadístico } \\
\text { J-T }\end{array}$ & $\begin{array}{l}\text { Error } \\
\text { Típico }\end{array}$ & Prueba S & $p$ \\
\hline $\begin{array}{l}\text { El seguimiento de los cuidados que prestan las } \\
\text { enfermeras es indispensable para la continuidad } \\
\text { de cuidados }\end{array}$ & 69369 & 2071,83 & 2,908 & 0,004 \\
\hline $\begin{array}{l}\text { Registrar los cuidados prestados es la mejor } \\
\text { medida posible para garantizar la continuidad }\end{array}$ & 73585,5 & 2066,51 & 4,949 & $<0,001$ \\
\hline $\begin{array}{l}\text { Las enfermeras son capaces de planificar } \\
\text { actuaciones a lo largo del turno de trabajo }\end{array}$ & 71164,5 & 2111,31 & 3,698 & $<0,001$ \\
\hline $\begin{array}{l}\text { Las enfermeras que trabajan en } \mathrm{UCI} \text { recogen datos } \\
\text { relacionados con los indicadores de calidad }\end{array}$ & 69900,5 & 2235,4 & 2,927 & 0,003 \\
\hline $\begin{array}{l}\text { Se realiza un seguimiento de los indicadores de } \\
\text { calidad }\end{array}$ & 70532,5 & 2246,63 & 3,194 & 0,001 \\
\hline $\begin{array}{l}\text { Es necesaria una correcta formación para } \\
\text { garantizar la seguridad clínica }\end{array}$ & 68102,5 & 1987,43 & 2,388 & 0,017 \\
\hline $\begin{array}{l}\text { Los equipos asistenciales de } \mathrm{UCI} \text { son capaces de } \\
\text { realizar su trabajo en un ambiente de presión y } \\
\text { estrés }\end{array}$ & 69532 & 2114,11 & 2,880 & 0,004 \\
\hline
\end{tabular}




\section{Ámbito de la gestión}

Estadístico $\mathrm{J}-\mathrm{T}$

\section{Error}

Típico

$69883,5 \quad 2054,14$

3,177

0,001

adaptación de las enfermeras en las situaciones urgentes y emergentes

Evitar ruidos innecesarios o bajar el volumen de luces y alarmas son acciones que fomentan el descanso del paciente crítico

Se fomentan acciones para el adecuado confort y descanso de los pacientes

$\begin{array}{llll}75178,5 & 2074,40 & 5,699 & <0,001 \\ 67941,5 & 2281,82 & 2,063 & \mathbf{0 , 0 3 9}\end{array}$

Nota. Prueba de Jonckheere-Terpstra (Prueba S). p valor: $p<0,05$

En el ámbito educativo y de desarrollo, se observa como los aspectos destinados a la formación han sido puntuados más positivamente por las enfermeras con menor experiencia profesional total. Por otra parte, el profesional con mayor experiencia profesional total consideró que la acogida de nuevo personal es muy importante y debe ser realizada de manera progresiva, ver tabla 53.

Tabla 53. Diferencias significativas de la puntuación de cada ítem del ámbito educativo y de desarrollo en función de la experiencia laboral total como enfermera.

\begin{tabular}{|c|c|c|c|c|}
\hline Ámbito educativo y de desarrollo & $\begin{array}{l}\text { Estadístico } \\
\mathrm{J}-\mathrm{T}\end{array}$ & $\begin{array}{l}\text { Error } \\
\text { Típico }\end{array}$ & Prueba S & $p$ \\
\hline $\begin{array}{l}\text { La realización de esta formación depende de la } \\
\text { motivación de la enfermera }\end{array}$ & 59031,5 & 2142,34 & $-2,019$ & 0,043 \\
\hline $\begin{array}{l}\text { La acogida del personal de nueva incorporación } \\
\text { debe ser realizada lenta y progresivamente }\end{array}$ & 68190 & 2052,85 & 2,354 & 0,019 \\
\hline $\begin{array}{l}\text { La formación en } \mathrm{UCl} \text { se realiza sobre todo para el } \\
\text { cobro de incentivos, bolsas de empleo y } \\
\text { oposiciones }\end{array}$ & 58284,5 & 2251,11 & $-2,254$ & 0,024 \\
\hline
\end{tabular}

Nota. Prueba de Jonckheere-Terpstra (Prueba S). p valor: $p<0,05$.

El ámbito de dimensión y formación sigue la misma tendencia. Se observa que las enfermeras de mayor experiencia laboral puntuaron las afirmaciones con mayores puntuaciones en 5 de los 12 ítems que conforman la parte B del cuestionario, ver tabla 54.

Tabla 54. Diferencias significativas de la puntuación de cada ítem de la parte B de la encuesta en función de la experiencia laboral total como enfermera.

Ámbito de Dimensión y formación
$\begin{aligned} & \text { La enfermera de nueva incorporación debería } \\ & \text { J-T }\end{aligned}$




\begin{tabular}{|lccccc}
\hline \multicolumn{2}{|c}{ Ámbito de Dimensión y formación } & $\begin{array}{c}\text { Estadístico } \\
\text { J-T }\end{array}$ & $\begin{array}{c}\text { Error } \\
\text { Típico }\end{array}$ & Prueba S & $\boldsymbol{p}$ \\
\hline $\begin{array}{l}\text { La inteligencia emocional es necesaria de ser } \\
\text { desarrollada en las enfermeras de UCl }\end{array}$ & 67846,5 & 2164,01 & 3,074 & $\mathbf{0 , 0 3 8}$ \\
\hline
\end{tabular}

Nota. Prueba de Jonckheere-Terpstra (Prueba S). p valor: $p<0,05$.

La tabla 55 presenta los resultados de analizar, mediante la prueba de Jonckheere-Terpstra, cada uno los ámbitos en función de la experiencia laboral total. En el ámbito educativo y de desarrollo se observa que se puntuó sobre 46 de 60 puntos posibles, lo que representa más del $75 \%$ de la puntuación posible.

Tabla 55. Diferencias entre las puntuaciones de los distintos ámbitos y la experiencia laboral total como enfermera.

\begin{tabular}{|c|c|c|c|c|c|c|c|c|c|c|}
\hline \multirow[t]{2}{*}{ Ámbito } & \multicolumn{2}{|c|}{$\begin{array}{c}\leq 10 \text { años } \\
(n=136)\end{array}$} & \multicolumn{2}{|c|}{$\begin{array}{c}\begin{array}{c}11-15 \text { años } \\
(n=130)\end{array} \\
\end{array}$} & \multicolumn{2}{|c|}{$\begin{array}{c}\text { 16-20 años } \\
(\mathrm{n}=124)\end{array}$} & \multicolumn{2}{|c|}{$\begin{array}{l}>20 \text { años } \\
(n=178)\end{array}$} & \multirow[t]{2}{*}{ Prueba S } & \multirow[t]{2}{*}{$p$} \\
\hline & Media & D.T. & Media & D.T. & Media & D.T. & Media & D.T. & & \\
\hline Clínico & 165,52 & 9,09 & 163,70 & 9,18 & 164,14 & 9,76 & 164,53 & 10,65 & 2,144 & 0,032 \\
\hline Profesional & 120,09 & 8,46 & 120,80 & 9,37 & 121,48 & 9,60 & 124,37 & 10,72 & 4,203 & $<0,001$ \\
\hline Gestión & 133,50 & 10,75 & 134,20 & 10,74 & 133,52 & 11,14 & 138,89 & 12,13 & 4,340 & $<0,001$ \\
\hline $\begin{array}{l}\text { Educativo y de } \\
\text { desarrollo }\end{array}$ & 46,96 & 5,78 & 46,10 & 6,09 & 46,49 & 5,69 & 46,43 & 5,97 & 0,501 & 0,617 \\
\hline Parte A & 463,08 & 26,01 & 464,81 & 26,55 & 465,64 & 28,10 & 474,23 & 32,98 & 3,859 & $<0,001$ \\
\hline Formación & 105,95 & 7,88 & 105,78 & 9,83 & 105,92 & 8,85 & 108,08 & 9,93 & 2,682 & 0,007 \\
\hline Parte Total & 569,03 & 31,02 & 570,59 & 33,45 & 571,56 & 34,13 & 582,31 & 40,17 & 3,810 & $<0,001$ \\
\hline
\end{tabular}

Nota. Prueba de Jonckheere-Terpstra (Prueba S). p valor: $p<0,05$.

A continuación, y para identificar si la agrupación de los ámbitos sigue las mismas tendencias detectadas en los ítems de manera individual, realizamos los análisis gráficos post-hoc de las pruebas Jonckheere-Terpstra practicadas en la tabla anterior. Los rangos promedios analizados se encuentran debajo de cada grupo y observamos que las diferencias significativas entre las experiencias laborales de ambos extremos son las más marcadas.

En el ámbito clínico, la única diferencia con valor $p=0,013$ es relacionada entre las enfermeras veteranas y las de menor experiencia laboral total, ver figura 12 . 
Figura 12. Análisis de comparación por parejas entre ámbito clínico y experiencia profesional total.

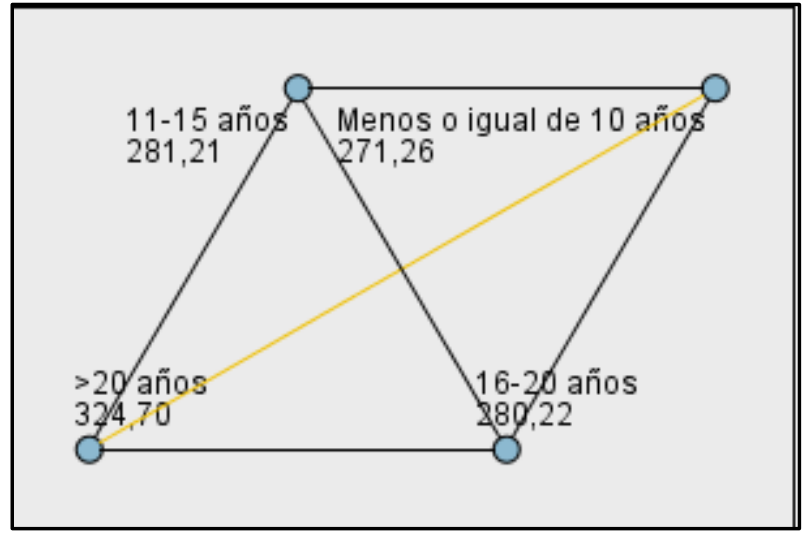

La figura 13, relacionada con el ámbito profesional, muestra que el grupo con mayor experiencia laboral total presenta diferencias significativas $(p \leq 0,001),(p=0,003)$ y $(p=0,021)$ respectivamente en los grupos en orden ascendente. Este hecho es particularmente interesante, en el ámbito de la gestión, en el que el grupo de $>20$ años mantiene diferencias significativas de $p \leq 0,001$ con los tres grupos restantes, lo mismo sucede cuando se evalúan ítems relacionados con calidad y seguridad clínica, ver figura 14.

Figura 13. Análisis de comparación por parejas entre ámbito profesional y experiencia profesional total.

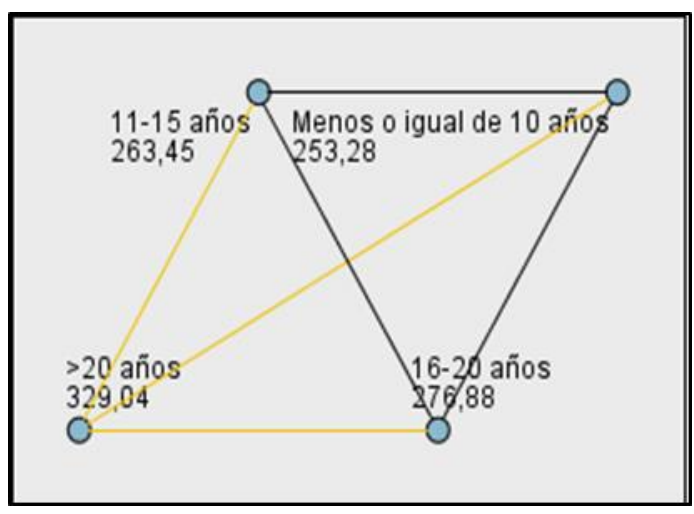

Figura 14. Análisis de comparación por parejas entre el ámbito de la gestión y experiencia profesional total.

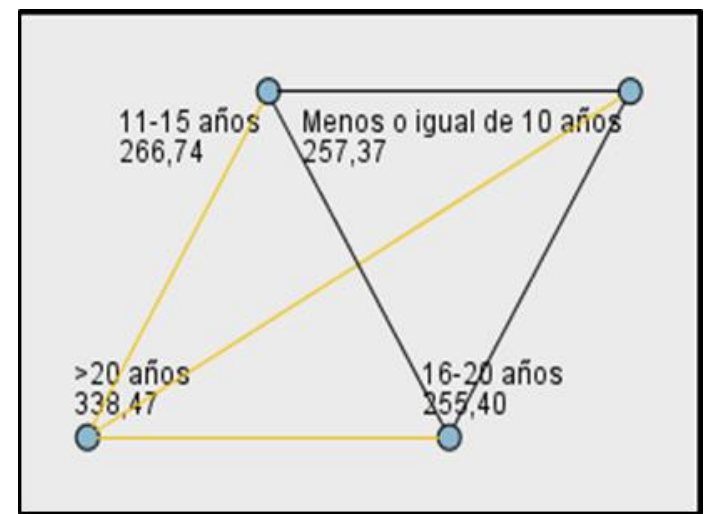

La figura 15 muestra, mediante diagrama de cajas, un incremento progresivo de los valores. En lo que se refiere, a las puntuaciones globales de cada una de las secciones del cuestionario y su encuesta total hallamos que, las enfermeras con mayor experiencia laboral tienen un rango promedio de 328,22 muy significativo con respecto a los otros grupos. Resultados significativos para el grupo $\leq 10$ años $(p \leq 0,001)$, para el grupo de $11-15$ años $(p=0,002)$ y para el grupo de $16-20$ años $(p=0,013)$, ver figura 16 . 
Figura 15. Diagrama de caja de la puntuación total parte $A$ y años de experiencia laboral total.

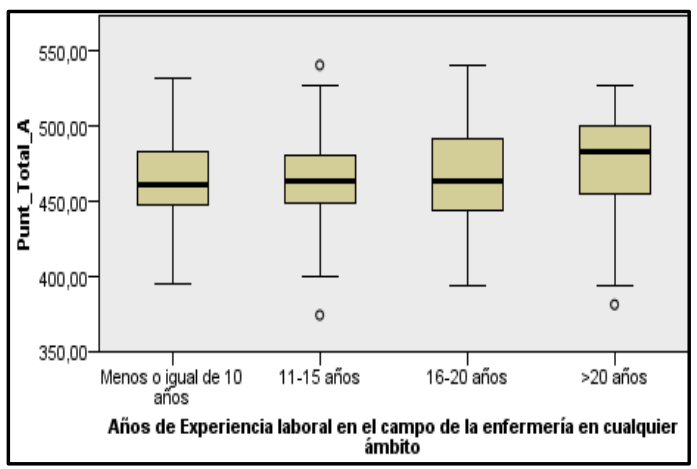

Figura 16. Análisis de comparación por parejas entre puntuación total parte A y experiencia laboral total.

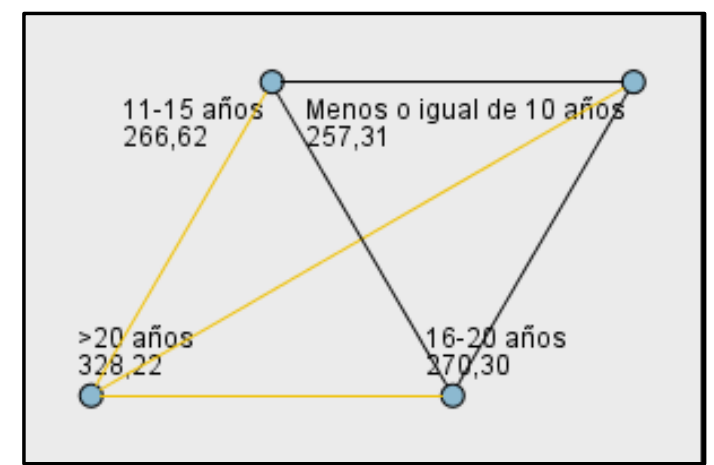

Como se observa en la figura 17, en la parte B de la encuesta (dimensiones y formación) no se obtuvo resultado significativo en la valoración entre el grupo de veteranos, y el grupo de 11-15 años. Si trabajamos con la puntuación total del cuestionario, estas diferencias siguen siendo marcadas entre un grupo y los restantes; con valores que oscilan entre $p \leq 0,001 ; p=0,003$ y $p=0,009$ tal y como se observa en la figura 18.

Figura 17. Análisis de comparación por parejas entre puntuación total parte B y experiencia laboral total.

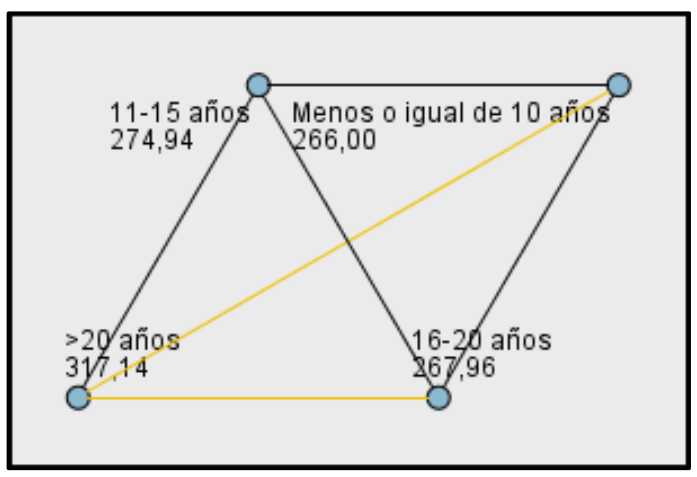

Figura 18. Análisis de comparación por parejas entre la puntuación total del cuestionario y la experiencia profesional total.

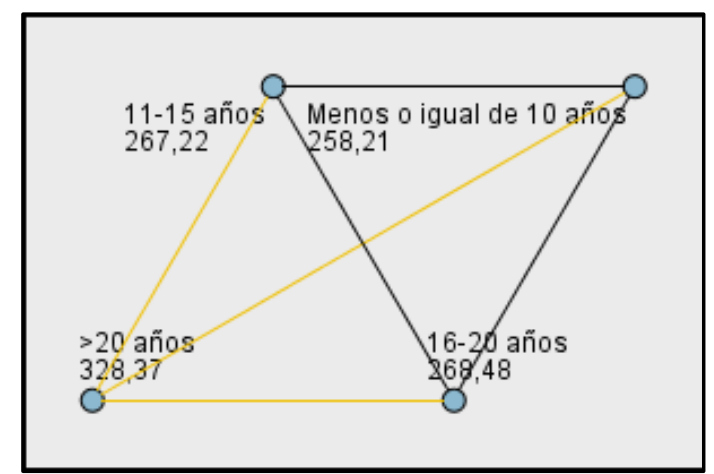

En función de la experiencia laboral como enfermera de UCI.

En este apartado resulta pertinente el análisis de la experiencia laboral en UCI. En este sentido, y por criterios de homogeneidad se agruparon también en 4 grupos de experiencia laboral en $\mathrm{UCl}$, con la intención de crear grupos homogéneos. Los datos de la tabla 11, fueron agrupados de la siguiente manera: $\leq 5$ años, 6-10 años, 11-15 años y >15 años. Estos grupos englobaban a $192(33,8 \%), 138$ $(24,3 \%), 96(16,9 \%)$ y $142(25,0 \%)$ enfermeras con experiencia laboral en UCI, respectivamente.

Los resultados de evaluar los 66 ítems del cuestionario según la experiencia laboral específica en UCI tienen un comportamiento similar al hallado al analizar la experiencia laboral total. En el ámbito 
clínico las diferencias afectan a los mismos 12 ítems y, en el mismo sentido. El grupo de $>15$ años es el que mayor diferencia significativa demuestra; sin embargo, el grupo de 11-15 años, también presenta diferencias en 4 ítems con los grupos más jóvenes. En este contexto parece que surge una diferencia en la valoración en el ámbito clínico con una experiencia en $\mathrm{UCl}$ que se va constituyendo en un eje vertebrador de las necesidades formativas a partir de los 10 años. Los 6 ítems no significativos se agrupan como áreas de fuertes consenso entre los distintos grupos, así cabe la pena señalar cuatro de ellos que son puntuados por todos los grupos con puntuaciones superiores al 90\%,como son: "las enfermeras de UCI deben tener conocimientos extensos de enfermería básica", "la integración e interrelación de datos es una habilidad muy importante de las enfermeras de UCl", "la capacidad de priorización es una habilidad imprescindible" y "el razonamiento clínico (qué pasa, y qué puede llegar a pasar) debe ser fomentado en las enfermeras de UCI". Ver tabla 56.

Tabla 56. Diferencias significativas de la puntuación de cada ítem del ámbito clínico en función de la experiencia laboral como enfermera de $\mathrm{UCI}$.

\begin{tabular}{|c|c|c|c|c|}
\hline Ámbito clínico & $\begin{array}{l}\text { Estadístico } \\
\qquad \mathrm{J}-\mathrm{T}\end{array}$ & $\begin{array}{l}\text { Error } \\
\text { Típico }\end{array}$ & Prueba S & $p$ \\
\hline $\begin{array}{l}\text { Las enfermeras de } \mathrm{UCl} \text { deben desarrollar } \\
\text { habilidades específicas para la atención al paciente } \\
\text { crítico }\end{array}$ & 63618 & 1680,47 & 2,549 & 0,011 \\
\hline $\begin{array}{l}\text { La observación es una herramienta necesaria para } \\
\text { obtener datos en la valoración del paciente crítico }\end{array}$ & 66634 & 1850,99 & 4,042 & $<0,001$ \\
\hline $\begin{array}{l}\text { La monitorización es una herramienta fundamental } \\
\text { para obtener datos para la valoración del paciente } \\
\text { crítico }\end{array}$ & 63929,5 & 1922,91 & 2,390 & 0,017 \\
\hline $\begin{array}{l}\text { El uso de escalas es necesarias para la valoración } \\
\text { del paciente crítico }\end{array}$ & 64058,5 & 2078,63 & 2,273 & 0,023 \\
\hline $\begin{array}{l}\text { La empatía y el respeto a la intimidad son } \\
\text { fundamentales para la enfermera de } \mathrm{UCl}\end{array}$ & 67116 & 1889,89 & 4,118 & $<0,001$ \\
\hline $\begin{array}{l}\text { Hay que involucrar al paciente y a la familia en el } \\
\text { proceso de recuperación }\end{array}$ & 63458,5 & 2071,05 & 1,992 & 0,046 \\
\hline $\begin{array}{l}\text { Observar, analizar e interpretar situaciones y/o } \\
\text { problemas en un paciente crítico es necesario para } \\
\text { realizar un examen físico }\end{array}$ & 63948,5 & 2041,69 & 2,260 & 0,024 \\
\hline $\begin{array}{l}\text { Las medidas de soporte son el pilar fundamental } \\
\text { de las actividades enfermeras }\end{array}$ & 54005 & 2103,84 & $-2,533$ & 0,011 \\
\hline $\begin{array}{l}\text { Las enfermeras de } \mathrm{UCl} \text { deben estar formadas en la } \\
\text { atención de los distintos tipos de shock }\end{array}$ & 54963 & 1834,72 & $-2,382$ & 0,017 \\
\hline $\begin{array}{l}\text { El cálculo de fármacos y drogas es una } \\
\text { competencia imprescindible }\end{array}$ & 54764 & 1794,97 & $-2,546$ & 0,011 \\
\hline $\begin{array}{l}\text { El cuidado integral de un paciente crítico forma } \\
\text { parte de la actuación principal del profesional de } \\
\text { enfermería }\end{array}$ & 65312,5 & 1769,11 & 3,379 & 0,001 \\
\hline $\begin{array}{l}\text { La reevaluación continua es la principal medida } \\
\text { que debe implementar la enfermera para evaluar } \\
\text { estrategias de mejora en el plan de cuidados }\end{array}$ & 66516 & 2053,64 & 3,497 & $<0,001$ \\
\hline
\end{tabular}

Nota. Prueba de Jonckheere-Terpstra (Prueba S). p valor: $p<0,05$.

Los 10 ítems del ámbito profesional significativos son los mismos encontrados en la experiencia laboral total. Su relación es significativa entre el grupo de $>15$ años y los $\leq 5$ años de experiencia en $\mathrm{UCl}$, esto es así en todos menos en los relacionados con la muerte que se halla diferencias significativas entre el grupo de 11-15 años y el de menor experiencia laboral. El grupo de 6-10 años sólo demuestra diferencias significativas con puntuaciones menores respecto al grupo de mayor 
experiencia laboral en $\mathrm{UCl}$ en las siguientes variables: "la comunicación escrita en $\mathrm{UCl}$ se debe fomentar siempre, pues es indispensable para la continuidad de cuidados", "las principales herramientas de comunicación son la asertividad, la empatía y la escucha activa tanto con usuarios y familia como con profesionales" y "el lenguaje verbal y no verbal son fundamentales en la comunicación de UCI".

De los 4 valores no significativos hay que destacar dos ítems: "las decisiones del cuidado son muy complejas y requieren una formación extensa" y "las enfermeras de UCl tienen mucha autonomía, por lo que es necesario una formación reglada y adecuada al puesto de trabajo"; dichos ítems puntúan en todos los grupos de experiencia laboral en UCI con valores próximos a 9, lo que representa un elevado nivel de consenso, ver tabla 57.

Tabla 57. Diferencias significativas de la puntuación de cada ítem del ámbito profesional en función de la experiencia laboral como enfermera de UCl.

\begin{tabular}{|c|c|c|c|c|}
\hline Ámbito profesional & $\begin{array}{l}\text { Estadístico } \\
\text { J-T }\end{array}$ & $\begin{array}{l}\text { Error } \\
\text { Típico }\end{array}$ & Prueba S & $p$ \\
\hline $\begin{array}{l}\text { Ante situaciones complejas, la ayuda y el apoyo de } \\
\text { compañeros más experimentados ayudan a } \\
\text { resolver problemas }\end{array}$ & 64915,5 & 1875,41 & 2,976 & 0,003 \\
\hline $\begin{array}{l}\text { Las enfermeras pueden hacer frente a decisiones } \\
\text { complejas gracias a la experiencia laboral obtenida } \\
\text { en UCI }\end{array}$ & 64992,5 & 2026,83 & 2,792 & 0,005 \\
\hline $\begin{array}{l}\text { La enfermera de UCI suele afrontar bien la } \\
\text { decisión de limitación de soporte vital (esfuerzo } \\
\text { terapéutico) }\end{array}$ & 65354 & 2118,82 & 2,841 & 0,004 \\
\hline $\begin{array}{l}\text { La enfermera debería participar en las decisiones } \\
\text { de limitación del soporte vital (esfuerzo } \\
\text { terapéutico) }\end{array}$ & 69645 & 2099,52 & 4,911 & $<0,001$ \\
\hline $\begin{array}{l}\text { La enfermera de UCl afronta peor el } \\
\text { encarnizamiento terapéutico }\end{array}$ & 68643,5 & 2055,12 & 4,503 & $<0,001$ \\
\hline $\begin{array}{l}\text { El lenguaje verbal y no verbal son fundamentales } \\
\text { en la comunicación en } \mathrm{UCl}\end{array}$ & 67261,5 & 2025,96 & 3,913 & $<0,001$ \\
\hline $\begin{array}{l}\text { En situaciones de estrés, las enfermeras se deben } \\
\text { comunicar de manera técnica, concisa y clara, } \\
\text { ajustando la información a las características del } \\
\text { interlocutor }\end{array}$ & 63775,5 & 2053,35 & 2,163 & 0,031 \\
\hline $\begin{array}{l}\text { Las principales herramientas de comunicación son } \\
\text { la asertividad, la empatía y la escucha activa tanto } \\
\text { con usuarios y familia como con profesionales }\end{array}$ & 67043,5 & 2040,86 & 3,778 & $<0,001$ \\
\hline $\begin{array}{l}\text { Las tecnologías de la información y comunicación } \\
\text { (TIC) son herramientas esenciales que permiten la } \\
\text { formación, el aprendizaje y el desarrollo de la } \\
\text { profesión }\end{array}$ & 65028,5 & 2095,62 & 2,717 & 0,007 \\
\hline $\begin{array}{l}\text { La comunicación escrita en } \mathrm{UCl} \text { se debe fomentar } \\
\text { siempre, pues es indispensable para la continuidad } \\
\text { de cuidados }\end{array}$ & 67131,5 & 2042,34 & 3,818 & $<0,001$ \\
\hline
\end{tabular}

Nota. Prueba de Jonckheere-Terpstra (Prueba S). p valor: $p<0,05$

Al analizar el ámbito de la gestión se hallaron diferencias significativas entre los grupos, en 8 de los 16 ítems que componen este ámbito. Se sigue una tendencia similar a la presentada en la experiencia laboral total. Las diferencias estadísticas son en todos los casos entre el grupo de $>15$ años y los dos grupos más jóvenes. Sólo en dos casos la diferencia se establece entre el grupo más veterano y el 
más joven. Es de destacar que dentro de las áreas de consenso entre los grupos de edad, en este ámbito de la gestión, hay dos afirmaciones que siguen una tendencia homogénea, como es "las enfermeras de $\mathrm{UCl}$ deben ser capaces de actuar rápidamente ante el deterioro del usuario y ante eventos adversos" con unas puntuaciones de todos los grupos de experiencia laboral en UCl sobre el 9,5 y en el lado contrario, "se gestiona adecuadamente la carga de trabajo de las enfermeras de UCl" siendo este el único elemento puntuado por todos los grupos sobre 5,5; además, el único ítem que presentó una puntuación inferior a 6 . Ver tabla 58.

Tabla 58.Diferencias significativas de la puntuación de cada ítem del ámbito de la gestión en función de la experiencia laboral como enfermera de $\mathrm{UCI}$.

\begin{tabular}{|c|c|c|c|c|}
\hline Ámbito de la gestión & $\begin{array}{l}\text { Estadístico } \\
\text { J-T }\end{array}$ & $\begin{array}{l}\text { Error } \\
\text { Típico }\end{array}$ & Prueba S & $p$ \\
\hline $\begin{array}{l}\text { El seguimiento de los cuidados que prestan las } \\
\text { enfermeras es indispensable para la continuidad } \\
\text { de cuidados }\end{array}$ & 64034,5 & 1987,61 & 2,365 & 0,018 \\
\hline $\begin{array}{l}\text { Registrar los cuidados prestados es la mejor } \\
\text { medida posible para garantizar la continuidad }\end{array}$ & 67965 & 1979,63 & 4,360 & $<0,001$ \\
\hline $\begin{array}{l}\text { Las enfermeras son capaces de planificar } \\
\text { actuaciones a lo largo del turno de trabajo }\end{array}$ & 67316 & 2020,16 & 3,951 & $<0,001$ \\
\hline $\begin{array}{l}\text { Se realiza un seguimiento de los indicadores de } \\
\text { calidad }\end{array}$ & 64781,5 & 2152,36 & 2,531 & 0,011 \\
\hline $\begin{array}{l}\text { Es necesaria una correcta formación para } \\
\text { garantizar la seguridad clínica }\end{array}$ & 63921 & 1907,94 & 2,404 & 0,016 \\
\hline $\begin{array}{l}\text { Los equipos asistenciales de } \mathrm{UCl} \text { son capaces de } \\
\text { realizar su trabajo en un ambiente de presión y } \\
\text { estrés }\end{array}$ & 67268 & 2056,49 & 3,858 & $<0,001$ \\
\hline $\begin{array}{l}\text { En una UCl es fundamental la capacidad de } \\
\text { adaptación de las enfermeras en las situaciones } \\
\text { urgentes y emergentes }\end{array}$ & 64675,5 & 1968,89 & 2,714 & 0,007 \\
\hline $\begin{array}{l}\text { Evitar ruidos innecesarios o bajar el volumen de } \\
\text { luces y alarmas son acciones que fomentan el } \\
\text { descanso del paciente crítico }\end{array}$ & 71210 & 1990,14 & 5,967 & $<0,001$ \\
\hline
\end{tabular}

Nota. Prueba de Jonckheere-Terpstra (Prueba S). p valor: $p<0,05$.

En el ámbito educativo y de desarrollo sólo un ítem generó diferencias significativas. En este caso fue el grupo de 6-10 años, el que mostró una puntuación mayor y generó diferencias sólo con el grupo de 11-15 años. Los resultados no significativos indicaban que todas las enfermeras consideraban que la formación repercutía positivamente a nivel clínico con valores en torno a 9,2; lo que indicó un fuerte consenso. En el lado opuesto, notamos una puntuación muy crítica con las instituciones sanitarias y su colaboración con la formación específica de las enfermeras de $\mathrm{UCl}$, con valores cercanos a 6. En este sentido, el grupo de entre 11-15 años mostró un valor medio en esta afirmación muy bajo $(4,92)$, ver tabla 59 .

Tabla 59. Diferencias significativas de la puntuación de cada ítem del ámbito educativo y de desarrollo en función de la experiencia laboral como enfermera de UCl.

\begin{tabular}{|l|cccc|}
\hline \multicolumn{1}{|c|}{ Ámbito educativo y de desarrollo } & $\begin{array}{c}\text { Estadístico } \\
\text { J-T }\end{array}$ & $\begin{array}{c}\text { Error } \\
\text { Típico }\end{array}$ & Prueba S & $p$ \\
\hline $\begin{array}{l}\text { La realización de esta formación depende de la } \\
\text { motivación de la enfermera }\end{array}$ & 55199 & 2053,13 & $-2,014$ & $\mathbf{0 , 0 4 4}$ \\
\hline
\end{tabular}

Nota. Prueba de Jonckheere-Terpstra (Prueba S). p valor: $p<0,05$. 
En la parte B del cuestionario, podemos observar como se mantiene la tendencia del ser el grupo de mayor experiencia profesional el que mejor puntuó cada ítem. Llama la atención que el personal veterano considera que a las enfermeras noveles se les exijan conocimientos previos antes de comenzar a trabajar en UCl; sin embargo, las enfermeras más jóvenes no lo consideran necesario. En los otros dos ítems significativos se observó que los dos grupos de enfermeras con menor experiencia profesional ( $\geq 5$ años y 6-10 años) puntuaron estas afirmaciones con menores valores que las enfermeras más veteranas. En cuanto a los ítems no significativos, se observó que las enfermeras de $\geq 5$ años eran las que consideraban más necesaria la presencia de un enfermero tutor, con valor medio $(9,58)$. Resulta relevante para el presente trabajo que haya unanimidad entre los grupos analizados en relación con la solicitud de una formación específica para proveer los mejores resultados. Ver tabla 60.

Tabla 60. Diferencias significativas de la puntuación de cada ítem de las dimensiones y formación en función de la experiencia laboral como enfermera de UCI.

\begin{tabular}{|c|c|c|c|c|}
\hline Ámbito de Dimensión y formación & $\begin{array}{l}\text { Estadístico } \\
\quad \mathrm{J}-\mathrm{T}\end{array}$ & $\begin{array}{l}\text { Error } \\
\text { Típico }\end{array}$ & Prueba S & $p$ \\
\hline $\begin{array}{l}\text { La enfermera de nueva incorporación debería tener } \\
\text { conocimientos hemodinámicos, de ventilación } \\
\text { mecánica, reanimación cardiopulmonar básica y } \\
\text { avanzada, además de monitorización }\end{array}$ & 66558 & 2042,59 & 3,547 & $<0,001$ \\
\hline $\begin{array}{l}\text { Son habilidades para desarrollar por las enfermeras de } \\
\mathrm{UCI} \text {, la calma, ser metódico y resolutivas }\end{array}$ & 66133,5 & 2055,28 & 3,308 & 0,001 \\
\hline $\begin{array}{l}\text { La inteligencia emocional es necesaria de ser } \\
\text { desarrollada en las enfermeras de } \mathrm{UCl}\end{array}$ & 63669,5 & 2073,21 & 2,091 & 0,037 \\
\hline
\end{tabular}

Nota. Prueba de Jonckheere-Terpstra (Prueba S). p valor: $p<0,05$.

La tabla 61, mediante la prueba de Jonckheere-Terpstra, presenta las diferencias significativas a la hora de valorar los ítems agrupados en función de la experiencia laboral como enfermera UCI. En las 7 agrupaciones realizadas hay 5 con diferencias significativas con la misma tendencia a favor del grupo de mayor experiencia laboral en UCl, ver tabla 61.

Tabla 61. Prueba de Jonckheere-Terpstra de las distintas secciones y puntuaciones globales en función de la experiencia profesional como enfermera de $\mathrm{UCl}$.

\begin{tabular}{|c|c|c|c|c|c|c|c|c|c|c|}
\hline \multirow[t]{2}{*}{ Ámbito } & \multicolumn{2}{|c|}{$\begin{array}{l}\leq 5 \text { años } \\
\text { ( } n=192)\end{array}$} & \multicolumn{2}{|c|}{ 6-10 años (n=138) } & \multicolumn{2}{|c|}{$11-15$ años $(n=96)$} & \multicolumn{2}{|c|}{$\begin{array}{c}>15 \text { años } \\
(n=142)\end{array}$} & \multirow{2}{*}{$\begin{array}{c}\text { Prueba } \\
S\end{array}$} & \multirow[t]{2}{*}{$p$} \\
\hline & Media & D.T. & Media & D.T. & Media & D.T. & Media & D.T. & & \\
\hline Clínico & 163,11 & 8,69 & 164,05 & 10,39 & 163,29 & 10,04 & 164,74 & 10,36 & 1,761 & 0,078 \\
\hline Profesional & 120,26 & 9,25 & 121,43 & 8,85 & 121,85 & 10,57 & 124,60 & 10,36 & 4,071 & $<0,001$ \\
\hline Gestión & 134,14 & 10,75 & 134,30 & 12,09 & 133,60 & 11,24 & 139,20 & 11,35 & 3,763 & $<0,001$ \\
\hline $\begin{array}{l}\text { Educativo y de } \\
\text { desarrollo }\end{array}$ & 46,88 & 5,86 & 46,57 & 5,54 & 44,97 & 6,17 & 46,95 & 5,95 & $-0,475$ & 0,635 \\
\hline Parte A & 464,40 & 26,58 & 466,35 & 29,78 & 463,72 & 27,69 & 475,49 & 31,77 & 3,377 & 0,001 \\
\hline Formación & 105,92 & 9,05 & 106,51 & 9,25 & 106,10 & 8,46 & 107,82 & 9,98 & 1,959 & 0,051 \\
\hline Parte Total & 570,32 & 32,64 & 572,86 & 36,87 & 569,82 & 33,28 & 583,32 & 38,54 & 3,345 & 0,001 \\
\hline
\end{tabular}

Nota. Prueba de Jonckheere-Terpstra (Prueba S). p valor: $p<0,05$.

En el ámbito profesional, el grupo de más veteranos presenta en relación con los grupos de $\leq 5$ años, 6-10 años, diferencias significativas de $(p<0,001$ y $p=0,010)$ respectivamente. Resulta un hecho a 
resaltar que sea este grupo con gran experiencia laboral en $\mathrm{UCl}$, el que evalúa las necesidades de las enfermeras de una manera tan importante, ver figura 19.

Figura 19. Análisis de comparación por parejas del ámbito profesional en función de la experiencia laboral en UCl.

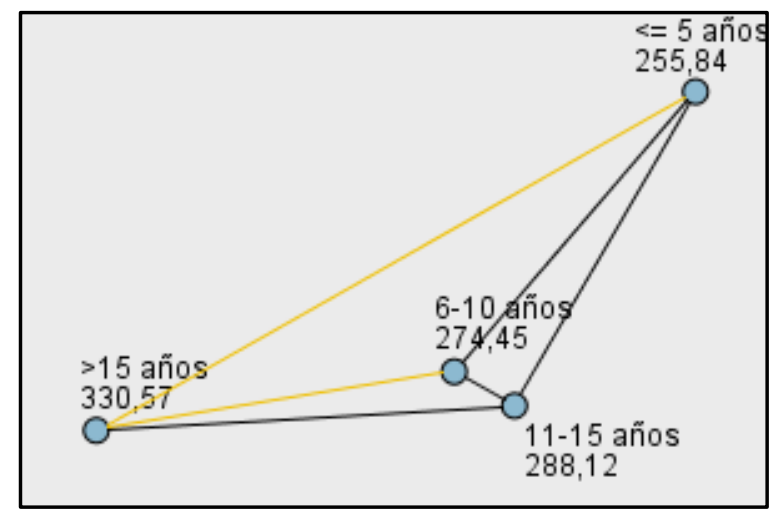

Como se puede observar en las figuras 20 y 21, en el ámbito de la gestión el grupo de veteranos genera diferencias significativas con los restantes grupos. En el grupo de $\leq 5$ años con $p$ valor menor de 0,001, en el grupo de 6-10 años $(p=0,002)$ y en el grupo de 11-15 años el $p$ valor es igual a 0,001. Una mayor experiencia profesional en $\mathrm{UCl}$ se podría traducir en una mayor conciencia de responsabilidad en el ámbito de la gestión sanitaria.

Figura 20. Análisis de comparación por parejas del ámbito de la gestión en función de la experiencia laboral en UCI.

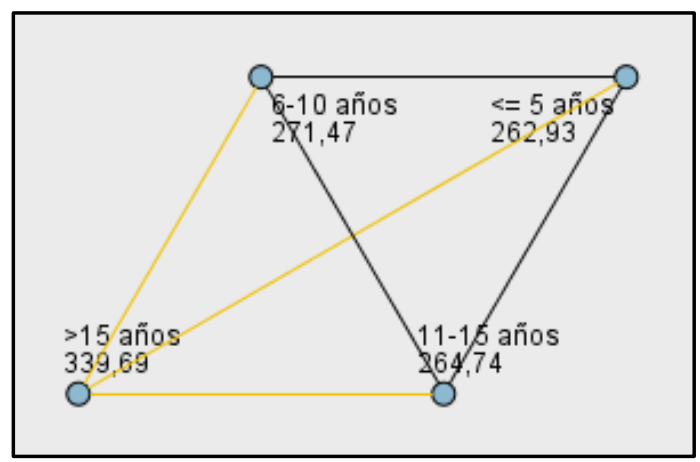

Figura 21. Diagrama de caja de la prueba Samples de Jonckheere-Terpstra del ámbito de la gestión en función de la experiencia laboral en $\mathrm{UCI}$.

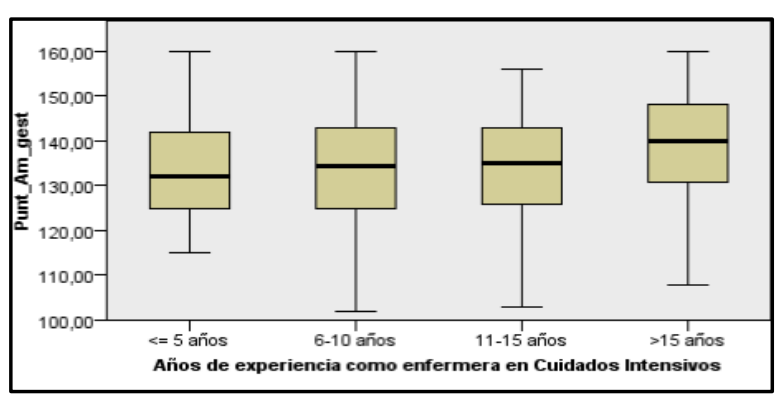

En la puntuación total de la parte $A$, encontramos que las diferencias entre los rangos medios de los grupos de experiencia laboral en $\mathrm{UCl}$, representan valores significativos $(p<0,001, p=0,023$ y $p=0,009$ ) en sentido ascendente de los grupos de experiencia laboral en $\mathrm{UCl}$, ver figura 22. 
Figura 22. Análisis de comparación por parejas de la puntuación total $A$ en función de la experiencia laboral en UCI.

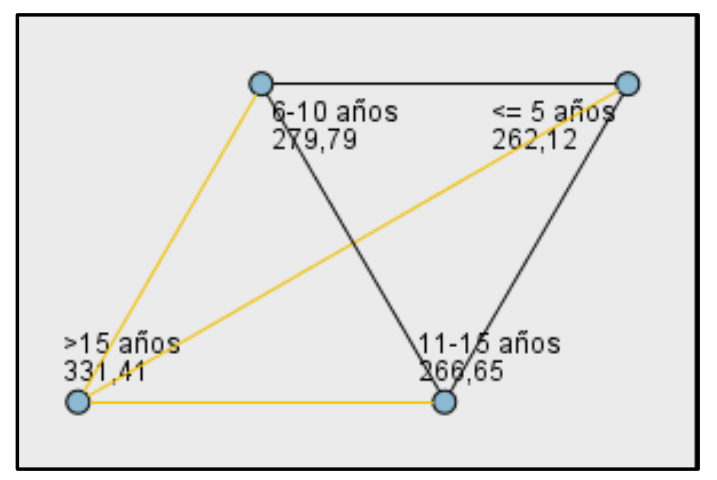

En esta misma forma, se observa en la puntuación total del cuestionario existen diferencias significativas $(p=0,001)$ con la comparación $\leq 5$ años $y>15$ años y de $(p=0,013)$ entre los grupos 11-15 años- $>15$ años, no habiendo diferencia significativa entre la pareja 6-10 años y >15 años. Ver figuras 23 y 24.

Figura 23. Diagrama de caja de la prueba Samples de Figura 24. Análisis de comparación por parejas de la Jonckheere-Terpstra de la puntuación total del puntuación total del cuestionario en función de la cuestionario en función de la experiencia laboral en experiencia laboral en UCI.

$\mathrm{UCl}$.
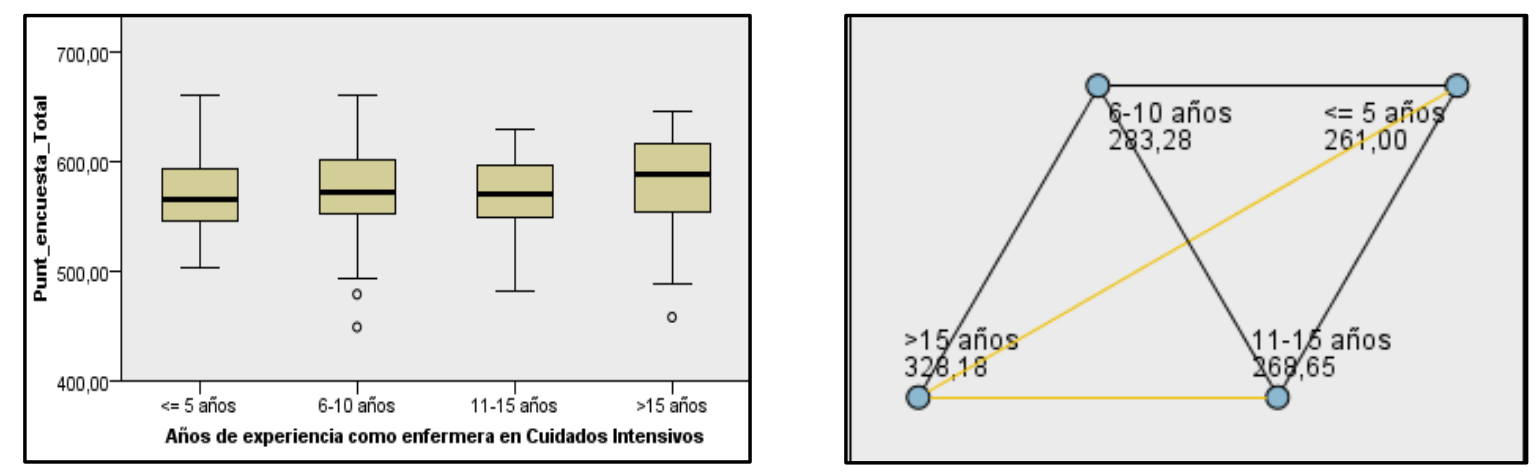

\subsubsection{Analizar la valoración de las enfermeras ante requisitos previos a la hora de comenzar la} labor profesional en UCI.

Un elemento que debe ser valorado son las cualidades de los profesionales enfermeros antes de poder abordar con seguridad su desempeño laboral efectivo en un área específica. Así de las 568 enfermeras encuestadas a nivel nacional, a la pregunta "Según su opinión, para empezar a trabajar en $\mathrm{UCl}$ es preciso tener alguna experiencia o formación previa", el 91,2\% de ellas respondieron que sí era preciso una formación y/o experiencia previa, esto significó que únicamente 50 enfermeras consideraron que no era preciso ninguna experiencia ni formación previo acceso a $\mathrm{UCI}$. De estas 50 
enfermeras, es necesario remarcar que 35 de ellas tenían menos de 10 años de experiencia laboral en UCl ( $21 \leq 5$ años y 14 entre 6-10 años) lo que representó el $70 \%$ de las contestaciones negativas.

Se valoró de manera distinta, la experiencia laboral en servicios parecidos como (quirófano y urgencias) y distintos como los servicios de hospitalización. Estas preguntas pudieron ser contestadas por 518 enfermeras que contestaron a la pregunta inicial afirmativamente.

Cómo se observa en la tabla 62, una experiencia en ambos tipos de servicios enfermeros de 1 año, es la opción más valorada en cada caso. La experiencia de 1 año en urgencias y/o quirófano se consideró la mejor valorada con un porcentaje del 64,45\%. En lo referente a la experiencia en hospitalización las opciones inferiores a 2 años de experiencia aglutinaron la mayoría de las respuestas con el $78,76 \%$, ver tabla 62 . Hay que destacar que de las enfermeras que podían contestar esta pregunta condicional, no contestaron $74(14,28 \%)$ a la experiencia laboral previa en urgencias y/o quirófano, siendo sólo 5 las que no contestaron la pregunta de experiencia laboral previa en hospitalización.

Tabla 62. Frecuencias de opinión frente a requisitos previos de experiencia laboral.

\begin{tabular}{|c|c|c|c|c|c|}
\hline & Frecuencia & $\begin{array}{c}\text { Porcentaje } \\
\text { (\%) }\end{array}$ & & Frecuencia & $\begin{array}{c}\text { Porcentaje } \\
\text { (\%) }\end{array}$ \\
\hline $\begin{array}{l}\text { Experiencia laboral en } \\
\text { urgencias y/o quirófano de } \\
\text { al menos } 1 \text { año }\end{array}$ & 339 & 65,45 & $\begin{array}{l}\text { Experiencia laboral en } \\
\text { hospitalización de al } \\
\text { menos } 1 \text { año }\end{array}$ & 220 & 42,47 \\
\hline $\begin{array}{l}\text { Experiencia laboral en } \\
\text { urgencias y/o quirófano de } \\
\text { al menos } 2 \text { años }\end{array}$ & 74 & 14,28 & $\begin{array}{l}\text { Experiencia laboral en } \\
\text { hospitalización de al } \\
\text { menos } 2 \text { años }\end{array}$ & 188 & 36,29 \\
\hline $\begin{array}{l}\text { Experiencia laboral en } \\
\text { urgencias y/o quirófano de } \\
\text { al menos } 3 \text { años }\end{array}$ & 12 & 2,32 & $\begin{array}{l}\text { Experiencia laboral en } \\
\text { hospitalización de al } \\
\text { menos } 3 \text { años }\end{array}$ & 66 & 12,74 \\
\hline $\begin{array}{l}\text { Experiencia laboral en } \\
\text { urgencias y/o quirófano de } \\
\text { al menos } 4 \text { años }\end{array}$ & 19 & 3,67 & $\begin{array}{l}\text { Experiencia laboral en } \\
\text { hospitalización de al } \\
\text { menos } 4 \text { años }\end{array}$ & 39 & 7,53 \\
\hline No contesta & 74 & 14,28 & No contesta & 5 & 0,97 \\
\hline Total & 518 & 100 & Total & 518 & 100 \\
\hline
\end{tabular}

Nota. Resultados expresados como frecuencias y porcentajes (\%).

Al solicitar la opinión de todos los participantes $(n=568)$ en cuanto a "¿Qué formación mínima previa sería aconsejable antes de comenzar a trabajar en UCI?" observamos que hay dos opciones que agrupan un mayor porcentaje de respuestas. La primera de ellas, son los planes de acogida de las propias unidades $(39,97 \%)$ de los encuestados y el segundo, es la formación mediante experto universitarios con un $25,35 \%$. Obsérvese que en este caso las enfermeras que contestaron que no era necesaria ninguna formación fueron 45 , siendo 5 menos que las 50 que no consideraron solicitar ningún tipo de experiencia labora previa. Por tanto, hubo más enfermeras que solicitaron formación previa 523 frente a las 518 que pedían experiencia laboral previa. Ver tabla 63. 
Tabla 63. Formación previa aconsejable antes de comenzar a trabajar en UCI.

\begin{tabular}{lcc}
\hline Items (n=568) & Frecuencia & $\begin{array}{c}\text { Porcentaje } \\
\text { (\%) }\end{array}$ \\
\hline $\begin{array}{l}\text { Formación de post-grado con créditos de formación continuada de } \\
\text { las profesiones sanitarias }\end{array}$ & 70 & 12,32 \\
\hline $\begin{array}{l}\text { Formación de post-grado en forma de experto universitario (con } \\
\text { prácticas incluidas) }\end{array}$ & 144 & 25,35 \\
$\begin{array}{l}\text { Formación de post-grado en forma de máster universitario (con } \\
\text { prácticas incluidas) }\end{array}$ & 82 & 14,44 \\
$\begin{array}{l}\text { Formación de post-grado mediante planes de acogida de las } \\
\text { propias unidades }\end{array}$ & 227 & 39,97 \\
$\begin{array}{l}\text { No es necesaria ninguna formación extra, salvo la proporcionada } \\
\text { en los estudios de enfermería. }\end{array}$ & 45 & 7,92 \\
\hline
\end{tabular}

Nota. Resultados expresados como frecuencias y porcentajes (\%).

Por lo tanto, 297 encuestados solicitaron una formación previa en las propias instituciones sanitarias lo que representó el 56,78\% de las respuestas; por el contrario, el 43,21\% (226) enfermeras solicitaron una formación previa en el contexto universitario.

Este hecho se relacionó con la pregunta "según su opinión, ¿sería aconsejable una formación especializada tipo EIR, para trabajar en UCI?". Es destacable que 426 de las 568 enfermeras consultadas a nivel nacional (75\%) del total consideraron que era necesaria una especialización de enfermería en cuidados críticos, ver figura 25.

Figura 25. Necesidad de formación especializada tipo EIR para las enfermeras de $\mathrm{UCl}$.

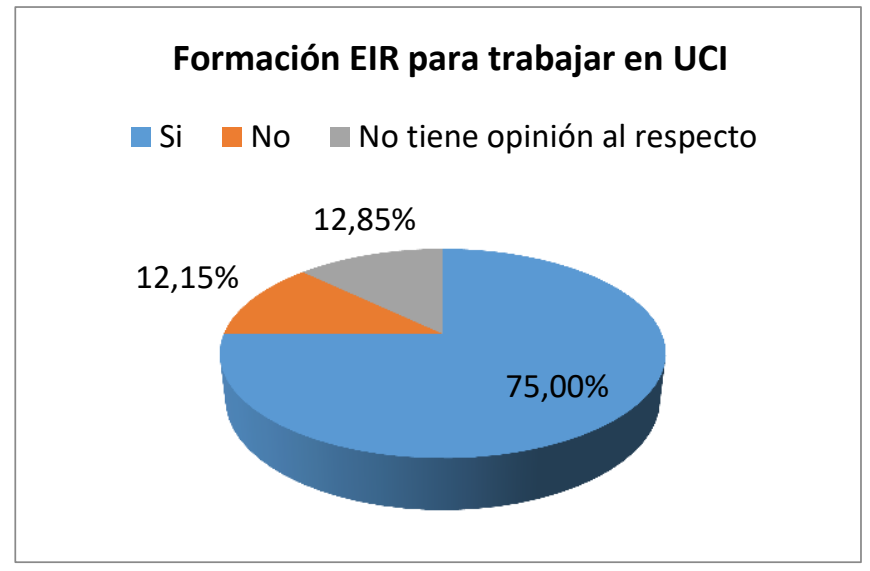

Al analizar las necesidades de formación con las características de las unidades donde se trabajaba no se halló ningún resultado significativo, pero si se observaron diferencias con el nivel de estudios de las enfermeras. La prueba de Chi-Cuadrado mostró asociación entre el nivel académico alcanzado y la necesidad de contar con una formación sanitaria especializada para trabajar en UCl. Curiosamente el $12,85 \%$ (42) de las enfermeras encuestadas no tenían opinión al respecto. Al contrario de lo que se pueda pensar, la edad, el sexo, la experiencia laboral total y la experiencia laboral en UCI no fueron factores influyentes, ya que de las 73 enfermeras sin opinión 38 tenían más de 40 años, lo que representó el $52 \%$ de las enfermeras sin opinión formada. 
Tabla 64.Tabla de contingencia entre necesidad formación tipo EIR y máximo nivel académico alcanzado.

\begin{tabular}{|c|c|c|c|c|c|}
\hline \multirow[b]{2}{*}{ Items ( $n=568)$} & & \multicolumn{4}{|c|}{ Máximo nivel académico alcanzado } \\
\hline & & Grado & $\begin{array}{c}\text { Experto } \\
\text { Universitario }\end{array}$ & $\begin{array}{l}\text { Máster como } \\
\text { título propio de } \\
\text { Universidad }\end{array}$ & $\begin{array}{c}\text { Postgrado } \\
\text { oficial }\end{array}$ \\
\hline \multirow{3}{*}{$\begin{array}{l}\text { Según su opinión. ¿Sería } \\
\text { aconsejable una formación } \\
\text { especializada sanitaria tipo EIR } \\
\text { para trabajar en UCI? }\end{array}$} & $\mathrm{Si}$ & 207 & 77 & 76 & 66 \\
\hline & No & 47 & 7 & 8 & 7 \\
\hline & $\begin{array}{l}\text { No tiene } \\
\text { opinión al } \\
\text { respecto }\end{array}$ & 42 & 11 & 6 & 14 \\
\hline
\end{tabular}

Nota: Chi-Cuadrado de Pearson $=13,647$ con 6 grados de libertad. $p=0,034$

Resulta interesante la percepción de aquellas enfermeras que no consideran necesaria ninguna experiencia o formación previa para comenzar a trabajar en $\mathrm{UCl}$, pero si consideran necesaria una formación tipo EIR. Sería interesante conocer qué razones fundamentan este resultado y para ello se combinaron estos hallazgos con las necesidades formativas previas a comenzar a trabajar en $\mathrm{UCl}$ y la experiencia laboral mediante una tabla de contingencia, ver tabla 65.

Tabla 65. Tabla de contingencia entre necesidad formación tipo EIR y experiencia o formación previa a comenzar a trabajar en $\mathrm{UCl}$.

\begin{tabular}{cccc} 
Items ( $\mathbf{n = 5 6 8 )}$ & $\begin{array}{l}\text { Según su opinión, para empezar a trabajar en UCI } \\
\text { es preciso tener algún tipo de experiencia o } \\
\text { formación previa }\end{array}$ \\
\cline { 2 - 3 } $\begin{array}{c}\text { Según su opinión. ¿Sería } \\
\text { aconsejable una formación } \\
\text { especializada sanitaria tipo EIR } \\
\text { para trabajar en UCl? }\end{array}$ & $\begin{array}{c}\text { No tiene opinión } \\
\text { al respecto }\end{array}$ & 400 & 26 \\
\hline
\end{tabular}

Nota: Chi-Cuadrado de Pearson= 15,508 con 2 grados de libertad. $p<0,001$

Por lo que debemos valorar que existe asociación entre la necesidad de formación tipo EIR, y tener formación previa; adquirida tanto en el ámbito sanitario como en el ámbito universitario. Observamos un valor del Chi-Cuadrado de Pearson de 65,654 con 8 grados de libertad con una significancia estadística de 0,000; como se puede observar en la tabla 66 . 
Tabla 66. Tabla de contingencia entre necesidad formación tipo EIR y formación mínima previa antes de comenzar a trabajar en $\mathrm{UCl}$.

\begin{tabular}{|c|c|c|c|c|c|c|}
\hline \multirow[b]{2}{*}{ Items $(n=568)$} & & \multicolumn{5}{|c|}{$\begin{array}{l}\text { Según su opinión, ¿Qué formación mínima previa sería aconsejable antes de comenzar a } \\
\text { trabajar en UCI? }\end{array}$} \\
\hline & & $\begin{array}{l}\text { Formación de } \\
\text { postgrado } \\
\text { con créditos } \\
\text { de formación } \\
\text { continuada } \\
\text { de las } \\
\text { profesiones } \\
\text { sanitarias }\end{array}$ & $\begin{array}{l}\text { Formación de } \\
\text { postgrado en } \\
\text { forma de } \\
\text { expertos } \\
\text { universitario } \\
\text { (con prácticas } \\
\text { incluidas) }\end{array}$ & $\begin{array}{l}\text { Formación de } \\
\text { postgrado en } \\
\text { forma de } \\
\text { master } \\
\text { universitario } \\
\text { (con prácticas } \\
\text { incluidas) }\end{array}$ & $\begin{array}{l}\text { Formación } \\
\text { de } \\
\text { postgrado } \\
\text { mediante } \\
\text { planes de } \\
\text { acogida de } \\
\text { las propias } \\
\text { unidades }\end{array}$ & $\begin{array}{l}\text { No es necesario } \\
\text { ninguna formación } \\
\text { extra, salvo la } \\
\text { proporcionada en } \\
\text { los estudios de } \\
\text { enfermería }\end{array}$ \\
\hline $\begin{array}{l}\text { Según su } \\
\text { opinión. ¿Sería } \\
\text { aconsejable }\end{array}$ & Si & 42 & 124 & 75 & 167 & 18 \\
\hline $\begin{array}{l}\text { una formación } \\
\text { especializada } \\
\text { sanitaria tipo }\end{array}$ & No & 13 & 9 & 4 & 26 & 17 \\
\hline $\begin{array}{c}\text { EIR para } \\
\text { trabajar en } \\
\text { UCI? }\end{array}$ & $\begin{array}{l}\text { No tiene } \\
\text { opinión } \\
\text { al } \\
\text { respecto }\end{array}$ & 15 & 11 & 3 & 34 & 10 \\
\hline
\end{tabular}

Nota: Chi-Cuadrado de Pearson= 65,654 con 8 grados de libertad. $p<0,001$

Al ser preguntas condicionales hay que recordar que como se comentó en la tabla 62, esta asociación se realizó con los 518 que sí respondieron afirmativamente a la pregunta "Según su opinión, para empezar a trabajar en $\mathrm{UCl}$ es preciso tener algún tipo de experiencia o formación previa“. En relación con la experiencia laboral previa en urgencias y/o quirófano no se encontró asociación significativa. Sin embargo, sí se encuentra asociación significativa entre solicitar experiencia laboral previa en hospitalización y considerar necesario una formación especializada tipo EIR, con valor del ChiCuadrado de Pearson de 22,346 y 8 grados de libertad para un nivel de significancia estadística de 0,004 , tal y como se muestra en la tabla 67.

Tabla 67. Tabla de contingencia entre necesidad formación tipo EIR y experiencia laboral mínima en hospitalización.

\begin{tabular}{ccccc} 
& \multicolumn{2}{c}{ ¿Qué experiencia mínima previa debieran tener los candidatos antes de comenzar a } \\
\cline { 2 - 5 } trabajar como enfermeros de UCI?
\end{tabular}

Nota: Chi-Cuadrado de Pearson $=22,346$ con 8 grados de libertad. $p=0,004$

Prueba realizada sin incluir las 5 encuestas sin contestación (tabla 62) 
Para conocer qué distribución geográfica presentaba la demanda de una formación EIR en críticos, se procedió a agrupar a las enfermeras con respuesta afirmativa por CCAA comparadas por la respuesta de su propia CCAA. En sentido descendente resultó: Murcia (100\%), País Vasco (100\%), Castilla-La Mancha (88,46\%), Galicia (86,67\%), Castilla y León $(84,37 \%)$, Andalucía $(78,20 \%)$, Islas Baleares (76,92\%), Canarias (76,67\%), Madrid (73,80\%), La Rioja (73,33\%), Comunidad Valenciana $(72,36 \%)$, Asturias $(71,42 \%)$, Aragón (70,96\%), Cataluña (66,17\%), Cantabria (60\%) y Extremadura (60\%). Todas las CCAA presentaron valores iguales o superiores al $60 \%$ por lo que se confirma una opinión firme en cuanto a la creación del EIR para cuidados intensivos.

\subsubsection{Analizar la valoración de las enfermeras sobre la necesidad de planes de acogida.}

Un aspecto que la bibliografía apoya es la adaptación lenta y progresiva de las enfermeras noveles a las unidades de alta complejidad como son las unidades de cuidados intensivos. En este contexto en la presente encuesta se formularon 4 preguntas, dos de ellas dicotómicas y dos de ellas de redacción de texto libre.

A pesar de las recomendaciones de las distintas sociedades científicas, los planes de acogida no están muy extendidos. 408 enfermeras negaron la presencia de planes de acogida al personal de nueva incorporación en sus unidades, ver figura 26.

Figura 26. Existencia de planes de acogida para el personal de nueva incorporación.

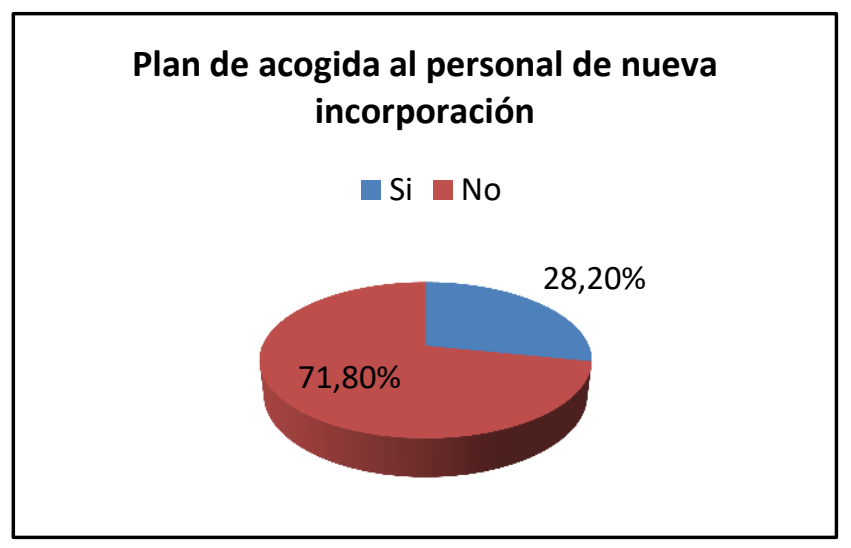

En este sentido, la distribución geográfica a nivel provincial no generó porcentajes elevados en casi ninguna provincia, las tres CCAA con más respuestas afirmativas fueron: País Vasco (50\%), Madrid $(48,8 \%)$ y Castilla-La Mancha (42,3\%). Sin embargo, otras CCAA presentaron porcentajes muy bajos, es el caso de: Canarias (10\%), Galicia $(6,6 \%)$ y La Rioja (0\%). El resto de CCAA se encuentran en el rango entre el $11,1 \%$ y el $31,57 \%$. Ninguna entidad territorial superó el $50 \%$. 
Figura 27. Necesidad de plan de acogida al personal de nueva incorporación.

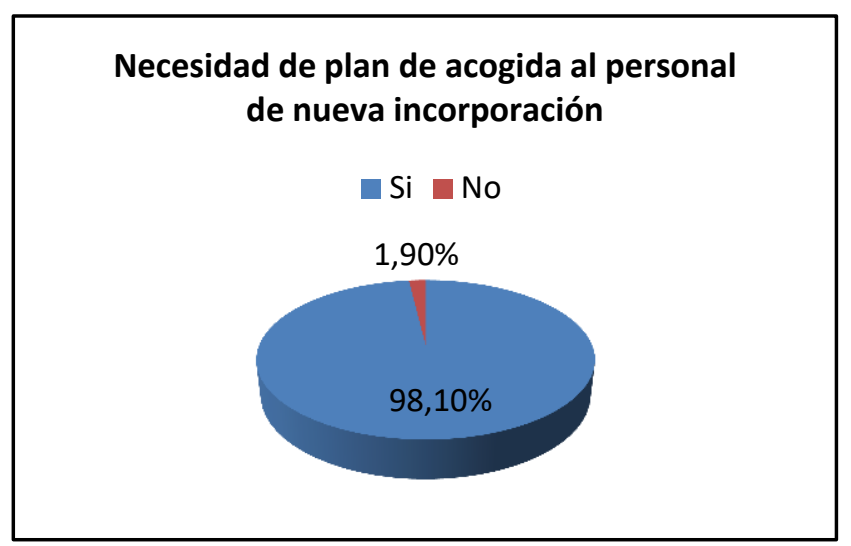

Si observamos la necesidad de planes de acogida en las UCl españolas, según la opinión de los encuestados, hallamos que un $98,1 \%$ (557) de respuestas fueron afirmativas. En todas las CCAA supera esta afirmación el $85 \%$ de las enfermeras consultadas, ver figura 27.

Si analizamos las respuestas afirmativas de las enfermeras en cuanto a la existencia de planes de acogida en sus respectivas unidades, obtenemos que, de las 160 respuestas afirmativas, contestaron a la pregunta “¿En qué consiste el plan de acogida?" 129 encuestados. El cuadro 2 indica las respuestas generadas.

Cuadro 2. Respuesta abierta “¿En qué consiste el plan de acogida?”

- Entrega de protocolos y dosieres de funcionamiento de la unidad: 43.

- Charlas exprés: 20.

- Bienvenida y acogida con charla del supervisor: 20

- Tutorización: 13.

- Supervisión por compañeros veteranos: 11 .

- Curso teórico: 11.

- Curso de adaptación teórico-práctico: 9.

- Supernumerario: 8.

- Prácticas previas no remuneradas: 5 .

- Turno de mañana: 4.

- Adaptación con pacientes menos complejos: 2

- Curso online: 2

- Dosieres generales poco específicos de la institución: 1 .

- Video tutoriales: 1.

- Estar en posesión del postgrado y máster propio de UCI: 1 .

- Contrato becario: 1.

En la segunda pregunta abierta los encuestados comentaron que: "Resultaban insuficientes o eran poco eficientes". El comentario más habitual fue: "Se hace cuando se puede y las condiciones lo permiten"; siendo en los contratos de verano cuando se realizan de una manera más estandarizada. 
Con el objetivo de aclarar los elementos agrupados se pasan a determinar los elementos comunes. El elemento más común fue la entrega de protocolos de las distintas unidades, algunas respuestas más específicas incluían protocolos de la unidad y proyectos ZERO. Algunas unidades impartían charlas sobre los elementos habituales de cada unidad. Otros se referían al plan de acogida como un acto de bienvenida por parte de los supervisores donde se les enseñaba la unidad, en otros casos se les entregaba documentación o se le da una charla general de elementos de la historia clínica o de que se tenía que hacer cada hora del día.

En algunas unidades se encontró la figura de un tutor que a lo largo de una serie de días iba resolviendo dudas durante la práctica clínica del personal novel. En otras unidades, se rodeaba al novel de personal veterano que es el que le asistía en dudas o explicaciones; algunas enfermeras reconocían que era una sobrecarga en su labor asistencial.

Había unidades que organizan cursos teóricos previos o simultáneos al comienzo de la etapa laboral, la duración iba desde 3 días hasta dos semanas. Además, otras unidades incorporaban en este programa algunos días de prácticas. Otros encuestados mencionaban la posibilidad de ir antes del inicio del período laboral a realizar prácticas in situ no remuneradas, acompañando al personal de la unidad. En algunos casos, se variaban las condiciones de los turnos de trabajo, tanto en tiempo, priorizando que estuviesen en turnos de mañana, como en la asignación de pacientes menos complejos.

En este contexto fue necesario valorar en qué debería consistir un plan de acogida. De los 557 encuestados que respondieron afirmativamente se obtuvieron 461 respuestas de texto libre. La demanda más habitual fue la presencia de un tutor, que estuviera liberado de la asistencia y se hiciera cargo del personal de nueva incorporación. A continuación, se detallan los elementos más comunes, ver cuadro 3.

Cuadro 3. Respuesta abierta "¿En qué debería consistir un Plan de acogida?".

- Tutorización (presencia de tutor): 136.

- Formación teórico-práctica específica: 59.

- Protocolos y guías de funcionamiento: 54.

- Formación teórica específica: 52.

- Supervisión del personal novel por el personal veterano: 44 .

- Prácticas previas: 43.

- Período de adaptación: 34.

- Supernumerario: 22.

- Formación básica: 19

- Formación del aparataje (monitores, bombas...): 18.

- Evaluación posterior a la formación: 16

- Becario: 16.

- Talleres específicos: 15.

- Plan de acogida: 14.

- Guías de práctica clínica de la unidad: 12.

- Formación en ventilación mecánica: 11.

- Formación en seguridad clínica: 11.

- Modificación de los turnos de trabajo (diurnos, preferiblemente mañanas): 11. 
- Plan formativo propio (presencial, online, tutela y exámenes): 11.

- Formación en Reanimación cardiopulmonar: 10.

- Necesaria formación previa acreditada: 9

- Formación en técnicas de soporte vital: 7

- Continuidad del personal formado: 6

- Manual de acogida: 5

- Comunicación: 5.

- Contratación 15 días antes: 4.

- Simulación clínica: 4.

- Entrevista y valoración previa: 4.

- Bolsa de empleo específica: 3.

- Mismo equipo y mismos veteranos: 3 .

- Formación específica por la consejería: 3.

- Cuidado de los padres: 3.

- Modificación de las ratios de pacientes: 3 .

- Aplicar el que tenemos: 2 .

- Asignar pacientes menos complejos al personal novel: 2.

- EIR: 2.

- Experiencia previa contrastada (empresa privada): 1.

- Explicar proyectos ZERO: 1.

Un elemento común fue cómo medir la consecución de los objetivos planteados mediante evaluación de capacitación, y seguir con períodos de supervisión por veteranos dentro de los distintos grupos de trabajo. El tiempo que indicaron los encuestados para destinar a esta formación fue muy variable. A continuación, se detallan los períodos de tiempo que se han nombrado por los encuestados en sentido descendente: 1 año (2), 6 meses (3), 3 meses (4), 2 meses (5), 1 mes (18), 2 semanas (15), 1 semana (21) y 2 días (2).

La mayoría de los comentarios fueron destinados a que un plan de acogida debía ser progresivo con la adquisición de competencias desde más generales a específicas y acompañados por la figura del tutor.

\subsubsection{Comparación entre las puntuaciones de los ámbitos de las necesidades formativas de las} enfermeras de cuidados intensivos entre el grupo Delphi y el grupo nacional.

En este apartado se compararon las necesidades formativas entre el grupo Delphi, del cual nace el cuestionario distribuido, y el grupo a nivel nacional. Se comparó la población total y su puntuación en cada uno de los ámbitos de la encuesta. Para orientar el tratamiento estadístico, en el grupo Delphi también se evaluó la normalidad de las variables mediante la prueba de Shapiro-Wilk; resultando un p-valor superior a 0,05 lo que indicó que se cumplían criterios de normalidad. Los valores obtenidos a nivel nacional se procesaron mediante la prueba de Kolmogorov-Smirnov, obteniéndose valores $p$ inferiores a 0,05 por lo que se asumió que los datos no provenían de una distribución normal. Por tanto, para valorar las diferencias se aplicó la prueba U-Mann-Whitney.

La tabla 68 presenta los resultados de comparar ambos grupos. No se hallaron diferencias significativas entre grupos, por lo cual se asume que no existen diferencias en la valoración de las necesidades formativas en ninguno de los ámbitos ni en las puntuaciones totales. Este hecho es 
relevante ya que el grupo de expertos generador del cuestionario no valoró de manera distinta las necesidades formativas de las enfermeras.

Tabla 68. Análisis de las diferencias entre las puntuaciones de las distintas secciones del cuestionario entre el grupo Delphi y el grupo nacional.

\begin{tabular}{|c|c|c|c|c|c|c|c|c|}
\hline \multirow{2}{*}{ Ámbito } & \multicolumn{3}{|c|}{$\begin{array}{l}\text { Grupo Nacional } \\
\qquad(n=568)\end{array}$} & \multicolumn{3}{|c|}{$\begin{array}{l}\text { Grupo Delphi } \\
\quad(n=15)\end{array}$} & \multirow{2}{*}{$\begin{array}{l}\text { U de Man } \\
\text { Whitney }\end{array}$} & \multirow{2}{*}{$\boldsymbol{p}$} \\
\hline & Media & D.T. & $\begin{array}{c}\text { Rango } \\
\text { Promedio }\end{array}$ & Media & D.T. & $\begin{array}{c}\text { Rango } \\
\text { Promedio }\end{array}$ & & \\
\hline Ámbito Clínico & 163,77 & 9,77 & 290,85 & 166,66 & 8,90 & 335,43 & 4951 & 0,319 \\
\hline Ámbito Profesional & 121,89 & 9,79 & 290,61 & 125,06 & 8,89 & 344,67 & 5050 & 0,220 \\
\hline $\begin{array}{l}\text { Ámbito de la } \\
\text { Gestión }\end{array}$ & 135,35 & 11,50 & 291,65 & 136,26 & 10,51 & 305,27 & 4459 & 0,757 \\
\hline $\begin{array}{l}\text { Ámbito Educativo y } \\
\text { de desarrollo }\end{array}$ & 46,50 & 5,88 & 292,15 & 46,40 & 6,33 & 286,47 & 4177 & 0,897 \\
\hline Puntuación parte $\mathrm{A}$ & 467,53 & 29,21 & 290,91 & 474,40 & 26,35 & 333,27 & 4879 & 0,336 \\
\hline Formación & 106,57 & 9,15 & 290,91 & 109,20 & 7,41 & 333,23 & 4878,5 & 0,336 \\
\hline Puntuación total & 574,10 & 35,66 & 290,77 & 583,60 & 30,73 & 338,50 & 4957,5 & 0,279 \\
\hline
\end{tabular}

Nota. Prueba U de Man Whitney. p valor: $p<0,05$.

Posteriormente se analizó cada ítem por separado hallando diferencias significativas en 7 de los 66 ítems que forman el cuestionario. En este sentido observamos mayor rango promedio en tres de los ítems por el grupo Delphi, los relacionados con el ámbito clínico y profesional, y uno de los relacionados con el ámbito educativo y de desarrollo. Sin embargo, el grupo nacional obtiene diferencias significativas en las restantes 4 afirmaciones, ver tabla 69 .

Tabla 69. Diferencias significativas en las afirmaciones de todos los ámbitos entre el grupo nacional y el grupo Delphi.

\begin{tabular}{|c|c|c|c|c|}
\hline Afirmación & $\begin{array}{l}\text { Rango Promedio } \\
\text { Grupo Nacional }\end{array}$ & $\begin{array}{l}\text { Rango Promedio } \\
\text { Grupo Delphi }\end{array}$ & $\begin{array}{l}\text { U de Man } \\
\text { Whitney }\end{array}$ & $p$ \\
\hline $\begin{array}{l}\text { El cálculo de fármacos y drogas es una } \\
\text { competencia imprescindible }\end{array}$ & 290,13 & 362,70 & 5320,5 & 0,045 \\
\hline $\begin{array}{l}\text { La comunicación escrita en UCl se debe } \\
\text { fomentar siempre, pues es } \\
\text { indispensable pata la continuidad de } \\
\text { cuidados }\end{array}$ & 289,67 & 380,27 & 5584 & 0,028 \\
\hline $\begin{array}{l}\text { Las enfermeras de UCl están } \\
\text { involucradas en la seguridad clínica }\end{array}$ & 294,74 & 188,17 & 2702,5 & 0,011 \\
\hline $\begin{array}{l}\text { Se fomentan acciones para el adecuado } \\
\text { confort y descanso de los pacientes }\end{array}$ & 294,42 & 200,30 & 2884,5 & 0,029 \\
\hline $\begin{array}{l}\text { En UCl, se toman medidas que ayudan a } \\
\text { prevenir o evitar el delirio o la } \\
\text { desorientación }\end{array}$ & 294,26 & 206,27 & 2974 & 0,043 \\
\hline $\begin{array}{l}\text { La institución colabora en una } \\
\text { formación específica de UCl }\end{array}$ & 294,32 & 204,20 & 2943 & 0,039 \\
\hline $\begin{array}{l}\text { La formación en UCl se realiza sobre } \\
\text { todo para el cobro de incentivos, bolsas } \\
\text { de empleo y oposiciones }\end{array}$ & 288,85 & 411,20 & 6048 & 0,005 \\
\hline
\end{tabular}

Nota. Prueba U de Man Whitney. p valor: $p<0,05$. 
4.3.8. Valorar los valores predictivos de las respuestas al cuestionario en función de las variables independientes.

Se planteó la necesidad de valorar si existía fuerza de la asociación y qué relación había entre las distintas variables estudiadas. Se plantearon distintos modelos con el ámbito clínico, profesional, gestión, educativo y de desarrollo, además de la parte B del cuestionario y la puntuación total del mismo. Al final de los distintos análisis realizados, se observó que la puntuación de la parte $\mathrm{A}$ del cuestionario era las más importante del estudio; por lo tanto, se seleccionaron las variables que habían resultado significativas en análisis previos (sexo, edad, relación con la universidad, número de camas del hospital donde trabajan, años de experiencia laboral total y años de experiencia laboral en UCI) y se procedió a la realización de un análisis de regresión múltiple. Además, se realizaron los gráficos de residuos y de los modelos resultantes, además del bootstrapping para valorar la validez del modelo.

Los datos significativos se han obtenido en relación con una mayor puntuación de los distintos ámbitos en relación con el personal de más edad, hospital universitario y de mayor edad y experiencia laboral total y en $\mathrm{UCl}$, y por supuesto el hecho de ser mujer. Se presentan los resultados en la tabla 70.

Tabla 70. Análisis univariante de la puntuación total A.

\begin{tabular}{|c|c|c|c|c|}
\hline & \multicolumn{4}{|c|}{ Análisis univariante (Regresión lineal simple) } \\
\hline & Beta & Error típico & $p$ & IC-95\% \\
\hline Sexo: Mujer & 8,53 & 3,08 & 0,006 & $2,49-14,58$ \\
\hline Hospital Universitario & $-9,30$ & 3,55 & 0,009 & $-16,27--2,33$ \\
\hline № Camas: $>500$ & $-7,45$ & 2,40 & 0,002 & $-12,16--2,74$ \\
\hline \multicolumn{5}{|l|}{ Edad: $\leq 35$ años } \\
\hline $36-40$ años & $-0,61$ & 3,25 & 0,85 & $-6,99-5,77$ \\
\hline $41-45$ años & 6,55 & 3,50 & 0,06 & $-0,33-13,42$ \\
\hline$>45$ años & 8,12 & 3,31 & 0,01 & $1,62-14,62$ \\
\hline \multicolumn{5}{|c|}{$\begin{array}{l}\text { Años experiencia laboral total: } \\
\leq 10 \text { años }\end{array}$} \\
\hline $11-15$ años & 2,44 & 3,51 & 0,49 & $-4,45-9,32$ \\
\hline $16-20$ años & 2,98 & 3,53 & 0,40 & $-3,95-9,90$ \\
\hline$>20$ años & 2,33 & 3,19 & 0,001 & $-3,94-8,60$ \\
\hline \multicolumn{5}{|c|}{$\begin{array}{l}\text { Años experiencia laboral UCl: } \\
\leq 5 \text { años }\end{array}$} \\
\hline 6-10 años & 2,33 & 3,19 & 0,47 & $-3,94-8,60$ \\
\hline 11-15 años & $-0,01$ & 3,50 & 0,99 & $-6,89-6,86$ \\
\hline$>15$ años & 10,98 & 3,19 & $<0,001$ & $4,72-17,23$ \\
\hline
\end{tabular}

Nota. Resultados regresión lineal simple (IC-95\%). p valor: $p<0,05$.

Como se puede observar los coeficientes obtenidos mediante bootstraping son similares a los obtenidos mediante la regresión lineal, lo que confirma la validez del modelo. El mejor modelo se consiguió con el método de pasos sucesivos, y se presenta a continuación en la tabla 71. 
Tabla 71. Regresión lineal multivariante en función de la puntuación total A.

\begin{tabular}{|c|c|c|c|c|c|c|}
\hline & \multicolumn{4}{|c|}{ Análisis univariante (Regresión lineal múltiple) } & \multicolumn{2}{|c|}{ Bootstraping } \\
\hline & Beta & $\begin{array}{l}\text { Error } \\
\text { típico }\end{array}$ & $\boldsymbol{p}$ & IC-95\% & Beta & IC-95\% \\
\hline Constante: & 463,40 & 4,75 & $<0,001$ & $454,1-472,7$ & 463,5 & $454,6-472,2$ \\
\hline Sexo: Mujer & 8,44 & 3,06 & 0,006 & $2,45-14,46$ & 8,45 & $2,48-14,69$ \\
\hline Hospital Universitario & $-4,88$ & 3,78 & 0,20 & $-12,30-2,54$ & $-4,71$ & $-10,89-2,57$ \\
\hline № Camas: $>500$ & $-5,85$ & 2,54 & 0,02 & $-10,83--0,86$ & $-5,84$ & $-10,89--0,86$ \\
\hline \multicolumn{7}{|l|}{ Edad: $\leq 35$ años } \\
\hline 36-40 años & $-3,33$ & 4,30 & 0,44 & $-11,57-5,11$ & $-3,06$ & $-11,16-5,11$ \\
\hline 41-45 años & 0,72 & 5,51 & 0,90 & $-10,10-11,54$ & 0,69 & $-9,94-10,68$ \\
\hline$>45$ años & $-3,54$ & 6,70 & 0,60 & $-16,69-9,61$ & $-3,37$ & $-16,32-9,69$ \\
\hline \multicolumn{7}{|c|}{$\begin{array}{l}\text { Años experiencia laboral total: } \\
\leq 10 \text { años }\end{array}$} \\
\hline 11-15 años & 4,85 & 4,45 & 0,28 & $-3,90-13,59$ & 4,85 & $-3,81-13,47$ \\
\hline 16-20 años & 4,99 & 5,63 & 0,38 & $-6,06-16,05$ & 4,96 & $-5,60-16,33$ \\
\hline$>20$ años & 8,72 & 7,13 & 0,22 & $-5,27-22,71$ & 8,71 & $-4,74-23,3$ \\
\hline \multicolumn{7}{|c|}{$\begin{array}{l}\text { Años experiencia laboral UCl: } \\
\leq 5 \text { años }\end{array}$} \\
\hline 6-10 años & 1,03 & 3,44 & 0,77 & $-5,73-7,78$ & 1,04 & $-5,90-7,64$ \\
\hline 11-15 años & $-1,77$ & 4,03 & 0,66 & $-9,68-6,14$ & $-1,83$ & $-9,47-5,84$ \\
\hline >15 años & 5,89 & 4,69 & 0,21 & $-3,32-15,10$ & 5,81 & $-3,53-15,47$ \\
\hline
\end{tabular}

Nota. Resultados regresión lineal múltiple (IC-95\%). p valor: $p<0,05$. IC: Intervalo de Confianza

Como se observa en la tabla 72, se cuentan con datos significativos, pero los valores predictivos determinados por el $\mathrm{R}$ cuadrado son bajos y sólo explicarían el 4,5\% de las respuestas dadas por las enfermeras.

Tabla 72. Mejor modelo de la regresión lineal multivariante para la puntuación total A.

\begin{tabular}{|c|c|c|c|c|c|c|}
\hline \multirow{2}{*}{ Modelo+ } & \multicolumn{2}{|c|}{$\begin{array}{l}\text { Coeficientes no } \\
\text { estandarizados }\end{array}$} & \multirow{2}{*}{$\begin{array}{c}\text { Coeficientes } \\
\text { tipificados } \\
\text { Beta }\end{array}$} & \multirow{2}{*}{$\boldsymbol{t}$} & \multirow{2}{*}{$\boldsymbol{p}$} & \multirow{2}{*}{ IC-95\% } \\
\hline & Beta & $\begin{array}{l}\text { Error } \\
\text { Típico }\end{array}$ & & & & \\
\hline Constante & 432,506 & 7,41 & & 58,351 & $<0,001$ & $417,95-447,06$ \\
\hline $\begin{array}{l}\text { Años de experiencia } \\
\text { laboral total }\end{array}$ & 3,591 & 1,041 & 0,144 & 3,476 & 0,001 & $1,556-5,625$ \\
\hline Sexo & 8,369 & 3,083 & 0,112 & 2,714 & 0,007 & $2,313-14,426$ \\
\hline $\begin{array}{l}\text { Relación con la } \\
\text { universidad }\end{array}$ & 9,241 & 3,509 & 0,108 & 2,633 & 0,009 & $2,348-16,134$ \\
\hline Modelo & $\begin{array}{l}\text { Suma de } \\
\text { cuadrados }\end{array}$ & gl & $\begin{array}{l}\text { Media } \\
\text { cuadrática }\end{array}$ & $\mathbf{F}$ & & $\boldsymbol{p}$ \\
\hline Regresión & 21889,017 & 3 & 7296,34 & \multirow{3}{*}{8,904} & \multirow{3}{*}{\multicolumn{2}{|c|}{$<0,001^{*}$}} \\
\hline Residual & 462160,413 & 564 & 819,433 & & & \\
\hline Total & 484049,430 & 567 & & & & \\
\hline \multicolumn{7}{|c|}{$\begin{array}{l}\text { *Variables predictoras: (Constantes), Años de Experiencia laboral total, sexo, relación con la universidad } \\
\text { +Variable dependiente: Puntuación total A }\end{array}$} \\
\hline \multicolumn{7}{|c|}{ Resumen del modelo } \\
\hline $\mathbf{R}$ & \multicolumn{2}{|l|}{ R cuadrado } & $\begin{array}{l}\text { R } \\
\text { Corregido }\end{array}$ & Irado & \multicolumn{2}{|c|}{ Error típico } \\
\hline 0,293 & 0,045 & & 0,040 & & 62 & \\
\hline
\end{tabular}

Nota. Resultados regresión lineal múltiple (IC-95\%). p valor: $p<0,05$. IC: Intervalo de Confianza. gl: grados de libertad 
A pesar de este hecho, se observa como los residuos siguen una distribución normal, así como la prueba de normalidad de Lilliefors (Kolmogorov-Smirnov) atestigua para una $D=0,033778$ y una $\mathrm{p}=0,1094$, y las figuras 28 y 29 reflejan los resultados.

Figura 28. Histograma de residuos del modelo creado para la puntuación total A.

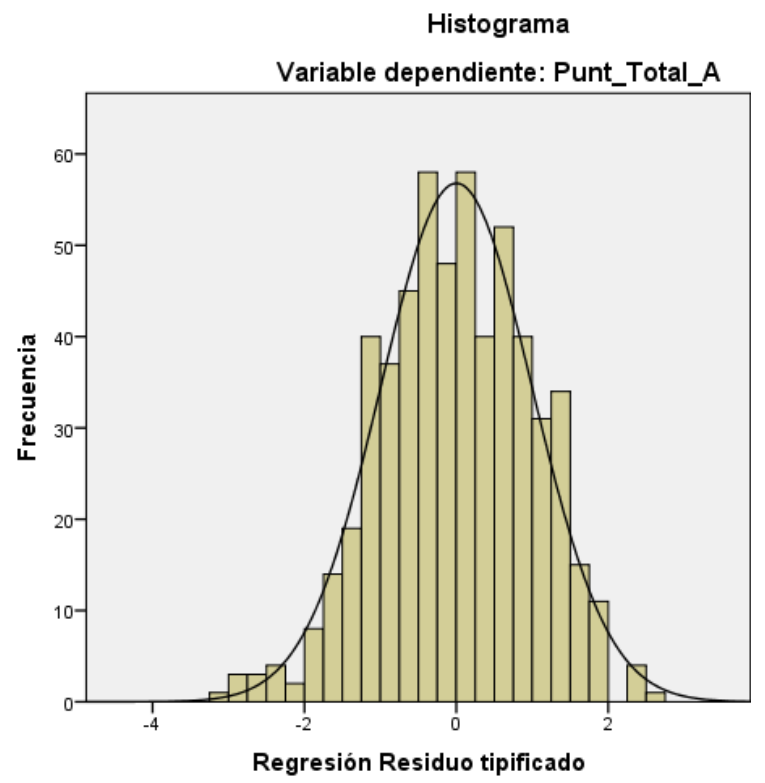

Figura 29. Gráfico de residuos tipificados del modelo creado para la puntuación total A.

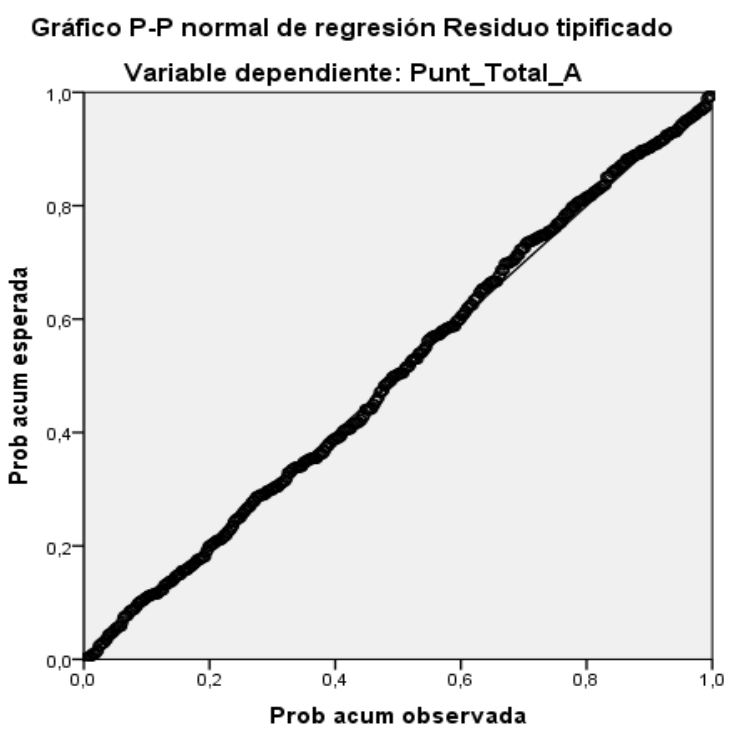

4.3.9. Análisis de las dimensiones presentes en la escala utilizada.

Tras analizar las respuestas dadas por los participantes y con el fin de valorar de una forma más global los resultados obtenidos, se ha procedido a realizar un análisis factorial exploratorio (AFE) 
mediante matrices policóricas y rotación Promin. El objetivo del AFE es la identificación de las posibles dimensiones existentes en la escala utilizada. Se buscó en todo momento que las dimensiones explicativas se ajustaran a la validez del contenido, y a la mejor solución, modificando las distintas rotaciones ortogonales y oblicuas disponibles en el paquete estadístico utilizado Factor Analysis. Los encuestados valoran positivamente las afirmaciones planteadas, pues la mayoría de ellas obtienen valores superiores al $70 \%$, tal y como se observa en las tablas anteriores con valores medios iguales o superiores a 7.

A la hora de realizar el AFE los resultados son satisfactorios para el análisis de matrices policóricas mediante rotación promin, tal y como se adjunta en la tabla 71. Las pruebas de idoneidad, como el índice Kaiser-Meyer-Olkin (KMO) y la esfericidad de Bartlett, aconsejaban la reducción de la dimensionalidad de la escala. El coeficiente KMO de nuestro análisis fue de 0,948 , los valores superiores a 0,80 indican que las correlaciones entre los pares de variables pueden ser explicadas por otras variables. La esfericidad de Bartlett analizó la adecuación de los datos con un resultado de $p<0,001$; contrastando la hipótesis nula referida a que la matriz de correlaciones es igual a la matriz identidad. Para el análisis se eliminaron aquellos valores con una comunalidad inferior a 0,300. La variable que no contó con ninguna agrupación satisfactoria fue la variable 22 definida en la siguiente afirmación: "Las enfermeras de UCI tienen mucha autonomía, por lo que es necesario una formación reglada y adecuada al puesto de trabajo".

El análisis factorial se determinó a través de la implementación óptima del análisis paralelo, y con eigenvalues (valores propios) superiores a la unidad. Se consideró adecuada aquella solución factorial con una explicación de la varianza total explicada superior al 50\%. En nuestro caso fue del 64,219\%. La adecuación del modelo factorial generado se evaluó mediante la comparación de la raíz media cuadrática residual (RMSR) y con el valor del Criterio de Kelly (CK). El valor de RMSR fue inferior al valor de CK, este hallazgo indica un modelo adecuado. Para analizar la fiabilidad y consistencia de la escala se analizó mediante el alfa de Cronbach con valores superiores al 0,80; en nuestro caso fue de 0,934. Ver tabla 73. 
突 悉

荬 雚

苛

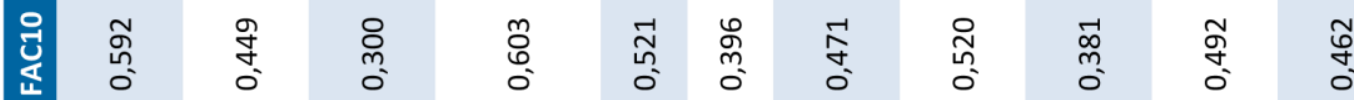

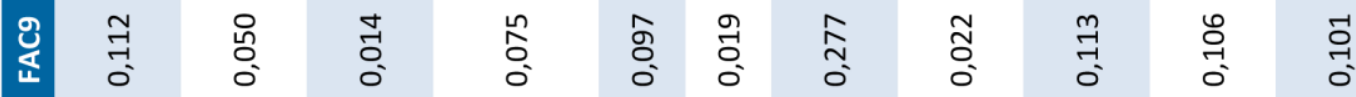

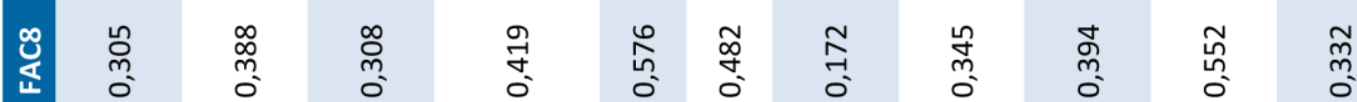

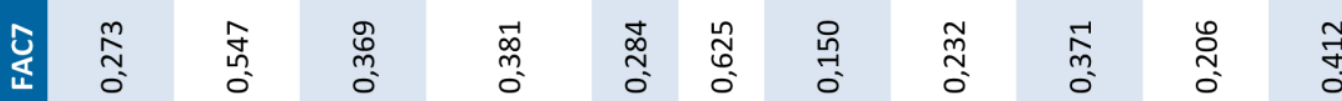

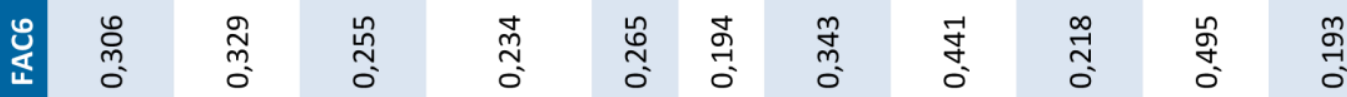

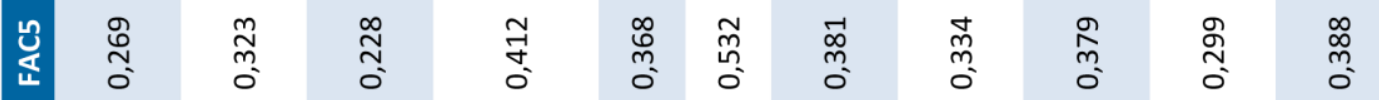

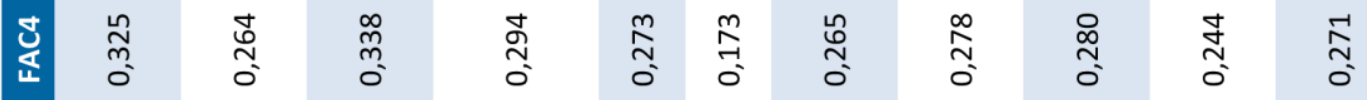

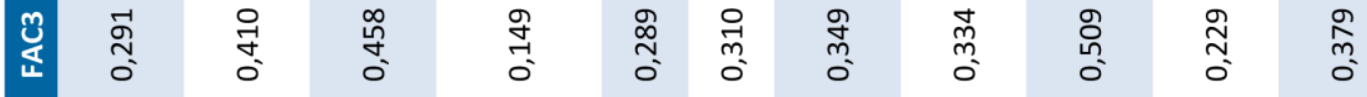

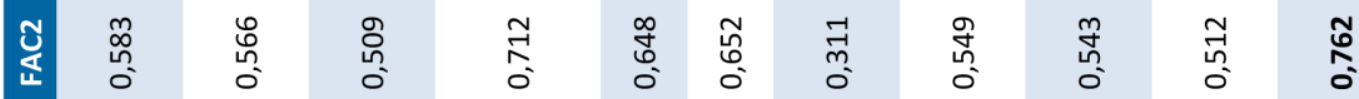

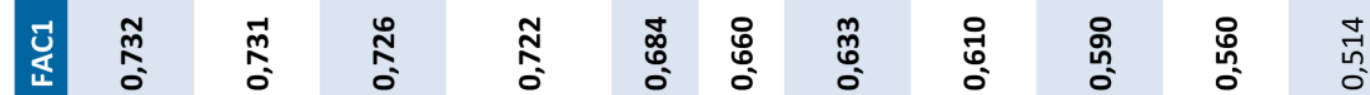

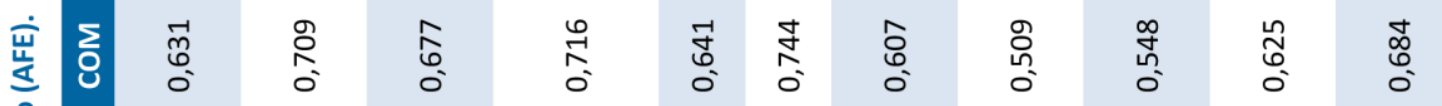

䓂

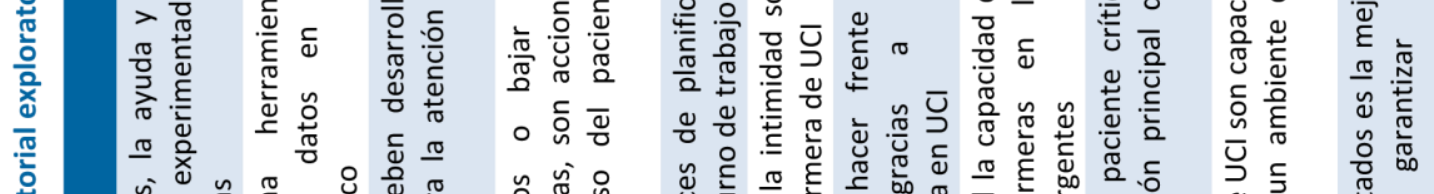

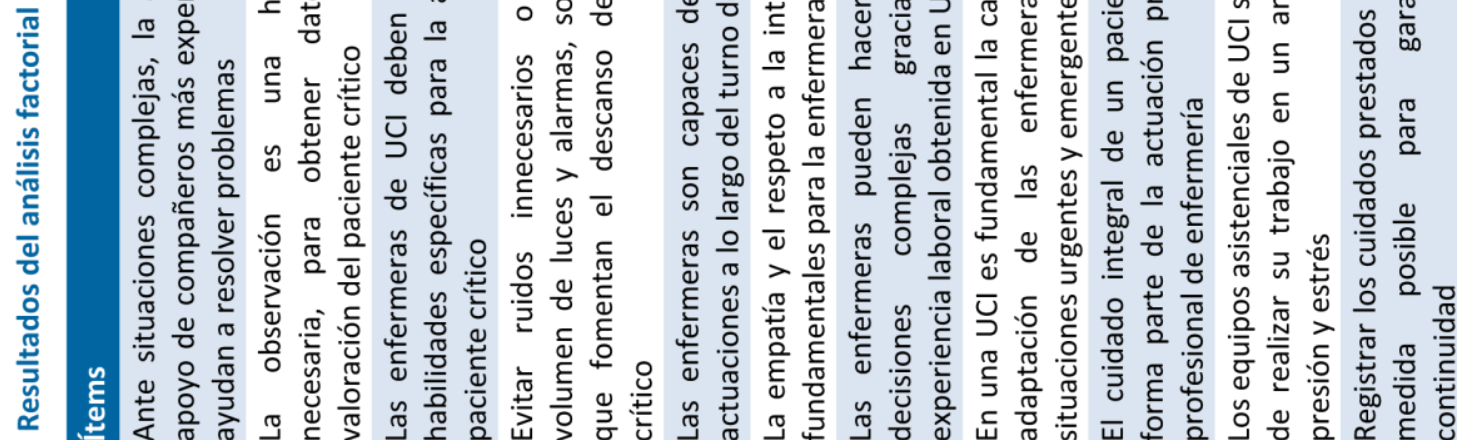
$\stackrel{n}{n}$

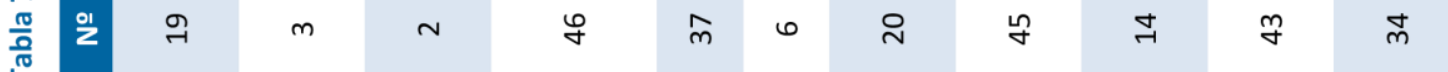




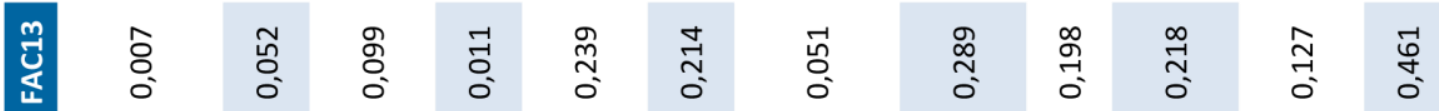

ปิ

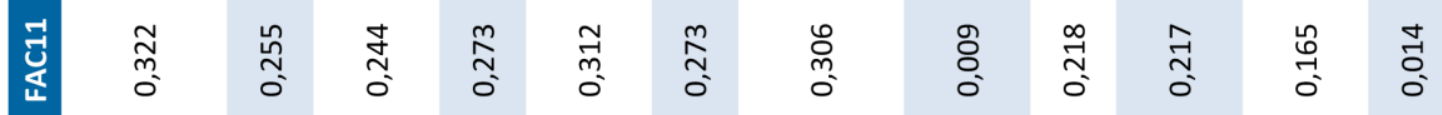

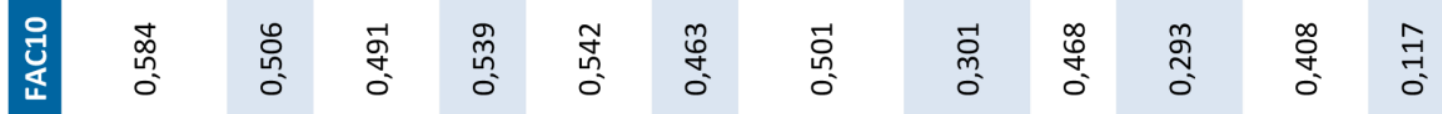

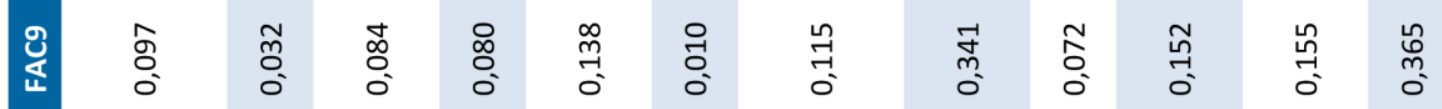

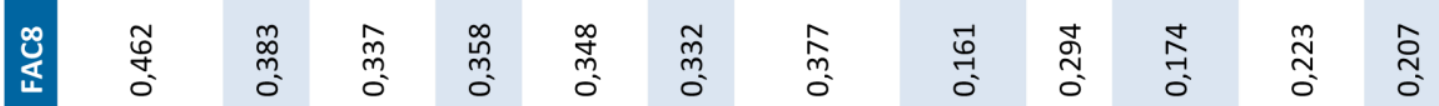

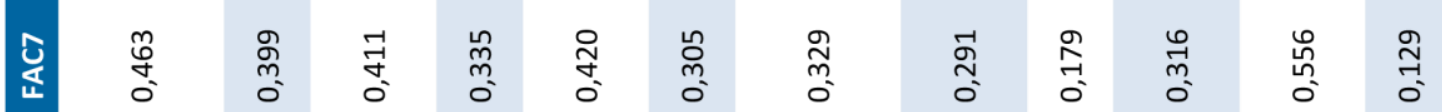

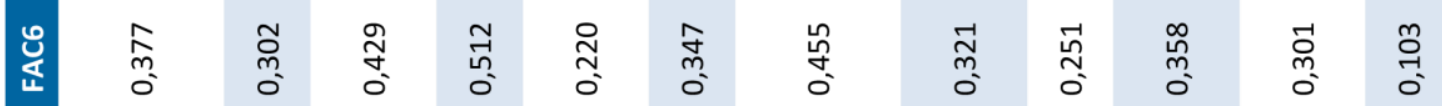

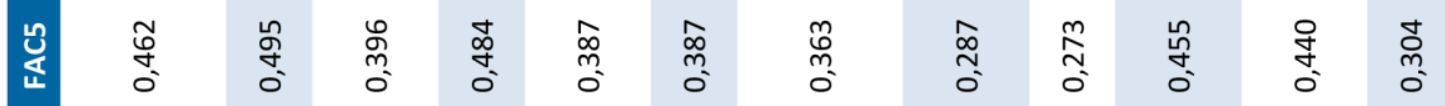

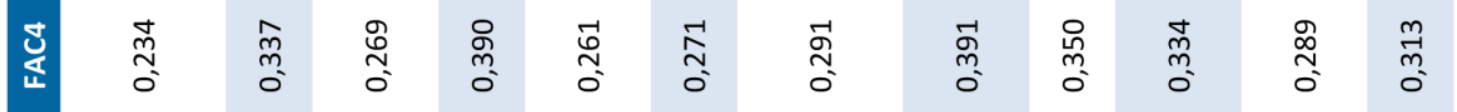

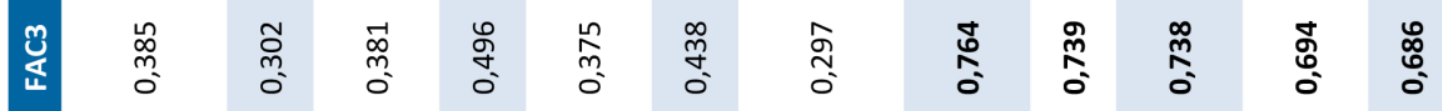

ปู

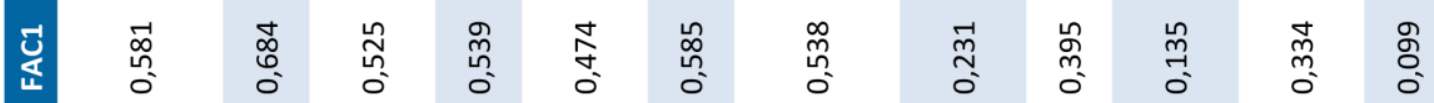

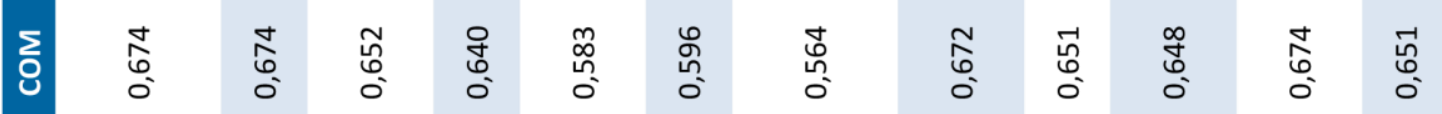

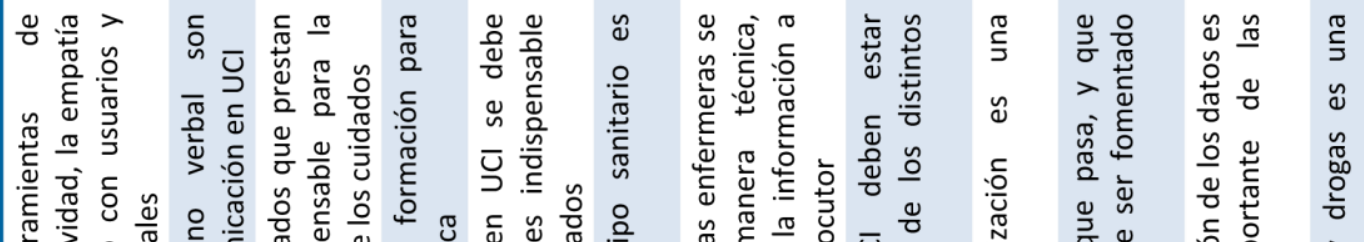

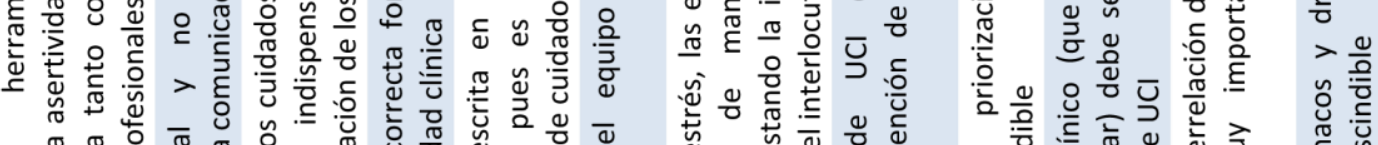

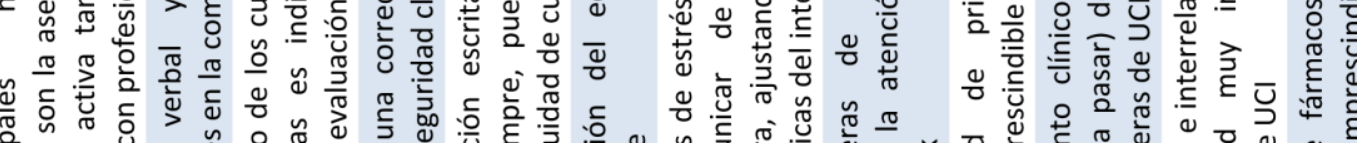

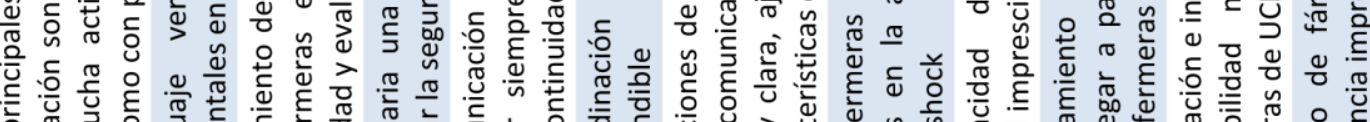

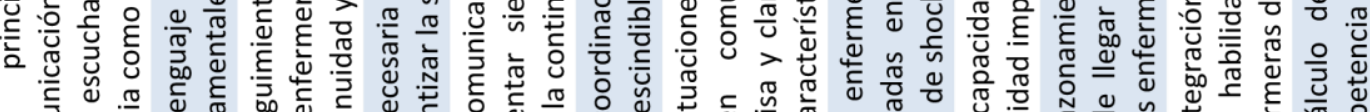

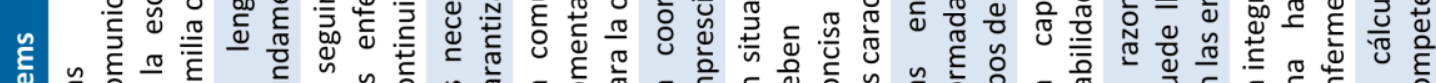

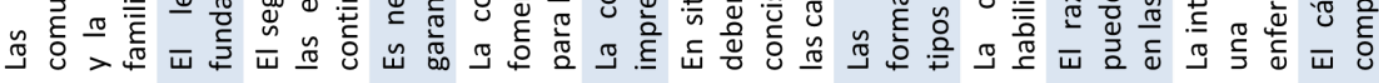

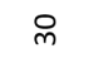
$\stackrel{\infty}{\sim}$

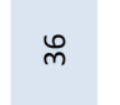
จ
ㄱำ
$\stackrel{\infty}{\sim}$
a $\stackrel{n}{\rightarrow}$

\begin{abstract}
$\stackrel{m}{m}$
\end{abstract}
$\div \approx$ 


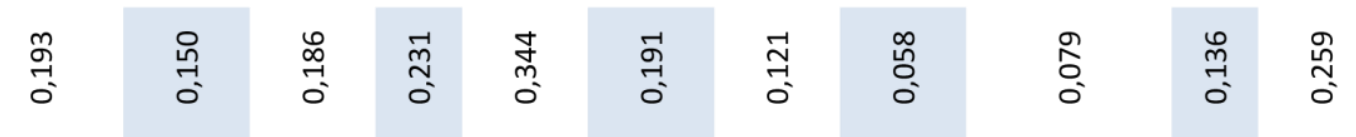

量

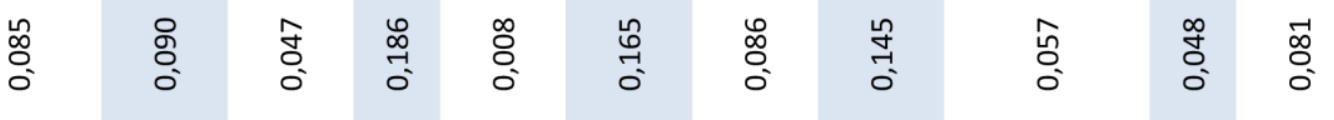

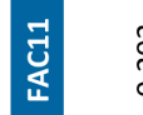

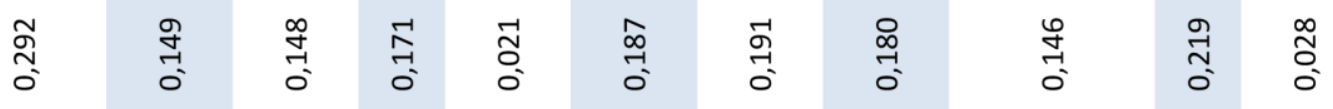

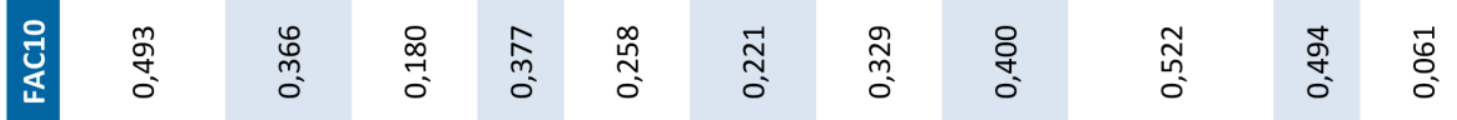

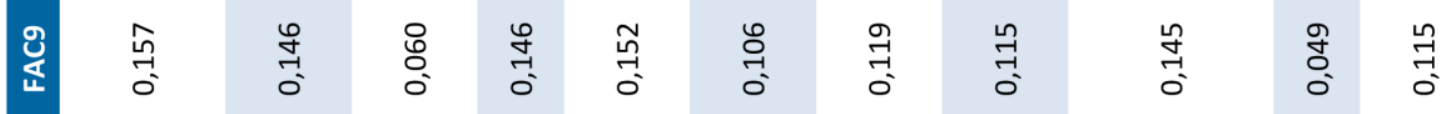

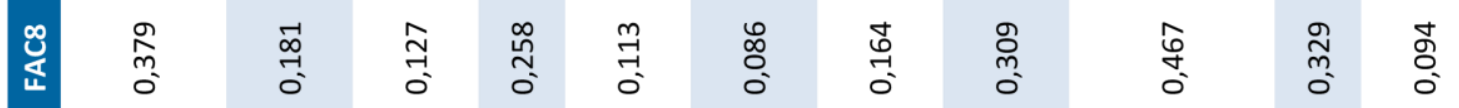

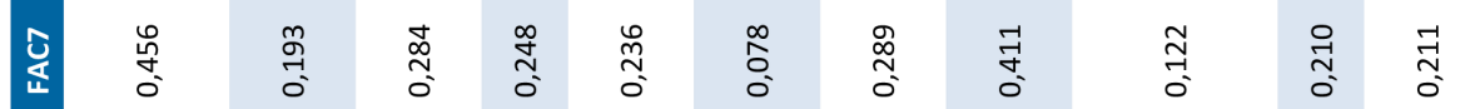

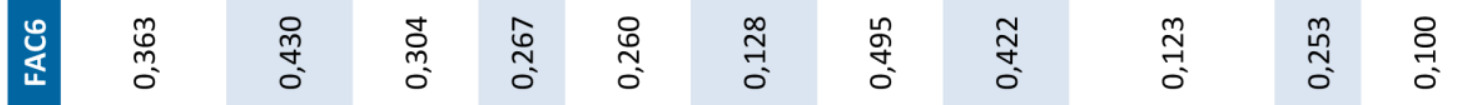

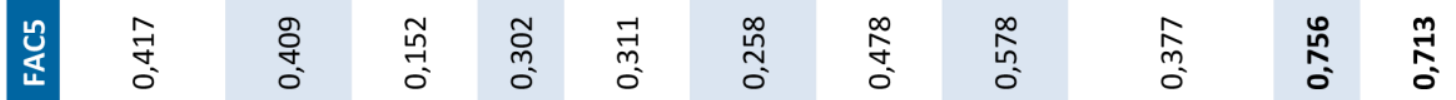

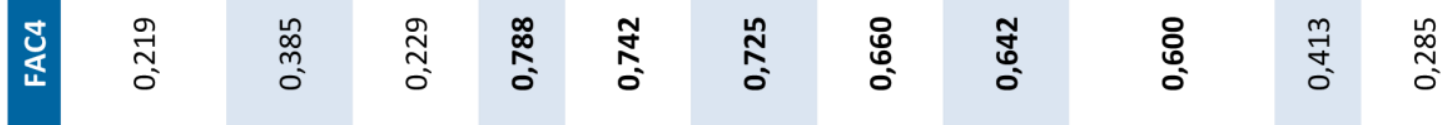

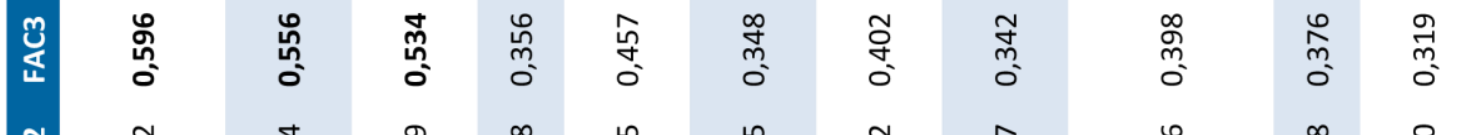

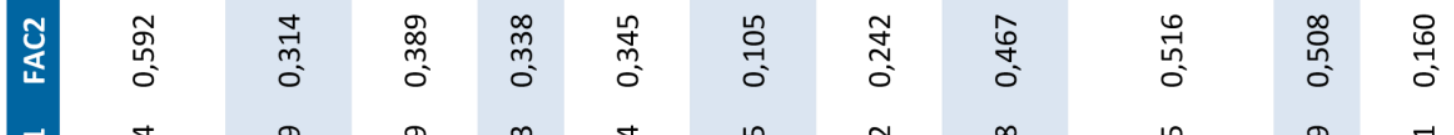

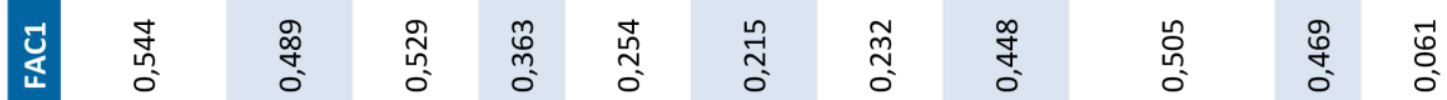

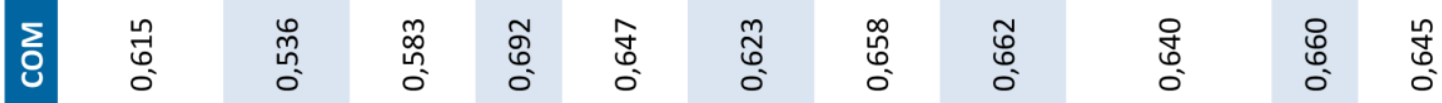

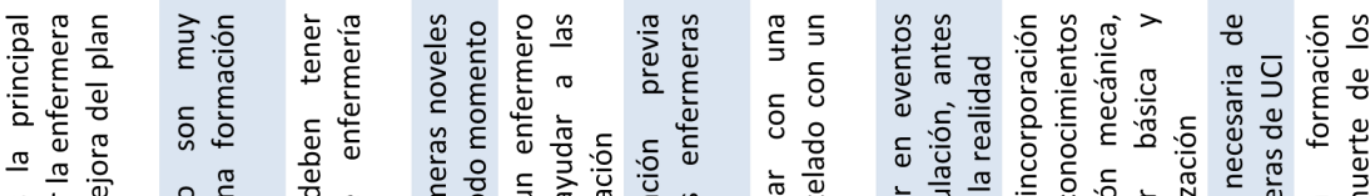

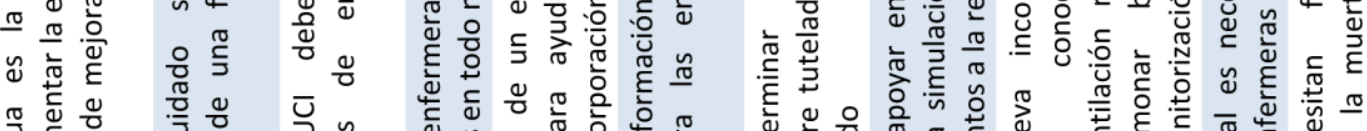

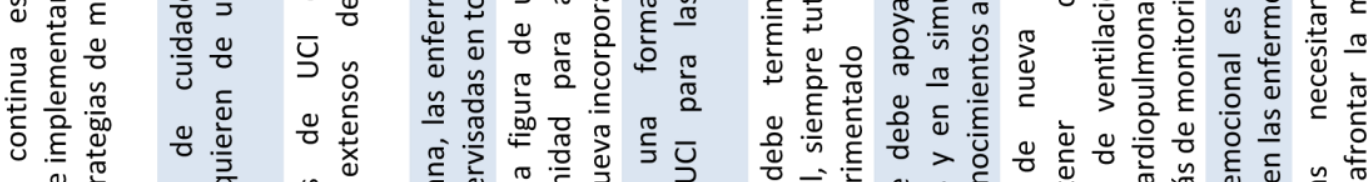

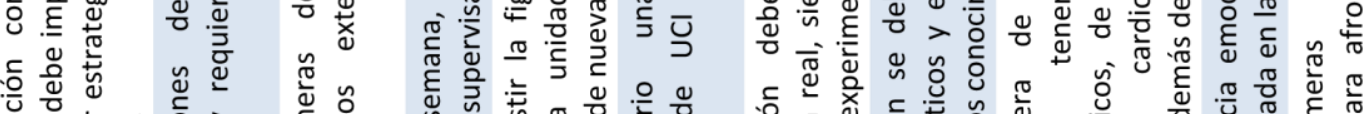

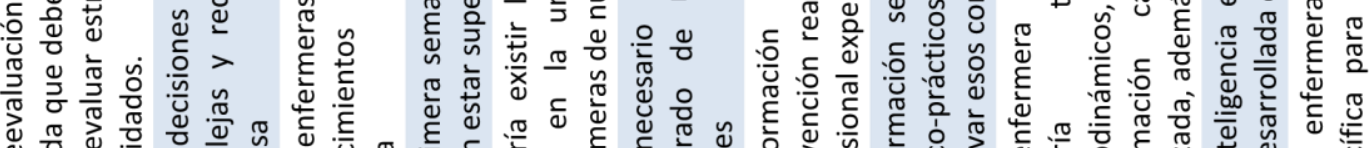

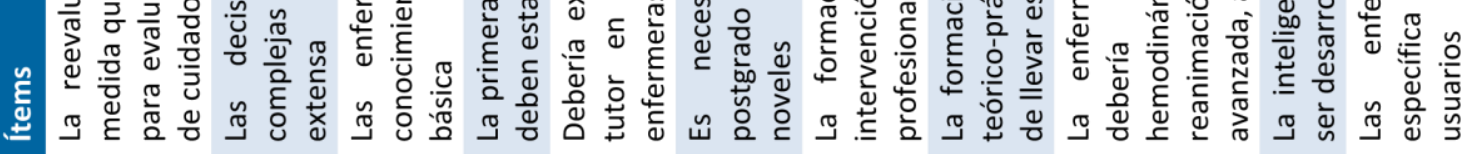

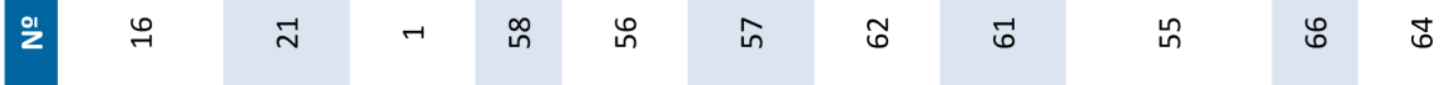




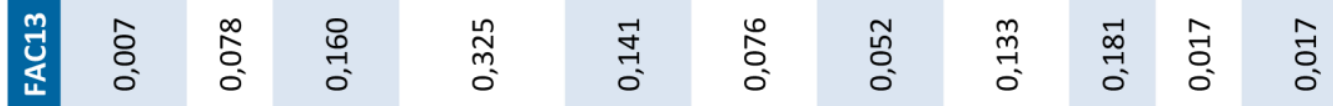

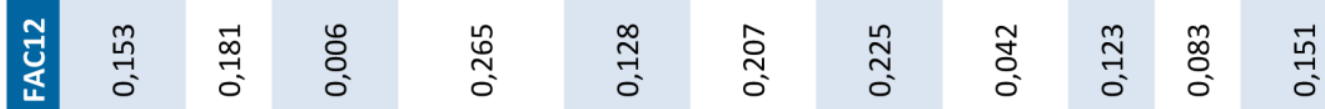

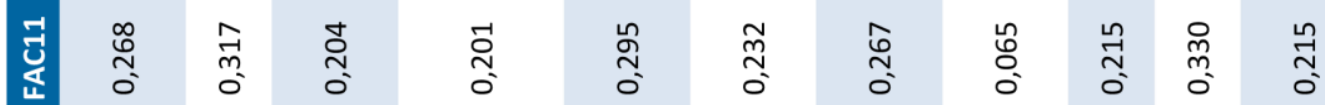

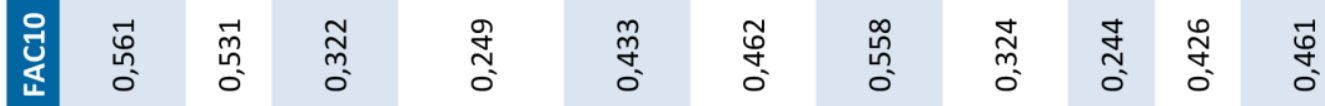

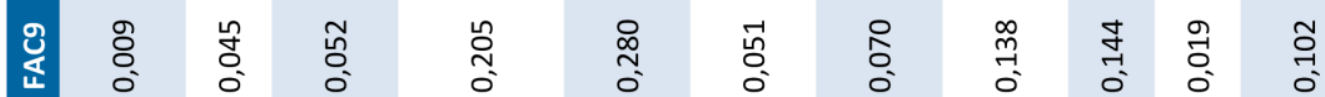

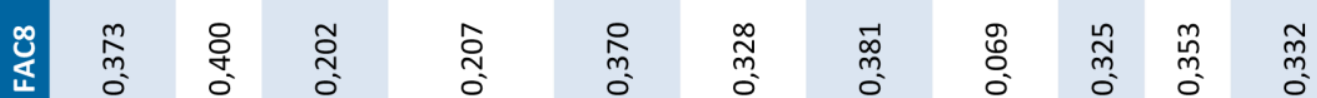

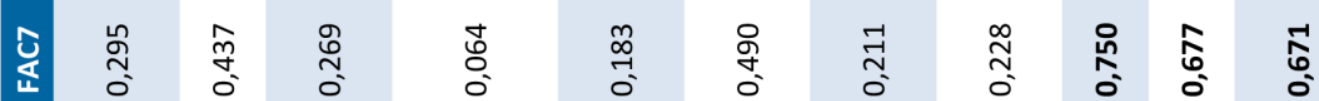

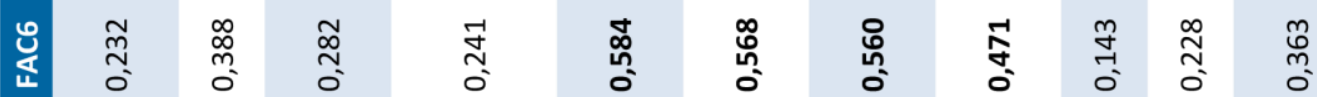

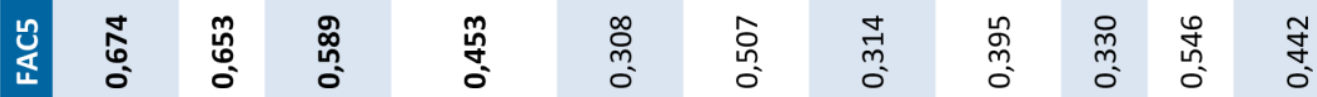

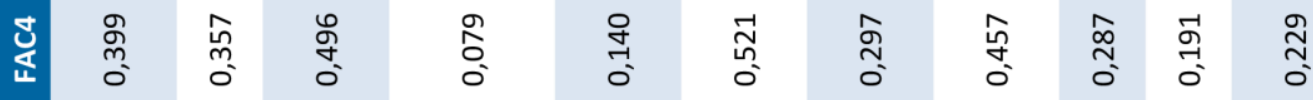

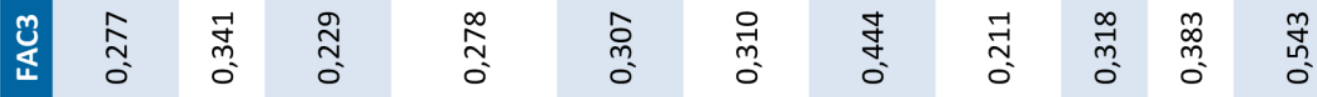

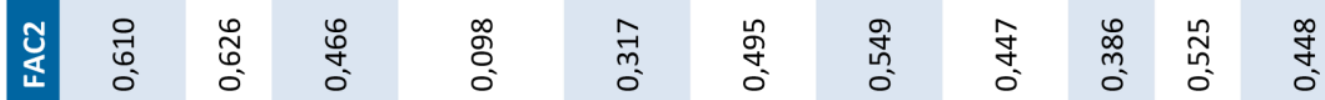

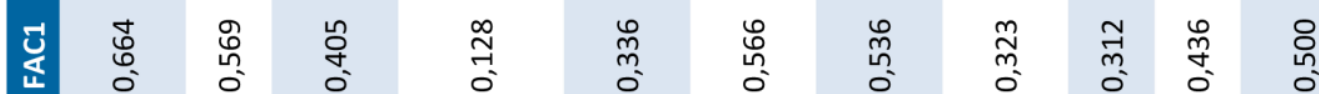

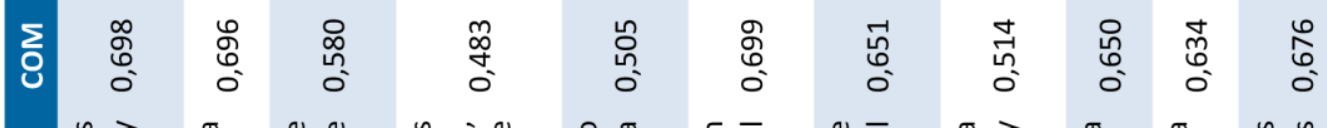

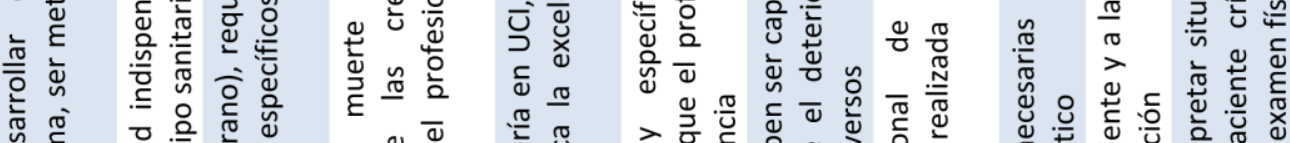

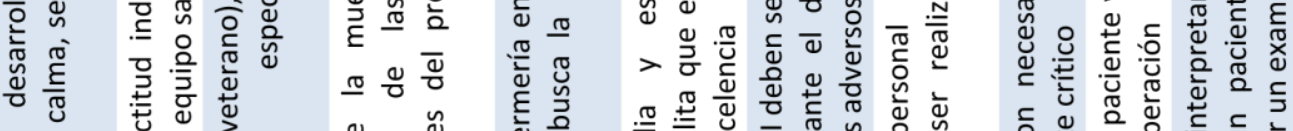
○

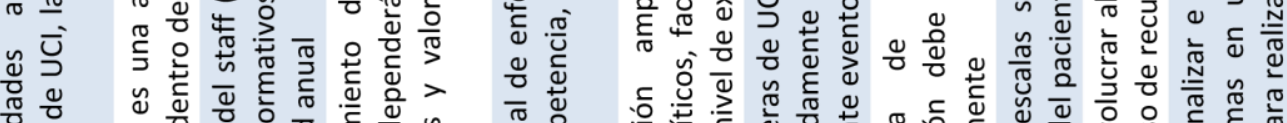
范

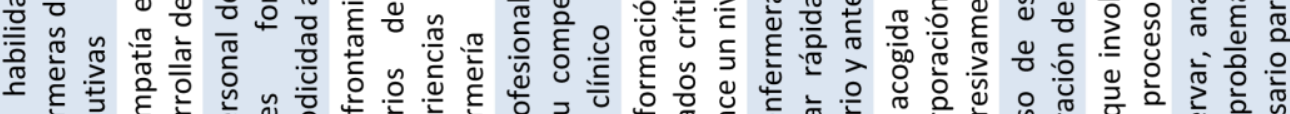

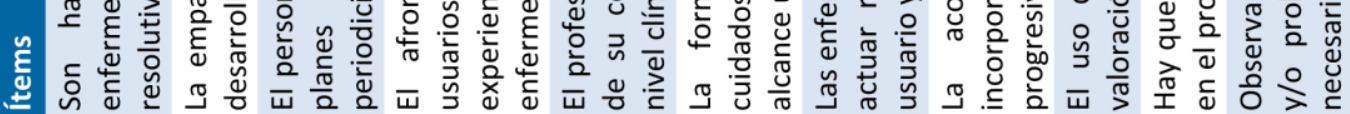
$\hat{\imath}$
8
ร $ก$ 


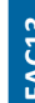

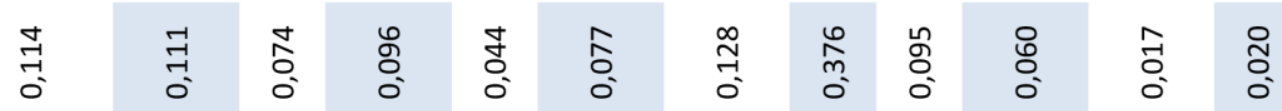

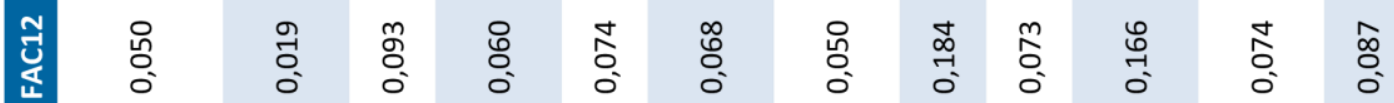

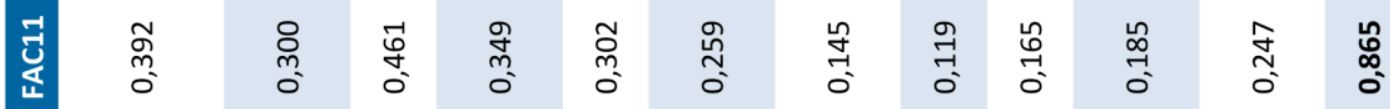

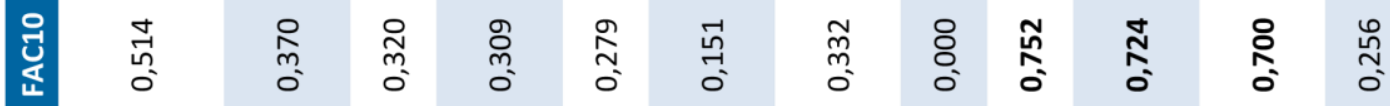

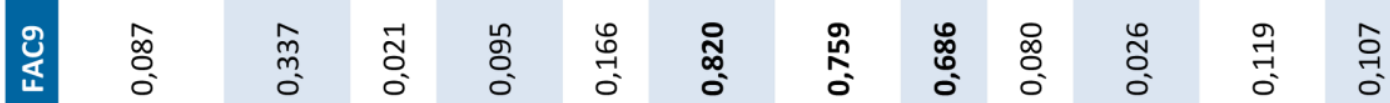

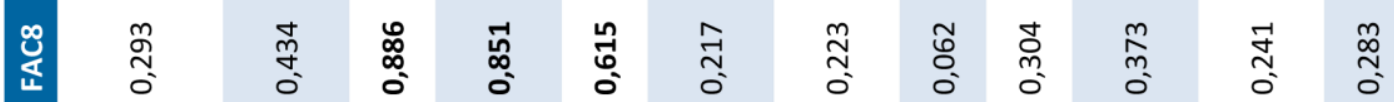

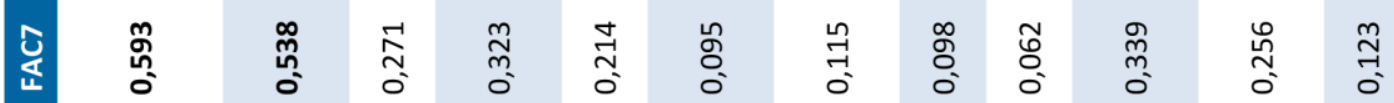

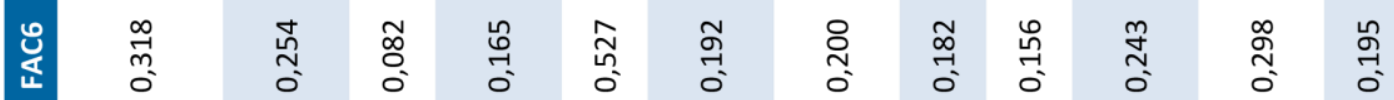

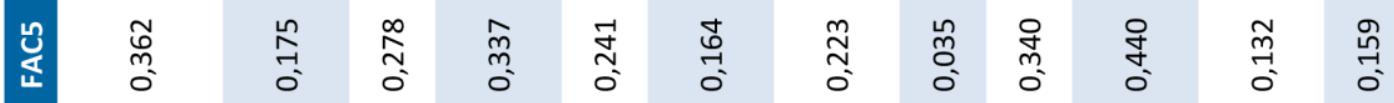

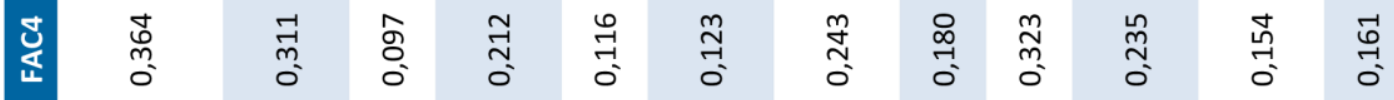

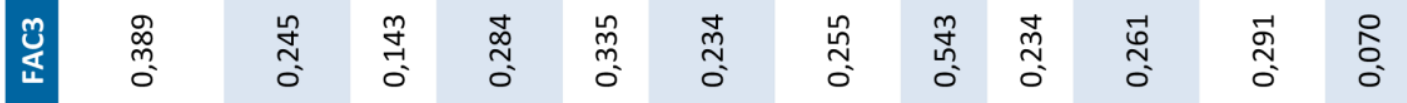

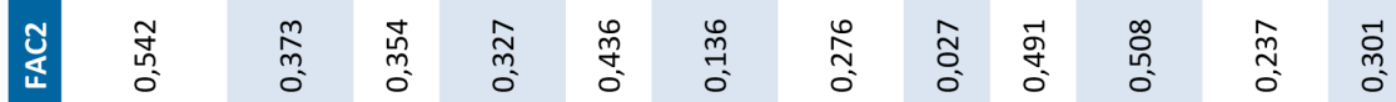

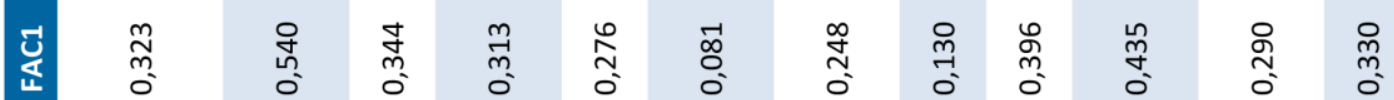

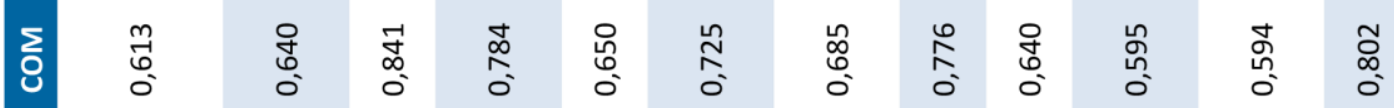

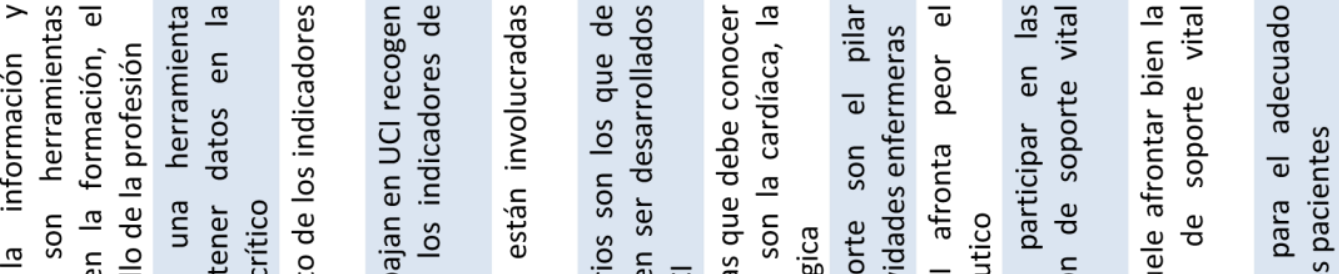

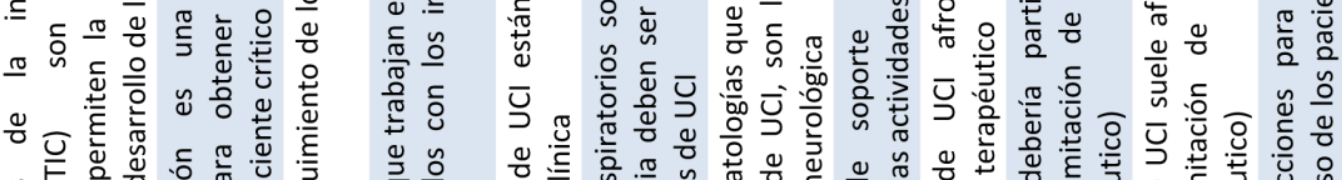

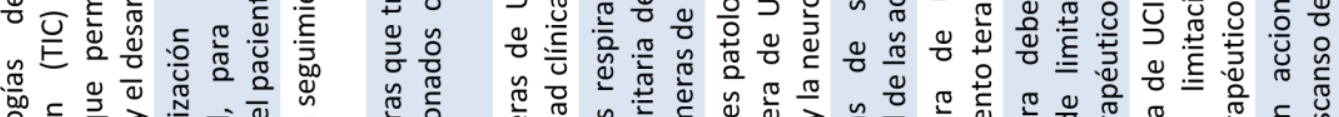

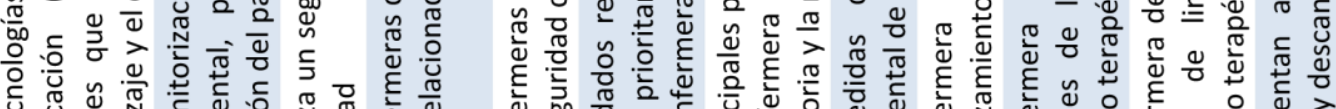

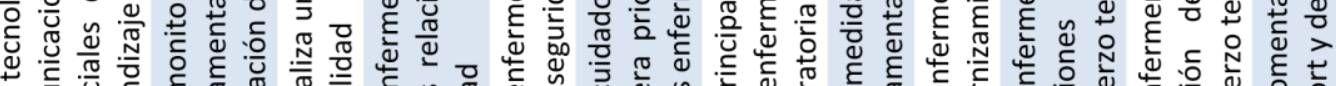

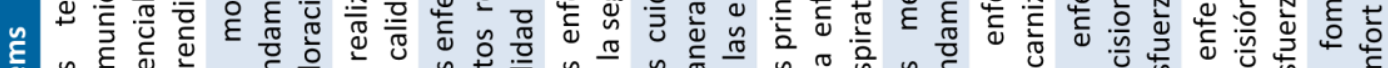

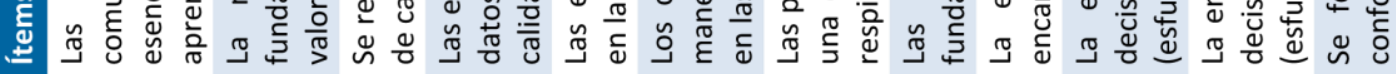
$\stackrel{\infty}{m}$
$\stackrel{n}{\circ}$
우 각
$\Rightarrow \stackrel{n}{ }$
$\stackrel{\Delta}{ }$
$\stackrel{\sim}{\sim}$ 


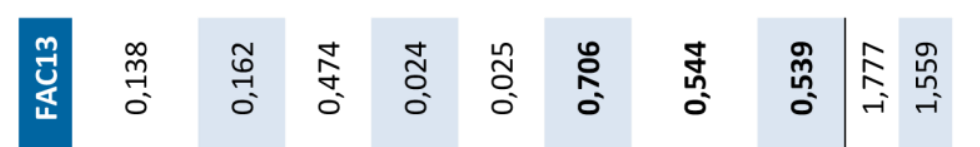

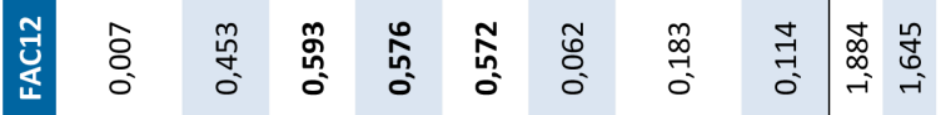

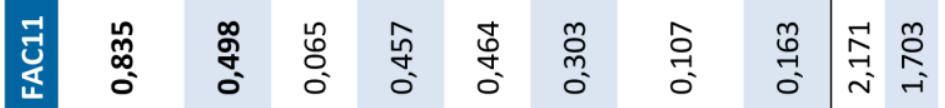

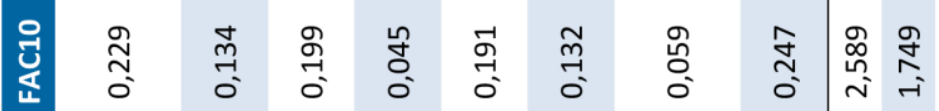

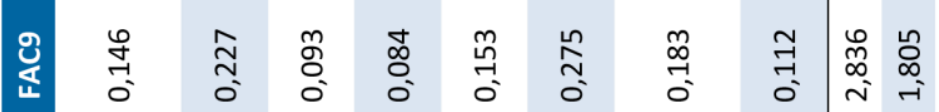

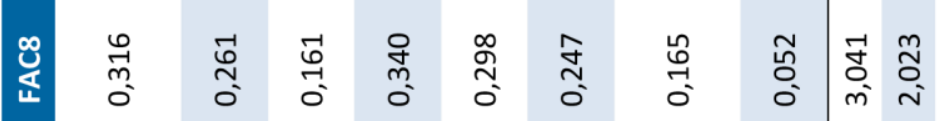

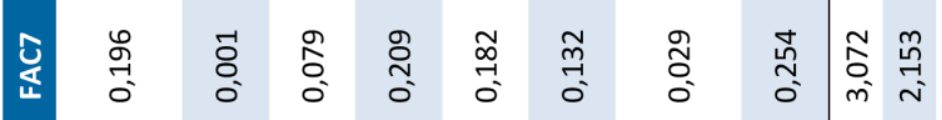

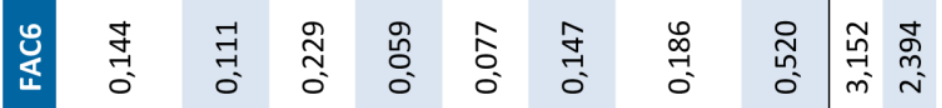

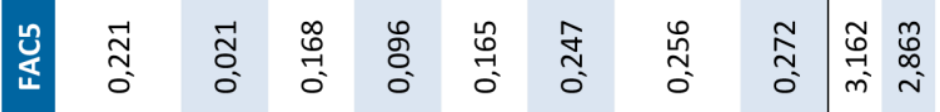

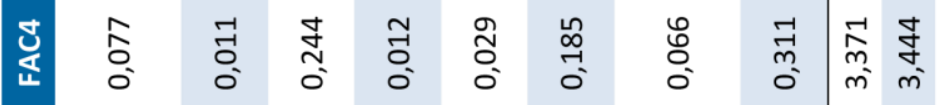

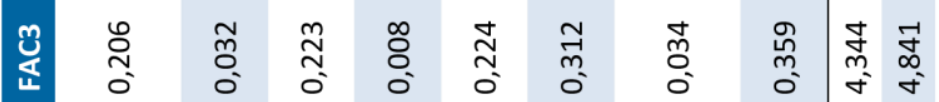

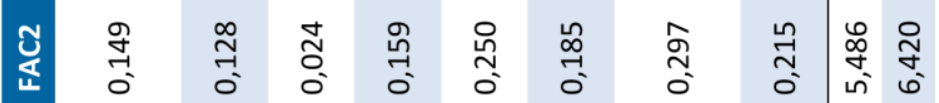

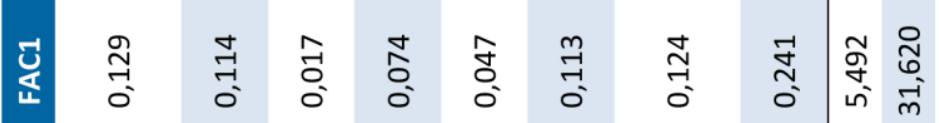

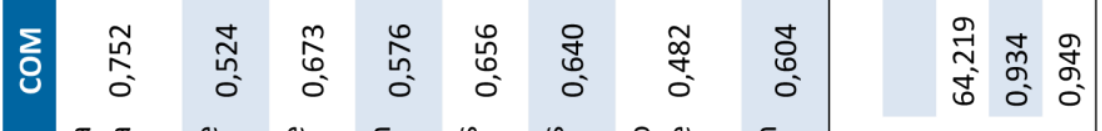

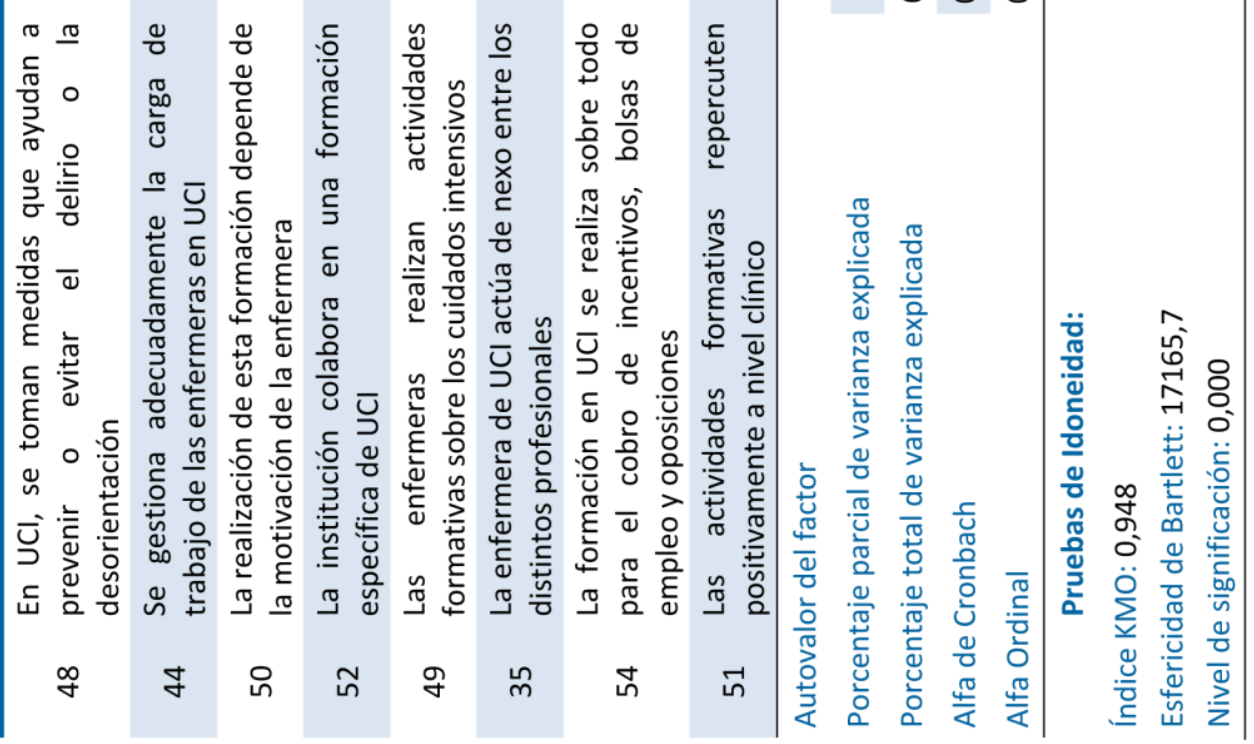




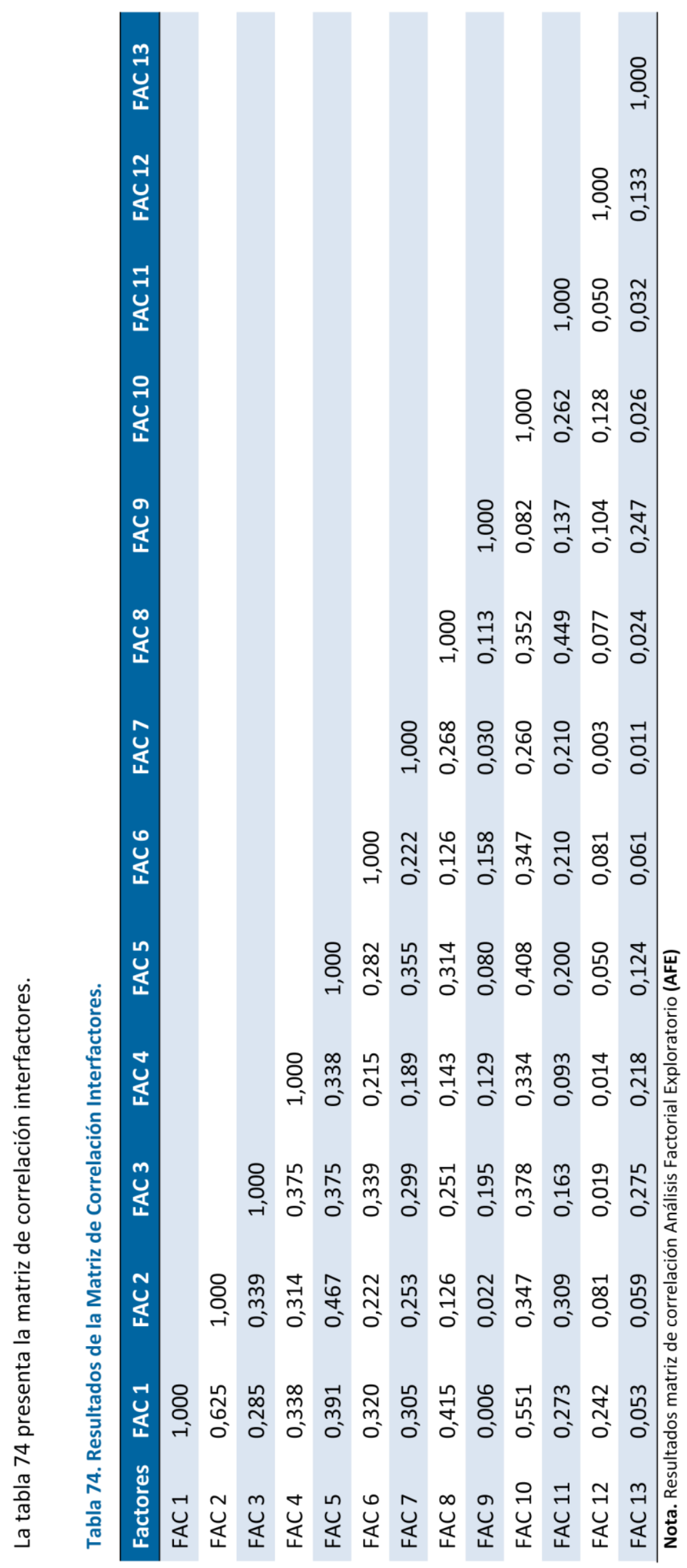


El AFE generó 13 factores y los análisis son satisfactorios debido a que la solución factorial creada explica el $64,219 \%$ de la varianza total. Además, podemos observar como las correlaciones entre los ítems que componen los distintos factores son elevados con cargas factoriales superiores o próximas a 0,5. Las proporciones de la varianza total explicadas a través de las comunalidades de cada ítem explican más de la mitad de la variabilidad de las respuestas de los encuestados, con la mayoría de las comunalidades entorno al $50 \%$.

Para una mejor valoración de las distintas dimensiones extraídas del análisis factorial se ha procedido a crear 13 variables con los valores medios de cada uno de los ítems que conforman cada factor y que se describen con los valores resultantes que se muestran en la tabla 75.

Tabla 75. Análisis descriptivo de los factores de la escala de Necesidades Formativas de las Enfermeras de UCl.

\begin{tabular}{|c|c|c|c|c|}
\hline Factoriales & Media & D.T & Test K-S & IC-95\% \\
\hline Habilidades en el cuidado del paciente critico & 9,28 & 0,61 & 0,000 & $9,23-9,33$ \\
\hline Comunicación y seguridad clínica & 9,17 & 0,69 & 0,000 & $9,12-9,23$ \\
\hline Conocimientos enfermeros y razonamiento clínico & 9,28 & 0,58 & 0,000 & $9,24-9,33$ \\
\hline Planes de acogida para enfermeras noveles & 8,98 & 0,85 & 0,000 & $8,91-9,06$ \\
\hline $\begin{array}{l}\text { Formación específica y continuada de las enfermeras de } \\
\text { plantilla (staff) }\end{array}$ & 8,49 & 0,91 & 0,000 & $8,41-8,57$ \\
\hline Excelencia en cuidados & 9,09 & 0,73 & 0,000 & $9,04-9,16$ \\
\hline Evaluación del paciente crítico, herramientas y tecnología & 8,89 & 0,78 & 0,000 & $8,83-8,96$ \\
\hline Gestión sanitaria & 7,62 & 1,55 & 0,000 & $7,49-7,75$ \\
\hline Aplicación de medidas de soporte & 8,10 & 1,32 & 0,000 & $7,99-8,21$ \\
\hline Toma de decisiones y afrontamiento al final de la vida & 8,38 & 1,24 & 0,000 & $8,28-8,48$ \\
\hline Medidas para mejorar el cuidado & 6,90 & 1,46 & 0,000 & $6,78-7,03$ \\
\hline Motivación para continuar con la formación & 7,32 & 1,43 & 0,000 & $7,21-7,44$ \\
\hline Repercusión de la formación & 8,05 & 1,16 & 0,000 & $7,96-8,15$ \\
\hline
\end{tabular}

Nota. Resultados expresados en media y desviación típica (DT). Prueba de Kolmogorov-Smirnov (K-S). p valor: $p<0,05$. Nivel de confianza (IC-95\%)

Como se puede observar ninguno de los factores creados tiene una distribución normal, por tanto, estas valoraciones están influenciadas por los distintos elementos que caractericen las opiniones de los encuestados, a través de sus experiencias, vivencias y conocimientos. Podemos observar como los factores hallados a través del AFE, pueden agruparse por dominios, según la esfera de actuación sobre las necesidades formativas de las enfermeras de UCI. 
Tabla 76. Agrupación de factoriales a través de los dominios en los cuales se pueden incluir.

\begin{tabular}{|c|c|c|c|c|}
\hline $\begin{array}{c}\text { Destrezas e } \\
\text { intervenciones }\end{array}$ & $\begin{array}{l}\text { Conocimientos } \\
\text { enfermeros }\end{array}$ & $\begin{array}{l}\text { Razonamiento } \\
\text { del cuidado }\end{array}$ & $\begin{array}{c}\text { Valores } \\
\text { personales }\end{array}$ & $\begin{array}{l}\text { Elementos de la } \\
\text { formación }\end{array}$ \\
\hline $\begin{array}{l}\text { Habilidades en el } \\
\text { cuidado del paciente } \\
\text { crítico }\end{array}$ & $\begin{array}{l}\text { Conocimientos } \\
\text { enfermeros } \\
\text { razonamiento } \\
\text { clínico }\end{array}$ & $\begin{array}{lr}\text { Medidas } & \text { para } \\
\text { mejorar } & \text { el } \\
\text { cuidado } & \end{array}$ & \multirow{4}{*}{$\begin{array}{l}\text { Motivación para } \\
\text { continuar con la } \\
\text { formación }\end{array}$} & $\begin{array}{l}\text { Planes de acogida } \\
\text { para enfermeras } \\
\text { noveles }\end{array}$ \\
\hline $\begin{array}{l}\text { Comunicación } \\
\text { seguridad clínica }\end{array}$ & \multirow[b]{2}{*}{$\begin{array}{l}\text { Toma de decisiones } \\
\text { y afrontamiento al } \\
\text { final de la vida }\end{array}$} & \multirow{3}{*}{$\begin{array}{l}\text { Excelencia en } \\
\text { cuidados }\end{array}$} & & Formación específica \\
\hline $\begin{array}{lr}\text { Evaluación } & \text { del } \\
\text { paciente } & \text { crítico, } \\
\text { herramientas } & y \\
\text { tecnología } & \end{array}$ & & & & $\begin{array}{ll}\text { y continuada de las } \\
\text { enfermeras de } \\
\text { plantilla (staff) }\end{array}$ \\
\hline $\begin{array}{l}\text { Aplicación de medidas } \\
\text { de soporte }\end{array}$ & Gestión sanitaria & & & $\begin{array}{l}\text { Repercusión de la } \\
\text { formación }\end{array}$ \\
\hline
\end{tabular}

\subsubsection{Análisis de las dimensiones de las necesidades formativas en función de las características} demográficas.

En este apartado se presentan los resultados de evaluar las diferencias entre necesidades formativas, utilizando las dimensiones generadas por el análisis factorial, en función de las variables que caracterizan a la muestra.

\section{En función del género.}

El análisis de esta sección fue realizado mediante la t de Student para varianzas iguales. Se observan diferencias significativas en tres dimensiones, son las mujeres quienes han puntuado más alto o más positivamente estas dimensiones, ver tabla 77.

Tabla 77. Análisis de las diferencias de las dimensiones detectadas en función del género.

\begin{tabular}{|c|c|c|c|c|c|c|c|c|}
\hline \multirow[t]{2}{*}{ Dimensiones } & \multicolumn{2}{|c|}{$\begin{array}{l}\text { Hombres } \\
(n=106)\end{array}$} & \multicolumn{2}{|c|}{$\begin{array}{l}\text { Mujeres } \\
(n=462)\end{array}$} & \multicolumn{2}{|c|}{$\begin{array}{l}\text { Prueba } \\
\text { Levene }\end{array}$} & \multirow[t]{2}{*}{$\mathbf{t}$} & \multirow[t]{2}{*}{$p$} \\
\hline & Media & D.T. & Media & D.T. & $\mathbf{F}$ & $p$ & & \\
\hline $\begin{array}{l}\text { Habilidades en el cuidado del } \\
\text { paciente critico }\end{array}$ & 9,19 & 0,60 & 9,30 & 0,62 & 0,452 & 0,502 & 1,758 & 0,079 \\
\hline $\begin{array}{l}\text { Comunicación y seguridad } \\
\text { clínica }\end{array}$ & 9,09 & 0,70 & 9,19 & 0,64 & 0,001 & 0,979 & 1,419 & 0,157 \\
\hline $\begin{array}{l}\text { Conocimientos enfermeros y } \\
\text { razonamiento clínico }\end{array}$ & 9,19 & 0,59 & 9,31 & 0,57 & 0,152 & 0,697 & 1,875 & 0,061 \\
\hline $\begin{array}{l}\text { Planes de acogida para } \\
\text { enfermeras noveles }\end{array}$ & 8,84 & 0,99 & 9,02 & 0,81 & 2,865 & 0,091 & 1,985 & 0,048 \\
\hline $\begin{array}{l}\text { Formación específica y } \\
\text { continuada de las enfermeras } \\
\text { de plantilla (staff) }\end{array}$ & 8,52 & 0,88 & 8,48 & 0,92 & 0,338 & 0,561 & 0,427 & 0,669 \\
\hline Excelencia en cuidados & 8,98 & 0,82 & 9,12 & 0,71 & 3,450 & 0,064 & 1,758 & 0,079 \\
\hline $\begin{array}{l}\text { Evaluación del paciente crítico, } \\
\text { herramientas y tecnología }\end{array}$ & 8,78 & 0,82 & 8,92 & 0,78 & 0,672 & 0,413 & 1,656 & 0,098 \\
\hline Gestión sanitaria & 7,52 & 1,57 & 7,64 & 1,54 & 0,269 & 0,604 & 0,725 & 0,469 \\
\hline
\end{tabular}




\begin{tabular}{|c|c|c|c|c|c|c|c|c|}
\hline \multirow[t]{2}{*}{ Dimensiones } & \multicolumn{2}{|c|}{$\begin{array}{l}\text { Hombres } \\
(n=106)\end{array}$} & \multicolumn{2}{|c|}{$\begin{array}{l}\text { Mujeres } \\
(n=462)\end{array}$} & \multicolumn{2}{|c|}{$\begin{array}{l}\text { Prueba } \\
\text { Levene }\end{array}$} & \multirow[t]{2}{*}{$\mathbf{t}$} & \multirow[t]{2}{*}{$p$} \\
\hline & Media & D.T. & Media & D.T. & $\mathbf{F}$ & $p$ & & \\
\hline $\begin{array}{l}\text { Aplicación de medidas de } \\
\text { soporte }\end{array}$ & 7,75 & 1,41 & 8,18 & 1,29 & 1,111 & 0,292 & 3,006 & 0,003 \\
\hline $\begin{array}{l}\text { Toma de decisiones y } \\
\text { afrontamiento al final de la vida }\end{array}$ & 8,28 & 1,23 & 8,40 & 1,25 & 0,019 & 0,890 & 0,850 & 0,396 \\
\hline $\begin{array}{l}\text { Medidas para mejorar el } \\
\text { cuidado }\end{array}$ & 6,43 & 1,54 & 7,01 & 1,43 & 1,495 & 0,222 & 3,680 & $<0,001$ \\
\hline $\begin{array}{l}\text { Motivación para continuar con } \\
\text { la formación }\end{array}$ & 7,13 & 1,42 & 7,37 & 1,44 & 0,124 & 0,725 & 1,551 & 0,122 \\
\hline Repercusión de la formación & 8,07 & 1,25 & 8,04 & 1,15 & 1,388 & 0,238 & 0,221 & 0,825 \\
\hline
\end{tabular}

Nota. Prueba t de Student ( $\boldsymbol{t})$. $\mathbf{p}$ valor: $p<0,05$.

\section{En función de la edad.}

Se analizan las 13 dimensiones en función de los grupos de edad ( $\leq 35$ años, 36-40 años, 41-45 años y $>45$ años). Para este análisis se utilizó la prueba no paramétrica de Jonckheere-Terpstra y se incluyeron los 568 participantes del grupo nacional, ver tabla 78.

Tabla 78. Test de Jonckheere-Terpstra para las dimensiones detectadas en función de los 4 niveles de rango de edad de los encuestados.

\begin{tabular}{|c|c|c|c|c|}
\hline Dimensiones & $\begin{array}{l}\text { Estadístico J-T } \\
\text { observado }\end{array}$ & $\begin{array}{c}\text { Error } \\
\text { típico } \\
\text { J-T }\end{array}$ & $\begin{array}{l}\text { Estadístico J-T } \\
\text { tipificado }\end{array}$ & $p$ \\
\hline Habilidades en el cuidado del paciente critico & 69880 & 2177,16 & 4,421 & $<0,001$ \\
\hline Comunicación y seguridad clínica & 68001 & 2173,95 & 3,563 & $<0,001$ \\
\hline $\begin{array}{l}\text { Conocimientos enfermeros y razonamiento } \\
\text { clínico }\end{array}$ & 60708,5 & 2176,20 & 0,208 & 0,835 \\
\hline Planes de acogida para enfermeras noveles & 63141,5 & 2177,90 & 0,208 & 0,835 \\
\hline $\begin{array}{l}\text { Formación específica y continuada de las } \\
\text { enfermeras de plantilla (staff) }\end{array}$ & 64182 & 2180,54 & 1,801 & 0,072 \\
\hline Excelencia en cuidados & 63348,5 & 2172,10 & 1,424 & 0,154 \\
\hline $\begin{array}{l}\text { Evaluación del paciente crítico, herramientas y } \\
\text { tecnología }\end{array}$ & 67068 & 2176,33 & 3,130 & 0,006 \\
\hline Gestión sanitaria & 66444,5 & 2178,50 & 2,841 & 0,001 \\
\hline Aplicación de medidas de soporte & 60944 & 2174,37 & 0,317 & 0,752 \\
\hline $\begin{array}{l}\text { Toma de decisiones y afrontamiento al final de la } \\
\text { vida }\end{array}$ & 68947,5 & 2174,77 & 3,997 & $<0,001$ \\
\hline Medidas para mejorar el cuidado & 62535,5 & 2177,79 & 1,047 & 0,295 \\
\hline Motivación para continuar con la formación & 61181,5 & 2175,63 & 0,426 & 0,670 \\
\hline Repercusión de la formación & 59233,5 & 2174,80 & 0,470 & 0,638 \\
\hline
\end{tabular}

Nota. Prueba de Jonckheere-Terpstra (Prueba J-T). p valor: $p<0,05$

En estos análisis por parejas la prueba de Jonckheere-Terpstra indicó que en la dimensión "Habilidades en el cuidado del paciente crítico" las diferencias se hallaron entre los grupos: 36-40 años y 41-45 años ( $p=0,002)$; entre 36-40 años y $>45$ años $(p<0,001)$; $y \leq 35$ años y $>45$ años $(p<0,001)$, tal y como se observa en la figura 30 . 
En la dimensión de comunicación y seguridad clínica se puede observar que el grupo de 36-40 años es el que menor rango promedio presenta. Las diferencias significativas son 36-40 años y 41-45 años $(p=0,029)$; entre $36-40$ años $y>45$ años $(p<0,001)$ y entre $\leq 35$ años y $>45$ años $(p=0,002)$. Estos resultados quedan representados en la figura 31.

Figura 30. Comparación por parejas de los grupos de edad de los encuestados y la dimensión habilidades en el cuidado del paciente crítico.

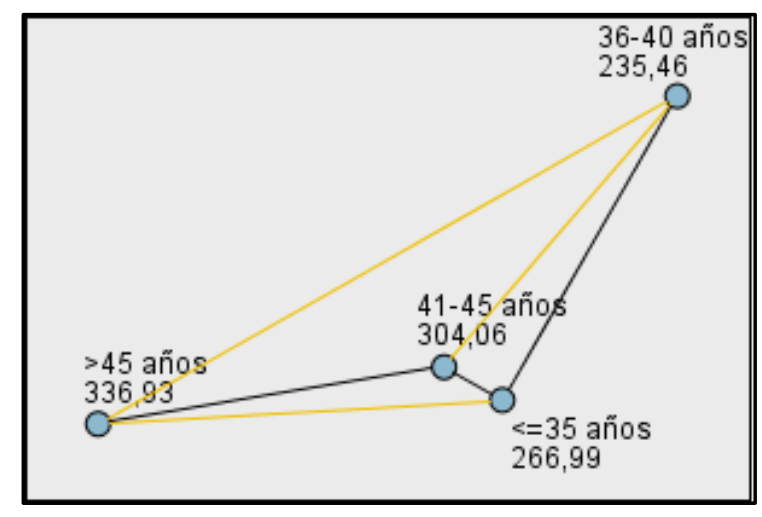

Figura 31. Comparación por parejas de los grupos de edad de los encuestados y la dimensión comunicación y seguridad clínica.

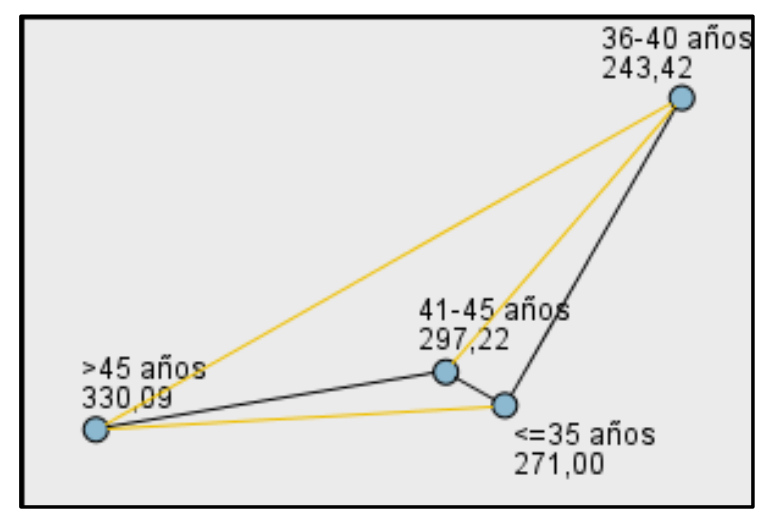

En lo referente a la dimensión de "Evaluación del paciente crítico, herramientas y tecnología" (Figura 32) resulta destacable que es el grupo de 36-40 años el que presenta una valoración menor en esta dimensión de la formación enfermera. Se observan diferencias significativas entre este grupo y los dos grupos de mayor edad, 41-45 años y >45 años, con un nivel de significancia de 0,002 y 0,001, respectivamente, ver figura 32. En la dimensión "Gestión sanitaria", el grupo con mayor puntuación es el grupo de $>45$ años, con un rango promedio de 324,40 muy diferente al de los grupos de las enfermeras más jóvenes, $\leq 35$ años con $273,25(p=0,014)$ y el grupo de $36-40$ años con rango de $259,65$ ( $p=0,005)$, figura 33 .

La figura 34 presenta los resultados relacionados con la formación en la toma de decisiones y el afrontamiento al final de la vida. Se observan diferencias significativas de $(p<0,001 ; p<0,001$ y $p=0,046$ ) en sentido ascendente de los grupos. La conciencia de esta formación se estructura progresivamente con los años e incluso se observa como el grupo colindante de 41-45 años, es significativo por un estrecho margen. 
Figura 32. Comparación por parejas de los grupos de edad de los encuestados y la dimensión evaluación del paciente crítico, herramientas y tecnología.

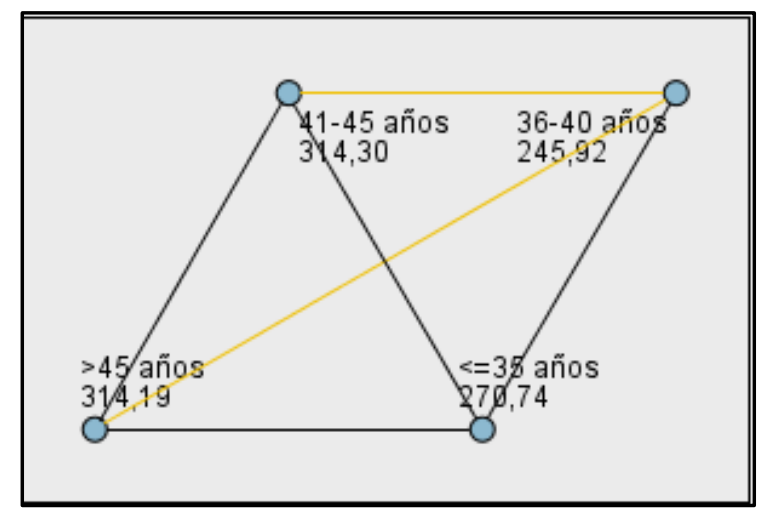

Figura 33. Comparación por parejas de los grupos de edad de los encuestados y la dimensión gestión sanitaria.

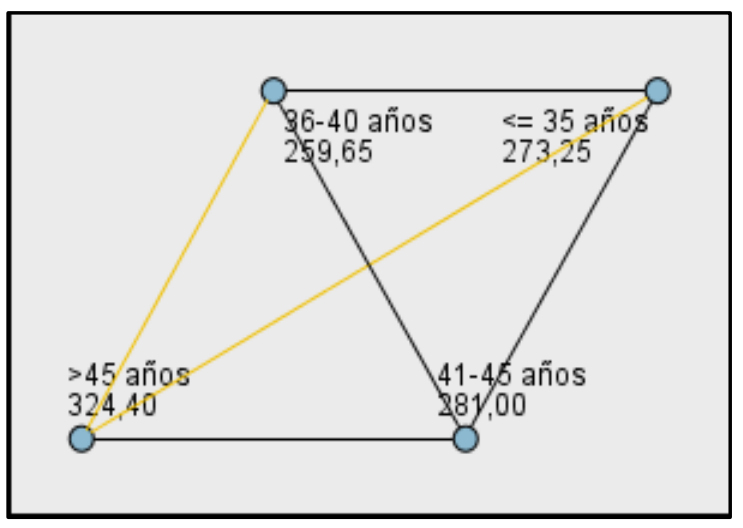

Figura 34. Comparación por parejas de los grupos de edad de los encuestados y la dimensión toma de decisiones y afrontamiento al final de la vida.

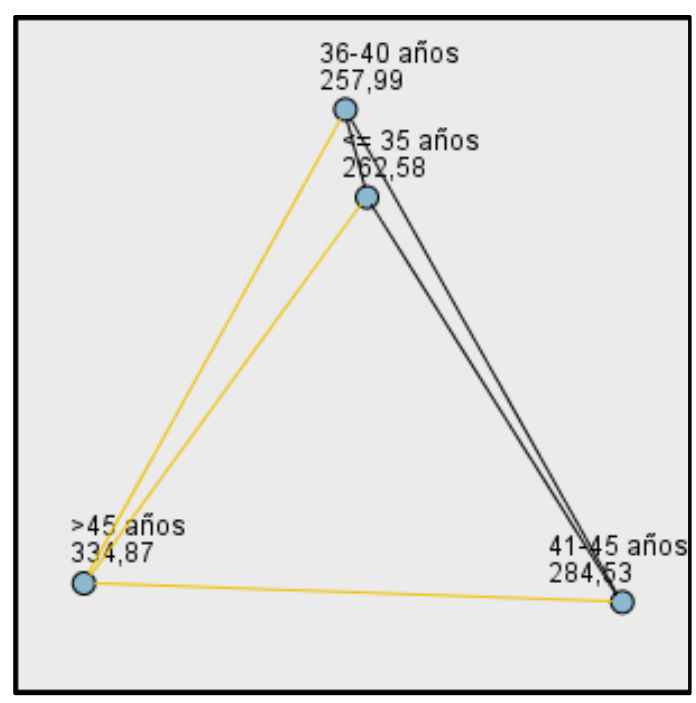

En función del máximo grado académico alcanzado.

Como se pudo observar al analizar los ítems de manera individual y en las distintas agrupaciones del cuestionario había diferencias significativas según el grado académico de los encuestados (grado, experto universitario, máster como título propio de la universidad y postgrado oficial). Se precisó conocer si este hecho también influía en las 13 dimensiones. El análisis se realizó mediante la prueba de Jonckheere-Terpstra, ver tabla 79. 
Tabla 79. Test de Jonckheere-Terpstra para las dimensiones detectadas en función del máximo rango académico alcanzado por los encuestados.

\begin{tabular}{|c|c|c|c|c|}
\hline Dimensiones & $\begin{array}{l}\text { Estadístico J- } \\
\text { T observado }\end{array}$ & $\begin{array}{l}\text { Error típico } \\
\qquad \mathrm{J}-\mathrm{T}\end{array}$ & $\begin{array}{l}\text { Estadístico J- } \\
\text { T tipificado }\end{array}$ & $p$ \\
\hline Habilidades en el cuidado del paciente critico & 48661 & 2070,77 & $-1,892$ & 0,059 \\
\hline Comunicación y seguridad clínica & 49141 & 2067,71 & $-1,662$ & 0,096 \\
\hline Conocimientos enfermeros y razonamiento clínico & 54948,5 & 2069,86 & 1,145 & 0,252 \\
\hline Planes de acogida para enfermeras noveles & 56105 & 2071,47 & 1,702 & 0,089 \\
\hline $\begin{array}{l}\text { Formación específica y continuada de las enfermeras } \\
\text { de plantilla (staff) }\end{array}$ & 57242,5 & 2073,98 & 2,249 & 0,025 \\
\hline Excelencia en cuidados & 52533 & 2065,96 & $-0,022$ & 0,982 \\
\hline $\begin{array}{l}\text { Evaluación del paciente crítico, herramientas y } \\
\text { tecnología }\end{array}$ & 52912,5 & 2069,98 & 0,161 & 0,872 \\
\hline Gestión sanitaria & 52593 & 2072,04 & 0,007 & 0,994 \\
\hline Aplicación de medidas de soporte & 51918 & 2068,11 & $-0,319$ & 0,749 \\
\hline Toma de decisiones y afrontamiento al final de la vida & 46985 & 2068,50 & $-2,714$ & 0,007 \\
\hline Medidas para mejorar el cuidado & 55431,5 & 2071,36 & 1,377 & 0,168 \\
\hline Motivación para continuar con la formación & 60941,5 & 2069,31 & 4,041 & $<0,001$ \\
\hline Repercusión de la formación & 59183,5 & 2068,53 & 3,193 & 0,001 \\
\hline
\end{tabular}

Nota. Prueba de Jonckheere-Terpstra (Prueba J-T). p valor: $p<0,05$

Resultaron afectadas por la formación académica del entrevistado 4 dimensiones. Es el grupo con mayor formación académica el que consideró más importante la formación continuada de las enfermeras de cuidados intensivos. Los resultados significativos fueron: con el grupo de grado universitario $(p=0,005)$ y con el grupo de experto universitario $(p<0,001)$, figura 35 .

También se extrae de este análisis que la toma de decisiones es muy valorada por todas las enfermeras, pero resulta sólo significativo entre las enfermeras de grado y las de máster como título propio de Universidad $(\mathrm{p}=0,004)$. La asociación presenta un rango negativo, por lo cual los encuestados con menor grado académico lo valoran más positivamente, tal y como se puede observar en la figura 36.

Figura 35. Comparación por parejas del nivel académico de las enfermeras encuestadas y la dimensión formación específica y continuada de las enfermeras de plantilla (staff).

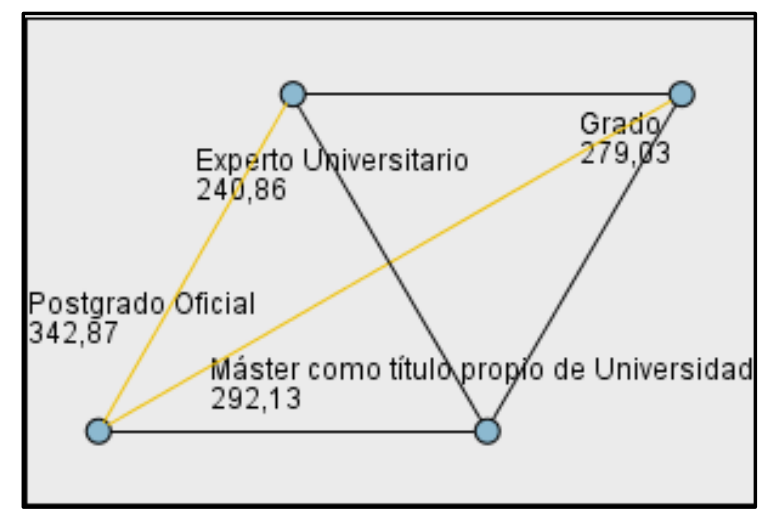

Figura 36. Comparación por parejas del nivel académico de las enfermeras encuestadas y la dimensión toma de decisiones y afrontamiento al final de la vida.

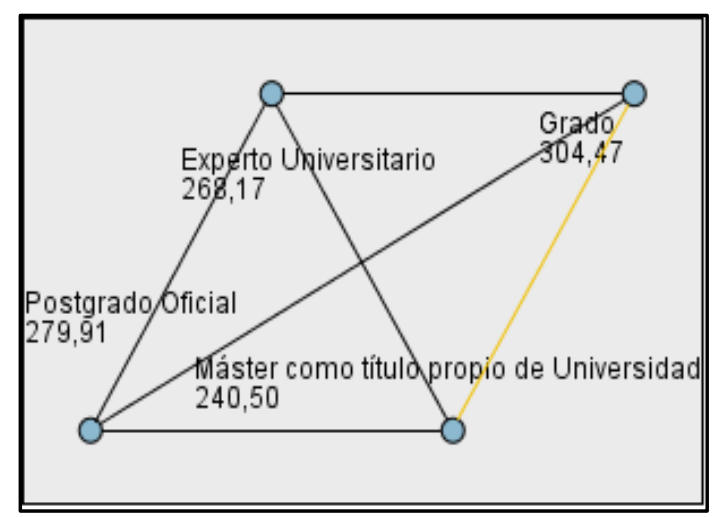


En cuanto a la dimensión "Motivación para continuar con la formación" se observó que los niveles académicos inferiores grado y experto universitario mostraron rangos menores y significativos con los dos niveles universitarios superiores. Por un lado, las enfermeras con máster como título propio de Universidad presentaban resultados significativos con el grupo de grado $(p=0,001)$ y con el grupo de experto universitario respectivamente $(p=0,007)$. Por otra parte, las enfermeras con postgrado oficial presentaban diferencias con los mismos grupos, siendo el valor $p$ de 0,005 con el grado universitario, y el valor $p$ de 0,018 con experto universitario. Ver figura 37.

En la dimensión "Repercusión de la formación" encontramos diferencias entre el grado con un rango promedio menor y los grupos de experto universitario y máster como título propio de Universidad, con unos valores de significancia estadística de $(p<0,001)$ y $(p=0,021)$ respectivamente. Estos resultados se pueden observar en la figura 38.

Figura 37. Comparación por parejas del nivel Figura 38. Comparación por parejas del nivel académico de las enfermeras encuestadas y la académico de las enfermeras encuestadas y la dimensión motivación para continuar con la dimensión repercusión de la formación.

formación.
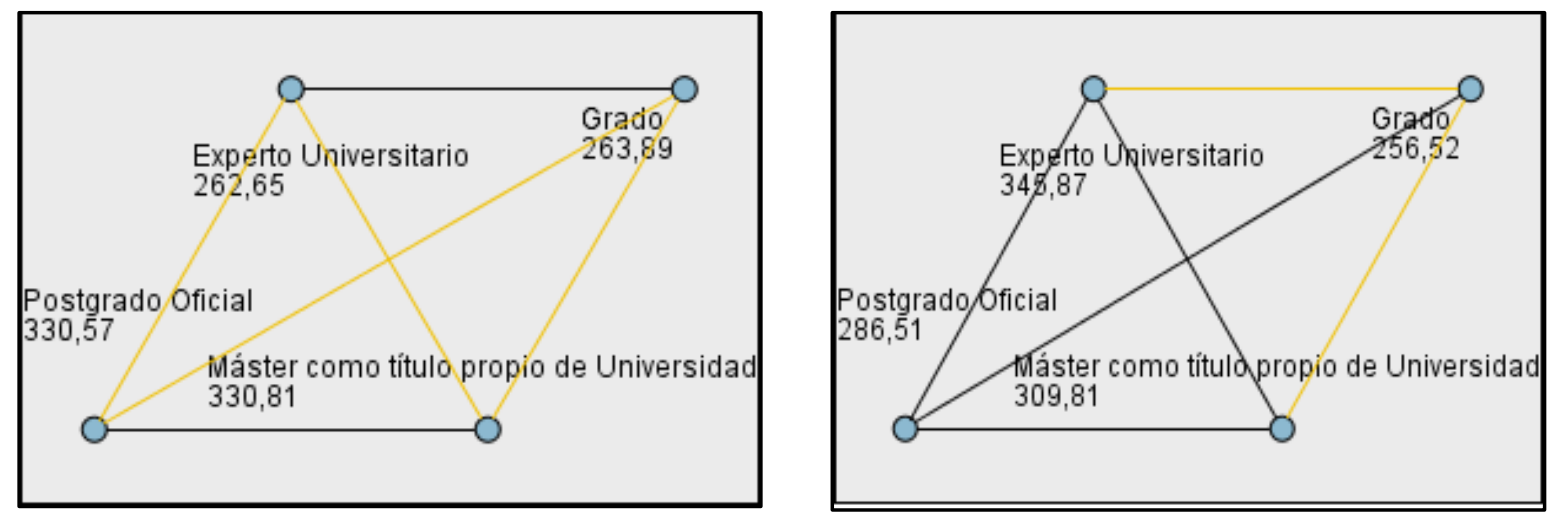

En función del tipo de gestión del Hospital.

A continuación, se analizó si el nivel de gestión de un hospital (gestión pública y gestión privadamixta en un mismo grupo) determinaba diferencias en alguna de las 13 dimensiones. Como se puede observar en la tabla 80, la gestión hospitalaria no modificó ninguna dimensión.

Tabla 80. Diferencias en la valoración de las dimensiones detectadas en función del tipo de gestión hospitalaria.

\begin{tabular}{|c|c|c|c|c|c|c|c|c|}
\hline \multirow[t]{2}{*}{ Dimensiones } & \multicolumn{2}{|c|}{$\begin{array}{l}\text { Gestión Pública } \\
\qquad(n=520)\end{array}$} & \multicolumn{2}{|c|}{$\begin{array}{l}\text { Gestión Mixta-Privada } \\
\qquad(\mathrm{n}=48)\end{array}$} & \multicolumn{2}{|c|}{ Prueba Levene } & \multirow[t]{2}{*}{$t$} & \multirow[t]{2}{*}{$p$} \\
\hline & Media & D.T. & Media & D.T. & $\mathbf{F}$ & $p$ & & \\
\hline $\begin{array}{l}\text { Habilidades en el cuidado del } \\
\text { paciente critico }\end{array}$ & 9,27 & 0,62 & 9,42 & 0,52 & 4,999 & 0,027 & 1,909 & 0,061 \\
\hline $\begin{array}{l}\text { Comunicación y seguridad } \\
\text { clínica }\end{array}$ & 9,16 & 0,70 & 9,25 & 0,64 & 2,667 & 0,103 & 0,822 & 0,412 \\
\hline $\begin{array}{l}\text { Conocimientos enfermeros y } \\
\text { razonamiento clínico }\end{array}$ & 9,29 & 0,58 & 9,23 & 0,60 & 0,228 & 0,633 & 0,721 & 0,471 \\
\hline
\end{tabular}




\begin{tabular}{|c|c|c|c|c|c|c|c|c|}
\hline \multirow[t]{2}{*}{ Dimensiones } & \multicolumn{2}{|c|}{$\begin{array}{l}\text { Gestión Pública } \\
\qquad(n=520)\end{array}$} & \multicolumn{2}{|c|}{$\begin{array}{l}\text { Gestión Mixta-Privada } \\
\qquad(n=48)\end{array}$} & \multicolumn{2}{|c|}{ Prueba Levene } & \multirow[t]{2}{*}{$t$} & \multirow[t]{2}{*}{$p$} \\
\hline & Media & D.T. & Media & D.T. & $\mathbf{F}$ & $p$ & & \\
\hline $\begin{array}{l}\text { Planes de acogida para } \\
\text { enfermeras noveles }\end{array}$ & 8,99 & 0,85 & 8,89 & 0,84 & 0,102 & 0,750 & 0,827 & 0,409 \\
\hline $\begin{array}{l}\text { Formación específica y } \\
\text { continuada de las enfermeras } \\
\text { de plantilla (staff) }\end{array}$ & 8,49 & 0,90 & 8,48 & 1,01 & 0,126 & 0,723 & 0,093 & 0,926 \\
\hline Excelencia en cuidados & 9,10 & 0,72 & 9,09 & 0,82 & 0,969 & 0,325 & 0,055 & 0,956 \\
\hline $\begin{array}{l}\text { Evaluación del paciente crítico, } \\
\text { herramientas y tecnología }\end{array}$ & 8,88 & 0,79 & 8,98 & 0,76 & 0,320 & 0,572 & 0,866 & 0,387 \\
\hline Gestión sanitaria & 7,61 & 1,54 & 7,76 & 1,62 & 0,223 & 0,637 & 0,639 & 0,523 \\
\hline $\begin{array}{l}\text { Aplicación de medidas de } \\
\text { soporte }\end{array}$ & 8,13 & 1,30 & 7,87 & 1,56 & 0,515 & 0,473 & 1,292 & 0,197 \\
\hline $\begin{array}{l}\text { Toma de decisiones y } \\
\text { afrontamiento al final de la vida }\end{array}$ & 8,37 & 1,26 & 8,55 & 1,11 & 0,951 & 0,330 & 1,008 & 0,314 \\
\hline $\begin{array}{l}\text { Medidas para mejorar el } \\
\text { cuidado }\end{array}$ & 6,91 & 1,49 & 6,88 & 1,22 & 1,803 & 0,180 & 0,113 & 0,910 \\
\hline $\begin{array}{l}\text { Motivación para continuar con } \\
\text { la formación }\end{array}$ & 7,35 & 1,42 & 7,05 & 1,61 & 0,773 & 0,380 & 1,369 & 0,171 \\
\hline Repercusión de la formación & 8,08 & 1,15 & 7,76 & 1,33 & 2,133 & 0,145 & 1,837 & 0,067 \\
\hline
\end{tabular}

Nota. Prueba t de Student (t). p valor: $p<0,05$.

En función de la relación con la universidad.

En este apartado se evaluó si las dimensiones generaban diferencias en función de si el hospital tenía vinculación o no con una universidad. Se establecieron diferencias significativas en seis de las trece dimensiones. Todas las diferencias siguieron la misma tendencia, donde las enfermeras de los centros no universitarios puntúan estas dimensiones con valores superiores. Ver tabla 81.

Tabla 81. Diferencias en la valoración de las dimensiones detectadas en función de la relación con la universidad.

\begin{tabular}{|c|c|c|c|c|c|c|c|c|}
\hline \multirow[t]{2}{*}{ Afirmaciones } & \multicolumn{2}{|c|}{$\begin{array}{l}\text { Centros Universitarios } \\
\qquad(n=491)\end{array}$} & \multicolumn{2}{|c|}{$\begin{array}{c}\text { Centros No } \\
\text { Universitarios }(n=77)\end{array}$} & \multicolumn{2}{|c|}{ Prueba Levene } & \multirow[t]{2}{*}{$t$} & \multirow[t]{2}{*}{$p$} \\
\hline & Media & D.T. & Media & D.T. & $\mathbf{F}$ & $p$ & & \\
\hline $\begin{array}{l}\text { Habilidades en el cuidado del } \\
\text { paciente critico }\end{array}$ & 9,25 & 0,62 & 9,49 & 0,52 & 5,374 & 0,021 & 3,650 & $<0,001$ \\
\hline Comunicación y seguridad clínica & 9,14 & 0,70 & 9,38 & 0,59 & 6,133 & 0,014 & 3,284 & 0,001 \\
\hline $\begin{array}{l}\text { Conocimientos enfermeros y } \\
\text { razonamiento clínico }\end{array}$ & 9,28 & 0,59 & 9,33 & 0,51 & 1,424 & 0,233 & 0,681 & 0,496 \\
\hline $\begin{array}{l}\text { Planes de acogida para enfermeras } \\
\text { noveles }\end{array}$ & 8,97 & 0,86 & 9,12 & 0,79 & 0,086 & 0,769 & 1,466 & 0,143 \\
\hline $\begin{array}{l}\text { Formación específica y continuada de } \\
\text { las enfermeras de plantilla (staff) }\end{array}$ & 8,49 & 0,92 & 8,47 & 0,88 & 0,238 & 0,626 & 0,196 & 0,844 \\
\hline Excelencia en cuidados & 9,06 & 0,74 & 9,32 & 0,63 & 3,357 & 0,067 & 2,925 & 0,004 \\
\hline $\begin{array}{l}\text { Evaluación del paciente crítico, } \\
\text { herramientas y tecnología }\end{array}$ & 8,86 & 0,80 & 9,10 & 0,64 & 2,381 & 0,123 & 2,472 & 0,014 \\
\hline Gestión sanitaria & 7,61 & 1,54 & 7,65 & 1,57 & 0,009 & 0,926 & 0,177 & 0,859 \\
\hline Aplicación de medidas de soporte & 8,08 & 1,38 & 8,28 & 0,86 & 10,982 & 0,001 & 1,798 & 0,074 \\
\hline $\begin{array}{l}\text { Toma de decisiones y afrontamiento } \\
\text { al final de la vida }\end{array}$ & 8,32 & 1,24 & 8,76 & 1,23 & 0,358 & 0,550 & 2,863 & 0,004 \\
\hline Medidas para mejorar el cuidado & 6,84 & 1,48 & 7,31 & 1,31 & 3,599 & 0,058 & 2,602 & 0,010 \\
\hline $\begin{array}{l}\text { Motivación para continuar con la } \\
\text { formación }\end{array}$ & 7,31 & 1,45 & 7,44 & 1,37 & 0,605 & 0,437 & 0,782 & 0,435 \\
\hline
\end{tabular}




\begin{tabular}{|c|c|c|c|c|c|c|c|c|}
\hline \multirow[t]{2}{*}{ Afirmaciones } & \multicolumn{2}{|c|}{$\begin{array}{l}\text { Centros Universitarios } \\
\qquad(\mathrm{n}=491)\end{array}$} & \multicolumn{2}{|c|}{$\begin{array}{c}\text { Centros No } \\
\text { Universitarios }(\mathbf{n}=\mathbf{7 7})\end{array}$} & \multicolumn{2}{|c|}{ Prueba Levene } & \multirow[t]{2}{*}{$\boldsymbol{t}$} & \multirow[t]{2}{*}{$p$} \\
\hline & Media & D.T. & Media & D.T. & $\mathbf{F}$ & $p$ & & \\
\hline Repercusión de la formación & 8,07 & 1,14 & 7,92 & 1,32 & 1,204 & 0,273 & 1,056 & 0,291 \\
\hline
\end{tabular}

Nota. Prueba t de Student (t). p valor: $p<0,05$.

En función del número de camas del hospital.

Un factor analizado fue pertenecer a centros hospitalarios grandes ( $>500$ camas) o pequeños ( $\leq 500$ camas) y su relación con las dimensiones detectadas. Observamos que, de las 13 dimensiones, 6 presentaron diferencias significativas en el mismo sentido. Las enfermeras de centros pequeños valoraron más las habilidades en el cuidado del paciente crítico, comunicación y seguridad clínica, excelencia en cuidados, evaluación del paciente, gestión sanitaria y la toma de decisiones; tal y como se observa en la tabla 82.

Tabla 82. Diferencias en la valoración de las dimensiones detectadas en función del tamaño del hospital.

\begin{tabular}{|c|c|c|c|c|c|c|c|c|}
\hline \multirow[t]{2}{*}{ Dimensiones } & \multicolumn{2}{|c|}{$\begin{array}{l}\text { Hospitales } \\
>\mathbf{5 0 0} \text { camas } \\
(\mathrm{n}=\mathbf{2 8 7})\end{array}$} & \multicolumn{2}{|c|}{$\begin{array}{l}\text { Hospitales } \\
\leq 500 \text { camas } \\
(n=281)\end{array}$} & \multicolumn{2}{|c|}{ Prueba Levene } & \multirow[t]{2}{*}{$\boldsymbol{t}$} & \multirow[t]{2}{*}{$p$} \\
\hline & Media & D.T. & Media & D.T. & $\mathbf{F}$ & $p$ & & \\
\hline $\begin{array}{l}\text { Habilidades en el cuidado del paciente } \\
\text { critico }\end{array}$ & 9,20 & 0,64 & 9,36 & 0,58 & 6,916 & 0,009 & 3,137 & 0,002 \\
\hline Comunicación y seguridad clínica & 9,09 & 0,72 & 9,25 & 0,66 & 2,723 & 0,099 & 2,740 & 0,006 \\
\hline $\begin{array}{l}\text { Conocimientos enfermeros y } \\
\text { razonamiento clínico }\end{array}$ & 9,25 & 0,60 & 9,32 & 0,56 & 0,482 & 0,488 & 1,533 & 0,126 \\
\hline $\begin{array}{l}\text { Planes de acogida para enfermeras } \\
\text { noveles }\end{array}$ & 8,94 & 0,85 & 9,03 & 0,84 & 0,000 & 0,987 & 1,225 & 0,221 \\
\hline $\begin{array}{l}\text { Formación específica y continuada de } \\
\text { las enfermeras de plantilla (staff) }\end{array}$ & 8,43 & 0,94 & 8,55 & 0,88 & 0,389 & 0,533 & 1,537 & 0,125 \\
\hline Excelencia en cuidados & 9,01 & 0,76 & 9,18 & 0,69 & 6,212 & 0,013 & 3,289 & 0,002 \\
\hline $\begin{array}{l}\text { Evaluación del paciente crítico, } \\
\text { herramientas y tecnología }\end{array}$ & 8,82 & 0,83 & 8,96 & 0,74 & 2,475 & 0,116 & 2,157 & 0,031 \\
\hline Gestión sanitaria & 7,48 & 1,55 & 7,77 & 1,53 & 0,402 & 0,526 & 2,234 & 0,026 \\
\hline Aplicación de medidas de soporte & 8,03 & 1,42 & 8,18 & 1,22 & 2,106 & 0,147 & 1,371 & 0,171 \\
\hline $\begin{array}{l}\text { Toma de decisiones y afrontamiento al } \\
\text { final de la vida }\end{array}$ & 8,23 & 1,30 & 8,53 & 1,17 & 7,347 & 0,007 & 2,917 & 0,004 \\
\hline Medidas para mejorar el cuidado & 6,79 & 1,50 & 7,01 & 1,42 & 3,842 & 0,052 & 1,779 & 0,076 \\
\hline $\begin{array}{l}\text { Motivación para continuar con la } \\
\text { formación }\end{array}$ & 7,28 & 1,40 & 7,37 & 1,47 & 0,039 & 0,843 & 0,768 & 0,443 \\
\hline Repercusión de la formación & 8,08 & 1,14 & 8,02 & 1,20 & 0,973 & 0,324 & 0,563 & 0,574 \\
\hline
\end{tabular}

Nota. Prueba t de Student $(\boldsymbol{t})$. $\mathbf{p}$ valor: $p<0,05$.

\section{En función del tipo de UCI.}

También fue de interés conocer, si la organización de la unidad influía en las dimensiones. Como se puede observar en la tabla 83, la única diferencia detectada fue en la dimensión de "Evaluación del paciente crítico, herramientas y tecnologías sanitarias" con puntuaciones más altas para las unidades polivalentes. 
Tabla 83. Diferencias en la valoración de las dimensiones detectadas en función del tipo de UCl.

\begin{tabular}{|c|c|c|c|c|c|c|c|c|}
\hline \multirow[t]{2}{*}{ Dimensiones } & \multicolumn{2}{|c|}{$\begin{array}{c}\text { Unidades } \\
\text { Polivalentes }(n=405) \\
\end{array}$} & \multicolumn{2}{|c|}{$\begin{array}{c}\text { Unidades } \\
\text { Específicas }(n=143)\end{array}$} & \multicolumn{2}{|c|}{ Prueba Levene } & \multirow[t]{2}{*}{$\boldsymbol{t}$} & \multirow[t]{2}{*}{$p$} \\
\hline & Media & D.T. & Media & D.T. & $\mathbf{F}$ & $p$ & & \\
\hline $\begin{array}{l}\text { Habilidades en el cuidado del } \\
\text { paciente critico }\end{array}$ & 9,28 & 0,63 & 9,29 & 0,58 & 1,241 & 0,266 & 0,305 & 0,760 \\
\hline Comunicación y seguridad clínica & 9,18 & 0,70 & 9,16 & 0,67 & 0,853 & 0,356 & 0,357 & 0,721 \\
\hline $\begin{array}{l}\text { Conocimientos enfermeros y } \\
\text { razonamiento clínico }\end{array}$ & 9,30 & 0,56 & 9,26 & 0,62 & 0,365 & 0,546 & 0,869 & 0,385 \\
\hline $\begin{array}{l}\text { Planes de acogida para enfermeras } \\
\text { noveles }\end{array}$ & 9,02 & 0,78 & 8,89 & 0,99 & 6,497 & 0,011 & 1,481 & 0,140 \\
\hline $\begin{array}{l}\text { Formación específica y continuada de } \\
\text { las enfermeras de plantilla (staff) }\end{array}$ & 8,49 & 0,92 & 8,48 & 0,89 & 0,058 & 0,810 & 0,171 & 0,865 \\
\hline Excelencia en cuidados & 9,09 & 0,73 & 9,11 & 0,72 & 0,043 & 0,837 & 0,375 & 0,707 \\
\hline $\begin{array}{l}\text { Evaluación del paciente crítico, } \\
\text { herramientas y tecnología }\end{array}$ & 8,95 & 0,75 & 8,75 & 0,85 & 0,031 & 0,860 & 2,773 & 0,006 \\
\hline Gestión sanitaria & 7,61 & 1,49 & 7,64 & 1,69 & 3,520 & 0,061 & 0,173 & 0,863 \\
\hline Aplicación de medidas de soporte & 8,08 & 1,36 & 8,15 & 1,23 & 0,180 & 0,672 & 0,534 & 0,593 \\
\hline $\begin{array}{l}\text { Toma de decisiones y afrontamiento } \\
\text { al final de la vida }\end{array}$ & 8,44 & 1,20 & 8,23 & 1,34 & 3,890 & 0,049 & 1,707 & 0,089 \\
\hline Medidas para mejorar el cuidado & 6,87 & 1,48 & 6,98 & 1,43 & 0,017 & 0,897 & 0,769 & 0,442 \\
\hline $\begin{array}{l}\text { Motivación para continuar con la } \\
\text { formación }\end{array}$ & 7,37 & 1,39 & 7,21 & 1,54 & 7,538 & 0,006 & 1,174 & 0,242 \\
\hline Repercusión de la formación & 8,06 & 1,19 & 8,03 & 1,10 & 0,007 & 0,933 & 0,286 & 0,775 \\
\hline
\end{tabular}

Nota. Prueba t de Student (t). $\mathbf{p}$ valor: $p<0,05$.

En función del número de camas de UCI de la unidad en la que las enfermeras trabajan.

Al evaluar si el número de camas de $\mathrm{UCl}$ (unidades pequeñas con 4-16 camas de $\mathrm{UCl}$ y unidades grandes con 17-40 camas de UCl) influía en alguna de las 13 dimensiones, observamos que afectaba a 2 de ellas. Las enfermeras de las $\mathrm{UCl}$ con mayor número de camas valoraron más positivamente las dimensiones "Planes de acogida de las enfermeras noveles" y "Formación continuada de todo el personal". Ver tabla 84.

Tabla 84. Diferencias en la valoración de las dimensiones detectadas en función del tamaño de UCl.

\begin{tabular}{|c|c|c|c|c|c|c|c|c|}
\hline \multirow[t]{2}{*}{ Dimensiones } & \multicolumn{2}{|c|}{$\begin{array}{l}\text { Unidades pequeñas } \\
\qquad(\mathrm{n}=352)\end{array}$} & \multicolumn{2}{|c|}{$\begin{array}{l}\text { Unidades grandes } \\
\qquad(n=216)\end{array}$} & \multicolumn{2}{|c|}{ Prueba Levene } & \multirow[t]{2}{*}{$\boldsymbol{t}$} & \multirow[t]{2}{*}{$p$} \\
\hline & Media & D.T. & Media & D.T. & $\mathbf{F}$ & $p$ & & \\
\hline $\begin{array}{l}\text { Habilidades en el cuidado del } \\
\text { paciente critico }\end{array}$ & 9,25 & 0,62 & 9,33 & 0,60 & 2,387 & 0,123 & 1,591 & 0,112 \\
\hline Comunicación y seguridad clínica & 9,15 & 0,69 & 9,22 & 0,70 & 0,007 & 0,933 & 1,165 & 0,245 \\
\hline $\begin{array}{l}\text { Conocimientos enfermeros y } \\
\text { razonamiento clínico }\end{array}$ & 9,30 & 0,58 & 9,27 & 0,57 & 0,223 & 0,637 & 0,505 & 0,614 \\
\hline $\begin{array}{l}\text { Planes de acogida para enfermeras } \\
\text { noveles }\end{array}$ & 8,90 & 0,87 & 9,11 & 0,80 & 0,090 & 0,764 & 2,775 & 0,006 \\
\hline $\begin{array}{l}\text { Formación específica y continuada } \\
\text { de las enfermeras de plantilla (staff) }\end{array}$ & 8,40 & 0,90 & 8,63 & 0,92 & 0,172 & 0,679 & 2,867 & 0,004 \\
\hline Excelencia en cuidados & 9,06 & 0,74 & 9,15 & 0,71 & 0,287 & 0,593 & 1,446 & 0,149 \\
\hline $\begin{array}{l}\text { Evaluación del paciente crítico, } \\
\text { herramientas y tecnología }\end{array}$ & 8,86 & 0,80 & 8,94 & 0,76 & 0,264 & 0,608 & 1,037 & 0,300 \\
\hline Gestión sanitaria & 7,57 & 1,55 & 7,70 & 1,54 & 0,430 & 0,512 & 0,951 & 0,342 \\
\hline Aplicación de medidas de soporte & 8,17 & 1,12 & 7,99 & 1,60 & 17,390 & $<0,001$ & 1,498 & 0,135 \\
\hline
\end{tabular}




\begin{tabular}{|c|c|c|c|c|c|c|c|c|}
\hline \multirow[t]{2}{*}{ Dimensiones } & \multicolumn{2}{|c|}{$\begin{array}{l}\text { Unidades pequeñas } \\
\qquad(\mathrm{n}=352)\end{array}$} & \multicolumn{2}{|c|}{$\begin{array}{l}\text { Unidades grandes } \\
\qquad(n=216)\end{array}$} & \multicolumn{2}{|c|}{ Prueba Levene } & \multirow[t]{2}{*}{$t$} & \multirow[t]{2}{*}{$p$} \\
\hline & Media & D.T. & Media & D.T. & $F$ & $p$ & & \\
\hline $\begin{array}{l}\text { Toma de decisiones y } \\
\text { afrontamiento al final de la vida }\end{array}$ & 8,32 & 1,25 & 8,47 & 1,23 & 0,404 & 0,525 & 1,399 & 0,162 \\
\hline Medidas para mejorar el cuidado & 6,97 & 1,41 & 6,80 & 1,56 & 5,680 & 0,017 & 1,254 & 0,211 \\
\hline $\begin{array}{l}\text { Motivación para continuar con la } \\
\text { formación }\end{array}$ & 7,37 & 1,40 & 7,25 & 1,49 & 2,342 & 0,126 & 0,979 & 0,328 \\
\hline Repercusión de la formación & 8,01 & 1,19 & 8,12 & 1,14 & 0,001 & 0,980 & 1,079 & 0,281 \\
\hline
\end{tabular}

Nota. Prueba t de Student (t). $\mathbf{p}$ valor: $p<0,05$.

En función de la experiencia laboral de las enfermeras.

Al explorar las 13 dimensiones en relación con experiencia laboral, se observó que los profesionales más veteranos puntuaban más alto que los noveles en casi todas las dimensiones excepto en las de carácter técnico.

a) Experiencia laboral como enfermera total.

En este punto analizamos la experiencia laboral ( $\leq 10$ años, 11-15 años, 16-20 años y >20 años) como enfermeras en todos los ámbitos profesionales de la enfermería. El análisis fue realizado mediante la prueba no paramétrico de Jonckeheere-Tepstra para cada una de las dimensiones.

Como se puede observar la experiencia laboral total influye en el $61,53 \%$ de las dimensiones detectadas, todas ellas en un sentido positivo, lo que quiere decir que a mayor experiencia laboral mayor valoración de las respectivas dimensiones, ver tabla 85 .

Tabla 85. Diferencias en la valoración de las dimensiones detectadas en función de la experiencia laboral como enfermera.

\begin{tabular}{|c|c|c|c|c|}
\hline Dimensiones & Estadístico J-T & Error Típico & Prueba S & $\boldsymbol{p}$ \\
\hline Habilidades en el cuidado del paciente critico & 72799 & 2174,53 & 5,867 & $<0,001$ \\
\hline Comunicación y seguridad clínica & 70374,5 & 2171,32 & 4,759 & $<0,001$ \\
\hline Conocimientos enfermeros y razonamiento clínico & 61412,5 & 2173,58 & 0,631 & 0,528 \\
\hline Planes de acogida para enfermeras noveles & 64618 & 2175,27 & 2,104 & 0,035 \\
\hline $\begin{array}{l}\text { Formación específica y continuada de las enfermeras } \\
\text { de plantilla (staff) }\end{array}$ & 65475 & 2177,91 & 2,495 & 0,013 \\
\hline Excelencia en cuidados & 65939,5 & 2169,48 & 2,718 & 0,007 \\
\hline $\begin{array}{l}\text { Evaluación del paciente crítico, herramientas y } \\
\text { tecnología }\end{array}$ & 69008,5 & 2173,71 & 4,125 & $<0,001$ \\
\hline Gestión sanitaria & 66947,5 & 2175,87 & 3,128 & 0,002 \\
\hline Aplicación de medidas de soporte & 58750,5 & 2171,74 & $-0,595$ & 0,552 \\
\hline Toma de decisiones y afrontamiento al final de la vida & 69774,5 & 2172,15 & 4,481 & $<0,001$ \\
\hline Medidas para mejorar el cuidado & 62160,5 & 2175,16 & 0,974 & 0,330 \\
\hline Motivación para continuar con la formación & 59315,5 & 2173,00 & $-0,334$ & 0,738 \\
\hline Repercusión de la formación & 56166,5 & 2172,18 & $-1,784$ & 0,074 \\
\hline
\end{tabular}

Nota. Prueba de Jonckheere-Terpstra (Prueba S). p valor: $p<0,05$. 
A continuación, se realizaron los análisis gráficos post-hoc de la prueba de Jonckheere-Terpstra, para valorar sobre que grupos recaían concretamente estas diferencias significativas, representadas por las líneas amarillas.

La dimensión "Habilidades en el cuidado del paciente crítico" mostró diferencias significativas en el mismo sentido entre el grupo de más veteranos y los restantes grupos analizados. El grupo de $>20$ años de experiencia laboral total mantuvo diferencias de $p=0,000$ con los restantes grupos analizados, ver figura 39.

Sucede lo mismo en la dimensión "Comunicación y seguridad clínica", en este caso las diferencias son entre el grupo de $>20$ años y el grupo de 16-20 años ( $p=0,002)$; para el grupo de 11-15 años $(p<0,001)$ y para el grupo $\leq 10$ años $(p<0,001)$.

En la dimensión de planes de acogida sólo existen diferencias significativas entre el grupo de $>20$ años y el de las enfermeras menos veteranas. Las enfermeras más veteranas apoyan más la adopción de medidas formativas en los planes de acogida.

Sin embargo, en la dimensión formación específica y continuada de las enfermeras de plantilla, se vuelve a dar la misma estructura, como se puede observar en la figura 40. El grupo de $>20$ años presentó diferencias entre los restantes grupos, con los siguientes resultados: $>20$ años- $\leq 10$ años $(p=0,014),>20$ años-11-15 años $(p=0,024)$ y $>20$ años-16-20años $(p=0,008)$.

Figura 39. Comparación por parejas de la experiencia laboral total como enfermera y la dimensión habilidades en el cuidado del paciente crítico.

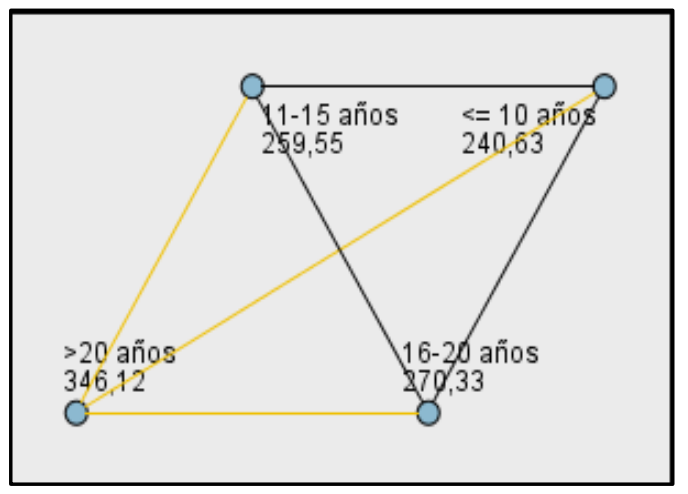

Figura 40. Comparación por parejas de la experiencia laboral total como enfermera y la dimensión formación específica y continuada de las enfermeras de plantilla.

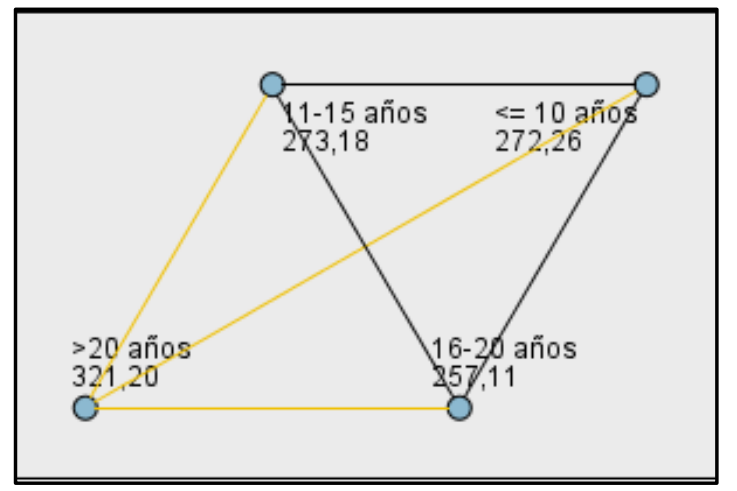

En la dimensión de "Excelencia en cuidados" sólo encontramos diferencias entre el grupo más novel con el más veterano con $\mathrm{p}$ valor de 0,008. La dimensión "Evaluación del paciente crítico, herramientas y tecnología" presentó una agrupación distinta. Hallamos diferencias significativas entre el grupo de veteranos y el grupo con $<10$ años $(p<0,001)$ y, entre los más veteranos y el grupo de 11 a 15 años ( $p=0,018)$. El grupo de 16 a 20 años no mostró resultado significativo, ver figura 41.

En cuanto a la dimensión "Gestión sanitaria", esta siguió la misma tendencia. Hay que destacar la diferencia entre $>20$ años y $16-20$ años $(p<0,001)$. El resto de los grupos presentaron los siguientes 
resultados en relación con el grupo de $>20$ años: $\leq 10$ años $p=0,002$ y $11-15$ años con una $p=0,018$. Ver figura 42.

Figura 41. Comparación por parejas de la experiencia laboral total como enfermera y la dimensión evaluación del paciente crítico, herramientas y sanitaria tecnología
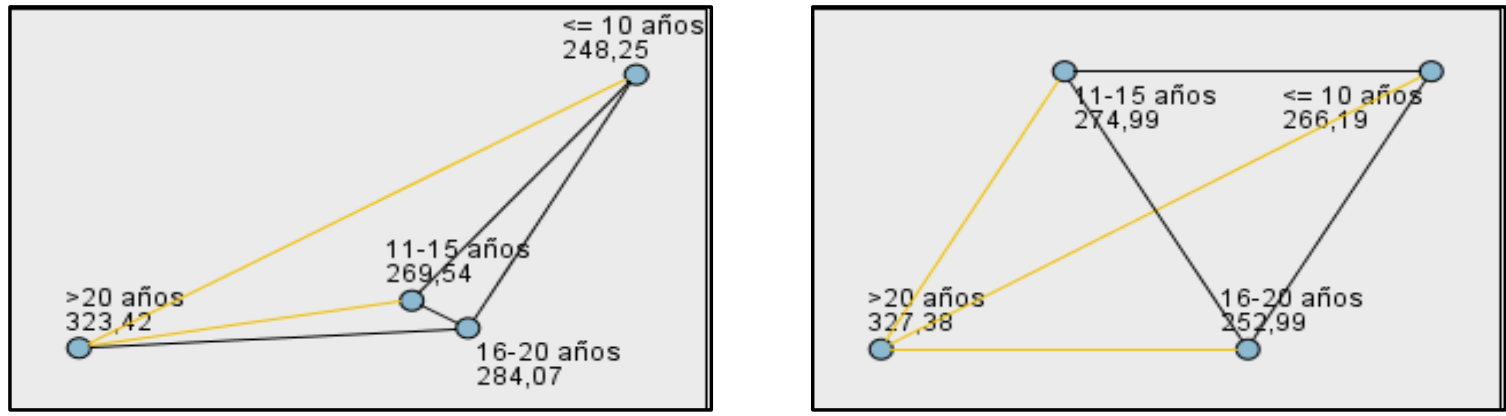

La dimensión de "Toma de decisiones y afrontamiento al final de la vida", presentó un desarrollo progresivo relacionado con la experiencia laboral total, así las diferencias entre los subgrupos analizados por parejas fueron los siguientes: $>20$ años frente $a \leq 10$ años $(p<0,001)$ y entre $>20$ años y 11-15 años $(p=0,004)$. Es de destacar que las dimensiones de formación que no obtuvieron diferencias significativas fueron puntuadas como de gran importancia por todos los participantes independientemente del grupo de experiencia laboral total.

b) Experiencia laboral como enfermera de UCI.

En el contexto de la experiencia laboral a continuación se analizaron las distintas dimensiones en función de la experiencia laboral específicamente como enfermeras de UCl ( $\leq 5$ años, 6-10 años, 1115 años y >15 años). Se observó una tendencia positiva relacionada con la experiencia laboral en UCl, así a mayor experiencia laboral en $\mathrm{UCl}$, mayor puntuación en las dimensiones, ver tabla 86.

Tabla 86. Diferencias en la valoración de las dimensiones detectadas en función de la experiencia laboral como enfermera de UCI.

\begin{tabular}{|c|c|c|c|c|}
\hline Dimensiones & Estadístico J-T & Error Típico & Prueba S & $\boldsymbol{p}$ \\
\hline Habilidades en el cuidado del paciente critico & 71957,5 & 2166,91 & 5,826 & $<0,001$ \\
\hline Comunicación y seguridad clínica & 69202 & 2163,71 & 4,561 & $<0,001$ \\
\hline Conocimientos enfermeros y razonamiento clínico & 59239,5 & 2165,96 & $-0,044$ & 0,965 \\
\hline Planes de acogida para enfermeras noveles & 62607,5 & 2167,64 & 1,510 & 0,131 \\
\hline $\begin{array}{l}\text { Formación específica y continuada de las enfermeras } \\
\text { de plantilla (staff) }\end{array}$ & 63279 & 2170,27 & 1,818 & 0,069 \\
\hline Excelencia en cuidados & 61953 & 2161,87 & 1,211 & 0,226 \\
\hline $\begin{array}{l}\text { Evaluación del paciente crítico, herramientas y } \\
\text { tecnología }\end{array}$ & 65709 & 2166,09 & 2,943 & 0,003 \\
\hline Gestión sanitaria & 64231,5 & 2168,24 & 2,259 & 0,024 \\
\hline Aplicación de medidas de soporte & 58135,5 & 2164,13 & $-0,554$ & 0,580 \\
\hline
\end{tabular}




\begin{tabular}{lcccc}
\hline \multicolumn{1}{c}{ Dimensiones } & Estadístico J-T & Error Típico & Prueba S & $\boldsymbol{p}$ \\
\hline Toma de decisiones y afrontamiento al final de la vida & 70268 & 2164,13 & 5,051 & $<\mathbf{0 , 0 0 1}$ \\
Medidas para mejorar el cuidado & 61006,5 & 2167,53 & 0,772 & 0,440 \\
\hline Motivación para continuar con la formación & 58653 & 2165,39 & $-0,314$ & 0,753 \\
Repercusión de la formación & 57240 & 2164,57 & $-0,967$ & 0,333 \\
\hline
\end{tabular}

Nota. Prueba de Jonckeheere-Tepstra (Prueba S). p valor: $p<0,05$.

En la tabla 87 se presentan los análisis post-hoc de las dimensiones que presentaron diferencias entre grupos. Las enfermeras de mayor experiencia laboral en $\mathrm{UCl}$ son las que generaron diferencias más acusadas.

Tabla 87. Comparativa por parejas de años de experiencia como enfermera de UCl en relación a las dimensiones con resultado significativo

\begin{tabular}{|c|c|c|c|}
\hline Dimensiones & Muestra 1- Muestra 2 & Prueba S & $\boldsymbol{p}$ \\
\hline \multirow{6}{*}{ Habilidades en el cuidado del paciente critico } & $\leq 5$ años - 6-10 años & 2,506 & 0,037 \\
\hline & $\leq 5$ años - 11-15 años & 2,252 & 0,073 \\
\hline & $\leq 5$ años - >15 años & 5,961 & $<0,001$ \\
\hline & 6-10 años - 11-15 años & 0,171 & 1,000 \\
\hline & 6-10 años - >15 años & 3,398 & 0,002 \\
\hline & $11-15$ años - >15 años & 2,764 & 0,017 \\
\hline \multirow{6}{*}{ Comunicación y seguridad clínica } & $\leq 5$ años - 6-10 años & 0,828 & 1,000 \\
\hline & $\leq 5$ años - 11-15 años & 1,222 & 0,665 \\
\hline & $\leq 5$ años - >15 años & 4,835 & $<0,001$ \\
\hline & 6-10 años - 11-15 años & 0,562 & 1,000 \\
\hline & 6-10 años - >15 años & 3,774 & $<0,001$ \\
\hline & 11-15 años - >15 años & 2,580 & 0,030 \\
\hline \multirow{6}{*}{$\begin{array}{l}\text { Evaluación del paciente crítico, herramientas y } \\
\text { tecnología }\end{array}$} & $\leq 5$ años - 6-10 años & 0,627 & 1,000 \\
\hline & $\leq 5$ años - $11-15$ años & 0,811 & 1,000 \\
\hline & $\leq 5$ años - >15 años & 3,258 & 0,003 \\
\hline & 6-10 años - 11-15 años & 0,160 & 1,000 \\
\hline & 6-10 años - >15 años & 2,193 & 0,085 \\
\hline & $11-15$ años - >15 años & 1,756 & 0,237 \\
\hline \multirow{6}{*}{ Gestión sanitaria } & $\leq 5$ años - 6-10 años & 0,096 & 1,000 \\
\hline & $\leq 5$ años - $11-15$ años & $-0,497$ & 1,000 \\
\hline & $\leq 5$ años - >15 años & 2,713 & 0,020 \\
\hline & 6-10 años - 11-15 años & $-0,248$ & 1,000 \\
\hline & 6-10 años - >15 años & 2,587 & 0,029 \\
\hline & $11-15$ años - >15 años & 2,598 & 0,028 \\
\hline \multirow{6}{*}{$\begin{array}{l}\text { Toma de decisiones y afrontamiento al final de la } \\
\text { vida }\end{array}$} & $\leq 5$ años - $6-10$ años & 1,262 & 0,621 \\
\hline & $\leq 5$ años - $11-15$ años & 2,738 & 0,019 \\
\hline & $\leq 5$ años - >15 años & 4,900 & $<0,001$ \\
\hline & 6-10 años - 11-15 años & 1,666 & 0,287 \\
\hline & 6-10 años - >15 años & 3,469 & 0,002 \\
\hline & 11-15 años - >15 años & 1,169 & 0,728 \\
\hline
\end{tabular}

Nota. Prueba de Jonckeheere-Tepstra (Prueba S). p valor: $p<0,05$.

Resulta especialmente llamativa, la diferencia representada en la figura 43, donde los dos grupos de mayor experiencia se confrontan a la valoración de las enfermeras con menos experiencia. La formación en la dimensión "Toma de decisiones y afrontamiento al final de la vida" se constituye en un punto más allá de los 11 años de experiencia laboral como enfermera de UCI. 
Figura 43. Comparación por parejas de la experiencia laboral como enfermera de UCI y la dimensión Toma de decisiones y afrontamiento al final de la vida.

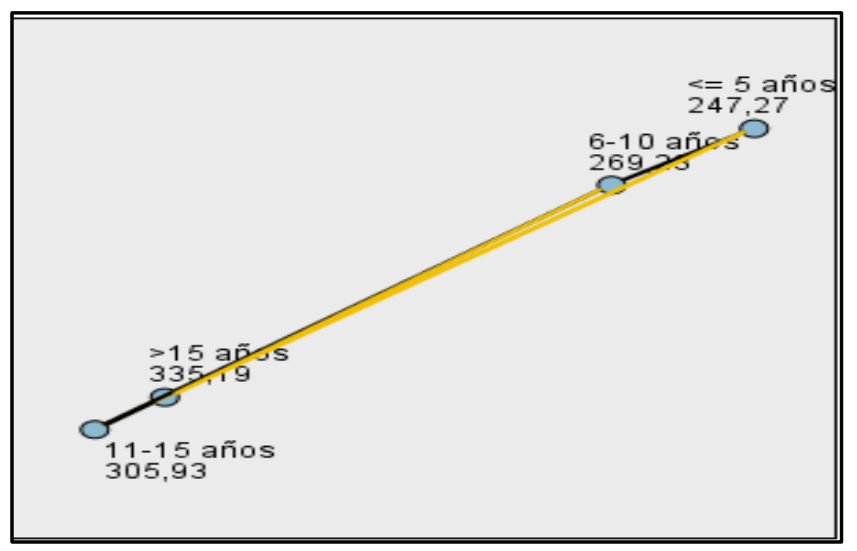

4.3.11. Análisis de la valoración de las dimensiones detectadas en las necesidades formativas de las enfermeras en relación a las preguntas dicotómicas de la encuesta.

En el cuestionario se incluyeron preguntas dicotómicas asociadas a necesidades formativas y/o experiencias laborales previas. Se precisó conocer si estas variables modificaban la valoración de las dimensiones. Para este análisis se crearon a partir de las dimensiones detectadas y sus valores medios, una nueva variable definida como: áreas de alta puntuación (valores iguales o superiores a la media) y baja puntuación (valores inferiores a la media). Ver tabla 88.

Tabla 88. Grupos de valoración de las dimensiones detectadas.

\begin{tabular}{|c|c|c|c|c|}
\hline Dimensiones & Media & Grupos & Frecuencia (n) & Porcentaje (\%) \\
\hline \multirow{2}{*}{ Habilidades en el cuidado del paciente critico } & \multirow{2}{*}{9,28} & Baja & 230 & 40,5 \\
\hline & & Alta & 338 & 59,5 \\
\hline \multirow{2}{*}{ Comunicación y seguridad clínica } & \multirow{2}{*}{9,18} & Baja & 270 & 47,5 \\
\hline & & Alta & 298 & 52,5 \\
\hline \multirow{2}{*}{ Conocimientos enfermeros y razonamiento clínico } & \multirow{2}{*}{9,29} & Baja & 266 & 46,8 \\
\hline & & Alta & 302 & 53,2 \\
\hline \multirow{2}{*}{ Planes de acogida para enfermeras noveles } & \multirow{2}{*}{8,99} & Baja & 242 & 42,6 \\
\hline & & Alta & 326 & 57,4 \\
\hline \multirow{2}{*}{$\begin{array}{l}\text { Formación específica y continuada de las enfermeras de } \\
\text { plantilla (staff) }\end{array}$} & \multirow{2}{*}{8,50} & Baja & 254 & 44,7 \\
\hline & & Alta & 314 & 55,3 \\
\hline \multirow{2}{*}{ Excelencia en cuidados } & \multirow{2}{*}{9,10} & Baja & 266 & 46,8 \\
\hline & & Alta & 302 & 53,2 \\
\hline \multirow{2}{*}{ Evaluación del paciente crítico, herramientas y tecnología } & \multirow{2}{*}{8,88} & Baja & 282 & 49,6 \\
\hline & & Alta & 286 & 50,4 \\
\hline \multirow{2}{*}{ Gestión sanitaria } & \multirow{2}{*}{7,62} & Baja & 246 & 43,3 \\
\hline & & Alta & 322 & 56,7 \\
\hline \multirow{2}{*}{ Aplicación de medidas de soporte } & \multirow{2}{*}{8,11} & Baja & 252 & 44,4 \\
\hline & & Alta & 316 & 55,6 \\
\hline \multirow{2}{*}{ Toma de decisiones y afrontamiento al final de la vida } & \multirow{2}{*}{8,39} & Baja & 275 & 48,4 \\
\hline & & Alta & 293 & 51,6 \\
\hline
\end{tabular}


Medidas para mejorar el cuidado

\begin{tabular}{llll}
\multirow{2}{6}{6,89} & Baja & 247 & 43,5 \\
& Alta & 321 & 56,5 \\
7,31 & Baja & 205 & 36,1 \\
& Alta & 363 & 63,9 \\
8,07 & Baja & 300 & 52,8 \\
& Alta & 268 & 47,2 \\
\hline
\end{tabular}

Nota. Resultados expresados en medias, frecuencias y porcentajes (\%).

Estos grupos de valoración se asociaron a las distintas respuestas dicotómicas para concretar si había relación entre estas respuestas y las valoraciones detectadas. A continuación, se detallan únicamente las respuestas estadísticamente significativas a través de la prueba Chi-Cuadrado de Pearson.

Como podemos observar en la tabla 87, existe una alta asociación en solicitar formación o experiencia previa con la alta valoración en seis de las trece dimensiones detectadas. Es de destacar que tres de estas dimensiones se corresponden con el área de formación de las enfermeras de UCI.

Tabla 89. Diferencias significativas en la valoración de las dimensiones detectadas en función de la opinión de precisar experiencia o formación previa para trabajar en $\mathrm{UCl}$.

\begin{tabular}{|c|c|c|c|c|c|}
\hline \multirow[t]{2}{*}{ Valoración de la dimensión } & & \multicolumn{2}{|c|}{$\begin{array}{l}\text { Según su opinión, para empezar a } \\
\text { trabajar en UCl es preciso tener algún } \\
\text { tipo de experiencia o formación previa }\end{array}$} & \multirow[t]{2}{*}{$x^{2}$} & \multirow[t]{2}{*}{$\boldsymbol{p}$} \\
\hline & & $\begin{array}{c}\text { SI } \\
(n=518)\end{array}$ & $\begin{array}{c}\text { NO } \\
(n=50)\end{array}$ & & \\
\hline \multirow{2}{*}{$\begin{array}{l}\text { Planes de acogida para enfermeras } \\
\text { noveles }\end{array}$} & Baja & 206 & 36 & \multirow{2}{*}{19,372} & \multirow{2}{*}{$<0,001$} \\
\hline & Alta & 312 & 14 & & \\
\hline \multirow{2}{*}{$\begin{array}{l}\text { Formación específica y continuada } \\
\text { de las enfermeras de plantilla (staff) }\end{array}$} & Baja & 225 & 29 & \multirow{2}{*}{3,912} & \multirow{2}{*}{0,048} \\
\hline & Alta & 293 & 21 & & \\
\hline \multirow{2}{*}{ Excelencia en cuidados } & Baja & 234 & 32 & \multirow{2}{*}{6,491} & \multirow{2}{*}{0,011} \\
\hline & Alta & 284 & 18 & & \\
\hline \multirow{2}{*}{ Aplicación de medidas de soporte } & Baja & 218 & 34 & \multirow{2}{*}{12,407} & \multirow{2}{*}{$<0,001$} \\
\hline & Alta & 300 & 16 & & \\
\hline \multirow{2}{*}{$\begin{array}{l}\text { Toma de decisiones y afrontamiento } \\
\text { al final de la vida }\end{array}$} & Baja & 243 & 32 & \multirow{2}{*}{5,332} & \multirow{2}{*}{0,021} \\
\hline & Alta & 275 & 18 & & \\
\hline \multirow{2}{*}{$\begin{array}{l}\text { Motivación para continuar con la } \\
\text { formación }\end{array}$} & Baja & 175 & 30 & \multirow{2}{*}{13,587} & \multirow{2}{*}{$<0,001$} \\
\hline & Alta & 343 & 20 & & \\
\hline
\end{tabular}

Nota. Prueba de Chi-Cuadrado $\left(\chi^{2}\right) . p$ valor: $p<0,05$.

Siguiendo la misma línea, se analizaron las solicitudes de formación sanitaria especializada EIR. Como se puede observar en la tabla 90, las enfermeras que valoraron muy positivamente estas dimensiones de formación también apoyaron que se debía incentivar las actividades formativas en el ámbito de la UCl y la formación vía EIR. 
Tabla 90. Diferencias significativas en la valoración de las dimensiones detectadas en función de la opinión de precisar una formación sanitaria especializada tipo EIR.

\begin{tabular}{|c|c|c|c|c|c|c|}
\hline \multirow[t]{2}{*}{ Valoración de la dimensión } & & \multicolumn{3}{|c|}{$\begin{array}{l}\text { Según su opinión, ¿Seria aconsejable } \\
\text { una formación especializada sanitaria } \\
\text { tipo EIR para trabajar en UCI? }\end{array}$} & \multirow[t]{2}{*}{$x^{2}$} & \multirow[t]{2}{*}{$\boldsymbol{p}$} \\
\hline & & $\begin{array}{c}\text { SI } \\
(n=426)\end{array}$ & $\begin{array}{l}\text { NO SÉ } \\
(n=73)\end{array}$ & $\begin{array}{c}\text { NO } \\
(n=69)\end{array}$ & & \\
\hline \multirow{2}{*}{$\begin{array}{l}\text { Habilidades en el cuidado del } \\
\text { paciente critico }\end{array}$} & Baja & 176 & 35 & 19 & \multirow{2}{*}{6,609} & \multirow{2}{*}{0,037} \\
\hline & Alta & 250 & 38 & 50 & & \\
\hline \multirow{2}{*}{$\begin{array}{l}\text { Planes de acogida } \\
\text { enfermeras noveles }\end{array}$} & Baja & 168 & 40 & 34 & \multirow{2}{*}{7,440} & \multirow{2}{*}{0,024} \\
\hline & Alta & 258 & 33 & 35 & & \\
\hline \multirow{2}{*}{ Medidas para mejorar el cuidado } & Baja & 178 & 43 & 26 & \multirow{2}{*}{8,509} & \multirow{2}{*}{0,014} \\
\hline & Alta & 248 & 30 & 43 & & \\
\hline \multirow{2}{*}{$\begin{array}{l}\text { Motivación para continuar con la } \\
\text { formación }\end{array}$} & Baja & 142 & 28 & 35 & \multirow{2}{*}{7,973} & \multirow{2}{*}{0,019} \\
\hline & Alta & 284 & 45 & 34 & & \\
\hline \multirow{2}{*}{ Repercusión de la formación } & Baja & 213 & 42 & 45 & \multirow{2}{*}{6,266} & \multirow{2}{*}{0,044} \\
\hline & Alta & 213 & 31 & 24 & & \\
\hline
\end{tabular}

Nota. Prueba de Chi-Cuadrado $\left(\chi^{2}\right) \cdot \mathbf{p}$ valor: $p<0,05$.

Por otro lado, las enfermeras que solicitaban un plan de acogida específico en las unidades de cuidados intensivos presentaban asociación en 4 dimensiones. Tal y como se observa en la tabla 91. Los ítems englobados en las dimensiones de planes de acogida para enfermeras noveles mostraron asociación con la pregunta dicotómica de solicitar planes de acogida para las enfermeras noveles. Destacar que aquellas enfermeras que solicitaban formación para las enfermeras noveles también lo hacían para el resto de los profesionales de la UCI.

Tabla 91. Diferencias significativas en la valoración de las dimensiones detectadas en función de la opinión de precisar un plan de acogida al personal de nueva incorporación.

\begin{tabular}{|c|c|c|c|c|c|}
\hline \multirow[t]{2}{*}{ Valoración de la dimensión } & & \multicolumn{2}{|c|}{$\begin{array}{l}\text { Según su experiencia personal, } \\
\text { ¿Sería necesario un plan de } \\
\text { acogida para el personal de nueva } \\
\text { incorporación? }\end{array}$} & \multirow[t]{2}{*}{$x^{2}$} & \multirow[t]{2}{*}{$\boldsymbol{p}$} \\
\hline & & $\begin{array}{c}S I \\
(n=557)\end{array}$ & $\begin{array}{c}\text { NO } \\
(n=11)\end{array}$ & & \\
\hline \multirow{2}{*}{ Comunicación y seguridad clínica } & Baja & 261 & 9 & \multirow{2}{*}{5,286} & \multirow{2}{*}{0,030} \\
\hline & Alta & 296 & 2 & & \\
\hline \multirow{2}{*}{$\begin{array}{l}\text { Conocimientos enfermeros y } \\
\text { razonamiento clínico }\end{array}$} & Baja & 255 & 11 & \multirow{2}{*}{12,735} & \multirow{2}{*}{$<0,001$} \\
\hline & Alta & 302 & 0 & & \\
\hline \multirow{2}{*}{$\begin{array}{l}\text { Planes de acogida para enfermeras } \\
\text { noveles }\end{array}$} & Baja & 231 & 11 & \multirow{2}{*}{15,111} & \multirow{2}{*}{$<0,001$} \\
\hline & Alta & 326 & 0 & & \\
\hline \multirow{2}{*}{$\begin{array}{l}\text { Formación específica y continuada de } \\
\text { las enfermeras de plantilla (staff) }\end{array}$} & Baja & 245 & 9 & \multirow{2}{*}{6,245} & \multirow{2}{*}{0,013} \\
\hline & Alta & 312 & 2 & & \\
\hline
\end{tabular}

Nota. Prueba de Chi-Cuadrado $\left(\chi^{2}\right)$. $\mathbf{p}$ valor: $p<0,05$.

Para las variables en tabla de $2 \times 2$ con una casilla con valor inferior a 5, se utilizó el test de Fisher. 
4.3.12. Análisis de la valoración de las dimensiones detectadas en las necesidades formativas de las enfermeras en relación a las características de las enfermeras encuestadas.

En apartados anteriores, distintos elementos han explicado las puntuaciones de los ítems y de sus agrupaciones. A continuación, detallamos aquellos elementos que fueron significativos en la valoración de las dimensiones.

Como se puede observar en la tabla 92, tres dimensiones expresaron asociación con la percepción de las necesidades formativas de las enfermeras de $\mathrm{UCl}$ en relación con el género. Se observa que las mujeres valoraron de manera más importante las habilidades en el cuidado, las herramientas y tecnología y, en la evaluación del paciente crítico. Resulta llamativa la diferencia mostrada en función del género en relación con la destreza en la aplicación de las medidas de soporte; ya que las mujeres la valoraron como un área más necesaria. En las restantes 10 dimensiones no se obtuvo ninguna diferencia significativa.

Tabla 92. Diferencias significativas en la valoración de las dimensiones detectadas en función del género.

\begin{tabular}{|c|c|c|c|c|c|}
\hline \multirow[b]{2}{*}{ Valoración de la dimensión } & & \multicolumn{2}{|c|}{ Género } & \multirow[b]{2}{*}{$x^{2}$} & \multirow[b]{2}{*}{$p$} \\
\hline & & $\begin{array}{l}\text { Hombre } \\
(n=106)\end{array}$ & $\begin{array}{c}\text { Mujer } \\
(n=426)\end{array}$ & & \\
\hline \multirow{2}{*}{$\begin{array}{l}\text { Habilidades en el cuidado del paciente } \\
\text { critico }\end{array}$} & Baja & 52 & 178 & \multirow{2}{*}{3,966} & \multirow{2}{*}{0,046} \\
\hline & Alta & 54 & 284 & & \\
\hline \multirow{2}{*}{$\begin{array}{l}\text { Evaluación del paciente crítico, } \\
\text { herramientas y tecnología }\end{array}$} & Baja & 62 & 220 & \multirow{2}{*}{4,076} & \multirow{2}{*}{0,043} \\
\hline & Alta & 44 & 242 & & \\
\hline \multirow{2}{*}{ Aplicación de medidas de soporte } & Baja & 61 & 191 & \multirow{2}{*}{9,173} & \multirow{2}{*}{0,002} \\
\hline & Alta & 45 & 271 & & \\
\hline
\end{tabular}

Nota. Prueba de Chi-Cuadrado $\left(\chi^{2}\right) . p$ valor: $p<0,05$.

Un elemento para resaltar fue la edad de las enfermeras, es por ello por lo que resulta interesante valorar si estas diferencias se mantienen con las dimensiones detectadas. La prueba Chi-Cuadrado mostró un incremento progresivo en el porcentaje de las dimensiones de habilidades en el cuidado, comunicación y seguridad clínica y, en la de toma de decisiones; el grupo $>45$ años obtuvo las puntuaciones más elevadas.

En la dimensión "Gestión sanitaria" también se halló un resultado similar pero no fue progresivo ya que el grupo de 36-40 fue el que puntuó más alto seguido del grupo de edad $\leq 35$ años. En la evaluación del paciente crítico sigue existiendo asociación, pero manteniéndose en una diferencia muy marcada entre los dos grupos mayores y los dos grupos más jóvenes. Ver tabla 93. 
Tabla 93. Diferencias significativas en la valoración de las dimensiones detectadas en función del grupo de edad de las enfermeras consultadas.

\begin{tabular}{|c|c|c|c|c|c|c|c|}
\hline \multirow[b]{2}{*}{ Valoración de la dimensión } & & \multicolumn{4}{|c|}{ Grupos de edad } & \multirow[b]{2}{*}{$x^{2}$} & \multirow[b]{2}{*}{$p$} \\
\hline & & $\begin{array}{c}\leq 35 \\
\text { años } \\
(n=159)\end{array}$ & $\begin{array}{c}\text { 36-40 } \\
\text { años } \\
(n=146)\end{array}$ & $\begin{array}{c}\text { 41-45 } \\
\text { años } \\
(n=117)\end{array}$ & $\begin{array}{c}>45 \\
\text { años } \\
(n=146)\end{array}$ & & \\
\hline \multirow{2}{*}{$\begin{array}{l}\text { Habilidades en el cuidado del } \\
\text { paciente critico }\end{array}$} & Baja & 72 & 74 & 46 & 38 & \multirow{2}{*}{20,554} & \multirow{2}{*}{$<0,001$} \\
\hline & Alta & 87 & 72 & 71 & 108 & & \\
\hline \multirow{2}{*}{$\begin{array}{l}\text { Comunicación y seguridad } \\
\text { clínica }\end{array}$} & Baja & 76 & 90 & 55 & 49 & \multirow{2}{*}{23,101} & \multirow{2}{*}{$<0,001$} \\
\hline & Alta & 83 & 56 & 62 & 97 & & \\
\hline \multirow{2}{*}{$\begin{array}{l}\text { Evaluación del paciente } \\
\text { crítico, herramientas y } \\
\text { tecnología }\end{array}$} & Baja & 85 & 86 & 49 & 62 & \multirow{2}{*}{11,764} & \multirow{2}{*}{0,008} \\
\hline & Alta & 74 & 60 & 68 & 84 & & \\
\hline \multirow{2}{*}{ Gestión sanitaria } & Baja & 72 & 76 & 51 & 47 & \multirow{2}{*}{12,104} & \multirow{2}{*}{0,007} \\
\hline & Alta & 87 & 70 & 66 & 99 & & \\
\hline \multirow{2}{*}{$\begin{array}{l}\text { Toma de decisiones y } \\
\text { afrontamiento al final de la } \\
\text { vida }\end{array}$} & Baja & 88 & 82 & 55 & 50 & \multirow{2}{*}{18,397} & \multirow{2}{*}{$<0,001$} \\
\hline & Alta & 71 & 64 & 62 & 96 & & \\
\hline
\end{tabular}

Nota. Prueba de Chi-Cuadrado $\left(\chi^{2}\right)$. p valor: $p<0,05$.

El nivel académico fue el que mayor diferencia significativa mostró, afectando a 9 de las 13 dimensiones. En este caso no se observó un incremento progresivo en la valoración de las dimensiones en función del mayor nivel académico. Surgen dos valoraciones contrapuestas entre los grupos de grado y postgrado oficial versus el grupo de experto universitario y máster como título propio de universidad. En la dimensión "Toma de decisiones" el grupo de enfermeras con el grado presentaron una mayor valoración y en la dimensión "Repercusión de la formación" el grupo de experto universitario fue el que mostró mayores puntuaciones. Ver tabla 94.

Tabla 94. Diferencias significativas en la valoración de las dimensiones detectadas en función del máximo nivel académico alcanzado por las enfermeras consultadas.

\begin{tabular}{|c|c|c|c|c|c|c|c|}
\hline \multirow{2}{*}{ Valoración de la dimensión } & & \multicolumn{4}{|c|}{ Máxima Formación académica alcanzada } & \multirow[b]{2}{*}{$x^{2}$} & \multirow[b]{2}{*}{$\boldsymbol{p}$} \\
\hline & & $\begin{array}{l}\text { Grado } \\
(n=296)\end{array}$ & $\begin{array}{l}\text { Experto } \\
\text { Universitario } \\
\quad(n=95) \\
\end{array}$ & $\begin{array}{l}\text { Máster } \\
\text { propio* } \\
(\mathrm{n}=90)\end{array}$ & $\begin{array}{c}\text { Postgrado } \\
\text { Oficial } \\
(n=87) \\
\end{array}$ & & \\
\hline \multirow{2}{*}{$\begin{array}{l}\text { Habilidades en el cuidado del } \\
\text { paciente critico }\end{array}$} & Baja & 95 & 58 & 50 & 27 & \multirow{2}{*}{37,004} & \multirow{2}{*}{$<0,001$} \\
\hline & Alta & 201 & 37 & 40 & 60 & & \\
\hline \multirow{2}{*}{ Comunicación y seguridad clínica } & Baja & 120 & 63 & 54 & 33 & \multirow{2}{*}{28,067} & \multirow{2}{*}{$<0,001$} \\
\hline & Alta & 176 & 32 & 36 & 54 & & \\
\hline \multirow{2}{*}{$\begin{array}{l}\text { Planes de acogida para enfermeras } \\
\text { noveles }\end{array}$} & Baja & 124 & 48 & 44 & 26 & \multirow{2}{*}{9,709} & \multirow{2}{*}{0,021} \\
\hline & Alta & 172 & 47 & 46 & 61 & & \\
\hline \multirow{2}{*}{$\begin{array}{l}\text { Formación específica y continuada } \\
\text { de las enfermeras de plantilla } \\
\text { (staff) }\end{array}$} & Baja & 133 & 53 & 42 & 26 & \multirow[b]{2}{*}{12,597} & \multirow[b]{2}{*}{0,006} \\
\hline & Alta & 163 & 42 & 48 & 61 & & \\
\hline \multirow{2}{*}{$\begin{array}{l}\text { Evaluación del paciente crítico, } \\
\text { herramientas y tecnología }\end{array}$} & Baja & 139 & 59 & 55 & 29 & \multirow{2}{*}{20,747} & \multirow{2}{*}{$<0,001$} \\
\hline & Alta & 157 & 36 & 35 & 58 & & \\
\hline
\end{tabular}




\begin{tabular}{|c|c|c|c|c|c|c|c|}
\hline \multirow{2}{*}{ Valoración de la dimensión } & & \multicolumn{4}{|c|}{ Máxima Formación académica alcanzada } & \multirow[b]{2}{*}{$x^{2}$} & \multirow[b]{2}{*}{$\boldsymbol{p}$} \\
\hline & & $\begin{array}{l}\text { Grado } \\
(n=296)\end{array}$ & $\begin{array}{c}\text { Experto } \\
\text { Universitario } \\
\quad(n=95) \\
\end{array}$ & $\begin{array}{l}\text { Máster } \\
\text { propio* } \\
(\mathrm{n}=90)\end{array}$ & $\begin{array}{c}\text { Postgrado } \\
\text { Oficial } \\
(n=87) \\
\end{array}$ & & \\
\hline \multirow{2}{*}{ Gestión sanitaria } & Baja & 121 & 55 & 42 & 28 & \multirow{2}{*}{13,743} & \multirow{2}{*}{0,003} \\
\hline & Alta & 175 & 40 & 48 & 59 & & \\
\hline \multirow{2}{*}{$\begin{array}{l}\text { Toma de decisiones y } \\
\text { afrontamiento al final de la vida }\end{array}$} & Baja & 127 & 50 & 52 & 46 & \multirow{2}{*}{8,125} & \multirow{2}{*}{0,043} \\
\hline & Alta & 169 & 45 & 38 & 41 & & \\
\hline \multirow{2}{*}{$\begin{array}{l}\text { Motivación para continuar con la } \\
\text { formación }\end{array}$} & Baja & 124 & 35 & 19 & 27 & \multirow{2}{*}{14,062} & \multirow{2}{*}{0,003} \\
\hline & Alta & 172 & 60 & 71 & 60 & & \\
\hline \multirow{2}{*}{ Repercusión de la formación } & Baja & 180 & 34 & 40 & 46 & \multirow{2}{*}{21,174} & \multirow{2}{*}{$<0,001$} \\
\hline & Alta & 116 & 61 & 50 & 41 & & \\
\hline
\end{tabular}

Nota. Prueba de Chi-Cuadrado $\left(\chi^{2}\right)$. p valor: $p<0,05$.

* Master como título propio de Universidad.

Seguidamente se analizó como influía el hecho de que el hospital tuviese o no vinculación con la universidad en las puntuaciones de cada dimensión. Debido a las diferencias en los tamaños muestrales de cada grupo se utilizó la corrección de Yates, comprobando que los valores esperados de la tabla fueran superiores a 5 en el $100 \%$ de las celdas.

Cómo se observa en la tabla 95, las enfermeras que trabajaban en centros universitarios presentaron mayores valoraciones en las habilidades en el cuidado del paciente crítico y en las medidas para mejorar el cuidado. Las enfermeras de centros no universitarios valoraron más positivamente las necesidades de comunicación, toma de decisiones, evaluación del paciente crítico y excelencia en cuidados.

Tabla 95. Diferencias significativas en la valoración de las dimensiones detectadas en función de la pertenencia a centros universitarios o no universitarios.

\begin{tabular}{|c|c|c|c|c|c|}
\hline \multirow{2}{*}{ Valoración de la dimensión } & & \multicolumn{2}{|c|}{$\begin{array}{c}\text { Relación con la Universidad del Centro } \\
\text { Hospitalario }\end{array}$} & \multirow{2}{*}{$x^{2}$} & \multirow{2}{*}{$p$} \\
\hline & & $\begin{array}{l}\text { Universitarios } \\
\text { ( } n=491)\end{array}$ & $\begin{array}{l}\text { No Universitarios } \\
(n=77)\end{array}$ & & \\
\hline \multirow{2}{*}{$\begin{array}{l}\text { Habilidades en el cuidado } \\
\text { del paciente critico }\end{array}$} & Baja & 209 & 21 & \multirow{2}{*}{6,461} & \multirow{2}{*}{0,011} \\
\hline & Alta & 282 & 56 & & \\
\hline \multirow{2}{*}{$\begin{array}{l}\text { Comunicación y seguridad } \\
\text { clínica }\end{array}$} & Baja & 245 & 25 & \multirow{2}{*}{8,109} & \multirow{2}{*}{0,004} \\
\hline & Alta & 246 & 52 & & \\
\hline \multirow{2}{*}{ Excelencia en cuidados } & Baja & 241 & 25 & \multirow{2}{*}{7,380} & \multirow{2}{*}{0,007} \\
\hline & Alta & 250 & 52 & & \\
\hline \multirow{2}{*}{$\begin{array}{l}\text { Evaluación del paciente } \\
\text { crítico, herramientas y } \\
\text { tecnología }\end{array}$} & Baja & 252 & 30 & \multirow{2}{*}{4,069} & \multirow{2}{*}{0,044} \\
\hline & Alta & 239 & 47 & & \\
\hline \multirow{2}{*}{$\begin{array}{l}\text { Toma de decisiones y } \\
\text { afrontamiento al final de la } \\
\text { vida }\end{array}$} & Baja & 246 & 29 & \multirow{2}{*}{4,124} & \multirow{2}{*}{0,042} \\
\hline & Alta & 245 & 48 & & \\
\hline
\end{tabular}




\begin{tabular}{|c|c|c|c|c|c|}
\hline \multirow{2}{*}{ Valoración de la dimensiór } & & \multicolumn{2}{|c|}{$\begin{array}{c}\text { Relación con la Universidad del Centro } \\
\text { Hospitalario }\end{array}$} & \multirow{2}{*}{$x^{2}$} & \multirow{2}{*}{$p$} \\
\hline & & $\begin{array}{l}\text { Universitarios } \\
\quad(n=491)\end{array}$ & $\begin{array}{l}\text { No Universitarios } \\
(n=77)\end{array}$ & & \\
\hline \multirow{2}{*}{$\begin{array}{l}\text { Medidas para mejorar el } \\
\text { cuidado }\end{array}$} & Baja & 224 & 23 & \multirow{2}{*}{6,720} & \multirow{2}{*}{0,010} \\
\hline & Alta & 267 & 54 & & \\
\hline
\end{tabular}

Nota. Prueba de Chi-Cuadrado $\left(\chi^{2}\right) \cdot p$ valor: $p<0,05$.

El tipo de gestión no influyó en ninguna de las 13 dimensiones exploradas al igual que la organización en unidades polivalentes o específicas. Sin embargo, el tamaño del centro hospitalario si mostró diferencias. La pertenencia a centros hospitalarios de pequeño tamaño definidos con menores o iguales a 500 camas fue un factor que afectó a 5 de las 13 dimensiones con alta valoración. Ver tabla 96.

Tabla 96. Diferencias significativas en la valoración de las dimensiones detectadas en función del número de camas del centro hospitalario

\begin{tabular}{|c|c|c|c|c|c|}
\hline \multirow{2}{*}{ Valoración de la dimensión } & & \multicolumn{2}{|c|}{ Tamaño del centro hospitalario } & \multirow[b]{2}{*}{$x^{2}$} & \multirow[b]{2}{*}{$p$} \\
\hline & & $\begin{array}{c}>500 \text { camas } \\
(n=287)\end{array}$ & $\begin{array}{c}\leq 500 \text { camas } \\
(n=281)\end{array}$ & & \\
\hline \multirow{2}{*}{$\begin{array}{l}\text { Habilidades en el cuidado del } \\
\text { paciente critico }\end{array}$} & Baja & 136 & 94 & \multirow{2}{*}{11,401} & \multirow{2}{*}{0,001} \\
\hline & Alta & 151 & 187 & & \\
\hline \multirow{2}{*}{ Comunicación y seguridad clínica } & Baja & 152 & 118 & \multirow{2}{*}{6,850} & \multirow{2}{*}{0,009} \\
\hline & Alta & 135 & 163 & & \\
\hline \multirow{2}{*}{ Excelencia en cuidados } & Baja & 149 & 117 & \multirow{2}{*}{6,025} & \multirow{2}{*}{0,014} \\
\hline & Alta & 138 & 164 & & \\
\hline \multirow{2}{*}{ Gestión sanitaria } & Baja & 137 & 109 & \multirow{2}{*}{4,627} & \multirow{2}{*}{0,031} \\
\hline & Alta & 150 & 172 & & \\
\hline \multirow{2}{*}{ Medidas para mejorar el cuidado } & Baja & 139 & 108 & \multirow{2}{*}{5,775} & \multirow{2}{*}{0,016} \\
\hline & Alta & 148 & 173 & & \\
\hline
\end{tabular}

Nota. Prueba de Chi-Cuadrado $\left(\chi^{2}\right)$. p valor: $p<0,05$.

Al analizar el tamaño de $\mathrm{UCl}$, se observó que sólo se afectaban 2 dimensiones; resulta curioso que el tamaño de la estructura hospitalaria total influyó en más dimensiones que el propio tamaño de la unidad. Ver tabla 97. 
Tabla 97. Diferencias significativas en la valoración de las dimensiones detectadas en función del tamaño de la UCl.

\begin{tabular}{|c|c|c|c|c|c|}
\hline \multirow[b]{2}{*}{ Valoración de la dimensión } & & \multicolumn{2}{|c|}{ Tamaño de la UCI } & \multirow[b]{2}{*}{$x^{2}$} & \multirow[b]{2}{*}{$\boldsymbol{p}$} \\
\hline & & $\begin{array}{c}\text { Unidades } \\
\text { pequeñas } \\
(n=352)\end{array}$ & $\begin{array}{c}\text { Unidades } \\
\text { grandes } \\
(n=216)\end{array}$ & & \\
\hline \multirow[b]{2}{*}{ Habilidades en el cuidado del paciente critico } & Baja & 155 & 75 & \multirow[b]{2}{*}{4,817} & \multirow[b]{2}{*}{0,028} \\
\hline & Alta & 197 & 141 & & \\
\hline \multirow{2}{*}{$\begin{array}{l}\text { Formación específica y continuada de las } \\
\text { enfermeras de plantilla (staff) }\end{array}$} & Baja & 176 & 78 & \multirow{2}{*}{10,405} & \multirow{2}{*}{0,001} \\
\hline & Alta & 176 & 138 & & \\
\hline
\end{tabular}

Nota. Prueba de Chi-Cuadrado $\left(\chi^{2}\right) \cdot \mathbf{p}$ valor: $p<0,05$

En cuanto a la experiencia laboral total como enfermera en la valoración de las dimensiones del cuidado, observamos que siguen las mismas tendencias que los ítems y los subgrupos de apartados anteriores, ya que las enfermeras de $>20$ años valoraron de manera significativamente más alta. Ver tabla 98.

Tabla 98. Diferencias significativas en la valoración de las dimensiones detectadas en función de la experiencia laboral total como enfermera.

\begin{tabular}{|c|c|c|c|c|c|c|c|}
\hline \multirow{2}{*}{ Valoración de la dimensión } & & \multicolumn{4}{|c|}{$\begin{array}{l}\text { Años de experiencia laboral como } \\
\text { enfermera en cualquier ámbito }\end{array}$} & \multirow[b]{2}{*}{$x^{2}$} & \multirow[b]{2}{*}{$p$} \\
\hline & & $\begin{array}{l}\leq 10 \text { años } \\
(n=136)\end{array}$ & $\begin{array}{c}11-15 \\
\text { años } \\
(n=130)\end{array}$ & $\begin{array}{c}16-20 \\
\text { años } \\
(n=124)\end{array}$ & $\begin{array}{c}>20 \\
\text { años } \\
(n=178)\end{array}$ & & \\
\hline \multirow{2}{*}{$\begin{array}{l}\text { Habilidades en el cuidado del paciente } \\
\text { critico }\end{array}$} & Baja & 72 & 60 & 54 & 44 & \multirow{2}{*}{29,335} & \multirow{2}{*}{$<0,001$} \\
\hline & Alta & 64 & 70 & 70 & 134 & & \\
\hline \multirow{2}{*}{ Comunicación y seguridad clínica } & Baja & 75 & 70 & 65 & 60 & \multirow{2}{*}{20,068} & \multirow{2}{*}{$<0,001$} \\
\hline & Alta & 61 & 60 & 59 & 118 & & \\
\hline \multirow{2}{*}{$\begin{array}{l}\text { Formación específica y continuada de las } \\
\text { enfermeras de plantilla (staff) }\end{array}$} & Baja & 66 & 59 & 71 & 58 & \multirow{2}{*}{19,311} & \multirow{2}{*}{$<0,001$} \\
\hline & Alta & 70 & 71 & 53 & 120 & & \\
\hline \multirow{2}{*}{$\begin{array}{l}\text { Evaluación del paciente } \\
\text { herramientas y tecnología }\end{array}$} & Baja & 81 & 71 & 60 & 70 & \multirow{2}{*}{14,292} & \multirow{2}{*}{0,003} \\
\hline & Alta & 55 & 59 & 64 & 108 & & \\
\hline \multirow{2}{*}{ Gestión sanitaria } & Baja & 63 & 60 & 66 & 57 & \multirow{2}{*}{15,134} & \multirow{2}{*}{0,002} \\
\hline & Alta & 73 & 70 & 58 & 121 & & \\
\hline \multirow{2}{*}{$\begin{array}{l}\text { Toma de decisiones y afrontamiento al } \\
\text { final de la vida }\end{array}$} & Baja & 79 & 74 & 58 & 64 & \multirow{2}{*}{20,062} & \multirow{2}{*}{$<0,001$} \\
\hline & Alta & 57 & 56 & 66 & 114 & & \\
\hline
\end{tabular}

Nota. Prueba de Chi-Cuadrado $\left(\chi^{2}\right) . p$ valor: $p<0,05$.

En lo que respecta a la valoración de las dimensiones en relación con la experiencia laboral como enfermera de $\mathrm{UCl}$, el análisis mediante Chi-Cuadrado indicó diferencias significativas en 5 dimensiones y estas coinciden con las mismas expresadas en la tabla 96, y en el mismo sentido; excepto en la dimensión "Gestión sanitaria" ya que la experiencia en $\mathrm{UCl}$ no influye de forma significativa. La única dimensión que sigue una tendencia distinta es la "Motivación para continuar la formación", son las enfermeras con menor experiencia laboral en $\mathrm{UCl}$ quienes obtienen mayores porcentajes de alta valoración. Ver tabla 99. 
Tabla 99. Diferencias significativas en la valoración de las dimensiones detectadas en función de la experiencia laboral como enfermera de $\mathrm{UCl}$.

\begin{tabular}{|c|c|c|c|c|c|c|c|}
\hline \multirow[b]{2}{*}{ Valoración de la dimensión } & & \multicolumn{4}{|c|}{$\begin{array}{l}\text { Años de experiencia laboral como } \\
\text { enfermera de cuidados intensivos }\end{array}$} & \multirow[b]{2}{*}{$x^{2}$} & \multirow[b]{2}{*}{$p$} \\
\hline & & $\begin{array}{c}\leq 5 \\
\text { años } \\
(n=192)\end{array}$ & $\begin{array}{c}\text { 6-10 } \\
\text { años } \\
(n=138)\end{array}$ & $\begin{array}{c}\begin{array}{c}11-15 \\
\text { años } \\
(n=96)\end{array} \\
\end{array}$ & $\begin{array}{c}>15 \\
\text { años } \\
(n=142)\end{array}$ & & \\
\hline \multirow{2}{*}{$\begin{array}{l}\text { Habilidades en el cuidado del paciente } \\
\text { critico }\end{array}$} & Baja & 98 & 56 & 39 & 37 & \multirow{2}{*}{21,150} & \multirow{2}{*}{$<0,001$} \\
\hline & Alta & 94 & 82 & 57 & 105 & & \\
\hline \multirow{2}{*}{ Comunicación y seguridad clínica } & Baja & 107 & 71 & 45 & 47 & \multirow{2}{*}{17,900} & \multirow{2}{*}{$<0,001$} \\
\hline & Alta & 85 & 67 & 51 & 95 & & \\
\hline \multirow{2}{*}{$\begin{array}{l}\text { Formación específica y continuada de } \\
\text { las enfermeras de plantilla (staff) }\end{array}$} & Baja & 99 & 61 & 44 & 50 & \multirow{2}{*}{8,893} & \multirow{2}{*}{0,031} \\
\hline & Alta & 93 & 77 & 52 & 92 & & \\
\hline \multirow{2}{*}{$\begin{array}{l}\text { Evaluación del paciente crítico, } \\
\text { herramientas y tecnología }\end{array}$} & Baja & 110 & 68 & 48 & 56 & \multirow{2}{*}{10,423} & \multirow{2}{*}{0,015} \\
\hline & Alta & 82 & 70 & 48 & 86 & & \\
\hline \multirow{2}{*}{$\begin{array}{l}\text { Toma de decisiones y afrontamiento } \\
\text { al final de la vida }\end{array}$} & Baja & 115 & 71 & 41 & 48 & \multirow{2}{*}{24,034} & \multirow{2}{*}{$<0,001$} \\
\hline & Alta & 77 & 67 & 55 & 94 & & \\
\hline \multirow{2}{*}{$\begin{array}{l}\text { Motivación para continuar con la } \\
\text { formación }\end{array}$} & Baja & 59 & 54 & 46 & 46 & \multirow{2}{*}{9,608} & \multirow{2}{*}{0,022} \\
\hline & Alta & 133 & 84 & 50 & 96 & & \\
\hline
\end{tabular}

Nota. Prueba de Chi-Cuadrado $\left(\chi^{2}\right) \cdot \mathbf{p}$ valor: $p<0,05$.

4.3.13. Análisis de la valoración de las dimensiones detectadas en las necesidades formativas de las enfermeras en relación a la experiencia laboral y formación previa necesaria según los encuestados.

En este apartado se busca la relación entre las 13 dimensiones y las preguntas que demandan unos requisitos previos, experiencia laboral previa en hospitalización, antes de comenzar a trabajar en $\mathrm{UCl}$. Emitieron su opinión 513 encuestados y se encontró asociación significativa en 11 de las 13 dimensiones.

En este caso se observa que existe una asociación significativa entre una valoración alta de las dimensiones y solicitar al menos 1 año de experiencia en hospitalización antes de comenzar a trabajar en $\mathrm{UCl}$. Este hecho es muy consistente en los 7 primeros elementos de la tabla 97. Las necesidades en la aplicación de medidas de soporte y la repercusión de la formación apoyaban que esta formación fuera al menos de 2 años, ver tabla 100.

Tabla 100. Diferencias significativas en la valoración de las dimensiones detectadas en función de los requisitos laborales previos en hospitalización.

\begin{tabular}{|c|c|c|c|c|c|c|c|}
\hline \multirow[b]{2}{*}{ Valoración de la dimensión } & & \multicolumn{4}{|c|}{$\begin{array}{c}\text { Experiencia laboral previa en hospitalización a } \\
\text { la hora de comenzar a trabajar en UCI }\end{array}$} & \multirow[b]{2}{*}{$x^{2}$} & \multirow[b]{2}{*}{$p$} \\
\hline & & $\begin{array}{c}\text { Al menos } \\
1 \text { año } \\
(n=220)\end{array}$ & $\begin{array}{l}\text { Al menos } \\
2 \text { años } \\
(n=188)\end{array}$ & $\begin{array}{l}\text { Al menos } \\
3 \text { años } \\
(n=66)\end{array}$ & $\begin{array}{c}\text { Al menos } \\
4 \text { años } \\
(n=39)\end{array}$ & & \\
\hline \multirow{2}{*}{$\begin{array}{l}\text { Habilidades en el cuidado del } \\
\text { paciente critico }\end{array}$} & Baja & 63 & 96 & 36 & 14 & \multirow{2}{*}{27,426} & \multirow{2}{*}{$<0,001$} \\
\hline & Alta & 157 & 92 & 30 & 25 & & \\
\hline
\end{tabular}




\begin{tabular}{|c|c|c|c|c|c|c|c|}
\hline \multirow{2}{*}{ Valoración de la dimensión } & & \multicolumn{4}{|c|}{$\begin{array}{c}\text { Experiencia laboral previa en hospitalización a } \\
\text { la hora de comenzar a trabajar en UCI }\end{array}$} & \multirow[b]{2}{*}{$x^{2}$} & \multirow[b]{2}{*}{$\boldsymbol{p}$} \\
\hline & & $\begin{array}{l}\text { Al menos } \\
1 \text { año } \\
(n=220)\end{array}$ & $\begin{array}{l}\text { Al menos } \\
2 \text { años } \\
\text { ( } \mathrm{n}=\mathbf{1 8 8})\end{array}$ & $\begin{array}{l}\text { Al menos } \\
3 \text { años } \\
(n=66)\end{array}$ & $\begin{array}{l}\text { Al menos } \\
4 \text { años } \\
(n=39)\end{array}$ & & \\
\hline \multirow{2}{*}{ Comunicación y seguridad clínica } & Baja & 78 & 108 & 43 & 16 & \multirow{2}{*}{29,251} & \multirow{2}{*}{$<0,001$} \\
\hline & Alta & 142 & 80 & 23 & 23 & & \\
\hline \multirow{2}{*}{$\begin{array}{l}\text { Planes de acogida para enfermeras } \\
\text { noveles }\end{array}$} & Baja & 74 & 88 & 34 & 8 & \multirow{2}{*}{34,300} & \multirow{2}{*}{$<0,001$} \\
\hline & Alta & 146 & 100 & 32 & 31 & & \\
\hline \multirow{2}{*}{$\begin{array}{l}\text { Formación específica y continuada } \\
\text { de las enfermeras de plantilla } \\
\text { (staff) }\end{array}$} & Baja & 83 & 92 & 33 & 14 & \multirow{2}{*}{11,708} & \multirow{2}{*}{$<0,001$} \\
\hline & Alta & 137 & 96 & 33 & 25 & & \\
\hline \multirow{2}{*}{ Excelencia en cuidados } & Baja & 88 & 90 & 39 & 16 & \multirow{2}{*}{12,547} & \multirow{2}{*}{0,014} \\
\hline & Alta & 132 & 98 & 27 & 23 & & \\
\hline \multirow{2}{*}{$\begin{array}{l}\text { Evaluación del paciente crítico, } \\
\text { herramientas y tecnología }\end{array}$} & Baja & 91 & 106 & 36 & 18 & \multirow{2}{*}{11,267} & \multirow{2}{*}{0,024} \\
\hline & Alta & 129 & 82 & 30 & 21 & & \\
\hline \multirow{2}{*}{ Gestión sanitaria } & Baja & 71 & 96 & 32 & 16 & \multirow{2}{*}{20,139} & \multirow{2}{*}{$<0,001$} \\
\hline & Alta & 149 & 92 & 34 & 23 & & \\
\hline \multirow{2}{*}{ Aplicación de medidas de soporte } & Baja & 100 & 76 & 25 & 14 & \multirow{2}{*}{15,239} & \multirow{2}{*}{0,004} \\
\hline & Alta & 120 & 112 & 41 & 25 & & \\
\hline \multirow{2}{*}{$\begin{array}{l}\text { Toma de decisiones y } \\
\text { afrontamiento al final de la vida }\end{array}$} & Baja & 86 & 99 & 42 & 13 & \multirow{2}{*}{23,791} & \multirow{2}{*}{$<0,001$} \\
\hline & Alta & 134 & 89 & 24 & 26 & & \\
\hline \multirow{2}{*}{$\begin{array}{l}\text { Motivación para continuar con la } \\
\text { formación }\end{array}$} & Baja & 70 & 61 & 24 & 17 & \multirow{2}{*}{17,407} & \multirow{2}{*}{0,002} \\
\hline & Alta & 150 & 127 & 42 & 22 & & \\
\hline \multirow{2}{*}{ Repercusión de la formación } & Baja & 138 & 82 & 26 & 17 & \multirow{2}{*}{25,772} & \multirow{2}{*}{$<0,001$} \\
\hline & Alta & 82 & 106 & 40 & 22 & & \\
\hline
\end{tabular}

Nota. Prueba de Chi-Cuadrado $\left(\chi^{2}\right) . p$ valor: $p<0,05$.

Otro elemento para reseñar es la pregunta donde se solicitaba experiencia previa en servicios similares a UCl (urgencias y quirófano). Emitieron su opinión 444 encuestados. Como se puede observar los encuestados solicitaban al menos 1 año de experiencia previa en los servicios mencionados. Se muestra que existe un mayor número de encuestados que piden menos tiempo en los servicios de urgencias y/o quirófano que en los de hospitalización. Ver tabla 101.

Tabla 101. Diferencias significativas en la valoración de las dimensiones detectadas en función de los requisitos laborales previos en urgencias y/o quirófano.

\begin{tabular}{|c|c|c|c|c|c|c|c|}
\hline \multirow{2}{*}{ Valoración de la dimensión } & & \multicolumn{4}{|c|}{$\begin{array}{c}\text { Experiencia laboral previa en urgencias y/o } \\
\text { quirófano a la hora de comenzar } \\
\text { a trabajar en UCl }\end{array}$} & \multirow{2}{*}{$x^{2}$} & \multirow{2}{*}{$p$} \\
\hline & & $\begin{array}{l}\text { Al menos } \\
1 \text { año } \\
(n=339) \\
\end{array}$ & $\begin{array}{l}\text { Al menos } \\
2 \text { años } \\
(n=74)\end{array}$ & $\begin{array}{l}\text { Al menos } \\
3 \text { años } \\
(n=12)\end{array}$ & $\begin{array}{l}\text { Al menos } \\
4 \text { años } \\
(n=19)\end{array}$ & & \\
\hline \multirow{2}{*}{$\begin{array}{l}\text { Habilidades en el cuidado del } \\
\text { paciente critico }\end{array}$} & Baja & 132 & 17 & 1 & 8 & \multirow{2}{*}{30,827} & \multirow{2}{*}{$<0,001$} \\
\hline & Alta & 207 & 57 & 11 & 11 & & \\
\hline \multirow{2}{*}{ Comunicación y seguridad clínica } & Baja & 147 & 29 & 2 & 8 & \multirow{2}{*}{29,544} & \multirow{2}{*}{$<0,001$} \\
\hline & Alta & 192 & 45 & 10 & 11 & & \\
\hline
\end{tabular}




\begin{tabular}{|c|c|c|c|c|c|c|c|}
\hline \multirow{2}{*}{ Valoración de la dimensión } & & \multicolumn{4}{|c|}{$\begin{array}{c}\text { Experiencia laboral previa en urgencias y/o } \\
\text { quirófano a la hora de comenzar } \\
\text { a trabajar en UCI }\end{array}$} & \multirow{2}{*}{$x^{2}$} & \multirow{2}{*}{$\boldsymbol{p}$} \\
\hline & & $\begin{array}{c}\text { Al menos } \\
1 \text { año } \\
(n=339)\end{array}$ & $\begin{array}{l}\text { Al menos } \\
2 \text { años } \\
(n=74)\end{array}$ & $\begin{array}{l}\text { Al menos } \\
3 \text { años } \\
(n=12)\end{array}$ & $\begin{array}{l}\text { Al menos } \\
4 \text { años } \\
(n=19)\end{array}$ & & \\
\hline \multirow{2}{*}{$\begin{array}{l}\text { Planes de acogida para enfermeras } \\
\text { noveles }\end{array}$} & Baja & 129 & 21 & 1 & 5 & \multirow{2}{*}{53,108} & \multirow{2}{*}{$<0,001$} \\
\hline & Alta & 210 & 53 & 11 & 14 & & \\
\hline \multirow{2}{*}{$\begin{array}{l}\text { Formación específica y continuada } \\
\text { de las enfermeras de plantilla (staff) }\end{array}$} & Baja & 143 & 27 & 2 & 8 & \multirow{2}{*}{18,007} & \multirow{2}{*}{$<0,001$} \\
\hline & Alta & 196 & 47 & 10 & 11 & & \\
\hline \multirow{2}{*}{ Excelencia en cuidados } & Baja & 151 & 30 & 1 & 10 & \multirow{2}{*}{17,507} & \multirow{2}{*}{0,002} \\
\hline & Alta & 188 & 44 & 11 & 9 & & \\
\hline \multirow{2}{*}{$\begin{array}{l}\text { Evaluación del paciente crítico, } \\
\text { herramientas y tecnología }\end{array}$} & Baja & 163 & 27 & 2 & 8 & \multirow{2}{*}{24,587} & \multirow{2}{*}{$<0,001$} \\
\hline & Alta & 176 & 47 & 10 & 11 & & \\
\hline \multirow{2}{*}{ Gestión sanitaria } & Baja & 135 & 22 & 6 & 6 & \multirow{2}{*}{26,346} & \multirow{2}{*}{$<0,001$} \\
\hline & Alta & 204 & 52 & 6 & 13 & & \\
\hline \multirow{2}{*}{$\begin{array}{l}\text { Toma de decisiones y afrontamiento } \\
\text { al final de la vida }\end{array}$} & Baja & 151 & 28 & 6 & 4 & \multirow{2}{*}{32,828} & \multirow{2}{*}{$<0,001$} \\
\hline & Alta & 188 & 46 & 6 & 15 & & \\
\hline
\end{tabular}

Nota. Prueba de Chi-Cuadrado $\left(\chi^{2}\right) \cdot p$ valor: $p<0,05$.

4.3.14. Comparación entre las puntuaciones de las dimensiones de las necesidades formativas de las enfermeras de cuidados intensivos entre el grupo Delphi y el grupo nacional.

Una de las hipótesis de la presente tesis es "Las enfermeras de cuidados intensivos tienen las mismas necesidades y desempeñan las mismas competencias en todo el territorio nacional". Por este hecho, se adjuntan los resultados de cada una de las dimensiones en cada uno de los grupos tanto el nacional como el grupo Delphi. En la tabla 102 se presentan los resultados descriptivos de ambos grupos.

Tabla 102. Estadísticos descriptivos de las puntuaciones de las dimensiones de las necesidades formativas de las enfermeras de $\mathrm{UCl}$ tanto del grupo nacional como del grupo Delphi.

\begin{tabular}{|c|c|c|c|c|}
\hline \multirow[t]{2}{*}{ Dimensiones } & \multicolumn{2}{|c|}{$\begin{array}{c}\text { Grupo } \\
\text { Nacional } \\
\text { (n=568) }\end{array}$} & \multicolumn{2}{|c|}{$\begin{array}{l}\text { Grupo } \\
\text { Delphi } \\
(n=15)\end{array}$} \\
\hline & Media & D.T. & Media & D.T. \\
\hline Habilidades en el cuidado del paciente critico & 9,28 & 0,61 & 9,42 & 0,54 \\
\hline Comunicación y seguridad clínica & 9,17 & 0,69 & 9,43 & 0,60 \\
\hline Conocimientos enfermeros y razonamiento clínico & 9,29 & 0,58 & 9,47 & 0,46 \\
\hline Planes de acogida para enfermeras noveles & 8,99 & 0,85 & 9,20 & 0,53 \\
\hline Formación específica y continuada de las enfermeras de plantilla (staff) & 8,49 & 0,91 & 8,84 & 0,77 \\
\hline Excelencia en cuidados & 9,10 & 0,73 & 9,24 & 0,88 \\
\hline Evaluación del paciente crítico, herramientas y tecnología & 8,89 & 0,79 & 8,75 & 0,91 \\
\hline Gestión sanitaria & 7,62 & 1,55 & 7,64 & 1,16 \\
\hline Aplicación de medidas de soporte & 8,10 & 1,32 & 8,49 & 0,88 \\
\hline Toma de decisiones y afrontamiento al final de la vida & 8,38 & 1,24 & 8,71 & 0,98 \\
\hline
\end{tabular}




\begin{tabular}{lcccc}
\hline \multirow{2}{*}{ Dimensiones } & \multicolumn{2}{c}{$\begin{array}{c}\text { Grupo } \\
\text { Nacional } \\
\text { (n=568) }\end{array}$} & \multicolumn{2}{c}{$\begin{array}{c}\text { Grupo } \\
\text { Delphi } \\
(\mathbf{n = 1 5})\end{array}$} \\
\cline { 2 - 5 } & Media & D.T. & Media & D.T. \\
\hline Medidas para mejorar el cuidado & 6,90 & 1,47 & 6,49 & 1,68 \\
\hline Motivación para continuar con la formación & 7,33 & 1,43 & 6,84 & 1,27 \\
Repercusión de la formación & 8,05 & 1,17 & 8,93 & 0,78 \\
\hline
\end{tabular}

Nota. Resultados expresados en media y desviación típica (DT).

Se realizó posteriormente una comparación entre ambos grupos mediante la prueba no paramétrica de la $\mathrm{U}$ de Mann-Whitney. Como se puede observar en la tabla 103, únicamente existen diferencias significativas en las dimensiones de "repercusión de la formación", el grupo Delphi presentó una mediana mayor que el grupo nacional de manera significativa, este hecho nos vincula que el grupo de experto es más proactivo y cree que la formación tiene repercusiones positivas a nivel clínico.

Tabla 103. Comparación de las puntuaciones de las dimensiones de las necesidades formativas de las enfermeras entre el grupo nacional y el grupo Delphi.

\begin{tabular}{|c|c|c|c|c|}
\hline Dimensiones & $\begin{array}{c}\text { Rango Promedio } \\
\text { Grupo Nacional } \\
\text { (n=568) }\end{array}$ & $\begin{array}{c}\text { Rango Promedio } \\
\text { Grupo Delphi } \\
(n=15)\end{array}$ & $\begin{array}{l}\text { U de Man } \\
\text { Whitney }\end{array}$ & $\boldsymbol{p}$ \\
\hline Habilidades en el cuidado del paciente critico & 291,09 & 326,47 & 4777 & 0,421 \\
\hline Comunicación y seguridad clínica & 290,25 & 358,37 & 5255,5 & 0,120 \\
\hline $\begin{array}{l}\text { Conocimientos enfermeros y razonamiento } \\
\text { clínico }\end{array}$ & 290,76 & 338,97 & 4964,5 & 0,272 \\
\hline Planes de acogida para enfermeras noveles & 291,19 & 322,57 & 4718,5 & 0,475 \\
\hline $\begin{array}{l}\text { Formación específica y continuada de las } \\
\text { enfermeras de plantilla (staff) }\end{array}$ & 290,40 & 352,57 & 5168,5 & 0,158 \\
\hline Excelencia en cuidados & 290,76 & 339,00 & 4965 & 0,271 \\
\hline $\begin{array}{l}\text { Evaluación del paciente crítico, herramientas y } \\
\text { tecnología }\end{array}$ & 292,68 & 266,30 & 3875 & 0,548 \\
\hline Gestión sanitaria & 292,22 & 283,50 & 4132,5 & 0,843 \\
\hline Aplicación de medidas de soporte & 291,00 & 329,97 & 4829,5 & 0,374 \\
\hline $\begin{array}{l}\text { Toma de decisiones y afrontamiento al final de } \\
\text { la vida }\end{array}$ & 291,01 & 329,30 & 4819,5 & 0,374 \\
\hline Medidas para mejorar el cuidado & 292,97 & 255,43 & 3711,5 & 0,393 \\
\hline Motivación para continuar con la formación & 293,76 & 225,40 & 3261 & 0,119 \\
\hline Repercusión de la formación & 288,53 & 423,57 & 6233,5 & 0,002 \\
\hline
\end{tabular}

Nota. Prueba de U de Mann-Whitney. $\mathbf{p}$ valor: $p<0,05$.

\subsubsection{Análisis factorial confirmatorio del modelo generado.}

Se realizó un análisis factorial confirmatorio (AFC) a través de las dimensiones obtenidas en el AFE buscando en todo momento mantener el constructo generado. Al aplicar las distintas dimensiones estudiadas a la mitad de la muestra total elegida de manera aleatoria, se observó que las dimensiones de: excelencia en cuidados, toma de decisiones, afrontamiento al final de la vida y repercusión de la formación; no influían adecuadamente en el modelo, y sus valores de covarianza tenían valores inferiores a los adecuados, por lo cual se retiraron de la estructura; retirando también 
todos aquellos ítems cuya carga factorial fuera inferior a 0,5 ; manteniendo en todo momento al menos dos factores por cada variable latente. Tras el análisis de numerosos modelos, se observó que el modelo con mejores valores estadísticos fue aquella solución con 10 factores, y 33 variables y que a continuación se observa en la figura:

Figura 44. Análisis Factorial Confirmatorio

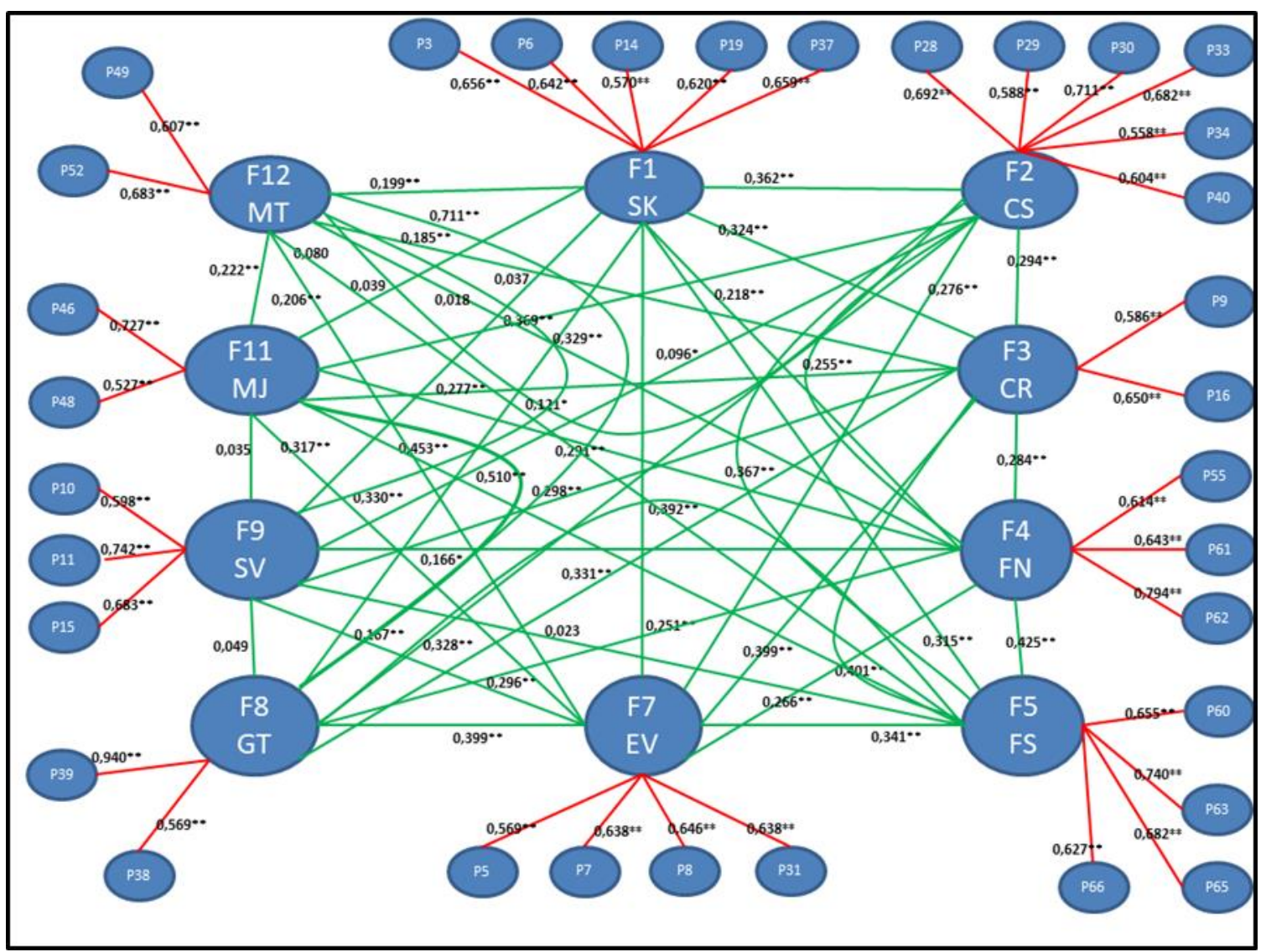

GOODNESS OF FIT

$\chi^{2}=8952(p=0,000), C M I N / D F=2,780, C F I=0,883, T L I=0,830$, RMSEA $=0,055(0,052-0,059)$

Nota: F1SK: Habilidades en el cuidado del paciente crítico; F2CS: Comunicación y Seguridad Clínica; F3CR: Conocimientos enfermeros y razonamiento clínico; F4FN: Planes de Acogida para enfermeras noveles; F5FS: Formación específica y continuada de las enfermeras de plantilla (staff); F7EV: Evaluación del paciente crítico, herramientas y tecnología; F8GT: Gestión sanitaria; F9SV=Aplicación de medidas de soporte; F11MJ:Medidas para mejorar el cuidado; F12MT: Motivación para continuar con la formación. ${ }^{* *} p \leq 0,01 * p \leq 0,05$

Para una mejor visualización se incluyen las covarianzas de las variables incluidas en la siguiente tabla:

Tabla 104. Covarianzas en el modelo estudiado.

\begin{tabular}{cccccc}
\hline $\begin{array}{c}\text { Parejas de Variables } \\
\text { latentes }\end{array}$ & Covarianza & $\boldsymbol{p}$ & $\begin{array}{c}\text { Parejas de } \\
\text { Variables latentes }\end{array}$ & Covarianza & $\boldsymbol{p}$ \\
\hline F1SK-F2CS & 0,362 & $* *$ & F4FN-F5FS & 0,425 & $* *$ \\
\hline F1SK-F3CR & 0,324 & $* *$ & F4FN-F7EV & 0,266 & $* *$ \\
F1SK-F4FN & 0,218 & $* *$ & F4FN-F8GT & 0,296 & $* *$ \\
\hline F1SK-F5FS & 0,315 & $* *$ & F4FN-F9SV & 0,166 & $\mathbf{0 , 0 0 2} *$ \\
F1SK-F7EV & 0,251 & $* *$ & F4FN-F11MJ & 0,291 & $* *$ \\
\hline
\end{tabular}




\begin{tabular}{|c|c|c|c|c|c|}
\hline $\begin{array}{c}\text { Parejas de Variables } \\
\text { latentes }\end{array}$ & Covarianza & $p$ & $\begin{array}{c}\text { Parejas de } \\
\text { Variables latentes }\end{array}$ & Covarianza & $p$ \\
\hline F1SK-F8GT & 0,329 & $* *$ & F4FN-F12MT & 0,018 & 0,710 \\
\hline F1SK-F9SV & 0,037 & 0,325 & F5FS-F7EV & 0,341 & $* *$ \\
\hline F1SK-F11MJ & 0,039 & 0,265 & F5FS-F8GT & 0,392 & $* *$ \\
\hline F1SK-F12MT & 0,199 & $* *$ & F5FS-F9SV & 0,023 & 0,665 \\
\hline F2CS-F3CR & 0,294 & $* *$ & F5FS-F11MJ & 0,453 & $* *$ \\
\hline F2CS-F4FN & 0,255 & $* *$ & F5FS-F12MT & 0,080 & 0,107 \\
\hline F2CS-F5FS & 0,367 & $* *$ & F7EV-F8GT & 0,399 & $* *$ \\
\hline F2CS-F7EV & 0,276 & $* *$ & F7EV-F9SV & 0,167 & $* *$ \\
\hline F2CS-F8GT & 0,328 & $* *$ & F7EV-F11MJ & 0,317 & $* *$ \\
\hline F2CS-F9SV & 0,096 & $0,037 *$ & F7EV-F12MT & 0,206 & $* *$ \\
\hline F2CS-F11MJ & 0,369 & $* *$ & F8GT-F9SV & 0,049 & 0,616 \\
\hline F2CS-F12MT & 0,121 & $0,002 *$ & F8GT-F11MJ & 0,510 & $* *$ \\
\hline F3CS-F4FN & 0,284 & $* *$ & F8GT-F12MT & 0,711 & $* *$ \\
\hline F3CS-F5FS & 0,401 & $* *$ & F9SV-F11MJ & 0,035 & 0,578 \\
\hline F3CS-F7EV & 0,399 & $* *$ & F9SV-F12MT & 0,330 & $* *$ \\
\hline F3CS-F8GT & 0,331 & $* *$ & F11MJ-F12MT & 0,222 & $* *$ \\
\hline F3CS-F9SV & 0,298 & $* *$ & & & \\
\hline F3CS-F11MJ & 0,277 & $* *$ & & & \\
\hline F3CS-F12MT & 0,185 & $* *$ & & & \\
\hline
\end{tabular}

Nota: F1SK: Habilidades en el cuidado del paciente crítico; F2CS: Comunicación y Seguridad Clínica; F3CR: Conocimientos enfermeros y razonamiento clínico; F4FN: Planes de Acogida para enfermeras noveles; F5FS: Formación específica y continuada de las enfermeras de plantilla (staff); F7EV: Evaluación del paciente crítico, herramientas y tecnología; F8GT: Gestión sanitaria; F9SV=Aplicación de medidas de soporte; F11MJ:Medidas para mejorar el cuidado; F12MT: Motivación para continuar con la formación. ** $p \leq 0,01 * p \leq 0,05$

El modelo creado es un modelo que tiene un ajuste que sin alcanzar los mejores valores de un AFC, sí consigue una adecuada relación entre las variables analizadas. Como se podía esperar tras observar las diferencias expresadas en el resto del trabajo, la diferente valoración por las características tanto demográficas como laborales y académicas, influyen en nuestros resultados. A continuación se detallan las relaciones entre cada una de las variables estudiadas:

Tabla 105. Relación de las variables incluidas en el AFC y sus variables latentes.

\begin{tabular}{|c|c|c|c|c|c|c|}
\hline \multirow[b]{2}{*}{ Relaciones } & \multicolumn{3}{|c|}{ Fiabilidad Individual } & \multicolumn{2}{|c|}{ Consistencia interna } & \multirow{2}{*}{$\begin{array}{c}\text { Varianza } \\
\text { Extraída } \\
\text { (AVE) }\end{array}$} \\
\hline & $\begin{array}{l}\text { Estimadores } \\
\text { Estandarizados }\end{array}$ & $\boldsymbol{t}$ & $\boldsymbol{p}$ & $\begin{array}{l}\text { Alfa de } \\
\text { Cronbach }\end{array}$ & $\begin{array}{l}\text { Fiabilidad } \\
\text { Compuesta }\end{array}$ & \\
\hline \multicolumn{7}{|c|}{ Habilidades en el cuidado del paciente crítico (F1SK) } \\
\hline $\mathrm{P} 3 \leftarrow \mathrm{F} 1 \mathrm{SK}$ & 0,645 & & & & & \\
\hline $\mathrm{P} 6 \leftarrow \mathrm{F} 1 \mathrm{SK}$ & 0,694 & 13,289 & 0,000 & & & \\
\hline $\mathrm{P} 14 \leftarrow \mathrm{F} 1 \mathrm{SK}$ & 0,534 & 11,243 & 0,000 & 0,749 & 0,782 & 0,612 \\
\hline $\mathrm{P} 15 \leftarrow \mathrm{F} 1 \mathrm{SK}$ & 0,558 & 11,669 & 0,000 & & & \\
\hline $\mathrm{P} 37 \leftarrow \mathrm{F} 1 \mathrm{SK}$ & 0,637 & 13,048 & 0,000 & & & \\
\hline
\end{tabular}




\begin{tabular}{|c|c|c|c|c|c|c|}
\hline \multirow[b]{2}{*}{ Relaciones } & \multicolumn{3}{|c|}{ Fiabilidad Individual } & \multicolumn{2}{|c|}{ Consistencia interna } & \multirow{2}{*}{$\begin{array}{c}\text { Varianza } \\
\text { Extraída } \\
\text { (AVE) }\end{array}$} \\
\hline & $\begin{array}{c}\text { Estimadores } \\
\text { Estandarizados }\end{array}$ & $t$ & $p$ & $\begin{array}{c}\text { Alfa de } \\
\text { Cronbach }\end{array}$ & $\begin{array}{l}\text { Fiabilidad } \\
\text { Compuesta }\end{array}$ & \\
\hline \multicolumn{7}{|c|}{$\begin{array}{l}\text { Comunicación y Seguridad Clínica (F2CS) } \\
\text { Goodness of fit: } \chi^{2}=32502, p=0,000, C F I=0,977\end{array}$} \\
\hline $\mathrm{P} 40<\mathrm{F} 2 \mathrm{CS}$ & 0,630 & & & \multirow{6}{*}{0,818} & \multirow{6}{*}{0,852} & \multirow{6}{*}{0,658} \\
\hline $\mathrm{P} 34 \leftarrow \mathrm{F} 2 \mathrm{CS}$ & 0,578 & 12,000 & 0,000 & & & \\
\hline $\mathrm{P} 33 \leftarrow \mathrm{F} 2 \mathrm{CS}$ & 0,644 & 13,107 & 0,000 & & & \\
\hline $\mathrm{P} 30 \leftarrow \mathrm{F} 2 \mathrm{CS}$ & 0,730 & 14,440 & 0,000 & & & \\
\hline $\mathrm{P} 29 \leftarrow \mathrm{F} 2 \mathrm{CS}$ & 0,624 & 12,783 & 0,000 & & & \\
\hline $\mathrm{P} 28 \leftarrow \mathrm{F} 2 \mathrm{CS}$ & 0,727 & 14,404 & 0,000 & & & \\
\hline
\end{tabular}

Conocimientos enfermeros y razonamiento clínico (F3CR)

Goodness of fit: $\chi^{2}=2164, p=0,339, \mathrm{CFI}=0,999, \mathrm{TLI}=0,992, \mathrm{RMSEA}=0,012(0,000-0,084)$

\begin{tabular}{lllllll}
\hline $\mathrm{P} 9 \leftarrow \mathrm{F} 3 C R$ & 0,716 & & & 0,594 & 0,624 & 0,753 \\
$\mathrm{P} 16 \leftarrow \mathrm{F} 3 \mathrm{CR}$ & 0,834 & 8,322 & 0,000 & 0,594
\end{tabular}

Planes de Acogida para enfermeras noveles (F4FN)

Goodness of fit: $\chi^{2}=42149, p=0,000, C F I=0,930, T L I=0,922, \operatorname{RMSEA}=0,113(0,083-0,146)$

\begin{tabular}{|c|c|c|c|c|c|c|}
\hline $\mathrm{P} 55 \leftarrow \mathrm{F} 4 \mathrm{FN}$ & 0,549 & & & \multirow{3}{*}{0,653} & \multirow{3}{*}{0,667} & \multirow{3}{*}{0,625} \\
\hline $\mathrm{P} 61 \leftarrow \mathrm{F} 4 \mathrm{FN}$ & 0,749 & 11,160 & 0,000 & & & \\
\hline $\mathrm{P} 62 \leftarrow \mathrm{F} 4 \mathrm{FN}$ & 0,605 & 10,147 & 0,000 & & & \\
\hline
\end{tabular}

Formación específica y continuada de las enfermeras de plantilla (staff) (F5FS)

Goodness of fit: $\chi^{2}=12238, p=0,002, C F I=0,930, T L I=0,922, \operatorname{RMSEA}=0,113(0,083-0,146)$

\begin{tabular}{|c|c|c|c|c|c|c|}
\hline $\mathrm{P} 60<\mathrm{F} 5 \mathrm{FS}$ & 0,645 & & & \multirow{4}{*}{0,767} & \multirow{4}{*}{0,798} & \multirow{4}{*}{0,665} \\
\hline $\mathrm{P} 63 \leftarrow \mathrm{F} 5 \mathrm{FS}$ & 0,614 & 12,743 & 0,000 & & & \\
\hline $\mathrm{P} 65 \leftarrow \mathrm{F} 5 \mathrm{FS}$ & 0,695 & 14,118 & 0,000 & & & \\
\hline $\mathrm{P} 66 \leftarrow \mathrm{F} 5 \mathrm{FS}$ & 0,745 & 14,888 & 0,000 & & & \\
\hline
\end{tabular}

Evaluación del paciente crítico, herramientas y tecnología (F7EV)

Goodness of fit: $\chi^{2}=1529, p=0,466, C F I=1,000, T L I=0,996, \operatorname{RMSEA}=0,000(0,000-0,076)$

\begin{tabular}{|c|c|c|c|c|c|c|}
\hline P5 $\leftarrow$ F7EV & 0,584 & & & \multirow{4}{*}{0,710} & \multirow{4}{*}{0,735} & \multirow{4}{*}{0,689} \\
\hline $\mathrm{P} 7 \leftarrow \mathrm{F} 7 \mathrm{EV}$ & 0,675 & 11,591 & 0,000 & & & \\
\hline $\mathrm{P} 8 \leftarrow \mathrm{F} 7 \mathrm{EV}$ & 0,647 & 11,304 & 0,000 & & & \\
\hline $\mathrm{P} 31 \leftarrow \mathrm{F} 7 \mathrm{EV}$ & 0,693 & 10,697 & 0,000 & & & \\
\hline
\end{tabular}

\section{Gestión sanitaria (F8GT)}

Goodness of fit: $\chi^{2}=3254, p=0,654, \mathrm{CFI}=0,998, \mathrm{TLI}=0,994, \mathrm{RMSEA}=0,554(0,515-0,574)$

\begin{tabular}{lllllll}
\hline $\mathrm{P} 38 \leftarrow \mathrm{F} 8 \mathrm{GT}$ & 0,756 & & 0 & 0,837 & 0,841 & 0,853
\end{tabular}

Aplicación de medidas de soporte (F9SV)

Goodness of fit: $\chi^{2}=10536, p=0,005, C F I=0,976, T L I=0,971$, RMSEA $=0,086(0,040-0,140)$

\begin{tabular}{|c|c|c|c|c|c|c|}
\hline $\mathrm{P} 11 \leftarrow \mathrm{F} 9 \mathrm{SV}$ & 0,742 & & & \multirow{3}{*}{0,715} & \multirow{3}{*}{0,727} & \multirow{3}{*}{0,692} \\
\hline $\mathrm{P} 10 \leftarrow \mathrm{F} 9 \mathrm{SV}$ & 0,598 & 10,729 & 0,000 & & & \\
\hline $\mathrm{P} 15 \leftarrow \mathrm{F} 9 \mathrm{SV}$ & 0,683 & 11,177 & 0,000 & & & \\
\hline
\end{tabular}

Medidas para mejorar el cuidado (F11MJ)

Goodness of fit: $\chi^{2}=2,782, p=0,751, C F I=0,988, T L I=0,974, \operatorname{RMSEA}=0,457(0,431-0,484)$

\begin{tabular}{|c|c|c|c|c|c|c|}
\hline $\mathrm{P} 46 \leftarrow \mathrm{F} 11 \mathrm{MJ}$ & 0,701 & & & \multirow{2}{*}{0,593} & \multirow{2}{*}{0,612} & \multirow{2}{*}{0,596} \\
\hline $\mathrm{P} 48 \leftarrow \mathrm{F} 11 \mathrm{MJ}$ & 0,531 & 8,391 & 0,000 & & & \\
\hline
\end{tabular}

Motivación para continuar con la formación (F12MT)

Goodness of fit: $\chi^{2}=2,935, p=0,732, C F I=0,894, T L I=0,919$, RMSEA=0,251 (0,229-0,268)

\begin{tabular}{lllcccc}
\hline $\mathrm{P} 49 \leftarrow \mathrm{F} 12 \mathrm{MT}$ & 0,696 & & \multirow{2}{*}{0,632} & 0,644 & 0,678 \\
$\mathrm{P} 52 \leftarrow \mathrm{F} 12 \mathrm{MT}$ & 0,702 & 9,262 & 0,000 & 0,632
\end{tabular}

Nota: F1SK: Habilidades en el cuidado del paciente crítico; F2CS: Comunicación y Seguridad Clínica; F3CR: Conocimientos enfermeros y razonamiento clínico; F4FN: Planes de Acogida para enfermeras noveles; F5FS: Formación específica y 
continuada de las enfermeras de plantilla (staff); F7EV: Evaluación del paciente crítico, herramientas y tecnología; F8GT: Gestión sanitaria; F9SV=Aplicación de medidas de soporte; F11MJ:Medidas para mejorar el cuidado; F12MT: Motivación para continuar con la formación. ** $p \leq 0,01 * p \leq 0,05$

Como podemos observar en la tabla anterior, la relación de las variables dentro del constructo es muy desigual dependiendo de cómo se relacionan entre ellas; así podemos observar como el haber retirado algunas variables para poder realizar un AFC, ha provocado que los índices de fiabilidad interna de nuestro cuestionario hayan caído por debajo del 0,8 en el caso del alfa de Cronbach, sin embargo varias variables latentes mantienen valores de fiabilidad compuesta por encima de 0,7 y de varianza extraída por encima de 0,5. 


CAPÍTULO 5 DISCUSIÓN 




\section{Capítulo 5. Discusión}

Cuando planteamos el presente trabajo, ninguno de los implicados - ni directores ni doctorandohubiésemos podido pensar que los profesionales de cuidados intensivos $y$, en concreto, las enfermeras seriamos uno de los colectivos profesionales más citados en los medios de comunicación. Lamentablemente, el SARS-CoV-2, el nuevo coronavirus causante del síndrome COVID-19, ha puesto de manifiesto la extrema escasez en cuanto la dotación de camas de $\mathrm{UCl}$ en España y la urgente necesidad de disponer de enfermeras adecuadamente formadas y entrenadas para atender a pacientes críticos. La responsabilidad, las competencias y las habilidades que precisa una enfermera de cuidados intensivos van más allá de las adquiridas como graduadas, pero ha tenido que ocurrir una crisis sanitaria mundial para que estas necesidades formativas, que ya identifican y remarcan las enfermeras en este trabajo de investigación, hayan sido visibles.

La presente tesis ha seguido el organigrama presentado por la $\mathrm{EfCCNa}^{(48,182)}$, por lo que seguiremos la misma metodología a la hora de discutir nuestros resultados. Las fases secuenciales, en las cuales se ha realizado este trabajo, son necesarias a la hora de reconocer los resultados y su relación con investigaciones llevadas a cabo en el mismo campo.

\subsection{FASE 1}

\section{A) Ámbito clínico}

Las enfermeras entrevistadas en la fase 1 reconocieron la necesidad de poder aplicar numerosos cuidados en este ámbito. Un elemento reseñado es que al egresar de la universidad no eran capaces de tener una aplicación de cuidados tan específica y un juicio clínico totalmente desarrollado para hacer frente a las necesidades de los pacientes. En este sentido, se han realizado distintos intentos para medir las competencias clínicas de las enfermeras de cuidados críticos, como el realizado por Fisher et al. ${ }^{(208)}$, en el que los autores ponían en tela de juicio la validez de la estructura de las 20 competencias estándar sugeridas por la Australian Collegue of Critical Care Nurses (ACCCN) ${ }^{(209)}$.

El hecho de evaluar un programa, ya definido e implantado, provocó la generación de un cambio en la organización y planificación de los elementos formativos incluidos para adquirir las competencias enfermeras en cuidados críticos. Esta evaluación posterior de los estándares de la ACCCN no hizo sino reforzar la necesidad de definir una estructura homogénea para las enfermeras de cuidados críticos en Australia ${ }^{(12,210,211)}$. Así, podemos observar como el estudio de Marshall et al. encontró consenso en un grupo general de competencias clínicas en todas las enfermeras y, además, detectó consensos y necesidades agrupando enfermeras de distintos niveles académicos ${ }^{(210)}$. Esto nos hace pensar que, a lo largo, tanto del continuum profesional, como del desarrollo académico, se enfoca la formación según los elementos detectados por los propios profesionales.

En nuestro estudio, las enfermeras consultadas en la primera fase enumeraron competencias relacionadas con elementos de conocimiento, análisis, habilidades y destrezas. Este hecho indica la necesidad de que las enfermeras dispongan de unos conocimientos amplios para poder aplicar cuidados, medidas de soporte y control de la monitorización ${ }^{(212)}$. 
Las enfermeras argumentan que "cuidar" es un proceso complejo, que requiere actuar según criterios de seguridad, apoyándose en la evidencia científica y en la necesidad de saber tanto qué hacer como no hacer ${ }^{(37,126,133,137,213-215)}$. Además, muestran implicación y concienciación en relación con el elemento "seguridad", coincidiendo con distintos estudios que incorporan al cuidado "bundles" o paquetes de medidas para implementar la seguridad en las $\mathrm{UCl}$, tales como los proyectos ZERO ${ }^{(134-137,216)}$

Las enfermeras valoran la "formación" centrada en saber qué hacer en cada momento; permitiendo aplicar un análisis de riesgo-beneficio a sus intervenciones, siguiendo las recomendaciones de la SEMICYUC ${ }^{(126,217)}$. En esta línea Hassani et al. ${ }^{(164)}$ indicaron que no hay posibilidad de tener unos adecuados resultados dependiendo únicamente de la intuición de las enfermeras, se precisa desarrollar programas formativos para que las enfermeras adquieran la formación necesaria para poder cuidar adecuadamente ${ }^{(37,55,218)}$. Apoyar esta formación para obtener mejores resultados ha sido una demanda de nuestros entrevistados; esta petición coincide con lo reportado en la literatura que pone de manifiesto la solicitud de una formación reglada y homogénea centrada en las mejores prácticas $^{(219-221)}$.

La formación ha de centrarse en procurar que el profesional alcance unos cuidados de excelencia y sepa abordar las necesidades cambiantes de un paciente tan complejo como es el paciente crítico $^{(25,30,31,55)}$. Como mencionaron Currey et al. ${ }^{(31)}$, la formación ha de ir ligada a la evaluación de los objetivos planteados en cada organización y ha de promover el trabajo en equipo, puesto que este mejora el nivel de satisfacción de las enfermeras, así como el compromiso con el propio aprendizaje. Woods y Summers ${ }^{(67)}$ afirman que es necesario un análisis previo de la organización para desarrollar un programa de competencias básicas y específicas de cada departamento. Además, las enfermeras entrevistadas coinciden en que la $\mathrm{UCl}$ es un servicio muy exigente y que habría que evaluar los conocimientos de estas profesionales para garantizar la seguridad clínica; esto coincide con lo aportado por Nasrabi et al. ${ }^{(82)}$, quienes indicaron que las enfermeras tienen un papel muy importante a la hora de gestionar los eventos adversos para minimizar los riesgos y sus consecuencias.

El análisis de competencias es un hecho que apoya la necesidad de formación desde las distintas vertientes en las cuales se ha investigado. Lakanmaa et al. ${ }^{(51)}$ incluyeron las habilidades personales como elemento en la formación de las enfermeras para poder hacer frente a las exigencias del cuidado; en este sentido, nuestros entrevistados comentan que para ofrecer unos cuidados de calidad tienen que ser reflexivos en las decisiones y saber manejar el estrés que genera el trabajo en las unidades de intensivos. Por ello, no debemos solo centrarnos en la adquisición de destrezas y habilidades sino en desarrollar un pensamiento crítico que apoye nuestras decisiones, tal y como Yurdanur ${ }^{(222)}$ mencionaba en su estudio.

Por otra parte, interpretar todos los datos en el ambiente clínico que proporciona el paciente crítico es un reto para las enfermeras, las cuales deben poseer una serie de habilidades acompañadas de un proceso de reflexión y resolución lógica de los problemas detectados ${ }^{(141)}$. Jacob et al. ${ }^{(143)}$ hallaron que el pensamiento crítico mejora la seguridad y los cuidados en los distintos entornos sanitarios y, por tanto, recomiendan la creación de herramientas que puedan ser incorporadas por los educadores de los profesionales sanitarios. En el ámbito de cuidados críticos Morris et al. ${ }^{(145)}$ identificaron una mayor satisfacción en las enfermeras y en la fidelización a sus puestos de empleo cuando se 
aplicaban modelos de orientación al personal novel en $\mathrm{UCl}$. Nuestros encuestados afirman que la experiencia en $\mathrm{UCl}$ es la que les ha dotado de la citada habilidad, pero reconocen que se deben hacer actividades formativas para acelerar el proceso de adquisición de esta competencia; tal y como recomiendan numerosos autores centrados en la obtención de la habilidad de pensamiento crítico para resolver problemas mediante simulación clínica ${ }^{(39,41,223)}$. Por otra parte, otros autores desarrollan la necesidad de adquirir habilidades clínicas mediante simulación ${ }^{(37,40,103,224,225)}$. Nuestros entrevistados se inclinan, en mayor medida, por las figuras de los mentores y tutores en el ambiente clínico, como guía a la hora de desarrollar una acogida más controlada del personal de nueva incorporación, coincidiendo con lo indicado por otros autores ${ }^{(35,226-228)}$.

\section{B) Ámbito profesional}

En nuestro estudio, las enfermeras indican que para afrontar las dudas que existen a la hora de actuar en este ámbito, el apoyo de compañeros es un elemento fundamental. En este sentido, incluir a todos los miembros del equipo multidisciplinar se observa como una fortaleza que debe potenciarse. El trabajo en equipo es citado como competencia transversal necesaria en múltiples artículos $^{(229-231)}$, además de un elemento fundamental para mejorar la comunicación y prevenir eventos adversos ${ }^{(79,83,101,110,111,139,223,232)}$. Porque como dice $D^{\prime}$ Lima et al. ${ }^{(233)}$, las dinámicas de los equipos junto con la mezcla de distintos profesionales deben evitar que personal sin experiencia, 0 sin la cualificación suficiente, pueda generar riesgos durante su actuación profesional, provocando una situación de tensión interdisciplinar que no favorece la confianza dentro del equipo asistencial. Weller et al. ${ }^{(83)}$ consideraban que se debía poder medir el trabajo en equipo, ya que la actuación de los profesionales, el liderazgo y la coordinación afectan a los resultados de las actuaciones en el ámbito asistencial. En nuestro estudio las enfermeras indican que, para afrontar las dudas que existen a la hora de actuar en el ámbito profesional, el apoyo de compañeros es un elemento fundamental. En este sentido, la inclusión de todos los miembros del equipo multidisciplinar se observa como una fortaleza que debe ser potenciada. El trabajo en equipo es nombrado como competencia transversal necesaria en múltiples artículos ${ }^{(229-231)}$ además es un elemento fundamental para mejorar la comunicación y prevenir eventos adversos ${ }^{(79,83,101,110,111,139,223,232)}$.

Los entrevistados destacan que el personal de nueva incorporación en $\mathrm{UCl}$ representa un riesgo que genera fenómenos disruptivos y pone en peligro la seguridad clínica. En esta línea, Ervin et al. ${ }^{(107)}$ mencionaron que los miembros del equipo sanitario son interdependientes y aportan distintas visiones en relación con el cuidado del paciente crítico, con el único objetivo de lograr los mejores resultados, mediante una colaboración efectiva y la aplicación de herramientas como protocolos y checklist. La colaboración entre profesionales es un elemento esencial que surge repetidamente en los discursos de los entrevistados "consulta a compañeros es la fuente fundamental (...) pero generalmente las enfermeras experimentadas tienen la mayoría de las respuestas y suelen ser las más adecuadas". Se observa como la colaboración interprofesional es más valorada por los profesionales con menos experiencia, hecho que coincide con el estudio de Serrano-Guemes y RichRuiz ${ }^{(86)}$, donde se muestra que los profesionales con menos de 8 años de experiencia en críticos puntuaban más estos valores. Por su parte, Fukuda et al. ${ }^{(234)}$, tras aplicar un programa formativo durante 4 años, dirigido a adquirir habilidades para comunicar dentro del equipo y dentro de la organización, manteniendo una colaboración interprofesional, encontraron que disminuía la estancia en UCl de manera significativa. 
Nuestros resultados indican la necesidad de una formación específica en cuidados críticos para poder desempeñar la labor de enfermera de cuidados críticos, al igual que otros profesionales que trabajan en estas áreas. Como se afirma en el estudio de Pirret ${ }^{(235)}$, este trabajo se desarrolla en un escenario en el que su contribución al cuidado es muy amplia; además, su capacitación y formación les permite, incluso, ser prescriptoras de fármacos consensuados dentro del propio equipo. Además, la experiencia se valora como un elemento muy relevante que facilita la aplicación de las herramientas de evaluación características del paciente crítico y permite tomar decisiones clínicas fundamentadas.

Por otra parte, el trabajo en equipo es un elemento esencial que influye tanto en los resultados de la organización, del personal y del paciente ${ }^{(110)}$. La toma de decisiones, tal como menciona Kvande et al. ${ }^{(236)}$ es un elemento fundamental del cuidado del paciente de la UCl por parte de las enfermeras, contribuyendo a alcanzar los objetivos terapéuticos, para lo cual es necesario que participen en los procesos de decisión y mediante métodos educativos fortalecer su formación y la creación de rutinas a la hora de generar información clínica. En este estudio, los entrevistados reconocen que sus inicios en UCl fueron duros, ya que no estaban preparados para asumir los cuidados del paciente crítico, por lo que apoyan la necesidad de una formación práctica reglada.

Otro elemento que las enfermeras consideran fundamental es la comunicación, y es que, como ellas mismas indican, hay que asegurar el mensaje emitido para evitar crear otro problema. Las enfermeras reconocen la importancia de la comunicación en todas sus vertientes, tanto escrita como verbal, en situaciones tanto de calma como en las complicadas, poniendo especial atención a la seguridad y a la continuidad asistencial. En este sentido, Sierra Talamantes et al. ${ }^{(199)}$ valoraron la comunicación entre las enfermeras como un indicador de calidad de una unidad de cuidados intensivos cardiológicos. Las enfermeras realzan el papel que tiene la empatía, la asertividad y la adaptación del mensaje a las distintas situaciones del cuidado para lograr la comunicación con pacientes y familiares, en el día a día, coincidiendo con datos aportados por estudios previos $^{(100,110,112,237-240)}$. Una adecuada comunicación es un elemento central para conseguir óptimos resultados, como menciona Van Mol et al. ${ }^{(241)}$, los cuales recomiendan que, desde el ingreso hasta el alta, se debe ir fomentando la comunicación con pacientes y familiares por parte del personal de enfermería, lo cual no solo es beneficioso para el personal sanitario evitando episodios de ansiedad, sino también para el paciente que ya ha llegado a hospitalización. Otros autores apoyan la creación de modelos de información a familiares y de consenso dentro de los equipos sanitarios ${ }^{(242)}$.

Pero la comunicación es un elemento fundamental también entre el equipo sanitario y es que, como reconocían Mahvar et al. ${ }^{(243)}$, las interacciones de la vida laboral, el profesionalismo, el clima organizacional y la experiencia influyen en cómo se desarrolla y percibe esta comunicación. Estas 5 dimensiones repercuten claramente en la comunicación, por lo que se debe actuar sobre todas para garantizar que sea adecuada dentro del equipo asistencial tratándola como un aspecto a desarrollar mediante formación ${ }^{(80,110,111,244,245)}$. En este contexto de la pandemia, la comunicación dentro de la organización se ha convertido en una necesidad acuciante para que el equipo sanitario, incluyendo evidentemente a las enfermeras, pueda reconocer los riesgos y cuidados relacionados con esta nueva enfermedad ${ }^{(246)}$.

Un déficit reconocido por nuestras enfermeras es el de la formación recibida para informar, apostando por la necesidad de formarse en este contexto. Song et al. ${ }^{(247)}$ hallaron que las 
enfermeras, de mayor edad, mayor formación académica y mayor tiempo trabajado en UCI, poseen mayores habilidades de comunicación; apoyando, por tanto, estos autores que la formación en comunicación e información se debe mantener durante todo el ejercicio profesional. En lo que respecta a una información y comunicación muy específica, como es la centrada en los cuidados al final de la vida, Anderson et al. ${ }^{(248)}$ detectaron que una de las funciones más importantes de las enfermeras de $\mathrm{UCl}$ es identificar las necesidades de información que presentaban los familiares sobre la enfermedad y los tratamientos del paciente, encontrando diferencias y falta de información, asumiendo que las enfermeras con formación específica son más proclives a subsanar estos déficits y al mismo tiempo brindar apoyo emocional.

Uno de los aspectos destacados del ámbito profesional fueron tanto el afrontamiento personal como las decisiones de limitación de los tratamientos de soporte vital (LTSV). La mayoría de las enfermeras reconocían que adquirían un rol pasivo ante esta toma de decisiones y consideraban que deberían participar, en mayor medida, reconociendo que el encarnizamiento terapéutico les afectaba personalmente. En este mismo sentido, distintos autores coinciden con nuestros resultados y relacionan el afrontamiento personal con la capacidad de comunicación de las enfermeras con los familiares, indicando que los resultados de todo el proceso de cuidar dependen de las habilidades en comunicación ${ }^{(124,249-251)}$, sobre todo, en un procedimiento de LTSV, que requiere de formación específica y consenso entre el equipo profesional ${ }^{(252,253)}$. Como menciona Hernández-Tejedor et al. ${ }^{(252)}$, las decisiones se suelen adoptar de manera conjunta entre el equipo médico-paciente-familia, no incluyendo a las enfermeras en esta toma de decisiones. Como mencionan Lind et al. ${ }^{(249)}$, la imprecisión de la comunicación de las enfermeras puede poner en riesgo la relación enfermerapaciente-familia, recomendando una adecuada interacción entre el equipo sanitario; a su vez, indican que resulta extraño que en este tipo de toma de decisiones no se incluyan a las enfermeras, ya que son las responsables de aplicar los cuidados. Por todo esto, recomienda la adopción de una acogida de los familiares valorando sus propias necesidades y cada momento asistencial ${ }^{(254-256)}$.

Es fundamental, por tanto, identificar el rol de las enfermeras en los cuidados al final de la vida en las $\mathrm{UCl}$. Algunos autores reclaman la adopción de guías y protocolos de trabajo, consensuados entre los profesionales, que marquen los objetivos del plan de cuidados ${ }^{(124,130,251,257-260)}$. Souza da Silva et al. ${ }^{(261)}$ afirmaron que los objetivos planteados por las enfermeras deben ser siempre conseguir la "buena muerte" centrada en la promoción del confort, la ausencia de dolor y el respeto de la voluntad planteada, tanto por los familiares como por el paciente, antes de la muerte. Según los distintos estudios consultados, las enfermeras deben hacer una aproximación holística de los cuidados incluyendo y acompañando a los familiares; esta manera de cuidar favorece el proceso de duelo y la aceptación de la situación clínica ${ }^{(251)}$.

Fortalecer el rol de las enfermeras en la toma de decisiones, mediante formación en ética, brinda la oportunidad de evitar los obstáculos dentro del equipo y evita las dificultades emocionales ${ }^{(124,130,260,262,263)}$. Así, el estudio de Del Barrio et al. ${ }^{(264)}$ detectó una serie de obstáculos a la hora de aplicar cuidados al final de la vida dividiéndolos en una escala que iba desde "bajo" hasta "mucho obstáculo"; entre los de mucho obstáculo resaltaban: la presencia de dolor incontrolable, aplicar cuidados dolorosos, la falta de consenso entre los médicos o la falta de información respecto a la situación actual, así como la falta de aceptación de la familia. Resolver los obstáculos y aplicar una formación específica en LTSV tiene otros beneficios como observó Lomero et al. ${ }^{(128)}$, quienes 
reconocían que incluir a las enfermeras en este tipo de decisiones favorece su participación y colaboración en el proceso de donación de órganos. Y es que la mayoría de los autores mencionan que se tiene una formación basada en la experiencia en este tipo de situaciones ${ }^{(261)}$; Gálvez et al. ${ }^{(124)}$, al igual que otros autores, coincidieron en que a mayor experiencia laboral menores dificultades a la hora de adoptar la decisión de LTSV. Nuestros entrevistados expresaron la necesidad personal, emocional y profesional de entender la situación de LTSV y como mencionaron: "no ir llorando por los rincones". En este mismo sentido, González-Rincón et al. ${ }^{(260)}$ concluyeron que las enfermeras adquieren un rol de "negociadora de la reorientación", y que este rol es asumido, de una manera más eficaz y satisfactoria, por las enfermeras experimentadas que desarrollan su labor a su vez como tutoras frente a las enfermeras noveles.

La ansiedad que sufre el profesional ante la muerte de los pacientes es una constante, por lo cual se precisan implementar en el entorno clínico medidas de soporte emocional ${ }^{(265,266)}$. Nuestros entrevistados también mencionaron que la muerte de determinados pacientes les afectaba en mayor medida; las circunstancias del proceso terapéutico y las características propias del paciente eran fundamentales; así, las muertes traumáticas y en jóvenes parecen, según estos comentarios, las de peor afrontamiento. Henao-Castaño et al. ${ }^{(267)}$ afirman que la muerte en unidades de cuidados intensivos pediátricos requiere de un acompañamiento muy específico de las enfermeras a los niños y sus familiares, siendo la comunicación, en este caso, una herramienta básica destinada a aplicar cuidados paliativos de calidad.

Especial atención merece el estudio de Santana Cabrera et al. ${ }^{(258)}$, realizado en 2010 en la misma unidad donde desarrollan su labor profesional los expertos que colaboraron en esta fase de la tesis. El estudio observó una falta de hábito de participación de las enfermeras en el proceso de toma de decisiones sobre LTSV, siendo una de las recomendaciones motivar la participación consensuada de las enfermeras en el citado proceso. Uno de los aspectos que pueden mejorar la implicación de las enfermeras es la utilización del documento de voluntades anticipadas, tal como comentaron VelascoSanz y Rayón-Valpuesta ${ }^{(268)}$, y facilitar la participación de los familiares y del propio paciente ${ }^{(251,261,262,269,270)}$. Downar et al. ${ }^{(257)}$ recomendaban la puesta en práctica de un "debriefing" interprofesional destinado a mejorar la comunicación y lograr una interacción fluida entre las enfermeras responsables del paciente y el resto de implicados en el proceso.

\section{C) Ámbito de la gestión}

Respecto al ámbito de la gestión, nuestros entrevistados mencionaron que una de las mayores fortalezas de la $\mathrm{UCl}$, y un valor fundamental de las enfermeras, es garantizar la continuidad asistencial, iniciándose esta al ingreso del paciente, continuando a lo largo de la estancia y más allá del alta hospitalaria ${ }^{(36,213,241,271-273)}$. Garantizar esta continuidad es un elemento también citado por los distintos programas nacionales ${ }^{(49,61,62)}$.

Un elemento que debe ser mencionado es la necesidad de mantener en todo momento una información de calidad que garantice la continuidad de los cuidados; en este sentido, Loefgren Vretare y Anderzén-Carlsson ${ }^{(271)}$ consideraron que para garantizar un correcto traspaso de información se deben cumplir las siguientes categorías: comunicación entre el personal, oportunidad de aprendizaje, información centrada en el paciente como garantía de continuidad de cuidados, 
responsabilidad del equipo, seguridad y calidad en los cuidados. La necesidad de aprendizaje es nombrada por nuestros participantes repetidamente; por tanto, la protocolización de la información es también un elemento a trabajar para que ninguna información pertinente se pierda durante los ingresos ${ }^{(140,241,274)}$. Nuestros entrevistados también muestran la necesidad de fomentar el traspaso de información para garantizar los cuidados mediante el uso de las TIC o de la historia clínica, por lo que apoyan incentivar la comunicación escrita. Así, podemos observar como el uso de la historia clínica electrónica ha tenido repercusión en la menor estancia de pacientes en $\mathrm{UCl}^{(275)}$. Por tanto, resulta necesario incentivar tanto la formación como la participación de las enfermeras en el desarrollo de estas herramientas, ya que mejoran la calidad y eficiencia de los registros de enfermería ${ }^{(276)}$.

Disponer de todos los datos que reflejen la evolución del paciente facilita el traspaso de información; tal y como desarrolló en su tesis Martínez-López, quien indicó que mantener un programa de continuidad asistencial permitía una transición ordenada, principalmente en los pacientes frágiles; y cito textualmente: "La continuidad asistencial entendida como la no interrupción de orientación diagnóstica y terapéutica del paciente al trasladarse de la UCl a la planta, constituye una estrategia eficaz en términos de reducción de la mortalidad y disminuye los reingresos en la $\mathrm{UCl}^{\prime{ }^{\prime 2}}{ }^{273)}$. En este contexto, las enfermeras son responsables de garantizar una transición ordenada de los cuidados en otra área con recursos humanos y materiales totalmente distintos, así Sirgo et al. ${ }^{(277)}$ apoyaron el uso de modelos para garantizar el traspaso de información ( $\mathrm{TI}$ ), indicando que el proceso de $\mathrm{TI}$ es un elemento fundamental en las decisiones, puntualizando que la participación de las enfermeras junto con el soporte documental del alta de enfermería y el acompañamiento del paciente por esta hasta la unidad de destino garantizaban la continuidad de la atención. Promover el estudio de los procesos de TI debe ser un elemento central de la gestión sanitaria; además de valorar en todo momento las barreras y los aspectos que facilitan una comunicación efectiva en la cual la cultura organizacional tiene especial relevancia ${ }^{(278)}$. En esta línea, la figura de las "enfermeras de enlace" entre UCI y hospitalización convencional ha mostrado ser francamente eficaz, tal y como presenta el modelo australiano $^{(279)}$.

Los indicadores de calidad son considerados por nuestros entrevistados un elemento no fundamental del trabajo enfermero, comentarios como: "que es algo demorable" o "se hace cuando se puede" aparecen varias veces en sus discursos; aun así, se considera que se pierden muchos datos que podrían servir para mejorar la asistencia sanitaria y la realización de investigaciones que mejoren la calidad de los cuidados. Las enfermeras asistenciales no son tan conscientes, como sería deseable, de las recomendaciones sobre los indicadores de calidad propuestos por las sociedades científicas ${ }^{(280,281)}$, ni de la importancia de los datos recogidos en la historia clínica electrónica como fuente de información para lograr mejoras asistenciales ${ }^{(276,282-284)}$. Pita et al. ${ }^{(285)}$ manifestaron que estos indicadores dan la oportunidad de ofrecer una respuesta precoz, observar desviaciones de la práctica habitual y servir de señales de alarma para mejorar los resultados. Esta situación es fundamental a la hora de poder medir los distintos paquetes de medidas relacionadas con los proyectos ZERO, en los cuales las UCI tienen una aportación muy importante $\mathrm{e}^{(134-137,216,286)}$.

Para Romero-García et al. ${ }^{(287)}$ la satisfacción de los pacientes tiene mucho que ver con los cuidados enfermeros. Los pacientes, que también presentan una visión holística, valoran los cuidados físicos, psicoemocionales y espirituales que mediante lenguaje verbal, no verbal y destreza profesional son capaces de dispensar las enfermeras de una manera eficiente mediante el juicio clínico, la rapidez, la 
precisión, la actitud, la vocación y el trabajo en equipo. Este análisis de mejora alcanza incluso a los familiares, como mencionaban Jensen et al. ${ }^{(100)}$ en su estudio de diferentes países europeos, los familiares puntúan de manera elevada los cuidados en $\mathrm{UCl}$, el entorno asistencial, el manejo de la disnea y la facilidad de obtener información; siendo los elementos mejorables en términos de satisfacción: el manejo de la agitación, el apoyo a la familia, la consistencia de la información, la inclusión y apoyo en el proceso de toma de decisiones. Además, es importante valorar también la concordancia entre la satisfacción de los familiares y la de los pacientes con la $\mathrm{UCl}$, ya que como mencionaban Holanda-Peña et al. ${ }^{(288)}$, en determinados aspectos se presentan asimetrías. Los pacientes valoraban más positivamente las 6 facetas analizadas en el estudio; sin embargo, los familiares valoraban significativamente peor la comunicación y el respeto. Según el modelo de Donabedian, la participación de los familiares y usuarios se observa como fundamental a la hora de obtener resultados adecuados en la categoría de proceso tal y como mencionaban Ramírez Perdomo et al. ${ }^{(284)}$. Estos elementos son necesarios para la adopción de medidas de mejora en la calidad percibida de los cuidados enfermeros ${ }^{(289,290)}$, debido a que la comunicación y la satisfacción en la atención sanitaria se han observado muy relacionadas en las $\mathrm{UCI}^{(287,291,292)}$.

Uno de los elementos que preocupan a las enfermeras es la especial disposición que deben tener a la hora de dar respuestas rápidas y precoces ante el deterioro de los pacientes, y constatan que para eso es necesario una formación extensa y apropiada a las especiales características de estas unidades $^{(28)}$; en esta línea, distintos autores recomiendan la simulación clínica para hacer frente a este tipo de habilidades profesionales ${ }^{(40,41,97,103,225,293,294)}$. Las enfermeras consultadas están muy involucradas, pero mencionan que el inicio de la actividad laboral de muchos profesionales, en corto periodo de tiempo, dificulta la asistencia sanitaria y puede poner en riesgo la seguridad clínica; en este sentido, trabajar con protocolos y guías clínicas se considera un elemento que debe desarrollarse a través de formación específica ${ }^{(38,84,93,101,295,296)}$. Nuestros entrevistados consideran que la formación específica de $\mathrm{UCl}$ y el entrenamiento en escenarios simulados son elementos que ayudan a la concienciación y a la posterior implementación de cuidados seguros. Este hecho es valorado también por autores como Cook et al. observaron como se adquieren mejores resultados educativos con la simulación frente a otros métodos ${ }^{(173)}$.

Las enfermeras están muy concienciadas en trabajar de una manera que evite las complicaciones potenciales de la hospitalización en UCl. En sus discursos, el manejo del dolor, la identificación precoz del delirio y la mejora del sueño son elementos comunes, y es que, como se puede extraer de sus discursos, lograr el confort del paciente es una necesidad para las propias enfermeras. En este sentido, se ponen de manifiesto los distintos paquetes de medidas creados para garantizar unos cuidados adecuados en el delirio ${ }^{(95,96,297-300)}$, dolor ${ }^{(94,300-302)}$ y sueño ${ }^{(303-306)}$. Para poder extraer un paralelismo de estos discursos, con la evidencia científica contamos con el estudio ASCyD, descriptivo transversal realizado en $158 \mathrm{UCl}$ para valorar la analgesia, sedación, dolor y delirio en el ámbito nacional, en el cual "tenían dolor el $80 \%$ de los pacientes agitados, el $46,8 \%$ de los considerados con sedación adecuada y el $22,6 \%$ de pacientes con sedación profunda"(307). El dolor también es una fuente de preocupación para las sociedades científicas, así Devlin et al. ${ }^{(94)}$, en su guía clínica práctica determinaron como un factor importante evaluar el dolor en todas las $\mathrm{UCl}$ aplicando las medidas farmacológicas y no farmacológicas, ya que su no valoración influía en la aparición de eventos adversos como agitación, insomnio y delirio. En estas recomendaciones se consideró esencial tratar 
el dolor, otorgando un papel relevante a las enfermeras, y como estas con una formación dirigida a los cuidados relacionados con el dolor generaban mejores resultados asistenciales ${ }^{(300,301,308)}$.

Permitir el descanso del paciente y facilitar el sueño también han sido valorados por los entrevistados como elementos centrales del cuidado y generadores de mejores resultados asistenciales. Los estudios de Pisani et al. ${ }^{(306)}$ y Beltrami et al. ${ }^{(303)}$ informaban que un sueño de peor calidad provoca disfunciones cerebrales que junto con las características intrínsecas del paciente crítico impiden una recuperación efectiva. Para ello, ambos autores sugirieron una aproximación multidisciplinar y centrada en mantener un sueño reparador que, como ellos mismos asumían, sirva de prevención de episodios de delirio. Las enfermeras, como refería Beltrami et al. ${ }^{(303)}$ deben controlar el entorno: ruido, luces y actividades con pacientes; ya que todos ellos están identificados como factores disruptores del sueño. Minimizar los estresores del entorno de $\mathrm{UCl}$ fue el objetivo principal del ensayo clínico aleatorizado de $\mathrm{Hu}$ et al. ${ }^{(309)}$, quienes observaron que medidas no farmacológicas implementadas por las enfermeras como tapones en los oídos, antifaz ocular y música relajante de fondo mejoraba el sueño de los pacientes incluidos en el grupo intervención. No poder descansar adecuadamente es un elemento que preocupa a nuestras enfermeras consultadas, ya que intentan en todo momento la "reorientación verbal" como herramienta para tranquilizar y procurar el descanso de los pacientes. Otros autores recomiendan la adopción de herramientas para evaluar el sueño de los pacientes críticos y los factores medioambientales, que servirían de guía para aplicar cuidados o soluciones a los problemas detectados ${ }^{(310)}$.

Hemos de destacar, en este epígrafe, un elemento como es el delirio del paciente crítico, y que las enfermeras consultadas han identificado como un serio obstáculo para cumplir los objetivos planteados en los planes de cuidados. Las actuaciones de las enfermeras, según recomiendan varios de nuestros entrevistados, deben ir claramente dirigidas a la prevención y promoción de estados de conciencia y de colaboración del propio paciente. El delirio continúa siendo objeto de estudio y tema por resolver. La prevención es un elemento fundamental, sobre todo por sus posteriores consecuencias como es el caso del síndrome post-UCl ${ }^{(299,300,311-314)}$ o el uso de contenciones mecánicas ${ }^{(165,198,315)}$. A pesar de esta preocupación, Arias-Rivera et al. ${ }^{(307)}$ indicaron que el uso de herramientas para la valoración del delirio no llega a aplicarse ni en el $25 \%$ de las UCl españolas. Este estudio indicaba que el nivel de delirio de las unidades es menor que el de otros estudios similares, pudiendo asociarse a un menor porcentaje de pacientes sin dolor o dolor moderado. El uso de las terapias no farmacológicas está muy extendido en el ámbito español ${ }^{(307)}$, siguiendo las recomendaciones de las guías clínicas internacionales, pero requiere mucha formación por parte de las enfermeras ${ }^{(94,96)}$. La presencia de delirio y el uso de contenciones mecánicas continúan desafortunadamente relacionados, y como menciona Via-Clavero et al. ${ }^{(315)}$ es necesaria una mayor formación y sensibilización de las enfermeras sobre el uso de medidas de contención, ya que a pesar de las recomendaciones de las distintas guías internacionales el $18,3 \%$ de su muestra consideraba el uso de las contenciones la primera opción para evitar la auto-retirada de dispositivos, sin previamente haber agotado el resto de opciones. En este sentido, nuestras enfermeras entrevistadas consideran que un paciente confortable no debería desarrollar delirio si no tiene dolor, descansa bien y está orientado en tiempo y espacio; apreciaciones coincidentes con otros estudios ${ }^{(303,314)}$. En este mismo sentido, Roh $^{(316)}$ concluye en su estudio que las enfermeras desempeñan un rol tan importante en el manejo clínico del delirio que es imprescindible una formación específica. 


\section{D) Ámbito educativo y de desarrollo}

En este ámbito las enfermeras entrevistadas reconocen realizar formación relacionada con los cuidados intensivos, pero esta formación generalmente depende de su motivación o de intereses personales. Sí reconocen que toda la formación repercute positivamente en el ámbito clínico ${ }^{(93,221,272,317)}$. Un elemento que valoran es la contribución de la organización en la cual trabajan en su propia formación posibilitando medidas de aprendizaje. Este hecho es recogido en distintos estudios relacionados con la satisfacción de las enfermeras y con la permanencia de las mismas en las organizaciones, principalmente cuando la cobertura de los puestos es más dificultosa y se han aplicado distintos programas denominados de residencia ${ }^{(53,55,145,147,318)}$. Nuestras entrevistadas reconocen que los primeros momentos en una $\mathrm{UCl}$, cuando no estaban entrenadas para llevar a cabo todo aquello que requerían, el apoyo de los profesionales expertos fue una de sus herramientas para resolver esas carencias; además, la ausencia de una formación previa la consideran como una fuente de dificultad. A pesar de que algunos planes de acogida muestran la necesidad de formación previa como un indicador de los servicios de cuidados intensivos ${ }^{(280,281,319)}$ reconocen ampliamente su ausencia. Este hecho contradice las recomendaciones del propio Ministerio de Sanidad y Política Social, que reconocía, ya en 2010 , la necesidad de brindar a los profesionales de un plan de acogida dentro de las medidas para garantizar la seguridad clínica ${ }^{(152)}$.

La educación de estas enfermeras debe ir destinada a la posibilidad de desarrollar todas sus competencias en un entorno tan complejo como las $\mathrm{UCl}$, y es que, como mencionan nuestras entrevistadas, se requiere una puesta al día permanente, siendo la educación continuada fundamental ${ }^{(103,221)}$. Algunos autores ponen de manifiesto que la aplicación de paquetes de medidas mejoran la formación y el entrenamiento en cuidados a paciente crítico logrando mejores resultados asistenciales ${ }^{(93,134,138,286,295,296,320-322)}$. Uno de los elementos que rigen esta necesidad de formación es la motivación de las enfermeras y el impulso que se lleve a cabo desde las propias organizaciones; además, la necesidad de un liderazgo clínico en los cuidados puede ser apoyado mediante formación pero debe ser apoyado desde las propias instituciones sanitarias ${ }^{(323)}$. Si nos detuviéramos a analizar todo el proceso asistencial detectaríamos áreas de mejora a partir de las cuales se generarían programas de formación o intervenciones puntuales ${ }^{(25,53,97,238,250,294,324-326)}$. Así observamos, como un elemento que preocupa, la gestión de programas que garanticen la seguridad clínica; en este sentido, Escrivá-Gracia et al. ${ }^{(324)}$ detectaron una relación entre bajos conocimientos y la posibilidad de cometer errores de medicación en una $\mathrm{UCl}$, otros autores proponen la realización de análisis causaraíz como elemento destacado para prevenir los eventos adversos, que también preocupan a nuestros participantes ${ }^{(233,271,277,278,297)}$. En un análisis retrospectivo a 5 años, Danielis et al. ${ }^{(327)}$ observaron un incremento en las notificaciones de errores sanitarios donde las enfermeras son el colectivo que más reportan esos errores, constituyéndose en un elemento de información y de seguridad de los procesos clínicos.

Otro elemento preocupante para nuestras enfermeras son las habilidades de comunicación tanto en las situaciones críticas como en el trabajo cotidiano. Esta preocupación va dirigida a detectar errores y optimizar las actuaciones tal y como también describe la literatura ${ }^{(232,274,277,328)}$. Debemos destacar el trabajo de Ayuso-Murillo et al. ${ }^{(329)}$, quienes detectaron un menor nivel de habilidades comunicativas entre la cohorte de enfermeras de $\mathrm{UCl}$ estudiadas en dos hospitales de Madrid. Los citados autores relacionaban las causas de las bajas puntuaciones en habilidades de comunicación, 
obtenidas por esta cohorte, con estar trabajando en un entorno estresante y con estar enfrentándose a pacientes que se hallan entre la vida y la muerte; además, identificaron esta carencia como un mecanismo de protección ante los familiares y pacientes. Diversos autores coinciden en la necesidad de formación en comunicación para enfermeras de $\mathrm{UCI}^{(247,259,330-332)}$.

\section{E) Dimensiones y formación}

En este sentido, las enfermeras consultadas son proclives a solicitar requisitos previos a la hora de comenzar a trabajar en $\mathrm{UCl}$. Este requerimiento se fundamenta en las especiales características de los cuidados al paciente crítico, que en muchas ocasiones son propios y únicos de las enfermeras de $\mathrm{UCl}$, y que solo muestran cierto paralelismo con otras áreas como urgencias y quirófano ${ }^{(27,36,51,333)}$. Estudios previos pusieron en marcha programas de identificación de requisitos para enfermeras de $\mathrm{UCl}$, muchos de los cuales fueron de carácter asistencial, aunque también citaban la importancia de disponer de un bagaje previo ${ }^{(13,41,80,84)}$. Como mencionaba Henriques-Camelo ${ }^{(36)}$, las enfermeras deben ser capaces de gestionar los elementos del cuidado enfermero, la toma de decisiones, el liderazgo, la aplicación de cuidados de alta complejidad, la comunicación y la gestión de recursos humanos y materiales, sin olvidar lo necesario que es una educación continua y permanente.

Esta aproximación deriva en dos cuestiones. La primera es la necesidad del profesional novel de recibir una adaptación progresiva y continua al complejo entorno de una UCI. El segundo es la necesidad de los profesionales veteranos de seguir continuamente aprendiendo y recibiendo formación y actualización. El personal novel se enfrenta a una situación nueva y estresante tal y como mencionan distintos estudios ${ }^{(68,69,146,227,334)}$. Para nuestros entrevistados resulta necesario crear medidas regladas dentro de la organización para evitar los riesgos derivados de que haya un gran volumen de personal novel sin posibilidad de control por parte de los veteranos ${ }^{(28,29)}$. Apoyarse en elementos como la formación teórico-práctica mediante simulación, terminando con las intervenciones in situ, siendo estas controladas por un profesional cualificado se mencionan como una de las mejores medidas para garantizar el acceso a $\mathrm{UCl}$ de personal de nueva incorporación ${ }^{(40,103,335)}$. Esta formación debería ser acreditada tanto para los docentes como para los estudiantes, incorporando dentro de la institución sanitaria un procedimiento formativo adaptado a las necesidades del personal asistencial.

Vincular la formación, tanto de profesionales noveles como de profesionales seniors, a la realidad asistencial es un tema que continúa siendo tratado en la literatura ${ }^{(13,30,51,209,333,336,337)}$. La forzosa actualidad creada por la pandemia COVID-19 no ha hecho más que poner públicamente de manifiesto las necesidades formativas y cualidades profesionales que ya nuestros participantes remarcaban durante las entrevistas. La gestión de los equipos de enfermería ha resultado un hecho fundamental como se ha demostrado ante la necesidad de que tutelar a las enfermeras de nueva incorporación fuera una de las grandes preocupaciones de las enfermeras gestoras de $\mathrm{UCl}^{(338)}$. La formación mínima que han y están recibiendo algunas de las enfermeras noveles en situación de pandemia se está realizando en circunstancias nada convencionales, sin tiempo ni planificación, "conocíamos a través de los medios de comunicación que se estaban reclutando para la UCl enfermeras no formadas ni entrenadas en la atención al paciente crítico" ${ }^{(339)}$. Esto precisó la creación de planes de contingencia y de una formación acelerada coincidente con el reclutamiento, nos encontramos con la necesidad de formar a un número de enfermeras desorbitado y de asumir 
pacientes críticos fuera del "ambiente controlado" de una UCl, ya que los pacientes críticos ocupaban también otras dependencias de los hospitales ${ }^{(339,340)}$. Esta situación, a pesar de considerarse caótica, refuerza los hallazgos de nuestros participantes de que tras ser egresados de las universidades no están preparados para asumir los cuidados de los pacientes $\operatorname{críticos}^{(69,209,341)}$.

Adaptarse a las nuevas necesidades de cuidados durante esta pandemia desde un nivel experto o desde un nivel novel, no ha resultado nada sencillo, y es que esta nueva situación y cuidados $^{(338,342,343)}$ ha provocado una actualización de conocimientos casi constante que ha modificado recomendaciones previas $^{(217,344)}$. Un reto elemental de esta situación ha sido la necesidad de formación en protección de los grandes activos de esta pandemia que son el conjunto de sanitarios y entre ellos las enfermeras de $\mathrm{UCl}^{(345-349)}$. Los equipos de protección personal y su manejo ha sido uno de los grandes retos formativos de esta pandemia ${ }^{(338,350)}$.

Nuestros expertos han mencionado reiteradamente las dificultades que les genera el trabajo estresante de las unidades de cuidados intensivos indicando que la combinación de experiencia y formación les ha ayudado a soportarlo. Tal y como pone de manifiesto el estudio de Shen et al. ${ }^{(351)}$, las enfermeras jóvenes, que han iniciado su trabajo en situación de pandemia, han tenido crisis psicológicas cuyas manifestaciones más habituales han sido: pérdida de apetito, fatiga y dificultad para dormir. Este hecho está reflejado también en el metaanálisis de Pappa et al. ${ }^{(352)}$, quienes han hallado que en el global de los profesionales sanitarios las enfermeras tenían un mayor porcentaje de insomnio y depresión; encontrando que todos los profesionales sanitarios habían tenido una importante crisis psicológica, que debería ser tratada para su superación. Estos hallazgos son compatibles también con otros estudios que detectan en el mismo sentido, las dificultades que han afrontada las enfermeras en UCI durante la pandemia ${ }^{(353-355)}$. Esta situación ha potenciado sin lugar a dudas la necesidad de formación en inteligencia emocional como se incluyó en nuestro estudio; y como otros autores han apuntado previamente ${ }^{(356-359)}$.

\subsection{FASE 2}

Esta fase se inicia a partir del análisis de los datos proporcionados por los entrevistados que permitió la creación de preguntas por parte de equipo investigador, siguiendo las directrices ya aplicadas en otros estudios en ciencias de la salud ${ }^{(183,184,187,360)}$. A pesar de seguir las directrices de la EfCCNa, se observa como algunos elementos son transversales a los propios ámbitos y subámbitos creados ${ }^{(48)}$.

Así se extrajeron distintos elementos comunes que agrupaban distintos ámbitos como eran las necesidades de implementar cuidados avanzados, comunicación efectiva y toma de decisiones. Este método permitió valorar la idoneidad de los ítems incluidos teniendo en cuenta que, tras las sucesivas rondas, se fueron disminuyendo desde las 92 preguntas iniciales hasta los 66 ítems definitivos. Estos 66 ítems se valoraron mediante una escala tipo Likert de 10 puntos; además, se incluyeron las preguntas sociodemográficas también valoradas por el grupo de expertos. La metodología seguida ha sido similar a la empleada por otros estudios para tratar temas en el mismo contexto $^{(12,51,363,56,80,84,85,199,257,361,362)}$ o incluso temas generales que afectan al conocimiento enfermero $^{(143,188,190,192,193,211,364-367)}$. En cuanto a la extensión del cuestionado generado, podemos observar en la literatura que la evaluación de competencias depende del modelo elegido, de los 
dominios y de los subdominios que evalúe, encontrando cuestionarios que cuentan con distinto número de ítems ${ }^{(68,208,334)}$.

Los estudios consultados parten también de entrevistas previas para la generación de los cuestionarios iniciales tal y como hemos realizado ${ }^{(80,187,199,363)}$. La generación de varias rondas, en nuestro caso de tres rondas, siguen la tendencia de varios estudios que precisaron entre 2 y 4 rondas $^{(51,80,85,143,188,192,368)}$. La posibilidad de haber podido usar las TIC nos hace seguir la tendencia ya usada por Gill et al. ${ }^{(190)}$. Muchos estudios nombraban como una de las grandes dificultades la pérdida de panelistas a lo largo del proceso ${ }^{(80,192)}$, aunque no es nuestro caso pues los 15 panelistas seleccionados inicialmente finalizaron todas las rondas.

La posibilidad de tener un feedback continuo ha sido una de las ventajas que mencionaban distintos autores con respecto a esta técnica ${ }^{(184,185,187)}$. La retirada de los elementos que no alcanzaron las puntuaciones consideradas de consenso por parte del equipo investigador o que fueron encontradas redundantes por parte de los participantes, generó la disminución de los ítems incorporados a la encuesta desarrollando áreas de estudio cada vez más centradas en el constructo generado ${ }^{(186,190,363)}$. Seguir el modelo recomendado por la European Federation ha precisado de la incorporación de preguntas sociodemográficas y de áreas de formación específica para homogeneizarlo con otros modelos que son muy utilizados en la investigación enfermera ${ }^{(14,56,69)}$. En nuestro caso hemos incluido aspectos de experiencia, formación continuada, actitudes y conocimientos básicos; como también se incorporaban en el estudio de Lakanmaa et al., ${ }^{(369)}$ que indicaba que para adquirir las competencias básicas (mejor ajuste de modelo, modelo IVa) en UCl era necesaria la incorporación de: fundamentos de enfermería, guías clínicas, intervenciones enfermeras, ética y conocimientos legales, toma de decisiones, desarrollo laboral y colaboración.

Se observa una preocupación no solo en determinar las competencias enfermeras ${ }^{(36,39,208,209)}$ sino su oportuno desarrollo para disponer de profesionales de cuidados críticos con competencias ajustadas a la realidad de las demandas asistenciales ${ }^{(12,60,370)}$. La agrupación de competencias ha sido un elemento común a distintos autores, en nuestro caso por ámbitos del cuidado, creando estructuras dimensionales que agrupan los ítems que hemos analizados. En el caso de otros autores ha sido el propuesto por Harden et al. ${ }^{(371)}$, quienes agrupaban las competencias enfermeras en tres categorías: técnicas, intelectuales y personales.

La incorporación de medidas formativas distintas según se trate de personal novel o de personal veterano; además de la incorporación de preguntas relacionadas con la formación previa y experiencia laboral previa, nos ayuda a explorar las necesidades de los distintos grupos de enfermeras. Según Benner ${ }^{(14,50)}$, la adquisición de competencias provoca un crecimiento profesional en el que se desarrollan habilidades propias de la razón de ser de las enfermeras, que es el papel de cuidador. El profesional enfermero no es un ser estático, ya que precisa de la incorporación continua de habilidades, destrezas y conocimientos; este hecho requiere una formación específica ajustada al contexto clínico en el que se desenvuelve el profesional ${ }^{(166)}$.

Uno de los elementos fundamentales de esta parte del estudio Delphi es su localización geográfica, el marco educativo y el sistema sanitario español, que difiere en muchas cosas con otros sistemas de salud y, por lo tanto, los estudios realizados en esos ámbitos no siempre son comparables ${ }^{(372)}$. Por 
tanto, adaptar las competencias de las enfermeras al ámbito del paciente crítico, teniendo en cuenta la citada diversidad, resulta un reto ${ }^{(10,12,49,69,208,229,373)}$. En este sentido y centrándonos en las recomendaciones realizadas en 2010 por el Ministerio de Sanidad y Política Social ${ }^{(152)}$, se añadieron para la valoración preguntas dicotómicas relacionadas con la existencia o la necesidad de que hubieran planes de acogida, considerando los participantes también la inclusión de preguntas de texto libre para que los participantes pudieran evaluar su propio plan de acogida.

En cuanto a la experiencia de los participantes en nuestro grupo Delphi, esta era mayoritariamente superior a 10 años. El grupo Delphi identifica la necesidad de disponer de planes de acogida, con distintos niveles formativos, como apoyo a la incorporación de enfermeras en $\mathrm{UCl}^{(35,152,338,374) \text {; }}$ además, señala como necesaria una formación tipo EIR tal y como mencionaron otros autores ${ }^{(20,28)}$. Todo ello también es una recomendación del Ministerio de Sanidad que cita: "El personal de enfermería que presta servicio en la UCl debe tener formación específica en cuidados críticos que le aporte un profundo conocimiento científico de los procesos fisiopatológicos de los pacientes y de las respuestas del paciente a la enfermedad" ${ }^{(152)}$.

\subsection{FASE 3}

En la tercera fase del estudio se distribuyó la versión final del cuestionario entre UCl de distintos hospitales españoles. Para valorar las respuestas obtenidas en esta fase se excluyeron los cuestionarios en los que no se había respondido adecuadamente a las preguntas control también denominadas "trap questions". Esta medida estuvo destinada a mejorar la calidad de las encuestas on line; pero esta técnica debe ser aplicada cuidadosamente tal y como mencionan Liu y Wronsky ${ }^{(375)}$ quienes detectaron una mejora de los cuestionarios, sobre todo en aquellos participantes que no ponían suficiente atención a los ítems explorados. En nuestro caso, de los 630 cuestionarios recogidos, 62 participantes contestaron erróneamente estos ítems, estos 62 cuestionarios no fueron computados para este estudio asegurando así la calidad de las respuestas obtenidas.

En la muestra analizada (568 cuestionarios) observamos un predominio femenino tal y como es la realidad de la enfermería, con una experiencia profesional mayoritaria superior a los 10 años; experiencia nada despreciable. Además, se incorpora una distribución nacional bastante extensa, tal y como otros trabajos previos realizaron para analizar las competencias enfermeras ${ }^{(55,58,68,208)}$. Nuestra muestra está compuesta mayoritariamente por enfermeras que desempeñan su labor profesional en centros de gran tamaño ( $>500$ camas), siendo la organización de las unidades de cuidados más habituales la polivalente. Los ratios más habituales son de una enfermera por cada dos-tres pacientes críticos, por lo que nos encontramos mayoritariamente con unidades de cuidados intensivos de nivel I y II como determinan las recomendaciones del ministerio ${ }^{(152)}$. El análisis de los datos reportados por nuestros participantes incluye un análisis factorial, realizado con el ánimo de explorar si existía alguna dimensión subyacente en el cuestionario aplicado. Este análisis ha posibilitado hallar elementos generales de agrupación que son comunes al concepto estudiado como son las necesidades formativas de las enfermeras de UCl; elementos de análisis que son cada vez más comunes en este tipo de estudios ${ }^{(68,195,196,198,208,333)}$. Así, el AFE determina una serie de dimensiones que fueron evaluadas a través de las recomendaciones actuales con este tipo de estudios, y que permitió agrupar ítems que evaluaban un mismo constructo ${ }^{(195,203-205,316)}$. Además, el AFC ha permitido relacionar las variables detectadas en el conjunto de hallazgos de un cuestionario ${ }^{(194,206,376)}$; 
encontrando en nuestras 13 dimensiones detectadas diferencias dentro de los grupos estudiados, tal y como otros estudios también han desarrollado, ejemplos como el de Ääri et al. ${ }^{(373)}$ y Lakanmaa et al. ${ }^{(56)}$, que se incorporan en los cuadros 1 y 2.

Cuadro 1. Requisitos de competencias en enfermería de cuidados críticos, extraído de Ääri et al. ${ }^{(373)}$

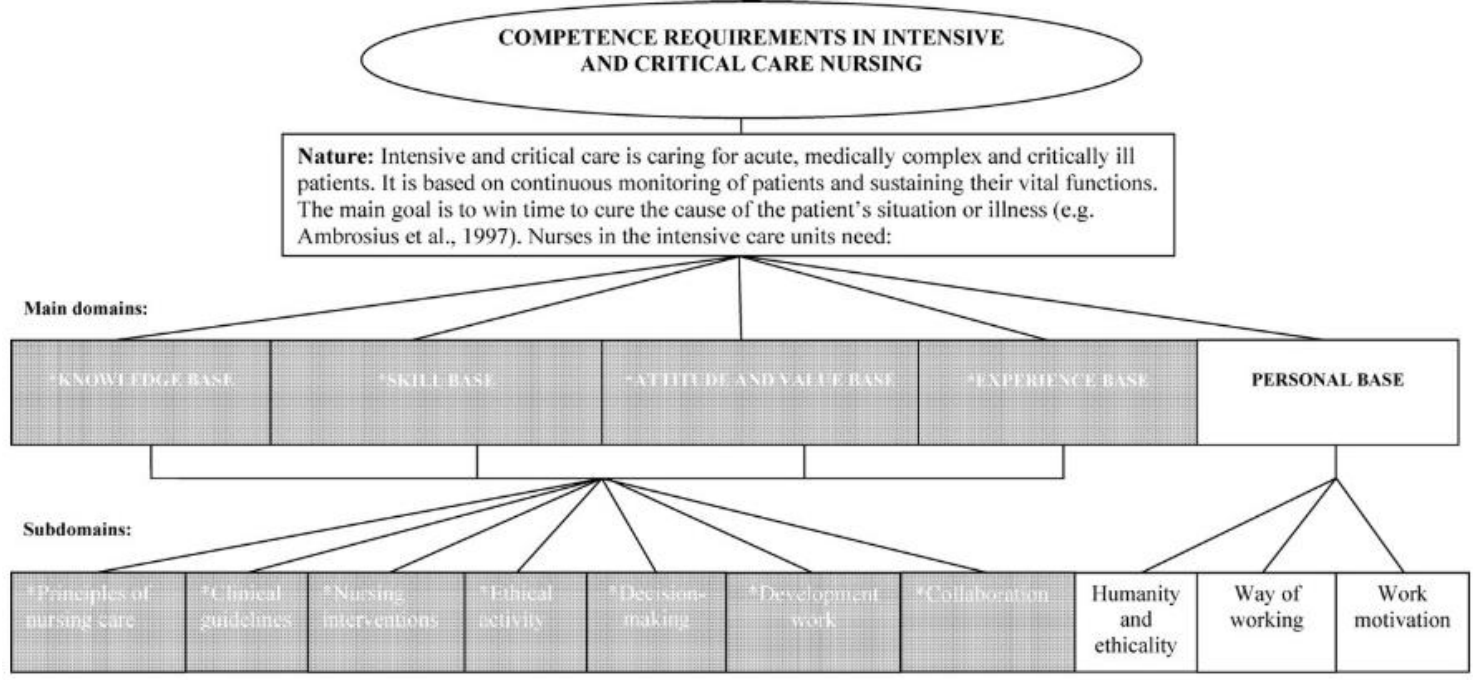

Cuadro 2. Modelo de competencias básicas extraído de Lakanmaa et al. ${ }^{(56)}$

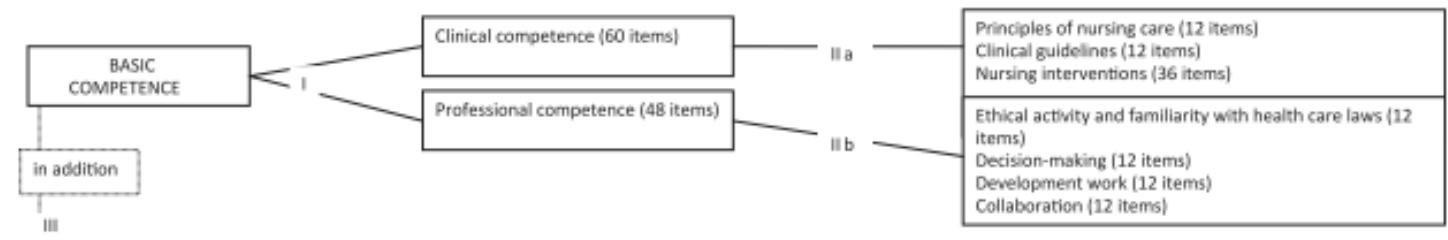

Knowledge base (36 items): principles of nursing care [4 items), clinical guidelines (4 items), nursing interventions (12 items), ethical activity and familiarity of health care laws (4 items), decision-making (4 items), development work (4 items), collaboration (4 items)

Skill base ( 36 items): principles of nursing care ( 4 items), clinical guidelines ( 4 items), nursing interventions (12 items), ethical activity and familarity of health care laws ( 4 items), decision-making ( 4 items), development work [4 items), collaboration [4 items)

Attitude and value base ( 36 items): principles of nursing care ( 4 items), clinical guidelines ( 4 items), nursing interventions (12 items), ethical activity and familiarity of health care laws (4 items), decision-makine (4 items), development work (4 items), collaboration (4 items)

Na,b,c

I= Model I basic competence: clinical competence and professional competence factors

IIb=Model Iib professional competence: ethical activity and familiarity with health care laws, decision-making, development work and collaboration factors

III =Model III basic competence: knowiedge base, skill base and attitude and value base factors

IVa=Model Na knowledge base: principles of nursing care, clinical guidelines, nursing interventions, ethical activity and familiarity of health care laws, decision-making

development work and collaboration factors

IVb=Model IVb skill base: principles of nursing care, clinical guidelines, nursing interventions, ethical activity and familiaity of health care laws, decision-making, development work

and collaboration factors

development work and collaboration factors

A la hora de analizar los ítems incorporados al cuestionario y valorados mediante escala tipo Likert, en las secciones: ámbito clínico, ámbito profesional, ámbito de la gestión, ámbito educativo y de desarrollo, y formación; hallamos que la mayoría de los 66 ítems también superan ampliamente el valor promedio designado por el grupo Delphi (media de 6,1). De todos estos, solo 2 ítems no cumplen este requisito y son aquellos ítems donde la gestión y el entorno propio tienen una gran repercusión, es el caso de: "Se gestiona adecuadamente la carga de trabajo de las enfermeras en UCl" y "la institución colabora en una formación específica de UCl". La unificación de criterios para evaluar la carga de trabajo de las enfermeras es un elemento común de distintos estudios ${ }^{(161,377-380)}$. Así podemos observar como Lee et al. determinó en su muestra que exponer al paciente crítico a 
elevadas cargas de trabajo del personal de enfermería disminuye la supervivencia ${ }^{(161)}$. Nuestros resultados muestran nuevamente que la sobrecarga laboral es un factor a mejorar tal y como ya indicaba el estudio SYREC de $2007^{(381)}$ utilizando la escala NEMS (Nine Equivalents of Nursing Manpower Use Score) para evaluar el citado factor. Además, hay una relación positiva entre sobrecarga laboral y dimensión del hospital, incrementándose en centros con más de 500 camas $^{(381)}$.

Un hecho relevante para este estudio, centrado en formación y competencias en $\mathrm{UCl}$, es que el ítem de colaboración de la institución en una formación específica no alcanza el valor fijado para el grupo Delphi, este hecho es claramente debido a la pertenencia de nuestra muestra a distintos sistemas de salud autonómicos con directrices distintas; hecho que sucede curiosamente a la hora de evaluar el cuestionario definitivo por el propio grupo Delphi. Lo que nos hace pensar que es un elemento muy relacionado con las condiciones actuales de las instituciones. La falta de colaboración también ha sido considerada por nuestros participantes como un aspecto de mejora. Distintos estudios recomiendan la creación de programas dentro de las instituciones para mejorar la captación y fidelización de los empleados, además de ser considerados una herramienta para mejorar en los resultados de los cuidados ${ }^{(93,152,238,335,382)}$. A pesar de estos hallazgos observamos que nuestros ítems no tienen una distribución normal y al igual que otros autores podemos intuir que están mediados por otros factores como la experiencia y las circunstancias personales ${ }^{(69,373)}$.

A la hora de evaluar nuestras respuestas en función del género nos hemos encontrado 12 diferencias en los 66 ítems explorados, todos ellos en el mismo sentido. Las mujeres valoran más positivamente, y por tanto, con mayor puntuación. Se demuestran los mismos hallazgos al tratar los datos en las distintos ámbitos en los que se engloban, encontrando diferencias significativas en la puntuación del ámbito clínico, de la gestión, de la parte A del cuestionario y de la puntuación total del cuestionario.

Durante el análisis de nuestros ítems relacionándolos con el rango de edad de los participantes; hallamos que los grupos de $>45$ años y 41-45 años, son los grupos que se encuentran en contraposición de los otros dos grupos, siempre puntuando más positivamente las necesidades formativas enumeradas en 27 de los 66 ítems. La única excepción es la encontrada en el ítem "el cálculo de fármacos y drogas es una competencia imprescindible", donde el grupo de $<35$ años son los que las valoran más positivamente. Las enfermeras de mayor edad puntúan estas necesidades formativas con valores superiores, además puntúan más los ítems englobados en el ámbito profesional, de la gestión y de la parte total A, y total del cuestionario. Este hecho se genera como un desarrollo de la identidad profesional de los consultados y de que la importancia que las enfermeras otorgan a cada uno de los ámbitos consultados, tiene elementos relacionados con la edad ${ }^{(104,168)}$. Así podemos asumir que en el ámbito de la gestión indica la importancia de la variable "edad" o bien la relación subyacente entre mayor edad y ocupar puestos de gestión.

Un elemento a reseñar es que las enfermeras con mayor formación académica, postgrado oficial, según la agrupación que hemos utilizado en nuestro análisis, son las enfermeras que muestran diferencias significativas con una puntuación superior de todos los ámbitos excepto del ámbito profesional. Podemos constatar que la formación académica tiene una relación a la hora de evaluar las necesidades formativas de las enfermeras de $\mathrm{UCl}$. El nivel académico es un elemento que posibilita la adquisición de nuevos roles que mejoran la expertía en distintos ámbitos de la enfermería y que, como observamos en nuestro trabajo, influye en su valoración ${ }^{(383-386)}$. Como 
mencionaban Cotteril-Walker ${ }^{(54)}$, coincidiendo con otros autores, haber desarrollado un máster aportaba mayores habilidades y destrezas a las enfermeras para brindar unos mejores cuidados $^{(32,80,337,385)}$.

Analizando los elementos del entorno donde las enfermeras desarrollan su labor profesional nos encontramos que más del $90 \%$ trabajan en instituciones públicas. A la hora de valorar los distintos ítems observamos que solo 3 de los 66 presentan diferencias significativas. Dos de ellos podrán tener repercusión directa en la forma de gestión, ya que planificar actuaciones a lo largo del turno y la gestión de las cargas de trabajo son elementos relacionados con los recursos humanos y materiales de las distintas unidades. Así menciona González-Nahuelquin ${ }^{(27)}$ que la planificación de actuaciones es una competencia clave de las enfermeras de UCl. A pesar de ser ambas poblaciones, gestión pública y gestión mixta-privada, muy críticas con la gestión de la carga de trabajo, en la gestión mixta-privada se acentúa la tendencia crítica. Este hecho es fundamental pues, como distintos estudios indican, la falta de dotación adecuada es un riesgo para la atención sanitaria ${ }^{(15,146,152,278,338)}$. A la hora de agrupar los ámbitos, la única diferencia encontrada ha estado relacionada con la puntuación total del ámbito educativo y de desarrollo.

Al contrario de lo que se pudiera pensar, la valoración de las enfermeras de centros no universitarios es significativamente mayor que aquellas de centros universitarios en 18 de los 20 ítems donde se encontraron diferencias notorias. Los ámbitos clínico, profesional, gestión, parte $\mathrm{A}$, y parte total del cuestionario han sido mejor puntuados por las enfermeras de centros no universitarios, y esta diferencia ha resultado significativa con $p$ valor inferior 0,05 . Al comparar las valoraciones entre las enfermeras que desarrollan su labor profesional según el tamaño de los centros hospitalarios; en el grupo de las enfermeras pertenecientes a centros de $\leq 500$ camas, se observa que en 21 de los 66 ítems estudiados existen diferencias significativas, siendo todas en el mismo sentido, y es que las enfermeras de estos centros puntúan más estos ítems; este hecho parece que es influido por las características propias de los centros pequeños. Este hallazgo se encuentra también en todas las agrupaciones de ítems desarrolladas en esta tesis, excepto en el ámbito educativo y de desarrollo, y en la parte B de la encuesta.

Nuestra muestra presenta una distribución de la atención de carácter polivalente, y al comparar unidades polivalentes con unidades específicas; se encontraron solo 4 diferencias significativas en los ítems individuales, no encontrándose diferencias en los ámbitos agrupados. Las enfermeras valoran sus necesidades formativas prácticamente por igual, independientemente de la organización de la $\mathrm{UCl}$. Las enfermeras que trabajan en unidades de tamaño grande ( $>16$ camas de $\mathrm{UCl}$ ) si observan la necesidad de más medidas relacionadas con la formación específica de $\mathrm{UCl}$, quizás se podría inferir el paralelismo de que las unidades más grandes pertenecen a hospitales de referencia, donde se atienden situaciones de mayor complejidad.

Uno de los hallazgos más importantes de la presente tesis es la valoración de los grupos de mayor experiencia laboral tanto como enfermera general como enfermera de UCl. Así observamos en nuestro estudio que las enfermeras con menor experiencia tienen una mayor predisposición hacia los elementos técnicos y las enfermeras más veteranas hacia el cuidado en sí mismo y la continuidad asistencial. Como mencionaba Henriques-Camelo ${ }^{(36)}$ la incorporación de todas las competencias es un reto para las enfermeras de $\mathrm{UCl}$ y la gestión adecuada de esas competencias influye en la 
satisfacción de los pacientes ingresados ${ }^{(288)}$. La existencia de diferencias significativas en la valoración en más de la mitad de los ítems explorados (39 de 66), nos hace pensar que las necesidades formativas se relacionan con la experiencia profesional. Observamos como las enfermeras más experimentadas puntúan con valores superiores todos los ámbitos explorados. Tener más de 20 años de experiencia laboral provoca una mayor valoración que el resto de grupos explorados, en todos los ámbitos excepto en el educativo y de desarrollo. En este último, las enfermeras más jóvenes valoran mucho la necesidad de formación y sus factores relacionados; encontrándose que las enfermeras de mayor experiencia valoran la necesidad de planes de acogida dentro de las propias unidades. Este hecho, es estudiado por distintos autores buscando soluciones para asegurar una formación adecuada para UCI ${ }^{(35,40-42,238,387)}$ a pesar de que "formar enfermeras expertas en cuidados críticos requiere de meses de formación de posgrado"(338). Este elemento es especialmente simétrico a lo expresado por las enfermeras de mayor experiencia laboral de nuestra muestra y demostrado en las pruebas de comparación por parejas del test de Jonckheere-Terpstra.

La experiencia laboral como enfermera de UCI tiene similar valoración a la experiencia laboral total. No se encontraron diferencias significativas en el ámbito clínico, educativo y de desarrollo y en la parte de la formación. Aun así, sí se obtuvieron diferencias significativas en varios ítems que siguen la misma tendencia que en el párrafo anterior. Las enfermeras de $>15$ años de experiencia laboral como enfermeras de $\mathrm{UCl}$, son el grupo que puntúa más las necesidades formativas expresadas en nuestro cuestionario; siendo, además, muy proactivas en las decisiones en gestión sanitaria y el papel que las enfermeras desarrollan en este tipo de unidades, quizás, como dice Benner ${ }^{(14,166)}$, las capacidades adquiridas por el personal experto hacen que el juicio crítico profesional sea un elemento de mayor valor.

A la hora de evaluar la experiencia previa para poder trabajar en una unidad de cuidados intensivos (ya sea en el ámbito laboral como en el académico) nos encontramos que nuestra muestra es especialmente proactiva a requerir algún tipo de formación o experiencia previa; coincidiendo con lo ya expresado por otros autores ${ }^{(32,211,372,388)}$. Mientras algunos autores destacaron las ventajas que aporta un nivel académico de máster como mejora en la atención sanitaria ${ }^{(54)}$, en el aspecto de los cuidados intensivos sigue abierto el debate ${ }^{(32,221)}$. En nuestro caso, más de la mitad de los encuestados reconocen que sería necesaria una experiencia laboral de un año en urgencias y/o quirófano, o bien una experiencia de al menos dos años en hospitalización. Un hecho relevante es que la formación más apoyada por nuestros participantes ha sido el desarrollo y aplicación de planes propios de acogida en las unidades y la formación académica como expertos universitarios con prácticas incluidas. Lo que le da un valor potente a la formación in situ de las enfermeras en el entorno $\mathrm{UCl}$.

Debemos destacar que el $75 \%$ de las encuestadas consideraban que era absolutamente necesario un programa de formación especializada sanitaria (EIR) para las enfermeras de críticos a largo de todo el país. Este hecho tiene relación con la necesidad detectada por las enfermeras consultadas de solicitar requisitos previos de formación para trabajar en $\mathrm{UCl}$, y por tanto, del insuficiente entrenamiento para abordar los cuidados encomendados ${ }^{(88,146)}$; siendo elementos necesarios y valorados por otros estudios adaptar la formación mediante programas de especialización de distintos tipos ${ }^{(30,62,80,389,390)}$. La certificación promovida y avalada por la SEEIUC, desde finales de los años 90 para enfermeras de cuidados intensivos, no ha sido reconocida ni apoyada por ninguna institución ${ }^{(339,372)}$. 
Uno de los elementos llamativos de nuestros hallazgos es la pobre existencia de planes de acogida para personal de nueva incorporación con un porcentaje inferior al $30 \%$, y en cuanto a su distribución territorial ninguna CCAA tiene más del $50 \%$, hecho este que apunta a una implicación deficiente por parte de las instituciones sanitarias. Por lo tanto, observamos con tristeza la falta de cumplimiento de las recomendaciones e indicadores de calidad para las $\mathrm{UCl}^{(152,280,281)}$. Aún más, si cabe, al observar que es una reclamación de casi la totalidad de nuestros encuestados, ya que el 98 $\%$ así lo han afirmado. Entendiendo que los planes de acogida que se desarrollan actualmente son muy mejorables y no reales, ya que se centran en la entrega de documentos o charlas rápidas y, esto dista de ser un plan de acogida eficaz. Proulx y Bourcier $^{(70)}$ ya puso de manifiesto lo mismo que expresan nuestros encuestados en cuanto a la necesidad de que los planes de acogida incluyan la figura de un tutor y de que permitan el seguimiento del profesional novel.

Uno de los elementos que apoyan nuestro cuestionario son las escasas diferencias significativas encontradas en los ítems individuales ( 7 de 66) y la ausencia de ninguna diferencia en los grupos generados entre el grupo de nuestros expertos y el grupo nacional.

El análisis de los datos generó dimensiones subyacentes a partir de los ítems explorados, tal y como se observa en los resultados apartado 3,9. En este contexto detectamos 13 dimensiones en las necesidades formativas de las enfermeras de $\mathrm{UCl}$ a través de un AFE. Observamos que las enfermeras consultadas siguen la propuesta asignada por $\operatorname{Harden}^{(371)}$, quien estructuraba las competencias en tres esferas o círculos: competencias técnicas, intelectuales y personales. En su modelo, las habilidades técnicas incluían las destrezas en comunicación, en las intelectuales se incluían además de los conocimientos, la toma de decisiones. En relación con los valores personales el objetivo es hacer lo correcto, con el enfoque correcto y con el personal correcto. En nuestro estudio hemos buscado además como mejorar nuestras propias capacidades y a través de qué elementos.

Como comenta Fisher ${ }^{(208)}$, las competencias deben ir destinadas a resolver los problemas detectados. Así engloban como competencias estándar: habilidades, resolución de problemas, práctica profesional, práctica reflexiva, trabajo en equipo y liderazgo ${ }^{(208)}$. Nuestros hallazgos están destinados a cómo evaluar las necesidades formativas, así observamos como las enfermeras, para desarrollar su trabajo en $\mathrm{UCl}$, precisan conocer las destrezas e intervenciones propias, los conocimientos y el razonamiento necesario adaptado al cuidado del paciente crítico. Siendo necesario como componente personal, la motivación para desarrollar esa formación. Teniendo en cuenta que no todos los profesionales tienen las mismas necesidades a lo largo del tiempo ${ }^{(14,40)}$, y que según recomiendan distintos autores el aprendizaje se debe basar en una actualización constante de las evidencias científicas disponibles ${ }^{(308,370)}$.

Las dimensiones son valoradas con puntuaciones elevadas por nuestros participantes. Encontrando diferencias más positivas a favor de las enfermeras (mujeres) en tres dimensiones: planes de acogida de enfermeras noveles, aplicación de medidas de soporte y de medidas para mejorar el cuidado. Un elemento que llama la atención es la mayor valoración de cinco dimensiones estadísticamente significativas por parte del grupo de mayor edad ( $>45$ años) siendo más críticas en sus necesidades y valorando estas áreas con mayor puntuación que los restantes grupos de edad estudiados. 
Al analizar el grado académico relacionado con la valoración de las dimensiones halladas encontramos que las enfermeras con postgrado oficial le confieren mayor importancia a la formación continuada de todo el personal de $\mathrm{UCl}$, la motivación para continuar la formación y la repercusión de esta. En este sentido, Sumande y Ruiz ${ }^{(391)}$ detectaron también que las enfermeras con máster valoraban más sus competencias y su formación, siendo las enfermeras de $\mathrm{UCl}$ competentes o muy competentes según el cuestionario utilizado. Por otro lado, en un ámbito general, Massimi et al. ${ }^{(392)}$ detectaron que las enfermeras con máster adquieren unas mayores competencias y observan la importancia de esta formación en el ámbito asistencial a pesar de todavía existir resistencias para el desarrollo pleno de algunas competencias. Por otra parte, las enfermeras que poseen únicamente el título de grado observan con mayor importancia la necesidad de formación en la toma de decisiones.

Un dato para resaltar es que las enfermeras de centros no universitarios y de menor tamaño $(\leq 500$ camas) presentan diferencias significativas; asumiendo una mayor importancia a distintas competencias. Este hecho indica que valoran más positivamente la necesidad de alcanzar un mayor nivel de competencia en relación con las entrevistadas pertenecientes a centros de más de 500 camas. Por un lado, en los centros no universitarios las destrezas e intervenciones (excepto la aplicación de medidas de soporte), la toma de decisiones y el razonamiento del cuidado han sido muy valoradas por este grupo de enfermeras. Por otro lado, en los centros más pequeños valoran prácticamente las mismas dimensiones excepto que le dan un valor más importante a la gestión sanitaria.

Cabe reseñar que las enfermeras que trabajan en unidades grandes (17-40 camas de UCl) valoran muy positivamente la formación tanto del personal novel como la formación continuada. El mayor número de camas quizás influye en la capacidad de soporte interprofesional, ya que como argumentaban Serrano-Gemes y Rich-Ruiz ${ }^{(86)}$ es una de las capacidades más importantes para afrontar las decisiones del cuidado, estos autores redactaron su investigación en una unidad de 32 camas. Además, enunciaban que las enfermeras con menos experiencia tenían más interés en colaborar y, por tanto, en aprender. En el mismo sentido que Kaihlanen et al. ${ }^{(227)}$ observaron también que estaban más interesadas en la figura del mentor y en sus posibilidades de aprendizaje.

La valoración de las enfermeras de mayor experiencia laboral (>20 años), respecto a las dimensiones presenta mayores diferencias significativas que cuando se valora la experiencia laboral solo en $\mathrm{UCl}$. Existiendo en ambos casos coincidencia con las habilidades del cuidado del paciente crítico, comunicación y seguridad clínica, la evaluación del paciente crítico, herramientas y tecnología, y la toma de decisiones. Llama la atención la mayor valoración de los aspectos de formación, tanto de los noveles como de los veteranos, en los de mayor experiencia laboral total no siendo así en las enfermeras con mayor experiencia laboral en UCI. Como mencionaban Griffiths et al. ${ }^{(393)}$, una mayor cualificación de las enfermeras redunda en unos mejores resultados, siendo la experiencia laboral una parte importante de los atributos de los profesionales ${ }^{(14)}$. Aunque la ausencia de suficientes profesionales para tutelar a los nuevos incorporados genera un problema de seguridad en los ambientes clínicos ${ }^{(41,79,163,394)}$. Un aspecto interesante es que en la tesis de Orkaizaguirre ${ }^{(163)}$ detectó que las enfermeras veteranas cometían y notificaban más errores que las noveles en el ámbito hospitalario, por lo que se refuerza la necesidad de una formación continuada. 
Resulta especialmente llamativa la contraposición tan clara del personal con más de 10 años de experiencia laboral en $\mathrm{UCl}$ y la dimensión de toma de decisiones y afrontamiento al final de la vida con el resto de encuestados. Podríamos explicar este resultado basándonos en lo indicado por otros autores, y diciendo que la experiencia, al igual que otros factores, como la posibilidad de que al llevar más tiempo en $\mathrm{UCl}$ hayan podido generar una mejor formación al respecto o facilitar la construcción de un juicio profesional que les hace valorar esta competencia como más importante. ${ }^{(251,260,270)}$. González-Rincón et al. ${ }^{(260)}$ en su revisión bibliográfica encontraron que es la experiencia uno de los componentes principales a través de los cuales las enfermeras son capaces de brindar cuidados efectivos al final de la vida, hecho que apoya nuestro hallazgo.

Un hecho que llama la atención es que la valoración de las dimensiones en bajas o altas puntuaciones presenta niveles de asociación con las variables sociolaborales analizadas. Así podemos observar que se puntúa más positivamente la necesidad de elementos de formación relacionada con solicitar algún tipo de formación y experiencia previa. Los planes de acogida a noveles, la formación específica, la aplicación de medidas de soporte, la excelencia en cuidados, la toma de decisiones y la motivación para desarrollar actividades formativas tienen una relación significativa con solicitar requisitos previos. Poder seguir de una manera adecuada las guías de cuidados específicas de la UCI requiere un bagaje profesional extenso. Bajo el hecho de solicitar requisitos previos, por parte de nuestros encuestados, subyace que esta experiencia pueda influir en una consecución más precoz para lograr una adaptación a las circunstancias propias de este tipo de unidades ${ }^{(30,386,395)}$.

Los resultados muestran un hecho interesante, ya que una alta puntuación en habilidades técnicas, en este caso tres de las cuatro tiene relación significativa con ser mujer. Otro hecho relevante es que los grupos de mayor edad tienden a considerar las dimensiones estudiadas con una puntuación con diferencia en cinco de ellas. Es un elemento discutible que a mayor edad podrían existir unos componentes personales propios que fundamentaran la valoración de las competencias necesarias, como indican algunos modelos competenciales ${ }^{(333,373)}$.

Nuestras dimensiones tienen una clara influencia en su valoración relacionada con la formación de las enfermeras. Formación académica y alta valoración de las dimensiones estudiadas tienen relación estadística. La formación académica de postgrado oficial promueve un pensamiento crítico que fomenta una valoración positiva de las necesidades formativas de las enfermeras de UCl. Un elemento que pudiera estar apoyado por el desarrollo de un pensamiento crítico profesional, ¿qué somos? ¿qué hacemos? ¿cómo lo hacemos ${ }^{(371)}$; indirectamente la formación académica ha posibilitado un desarrollo profesional a través del reconocimiento de sus propias necesidades ${ }^{(36,168,213,396,397)}$. Así encontramos como el estudio de Haegdorens et al. ${ }^{(398)}$ relacionaba que tanto el número de personal de enfermería, su composición y su formación académica, en este caso Bachelor in nursing, tienen influencia en la mortalidad y los resultados de los pacientes ingresados en unidades de hospitalización, estos hallazgos apoyan otros anteriores ${ }^{(154,161,337,388,399,400)}$. A pesar de ser ámbitos distintos a $\mathrm{UCl}$, podríamos decir que nuestros encuestados son conscientes de la necesidad de formación para poder aplicar cuidados de calidad y seguros; y esto influiría en los resultados asistenciales.

Los resultados apoyan que los centros pequeños y no universitarios valoran que precisan unas mayores necesidades formativas que los centros universitarios y de mayor tamaño. De este hecho se 
puede desprender una sensación de falta de formación en el primer grupo de centros. Las actuaciones formativas y sus implicaciones en el cuidado profesional es un elemento que debe ser fomentado en cualquier tipo de institución sanitaria ${ }^{(40)}$. Sin embargo, las unidades de cuidados intensivos de gran tamaño sí valoran más positivamente la necesidad de formación continuada de todo el personal de $\mathrm{UCl}$, contar con una formación específica es una iniciativa solicitada por distintos autores $^{(386,401-404)}$.

Tanto la experiencia laboral previa como enfermera y también como enfermera de UCI son elementos relacionados con las demandas y la valoración de la formación. Así, los grupos de mayor experiencia tienen diferencias significativas en este contexto; como anteriormente afirmamos, la experiencia es un elemento central, por ejemplo, en los cuidados sobre todo al trabajar en circunstancias donde la cotidianidad es cuidar de pacientes críticamente enfermos y en riesgo de morir ${ }^{(28,244,405,406)}$; este hecho se refuerza a la hora de valorar con mayor puntuación nuestras dimensiones. Distintos estudios valoran el propio aprendizaje en el autocuidado de los profesionales y la resiliencia para poder evitar las complicaciones en $\mathrm{UCI}^{(351,352,407-410)}$.

La valoración alta de las dimensiones de la formación se relaciona con exigir una experiencia previa tanto en hospitalización como en servicios que pueden desarrollar unos atributos profesionales parecidos a las enfermeras de $\mathrm{UCl}$. Así, los valores más solicitados son entre 1 y 2 años en hospitalización; y 1 en urgencias y/o quirófano; este hecho refuerza los hallazgos de nuestra primera fase que determinaba que comenzar la labor profesional en $\mathrm{UCl}$ era un riesgo tanto para los pacientes como para los profesionales ${ }^{(88)}$.

Para finalizar, hay que destacar que la valoración de las dimensiones realizada por el grupo de expertos no presenta diferencias significativas al compararla con la realizada al grupo nacional, salvo en la dimensión de "repercusión de la formación". En este caso, el grupo de expertos ha sido más proactivo a la hora de valorar que la formación es un elemento indispensable en las enfermeras en $\mathrm{UCl}$. Hecho que se ve sustentado por artículos que apoyan la formación específica en las distintas habilidades, destrezas y cuidados que llevan a cabo las enfermeras de $\operatorname{críticos}^{(37,91,330,387,411-}$ $417,92,93,209,231,238,293,304,317)$

Dentro de los hallazgos hemos creado un modelo factorial confirmatorio, hemos obtenido valores interesantes que nos acercan a los valores referidos a este tipo de análisis ${ }^{(194,206,207)}$. Así Freiberg et al. ${ }^{(194)}$ recomienda el análisis que hemos realizado a través del método de mínimos cuadrados no ponderados. Así, hemos presentado, tanto los valores del modelo general, que se aproxima a los valores ideales, como los valores que adquieren las variables latentes en este constructo, y que algunas de ellas no obtienen valores adecuados, pero por necesidad de mantener la guía y fundamentos usados a lo largo de todo el trabajo no ha sido posible su depuración. Los valores de RMSEA, CFI, TLI nos indican que existe una relación entre ellos, no siendo perfecta. La retirada de valores para desarrollar el modelo ha provocado la disminución del alfa de Cronbach, pero ha mantenido en unos valores aceptables la fiabilidad compuesta y la varianza extraída, por lo que debemos seguir mejorando el cuestionario inicial con los hallazgos obtenidos hasta el momento. Observando las diferencias encontradas en nuestros participantes según sus características y ajustando el modelo a estas. 
Es un elemento reconocido, y que ahora es apoyado también por nuestro estudio, que la formación de las enfermeras de $\mathrm{UCl}$ es tan específica que precisa crear modelos de enfermería en la atención al paciente crítico. Nuestros participantes tienen una visión crítica del modelo actual y remarcan que se precisa implementar un modelo formativo extenso; así como identificar con claridad qué hacen nuestras enfermeras de $\mathrm{UCl}$ y qué las diferencia de otras enfermeras ${ }^{(397,418)}$. Desde 2007 y en todo el mundo, se destaca la necesidad de contar con programas formativos específicos y el desarrollo de competencias en el ámbito del paciente crítico $^{(362)}$. Tanto este trabajo como la literatura previa fundamentan de forma inequívoca la necesidad de formación especializada para enfermeras de cuidados intensivos, ahora solo falta que esto se convierta en realidad y que las instituciones públicas y privadas sean conscientes del problema y den una respuesta a una demanda profesional que la actual pandemia ha convertido en una demanda social ${ }^{(419)}$.

\subsection{Limitaciones del estudio}

La presente tesis ha sido desarrollada con los medios propios del doctorando, contando con los colaboradores en cada una de las fases que aparecen en la tesis. Tal y como se valoró por parte de los directores, la distribución de las encuestas en la fase 3 fue realizada contando con colaboradores en cada una de las unidades. La captación de participantes ha estado, sin lugar a duda, influida por este hecho, por el carisma y empeño de cada uno de los colaboradores. Esto nos ha ayudado a garantizar que la cumplimentación del cuestionario haya sido realizada por enfermeras de críticos.

A pesar de que se intentó reclutar un mayor número de centros, la muestra final es bastante representativa; tal vez se hubiera precisado mayor participación de instituciones privadas, ya que su representación en el estudio ha sido mínima.

Otras de las limitaciones del estudio son aquellas habituales a los análisis descriptivos transversales, donde los datos analizados pertenecen a un momento único y con las circunstancias propias de ese momento, los cuales pueden ser influidos por circunstancias no controladas por el investigador.

El análisis factorial confirmatorio a pesar de haber depurado los ítems y la creación de distintos modelos con las dimensiones detectadas en el exploratorio no ha incrementado los valores de TLI y CFI por encima de 0,9 como distintos estudios apoyan. Mantener la validez del contenido y del modelo utilizado ha sido una de las razones por las cuales no hemos depurado más los valores incluidos. A pesar de todo esto, sí nos encontramos con valores dentro de los rangos establecidos como adecuados, por lo que presentarlos es una obligación para seguir trabajando en un futuro en líneas de investigación simétricas a las expresadas en esta tesis. Plantear el desarrollo de ecuaciones estructurales pudiera ser en un futuro, una realidad que mejore el constructo generado. 


CAPÍTULO 6 CONCLUSIÓN 




\section{Capítulo 6. Conclusión}

En este punto de la investigación es pertinente concluir adecuadamente el proceso iniciado hace 4 años. El inicio de cada uno de los pasos se ha llevado a través de la consecución de las hipótesis y objetivos planteados. Las distintas fases nos han ido guiando a lo largo del proceso investigador y cada una de ellas ha dado unos resultados que nos apoyan a inferir que:

Sin lugar a duda, las enfermeras de UCI tienen unas competencias claramente definidas, centradas en la atención con calidad y seguridad de los pacientes críticos. Para ello, requieren de una formación específica que les asegure unas capacidades adecuadas a las demandas asistenciales en este tipo de unidades.

El grupo de expertos admitía que la formación académica de grado no aseguraba adecuadamente la atención sanitaria, tal y como se requiere en este tipo de unidades. Este hallazgo se ve apoyado por las diferencias significativas encontradas entre la valoración de los ítems estudiados y las dimensiones exploradas entre los grupos de mayor edad, mayor experiencia laboral en UCl y en total. La excelencia en los cuidados, que nos planteábamos en una de nuestras hipótesis, parece que se consigue con una suma de factores entre los cuales se incluyen la experiencia, la formación postgrado y la formación in situ.

La valoración de las necesidades formativas a lo largo de todo el país no muestra diferencias, puesto que el global de las enfermeras demandan una formación específica. La expertia del grupo de enfermeras con más experiencia laboral hace pensar que estas se constituyen como profesionales con un juicio crítico más asentado y que valoran en conjunto una formación propia y reglada.

Cuidar al paciente crítico requiere de competencias específicas que engloban no solo el hacer, sino cómo y cuándo; por lo que no solo hemos encontrado una gran respuesta en necesidades de formación en habilidades y destrezas, sino también en razonamiento clínico, comunicación y seguridad clínica. La formación constituye un elemento a desarrollar a lo largo de todo el proceso como enfermero; con un marcado carácter de profesionalismo. Hay que destacar la gran importancia que los trabajadores le confieren a los planes de acogida de enfermeras noveles y a la formación continuada de todo el personal. Desgraciadamente, podemos afirmar que los planes de acogida actuales son pobres y solo suelen ser realizados cuando las necesidades asistenciales así lo permiten.

Nuestro cuestionario ha detectado numerosas dimensiones que influyen tanto en la formación como en las competencias que desarrollan las enfermeras actualmente en cuidados intensivos. Así, sin lugar a dudas, hemos hallado que las destrezas e intervenciones, conocimientos y el razonamiento son necesidades claras de formación de las enfermeras. Llama la atención la importancia que le otorgan los entrevistados, tanto a la comunicación como a la seguridad clínica.

La formación está mediada tanto por el grado de expertia como por factores personales, en los que la motivación, la edad y experiencia laboral se han constituido como elementos comunes. La demanda de formación es alta en todos los grupos estudiados y en todos los niveles asistenciales. Hay que destacar las diferencias detectadas a la hora de reclamar formación en centros no universitarios y hospitales de menos o igual de 500 camas. 
Las enfermeras, en todo el país, tienen las mismas necesidades formativas e, incluso, apoyan de una manera muy importante, por una parte, la necesidad de una formación reconocida tipo EIR y, por otra, la de planes de acogida más extensos, reglados y programados para asegurar una formación adecuada. Además, las enfermeras de cuidados intensivos detectan grandes carencias en el desarrollo e implementación de una formación reglada en el sistema nacional de la salud. La formación específica y los planes de acogida se podrían considerar un gasto extraordinario, aunque subyace la sensación de que no invertir en formación vulnera la seguridad clínica, ya que los resultados ponen de manifiesto la importancia de la dimensión en comunicación y seguridad clínica. El coste en formación debe interpretarse como una inversión que logre mejores resultados asistenciales. Este hecho debe ser apoyado por la incorporación de programas acreditados para los profesionales y reconocidos por los gestores sanitarios.

Los resultados muestran que las enfermeras, como miembros del equipo sanitario de atención al paciente crítico, precisan y reclaman una formación que les fundamente la aplicación de cuidados adecuados desde una perspectiva de pensamiento crítico y siempre en función de los requisitos que requiere el paciente en cada momento. El desarrollo de las competencias debe ir centrado en las dimensiones detectadas en el AFE.

- Asegurar unas destrezas en las intervenciones que se debe aplicar al paciente crítico. Competencias en:

- Habilidades en el cuidado del paciente crítico.

- Comunicación y seguridad clínica.

- Evaluación del paciente crítico, herramientas y tecnología.

- Aplicación de medidas de soporte.

- Desarrollar un conocimiento propio como profesional de la salud, que motive todas y cada una de las actuaciones, manteniendo un liderazgo profesional, trabajo en equipo y empatía en sus decisiones. Competencias en:

- Conocimientos enfermeros y razonamiento clínico.

- Toma de decisiones y afrontamiento al final de la vida.

- Gestión sanitaria.

- Extender el conocimiento y sus actuaciones con un juicio profesional que mejore de manera continua la atención sanitaria guiándose por la evidencia científica actual, y brindando la mayor calidad posible en cada momento.

- Medidas para mejorar el cuidado.

- Excelencia en cuidados.

La motivación de las enfermeras, como característica personal, ha mostrado repercusión positiva sobre la necesidad de formación y su valoración. Los elementos formativos se valoran según el momento profesional que vivimos (desde novel hasta experto).

Las enfermeras con mayor experiencia laboral son más conscientes de sus responsabilidades y sus necesidades formativas, este elemento puede estar constituido en parte por un juicio crítico fundamentado en experiencias laborales previas. Además, pudiera existir un factor de confusión mediado por la estabilidad laboral de las enfermeras con menor tiempo de trabajo, ya que aumentar los requisitos y la formación pudiera recaer directamente en ellas mismas, que están iniciando su formación laboral. 
El análisis factorial realizado, tanto en su vertiente exploratoria como confirmatoria, nos presenta una realidad en continuo desarrollo. Las dimensiones detectadas son consideradas como áreas de consenso en el exploratorio, encontrado que existen unas realidades diferenciadas entre el personal experto y el novel. Estas diferencias deben ser analizadas en otros estudios, pues podría asumirse que las diferencias formativas y su valoración cambian con el bagaje profesional. Este elemento, sin lugar a dudas, nos presenta una realidad donde los planes formativos de las enfermeras de cuidados intensivos deben adaptarse continuamente a las realidades diarias. En referencia al AFC, a pesar de no conseguir unos valores tan óptimos como los valores estadísticos pudieran, sí nos abre una posibilidad manifiesta de seguir trabajando en una dirección marcada ya en esta investigación. Revelar la realidad que nos han insinuado nuestros hallazgos estadísticos es muy valioso en el ámbito profesional.

Los hallazgos de esta investigación se constituyen como elementos de reflexión sobre cuál es el perfil de enfermeras en la actualidad y sus demandas profesionales. La constitución de un cuerpo de conocimientos de atención al paciente crítico se constituye en una necesidad urgente para los gestores del sistema nacional de salud. Mientras que la pandemia COVID19 se ha constituido en un factor distorsionador del propio sistema sanitario para las enfermeras de críticos, al mismo tiempo se presenta como una oportunidad única de desarrollar un modelo sólido y específico que se adhiera a las necesidades detectadas.

\subsection{Consideraciones personales}

El desarrollo de este estudio ha permitido realizar un proceso reflexivo intenso de las necesidades de formación detectadas por el investigador tanto en su entorno inmediato como en el ámbito nacional. Debemos entender, tras los hallazgos de esta tesis, que son las propias enfermeras las que precisan analizar, evaluar y desarrollar un marco común en su formación.

La elección de expertos para el análisis de datos nos posibilitó crear una herramienta distribuible a lo largo del país y encontrar nexos de unión entre enfermeras de críticos de diferentes CCAA. El proceso iniciado con esta investigación es un primer paso para desarrollar elementos homogéneos centrados en la adquisición de competencias. La investigación enfermera nos ha dado la oportunidad de encontrar cuestiones pendientes de desarrollar e implementar en las enfermeras de críticos. Sin lugar a dudas, esto es el comienzo de un proceso de análisis y reflexión centrado en garantizar una atención de calidad. Queda resaltado por los ítems analizados que las enfermeras confieren mucha importancia al cuidado profesional, generando los mejores resultados y garantizando una calidad y seguridad adecuadas. El primum non nocere se constituye dentro de las enfermeras de críticos como criterio fundamental de su actuación y, probablemente, la motivación de toda actividad formativa asistencial. El humanismo intrínseco de la profesión enfermera nos brinda la oportunidad de apoyarnos en estas circunstancias para desarrollar una formación ad hoc.

Mientras que, para otras investigaciones, la situación actual de pandemia pudiera ser fuente de obstáculo, para esta investigación es un apoyo tan fundamental como sólido. Teniendo en cuenta los hallazgos de esta tesis y con una recogida de datos previa a la situación de pandemia, no me cabe la menor duda, desde mi puesto como profesional sanitario involucrado en el ámbito asistencial, que las opiniones de las enfermeras y los resultados de esta tesis se refuerzan lamentablemente por la 
luctuosa realidad sanitaria. No se puede esconder que esta pandemia ha sido el mayor reto tanto para los médicos como para las enfermeras de cuidados intensivos. Esperemos que todos podamos haber aprendido de esta situación y que pasado un tiempo la memoria no nos permita olvidar y nos lleve a actuar para crear una formación y un conocimiento enfermero dirigido al paciente gravemente enfermo.

\subsection{Futuras líneas de investigación}

Las futuras líneas de investigación deben ir destinadas al desarrollo de intervenciones que implementen cada una de las dimensiones que afectan a las necesidades formativas de las enfermeras de $\mathrm{UCl}$. Se han identificado numerosas áreas de mejora a través de las cuales se puede conseguir una mejor cualificación de las enfermeras de críticos y esto redundaría en unos mejores resultados asistenciales.

Implementar unos requisitos mínimos y homogéneos que tengan como fin último una formación adecuada en cada momento precisa de un análisis de estrategias, así como modificar y reevaluar el proceso; es por ello que las futuras líneas de investigación deben ir centradas en:

$\checkmark$ Análisis de formación en habilidades clínicas.

$\checkmark$ Valoración de herramientas efectivas en comunicación clínica.

$\checkmark$ Planificación de un programa de postgrado efectivo y específico para las enfermeras de críticos.

$\checkmark$ Desarrollo de conocimientos y habilidades para garantizar la actividad clínica.

$\checkmark$ Análisis de los componentes personales que fomentan la participación en actividades educativas.

$\checkmark$ Obtención de los componentes necesarios para desarrollar un pensamiento crítico y reflexivo de las circunstancias asistenciales. A los que una enfermera de crítico debe hacer frente.

$\checkmark$ Explorar las actividades formativas y sus modalidades que generan unos mejores resultados a nivel asistencial y de adquisición de competencias.

$\checkmark$ Desarrollo de ecuaciones estructurales que desarrollen y/o depuren los análisis factoriales realizados.

\subsection{Conflicto de interés}

$\mathrm{Ni}$ el doctorando ni los directores de tesis tienen relación con ninguna institución pública ni privada que pudiera considerarse conflicto de interés. El doctorando no ha recibido becas ni remuneración económica alguna por el diseño y realización de esta tesis.

El doctorando es socio de la Sociedad Española de Enfermería de Intensivos y Unidades Coronarias, pero la redacción la ha realizado a título personal y sin la participación de otros miembros reconocidos de esa institución. 
BIBLIOGRAFÍA 



\section{Bibliografía}

1. Gobierno de España. Ley Orgánica 4/2007, de 12 de abril, por la que se modifica la Ley Orgánica 6/2001, de 21 de diciembre. 89 España: Boletin Oficial del Estado; 2007 p. 16241-16260.

2. Ministerio de Educación y Ciencia. Real Decreto 1393/2007, de 29 de octubre, por el que se establece la ordenación de las enseñanzas universitarias oficiales. Boletin oficial del estado. 2007; 44037-44048.

3. Martínez Martin ML. 30 años de evolución de la formación enfermera en España. Educación médica. 2007;10(2): 93-96.

4. Alexander MF, Runciman PJ. Marco de competencias del CIE para la enfermera generalista. [En línea] 2003 [Accedido: 10 de mayo de 2019]. Disponible en: http://cnde.es/contenido/ficheros/Marco_Competencias_CIE_Enfermera_Generalista .pdf [Accedido: 10 de mayo de 2019]

5. García Manjón JV, Pérez López MC. Espacio Europeo de Educación Superior , competencias profesionales y empleabilidad. Revista Iberoamericana de Educación. 2016;(June): 1-12.

6. Bunk G. La transmisión de las competencias en la formación y perfeccionamiento profesionales. Vocational Training European Journal. 1994;1: 8-14.

7. Boletin oficial del Estado. Ley 44/2003, de 21 de noviembre, de ordenación de las profesiones sanitarias. [En línea] Boletin oficial del estado. Disponible en: https://www.boe.es/buscar/pdf/2003/BOE-A-2003-21340-consolidado.pdf [Accedido: 10 de enero de 2017]

8. Ministerio de la Presidencia. Real Decreto 450/2005, de 22 de abril, sobre especialidades de Enfermería. 2005 p. 15480-15486.

9. Maciá Soler L. Investigación en enfermería. Enfermería Clínica. [En línea] 2008;18(6): 287-288. Disponible en: doi:10.1016/S1130-8621(08)75849-2

10. American Association of Critical-Care Nurses. AACN Scope and Standards for Progressive and Critical Care Nursing Practice. [En línea] Linda Bell (ed.) Critical Care Nurse. 2019 [Accedido: 10 de mayo de 2019]. Disponible en: doi:10.4037/ccn2019865 [Accedido: 10 de mayo de 2019]

11. American Association of Critical-Care Nurses. AACN standards for establishing and sustaining healthy work environments: $A$ journey to excellence. [En línea] American Journal of Critical Care. American Association of Critical Care Nurses; 2005. p. 187197. Disponible en: http://www.ncbi.nlm.nih.gov/pubmed/15840893 [Accedido: 4 de octubre de 2017]

12. Gill FJ, Kendrick T, Davies H, Greenwood M. A two phase study to revise the Australian Practice Standards for Specialist Critical Care Nurses. Australian Critical Care. [En línea] Australian College of Critical Care Nurses Ltd; 2017;30(3): 173-181. Disponible en: doi:10.1016/j.aucc.2016.06.001

13. Juers A, Wheeler M, Pascoe H, Gregory N, Steers C. Transition to intensive care nursing: a state-wide, workplace centred program-12 years on. Australian critical care : official journal of the Confederation of Australian Critical Care Nurses. [En línea] 
2012;25(2): 91-99. Disponible en: doi:10.1016/j.aucc.2011.09.001 [Accedido: 6 de febrero de 2017]

14. Benner PE. From novice to expert : excellence and power in clinical nursing practice. Prentice Hall; 2001. 307 p.

15. Martín MC, León C, Cuñat J, Del Nogal F. Recursos estructurales de los Servicios de Medicina Intensiva en España. Med Intensiva. [En línea] 2013;37(7): 443-451. Disponible en: doi:10.1016/j.medin.2013.06.002

16. Consejería de Sanidad y Consumo del Gobierno de Canarias. Resolución de 16 de noviembre de 1999, por la que se convoca proceso selectivo para la apertura y actualización de las listas de aspirantes a prestar Servicios en las Instituciones Sanitarias del Servicio Canario de la Salud, mediante nombramiento o contr. [En línea] 153 España: Boletin Oficial de Canarias; 1999 p. 15717-15733. Disponible en: http://www.gobiernodecanarias.org/boc/1999/153/boc-1999-153-004.pdf [Accedido: 29 de octubre de 2019]

17. Consejería de Salud de la Junta de Andalucía. RESOLUCIÓN de 21 de junio de 2010, de la Dirección General de Personal y Desarrollo Profesional del Servicio Andaluz de Salud, por la que se dispone la aprobación y publicación del texto refundido y actualizaciones del Pacto de Mesa Sectorial de Sanidad, . 137 España: Boletin Oficial de la Junta de Andalucia; 2010 p. 42-57.

18. García Moya A, Sanz Pacheco B, Torres Pérez L, Pereira Padilla V, Martín García SM. Manual de Acreditación de competencias profesionales. Enfermero/a de Cuidados Críticos. Agencia de Calidad Sanitaria de Andalucía. Consejería de Salud. 2016.

19. Consejería de Sanidad Comunidad de Castilla y León. ORDEN SAN/713/2016, de 29 de julio, por la que se regulan las bases comunes para la constitución de bolsas de empleo de personal estatutario temporal, de los centros e instituciones sanitarias de la Gerencia Regional de Salud de Castilla y León. Españal: Boletín Oficial de Castilla y León; 2016 p. 38374-38393.

20. Lastra Cubel PM. La especialidad en cuidados intensivos, una especialidad necesaria. Enferm Intensiva. 2006;17(1): 1-2.

21. Carbajosa A. Alemania trata de cubrir con extranjeros 1,4 millones de empleos. EI País. [En línea] Berlin; 2019; Disponible en: https://elpais.com/internacional/2019/12/16/actualidad/1576513166_851153.html [Accedido: 17 de diciembre de 2019]

22. Aiken LH. Hospital Nurse Staffing and Patient Mortality, Nurse Burnout, and Job Dissatisfaction. Jama. [En línea] 2002;288(16): 1987. Disponible en: doi:10.1001/jama.288.16.1987

23. Penoyer DA. Nurse staffing and patient outcomes in critical care: A concise review. [En línea] Critical Care Medicine. Lippincott Williams and Wilkins; 2010. p. 1521-1528. Disponible en: doi:10.1097/CCM.0b013e3181e47888

24. McGahan M, Kucharski G, Coyer F. Nurse staffing levels and the incidence of mortality and morbidity in the adult intensive care unit: A literature review. [En línea] Australian Critical Care. 2012. p. 64-77. Disponible en: doi:10.1016/j.aucc.2012.03.003

25. Lindberg E. Competence in Critical Care. What It Is and How to Gain It: A Qualitative 
Study From the Staff's Point of View. Dimensions of Critical Care Nursing. [En línea] 2006;25(2): 77-81. Disponible en: doi:10.1097/00003465-200603000-00009

26. Ministerio de Sanidad y politica social. Incidentes y eventos adversos en medicina intensiva. Seguridad y riesgo en el enfermo crítico. SYREC 2007. [En línea] 2009 [Accedido: 10 de mayo de 2019]. Disponible en:

http://www.semicyuc.org/sites/default/files/syrec.pdf [Accedido: 10 de mayo de 2019]

27. González Nahuelquin C. Competencias profesionales en enfermeras que desempeñan su labor en una unidad de cuidados intensivos. Revista Iberoamericana de Educación e investigación en enfermería. 2015;5(1): 35-46.

28. Roselló Hervás M, Valls Andrés S. Determinación del perfil de Enfermería en las unidades de cuidados intensivos cardiológicos. Enferm Cardiol. Año XIX. 2012;57: 5158.

29. Brediger R. Developing a mentor program: For our cardiovascular ICU. Critical Care Nurse. [En línea] 2009;29(2): 111-112. Disponible en: doi:10.4037/ccn2009771

30. Currey J, Eustace P, Oldland E, Glanville D, Story I. Developing professional attributes in critical care nurses using Team-Based Learning. Nurse education in practice. [En línea] 2015;15(3): 232-238. Disponible en: doi:10.1016/j.nepr.2015.01.011 [Accedido: 6 de febrero de 2017]

31. Currey J, Oldland E, Considine J, Glanville D, Story I. Evaluation of postgraduate critical care nursing students' attitudes to, and engagement with, Team-Based Learning: A descriptive study. Intensive and Critical Care Nursing. [En línea] 2015;31: 19-28. Disponible en: doi:10.1016/j.iccn.2014.09.003

32. Pirret A, Aitken LM, Currey J, Marshall A, Elliot D, Cribb A, et al. Master's level critical care nursing education: a time for review and debate. Intensive \& critical care nursing. [En línea] Elsevier; 2007;23(4): 183-186. Disponible en: doi:10.1016/j.iccn.2007.05.001 [Accedido: 11 de enero de 2017]

33. Tomes CM. Developing Characteristics of Nursing Excellence. Critical care nurse. 2008;28(4): 78-80.

34. Kaihlanen A-M, Lakanmaa R-L, Salminen $L$. The transition from nursing student to registered nurse: the mentor's possibilities to act as a supporter. Nurse education in practice. [En línea] 2013;13(5): 418-422. Disponible en: doi:10.1016/j.nepr.2013.01.001 [Accedido: 16 de enero de 2017]

35. Navarro Arnedo JM, Orgiler Uranga PE, De Haro Marín S. Guía práctica de enfermería en el paciente crítico. Enferm Intensiva. 2005;16(1): 15-22.

36. Henriques Camelo S. Competencias profesionales de los enfermeros para trabajar en Unidades de Cuidados Intensivos: una revisión integradora. Rev. Latino-Am.

Enfermagem. [En línea] 2012;20(1): 1-9. Disponible en: http://www.scielo.br/pdf/rlae/v20n1/es_25.pdf

37. Jarzemsky P, McCarthy J, Ellis N. Incorporating quality and safety education for nurses competencies in simulation scenario design. Nurse educator. [En línea] 2010;35(2): 9092. Disponible en: doi:10.1097/NNE.0b013e3181d52f6e

38. Johnson J, Drenkard K, Emard E, McGuinn K. Leveraging Quality and Safety Education 
for Nurses to Enhance Graduate-Level Nursing Education and Practice. Nurse Educator. [En línea] 2015;40(6): 313-317. Disponible en: doi:10.1097/NNE.0000000000000177

39. Hudgins K. Clinical Simulation Learning in Critical Care. Crit Care Nurse Q. [En línea] 2017;40(2): 108-110. Disponible en: doi:10.1097/CNQ.0000000000000147

40. Vázquez Guillamet B, Guillamet Lloveras A, Martínez Estalella G, Pérez Ramírez F. Innovaciones en los métodos de formación continuada/permanente de las enfermeras de cuidados intensivos. Enferm Intensiva. [En línea] 2014;25(2): 65-71. Disponible en: doi:10.1016/j.enfi.2013.11.002

41. Baid H, Hargreaves J. Quality and safety: Reflection on the implications for critical care nursing education. Nursing in Critical Care. [En línea] 2015;20(4): 174-182. Disponible en: doi:10.1111/nicc.12182

42. Brezis $M$, Lahat $Y$, Frankel $M$, Rubinov A, Bohm D, Cohen MJ, et al. What can we learn from simulation-based training to improve skills for end-of-life care? Insights from a national project in Israel. Israel Journal of Health Policy Research. [En línea] 2017;6(1): 48. Disponible en: doi:10.1186/s13584-017-0169-9 [Accedido: 13 de noviembre de 2017]

43. Freire Seoane M, Teijeiro Álvarez M, Blázquez Lozano F. Investigación y estudio sobre competencias profesionales: el caso de la Universidad de A Coruña. [En línea] 2013 [Accedido: 10 de mayo de 2019]. Disponible en: http://2011.economicsofeducation.com/malaga2011/freire.pdf [Accedido: 10 de mayo de 2019]

44. Villa A, Poblete M, García Olalla A, Malla Mora G, Marín Paredes JA, Moya Otero J, et al. Aprendizaje basado en competencias. Una propuesta para la evaluación de las competencias genéricas. [En línea] Ediciones Mensajero (ed.) Universidad de Deusto. Bilbao: Universidad de Deusto; 2007. 333 p. Disponible en:

http://scholar.google.com/scholar?hl=en\&btnG=Search\&q=intitle:APREnDIZAJE+BASA DO+En+comPETEnCIAS\#0

45. European Federation of Critical Care Nursing associations (EfCCNa). Declaración de Consenso en Educación de Postgrado para Enfermería de Cuidados Intensivos en Europa. [En línea] p. 1-9. Disponible en: http://www.seeiuc.com/efccna/educaposgrado.pdf [Accedido: 16 de enero de 2017]

46. Critical Care Nurse Education Review Forum. Critical Care NEtwork NAtional Nurse Leads, (CC3N). [En línea] Competency Framework for Critical Care Nurses. Disponible en: https://www.cc3n.org.uk/ [Accedido: 30 de octubre de 2019]

47. Waters D, Kokko A, Strunk H, Georgiou E, Hadjibalassi M, Satosek D, et al. EfCCNa Competencies for European Critical Care Nurses. 2013.

48. European federation of Critical Care Nursing associations (EfCCNa). Declaración de Consenso en Educación de Postgrado para Enfermería de Cuidados Intensivos en Europa. [En línea] 2004 p. 1-8. Disponible en: http://www.seeiuc.com/efccna/educaposgrado.pdf [Accedido: 31 de octubre de 2016]

49. American Association of Critical-Care Nurses. The AACN Synergy Model for Patient Care. [En línea] 2000 [Accedido: 10 de mayo de 2019]. Disponible en: 
https://www.aacn.org/ /media/aacn-website/nursingexcellence/standards/aacnsynergymodelforpatientcare.pdf?la=en [Accedido: 10 de mayo de 2019]

50. Benner $\mathrm{P}$, Spichiger $E$, Wallhagen MI. Nursing as a caring practice from a phenomenological perspective. Scandinavian Journal of Caring Sciences. [En línea] 2005;19(4): 303-309. Disponible en: doi:10.1111/j.1471-6712.2005.00350.x [Accedido: 15 de febrero de 2018]

51. Lakanmaa RL, Suominen T, Perttilä J, Puukka P, Leino-Kilpi H. Competence requirements in intensive and critical care nursing - Still in need of definition? A Delphi study. Intensive and Critical Care Nursing. [En línea] 2012;28(6): 329-336. Disponible en: doi:10.1016/j.iccn.2012.03.002 [Accedido: 11 de enero de 2017]

52. Juers A, Wheeler M, Pascoe H, Gregory N, Steers $C$. Transition to intensive care nursing: A state-wide, workplace centred program-12 years on. Australian Critical Care. [En línea] 2012;25(2): 91-99. Disponible en: doi:10.1016/j.aucc.2011.09.001

53. Boyle M, Butcher R, Conyers V, Kendrick T, MacNamara M, Lang S. Transition to intensive care nursing: Establishing a starting point. Australian Critical Care. [En línea] 2008; Disponible en: doi:10.1016/j.aucc.2008.06.001

54. Cotterill-Walker SM. Where is the evidence that master's level nursing education makes a difference to patient care? A literature review. Nurse education today. [En línea] 2012;32(1): 57-64. Disponible en: doi:10.1016/j.nedt.2011.02.001 [Accedido: 6 de febrero de 2017]

55. Thomason TR. ICU Nursing Orientation and Postorientation Practices. A National Survey. Crit Care Nurse Q. 2006;29(3): 237-245.

56. Lakanmaa R-L, Suominen T, Perttilä J, Ritmala-Castrén M, Vahlberg T, Leino-Kilpi H. Basic competence in intensive and critical care nursing: development and psychometric testing of a competence scale. Journal of clinical nursing. [En línea] 2014;23(5-6): 799-810. Disponible en: doi:10.1111/jocn.12057 [Accedido: 10 de enero de 2017]

57. Alspach G. Recognizing the primacy of competency and exposing the existence of incompetence. Critical care nurse. [En línea] 2008;28(4): 12-14. Disponible en: http://www.ncbi.nlm.nih.gov/pubmed/18669701 [Accedido: 29 de octubre de 2019]

58. Deacon KS, Baldwin A, Donnelly KA, Freeman P, Himsworth AP, Kinoulty SM, et al. The National Competency Framework for Registered Nurses in Adult Critical Care: An overview. Journal of the Intensive Care Society. [En línea] 2017;18(2): 149-156. Disponible en: doi:10.1177/1751143717691985 [Accedido: 6 de octubre de 2017]

59. Critical Care Network National Nurse Leads (CC3N), Critical Care Nurse Education Review Forum. National Standards for Adult Critical Care Nurse Education. 2015.

60. Critical Care Network National Nurse Leads (CC3N). National Competency Framework for Registered Nurses in Adult Critical Care. Step 2 Competencies. 2015.

61. Critical Care Networks-National Nurse Leads (CC3N). National Competency Framework for Registered Nurses in Adult Critical Care. Step 3. 2015.

62. Critical Care Network National Nurse Leads (CC3N). National Competency Framework for Registered Nurses in Adult Critical Care. Step 4. 2018. 
63. Jobmedic A. Nurse Banding in the UK. [En línea] Jobmedic.co.uk. Disponible en: https://blog.jobmedic.co.uk/nurse-banding-uk [Accedido: 19 de noviembre de 2019]

64. NursingTimesjobs.com. Nursing - Differences in Roles and Salaries. [En línea] NursingTimesjobs.com. Disponible en:

https://www.nursingtimesjobs.com/article/nursing-differences-in-roles-and-salaries/ [Accedido: 19 de noviembre de 2019]

65. Consejería de Sanidad del Gobierno de Canarias. Decreto 17/2010, de 25 de febrero, por el que se crea la Comisión Canaria de Formación Continuada de las profesiones sanitarias y se regula el procedimiento de acreditación de la formación continuada de las profesiones sanitarias de la Comunidad de Autóno. Boletin Oficial de Canarias España: Boletin Oficial de Canarias; 2010 p. 6889-6895.

66. Ministerio de Sanidad y Consumo. Real Decreto 1142/2007, de 31 de agosto, por el que se determina la composición y funciones de la Comisión de Formación Continuada de las Profesiones Sanitarias y se regula el sistema de acreditación de la formación continuada. [En línea] Boletin Oficial del Estado España: Boletin Oficial del Estado; 2007 p. 37544-37546. Disponible en: https://www.msssi.gob.es/profesionales/formacion/formacionContinuada/docs/RD_F C140907.pdf [Accedido: 19 de noviembre de 2019]

67. Summers BG, Woods WS. Competency Assessment a practical Guide to the Joint Commission standards. [En línea]. Third Edit. HCPro Inc (ed.) Massachusetts; 2008. 1780 p. Disponible en: www.hcmarketplace.com [Accedido: 19 de noviembre de 2019]

68. Lakanmaa R. Competence in intensive and Critical Care Nursing - development of a basic assessment scale for graduating nursing students. Turku, Finland; 2012.

69. Lakanmaa RL, Suominen T, Ritmala-Castrén M, Vahlberg T, Leino-Kilpi H. Basic competence of intensive care unit nurses: Cross-sectional survey study. BioMed Research International. [En línea] 2015;2015: 1-12. Disponible en: doi:10.1155/2015/536724 [Accedido: 16 de enero de 2017]

70. Proulx DM, Bourcier BJ. Graduate Nurses in the Intensive Care Unit: An Orientation Model. Critical Care Nurse. [En línea] 2008;28(4): 44-52. Disponible en: doi:10.4037/ccn2008.28.4.44

71. Newhouse RP, Hoffman JJ, Suflita J, Hairston DP. Evaluating an innovative program to improve new nurse graduate socialization into the acute healthcare setting. Nursing Administration Quarterly. [En línea] Lippincott Williams and Wilkins; 2007;31(1): 5060. Disponible en: doi:10.1097/00006216-200701000-00013 [Accedido: 20 de noviembre de 2019]

72. Beyea SC, von Reyn L (Kobokovich), Slattery MJ. A Nurse Residency Program for Competency Development Using Human Patient Simulation. Journal for Nurses in Staff Development (JNSD). [En línea] 2007;23(2): 77-82. Disponible en: doi:10.1097/01.NND.0000266613.16434.05 [Accedido: 20 de noviembre de 2019]

73. Van Camp J, Chappy S. The Effectiveness of Nurse Residency Programs on Retention: A Systematic Review. AORN Journal. [En línea] Elsevier; 2017;106(2): 128-144. Disponible en: doi:10.1016/j.aorn.2017.06.003

74. Pillai S, Manister NN, Coppolo MT, Ducey MS, McManus-Penzero J. Evaluation of a Nurse Residency Program. Journal for Nurses in Professional Development. [En línea] 
Lippincott Williams and Wilkins; 2018;34(6): E23-E28. Disponible en: doi:10.1097/NND.0000000000000499 [Accedido: 20 de noviembre de 2019]

75. Boyer SA, Valdez-Delgado KK, Huss JL, Barker AJ, Mann-Salinas EA. Impact of a Nurse Residency Program on Transition to Specialty Practice. Journal for Nurses in Professional Development. [En línea] 2017;33(5): 220-227. Disponible en: doi:10.1097/NND.0000000000000384

76. Square ND. Modeling Clinical Applications in Intensive Care Settings for Nursing Orientation. Advances in Neonatal Care. [En línea] 2010;10(6): 325-329. Disponible en: doi:10.1097/ANC.0b013e3181fc881b [Accedido: 6 de febrero de 2017]

77. Anderson G, Hair C, Todero C. Nurse Residency Programs: An Evidence-Based Review of Theory, Process, and Outcomes. Journal of Professional Nursing. [En línea] 2012;28(4): 203-212. Disponible en: doi:10.1016/j.profnurs.2011.11.020

78. Halbesleben JRB, Wakefield BJ, Wakefield DS, Cooper LB. Nurse burnout and patient safety outcomes: Nurse safety perception versus reporting behavior. Western Journal of Nursing Research. [En línea] 2008;30(5): 560-577. Disponible en: doi:10.1177/0193945907311322 [Accedido: 20 de noviembre de 2019]

79. Vifladt A, Simonsen BO, Lydersen S, Farup PG. The association between patient safety culture and burnout and sense of coherence: A cross-sectional study in restructured and not restructured intensive care units. Intensive and Critical Care Nursing. [En línea] Churchill Livingstone; 2016;36: 26-34. Disponible en: doi:10.1016/j.iccn.2016.03.004 [Accedido: 20 de noviembre de 2019]

80. Zhang X, Meng K, Chen S. Competency framework for specialist critical care nurses: A modified Delphi study. Nursing in Critical Care. [En línea] 2020;25(1): 45-52. Disponible en: doi:10.1111/nicc.12467

81. Oliveira EM de, Barbosa RL, Andolhe R, Eiras FRC das, Padilha KG. Ambiente das práticas de enfermagem e satisfação profissional em unidades críticas. Revista Brasileira de Enfermagem. [En línea] 2017;70(1): 79-86. Disponible en: doi:10.1590/0034-7167-2016-0211 [Accedido: 20 de noviembre de 2019]

82. Nasrabadi AN, Peyrovi H, Valiee S. Nurses' Error Management in Critical Care Units. Critical Care Nursing Quarterly. [En línea] 2017;40(2): 89-98. Disponible en: doi:10.1097/CNQ.0000000000000145

83. Weller J, Frengley R, Torrie J, Shulruf B, Jolly B, Hopley L, et al. Evaluation of an instrument to measure teamwork in multidisciplinary critical care teams. BMJ Quality \& Safety. [En línea] 2011;20(3): 216-222. Disponible en: doi:10.1136/bmjqs.2010.041913

84. Rolls KD, Elliott D. Using consensus methods to develop clinical practice guidelines for intensive care: The Intensive Care Collaborative project. Australian Critical Care. [En línea] 2008;21(4): 200-215. Disponible en: doi:10.1016/j.aucc.2008.08.003

85. Palomar-Aumatell X, Subirana-Casacuberta M, Mila-Villarroel R. Critical care nursing interventions and the time required for their completion in Intensive Care Units: A Delphi study. Intensive and Critical Care Nursing. [En línea] Elsevier Ltd; 2017;43: 8793. Disponible en: doi:10.1016/j.iccn.2017.05.001

86. Serrano-Gemes G, Rich-Ruiz M. Intensidad de colaboración interprofesional entre 
enfermeras de cuidados intensivos de un hospital de tercer nivel. Enferm Intensiva. [En línea] 2017;28(2): 48-56. Disponible en: doi:10.1016/j.enfi.2016.10.007

87. Blackwood B, Albarran JW, Latour JM. Research priorities of adult intensive care nurses in 20 European countries: a Delphi study. Journal of Advanced Nursing. [En línea] 2011;67(3): 550-562. Disponible en: doi:10.1111/j.1365-2648.2010.05512.x

88. Santana-Padilla YG, Santana-Cabrera L, Bernat-Adell MD, Linares-Pérez T, AlemánGonzález J, Acosta-Rodríguez RF. Necesidades de formación detectadas por enfermeras de una unidad de cuidados intensivos: un estudio fenomenológico. Enferm Intensiva. [En línea] Ediciones Doyma, S.L.; 2019;30(4): 181-191. Disponible en: doi:10.1016/j.enfi.2019.05.001 [Accedido: 22 de noviembre de 2019]

89. Kellum JA, Lameire N, Aspelin P, Barsoum RS, Burdmann EA, Goldstein SL, et al. Kidney disease: Improving global outcomes (KDIGO) acute kidney injury work group. KDIGO clinical practice guideline for acute kidney injury. [En línea] Kidney International Supplements. 2012. p. 1-138. Disponible en: doi:10.1038/kisup.2012.1 [Accedido: 3 de octubre de 2018]

90. Moore PK, Hsu RK, Liu KD. Management of Acute Kidney Injury: Core Curriculum 2018. American journal of kidney diseases : the official journal of the National Kidney Foundation. [En línea] 2018;72(1): 136-148. Disponible en: doi:10.1053/j.ajkd.2017.11.021 [Accedido: 3 de octubre de 2018]

91. Oh HJ, Lee MJ, Kim CH, Kim DY, Lee HS, Park JT, et al. The benefit of specialized team approaches in patients with acute kidney injury undergoing continuous renal replacement therapy: Propensity score matched analysis. Critical Care. [En línea] 2014;18(4): 1-9. Disponible en: doi:10.1186/s13054-014-0454-8

92. Kee YK, Kim EJ, Park KS, Han SG, Han IM, Yoon CY, et al. The Effect of Specialized Continuous Renal Replacement Therapy Team in Acute Kidney Injury Patients Treatment. Yonsei Medical Journal. [En línea] 2015;56(3): 658. Disponible en: doi:10.3349/ymj.2015.56.3.658 [Accedido: 2 de mayo de 2018]

93. Bloos F, Müller S, Harz A, Gugel M, Geil D, Egerland K, et al. Effects of staff training on the care of mechanically ventilated patients: A prospective cohort study. British Journal of Anaesthesia. [En línea] 2009;103(2): 232-237. Disponible en: doi:10.1093/bja/aep114

94. Devlin JW, Skrobik Y, Gélinas C, Needham DM, Slooter AJC, Pandharipande PP, et al. Clinical Practice Guidelines for the Prevention and Management of Pain, Agitation/Sedation, Delirium, Immobility, and Sleep Disruption in Adult Patients in the ICU. Critical care medicine. [En línea] NLM (Medline); 2018;46(9): 825-873. Disponible en: doi:10.1097/CCM.0000000000003299

95. Devlin JW, Fong JJ, Howard EP, Skrobik Y, Mccoy N, Marshall J. Assessment of delirium in the intensive care unit: Nursing Practices and perceptions. American Journal of Critical Care. [En línea] 2008;17(6): 555-565. Disponible en: doi:10.4037/ajcc2011243

96. Rowley-Conwy G. Critical care nurses' knowledge and practice of delirium assessment. British Journal of Nursing. [En línea] 2017;26(7): 412-417. Disponible en: doi:10.12968/bjon.2017.26.7.412

97. Ajmi SC, Advani R, Fjetland L, Kurz KD, Lindner T, Qvindesland SA, et al. Reducing doorto-needle times in stroke thrombolysis to $13 \mathrm{~min}$ through protocol revision and 
simulation training: A quality improvement project in a Norwegian stroke centre. BMJ Quality and Safety. [En línea] 2019;28(11): 939-948. Disponible en: doi:10.1136/bmjqs-2018-009117

98. Raurell-Torredá (coord.) M. La evaluacion de competencias en profesionales de la

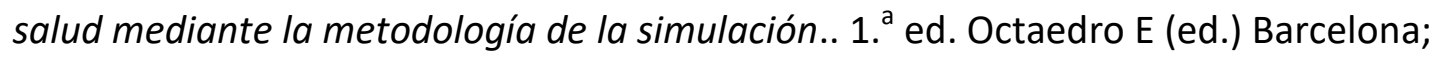
2013. 1-70 p.

99. Leclair LW, Dawson M, Howe A, Hale S, Zelman E, Clouser R, et al. A longitudinal interprofessional simulation curriculum for critical care teams: Exploring successes and challenges. Journal of Interprofessional Care. [En línea] Taylor \& Francis; 2018;32(3): 386-390. Disponible en: doi:10.1080/13561820.2017.1405920

100. Jensen HI, Gerritsen RT, Koopmans M, Downey L, Engelberg RA, Curtis JR, et al. Satisfaction with quality of ICU care for patients and families: the euroQ2 project. Critical Care. [En línea] 2017;21(1): 239. Disponible en: doi:10.1186/s13054-017-18267 [Accedido: 20 de noviembre de 2019]

101. Sherwood G, Nickel B. Integrating Quality and Safety Competencies to Improve Outcomes. Journal of Infusion Nursing. [En línea] 2017;40(2): 116-122. Disponible en: doi:10.1097/NAN.0000000000000210

102. Phillips NM, Duke MM, Weerasuriya R. Questioning skills of clinical facilitators supporting undergraduate nursing students. Journal of Clinical Nursing. [En línea] 2017; 1-9. Disponible en: doi:10.1111/jocn.13761

103. Chlalup Linn A, Aquino Caregnato RC, Nogueria de Souza E. Clinical simulation in nursing education in intensive therapy: an integrative review. Revista Brasileira de Enfermagem. [En línea] 2019;72(4): 1061-1070. Disponible en: doi:10.1590/00347167-2018-0217

104. Beltrán Salazar OA. La práctica de enfermería en cuidado intensivo. Aquichan. [En línea] 2008;8(1): 50-63. Disponible en: doi:10.5294/123

105. Radtke J V, Tate JA, Happ MB. Nurses' perceptions of communication training in the ICU. Intensive \& critical care nursing. [En línea] 2012;28(1): 16-25. Disponible en: doi:10.1016/j.iccn.2011.11.005 [Accedido: 10 de enero de 2017]

106. Song H-S, Choi J, Son Y-J. The relationship between professional communication competences and nursing performance of critical care nurses in South Korea. International Journal of Nursing Practice. [En línea] 2017;23(5): e12576. Disponible en: doi:10.1111/ijn.12576 [Accedido: 6 de octubre de 2017]

107. Ervin JN, Kahn JM, Cohen TR, Weingart LR. Teamwork in the Intensive Care Unit. American Psychologist. [En línea] 2018;73(4): 468-477. Disponible en: doi:10.1037/amp0000247

108. Benbenishty J, Gutysz-Wojnicka A, Harth I, Barkestad E, Satosek D, Jacobsson K, et al. The migrant crisis and the importance of developing cultural competence in the intensive care unit. Nursing in Critical Care. [En línea] 2017;22(5): 262-263. Disponible en: doi:10.1111/nicc.12313

109. Osmancevic S, Schoberer D, Lohrmann C, Großschädl F. Psychometric properties of instruments used to measure the cultural competence of nurses: a systematic review. International Journal of Nursing Studies. [En línea] Elsevier Ltd; 2020;113: 103789. 
Disponible en: doi:10.1016/j.ijnurstu.2020.103789

110. Rosen MA, Diaz Granados D, Dietz AS, Benishek LE, Thompson D, Pronovost PJ, et al. Teamwork in healthcare: Key discoveries enabling safer, high-quality care. American Psychologist. [En línea] 2018;73(4): 433-450. Disponible en: doi:10.1037/amp0000298

111. Salas E, Rosen MA. Building high reliability teams: Progress and some reflections on teamwork training. [En línea] BMJ Quality and Safety. 2013. p. 369-373. Disponible en: doi:10.1136/bmjqs-2013-002015

112. Hetland B, McAndrew N, Perazzo J, Hickman R. A qualitative study of factors that influence active family involvement with patient care in the ICU: Survey of critical care nurses. Intensive and Critical Care Nursing. [En línea] 2018;44: 67-75. Disponible en: doi:10.1016/j.iccn.2017.08.008

113. Blanca Gutiérrez JJ, Blanco Alvariño A, Luque Pérez M, Ramírez Pérez M. Experiencias, percepciones y necesidades en la UCl: revisión sistemática de estudios cualitativos. Enfermería Global. [En línea] 2008;7(1): 1-14. Disponible en: doi:10.6018/eglobal.7.1.822

114. Moreno-Casbas T, Fuentelsaz-Gallego C, Gil de Miguel Á, González-María E, Clarke SP. Spanish nurses' attitudes towards research and perceived barriers and facilitators of research utilisation: a comparative survey of nurses with and without experience as principal investigators. Journal of Clinical Nursing. [En línea] 2011;20(13-14): 19361947. Disponible en: doi:10.1111/j.1365-2702.2010.03656.x [Accedido: 15 de febrero de 2018]

115. Gehrke P, Binnie A, Chan SPT, Cook DJ, Burns KEA, Rewa OG, et al. Fostering community hospital research. Canadian Medical Association Journal. [En línea] 2019;191(35): E962-E966. Disponible en: doi:10.1503/cmaj.190055

116. Goldhamer MEJ, Cohen AP, Bates DW, Cook EF, Davis RB, Singer DE, et al. Protecting an Endangered Species: Training Physicians to Conduct Clinical Research. Academic Medicine. [En línea] 2009;84(4): 439-445. Disponible en: doi:10.1097/ACM.0b013e31819a7cb1 [Accedido: 15 de febrero de 2018]

117. Swenson-Britt E, Reineck C. Research education for clinical nurses: A pilot study to determine research self-efficacy in critical care nurses. Journal of Continuing Education in Nursing. [En línea] 2009;40(10): 454-461. Disponible en: doi:10.3928/00220124-20090923-05

118. Navarro Arnedo JM. Revisión de los estudios sobre profesionales de enfermería de las Unidades de Cuidados Intensivos de España. Enfermería Global. [En línea] 2012;26(1695-6141): 267-289. Disponible en: doi:10.4321/S169561412012000200018

119. Ramos-Morcillo AJ, Ruzafa-Martínez M. Investigación enfermera y políticas públicas de salud. De la «enfermeraginia» a la «enfermerología». Enfermería Clínica. [En línea] 2017;27(3): 141-143. Disponible en: doi:10.1016/j.enfcli.2017.04.008

120. Ortuño-Soriano I, Posada-Moreno P, Fernández-del-Palacio E. Actitud y motivación frente a la investigación en un nuevo marco de oportunidad para los profesionales de enfermería. Index de Enfermería. [En línea] Fundación Index; 2013;22(3): 132-136. Disponible en: doi:10.4321/S1132-12962013000200004 [Accedido: 15 de febrero de 2018] 
121. Santana-Padilla YG, Martin Santana JD, Santana-Cabrera L, Bernat Adell MD. Percepción de la calidad de la investigación enfermera en un hospital público. Journal of Healthcare Quality Research. [En línea] 2018;33(3): 157-169. Disponible en: doi:10.1016/j.jhqr.2018.03.003 [Accedido: 2 de agosto de 2018]

122. Santana-Cabrera L, Lorenzo-Torrent R, Sánchez-Palacios M, Martín Santana JD, Hernández Hernández JR. Análisis de la estancia y de la mortalidad en una unidad de cuidados intensivos. [En línea] Revista de Calidad Asistencial. 2014. p. 121-123. Disponible en: doi:10.1016/j.cali.2013.12.002 [Accedido: 26 de noviembre de 2019]

123. Santana Cabrera L, Sánchez-Palacios M, Hernández Medina E, Eugenio Robaina $P$, Villanueva-Hernández Á. Características y pronóstico de los pacientes mayores con estancia muy prolongada en una Unidad de Cuidados Intensivos. Medicina Intensiva. [En línea] 2008;32(4): 157-162. Disponible en: doi:10.1016/S0210-5691(08)70931-8 [Accedido: 4 de octubre de 2017]

124. Gálvez González M, Ríos Gallego F, Fernández Vargas L, del Águila Hidalgo B, Muñumel Alameda G, Fernández Luque C. El final de la vida en la Unidad de Cuidados Intensivos desde la perspectiva enfermera: un estudio fenomenológico. Enfermería Intensiva. [En línea] Elsevier; 2011;22(1): 13-21. Disponible en: doi:10.1016/j.enfi.2010.11.003 [Accedido: 4 de octubre de 2017]

125. Monzón Marín J, Saralegui Reta I, Abizanda I Campos R, Cabré Pericas L, Iribarren Diarasarri S, Martin Delgado $\mathrm{M}$, et al. Recomendaciones de tratamiento al final de la vida del paciente crítico. Med Intensiva. 2008;32(3): 121-133.

126. Hernández-Tejedor A, Peñuelas O, Sirgo Rodríguez G, Llompart-Pou JA, Palencia Herrejón E, Estella A, et al. Recomendaciones para el tratamiento de los pacientes críticos de los Grupos de Trabajo de la Sociedad Española de Medicina Intensiva, Crítica y Unidades Coronarias (SEMICYUC). Medicina Intensiva. [En línea] 2017;41(5): 285-305. Disponible en: doi:10.1016/j.medin.2017.03.004

127. White KR, Roczen ML, Coyne PJ, Wiencek C. Acute and Critical Care Nurses' Perceptions of Palliative Care Competencies: A Pilot Study. The Journal of Continuing Education in Nursing. [En línea] 2014;45(6): 265-277. Disponible en: doi:10.3928/00220124-20140528-01 [Accedido: 6 de febrero de 2017]

128. Lomero MDM, Jiménez-Herrera MF, Llaurado-Serra M, Bodí MA, Masnou N, Oliver E, et al. Impact of training on intensive care providers' attitudes and knowledge regarding limitation of life-support treatment and organ donation after circulatory death. Nursing \& health sciences. [En línea] 2018; 1-10. Disponible en: doi:10.1111/nhs. 12400

129. Hansen L, Goodell TT, DeHaven J, Smith MD. Nurses' perceptions of end-of-life care after multiple interventions for improvement. American Journal of Critical Care. [En línea] 2009;18(3): 263-271. Disponible en: doi:10.4037/ajcc2009727

130. Vallés-Fructuoso O, Ruiz-de Pablo B, Fernández-Plaza M, Fuentes-Mila V, VallésFructoso O, Martínez-Estalella G. Perspectiva de los profesionales de enfermería de unidades de cuidados intensivos sobre la limitación del tratamiento de soporte vital. Enferm Intensiva. 2016;27(4): 138-145.

131. Junta Directiva de la Sociedad Española de Medicina Intensiva Critica y Unidades Coronarias S. Medicina intensiva en España. Medicina Intensiva. [En línea] 2011;35(2): 
92-101. Disponible en: doi:10.1016/j.medin.2010.12.008

132. Miok-Kim, Sook-Kim K. Awareness and Practice about Respiratory System Nosocomial Infection Control of Clinical Nurses. Research Journal of Pharmacy and Technology. [En línea] 2019;12(7): 3418. Disponible en: doi:10.5958/0974-360X.2019.00578.X

133. Pronovost $\mathrm{P}$. Interventions to decrease catheter-related bloodstream infections in the ICU: the Keystone Intensive Care Unit Project. American journal of infection control. [En línea] 2008;36(10): 171-175. Disponible en: doi:10.1016/j.ajic.2008.10.008 [Accedido: 4 de octubre de 2018]

134. Álvarez-Lerma F, Oliva G, Ferrer JM, Riera A, Palomar M, Catalunya CA del P. Resultados de la aplicación del proyecto Bacteriemia Zero en Catalunya. Medicina Clínica. [En línea] 2014;143: 11-16. Disponible en: doi:10.1016/j.medcli.2014.07.006 [Accedido: 27 de noviembre de 2019]

135. Palomar Martínez M, Álvarez Lerma F, Riera Badía MA, León Gil C, López Pueyo MJ, Díaz Tobajas $C$, et al. Prevención de la bacteriemia relacionada con catéteres en $\mathrm{UCl}$ mediante una intervención multifactorial. Informe del estudio piloto. Medicina Intensiva. [En línea] 2010;34(9): 581-589. Disponible en: doi:10.1016/j.medin.2010.07.005

136. Álvarez Lerma F, Olaechea Astigarraga P, Nuvials X, Gimeno R, Catalán M, Gracia Arnillas MP, et al. ¿Es necesario un proyecto para prevenir las infecciones del tracto urinario en los pacientes ingresados en unidades de cuidados intensivos españolas? Medicina Intensiva. [En línea] 2019;43(2): 63-72. Disponible en: doi:10.1016/j.medin.2017.12.003

137. Álvarez-Lerma F, Palomar-Martínez M, Sánchez-García M, Martínez-Alonso M, Álvarez-Rodríguez J, Lorente $\mathrm{L}$, et al. Prevention of ventilator-Associated pneumonia: The multimodal approach of the Spanish ICU "pneumonia zero» program. Critical Care Medicine. [En línea] 2018;46(2): 181-188. Disponible en: doi:10.1097/CCM.0000000000002736

138. Cantón-Bulnes ML, Garnacho-Montero J. Antisepsia orofaríngea en el paciente crítico y en el paciente sometido a ventilación mecánica. Medicina Intensiva. [En línea] 2019;43: 23-30. Disponible en: doi:10.1016/j.medin.2018.06.011

139. Kane A, Tait C, Arcus K. Internationally qualified nurses' perceptions of the competencies that pertain to patient safety. Nurse Education in Practice. [En línea] Elsevier; 2019;38: 105-111. Disponible en: doi:10.1016/j.nepr.2019.06.001

140. Australian Commision on Safety and Quality in Healthcare. Implementation Toolkit for clinical handover improvement. [En línea] ACSQHC (ed.) Sydney; 2011. 60 p.

Disponible en: www.safetyandquality.gov.au [Accedido: 29 de noviembre de 2019]

141. Paul SA. Assessment of critical thinking: A Delphi study. Nurse Education Today. [En línea] Elsevier Ltd; 2014;34(11): 1357-1360. Disponible en: doi:10.1016/j.nedt.2014.03.008

142. Lapena-Monux YR, Cibanal-Juan L, Orts-Cortes MI, Macia-Soler L, Palacios-Cena D. Nurses' experiences working with nursing students in a hospital: a phenomenological enquiry. Revista Latino-Americana De Enfermagem. [En línea] 2016;24: e2788. Disponible en: doi:10.1590/15188345.1242.2788 
143. Jacob E, Duffield C, Jacob D. Development of an Australian nursing critical thinking tool using a Delphi process. Journal of Advanced Nursing. [En línea] 2018;74(9): 22412247. Disponible en: doi:10.1111/jan.13732

144. Flott $E A$, Linden $L$. The clinical learning environment in nursing education: a concept analysis. Journal of Advanced Nursing. [En línea] 2016;72(3): 501-513. Disponible en: doi:10.1111/jan.12861 [Accedido: 29 de noviembre de 2019]

145. Morris LL, Pfeifer P, Catalano R, Fortney R, Nelson G, Rabito R, et al. Outcome Evaluation of a New Model of Critical Care Orientation. American Journal of Critical Care. [En línea] 2009;18(3): 252-259. Disponible en: doi:10.4037/ajcc2009355

146. Marrero González CM, Manuel C. Estudio fenomenológico de la experiencia de incorporación al contexto laboral de enfermeras egresadas de la Universidad de La Laguna entre 2009 y 2014. [En línea] Universidad de la Laguna; 2017. Disponible en: https://riull.ull.es/xmlui/handle/915/4485 [Accedido: 4 de octubre de 2017]

147. Kram SL, Wilson J. Nurse residency program attracts and retains novice nurses. Nursing. [En línea] 2016;46(2): 15-16. Disponible en: doi:10.1097/01.NURSE.0000476245.39588.ff

148. World Health Organization. Official Records of the World Health Organization. Final Acts. International Health Conference. 1948.

149. González Gil T, Salvadores Fuentes P, Sánchez Sanz E, Carmona Monge FJ. Introducción al paciente crítico. En: Fundación Universitaria Ramon Areces (ed.) Enfermería en Cuidados Críticos. 1. ${ }^{a}$ ed. Madrid; 2011. p. 1-13.

150. Brilli RJ, Spevetz A, Branson RD, Campbell GM, Cohen H, Dasta JF, et al. Critical care delivery in the intensive care unit: Defining clinical roles and the best practice model. Crit Care Med. 2001;29(10): 2007-2019.

151. National Health System. Comprehensive Critical Care. A review of adult critical care services. 2000.

152. Ministerio de Sanidad y Politica Social. Unidad de cuidados intensivos: Estándares y Recomendaciones. [En línea] 2010 [Accedido: 5 de julio de 2017]. Disponible en: http://www.msssi.gob.es/organizacion/sns/planCalidadSNS/docs/UCI.pdf [Accedido: 5 de julio de 2017]

153. Ministerio de Sanidad y Consumo. Real Decreto $1277 / 2003$, de 10 de octubre, ppor el que se establecen las bases generales sobre autorizacion de centros, servicios y estableciemientos sanitarios. 254 España: Boletin Oficial del Estado; 2003 p. 3789337902.

154. Stimpfel AW, Sloane DM, McHugh MD, Aiken LH. Hospitals Known for Nursing Excellence Associated with Better Hospital Experience for Patients. Health services research. [En línea] 2016;51(3): 1120-1134. Disponible en: doi:10.1111/14756773.12357 [Accedido: 10 de enero de 2017]

155. Silber JH, Rosenbaum PR, McHugh MD, Ludwig JM, Smith HL, Niknam BA, et al. Comparison of the Value of Nursing Work Environments in Hospitals Across Different Levels of Patient Risk. JAMA surgery. [En línea] 2016;151(6): 527-536. Disponible en: doi:10.1001/jamasurg.2015.4908 [Accedido: 10 de enero de 2017]

156. McHugh MD, Rochman MF, Sloane DM, Berg RA, Mancini ME, Nadkarni VM, et al. 
Better Nurse Staffing and Nurse Work Environments Associated With Increased Survival of In-Hospital Cardiac Arrest Patients. Medical care. [En línea] 2016;54(1): 7480. Disponible en: doi:10.1097/MLR.0000000000000456 [Accedido: 10 de enero de 2017]

157. Van Oostveen CJ, Mathijssen E, Vermeulen H. Nurse staffing issues are just the tip of the iceberg: a qualitative study about nurses' perceptions of nurse staffing. International journal of nursing studies. [En línea] 2015;52(8). Disponible en: doi:10.1016/j.ijnurstu.2015.04.002

158. Kim J-H. Association of nurse staffing grade and 30-day mortality in intensive care units among cardiovascular disease patients. Medicine. [En línea] 2018;97(42): 1-7. Disponible en: doi:10.1097/MD.0000000000012895 [Accedido: 17 de diciembre de 2019]

159. Falk AC, Wallin EM. Quality of patient care in the critical care unit in relation to nurse patient ratio: A descriptive study. Intensive and Critical Care Nursing. [En línea] Churchill Livingstone; 2016;35: 74-79. Disponible en: doi:10.1016/j.iccn.2016.01.002

160. Law AC, Stevens JP, Hohmann S, Walkey AJ. Patient Outcomes After the Introduction of Statewide Intensive Care Unit Nurse Staffing Regulations HHS Public Access. Crit Care Med. [En línea] 2018;46(10): 1563-1569. Disponible en: doi:10.1097/CCM.0000000000003286

161. Lee A, Sing Leo Cheung Y, Matthew Joynt G, Chi Hung Leung C, Wong W-T, David Gomersall C. Are high nurse workload/staffing ratios associated with decreased survival in critically ill patients? A cohort study. Annals of Intensive Care. [En línea] 2017;7: 46. Disponible en: doi:10.1186/s13613-017-0269-2

162. Margadant C, Wortel S, Hoogendoorn M, Bosman R, Spijkstra JJ, Brinkman S, et al. The Nursing Activities Score Per Nurse Ratio Is Associated With In-Hospital Mortality, Whereas the Patients Per Nurse Ratio Is Not. Critical care medicine. [En línea] Ovid Technologies (Wolters Kluwer Health); 2020;48(1): 3-9. Disponible en: doi:10.1097/CCM.0000000000004005

163. Orkaizagirre A. La cultura de seguridad del paciente de las enfermeras hospitalarias. Universidad de Zaragoza; 2016.

164. Hassani P, Abdi A, Jalali R, Salari N. Relationship between the use of intuition in clinical practice and the clinical competence of critical care nurses. International journal of evidence-based healthcare. [En línea] 2017; 1. Disponible en: doi:10.1097/XEB.0000000000000113

165. Stinson KJ. Nurses' Attitudes, Clinical Experience, and Practice Issues With Use of Physical Restraints in Critical Care Units. American journal of critical care : an official publication, American Association of Critical-Care Nurses. [En línea] 2016;25(1): 21-26. Disponible en: doi:10.4037/ajcc2016428 [Accedido: 10 de enero de 2017]

166. Carrillo-Algarra AJ, García-Serrano L, Cárdenas-Orjuela CM, Díaz-Sánchez IR, YabrudyWilches N. La filosofía de Patricia Benner y la práctica clínica. Enfermería Global. [En línea] 2013;32: 346-361. Disponible en: http://scielo.isciii.es/pdf/eg/v12n32/revisiones5.pdf [Accedido: 20 de abril de 2017]

167. Ackerson K, Stiles KA. Value of nurse residency programs in retaining new graduate nurses and their potential effect on the nursing shortage. [En línea] Journal of 
Continuing Education in Nursing. 2018. 282-288 p. Disponible en: doi:10.3928/00220124-20180517-09

168. Arreciado A. Identidad profesional enfermera construcción y desarrollo en los estudiantes durante su formación universitaria. [En línea] Tesis doctoral. Universidad de Barcelona; 2014. Disponible en: http://www.tdx.cat/handle/10803/129270\%0Ahttp://hdl.handle.net/2445/49181

169. Medas JC, Amato S, Grimm D, Radziewicz R, Rhodes C, Van Horn C, et al. Outcomes of Comprehensive Nurse Residency Program. Wolters Kluwer Health. 2015;(November): 40-48.

170. Eckerson CM. The impact of nurse residency programs in the United States on improving retention and satisfaction of new nurse hires: An evidence-based literature review. Nurse Education Today. [En línea] Elsevier; 2018;71(January): 84-90. Disponible en: doi:10.1016/j.nedt.2018.09.003

171. Boling B, Hardin-Pierce M. The effect of high-fidelity simulation on knowledge and confidence in critical care training: An integrative review. Nurse Education in Practice. [En línea] Elsevier Ltd; 2016;16(1): 287-293. Disponible en: doi:10.1016/j.nepr.2015.10.004

172. Low XM, Horrigan D, Brewster DJ. The effects of team-training in intensive care medicine: A narrative review. Journal of Critical Care. [En línea] Elsevier Inc.; 2018;48: 283-289. Disponible en: doi:10.1016/j.jcrc.2018.09.015

173. Cook DA, Brydges R, Hamstra SJ, Zendejas B, Szostek JH, Wang AT, et al. Comparative effectiveness of technology-enhanced simulation versus other instructional methods: A systematic review and meta-analysis. Simulation in Healthcare. [En línea] 2012;7(5): 308-320. Disponible en: doi:10.1097/SIH.0b013e3182614f95

174. Del Rio P. La Integración de Métodos Cualitativos y Cuantitativos en un Estudio de Pobreza y Calidad de Vida. VI Congreso Chileno de Antropología. [En línea] Valdivia, Chile; 2007. p. 8. Disponible en: https://www.aacademica.org/vi.congreso.chileno.de.antropologia/69

175. Ruiz Olabuénaga JI. Teoría y práctica de la investigación cualitativa. Deusto U de (ed.) Bilbao; 2012.

176. Dunker CIL, Parker I. Modelos y métodos socio-críticos de la investigación cualitativa: cuatro casos psicoanalíticos y estrategias para la superación. Libro Estrategias y prácticas cualitativas de investigación social. Madrid: Pearson-Prentice Hall; 2008. p. 23-43.

177. Gordo-López Ás. On the psychologization of critical psychology. Annual Review of Critical Psychology. 2000;2: 55-71.

178. Flick U. Introducción a la investigación cualitativa.. Tercera. Morata SL (ed.) Madrid: Fundación Paideia Galiza; 2012. 324 p.

179. Denzin NK, Lincoln YS. El campo de la investigación cualitativa. Gedisa (ed.) Barcelona; 2012. $100 \mathrm{p}$.

180. Taylor S, Bogdan R. El trabajo con los datos. Análisis de los datos en investigación cualitativa. En: Paidós (ed.) Introducción a los métodos cualitativos de investigación. [En línea] 4. ${ }^{a}$ ed. Barcelona; 1998. p. 152-176. Disponible en: http://www.paidos.com 
181. Cotán Fernández A. El sentido de la investigacion cualitativa. Escuela Abierta. 2016;19: 33-48.

182. Waters D, Kokko A, Strunk H, Georgiou E, Hadjibalassi M, Satosek D, et al. Competencias enfermeras según la EfCCNa para las enfermeras de cuidados intensivos en Europa. European Federation of Critical Care Nurse Association. [En línea] 2013; 14. Disponible en: https://seeiuc.org/wpcontent/uploads/2017/10/competencias_enfermeras.pdf

183. Yañez Gallardo R, Cuadra Olmos R. La técnica DELPHI y la investigación en los servicios de salud. Ciencia y Enfermeria. [En línea] 2008;14(1): 9-15. Disponible en: doi:10.4067/S0717-95532008000100002

184. Landeta J, Barrutia J, Lertxundi A. Hybrid Delphi: A methodology to facilitate contribution from experts in professional contexts. Technological Forecasting and Social Change. [En línea] 2011;78(9): 1629-1641. Disponible en: doi:10.1016/j.techfore.2011.03.009

185. Powell C. The Delphi technique: Myths and realities. Journal of Advanced Nursing. [En línea] 2003;41(4): 376-382. Disponible en: doi:10.1046/j.1365-2648.2003.02537.x

186. Landeta J, Matey J, Ruíz V, Galter J. Results of a Delphi survey in drawing up the inputoutput tables for Catalonia. Technological Forecasting and Social Change. [En línea] 2008;75(1): 32-56. Disponible en: doi:10.1016/j.techfore.2007.01.005

187. Keeney S, Hasson F, McKenna H. The Delphi Technique in Nursing and Health Research. [En línea] John Wiley \& Sons Ltd (ed.) Oxford: Wiley/Blackwell (10.1111); 2011. 198 p. Disponible en: doi:10.1002/9781444392029 [Accedido: 23 de enero de 2020]

188. Reynaldos-Grandón KL, Saiz-Alvarez JM, Molina-Muñoz YP. Competencias profesionales, gestión clínica y grupos relacionados de diagnósticos. El caso de hospitales públicos chilenos. Revista de Salud Pública. [En línea] 2018;20(4): 472-478. Disponible en: doi:10.15446/rsap.v20n4.66564

189. Holanda FL de, Marra CC, Cunha ICKO. Professional competence of nurses in emergency services: evidence of content validity. Rev Bras Enferm. [En línea] 2019;72(Suppl 1): 66-73. Disponible en: doi:10.1590/0034-7167-2017-0518

190. Gill FJ, Leslie GD, Grech C, Latour JM. Using a web-based survey tool to undertake a Delphi study: Application for nurse education research. Nurse Education Today. [En línea] Elsevier Ltd; 2013;33(11): 1322-1328. Disponible en: doi:10.1016/j.nedt.2013.02.016

191. Orts-Cortés MI, Comet Cortés P, Moreno Casbas MT, Arribas CA, Grupo Investen-ISCII. Identificación de las prioridades de investigación en enfermería en España: Estudio Delphi. Enferm. clín. (Ed. impr.). 2000;10(1): 9-13.

192. Cremades Puerto J, Maciá Soler L, López Montesinos MJ, Orts Cortes I. Identificación de factores de estrés laboral en profesionales de enfermería. Cogitare Enferm. [En línea] 2011;16(4): 609-614. Disponible en: doi:10.1002/pmic.200600676

193. Eckardt $\mathrm{P}$, Hammer MJ, Barton-Burke M, McCabe $M$, Kovner $C T$, Behrens $L$, et al. All nurses need to be research nurses. Journal of Clinical and Translational Science. [En línea] 2017;1(5): 269-270. Disponible en: doi:10.1017/cts.2017.294 
194. Freiberg Hoffmann A, Stover JB, De la Iglesia G, Fernández Liporace M. Correlaciones policóricas y tetracóricas en estudios factoriales exploratorios y confirmatorios. Ciencias Psicológicas. 2013; VII(2): 151-164.

195. Lloret-Segura S, Ferreres-Traver A, Hernández-Baeza A, Tomás-Marco I. El análisis factorial exploratorio de los ítems: Una guía práctica, revisada y actualizada. Anales de Psicologia. [En línea] 2014;30(3): 1151-1169. Disponible en: doi:10.6018/analesps.30.3.199361

196. Calvo-Francés F. Internet Abusive Use Questionnaire: Psychometric properties. Computers in Human Behavior. [En línea] 2016;59: 187-194. Disponible en: doi:10.1016/j.chb.2016.01.038

197. Calvo-Francés F, Hernández Rodríguez JE. Validación de un cuestionario sobre la percepción del profesorado del manejo de situaciones de emergencias en el ámbito escolar. Metas Enferm. [En línea] 2015;18(9): 20-28. Disponible en: doi:10.5557/178

198. Fariña-López E, Estévez-Guerra GJ, Núñez González E, Calvo Francés F, Penelo E. Adaptación y validación española del Perception of Restraint Use Questionnaire (PRUQ) sobre el uso de restricciones físicas en personas mayors. Anales del Sistema Sanitario de Navarra. [En línea] 2016;39(1): 13-22. Disponible en: doi:10.4321/S1137$6627 / 2016000100003$

199. Sierra Talamantes C, Muñoz Izquierdo A, Peiró Andrés M, Valls S, López López I, Famoso Poveda $\mathrm{M}$, et al. Elaboración de un cuestionario para medir la calidad con los cuidados de enfermería en unidades de cuidados intensivos cardiológicos desde la percepción de los pacientes. Enfermería en Cardiología. 2009;(47-48): 71-79.

200. Jefatura del Estado. Ley Orgánica 3/2018, de 5 de diciembre, de Protección de Datos Personales y garantía de los derechos digitales. [En línea] 294 España: Boletin Oficial del Estado; 2018 p. 119788-119857. Disponible en: http://www.boe.es [Accedido: 20 de febrero de 2020]

201. Cisterna Cabrera F. Categorización y triangulación como proceso de validación del conocimiento en investigación cualitatitativa. Theoria. [En línea] 2005;14(1): 61-71. Disponible en: http://www.redalyc.org/pdf/299/29900107.pdf [Accedido: 25 de septiembre de 2017]

202. Lorenzo-Seva U, Ferrando PJ. Factor Analysis. [En línea] Tarragona: Universitat Rovira i Virgil; 2018. Disponible en: psico.fcep.urv.cat/utilitats/factor

203. Lorenzo-Seva U. Promin: A method for oblique factor rotation. Multivariate Behavioral Research. [En línea] Lawrence Erlbaum Associates Inc.; 1999;34(3): 347365. Disponible en: doi:10.1207/S15327906MBR3403_3 [Accedido: 23 de octubre de 2020]

204. Timmerman ME, Lorenzo-Seva U. Dimensionality assessment of ordered polytomous items with parallel analysis. Psychological Methods. [En línea] Psychol Methods; 2011;16(2): 209-220. Disponible en: doi:10.1037/a0023353 [Accedido: 23 de octubre de 2020]

205. Conway JM, Huffcutt Al. A Review and Evaluation of Exploratory Factor Analysis Practices in Organizational Research. Organizational Research Methods. [En línea] SAGE Publications; 2003;6(2): 147-168. Disponible en: doi:10.1177/1094428103251541 [Accedido: 23 de octubre de 2020] 
206. Morata-Ramirez MÁ, Holgado Tello FP, Barbero-García MI, Mendez G. Análisis factorial confirmatorio. Recomendaciones sobre mínimos cuadrados no ponderados en función del error Tipo I de Ji-Cuadrado y RMSEA. Acción Psicológica. [En línea] 2015;12(1): 79. Disponible en: doi:10.5944/ap.12.1.14362 [Accedido: 23 de octubre de 2020]

207. Kline RB. Principles and practice of Structural Equation Modeling.. 3. . ed. Kenny DA, Little TD (eds.) Social Sciences. New York: The Guilford Press; 2011. 445 p.

208. Fisher MJ, Marshall AP, Kendrick TS. Competency standards for critical care nurses: Do they measure up? Australian Journal of Advanced Nursing. 2005;22(4): 32-39.

209. Dunn S V., Lawson D, Robertson S, Underwood M, Clark R, Valentine T, et al. The development of competency standards for specialist critical care nurses. Journal of Advanced Nursing. [En línea] Blackwell Publishing Ltd; 2000;31(2): 339-346. Disponible en: doi:10.1046/j.1365-2648.2000.01292.x [Accedido: 8 de julio de 2020]

210. Marshall AP, Currey J, Aitken LM, Rn DE. Key stakeholders' expectations of educational outcomes from Australian critical care nursing courses: A Delphi study. Australian Critical Care. [En línea] 2007;20: 89-99. Disponible en: doi:10.1016/j.aucc.2007.05.001

211. Aitken LM, Currey J, Marshall A, Elliott D. The diversity of critical care nursing education in Australian universities. Australian Critical Care. [En línea] 2006;19(2): 4652. Disponible en: www.nnnet.gov.aul [Accedido: 8 de julio de 2020]

212. Santana Padilla YG, Linares Pérez T, Rodríguez Acosta RF, Alemán González J, Adell Bernat MD, Santana Cabrera L. Competencias enfermeras en el ámbito clínico en una Unidad de Cuidados Intensivos Polivalente mediante un estudio fenomenológico. [En línea] Granada: Fundación Index; 2017. p. 262. Disponible en: http://www.indexf.com/para/n27/262.php [Accedido: 21 de noviembre de 2017]

213. Reinoso A, Núñez LS. Modelos de Enfermería en Unidades de Paciente Crítico : un paso hacia el cuidado avanzado. Enfermería Global. 2014;34(1): 323-329.

214. Arias-Rivera S, Raurell-Torredà M, Thuissard-Vasallo IJ, Andreu-Vázquez C, Hodgson $\mathrm{CL}$, Ims-Es G, et al. Adaptation and validation of the ICU Mobility Scale in Spain. Enferm Intensiva. [En línea] 2020;31(3): 131-146. Disponible en: doi:10.1016/j.enfi.2019.10.001

215. Mjadu TM, Jarvis MA. Patients' safety in adult ICUs: Registered nurses' attitudes to critical incident reporting. International Journal of Africa Nursing Sciences. [En línea] Elsevier; 2018;9(September): 81-86. Disponible en: doi:10.1016/j.ijans.2018.09.001

216. Ministerio de Sanidad, Semicyuc, World Health Organization. Resumen del Proyecto de prevención de las Bacteriemias relacionadas con cateteres venosos centrales en las UCl españolas. [En línea] 2009 [Accedido: 4 de octubre de 2018]. Disponible en: http://www.cdc.gov/mmwr/PDF/rr/rr5110.pdf [Accedido: 4 de octubre de 2018]

217. González de Molina Ortiz FJ, Gordo Vidal F, Estella García A, Morrondo Valdeolmillos $\mathrm{P}$, Fernández Ortega JF, Caballero López J, et al. "Do not do" recommendations of the working groups of the Spanish Society of Intensive and Critical Care Medicine and Coronary Units (SEMICYUC) for the management of critically ill patients. Medicina Intensiva. [En línea] Ediciones Doyma, S.L.; 2018;42(7): 425-443. Disponible en: doi:10.1016/j.medin.2018.04.001 
218. Stacy KM. Progressive care units: different but the same. Critical care nurse. [En línea] 2011;31(3): 77-83. Disponible en: doi:10.4037/ccn2011644 [Accedido: 10 de enero de 2017]

219. Brenner ZR, lafrati NS. Incorporating best practices into undergraduate critical care nursing education. Critical Care Nurse. 2014;34(1): 61-66.

220. Gallagher L. Continuing education in nursing: A concept analysis. Nurse Education Today. [En línea] 2007;27(5): 466-473. Disponible en: doi:10.1016/j.nedt.2006.08.007 [Accedido: 4 de octubre de 2017]

221. Skees J. Continuing education: a bridge to excellence in critical care nursing. Critical care nursing quarterly. [En línea] 2010;33(2): 104-116. Disponible en: doi:10.1097/CNQ.0b013e3181d913a1

222. Yurdanur D. Critical Thinking Competence and Dispositions among Critical Care Nurses: A Descriptive Study. International Journal of Caring Sciences. 2016;9(2): 489496.

223. Pennington KM, Dong Y, Coville HH, Wang B, Gajic O, Kelm DJ. Evaluation of TEAM dynamics before and after remote simulation training utilizing CERTAIN platform. Medical Education Online. [En línea] Taylor and Francis Ltd.; 2018;23(1): 1485431. Disponible en: doi:10.1080/10872981.2018.1485431 [Accedido: 1 de julio de 2020]

224. Rhodes CA, Grimm D, Kerber K, Bradas C, Halliday B, McClendon S, et al. Evaluation of Nurse-Specific and Multidisciplinary Simulation for Nurse Residency Programs. Clinical Simulation in Nursing. [En línea] Elsevier Inc; 2016;12(7): 243-250. Disponible en: doi:10.1016/j.ecns.2016.02.010

225. Brown KM, Hunt EA, Duval-Arnould J, Shilkofski NA, Budhathoki C, Ruddy T, et al. Pediatric Critical Care Simulation Curriculum: Training Nurse Practitioners to Lead in the Management of Critically III Children. Journal of Pediatric Health Care. [En línea] Elsevier Inc.; 2020;34(6): 584-590. Disponible en: doi:10.1016/j.pedhc.2020.07.001

226. Cuzco Cabellos C, Guasch Pomés N. Aplicación y evaluación del plan de cuidados en pacientes ingresados en la unidad de cuidados intensivos. Enfermería Intensiva. [En línea] 2015;26(4): 137-143. Disponible en: doi:10.1016/j.enfi.2015.07.004

227. Kaihlanen A-M, Lakanmaa R-L, Salminen $L$. The transition from nursing student to registered nurse: The mentor's possibilities to act as a supporter. Nurse education in practice. [En línea] Elsevier Ltd; 2013;13(5): 418-422. Disponible en: doi:10.1016/j.nepr.2013.01.001

228. Butler MP, Cassidy I, Quillinan B, Fahy A, Bradshaw C, Tuohy D, et al. Competency assessment methods - Tool and processes: A survey of nurse preceptors in Ireland. Nurse Education in Practice. [En línea] Elsevier Ltd; 2011;11(5): 298-303. Disponible en: doi:10.1016/j.nepr.2011.01.006

229. Palominos E, López I. Competencias del profesional de Enfermería de Cuidados Intensivos Pediátricos: Refl exiones desde la mirada experta. Rev. Educ. Cienc de la salud. [En línea] 2011;8(1): 19-24. Disponible en: http://www2.udec.cl/ofem/recs/anteriores/vol812011/artinv8111c.pdf [Accedido: 16 de enero de 2017]

230. Okumura M, Ishigaki T, Mori K, Fujiwara Y. Development of an easy-to-use 
questionnaire assessing critical care nursing competence in Japan: A cross-sectional study. PLOS ONE. [En línea] Public Library of Science; 2019;14(11). Disponible en: doi:10.1371/journal.pone.0225668 [Accedido: 8 de julio de 2020]

231. DeGrande H, Liu F, Greene P, Stankus JA. Developing professional competence among critical care nurses: An integrative review of literature. Intensive and Critical Care Nursing. [En línea] Elsevier Ltd; 2018;49: 65-71. Disponible en: doi:10.1016/j.iccn.2018.07.008

232. Walsh T, Jairath N, Paterson MA, Grandjean C. Quality and Safety Education for Nurses Clinical Evaluation Tool. Journal of Nursing Education. [En línea] 2010;49(9): 517-522. Disponible en: doi:10.3928/01484834-20100630-06

233. D'Lima DM, Murray EJ, Brett SJ. Perceptions of Risk and Safety in the ICU: A Qualitative Study of Cognitive Processes Relating to Staffing. Critical Care Medicine. [En línea] 2018;46(1): 60-70. Disponible en: doi:10.1097/CCM.0000000000002773

234. Fukuda T, Sakurai H, Kashiwagi M. Efforts to reduce the length of stay in a lowintensity ICU: Changes in the ICU brought about by collaboration between Certified Nurse Specialists as head nurses and intensivists. PloS one. [En línea] NLM (Medline); 2020;15(6): e0234879. Disponible en: doi:10.1371/journal.pone.0234879 [Accedido: 8 de julio de 2020]

235. Pirret AM. A critical care nurse practitioner's prescribing using standing orders and authorised prescribing when performing a critical care outreach role: A clinical audit. Intensive and Critical Care Nursing. [En línea] Elsevier Ltd; 2012;28(1): 1-5. Disponible en: doi:10.1016/j.iccn.2011.10.008

236. Kvande M, Lykkeslet E, Storli SL. ICU nurses and physicians dialogue regarding patients clinical status and care options-A focus group study. International Journal of Qualitative Studies on Health and Well-being. [En línea] 2017;12(1): 1-8. Disponible en: doi:10.1080/17482631.2016.1267346

237. Faraji A, Karimi M, Azizi SM, Janatolmakan M, Khatony A. Evaluation of clinical competence and its related factors among ICU nurses in Kermanshah-Iran: A crosssectional study. International Journal of Nursing Sciences. [En línea] Chinese Nursing Association; 2019;6(4): 421-425. Disponible en: doi:10.1016/j.ijnss.2019.09.007 [Accedido: 8 de julio de 2020]

238. El Khamali R, Mouaci A, Valera S, Cano-Chervel M, Pinglis C, Sanz C, et al. Effects of a multimodal program including simulation on job strain among nurses working in intensive care units a randomized clinical trial. JAMA - Journal of the American Medical Association. [En línea] 2018;320(19): 1988-1997. Disponible en: doi:10.1001/jama.2018.14284

239. Davidson JE, Aslakson RA, Long AC, Puntillo KA, Kross EK, Hart J, et al. Guidelines for Family-Centered Care in the Neonatal, Pediatric, and Adult ICU. Critical Care Medicine. [En línea] Lippincott Williams and Wilkins; 2017;45(1): 103-128. Disponible en: doi:10.1097/CCM.0000000000002169 [Accedido: 1 de julio de 2020]

240. Buckley P, Andrews T. Intensive care nurses' knowledge of critical care family needs. Intensive and Critical Care Nursing. [En línea] 2011;27(5): 263-272. Disponible en: doi:10.1016/j.iccn.2011.07.001 [Accedido: 6 de febrero de 2017]

241. Van Mol M, Nijkamp M, Markham C, Ista E. Using an intervention mapping approach 
to develop a discharge protocol for intensive care patients. BMC Health Services Research. [En línea] 2017;17(1): 837. Disponible en: doi:10.1186/s12913-017-2782-2 [Accedido: 20 de noviembre de 2019]

242. Abizanda Campos R, Bernat Adell A, Ballester Arnal R, Bisbal Andrés E, Vidal Tegedor $B$, Cubedo Bort $M$, et al. Estrategias de información en una Unidad de Cuidados Intensivos polivalente. Medicina Intensiva. [En línea] 2008;32(5): 216-221. Disponible en: doi:10.1016/S0210-5691(08)70943-4 [Accedido: 5 de julio de 2017]

243. Mahvar T, Mohammadi N, Seyedfatemi N, Vedadhir A. Interpersonal Communication among Critical Care Nurses: an Ethnographic Study. Journal of Caring Sciences. [En línea] Maad Rayan Publishing Company; 2020;9(1): 57-64. Disponible en: doi:10.34172/jcs.2020.009 [Accedido: 8 de julio de 2020]

244. Cilla Intxaurraga A, Martínez Martín ML. "Nurse competency in the process of suitability of therapeutic effort in intensive care units". [En línea] Medicina Paliativa. Sociedad Espanola de Cuidados Paliativos; 2018. p. 195-202. Disponible en: doi:10.1016/j.medipa.2016.10.003

245. Pennington KM, Dong Y, Coville HH, Wang B, Gajic O, Kelm DJ. Evaluation of TEAM dynamics before and after remote simulation training utilizing CERTAIN platform. Medical Education Online. [En línea] Taylor \& Francis; 2018;23(1). Disponible en: doi:10.1080/10872981.2018.1485431

246. Lord H, Loveday C, Moxham L, Fernandez R. Effective communication is key to intensive care nurses' willingness to provide nursing care amidst the COVID-19 pandemic. Intensive and Critical Care Nursing. [En línea] Elsevier Ltd; 2020; 102946. Disponible en: doi:10.1016/j.iccn.2020.102946

247. Song HS, Choi J, Son YJ. The relationship between professional communication competences and nursing performance of critical care nurses in South Korea. International Journal of Nursing Practice. [En línea] 2017;(May): 1-7. Disponible en: doi:10.1111/ijn.12576

248. Anderson WG, Puntillo K, Boyle D, Barbour S, Turner K, Cimino J, et al. ICU Bedside Nurses' Involvement in Palliative Care Communication: A Multicenter Survey. Journal of Pain and Symptom Management. [En línea] Elsevier Inc; 2016;51(3): 589-596.e2. Disponible en: doi:10.1016/j.jpainsymman.2015.11.003

249. Lind R, Lorem GF, Nortvedt $P$, Hevrøy $O$. Intensive care nurses' involvement in the end-of-life process - perspectives of relatives. Nursing Ethics. [En línea] 2012;19(5): 666-676. Disponible en: doi:10.1177/0969733011433925

250. Leuter C, Petrucci C, Mattei A, Tabassi G, Lancia L. Ethical difficulties in nursing, educational needs and attitudes about using ethics resources. Nursing Ethics. [En línea] 2013;20(3): 348-358. Disponible en: doi:10.1177/0969733012455565

251. Rojas I, Vargas I, Ferrer L. Rol de enfermería en la limitación del esfuerzo terapéutico en el paciente crítico. Ciencia y Enfermeria. [En línea] Universidad de Concepción; 2013;19(3): 41-50. Disponible en: doi:10.4067/S0717-95532013000300005 [Accedido: 9 de julio de 2020]

252. Hernández-Tejedor A, Martín Delgado MC, Cabré Pericas L, Algora Weber A. Limitation of life-sustaining treatment in patients with prolonged admission to the ICU. Current situation in Spain as seen from the EPIPUSE Study. Medicina Intensiva. 
[En línea] Ediciones Doyma, S.L.; 2015;39(7): 395-404. Disponible en: doi:10.1016/j.medin.2014.06.005 [Accedido: 9 de julio de 2020]

253. Velasco-Sanz T, Lozano-García F, Del Barrio-Linares M, Velasco-Bueno JM, GómezPérez D, Ortega-Guerrero Á. Recomendaciones sobre la limitación de tratamientos de Soporte Vital en Unidades de Cuidados Intensivos. 2017.

254. Velasco-Sanz T, Velasco-Bueno JM, Ortega-Guerrero Á, Gómez-Pérez D, Lozano-García F, Del Barrio-Linares M. Recomendaciones sobre acogida de familiares en unidades de cuidados intensivos. [En línea] 2017 [Accedido: 21 de octubre de 2020]. Disponible en: http://seeiuc.org/wp-content/uploads/2017/10/RECOMENDACIONES-FAMILIAS.pdf [Accedido: 21 de octubre de 2020]

255. Knutsson S, Enskär K, Golsäter M. Nurses' experiences of what constitutes the encounter with children visiting a sick parent at an adult ICU. Intensive and Critical Care Nursing. [En línea] 2017;39: 9-17. Disponible en: doi:10.1016/j.iccn.2016.09.003

256. González-Gil MT, Alcolea-Cosín MT, Pérez-García S, Luna-Castaño P, Torrent-Vela S, Piqueras-Rodríguez $\mathrm{P}$, et al. La visita infantil a la unidad de cuidados intensivos pediátricos desde la experiencia de las enfermeras. Enferm Intensiva. [En línea] 2020;(xx). Disponible en: doi:10.1016/j.enfi.2020.06.003

257. Downar J, Delaney JW, Hawryluck L, Kenny L. Guidelines for the withdrawal of lifesustaining measures. Intensive Care Medicine. [En línea] 2016;42: 1003-1017. Disponible en: doi:10.1007/s00134-016-4330-7

258. Santana Cabrera L, Gil Hernández N, Méndez Santana A, Marrero Sosa I, Alayón Cabrera S, Martín González JC, et al. Percepción de las actitudes éticas de la enfermera de cuidados intensivos ante la limitación del tratamiento. Enfermeria Intensiva. [En línea] 2010;21(4): 142-149. Disponible en: doi:10.1016/j.enfi.2010.06.001

259. Griffiths I. What are the challenges for nurses when providing end-of-life care in intensive care units? British Journal of Nursing. [En línea] MA Healthcare Ltd; 2019;28(16): 1047-1052. Disponible en: doi:10.12968/bjon.2019.28.16.1047 [Accedido: 8 de julio de 2020]

260. González-Rincón M, Díaz de Herrera-Marchal P, Martínez-Martín ML. The role of the nurse at the end of the life of a critically ill patient. Enfermeria Intensiva. [En línea] Ediciones Doyma, S.L.; 2019;30(2): 78-91. Disponible en: doi:10.1016/j.enfi.2018.02.001 [Accedido: 21 de julio de 2020]

261. Souza da Silva R, Pereira Á, Carneiro Mussi F. Comfort for a good death: perspective nursing staff's of intensive care. Escola Anna Nery - Revista de Enfermagem. [En línea] GN1 Genesis Network; 2015;19(1): 40-46. Disponible en: doi:10.5935/14148145.20150006 [Accedido: 9 de julio de 2020]

262. Paredes Escobar MC. Limitación del esfuerzo terapéutico en la práctica clínica. Percepciones de profesionales médicos y de enfermería de unidades de pacientes críticos de un hospital público de adultos en la región metropolitana. Acta Bioethica. [En línea] 2012;18(2): 163-171. Disponible en: doi:10.4067/S1726569X2012000200004

263. Delgado Rodríguez J, Barbuzano AE, Rodríguez D, Barbuzano JE, Implicaciones A. Implicaciones éticas de la Limitación de Tratamientos de Soporte Vital desde la 
Perspectiva Enfermera. Revista Ene de Enfermería. [En línea] 2010;4(3): 18-26. Disponible en: http://enfermeros.org/revista [Accedido: 9 de julio de 2020]

264. Del Barrio Linares M, Jimeno San Martín L, López Alfaro P, Ezenarro Muruamendiaraz A, Margall Coscojuela MA, Asiain Erro MC. Cuidados del paciente al final de la vida: Ayudas y obstáculos que perciben las enfermeras de Cuidados Intensivos. Enfermeria Intensiva. [En línea] 2007;18(1): 3-14. Disponible en: doi:10.1016/S11302399(07)74384-5 [Accedido: 9 de julio de 2020]

265. Díaz Tobajas MC, Juarros Ortiz N, García Martínez B, Sáez Gavilán C. Estudio de la ansiedad del profesional de enfermeria de cuidados intensivos ante el proceso de la muerte. Enfermería Global. [En línea] 2017;45(1): 246-255. Disponible en: doi:10.6018/eglobal.16.1.232221

266. Jang SK, Park WH, Kim HI, Chang SO. Exploring nurses' end-of-life care for dying patients in the ICU using focus group interviews. Intensive and Critical Care Nursing. [En línea] Elsevier Ltd; 2019;52: 3-8. Disponible en: doi:10.1016/j.iccn.2018.09.007

267. Henao-Castaño M, Quiñonez-Mora MA. How nurses cope with death in the Paediatric Intensive Care Unit. Enfermeria Intensiva. [En línea] Ediciones Doyma, S.L.; 2019;30(4): 163-169. Disponible en: doi:10.1016/j.enfi.2018.10.005 [Accedido: 21 de julio de 2020]

268. Velasco-Sanz TR, Rayón-Valpuesta E. Instrucciones previas en cuidados intensivos: competencias de los profesionales sanitarios. Medicina Intensiva. [En línea] 2016;40(3): 154-162. Disponible en: doi:10.1016/j.medin.2015.04.011 [Accedido: 6 de febrero de 2017]

269. Cabeza de Vaca Lobón L, Padilla Sepúlveda L, Ruíz García S. Experiencia enfermera en la toma de decisiones sobre la Limitación del Esfuerzo Terapéutico (LET). Paraninfo Digital. [En línea] Granada: Fundación Index; 2014;año VIII(N. 20): 6. Disponible en: doi:1988-3439 [Accedido: 9 de julio de 2020]

270. Falcó-Pegueroles A. La enfermera frente a la limitación del tratamiento de soporte vital en las Unidades de Cuidados Intensivos. Aspectos técnicos y prácticos a considerar. Enfermeria Intensiva. [En línea] 2009;20(3): 104-109. Disponible en: doi:10.1016/S1130-2399(09)72590-8 [Accedido: 9 de julio de 2020]

271. Loefgren Vretare L, Anderzén-Carlsson A. The critical care nurse's perception of handover: A phenomenographic study. Intensive and Critical Care Nursing. [En línea] Churchill Livingstone; 2020;58. Disponible en: doi:10.1016/j.iccn.2020.102807 [Accedido: 8 de julio de 2020]

272. Swart RP, Pretorius R, Klopper H. Educational background of nurses and their perceptions of the quality and safety of patient care. Curationis. [En línea] 2015;38(1): 1-9. Disponible en: doi:10.4102/curationis.v38i1.1126

273. Martínez López P. Impacto de un programa de continuidad asistencial tras el alta de la Unidad de Cuidados Intensivos. [En línea] Publicaciones y Divulgación Científica. Universidad de Málaga. Malaga; 2013. Disponible en: doi:10.1017/СВ09781107415324.004

274. Malekzadeh J, Mazluom SR, Etezadi T, Tasseri A. A standardized shift handover protocol: improving nurses' safe practice in intensive care units. Journal of caring sciences. [En línea] J Caring Sci; 2013;2(3): 177-185. Disponible en: 
doi:10.5681/jcs.2013.022 [Accedido: 10 de julio de 2020]

275. Levesque E, Hoti E, Azoulay D, Ichai P, Samuel D, Saliba F. The implementation of an Intensive Care Information System allows shortening the ICU length of stay. Journal of clinical monitoring and computing. [En línea] Kluwer Academic Publishers; 2015;29(2): 263-269. Disponible en: doi:10.1007/s10877-014-9592-4 [Accedido: 8 de julio de 2020]

276. Qin Y, Zhou R, Wu Q, Huang X, Chen X, Wang W, et al. The effect of nursing participation in the design of a critical care information system: a case study in a Chinese hospital. BMC medical informatics and decision making. [En línea] 2017;17(1): 165. Disponible en: doi:10.1186/s12911-017-0569-3

277. Sirgo Rodríguez G, Chico Fernández M, Gordo Vidal F, García Arias M, Holanda Peña MS, Azcarate Ayerdi B, et al. Handover in Intensive Care. Medicina Intensiva. [En línea] Ediciones Doyma, S.L.; 2018;42(3): 168-179. Disponible en: doi:10.1016/j.medin.2017.12.002 [Accedido: 10 de julio de 2020]

278. Van Sluisveld N, Oerlemans A, Westert G, Van der Hoeven JG, Wollersheim H, Zegers $M$. Barriers and facilitators to improve safety and efficiency of the ICU discharge process: a mixed methods study. BMC Health Services Research. [En línea] BioMed Central Ltd.; 2017;17(1). Disponible en: doi:10.1186/s12913-017-2139-x [Accedido: 10 de julio de 2020]

279. Eliott S, Chaboyer W, Ernest D, Doric A, Endacott R. A national survey of Australian Intensive Care Unit (ICU) Liaison Nurse (LN) services. Australian Critical Care. [En línea] 2012;25(4): 253-262. Disponible en: doi:10.1016/j.aucc.2012.03.004

280. Ruiz J, Blanch L, Martín MC, Blanco J, Castillo F, Roca J, et al. Indicadores de calidad en el enfermo crítico. [En línea] Medicina Intensiva. 2008. 23-32 p. Disponible en: http://www.semicyuc.org/sites/default/files/actualizacion_indicadores_calidad_2011. pdf [Accedido: 10 de enero de 2017]

281. Martín Delgado MC, Cabré L, Ruiz J, Blanch L, Blanco J, Castillo F, et al. Indicadores de calidad en el enfermo crítico. [En línea] Medicina Intensiva. 2017. Disponible en: doi:10.1016/S0210-5691(08)70899-4

282. Huang H, Lee T-T. Evaluation of ICU nurses' use of the clinical information system in Taiwan. Computers, informatics, nursing : CIN. [En línea] 2011;29(4): 221-229. Disponible en: doi:10.1097/NCN.0b013e3181fcbe3d [Accedido: 10 de enero de 2017]

283. Bahar M, Inel EY. Use of software in the icu. [En línea] Ulusal Travma ve Acil Cerrahi Dergisi. Turkish Association of Trauma and Emergency Surgery; 2019. p. 535-544. Disponible en: doi:10.14744/tjtes.2019.28282 [Accedido: 8 de julio de 2020]

284. Ramírez Perdomo CA, Perdomo Romero AY, Galán González EF. Evaluación de la calidad del cuidado de enfermería en la unidad de cuidados intensivos. Avances en enfermería. [En línea] 2013;XXXI(1): 42-51. Disponible en: https://repositorio.unal.edu.co/handle/unal/74324 [Accedido: 13 de julio de 2020]

285. Pita MJ, Díaz-Agero C, Robustillo A, Prieto I, Gómez P, Monge V. Indicadores de calidad en una Unidad de Cuidados Intensivos: dos años de un sistema de vigilancia de la infección asociada a los cuidados sanitarios. Revista de Calidad Asistencial. [En línea] Elsevier; 2012;27(2): 103-107. Disponible en: doi:10.1016/j.cali.2011.09.011 [Accedido: 13 de julio de 2020] 
286. Lupión C, López-Cortés LE, Rodríguez-Baño J. [Preventive measures for avoiding transmission of microorganisms between hospitalised patients. Hand hygiene]. Enfermedades infecciosas y microbiologia clinica. [En línea] 2014;32(9): 603-609. Disponible en: doi:10.1016/j.eimc.2014.02.003 [Accedido: 6 de agosto de 2018]

287. Romero-García M, De la Cueva-Ariza L, Jover-Sancho C, Delgado-Hito P, AcostaMejuto B, Sola-Ribo M, et al. La percepción del paciente crítico sobre los cuidados enfermeros: una aproximación al concepto de satisfacción. Enfermeria Intensiva. [En línea] 2013;24(2): 51-62. Disponible en: doi:10.1016/j.enfi.2012.09.003

288. Holanda Peña MS, Talledo NM, Ots Ruiz E, Lanza Gómez JM, Ruiz Ruiz A, García Miguelez A, et al. Satisfacción en la Unidad de Cuidados Intensivos (UCI): la opinión del paciente como piedra angular. Medicina Intensiva. [En línea] Ediciones Doyma, S.L.; 2017;41(2): 78-85. Disponible en: doi:10.1016/j.medin.2016.06.007 [Accedido: 13 de julio de 2020]

289. Regaira Martínez E, Sola Iriarte M, Goñi Viguria R, Del Barrio Linares M, Margall Coscojuela MA, Asiain Erro MC. La calidad asistencial en cuidados intensivos evaluada por los pacientes mediante la escala SERVQUAL. Enfermería Intensiva. [En línea] 2010;21(1): 3-10. Disponible en: doi:10.1016/j.enfi.2009.10.001

290. Jover-Sancho C, Romero-García M, Delgado-Hito P, de la Cueva-Ariza L, Solà-Solé N, Acosta-Mejuto B, et al. Percepción de las enfermeras de $\mathrm{UCl}$ en relación al cuidado satisfactorio: convergencias y divergencias con la percepción del paciente crítico. Enfermería Intensiva. [En línea] 2015;26(1): 3-14. Disponible en: doi:10.1016/j.enfi.2014.12.002

291. Santana Cabrera L, Ramírez Rodríguez A, García Martul M, Sánchez-Palacios M. Valoración de las necesidades de los pacientes ingresados en una Unidad de Cuidados Intensivos. Medicina Intensiva. [En línea] 2007;31(4): 207-209. Disponible en: doi:10.1016/S0210-5691(07)74809-X

292. Santana Cabrera L, Ramírez Rodríguez A, García Martul M, Sánchez Palacios M, Martín González JC, Hernández Medina E. Encuesta de satisfacción a los familiares de pacientes críticos. Medicina Intensiva. [En línea] 2007;31(2): 57-61. Disponible en: doi:10.1016/S0210-5691(07)74776-9

293. Santhosh L, Brown W, Ferreira J, Niroula A, Carlos WG. Practical Tips for ICU Bedside Teaching. Chest. [En línea] American College of Chest Physicians; 2018;154(4): 760765. Disponible en: doi:10.1016/j.chest.2018.06.034

294. Murray DJ, Boyle WA, Beyatte MB, Knittel JG, Kerby PW, Woodhouse J, et al. Decisionmaking skills improve with critical care training: Using simulation to measure progress. Journal of Critical Care. [En línea] Elsevier Inc.; 2018;47: 133-138. Disponible en: doi:10.1016/j.jcrc.2018.06.021

295. Starmer AJ, Schnock KO, Lyons A, Hehn RS, Graham DA, Keohane C, et al. Effects of the I-PASS Nursing Handoff Bundle on communication quality and workflow. BMJ Quality and Safety. [En línea] BMJ Publishing Group; 2017;26(12): 949-957. Disponible en: doi:10.1136/bmjqs-2016-006224 [Accedido: 1 de julio de 2020]

296. Aloush SM, Alsaraireh FA. Nurses' compliance with central line associated blood stream infection prevention guidelines: Observational study. Saudi Medical Journal. [En línea] Saudi Arabian Armed Forces Hospital; 2018;39(3): 273-279. Disponible en: 
doi:10.15537/smj.2018.3.21497 [Accedido: 1 de julio de 2020]

297. Freeman S, Hallett C, Mchugh G. Physical restraint: Experiences, attitudes and opinions of adult intensive care unit nurses. Nursing in Critical Care. [En línea] Blackwell Publishing Ltd; 2016;21(2): 78-87. Disponible en: doi:10.1111/nicc.12197 [Accedido: 1 de julio de 2020]

298. Öztürk Birge A, Tel Aydin $\mathrm{H}$. The effect of nonpharmacological training on delirium identification and intervention strategies of intensive care nurses. Intensive and Critical Care Nursing. [En línea] Churchill Livingstone; 2017;41: 33-42. Disponible en: doi:10.1016/j.iccn.2016.08.009 [Accedido: 1 de julio de 2020]

299. Souza RC da S, Bersaneti MDR, Siqueira EMP, Meira L, Brumatti DL, Prado NR de O. Nurses' training in the use of a delirium screening tool. Revista gaucha de enfermagem. [En línea] 2017;38(1): e64484. Disponible en: doi:10.1590/19831447.2017.01.64484

300. Tan CM, Camargo M, Miller F, Ross K, Maximous R, Yung P, et al. Impact of a nurse engagement intervention on pain, agitation and delirium assessment in a community intensive care unit. BMJ Open Quality. [En línea] BMJ; 2019;8(3): e000421. Disponible en: doi:10.1136/bmjoq-2018-000421 [Accedido: 8 de julio de 2020]

301. Wøien H, Bjørk IT. Intensive care pain treatment and sedation: nurses' experiences of the conflict between clinical judgement and standardised care: an explorative study. Intensive \& critical care nursing. [En línea] 2013;29(3): 128-136. Disponible en: doi:10.1016/j.iccn.2012.11.003 [Accedido: 11 de enero de 2017]

302. Hylén $M$, Alm-Roijer $C$, Idvall E, Akerman E. To assess patients pain in intensive care: developing and testing the Swedish version of the Behavioural Pain Scale. Intensive and Critical Care Nursing. [En línea] 2019;52: 28-34. Disponible en: doi:10.1016/j.iccn.2019.01.003

303. Beltrami FG, Nguyen XL, Pichereau C, Maury E, Fleury B, Fagondes S. Sleep in the intensive care unit. Jornal Brasileiro de Pneumologia. [En línea] Sociedade Brasileira de Pneumologia e Tisiologia; 2015;41(6): 539-546. Disponible en: doi:10.1590/S180637562015000000056 [Accedido: 13 de julio de 2020]

304. Hu RF, Jiang XY, Chen J, Zeng Z, Chen XY, Li Y, et al. Non-pharmacological interventions for sleep promotion in the intensive care unit. [En línea] Cochrane Database of Systematic Reviews. John Wiley and Sons Ltd; 2015. Disponible en: doi:10.1002/14651858.CD008808.pub2 [Accedido: 13 de julio de 2020]

305. Schwab KE, Ronish B, Needham DM, To AQ, Martin JL, Kamdar BB. Actigraphy to evaluate sleep in the intensive care unit: A systematic review. [En línea] Annals of the American Thoracic Society. American Thoracic Society; 2018. p. 1075-1082. Disponible en: doi:10.1513/AnnalsATS.201801-004OC [Accedido: 1 de julio de 2020]

306. Pisani MA, Friese RS, Gehlbach BK, Schwab RJ, Weinhouse GL, Jones SF. Sleep in the intensive care unit. [En línea] American Journal of Respiratory and Critical Care Medicine. American Thoracic Society; 2015. p. 731-738. Disponible en: doi:10.1164/rccm.201411-2099Cl [Accedido: 13 de julio de 2020]

307. Arias-Rivera S, López-López C, Frade-Mera MJ, Via-Clavero G, Rodríguez-Mondéjar JJ, Sánchez-Sánchez MM, et al. Assessment of analgesia, sedation, physical restraint and delirium in patients admitted to Spanish intensive care units. Proyecto ASCyD. 
Enfermeria Intensiva. [En línea] Ediciones Doyma, S.L.; 2020;31(1): 3-18. Disponible en: doi:10.1016/j.enfi.2018.11.002

308. Woo BFY, Lee JXY, Tam WWS. The impact of the advanced practice nursing role on quality of care, clinical outcomes, patient satisfaction, and cost in the emergency and critical care settings: A systematic review. [En línea] Human Resources for Health. BioMed Central Ltd.; 2017. Disponible en: doi:10.1186/s12960-017-0237-9 [Accedido: 7 de julio de 2020]

309. Hu RF, Jiang XY, Hegadoren KM, Zhang YH. Effects of earplugs and eye masks combined with relaxing music on sleep, melatonin and cortisol levels in ICU patients: A randomized controlled trial. Critical Care. [En línea] BioMed Central Ltd.; 2015;19(1). Disponible en: doi:10.1186/s13054-015-0855-3 [Accedido: 13 de julio de 2020]

310. Bernat Adell MD, Bisbal Andrés E, Galarza Barrachina L, Cebrián Graullera G, Pages Aznar G, Melgarejo Urendez A, et al. Evaluación psicométrica del cuestionario Freedman para la valoración del sueño en el paciente crítico. Medicina Intensiva. [En línea] Ediciones Doyma, S.L.; 2020;44(6): 344-350. Disponible en: doi:10.1016/j.medin.2019.04.006 [Accedido: 23 de septiembre de 2020]

311. Raurell-Torredà M, Arias-Rivera S, Martí JD, Frade-Mera MJ, Zaragoza-García I, Gallart $E$, et al. Degree of implementation of preventive strategies for post-ICU syndrome: Multi-centre, observational study in Spain. Enfermeria Intensiva. [En línea] Ediciones Doyma, S.L.; 2019;30(2): 59-71. Disponible en: doi:10.1016/j.enfi.2018.04.004

312. Devlin JW, Skrobik Y, Gélinas C, Needham DM, Slooter AJC, Pandharipande PP, et al. Executive Summary: Clinical Practice Guidelines for the Prevention and Management of Pain, Agitation/Sedation, Delirium, Immobility, and Sleep Disruption in Adult Patients in the ICU. Critical care medicine. [En línea] NLM (Medline); 2018;46(9): 15321548. Disponible en: doi:10.1097/CCM.0000000000003259 [Accedido: 13 de julio de 2020]

313. Palacios-Ceña D, Cachón-Pérez JM, Martínez-Piedrola R, Gueita-Rodriguez J, Perez-DeHeredia M, Fernández-De-Las-Peñas $C$. How do doctors and nurses manage delirium in intensive care units? A qualitative study using focus groups. BMJ Open. [En línea] 2016;6(1): 1-11. Disponible en: doi:10.1136/bmjopen-2015-009678

314. Kamdar BB, Combs MP, Colantuoni E, King LM, Niessen T, Neufeld KJ, et al. The association of sleep quality, delirium, and sedation status with daily participation in physical therapy in the ICU. Critical Care. [En línea] BioMed Central Ltd.; 2016;20(1). Disponible en: doi:10.1186/s13054-016-1433-z [Accedido: 13 de julio de 2020]

315. Via-Clavero G, Claramunt-Domènech L, García-Lamigueiro A, Sánchez-Sánchez MM, Secanella-Martínez M, Aguirre-Recio E, et al. Analysis of a nurses' knowledge survey on the use of physical restraint in intensive care units. Enfermeria Intensiva. [En línea] Ediciones Doyma, S.L.; 2019;30(2): 47-58. Disponible en: doi:10.1016/j.enfi.2018.09.003

316. Roh YS. The training needs of Korean intensive care unit nurses regarding delirium. Intensive and Critical Care Nursing. [En línea] Elsevier Ltd; 2020;(xxxx): 102954. Disponible en: doi:10.1016/j.iccn.2020.102954

317. Bortman J, Mahmood F, Mitchell J, Feng R, Baribeau Y, Wong V, et al. Ultrasoundguided intravenous line placement course for certified registered nurse anesthetists: 
A necessary next step. AANA Journal. 2019;87(4): 269-276.

318. Currey J, Sprogis SK, Orellana L, Chander A, Meagher S, Kennedy R, et al. Specialty cardiac nurses' work satisfaction is influenced by the type of coronary care unit: $A$ mixed methods study. BMC Nursing. [En línea] Springer Science and Business Media LLC; 2019;18(1). Disponible en: doi:10.1186/s12912-019-0367-6 [Accedido: 8 de julio de 2020]

319. Martín MC, Cabré LI, Ruiz J, Blanch LI, Blanco J, Castillo F, et al. Indicadores de calidad en el enfermo crítico. Medicina Intensiva. Elsevier España, S.L.; 2008;32(1): 23-32.

320. Mwakanyanga ET, Masika GM, Tarimo EAM. Intensive care nurses' knowledge and practice on endotracheal suctioning of the intubated patient: A quantitative crosssectional observational study. PLoS ONE. [En línea] 2018;13(8): 1-13. Disponible en: doi:10.1371/journal.pone.0201743

321. Mortensen CB, Kjær M-BN, Egerod I. Caring for non-sedated mechanically ventilated patients in ICU: A qualitative study comparing perspectives of expert and competent nurses. Intensive and Critical Care Nursing. [En línea] 2019;52: 35-41. Disponible en: doi:10.1016/j.iccn.2019.01.004

322. Steinseth EB, Høye S, Hov R. Use of the CAM-ICU during daily sedation stops in mechanically ventilated patients as assessed and experienced by intensive care nurses - A mixed-methods study. Intensive and Critical Care Nursing. [En línea] 2018;47: 2329. Disponible en: doi:10.1016/j.iccn.2018.04.005

323. Hicks FD, Rosenberg L. Enacting a Vision for a Master's Entry Clinical Nurse Leader Program: Rethinking Nursing Education. Journal of Professional Nursing. [En línea] W.B. Saunders; 2016;32(1): 41-47. Disponible en: doi:10.1016/j.profnurs.2015.06.002 [Accedido: 1 de octubre de 2020]

324. Escrivá Gracia J, Brage Serrano R, Fernández Garrido J. Medication errors and drug knowledge gaps among critical-care nurses: A mixed multi-method study. BMC Health Services Research. [En línea] BioMed Central Ltd.; 2019;19(1). Disponible en: doi:10.1186/s12913-019-4481-7 [Accedido: 17 de septiembre de 2020]

325. Trogrlić Z, Van der Jagt $M$, Bakker J, Balas MC, Ely WE, Van der Voort PHJ, et al. A systematic review of implementation strategies for assessment, prevention, and management of ICU delirium and their effect on clinical outcomes. Critical Care. [En línea] BioMed Central Ltd.; 2015;19(1). Disponible en: doi:10.1186/s13054-015-08869 [Accedido: 17 de septiembre de 2020]

326. Irajpour A, Farzi S, Saghaei M, Ravaghi H. Effect of interprofessional education of medication safety program on the medication error of physicians and nurses in the intensive care units. Journal of Education and Health Promotion. [En línea] Wolters Kluwer Medknow Publications; 2019;8(1). Disponible en: doi:10.4103/jehp.jehp_200_19 [Accedido: 8 de julio de 2020]

327. Danielis $\mathrm{M}$, Bellomo F, Farneti F, Palese A. Critical incidents rates and types in Italian Intensive Care Units: A five-year analysis. Intensive and Critical Care Nursing. [En línea] Elsevier Ltd; 2020;(xxxx): 102950. Disponible en: doi:10.1016/j.iccn.2020.102950

328. Bagherian B, Sabzevari S, Mirzaei T, Ravari A. Effects of technology on nursing care and caring attributes of a sample of Iranian critical care nurses. Intensive and Critical Care Nursing. [En línea] Elsevier Ltd; 2017;39: 18-27. Disponible en: 
doi:10.1016/j.iccn.2016.08.011

329. Ayuso-Murillo D, Colomer-Sánchez A, Herrera-Peco I. Communication skills in ICU and adult hospitalisation unit nursing staff. Enfermería Intensiva (English ed.). [En línea] 2017;28(3): 105-113. Disponible en: doi:10.1016/j.enfie.2017.03.003

330. Krimshtein NS, Luhrs CA, Puntillo KA, Cortez TB, Livote EE, Penrod JD, et al. Training nurses for interdisciplinary communication with families in the intensive care unit: An intervention. Journal of Palliative Medicine. [En línea] 2011;14(12): 1325-1332.

Disponible en: doi:10.1089/.jpm.2011.0225

331. Sargeant J, MacLeod T, Murray A. An Interprofessional Approach to Teaching Communication Skills. Journal of Continuing Education in the Health Professions. [En línea] 2011;31(4): 265-267. Disponible en: doi:10.1002/chp.20139 [Accedido: 23 de septiembre de 2020]

332. Radtke J V., Tate JA, Happ MB. Nurses' perceptions of communication training in the ICU. Intensive and Critical Care Nursing. [En línea] Intensive Crit Care Nurs; 2012;28(1): 16-25. Disponible en: doi:10.1016/j.iccn.2011.11.005 [Accedido: 1 de julio de 2020]

333. Lakanmaa R-L, Suominen T, Ritmala-Castrén M, Vahlberg T, Leino-Kilpi H. Basic Competence of Intensive Care Unit Nurses: Cross-Sectional Survey Study. BioMed Research International. [En línea] 2015;2015(ii): 1-12. Disponible en: doi:10.1155/2015/536724

334. Sledge JA, Potter P, Stapleton P. Participant Voices: Making a Nurse Residency Program Better. Nurse Leader. [En línea] Mosby, Inc.; 2016;14(5): 358-364. Disponible en: doi:10.1016/j.mnl.2016.03.010

335. Macedo APMC, Padilha KG, Püschel VAA. Professional practices of education/training of nurses in an intensive care unit. Revista brasileira de enfermagem. [En línea] NLM (Medline); 2019;72(2): 321-328. Disponible en: doi:10.1590/0034-7167-2017-0793 [Accedido: 1 de julio de 2020]

336. Uhrenfeldt L, Lakanmaa RL, Flinkman M, Basto ML, Attree M. Collaboration: A SWOT analysis of the process of conducting a review of nursing workforce policies in five European countries. Journal of Nursing Management. [En línea] 2014;22(4): 485-498. Disponible en: doi:10.1111/j.1365-2834.2012.01466.x

337. Ge S, Xi X, Guo G. A systematic review of the impact of master's-educated nurses on inpatient care. International Journal of Nursing Sciences. [En línea] Chinese Nursing Association; 2015;2(4): 414-421. Disponible en: doi:10.1016/j.ijnss.2015.10.003 [Accedido: 1 de octubre de 2020]

338. Raurell-Torredá M. Gestión de los equipos de enfermería de UCI durante la pandemia COVID-19. Enferm Intensiva. 2020;31(2): 49-51.

339. Raurell-Torredà M, Martínez-Estalella G, Frade-Mera MJ, Carrasco Rodríguez-Rey LF, Romero de San Pío E. Reflexiones derivadas de la pandemia COVID-19. Enfermería Intensiva. [En línea] 2020;31(2): 90-93. Disponible en: doi:10.1016/j.enfi.2020.03.002

340. Sánchez S, José J, Mondéjar R, Jesús M, Mera F, Castillejos DG, et al. ¿ Qué ha sucedido con los cuidados durante la pandemia COVID-19 ? Enferm Intensiva. 2020;31(3): 10-13.

341. Ferrer R. Pandemia por COVID-19: el mayor reto de la historia del intensivismo. 
Medicina Intensiva. [En línea] 2020;44(6): 323-324. Disponible en: doi:10.1016/j.medin.2020.04.002 [Accedido: 23 de septiembre de 2020]

342. Marks S, Edwards S, Jerge EH. Rapid Deployment of Critical Care Nurse Education During the COVID-19 Pandemic. Nurse Leader. [En línea] Elsevier Inc.; 2020; 1-5. Disponible en: doi:10.1016/j.mnl.2020.07.008

343. Xie Y, Xiao Y, Zhou J, Li L. Demands of experiential training for ICU nurses in Hunan of China. International Journal of Nursing Sciences. [En línea] Elsevier Ltd; 2020;(xxxx): 05. Disponible en: doi:10.1016/j.ijnss.2020.09.010

344. Ballesteros Sanz M, Hernández-Tejedor A, Estella, Jiménez Rivera JJ, González de Molina Ortiz FJ, Sandiumenge Camps A, et al. Recommendations of the Working Groups from the Spanish Society of Intensive and Critical Care Medicine and Coronary Units (SEMICYUC) for the management of adult critically ill patients in the coronavirus disease (COVID-19). Medicina Intensiva. [En línea] Ediciones Doyma, S.L.; 2020;44(6): 371-388. Disponible en: doi:10.1016/j.medin.2020.04.001 [Accedido: 23 de septiembre de 2020]

345. The Lancet. COVID-19: protecting health-care workers. The Lancet. [En línea] Elsevier Ltd; 2020;395: 922. Disponible en: doi:10.1016/S0140-6736(20)30644-9

346. Huh S. How to train the health personnel for protecting themselves from novel coronavirus (COVID-19) infection during their patient or suspected case care. J Educ Eval Health Prof. [En línea] 2020;17(10). Disponible en: doi:10.3352/jeehp.2020.17.10

347. Zhang Z, Liu S, Xiang M, Li S, Zhao D, Huang C, et al. Protecting healthcare personnel from 2019-nCoV infection risks: lessons and suggestions. Frontiers of Medicine. [En línea] 2020; 2019-2021. Disponible en: doi:10.1007/s11684-020-0765-x

348. Credland N. Critical care nurses will need our support as COVID-19 cases rise. [En línea] Nursing Standard. Disponible en: https://rcni.com/nursingstandard/opinion/comment/critical-care-nurses-will-need-our-support-covid-19cases-rise-158836 [Accedido: 23 de septiembre de 2020]

349. Xiang $Y-T$, Jin $Y$, Wang $Y$, Zhang $Q$, Zhang $L$, Cheung $T$. Tribute to health workers in China: A group of respectable population during the outbreak of the COVID-19. International Journal of Biological Sciences. [En línea] 2020;16(10): 1739-1740. Disponible en: doi:10.7150/ijbs.45135

350. Tiefenhäler A. 'Health Care Kamikazes': How Spain's Workers Are Battling Coronavirus, Unprotected - The New York Times. [En línea] New York Times. Disponible en: https://www.nytimes.com/video/world/europe/100000007051789/coronavirus-ppeshortage-health-care-workers.html [Accedido: 8 de abril de 2020]

351. Shen X, Zou X, Zhong X, Yan J, Li L. Psychological stress of ICU nurses in the time of COVID-19. [En línea] Critical Care. BioMed Central Ltd.; 2020. Disponible en: doi:10.1186/s13054-020-02926-2 [Accedido: 24 de septiembre de 2020]

352. Pappa S, Ntella V, Giannakas T, Giannakoulis VG, Papoutsi E, Katsaounou P. Prevalence of depression, anxiety, and insomnia among healthcare workers during the COVID-19 pandemic: A systematic review and meta-analysis. [En línea] Brain, Behavior, and Immunity. Academic Press Inc.; 2020. p. 901-907. Disponible en: doi:10.1016/j.bbi.2020.05.026 [Accedido: 24 de septiembre de 2020] 
353. Hu D, Kong Y, Li W, Han Q, Zhang X, Zhu LX, et al. Frontline nurses' burnout, anxiety, depression, and fear statuses and their associated factors during the COVID-19 outbreak in Wuhan, China: A large-scale cross-sectional study. EClinicalMedicine. [En línea] 2020;24: 100424. Disponible en: doi:10.1016/j.eclinm.2020.100424 [Accedido: 9 de noviembre de 2020]

354. Wahlster S, Sharma M, Lewis AK, Patel P V., Hartog C, Jannotta G, et al. The COVID-19 Pandemic's Impact on Critical Care Resources and Providers: A Global Survey. Chest. [En línea] American College of Chest Physicians; 2020; Disponible en: doi:10.1016/j.chest.2020.09.070

355. González-Gil MT, González-Blázquez C, Parro-Moreno Al, Pedraz-Marcos A, PalmarSantos A, Otero-García L, et al. Nurses' perceptions and demands regarding COVID-19 care delivery in critical care units and hospital emergency services. Intensive and Critical Care Nursing. [En línea] Churchill Livingstone; 2020; 102966. Disponible en: doi:10.1016/j.iccn.2020.102966 [Accedido: 2 de noviembre de 2020]

356. Ordoñez-Rufat P, Polit-Martínez MV, Martínez-Estalella G, Videla-Ces S. Inteligencia emocional de las enfermeras de cuidados intensivos en un hospital terciario. Enfermería Intensiva. [En línea] 2020;(xx): 1-8. Disponible en: doi:10.1016/j.enfi.2020.05.001

357. Aradilla-Herrero A, Tomás-Sábado J, Gómez-Benito J. Perceived emotional intelligence in nursing: psychometric properties of the Trait Meta-Mood Scale. Journal of Clinical Nursing. [En línea] John Wiley \& Sons, Ltd; 2014;23(7-8): 955-966. Disponible en: doi:10.1111/jocn.12259 [Accedido: 9 de noviembre de 2020]

358. Aradilla A. Inteligencia Emocional y variables relacionadas en Enfermería. [En línea] Universitat de Barcelona. Universitat de Barcelona; 2013. Disponible en: http://www.tdx.cesca.cat/bitstream/handle/10803/119774/ARADILLA_TESIS.pdf?seq uence $=1$

359. Berrios Martos MDP, Augusto Landa JM, Aguilar Luzón MDC. Inteligencia emocional percibida y satisfacción laboral en contextos hospitalarios. Un estudio exploratorio con profesionales de enfermería. Index de Enfermeria. [En línea] 2006;15(54): 30-34. Disponible en: doi:10.4321/s1132-12962006000200006 [Accedido: 9 de noviembre de 2020]

360. Romero-Collado A. Elementos esenciales para elaborar un estudio con el método (e)Delphi. Enfermería Intensiva. [En línea] 2020;(xx): 1-5. Disponible en: doi:10.1016/j.enfi.2020.09.001

361. Bosch-Alcaraz A, Jordan-Garcia I, Alcolea-Monge S, Fernández-Lorenzo R, CarrasquerFeixa E, Ferrer-Orona M, et al. Validity of contents of a paediatric critical comfort scale using mixed methodology. Enfermeria Intensiva. [En línea] Sociedad Española de Enfermería Intensiva y Unidades Coronarias (SEEIUC); 2018;29(1): 21-31. Disponible en: doi:10.1016/j.enfi.2017.04.003

362. Williams G, Chaboyer W, Alberto L, Thorsteinsdottir R, Schmollgruber S, Fulbrook P, et al. Critical care nursing organizations and activities - A second worldwide review: Original Article. International Nursing Review. [En línea] 2007;54(2): 151-159. Disponible en: doi:10.1111/j.1466-7657.2007.00543.x

363. Tweed C, Tweed M. Intensive Care Nurses'Knowledge of Pressure Ulcers: 
Development of an assessment tool and effect of an educational program. American Journal of Critical Care. 2008;17(4): 338-346.

364. Yañez MR, Avila JA, Bermudez MI, De Miguel I, Bellver V, Guilabert M, et al. Estudio Delphi para identificar las competencias en gestión del directivo de enfermería. Revista de Calidad Asistencial. [En línea] 2016;31(2): 113-121. Disponible en: doi:10.1016/j.cali.2015.08.005

365. Scott ES, Murphy LS tankiewic., Warshawsky NE. Nursing Administration Research Priorities: Findings From a Delphi Study. The Journal of nursing administration. [En línea] 2016;46(5): 238-244. Disponible en: doi:10.1097/NNA.0000000000000337

366. García Manjon JV, Pérez López MC. Espacio Europeo de Educación Superior, Competencias profesionales y empleabilidad. [En línea] 2008 [Accedido: 10 de mayo de 2019]. Disponible en: https://www.researchgate.net/publication/28230605 [Accedido: 10 de mayo de 2019]

367. Sánchez-Gómez MB, Novo-Muñoz M, Rodríguez-Gómez JÁ, Romero-Martín M, Gómez-Salgado J, Duarte-Clíments G. Methodology Proposal for the Management of Nursing Competencies towards a Strategic Training. A Theoretical Analysis. Healthcare 2020, Vol. 8, Page 170. [En línea] Multidisciplinary Digital Publishing Institute; 2020;8(2): 170. Disponible en: doi:10.3390/HEALTHCARE8020170

368. George M, Hernandez C, Smith S, Narsavage G, Kapella MC, Carno M, et al. Nursing research priorities in critical care, pulmonary, and sleep: International Delphi survey of nurses, patients, and caregivers an official American Thoracic Society workshop report. Annals of the American Thoracic Society. [En línea] American Thoracic Society; 2020;17(1): 1-10. Disponible en: doi:10.1513/AnnalsATS.201909-705ST [Accedido: 8 de julio de 2020]

369. Uhrenfeldt L, Lakanmaa R-L, Flinkman M, Basto ML, Attree M. Collaboration: a SWOT analysis of the process of conducting a review of nursing workforce policies in five European countries. Journal of nursing management. [En línea] 2014;22(4): 485-498. Disponible en: doi:10.1111/j.1365-2834.2012.01466.x [Accedido: 6 de febrero de 2017]

370. Fisher C, Cusack G, Cox K, Feigenbaum K, Wallen GR. Developing Competency to Sustain Evidence-Based Practice. Journal of Nursing Administration. [En línea] Lippincott Williams and Wilkins; 2016;46(11): 581-585. Disponible en: doi:10.1097/NNA.0000000000000408 [Accedido: 7 de julio de 2020]

371. Harden RM, Crosby JR, Davis MH, Friedman M. AMEE Guide No. 14: Outcome-based education: Part 5 - From competency to meta-competency: A model for the specification of learning outcomes. [En línea] Medical Teacher. Informa Healthcare; 1999. p. 546-552. Disponible en: doi:10.1080/01421599978951 [Accedido: 24 de septiembre de 2020]

372. Pascual J, Bueno P, Cuenca M, Asiain MC, Marín B. Certificación de la competencia profesional de la enfermera de Cuidados Críticos: encuesta de opinión. Enferm Intensiva. [En línea] 1998;9(1): 16-20. Disponible en: http://www.seeiuc.com/forma/certifica98.pdf [Accedido: 5 de julio de 2017]

373. Ääri RL, Tarja S, Helena LK. Competence in intensive and critical care nursing: A literature review. Intensive and Critical Care Nursing. [En línea] Churchill Livingstone; 
2008;24(2): 78-89. Disponible en: doi:10.1016/j.iccn.2007.11.006

374. Rascado P, Ballesteros MA, Bodí MA, Carrasco LF, Castañedos Á. Plan De Contingencia Frente a La Pandemia Covid-19. Sociedad Española de Enfermeria Intensiva y Unidades coronarias. 2020; 73.

375. Liu M, Wronski L. Trap questions in online surveys: Results from three web survey experiments. International Journal of Market Research. [En línea] 2018;60(1): 32-49. Disponible en: doi:10.1177/1470785317744856

376. Rigo DY, Donolo D. Modelos de ecuaciones estructurales usos en investigación psicológica y educativa. Interamerican Journal of Psychology. 2018;52(3): 345-357.

377. Bruyneel A, Tack J, Droguet M, Maes J, Wittebole X, Miranda DR, et al. Measuring the nursing workload in intensive care with the Nursing Activities Score (NAS): A prospective study in 16 hospitals in Belgium. Journal of Critical Care. [En línea] 2019;54: 205-211. Disponible en: doi:10.1016/j.jcrc.2019.08.032

378. Oliveira AC, Garcia PC, Nogueira LS. Nursing workload and occurrence of adverse events in intensive care: a systematic review. Revista da Escola de Enfermagem da USP. [En línea] 2016;50(4): 683-694. Disponible en: doi:10.1590/S0080623420160000500020

379. Morini Altafin JA, Carvalho Grion CM, Toshyiuki Tanita M, Festti J, Queiroz Cardoso LT, Fonseca Veiga CF, et al. Nursing Activities Score and workload in the intensive care unit of a university hospital. Revista Brasileira de Terapia Intensiva. [En línea] 2014;26(3): 292-298. Disponible en: doi:10.5935/0103-507X.20140041

380. Solís Muñoz M. Asociación entre la ratio de enfermería y los desenlaces de los pacientes de UCl. Estudio multicéntrico. Enferm Intensiva. [En línea] 2016;27(2): 8183. Disponible en: doi:10.1016/j.enfi.2016.04.001

381. Ministerio de Sanidad y Politica Social. Incidentes y eventos adversos en medicina intensiva. Seguridad y riesgo en el enfermo crítico. SYREC 2007 Informe. Mayo 2009. 2009.

382. Kovacevic P, Dragic S, Kovacevic T, Momcicevic D, Festic E, Kashyap R, et al. Impact of weekly case-based tele-education on quality of care in a limited resource medical intensive care unit. Critical Care. [En línea] BioMed Central Ltd.; 2019;23(1). Disponible en: doi:10.1186/s13054-019-2494-6 [Accedido: 1 de julio de 2020]

383. Juvé Udina ME, Farrero Muñoz S, Matud Calvo C, Monterde Prat D, Fierro Barrabés G, Marsal Serra R. ¿Cómo definen los profesionales de enfermería hospitalarios sus competencias asistenciales? Nursing (edición española). 2007;25(7): 50-61.

384. Juvé Udina ME, Huguet M, Monterde D, Sanmartin MJ, Martí N, Cuevas B, et al. Marco teórico y conceptual para la definición y evaluación de competencias del profesional de enfermería en el ámbito hospitalario. Nursing. [En línea] 2007;25(4): 1689-1699. Disponible en: doi:10.1017/СBO9781107415324.004

385. Falcó-Pegueroles A. La nueva formación de profesionales: sobre la competencia profesional y la competencia del estudiante de enfermería. Educación médica. [En línea] 2004;7(1): 42-45. Disponible en:

http://scielo.isciii.es/scielo.php?script=sci_arttext\&pid=S1575-18132004000100007 [Accedido: 7 de julio de 2020] 
386. Baxter R, Edvardsson D. Impact of a critical care postgraduate certificate course on nurses' self-reported competence and confidence: A quasi-experimental study. Nurse Education Today. [En línea] 2018;65: 156-161. Disponible en:

doi:10.1016/j.nedt.2018.03.004

387. Fouilloux V, Gran C, Guervilly C, Breaud J, El Louali F, Rostini P. Impact of education and training course for ECMO patients based on high-fidelity simulation: a pilot study dedicated to ICU nurses. Perfusion (United Kingdom). [En línea] SAGE Publications Ltd; 2019;34(1): 29-34. Disponible en: doi:10.1177/0267659118789824 [Accedido: 1 de julio de 2020]

388. Conley P. Certified and Advanced Degree Critical Care Nurses Improve Patient Outcomes. Dimensions of Critical Care Nursing. [En línea] Lippincott Williams and Wilkins; 2019;38(2): 108-112. Disponible en: doi:10.1097/DCC.0000000000000342 [Accedido: 8 de julio de 2020]

389. Krapohl G, Manojlovich M, Redman R, Zhang L. Nursing specialty certification and nursing-sensitive patient outcomes in the intensive care unit. American Journal of Critical Care. [En línea] 2010;19(6): 490-498. Disponible en: doi:10.4037/ajcc2010406

390. Fukuda T, Sakurai H, Kashiwagi M. Impact of having a certified nurse specialist in critical care nursing as head nurse on ICU patient outcomes. PLOS ONE. [En línea] 2020; Disponible en: doi:10.1371/journal.pone.0228458 [Accedido: 28 de septiembre de 2020]

391. Sumande D V., Ruiz FB. Evaluation of staff nurses performance in Level III private hospitals in Region IV-A basis for continuing professional development program. Enfermería Clínica. [En línea] Elsevier Espa\&ntilde;a, S.L.U.; 2020;30: 42-47. Disponible en: doi:10.1016/j.enfcli.2019.09.034

392. Massimi A, Marzuillo C, Di Muzio M, Vacchio MR, D’Andrea E, Villari P, et al. Quality and relevance of master degree education for the professional development of nurses and midwives. Nurse Education Today. [En línea] Elsevier; 2017;53(December 2016): 54-60. Disponible en: doi:10.1016/j.nedt.2017.04.012

393. Griffiths P, Ball J, Drennan J, Dall'Ora C, Jones J, Maruotti A, et al. Nurse staffing and patient outcomes: Strengths and limitations of the evidence to inform policy and practice. A review and discussion paper based on evidence reviewed for the National Institute for Health and Care Excellence Safe Staffing guideline develo. International Journal of Nursing Studies. [En línea] Elsevier Ltd; 2016;63: 213-225. Disponible en: doi:10.1016/j.ijnurstu.2016.03.012

394. Melnyk BM, Fineout-Overholt E. Evidence-based practice in nursing healthcare : a guide to best practice. [En línea] Wolters Kluwer/Lippincott Williams \& Wilkins; 2011. 599 p. Disponible en:

https://books.google.es/books?hl=es\&lr=\&id=hHn7ESF1DJoC\&oi=fnd\&pg=PT15\&dq=e vidence+based+practice+in+nursing+and+healthcare+melnyk+pdf\&ots=HmFwkccb0\&sig=Kr_nB4OZKXqeSNYjcimrwf4U5dQ\#v=onepage\&q=evidence based practice in nursing and healthcare melnyk pdf\& [Accedido: 25 de septiembre de 2017]

395. Christensen M, Hewitt-Taylor J. Defining the expert ICU nurse. Intensive and Critical Care Nursing. [En línea] 2006;22(5): 301-307. Disponible en: doi:10.1016/j.iccn.2005.07.003 
396. Ali-Abadi T, Babamohamadi H, Nobahar M. Critical thinking skills in intensive care and medical-surgical nurses and their explaining factors. Nurse Education in Practice. [En línea] 2020;45. Disponible en: doi:10.1016/j.nepr.2020.102783

397. López-Ortega J, Morales-Asencio JM, Quesada-Moya A. Cuidados al paciente crítico adulto. First Edit. Madrid: Difusión de Avances de enfermería; 2007. p. 463-509.

398. Haegdorens F, Van Bogaert P, De Meester K, Monsieurs KG. The impact of nurse staffing levels and nurse's education on patient mortality in medical and surgical wards: an observational multicentre study. BMC Health Services Research. [En línea] 2019;19(864). Disponible en: doi:10.1186/s12913-019-4688-7

399. Aiken LH, Clarke SP, Cheung RB, Sloane DM, Silber JH. Educational Levels of Hospital Nurses and Surgical Patient Mortality. JAMA. [En línea] 2003;290(12): 1617-1623. Disponible en: doi:10.1001/jama.290.12.1617

400. Park JR, Wharrad H, Barker J, Chapple M. The knowledge and skills of pre-registration masters' and diploma qualified nurses: A preceptor perspective. Nurse Education in Practice. [En línea] Elsevier Ltd; 2011;11(1): 41-46. Disponible en: doi:10.1016/j.nepr.2010.06.004

401. Santana Cabrera L, Falcón Moreno R, Pérez Sánchez R, González González M. Percepción del personal de enfermería de hospitalización acerca de los cuidados intensivos. Enfermería Intensiva. [En línea] 2009;20(3): 127. Disponible en: doi:10.1016/S1130-2399(09)72594-5

402. Asiain Erro MC. Nursing competence and accreditation of nurses in the care of the critical patient. [En línea] Enferm Intensiva. Elsevier; 2005. p. 1-2. Disponible en: doi:10.1016/s1130-2399(05)73379-4 [Accedido: 1 de octubre de 2020]

403. Ania González N, Martínez Mingo A, Eseberri Sagardoy M, Margall Coscojuela M, Asiain Erro MC. Evaluación de la competencia práctica y de los conocimientos científicos de enfermeras de $\mathrm{UCl}$ en la aspiración endotraqueal de secreciones. Enferm Intensiva. [En línea] Elsevier; 2004;15(3): 101-111. Disponible en: doi:10.1016/S11302399(04)78151-1 [Accedido: 13 de febrero de 2019]

404. Asiain M, Margall M. Autoevaluación de la competencia profesional de enfermeras asistenciales. Enfermería U de C y D de la I en (ed.) Sevilla; 2004. 140-143 p.

405. Alberti M, Lores R, Menchaca A. Cuidados paliativos en la Unidad de Cuidados Intensivos Pediátricos. Rev Med Uruguay. [En línea] 2008;24: 50-55. Disponible en: doi:10.35667/metasenf.2019.20.1003081152

406. Abad Ruiz MD, Lorente Arnaiz S, Galindo Maycas S. Cuidados paliativos en la Unidad de Cuidados Intensivos Pediátricos. Metas de Enfermería. [En línea] 2017;20. Disponible en: doi:10.35667/metasenf.2019.20.1003081152 [Accedido: 9 de julio de 2020]

407. Rippstein-Leuenberger K, Mauthner O, Bryan Sexton J, Schwendimann R. A qualitative analysis of the Three Good Things intervention in healthcare workers. BMJ Open. [En línea] 2017;7(5): 3-8. Disponible en: doi:10.1136/bmjopen-2017-015826

408. Alharbi $\mathrm{H}$, Alshehry A. Perceived stress and coping strategies among ICU nurses in government tertiary hospitals in Saudi Arabia: A cross-sectional study. Annals of Saudi Medicine. [En línea] King Faisal Specialist Hospital and Research Centre; 2019;39(1): 
48-55. Disponible en: doi:10.5144/0256-4947.2019.48 [Accedido: 1 de julio de 2020]

409. Alharbi J, Jackson D, Usher K. The potential for COVID-19 to contribute to compassion fatigue in critical care nurses. [En línea] Journal of Clinical Nursing. Blackwell Publishing Ltd; 2020. Disponible en: doi:10.1111/jocn.15314 [Accedido: 8 de julio de 2020]

410. Qi J, Xu J, Li BZ, Huang JS, Yang Y, Zhang ZT, et al. The evaluation of sleep disturbances for Chinese frontline medical workers under the outbreak of COVID-19. Sleep Medicine. [En línea] Elsevier Ltd; 2020;72(December 2019): 1-4. Disponible en: doi:10.1016/j.sleep.2020.05.023

411. Al-Thani H, El-Menyar A, Asim M, Mollazehi M, Abdelrahman H, Parchani A, et al. Evolution of The Qatar Trauma System: The Journey from Inception to Verification. Journal of Emergencies, Trauma and Shock. [En línea] 2019;12: 209-217. Disponible en: doi:10.4103/JETS.JETS

412. Kim H, Chang SJ. Implementing an educational program to improve critical care nurses' enteral nutritional support. Australian Critical Care. [En línea] Elsevier Ltd; 2019;32(3): 218-222. Disponible en: doi:10.1016/j.aucc.2018.04.001

413. Adegboye MB, Zakari S, Ahmed BA, Olufemi GH. Knowledge, awareness and practice of infection control by health care workers in the intensive care units of a tertiary hospital in Nigeria. African Health Sciences. [En línea] 2018;18(1): 72. Disponible en: doi:10.4314/ahs.v18i1.11 [Accedido: 31 de julio de 2018]

414. Mottes T, Owens T, Niedner M, Juno J, Shanley TP, Heung M. Improving Delivery of Continuous Renal Replacement Therapy. Pediatric Critical Care Medicine. [En línea] 2013;14(8): 747-754. Disponible en: doi:10.1097/PCC.0b013e318297626e [Accedido: 4 de abril de 2018]

415. Farmani Z, Kargar M, Khademian Z, Paydar S, Zare N. The effect of training and awareness of subtle control on the frequency of hand hygiene among intensive care unit nurses. BMC Research Notes. [En línea] BioMed Central; 2019;12(1): 1-5. Disponible en: doi:10.1186/s13104-019-4635-z

416. Weare R, Green C, Olasoji M, Plummer V. ICU nurses feel unprepared to care for patients with mental illness: A survey of nurses' attitudes, knowledge, and skills. Intensive and Critical Care Nursing. [En línea] 2019;53: 37-42. Disponible en: doi:10.1016/j.iccn.2019.03.001

417. Ahn JW. Structural Equation Modeling of Cultural Competence of Nurses Caring for Foreign Patients. Asian Nursing Research. [En línea] Elsevier; 2017;11(1): 65-73. Disponible en: doi:10.1016/j.anr.2017.03.001

418. Donelan K, DesRoches CM, Guzikowski S, Dittus RS, Buerhaus P. Physician and nurse practitioner roles in emergency, trauma, critical, and intensive care. Nursing Outlook. [En línea] Elsevier Inc.; 2020;68(5): 591-600. Disponible en: doi:10.1016/j.outlook.2020.04.010

419. Serrano A. Seeiuc reclama la especialidad enfermera de Cuidados Críticos. [En línea] Diario Medico. Madrid; Disponible en: https://www.diariomedico.com/enfermeria/profesion/seeiuc-reclama-laespecialidad-enfermera-de-cuidados-criticos.html [Accedido: 30 de septiembre de 2020] 


\section{ANEXOS}





\section{Anexo 1}

Guion de la entrevista.

\section{Ámbito}

1. Ámbito Clínico.

\section{Preguntas}

¿Qué conocimientos tiene que tener una enfermera de $\mathrm{UCl}$ para realizar un examen físico en el contexto del paciente crítico?

¿Qué habilidades tiene que tener una enfermera de UCI para realizar un examen físico en el contexto del paciente crítico?

¿Qué herramientas debe ser capaz de utilizar para poder obtener datos para la valoración?

¿Qué aspectos emocionales tiene que tener en cuenta una enfermera de UCI para realizar un examen físico en el contexto del paciente crítico?

¿Qué aspectos personales tiene que tener en cuenta una enfermera de UCl para realizar un examen físico en el contexto del paciente crítico?

¿Qué aspectos sociales tiene que tener en cuenta una enfermera de $\mathrm{UCl}$ para realizar un examen físico en el contexto del paciente crítico?

¿Enumere los conocimientos y habilidades que tiene que tener la enfermera de cuidados intensivos para evaluar de manera crítica el plan de cuidados?

¿Cómo puede la enfermera de UCI buscar la mejor evidencia científica en relación a los cuidados?

¿Qué medidas debe conocer la enfermera a la hora de evaluar estrategias de mejora?

Priorice las patologías que debe conocer una enfermera de cuidados intensivos.

Priorice los cuidados que debe conocer una enfermera de cuidados intensivos.

Priorice las habilidades que debe tener una enfermera de cuidados intensivos en relación a los cuidados previamente citados.

Enumere las fuentes en las que una enfermera puede buscar información para solucionar situaciones complejas.

¿Qué conocimientos tiene que tener la enfermera de UCl para poder hacer frente a decisiones complejas?

¿Qué habilidades tiene que tener la enfermera de UCI para poder hacer frente a decisiones complejas?

¿Cómo afronta una enfermera de UCl las decisiones de limitación del esfuerzo terapéutico?

¿Qué habilidades tiene que tener una enfermera de UCI para afrontar la muerte de un paciente?

¿La enfermera de cuidados intensivos, busca la excelencia a nivel clínico?

¿Qué estrategias de comunicación debe saber utilizar una enfermera?

¿Cómo se deben comunicar las enfermeras de UCI, en situaciones complicadas?

¿Cómo debe ser la comunicación oral con el equipo?

¿Cómo debería ser la información y comunicación en UCI?

¿La comunicación escrita, con qué medidas debe fomentarse?

¿Qué usos le debe dar la enfermera de UCl a las tecnologías de la información? 
¿En qué medida es necesario el seguimiento de los cuidados prestados?

¿Qué medidas utiliza para garantizar una continuidad de los cuidados?

¿Cuál es la importancia del liderazgo de las enfermeras en los equipos sanitarios?

¿La coordinación del equipo sanitario, debe mantenerse?

¿Las enfermeras recogen datos relacionados con los indicadores de calidad?

¿Se hace un seguimiento para garantizar el cumplimiento de las actividades derivadas de los indicadores de calidad?

¿En qué medida es capaz de delegar actividades la enfermera de UCI?

¿Es capaz de planificar actuaciones a lo largo del tiempo?

¿Gestiona adecuadamente su tiempo durante su horario laboral?

¿Es capaz de gestionar y reevaluar las necesidades asistenciales a lo largo de turno de trabajo?

¿Cómo debe gestionar los recursos de la manera más eficiente?

¿Qué rol desempeña la enfermera de UCl como miembro de un grupo de trabajo?

¿Hay un adecuado clima de trabajo, con transparencia, confianza y respeto?

3. Ámbito de la Gestión.

¿Qué medidas se pueden adoptar para que haya un adecuado clima laboral?

¿Qué medidas debe tener un equipo de trabajo de enfermería para tener una adecuada cohesión intragrupo?

¿Se promueve el dialogo y la comunicación entre los miembros del equipo?

¿Cómo se debe potenciar la seguridad clínica en el equipo asistencial?

¿Cómo están de involucradas las enfermeras en la seguridad del paciente?

¿Qué medidas debe conocer una enfermera de $\mathrm{UCl}$ para prevenir y evitar eventos adversos?

¿Qué medidas deberían conocer las enfermeras para reconocer rápidamente signos y síntomas de alerta?

¿Son capaces los equipos asistenciales de trabajar bajo estrés?

¿Se gestiona adecuadamente la carga de trabajo dentro de la unidad?

¿Se posibilita la colaboración entre miembros del equipo?

¿Cómo debe la enfermera de UCl ser capaz de adaptarse a los cambios en las necesidades, a las situaciones urgentes y emergentes?

¿Cómo se deben potenciar las medidas de confort dentro de las Unidades de Cuidados Intensivos?

¿Se fomentan prácticas para lograr un adecuado descanso de los pacientes?

¿Qué medidas debe adoptar la enfermera para fomentar la orientación del paciente en tiempo y espacio?

¿Se toman medidas para prevenir y/o evitar el delirio o la desorientación? 
Ámbito

4. Ámbito educativo y de desarrollo.
Preguntas

¿Qué actividades formativas realizan las enfermeras para estar adecuadamente formadas y mantener un desarrollo profesional permanente?

¿Tienen las actividades formativas repercusión a nivel clínico?

¿Realiza la enfermera de $\mathrm{UCl}$ una formación reglada y relacionada con el ámbito de los cuidados intensivos?

¿Qué medidas debe adoptar la enfermera a la hora de potenciar la investigación enfermera en su campo de actuación?

¿Cómo colabora la institución en la formación continuada de las enfermeras de cuidados intensivos?

¿Qué conocimientos previos se le debe solicitar a una enfermera que comienza a trabajar en UCl?

¿Qué conocimientos debe desarrollar las enfermeras de UCl durante su trabajo para alcanzar un nivel de excelencia?

¿Qué formación debe realizar la enfermera a lo largo de su trabajo en UCl?

¿Cuáles habilidades técnicas debe conocer las enfermeras antes de empezar a trabajar en UCI?

¿Cuáles habilidades técnicas debe conocer las enfermeras durante su tiempo de trabajo en $\mathrm{UCl}$ ?

¿Qué habilidades técnicas debe controlar, manejar y formarse la enfermera de $\mathrm{UCl}$ ?

¿Qué habilidades de razonamiento clínico deben ser potenciadas en las

5. Dimensiones transversales enfermeras de UCI?

y formación
¿Cómo se deberían llevar los conocimientos teóricos a la realidad? ¿Cuáles serían sus propuestas?

¿Cuáles son las características de comunicación indispensables para trabajar en $\mathrm{UCI}$ ?

¿Cómo potenciaría el trabajo en equipo en UCl?

¿Cómo debe afrontar y que habilidades debe tener una enfermera de $\mathrm{UCl}$, para afrontar situaciones conflictivas?

¿Cuál sería la docencia mínima y en que campos, que se debería exigir a las enfermeras de UCI? ¿Con que periodicidad (anual, bianual, etc...)?

¿Qué herramientas o conocimientos son necesarios para el afrontamiento de la muerte de los usuarios?

¿Qué cualidades personales se debe potenciar en las enfermeras de UCI?

¿Cómo se debe desarrollar la inteligencia emocional en las enfermeras en UCI? 



\section{Anexo 2}

Cuestionario digital difundido.

\section{Cuestionario Necesidades formativas de las enfermeras de Cuidados Intensivos en España.}

\section{Introducción}

Apreciado/a Compañero/a.

Solicitamos su colaboración en este estudio para conocer las necesidades formativas de las enfermeras de cuidados intensivos en España. Este estudio se está realizando en el desarrollo de la tesis doctoral de Yeray Gabriel Santana Padilla en la Universidad Jaume I.

La European Federation of Critical Care Association creó en 2012, un listado de competencias que eran preciso desarrollar para adquirir un nivel de competencias óptimas en las enfermeras de Cuidados Intensivos ( $\mathrm{UCl}$ ) en toda Europa, es por ello que se pretende conocer su opinión como profesional de la enfermería en $\mathrm{UCl}$ sobre cada uno de los apartados desarrollados en este documento: ámbito clínico, profesional, gestión y educativo o de desarrollo. Estos ítems están desarrollados en escalas tipo likert de 1 a 10 , donde 1 siempre es poco importante, o en desacuerdo con el enunciado expresado y 10 , es muy importante o totalmente de acuerdo con el enunciado expresado.

Es totalmente anónimo y la participación es voluntaria. Los datos obtenidos serán confidenciales (Ley 15/1999 de Protección de Datos de Carácter Personal), los datos sólo serán usados con fines de carácter científico. Cumpliendo la ley de investigación biomédica 14/2007 y el reglamento UE 2016/679 de confidencialidad, pudiendo ejercer los derechos referidos (acceso, rectificación, cancelación, oposición, limitación del tratamiento de datos que sean incorrectos, solicitar una copia o que se trasladen a terceros) ante el doctorando en el correo al257600@uji.es .Este estudio ha sido aprobado por el CEI correspondiente a su centro laboral.

Pregunta inicial:

Es usted profesional de Enfermería de Cuidados Intensivos en España y acepta la realización de la presente encuesta.

$\square \mathrm{SI} \quad \square \mathrm{NO}$

\section{Ámbito Clínico.}

En este apartado se busca conocer y fomentar unos cuidados enfermeros que sean seguros y efectivos para el paciente crítico y sus familiares.

\begin{tabular}{|c|l|c|}
\hline P1 & Las enfermeras de UCl deben tener conocimientos extensos de enfermería básica & 12345678910 \\
\hline P2 & $\begin{array}{l}\text { Las enfermeras de UCl deben desarrollar habilidades específicas para la atención } \\
\text { al paciente crítico }\end{array}$ & 12345678910 \\
\hline
\end{tabular}




\begin{tabular}{|c|c|c|}
\hline P3 & $\begin{array}{l}\text { La observación es una herramienta necesaria, para obtener datos en la valoración } \\
\text { del paciente crítico }\end{array}$ & 12345678910 \\
\hline P4 & $\begin{array}{l}\text { La monitorización es una herramienta fundamental, para obtener datos en la } \\
\text { valoración del paciente crítico }\end{array}$ & 12345678910 \\
\hline P5 & El uso de escalas son necesarias para la valoración del paciente crítico & 12345678910 \\
\hline P6 & $\begin{array}{l}\text { La empatía y el respeto a la intimidad son fundamentales para la enfermera de } \\
\text { UCl }\end{array}$ & 12345678910 \\
\hline P7 & Hay que involucrar al paciente y a la familia en el proceso de recuperación & 12345678910 \\
\hline P8 & $\begin{array}{l}\text { Observar, analizar e interpretar situaciones y/o problemas en un paciente crítico } \\
\text { es necesario para realizar un examen físico. }\end{array}$ & 12345678910 \\
\hline P9 & $\begin{array}{l}\text { La integración e interrelación de los datos es una habilidad muy importante de las } \\
\text { enfermeras de } \mathrm{UCI}\end{array}$ & 12345678910 \\
\hline P10 & $\begin{array}{l}\text { Las principales patologías que debe conocer una enfermera de } \mathrm{UCl} \text {, son la } \\
\text { cardíaca, la respiratoria y la neurológica }\end{array}$ & 12345678910 \\
\hline P11 & Las medidas de soporte son el pilar fundamental de las actividades enfermeras & 12345678910 \\
\hline P12 & $\begin{array}{l}\text { Las enfermeras de UCI deben estar formadas en la atención de los distintos tipos } \\
\text { de shock }\end{array}$ & 12345678910 \\
\hline P13 & El cálculo de fármacos y drogas, es una competencia imprescindible & 12345678910 \\
\hline P14 & $\begin{array}{l}\text { El cuidado integral de un paciente crítico forma parte de la actuación principal del } \\
\text { profesional de enfermería }\end{array}$ & 12345678910 \\
\hline P15 & $\begin{array}{l}\text { Los cuidados respiratorios son los que de manera prioritaria deben ser } \\
\text { desarrollados en las enfermeras de } \mathrm{UCl}\end{array}$ & 12345678910 \\
\hline P16 & $\begin{array}{l}\text { La reevaluación continua es la principal medida que debe implementar la } \\
\text { enfermera para evaluar estrategias de mejora del plan de cuidados. }\end{array}$ & 12345678910 \\
\hline P17 & La capacidad de priorización es una habilidad imprescindible & 12345678910 \\
\hline P18 & $\begin{array}{l}\text { El razonamiento clínico (que pasa, y que puede llegar a pasar) debe ser } \\
\text { fomentado en las enfermeras de } \mathrm{UCl}\end{array}$ & 12345678910 \\
\hline
\end{tabular}

\section{Ámbito Profesional.}

En este apartado, se busca fomentar y potenciar la práctica profesional en cuidados intensivos.

\begin{tabular}{|l|l|l|}
\hline P19 & $\begin{array}{l}\text { Ante situaciones complejas, la ayuda y el apoyo de compañeros más } \\
\text { experimentados ayudan a resolver problemas }\end{array}$ & 12345678910 \\
\hline P20 & $\begin{array}{l}\text { Las enfermeras pueden hacer frente a decisiones complejas gracias a la } \\
\text { experiencia laboral obtenida en UCl }\end{array}$ & 12345678910 \\
\hline P21 & $\begin{array}{l}\text { Las decisiones de cuidado son muy complejas y requieren de una formación } \\
\text { extensa }\end{array}$ & 12345678910 \\
\hline P22 & $\begin{array}{l}\text { Las enfermeras de UCl tienen mucha autonomía, por lo que es necesario una } \\
\text { formación reglada y adecuada al puesto de trabajo }\end{array}$ & 12345678910 \\
\hline
\end{tabular}




\begin{tabular}{|c|c|c|}
\hline P23 & $\begin{array}{l}\text { La enfermera de UCI suele afrontar bien la decisión de limitación de soporte vital } \\
\text { (esfuerzo terapéutico) }\end{array}$ & 12345678910 \\
\hline P24 & $\begin{array}{l}\text { La enfermera debería participar en las decisiones de limitación de soporte vital } \\
\text { (esfuerzo terapéutico) }\end{array}$ & 12345678910 \\
\hline P25 & La enfermera de $\mathrm{UCl}$ afronta peor el encarnizamiento terapéutico & 12345678910 \\
\hline P26 & $\begin{array}{l}\text { El afrontamiento de la muerte de los usuarios dependerá de las creencias, } \\
\text { experiencias y valores del profesional de enfermería }\end{array}$ & 12345678910 \\
\hline P27 & $\begin{array}{l}\text { El profesional de enfermería en } \mathrm{UCl} \text {, dentro de su competencia, busca la } \\
\text { excelencia a nivel clínico }\end{array}$ & 12345678910 \\
\hline P28 & El lenguaje verbal y no verbal son fundamentales en la comunicación en $\mathrm{UCI}$ & 12345678910 \\
\hline P29 & $\begin{array}{l}\text { En situaciones de estrés, las enfermeras se deben comunicar de manera técnica, } \\
\text { concisa y clara, ajustando la información a las características del interlocutor }\end{array}$ & 12345678910 \\
\hline P30 & $\begin{array}{l}\text { La principales herramientas de comunicación son la asertividad, la empatía y la } \\
\text { escucha activa tanto con usuarios y familia como con profesionales }\end{array}$ & 12345678910 \\
\hline P31 & $\begin{array}{l}\text { Las tecnologías de la información y comunicación (TIC) son herramientas } \\
\text { esenciales que permiten la formación, el aprendizaje y el desarrollo de la } \\
\text { profesión }\end{array}$ & 12345678910 \\
\hline P32 & $\begin{array}{l}\text { La comunicación escrita en UCl se debe fomentar siempre, pues es indispensable } \\
\text { para la continuidad de cuidados }\end{array}$ & 12345678910 \\
\hline
\end{tabular}

\section{Ámbito de la Gestión.}

En este ámbito se busca explorar el desarrollo de conocimientos y habilidades en el campo de la gestión y organización relacionada con las enfermeras de cuidados intensivos.

\begin{tabular}{|l|l|l|}
\hline P33 & $\begin{array}{l}\text { El seguimiento de los cuidados que prestan las enfermeras es indispensable para } \\
\text { la continuidad y evaluación de los cuidados }\end{array}$ & 12345678910 \\
\hline P34 & $\begin{array}{l}\text { Registrar los cuidados prestados es la mejor medida posible para garantizar la } \\
\text { continuidad }\end{array}$ & 12345678910 \\
\hline P35 & La enfermera de UCl actúa de nexo entre los distintos profesionales & 12345678910 \\
\hline P36 & La coordinación del equipo sanitario es imprescindible & 12345678910 \\
\hline P37 & $\begin{array}{l}\text { Las enfermeras son capaces de planificar actuaciones a lo largo del turno de } \\
\text { trabajo }\end{array}$ & 12345678910 \\
\hline P38 & $\begin{array}{l}\text { Las enfermeras que trabajan en UCl recogen datos relacionados con los } \\
\text { indicadores de calidad }\end{array}$ & 12345678910 \\
\hline P39 & Se realiza un seguimiento de los indicadores de calidad & 12345678910 \\
\hline P40 & Es necesaria una correcta formación para garantizar la seguridad clínica & 12345678910 \\
\hline P41 & Las enfermeras de UCl están involucradas en la seguridad clínica & 12345678910 \\
\hline P42 & $\begin{array}{l}\text { Las enfermeras de UCl deben ser capaces de actuar rápidamente ante el deterioro } \\
\text { del usuario y ante eventos adversos }\end{array}$ & 12345678910 \\
\hline
\end{tabular}




\begin{tabular}{|l|l|l|}
\hline P43 & $\begin{array}{l}\text { Los equipos asistenciales de UCI son capaces de realizar su trabajo en un } \\
\text { ambiente de presión y estrés }\end{array}$ & 12345678910 \\
\hline P44 & Se gestiona adecuadamente la carga de trabajo de las enfermeras en UCl & 12345678910 \\
\hline P45 & $\begin{array}{l}\text { En una UCI es fundamental la capacidad de adaptación de las enfermeras en las } \\
\text { situaciones urgentes y emergentes }\end{array}$ & 12345678910 \\
\hline P46 & $\begin{array}{l}\text { Evitar ruidos innecesarios o bajar el volumen de luces y alarmas, son acciones que } \\
\text { fomentan el descanso del paciente crítico }\end{array}$ & 12345678910 \\
\hline P47 & Se fomentan acciones para el adecuado confort y descanso de los pacientes & 12345678910 \\
\hline P48 & $\begin{array}{l}\text { En UCl, se toman medidas que ayudan a prevenir o evitar el delirio o la } \\
\text { desorientación }\end{array}$ & 12345678910 \\
\hline
\end{tabular}

\section{Ámbito educativo y de desarrollo.}

En este ámbito se centran en explorar las competencias que influye en la educación y el desarrollo de las enfermeras de cuidados intensivos.

\begin{tabular}{|l|l|l|}
\hline P49 & Las enfermeras realizan actividades formativas sobre los cuidados intensivos & 12345678910 \\
\hline P50 & La realización de esta formación depende de la motivación de la enfermera & 12345678910 \\
\hline P51 & Las actividades formativas repercuten positivamente a nivel clínico & 12345678910 \\
\hline P52 & La institución colabora en una formación específica de UCl & 12345678910 \\
\hline P53 & $\begin{array}{l}\text { La acogida de personal de nueva incorporación debe ser realizada lenta y } \\
\text { progresivamente }\end{array}$ & 12345678910 \\
\hline P54 & $\begin{array}{l}\text { La formación en UCl se realiza sobre todo para el cobro de incentivos, bolsas de } \\
\text { empleo y oposiciones }\end{array}$ & 12345678910 \\
\hline
\end{tabular}

\section{Segunda fase. Dimensiones y formación.}

En este apartado se busca explorar como se puede mejorar la excelencia de los cuidados tanto del personal novel como veterano.

\begin{tabular}{|l|l|l|}
\hline P55 & $\begin{array}{l}\text { La enfermera de nueva incorporación debería tener conocimientos } \\
\text { hemodinámicos, de ventilación mecánica, reanimación cardiopulmonar básica y } \\
\text { avanzada, además de monitorización }\end{array}$ & 12345678910 \\
\hline P56 & $\begin{array}{l}\text { Debería existir la figura de un enfermero tutor en la unidad para ayudar a las } \\
\text { enfermeras de nueva incorporación }\end{array}$ & 12345678910 \\
\hline P57 & Es necesario una formación previa postgrado de UCl para las enfermeras noveles & 12345678910 \\
\hline P58 & $\begin{array}{l}\text { La primera semana, las enfermeras noveles deben estar supervisadas en todo } \\
\text { momento }\end{array}$ & 12345678910 \\
\hline P59 & $\begin{array}{l}\text { El personal del staff (veterano), requiere de planes formativos específicos de } \\
\text { periodicidad anual }\end{array}$ & 12345678910 \\
\hline
\end{tabular}




\begin{tabular}{|l|l|l|}
\hline P60 & $\begin{array}{l}\text { La formación amplia y específica en cuidados críticos, facilita que el profesional } \\
\text { alcance un nivel de excelencia }\end{array}$ & 12345678910 \\
\hline P61 & $\begin{array}{l}\text { La formación se debe apoyar en eventos teórico-prácticos y en la simulación, } \\
\text { antes de llevar esos conocimientos a la realidad }\end{array}$ & 12345678910 \\
\hline P62 & $\begin{array}{l}\text { La formación debe terminar con una intervención real, siempre tutelado con un } \\
\text { profesional experimentado }\end{array}$ & 12345678910 \\
\hline P63 & La empatía es una actitud indispensable a desarrollar dentro del equipo sanitario & 12345678910 \\
\hline P64 & $\begin{array}{l}\text { Las enfermeras necesitan formación específica para afrontar la muerte de los } \\
\text { usuarios }\end{array}$ & 12345678910 \\
\hline P65 & $\begin{array}{l}\text { Son habilidades a desarrollar en las enfermeras de UCl, la calma, ser metódico y } \\
\text { resolutivas }\end{array}$ & 12345678910 \\
\hline P66 & La inteligencia emocional es necesaria ser desarrollada en las enfermeras de UCl & 12345678910 \\
\hline
\end{tabular}

\section{Datos sociodemográficos}

\section{Características de su Hospital}

Clasificación del Hospital

$\square$ Hospital de gestión pública

$\square$ Hospital de gestión privada

$\square$ Hospital de gestión mixta

Relación con la Universidad

$\square$ Hospital Universitario

$\square$ Hospital No Universitario

Números de camas del Hospital donde se encuentra la UCI

$\square<200$ camas

$\square$ 200-500 camas

$\square>500$ camas

\section{Características de la Unidad de Cuidados Intensivos}

Tipo de UCl

$\square$ Cardiológica o Coronaria

$\square$ Respiratoria

$\square$ Postquirúrgica 


\section{$\square$ Polivalente \\ $\square$ Intermedios \\ Pediátricos \\ $\square$ Médica \\ $\square$ Quemados \\ $\square$ Trauma}

Número de camas de la $\mathrm{UCl}$ (respuesta numérica) :

Ratio Enfermera/Paciente

\section{$\square 1: 1 \quad \square 1: 2 \quad \square 1: 3 \quad \square 1: 4 \quad \square 1: \geq 5$}

Provincia donde está la UCl donde trabaja: Álava(Araba),Albacete, Alicante, Almería, Asturias, Ávila, Badajoz, Barcelona, Burgos, Cáceres, Cádiz, Cantabria, Castellón, Ceuta, Ciudad Real, Córdoba, cuenca, Gerona (Girona), Granada, Guadalajara, Guipúzcoa (Gipuzkoa), Huelva, Huesca, Islas Baleares, Jaén, La Coruña (A Coruña), La Rioja, Las Palmas, Lérida (Lleida), Lugo, Madrid, Málaga, Melilla, Murcia, Navarra, Orense (Ourense), Palencia, Pontevedra, Salamanca, Segovia, Sevilla, Soria, Tarragona, Tenerife, Teruel, Toledo, Valencia, Valladolid, Vizcaya (Bizkaia), Zamora, Zaragoza.

\section{Sección de Descripción muestral}

M1. Sexo

$\square$ Hombre $\quad \square$ Mujer

M2.Edad (rango de edad, que ocupa en el momento de rellenar esta encuesta)
$\square 22-25$
$\square 26-30$
31-35
$\square$ 36-40 $\square$ 40-45
$\square$ Mayor de 45

M3.Años de Experiencia laboral en el campo de la enfermería en cualquier ámbito.

$\square$ Menos de un año $\quad \square$ 1-5años $\quad \square 6$-10 años $\square$ 11-15 años $\quad \square 16$-20 años $\square$ Más de 20 años

M4.Años de experiencia como enfermera en Cuidados Intensivos.

$\square$ Menos de un año $\square$ 1-5años $\square$ 6-10 años $\square$ 11-15 años $\square 16-20$ años $\square$ Más de 20 años

M5.Máximo nivel académico alcanzado por usted.

口Diplomatura Universitaria.

$\square$ Grado Universitario. 
$\square$ Experto Universitario.

$\square$ Master como título propio de Universidad

$\square$ Master Universitario

口Doctorado

M6.Según su opinión, para empezar a trabajar en $\mathrm{UCl}$ es preciso tener algún tipo de experiencia o formación previa.

$\square \mathrm{Si} \square \mathrm{No}$

M7.Contestar sólo en el caso de haber contestado "Si", la pregunta M6. ¿Qué experiencia mínima previa debieran tener los candidatos antes de comenzar a trabajar como enfermeros de UCI?

$\square$ Experiencia laboral en hospitalización de al menos 1 año.

$\square$ Experiencia laboral en hospitalización de al menos 2 años.

$\square$ Experiencia laboral en hospitalización de al menos 3 años.

$\square$ Experiencia laboral en hospitalización de al menos 4 años.

M8. Contestar sólo en el caso de haber contestado "Si", la pregunta M6. ¿Qué experiencia mínima previa debieran tener los candidatos antes de comenzar a trabajar como enfermeros de $\mathrm{UCl}$ ?

$\square$ Experiencia laboral en urgencias y/o quirófano de al menos 1 año.

$\square$ Experiencia laboral en urgencias y/o quirófano de al menos 2 años.

$\square$ Experiencia laboral en urgencias y/o quirófano de al menos 3 años.

$\square$ Experiencia laboral en urgencias y/o quirófano de al menos 4 años.

M9.Según su opinión. ¿Qué formación mínima previa sería aconsejable antes de comenzar a trabajar en UCI?

$\square$ No es necesario ninguna formación extra, salvo la proporcionada en los estudios de enfermería.

口Formación de post-grado con créditos de formación continuada de las profesiones sanitarias.

$\square$ Formación de post-grado mediante planes de acogida de las propias unidades

口Formación de post-grado en forma de expertos universitario (Con prácticas incluidas)

$\square$ Formación de post-grado en forma de master universitario (Con prácticas incluidas) 
M10.Según su opinión. ¿Sería aconsejable una formación especializada sanitaria tipo EIR (Enfermero Interno Residente), para trabajar en UCI?

$\square \mathrm{Si} \quad \square$ No

M11. ¿Existe en su unidad, un plan de acogida del personal de nueva incorporación?

$\square \mathrm{Si} \quad \square$ No

M12. Si la respuesta M11, ha sido contestada de forma afirmativa. ¿En qué consiste?

M13. Según su experiencia personal, ¿Sería necesario un plan de acogida para el personal de nueva incorporación?

$\square \mathrm{Si} \quad \square$ No

M14.Si la respuesta, M13 ha sido contestada de forma afirmativa. ¿En qué debería consistir?

\section{Preguntas Control:}

Para asegurar que las respuestas se están haciendo de manera fidedigna, y que se está prestando atención a los enunciados de cada pregunta. Hay dos preguntas intercaladas, de control:

Tras la pregunta P22:

Si esta rellenando, esta encuesta de manera concienzuda, marque en esta pregunta la respuesta cinco (pregunta control) 123456789 10

Tras la pregunta 43:

Si esta rellenando, esta encuesta de manera concienzuda, marque en esta pregunta la respuesta tres (pregunta control) 


\section{Agradecimiento:}

Gracias, por participar en esta encuesta que tiene como objeto conocer las necesidades formativas de las enfermeras de Cuidados Intensivos. Estos datos serán utilizados para la realización de investigaciones al respecto en la Universidad Jaume I, en su Programa de Doctorado de Ciencias de la Enfermería. El Doctorando, Yeray Gabriel Santana Padilla y los directores de tesis agradecen el tiempo que ha dedicado a la cumplimentación de la presente

encuesta. 



\section{Anexo 3}

A continuación se detallan las unidades colaboradoras en el presente estudio. Con sus respectivos, datos suministrados por los investigadores colaboradores.

\section{A CORUÑA:}

Hospital: Complejo Hospitalario Arquitecto Marcide

Gestión: pública

Relación universidad: universitario

Colaborador Investigación: Mạ Luisa Fraga Sampedro

Camas Hospital: 437

1. Tipo de Unidad: polivalente

2. Colaborador unidad: Inmaculada Rodríguez Cazorla y Paula Rivera Herrero

3. Número de camas $\mathrm{UCl}: 10$

4. Número de Enfermeras totales UCI: 21

\section{ALBACETE:}

Hospital: Hospital de Hellín

Gestión: pública

Relación universidad: no universitario

Colaborador Investigación: Mario García Martínez

Camas Hospital: 135

1. Tipo de Unidad: polivalente

2. Colaborador unidad: Ramón Jesús Azor García

3. Número de camas UCI: 8

4. Número de Enfermeras totales UCI: 25

\section{ALICANTE:}

Hospital: Hospital de Dénia

Gestión: mixta (concesión administrativa)

Relación universidad: no universitario

Colaborador Investigación: Enrique España Álvarez

Camas Hospital: 206

1. Tipo de Unidad: polivalente 
2. Colaborador unidad: Vicent Salvá Costa

3. Número de camas UCl: 14

4. Número de Enfermeras totales UCl: 21

Hospital: Hospital General Universitario de Elda Virgen de la Salud

Gestión: pública

Relación universidad: Universitario

Camas Hospital: 513

1. Tipo de Unidad: Polivalente

2. Colaborador unidad: Antonio Hernández Ortuño

3. Número de camas UCl: 10

4. Número de Enfermeras totales UCl: 18

Hospital: Hospital Comarcal Marina Baixa

Gestión: público

Relación universidad: Universitario

Camas hospital: 270

1. Tipo de Unidad: polivalente

2. Colaborador unidad: Marie France Martínez Mestre

3. Número de camas UCl: 12

4. Número de Enfermeras totales UCl: 24

ALMERIA:

Hospital: Hospital de Poniente. Agencia Sanitaria Poniente.

Gestión: pública

Relación universidad: no universitario

Colaborador Investigación: Raúl García Martín

Camas hospital: 291

1. Tipo de Unidad: polivalente

2. Colaborador unidad: Sonia García Hita

3. Número de camas UCl: 12

4. Número de Enfermeras totales UCl: 15

Hospital: Complejo Hospitalario Torrecardenas de Almería

Gestión: pública 
1. Tipo de Unidad: polivalente

2. Colaborador unidad: Francisco Javier Lao Barón

3. Número de camas UCl: 12

4. Número de Enfermeras totales UCl: 25

1. Tipo de Unidad: coronaria

2. Colaborador unidad: Francisco Javier Lao Barón

3. Número de camas UCl: 8

4. Número de Enfermeras totales UCl: 15

\section{ASTURIAS:}

Hospital: Hospital Valle del Nalón

Gestión: público

Relación universidad: no universitario

Camas Hospital: 201

Colaborador Investigación: Moisés Sánchez Pérez

1. Tipo de Unidad: Polivalente

2. Colaborador unidad: Moisés Sánchez Pérez

3. Número de camas UCl: 6

4. Número de Enfermeras totales UCl: 12

Hospital: Hospital Universitario de Cabueñes

Gestión: pública

Relación universidad: universitario

Camas Hospital: 784

1. Tipo de Unidad: polivalente

2. Colaborador unidad: María Teresa Fernández Vega

3. Número de camas UCl: 14

4. Número de Enfermeras totales UCl: 32

BADAJOZ:

Hospital: Hospital de Mérida

Gestión: pública

Relación universidad: universitario

Colaborador Investigación: Alberto Barneto Clavijo 
Camas Hospital: 381

1. Tipo de Unidad: polivalente

2. Colaborador unidad: Juan José Romero Romero

3. Número de camas UCl: 10

4. Número de Enfermeras totales UCl: 20

Hospital: Hospital Infanta Cristina. Complejo Hospitalario Universitario de Badajoz

Gestión: pública

Relación universidad: universitario

Colaborador investigación: Teresa Fernández Alonso

Camas Hospital: 889

1. Tipo de Unidad: polivalente

2. Colaborador unidad: Isabel Macías Martin

3. Número de camas UCl: 26

4. Número de Enfermeras totales UCl: 45

\section{BALEARES}

Hospital: Hospital Universitario Son Espases

Gestión: pública

Relación universidad: universitario

Camas Hospital: 816

Colaborador Investigación: María Antonia Palou Oliver

1. Tipo de Unidad: polivalente

2. Colaborador unidad: Celia Sánchez Calvin

3. Número de camas UCI: 32

4. Número de Enfermeras totales UCI: 88

Hospital: Hospital comarcal de Inca

Gestión: pública

Relación universidad: no universitario

Camas Hospital: 165

Colaborador Investigación: María Victoria Ramis Banus

1. Tipo de Unidad: polivalente

2. Colaborador unidad: Catalina Feliu Roig 
3. Número de camas UCl: 4

4. Número de Enfermeras totales UCI: 16

Hospital: Hospital de Manacor

Gestión: pública

Relación universidad: universitario

Camas Hospital: 232

Colaborador Investigación: Roberto Oyarbide Lasarte

1. Tipo de Unidad: polivalente

2. Colaborador unidad: Eva Pérez Juan

3. Número de camas UCI: 6

4. Número de Enfermeras totales UCI: 20

Hospital: Hospital Juaneda Miramar

Gestión: privada

Relación universidad: no universitario

Camas Hospital: 273

Colaborador Investigación: Eloy Villalba Ballesteros

1. Tipo de Unidad: polivalente

2. Colaborador unidad: María Arseni González Ferragut

3. Número de camas UCl: 15

4. Número de Enfermeras totales UCI: 20

Hospital: Hospital Can Misses

Gestión: pública

Relación universidad: universitario

Camas Hospital: 273

Colaborador Investigación: Josefa Cardona Roselló

1. Tipo de Unidad: polivalente

2. Colaborador unidad: Manuela Vila Rumbo

3. Número de camas UCI: 12

4. Número de Enfermeras totales UCI: 32 


\section{BARCELONA:}

Hospital: Hospital de la Santa Creu y Sant Pau

Gestión: mixta

Relación universidad: universitario

Colaborador Investigación: Amalia Sillero

Camas Hospital: 644

1. Tipo de Unidad: polivalente

2. Colaborador unidad: María del Mar Vega Castosa

3. Número de camas UCl: 30

4. Número de Enfermeras totales UCl: 60

Hospital: Hospital Universitari de BellVitge

Gestión: pública

Relación universidad: universitario

Colaborador Investigación: Jordi Adamuz Tomás

Camas hospital: 960

1. Tipo de Unidad: polivalente

2. Colaborador unidad: Rafael Justel García

3. Número de camas UCl: 24

4. Número de Enfermeras totales UCl: 48

1. Tipo de Unidad: cardiaca

2. Colaborador unidad: Rafael Justel García

3. Número de camas UCl: 10

4. Número de Enfermeras totales UCl: 20

1. Tipo de Unidad: postquirúrgica

2. Colaborador unidad: Rafael Justel García

3. Número de camas UCl: 16

4. Número de Enfermeras totales UCI: 28

BURGOS:

Hospital: Complejo Asistencial de Burgos

Gestión: publica

Relación universidad: universitario 
Camas hospital: 754

Colaborador investigación: María Aranzazu Febrero Ortiz de Quintana

1. Tipo de Unidad: polivalente

2. Colaborador unidad: María Celia Díaz Tobajas

3. Número de camas UCl: 24

4. Número de Enfermeras totales UCl: 63

\section{CÁCERES:}

Hospital: Hospital San Pedro de Alcántara de Cáceres

Gestión: pública

Relación universidad: universitario

Camas Hospital: 520

1. Tipo de Unidad: polivalente

2. Colaborador unidad: Lara Mateos Hinojal

3. Número de camas UCl: 12

4. Número de Enfermeras totales UCI: 32

CÁDIZ:

Hospital: Hospital Universitario Puerta del Mar

Gestión: pública

Relación universidad: universitario

Camas Hospital: 1000

1. Tipo de Unidad: polivalente

2. Colaborador unidad: María del Carmen Fernández Gutiérrez

3. Número de camas UCI: 26

4. Número de Enfermeras totales UCl: 67

\section{CANTABRIA:}

Hospital: Hospital Universitario Marqués de Valdecilla

Gestión: pública

Relación universidad: universitario

Camas Hospital: 850

Colaborador Investigación: José Luis Cobo Sánchez 
1. Tipo de Unidad: polivalente

2. Colaborador unidad: María Gemma García López

3. Número de camas UCl: 24

4. Número de Enfermeras totales UCl: 63

1. Tipo de Unidad: coronaria

2. Colaborador unidad: María Gemma García López

3. Número de camas UCl: 18

4. Número de Enfermeras totales UCl: 40

\section{CASTELLÓN:}

Hospital: Hospital General Universitario de Castellón

Gestión: pública

Relación universidad: universitario

Camas Hospital: 574

1. Tipo de Unidad: polivalente

2. Colaborador unidad: LLedó Guillamon Guimeno

3. Número de camas UCl: 15

4. Número de Enfermeras totales UCl: 47

\section{Hospital: Hospital Comarcal de Vinaroz}

Gestión: pública

Relación universidad: no universitario

Camas Hospital: 152

1. Tipo de Unidad: polivalente

2. Colaborador unidad: María Adell Artola

3. Número de camas UCI: 5

4. Número de Enfermeras totales UCl: 14

\section{CIUDAD REAL:}

Hospital: Hospital General La Mancha Centro

Gestión: pública

Relación universidad: universitario

Camas hospital: 250

Colaborador Investigación: Antonio Gigante León 
1. Tipo de Unidad: pediátrica

2. Colaborador unidad: María Estela Morales Gómez

3. Número de camas UCl: 5

4. Número de Enfermeras totales UCI:13

\section{CORDOBA:}

Hospital: Hospital Infanta Margarita de Cabra

Gestión: publico

Relación universidad: no Universitario

Camas Hospital: 258

1. Tipo de Unidad: polivalente

2. Colaborador unidad: María del Rosario Gómez Espejo

3. Número de camas UCl: 10

4. Número de Enfermeras totales UCI: 13

\section{Hospital: Hospital Universitario Reina Sofía de Cordoba}

Gestión: publico

Relación universidad: universitario

Camas Hospital: 1302

1. Tipo de Unidad: pediátrica

2. Colaborador unidad: Ana María Duran Luengo

3. Número de camas UCI: 12

4. Número de Enfermeras totales UCl: 28

\section{CUENCA:}

Hospital: Hospital Virgen de la Luz de Cuenca

Gestión: pública

Relación universidad: universitario

Camas hospital: 411

Colaborador Investigación: Beatriz Cervera Monteagudo

1. Tipo de Unidad: polivalente

2. Colaborador unidad: José Antonio Simarro Blasco

3. Número de camas UCl: 12

4. Número de Enfermeras totales UCI: 43 
GRANADA:

Hospital: Hospital Clínico Universitario de Granada

Gestión: publica

Relación universidad: Universitario

Camas Hospital: 1362

1. Tipo de Unidad: pediátrica

2. Colaborador unidad: Nuria Núñez Cruz

3. Número de camas UCl: 8

4. Número de Enfermeras totales UCl: 18

\section{GUADALAJARA:}

Hospital: Hospital Universitario de Guadalajara

Gestión: público

Relación universidad: universitario

Colaborador Investigación: Esther Murillo Muñoz

Camas Hospital: 410

1. Tipo de Unidad: polivalente

2. Colaborador unidad: Rut García Molpeceres

3. Número de camas UCl: 10

4. Número de Enfermeras totales $\mathrm{UCl}: 23$

HUESCA:

Hospital: Hospital General San Jorge de Huesca

Gestión: publica

Relación universidad: no universitario

Colaborador Investigación: Lorena Laglera Bailo

Camas hospital: 312

1. Tipo de Unidad: polivalente

2. Colaborador unidad: Gemma María Mendoza Muro

3. Número de camas UCl: 10

4. Número de Enfermeras totales UCl: 19 
JAEN:

Hospital: Hospital Universitario de Jaén

Gestión: pública

Relación universidad: universitario

Camas hospital: 180

1. Tipo de Unidad: trauma

2. Colaborador unidad: María del Carmen Robles

3. Número de camas UCl: 10

4. Número de Enfermeras totales UCI: 20

LAS PALMAS:

Hospital: Hospital Universitario Insular de Gran Canaria- Complejo Hospitalario Universitario Insular Materno-Infantil

Gestión: pública

Relación universidad: universitario.

Camas Hospital: 905

1. Tipo de Unidad: polivalente

2. Colaborador unidad: Yeray Gabriel Santana Padilla (Investigador principal del estudio)

3. Número de camas UCl: 30

4. Número de Enfermeras totales UCI: 74

Hospital: Hospital Universitario Materno-Infantil de Canarias- Complejo Hospitalario Universitario Insular Materno-Infantil

Gestión: pública

Relación universidad: universitario.

Camas Hospital: 905

1. Tipo de Unidad: pediátrica

2. Colaborador unidad: Ángeles Batista Arteaga

3. Número de camas UCI: 10

4. Número de Enfermeras totales UCI: 25

Hospital: Hospital Universitario de Gran Canaria Doctor Negrín

Gestión: pública

Relación universidad: universitario. 
Camas Hospital: 621

1. Tipo de Unidad: coronarias

2. Colaborador unidad: Aday García Almeida

3. Número de camas UCl: 10

4. Número de Enfermeras totales UCl: 25

1. Tipo de Unidad: trauma

2. Colaborador unidad: Aday García Almeida

3. Número de camas UCl: 10

4. Número de Enfermeras totales UCl: 25

Hospital: Hospital Insular de Fuerteventura

Gestión: pública

Relación universidad: universitario.

Camas Hospital: 131

1. Tipo de Unidad: polivalente

2. Colaborador unidad: Juan Antonio Quesada Jiménez

3. Número de camas UCI: 6

4. Número de Enfermeras totales UCI: 15

Hospital: Hospital San Roque Maspalomas

Gestión: privada

Relación universidad: universitario.

Camas Hospital: 167

1. Tipo de Unidad: polivalente

2. Colaborador unidad: Vanessa Melián Castro

3. Número de camas UCI: 8

4. Número de Enfermeras totales UCI: 12

\section{LA RIOJA:}

Hospital: Hospital San Pedro de La Rioja

Gestión: pública

Relación universidad: universitario.

Camas Hospital: 630

1. Tipo de Unidad: polivalente. 
2. Colaborador unidad: Mari Cruz Berceo Sánchez

3. Número de camas $\mathrm{UCl}: 17$

4. Número de Enfermeras totales UCI: 37

LEÓN:

Hospital: Hospital del Bierzo-Ponferrada

Gestión: pública

Relación universidad: no universitario.

Camas Hospital: 369

Colaborador Investigación: Martin Ortega Gil

1. Tipo de Unidad: polivalente

2. Colaborador unidad: María Ángeles Yecora Soto

3. Número de camas UCl: 9

4. Número de Enfermeras totales UCI: 16

MADRID:

Hospital: Hospital Universitario Severo Ochoa

Gestión: pública

Relación universidad: universitario

Colaborador Investigación: Raúl del Olmo González

Camas hospital: 386

1. Tipo de Unidad: polivalente

2. Colaborador unidad: María Virtudes Camacho González

3. Número de camas $\mathrm{UCl}: 10$

4. Número de Enfermeras totales UCI: 27

Hospital: Hospital General de Villalba

Gestión: pública

Relación universidad: no universitario

Camas Hospital: 204

1. Tipo de Unidad: polivalente

2. Colaborador unidad: María Silgado Mansilla

3. Número de camas UCl: 9

4. Número de Enfermeras totales UCI: 15 


\section{Hospital: Hospital Universitario de Móstoles}

Gestión: pública

Relación universidad: universitario

Camas Hospital: 365

1. Tipo de Unidad: polivalente

2. Colaborador unidad: Saray Blanco Abril

3. Número de camas UCl: 12

4. Número de Enfermeras totales UCl: 29

\section{Hospital: Hospital Clínico San Carlos}

Gestión: pública

Relación universidad: universitario

Camas Hospital: 1193

Colaborador Investigación: Ismael Ortuño Soriano

1. Tipo de Unidad: polivalente

2. Colaborador unidad: José Antonio Espín Faba

3. Número de camas UCl: 30

4. Número de Enfermeras totales UCI: 80

1. Tipo de Unidad: polivalente

2. Colaborador unidad: Reyes Merino Martínez

3. Número de camas UCl: 16

4. Número de Enfermeras totales UCI: 39

\section{Hospital: Hospital Universitario La Paz}

Gestión: pública

Relación universidad: universitario

Colaborador Investigación: Patricia Luna Castaño

Camas Hospital: 1328

1. Tipo de Unidad: polivalente

2. Colaborador unidad: Patricia Luna Castaño

3. Número de camas UCl: 21

4. Número de Enfermeras totales UCl: 71

1. Tipo de Unidad: pediátrica

2. Colaborador unidad: Patricia Luna Castaño 
3. Número de camas UCI: 16

4. Número de Enfermeras totales UCl: 59

Hospital: Hospital General Universitario Gregorio Marañón

Gestión: pública

Relación universidad: universitario

Colaborador Investigación: María Nieves Moro Tejedor

Camas Hospital: 1351

1. Tipo de Unidad: intermedios

2. Colaborador unidad: Manuel Jesús Ruiz-Henestrosa Campos

3. Número de camas UCl: 11

4. Número de Enfermeras totales UCl: 16

1. Tipo de Unidad: polivalente

2. Colaborador unidad: Manuel Jesús Ruiz-Henestrosa Campos

3. Número de camas UCl: 18

4. Número de Enfermeras totales UCl: 52

1. Tipo de Unidad: postquirúrgica

2. Colaborador unidad: Manuel Jesús Ruiz-Henestrosa Campos

3. Número de camas UCl: 32

4. Número de Enfermeras totales UCl: 82

1. Tipo de Unidad: coronarias

2. Colaborador unidad: Manuel Jesús Ruiz-Henestrosa Campos

3. Número de camas UCl: 11

4. Número de Enfermeras totales UCl: 25

1. Tipo de Unidad: cardiológica

2. Colaborador unidad: Manuel Jesús Ruiz-Henestrosa Campos

3. Número de camas UCl: 14

4. Número de Enfermeras totales UCl: 38

Hospital: Hospital Universitario de Getafe

Gestión: pública

Relación universidad: universitario

Colaborador Investigación: Susana Arias Rivera

Camas Hospital: 510 
1. Tipo de Unidad: polivalente

2. Colaborador unidad: Mạ Mar Sánchez Sánchez

3. Número de camas UCl: 18

4. Número de Enfermeras totales UCl: 44

1. Tipo de Unidad: Quemados

2. Colaborador unidad: Mạ Mar Sánchez Sánchez

3. Número de camas UCl: 6

4. Número de Enfermeras totales UCl: 18

Hospital: Hospital Universitario Infanta Leonor

Gestión: pública

Relación universidad: universitario

Colaborador Investigación: Carmen Báez León

Camas Hospital: 264

1. Tipo de Unidad: polivalente

2. Colaborador unidad: Pablo Fuentes Sánchez

3. Número de camas UCl: 8

4. Número de Enfermeras totales UCl: 23

\section{MALAGA:}

Hospital: Hospital Universitario Virgen de la Victoria

Gestión: pública

Relación universidad: universitario

Camas Hospital: 717

1. Tipo de Unidad: polivalente

2. Colaborador unidad: Pilar Lara Domínguez

3. Número de camas UCl: 18

4. Número de Enfermeras totales UCl: 54

Hospital: Hospital Regional Universitario de Málaga Carlos Haya

Gestión: pública

Relación universidad: universitario

Camas hospital: 1013

1. Tipo de Unidad: pediátrica 
2. Colaborador unidad: Victoria Verónica Sánchez Molina

3. Número de camas $\mathrm{UCl}: 13$

4. Número de Enfermeras totales UCI: 32

Hospital: Hospital Comarcal de la Axarquía

Gestión: pública.

Relación universidad: no universitario

Camas Hospital: 193

1. Tipo de Unidad: polivalente

2. Colaborador unidad: Daniel Moral Alguacil

3. Número de camas UCl: 8

4. Número de Enfermeras totales UCI: 17

Hospital: Hospital General Serranía de Ronda

Gestión: pública

Relación universidad: universitario

Camas hospital: 152

1. Tipo de Unidad: polivalente

2. Colaborador unidad: Sonia Ríos Corbacho

3. Número de camas UCl: 6 camas

4. Número de Enfermeras totales UCI: 13 enfermeras

MURCIA:

Hospital: Hospital General Universitario Morales Meseguer

Gestión: pública

Relación universidad: universitario

Colaborador Investigación: Jesús Leal Llopis

Camas Hospital: 394

1. Tipo de Unidad: polivalente

2. Colaborador unidad: Susana Garnes González

3. Número de camas UCl: 18

4. Número de Enfermeras totales UCI: 37

Hospital: Hospital General Universitario Reina Sofia De Murcia

Gestión: pública 
Relación universidad: universitario

Camas hospital: 339

1. Tipo de Unidad: polivalente

2. Colaborador unidad: Alfredo Cano Reyes

3. Número de camas UCl: 12

4. Número de Enfermeras totales UCl: 22

\section{PONTEVEDRA:}

Hospital: Hospital Álvaro Cunqueiro -Complejo Hospitalario Universitario de Vigo- EOXI Vigo

Gestión: pública

Relación universidad: universitario

Camas hospital: 961

Colaborador Investigación: Laura del Carmen Moure Fernández

1. Tipo de Unidad: polivalente

2. Colaborador unidad: Laura de Carmen Moure Fernández

3. Número de camas UCI: 30

4. Número de Enfermeras totales UCl: 71

\section{SALAMANCA:}

Hospital: Complejo Asistencial Universitario de Salamanca (CAUSA)

Gestión: pública

Relación universidad: universitario

Colaborador Investigación: Emilia Ruiz Antúnez

Camas Hospital: 1010

1. Tipo de Unidad: polivalente

2. Colaborador unidad: Cristina Moreiro Jorge

3. Número de camas UCI: 12

4. Número de Enfermeras totales UCl: 48

\section{SEVILLA:}

Hospital: Hospital Universitario Virgen de la Macarena

Gestión: pública

Relación universidad: universitario 
Camas Hospital: 880

1. Tipo de Unidad: polivalente

2. Colaborador unidad: María Dolores González Caro

3. Número de camas $\mathrm{UCl}: 30$

4. Número de Enfermeras totales UCl: 76

Hospital: Hospital Universitario de Valme

Gestión: pública

Relación universidad: universitario

Camas hospital: 600

1. Tipo de Unidad: polivalente

2. Colaborador unidad: Manuel Montes Vázquez

3. Número de camas UCl: 14

4. Número de Enfermeras totales UCl: 32

\section{TARRAGONA:}

Hospital: Hospital Sant Pau y Santa Tecla

Gestión: mixta

Relación universidad: universitario

Camas hospital: 269

Colaborador Investigación: Rosalía Cepero Martí

1. Tipo de Unidad: polivalente

2. Colaborador unidad: Rosalía Cepero Martí

3. Número de camas UCl: 9

4. Número de Enfermeras totales UCI: 18

Hospital: Hospital Universitari Joan XXIII

Gestión: pública

Relación universidad: universitario

Camas Hospital: 383

1. Tipo de Unidad: polivalente

2. Colaborador unidad: Carmen Flores Moya

3. Número de camas UCl: 28

4. Número de Enfermeras totales UCI: 84 


\section{TENERIFE:}

Hospital: Hospital Universitario de Canarias

Gestión: pública

Relación universidad: universitario

Camas Hospital: 652

Colaborador Investigación: Alberto Hernández Marrero

1. Tipo de Unidad: polivalente

2. Colaborador unidad: Carmen Dolores Chinea Rodríguez y Carolina Martín Meana

3. Número de camas UCl: 24

4. Número de Enfermeras totales UCl: 74

Hospital: Hospital Universitario Nuestra Señora de la Candelaria

Gestión: pública

Relación universidad: universitario

Camas hospital: 895

1. Tipo de Unidad: polivalente

2. Colaborador unidad: José Carlos Bonilla Pérez

3. Número de camas UCl: 26

4. Número de Enfermeras totales UCl: 70

TOLEDO:

Hospital: Hospital Nuestra Señora del Prado de Talavera

Gestión: pública

Relación universidad: universitario

Camas hospital: 330

Colaborador Investigación: Francisco Roman Najarro Infante

1. Tipo de Unidad: polivalente

2. Colaborador unidad: Gema Martin Corrochano

3. Número de camas UCl: 10

4. Número de Enfermeras totales UCI: 21 


\section{VALENCIA:}

Hospital: Hospital Universitario Doctor Peset

Gestión: pública

Relación universidad: universitario

Camas Hospital: 531

1. Tipo de Unidad: polivalente

2. Colaborador unidad: Ana Vargas Dobon

3. Número de camas UCl: 16

4. Número de Enfermeras totales UCl: 37

\section{Hospital: Hospital Lluis de Alcanyis de Xátiva}

Gestión: pública

Relación universidad: universitario

Camas Hospital: 267

Colaborador Investigación: Alicia Fernández Martínez

1. Tipo de Unidad: polivalente

2. Colaborador unidad: Josefina Vaya Albelda

3. Número de camas UCl: 12

4. Número de Enfermeras totales UCl: 24

Hospital: Hospital Universitario y Politécnico La Fe

Gestión: pública

Relación universidad: universitario

Camas hospital: 1000

Colaborador Investigación: Eva Rueda García

1. Tipo de Unidad: médica

2. Colaborador unidad: Josefa María Monzón Soriano

3. Número de camas UCl: 32

4. Número de Enfermeras totales UCI: 80

VALLADOLID:

Hospital: Hospital Universitario de Valladolid

Gestión: pública

Relación universidad: universitario 
Camas hospital: 762

Colaborador Investigación: Mercedes Fernández Castro

1. Tipo de Unidad: pediátrica

2. Colaborador unidad: Mercedes Fernández Castro

3. Número de camas UCI: 6

4. Número de Enfermeras totales UCI: 17 enfermeras

VIZCAYA:

Hospital: Hospital Universitario de Basurto / OSI Bilbao Basurto

Gestión: pública

Relación universidad: universitario

Colaborador Investigación: Verónica Tíscar González

Camas hospital: 733

1. Tipo de Unidad: cardiológica y coronaria

2. Colaborador unidad: Verónica Tíscar González

3. Número de camas UCl: 7

4. Número de Enfermeras totales UCl: 16

Hospital: Hospital Galdakao-Usansolo OSI Barrualde-Galdakao

Gestión: pública

Relación universidad: universitario

Colaborador Investigación: María Nerea Ingunza Basterra

Numero de Camas hospital: 376

1. Tipo de Unidad: polivalente

2. Colaborador unidad: Ainara Arana Azula

3. Número de camas $\mathrm{UCl}: 10$

4. Número de Enfermeras totales UCl: 25

\section{ZAMORA:}

Hospital: Hospital Virgen de la Concha de Zamora

Gestión: pública

Relación universidad: universitario

Colaborador Investigación: Ana Belén Baéz Marín

Camas Hospital: 349 
1. Tipo de Unidad: polivalente

2. Colaborador unidad: María Esther Antón Torio

3. Número de camas UCl: 11

4. Número de Enfermeras totales UCl: 23

\section{ZARAGOZA:}

Hospital: Hospital Universitario Miguel Servet

Gestión: pública

Relación universidad: universitario

Camas hospital: 1400

Colaborador Investigación: Delia González de la Cuesta

1. Tipo de Unidad: coronaria

2. Colaborador unidad: María Trinidad Piquer Gómez

3. Número de camas UCI: 12

4. Número de Enfermeras totales UCl: 27

1. Tipo de Unidad: polivalente

2. Colaborador unidad: Roberto Álvarez Otazu

3. Número de camas UCl: 12

4. Número de Enfermeras totales UCl: 27

1. Tipo de Unidad: pediátrica

2. Colaborador unidad: Elana fuertes Aragües

3. Número de camas $\mathrm{UCl}: 6$

4. Número de Enfermeras totales UCI: 12

1. Tipo de Unidad: trauma

2. Colaborador unidad: María Belen Vicente de Vera Bellosta

3. Número de camas UCl: 12

4. Número de Enfermeras totales UCI: 27

1. Tipo de Unidad: Post-quirúrgica

2. Colaborador unidad: Julia Villabona Resano

3. Número de camas UCl: 10

4. Número de Enfermeras totales UCI: 26 



\section{Anexo 4}

\section{UNWESBSTRT \\ JAUME I}

Beatriz Tomás Mallén, secretaria de la Comisión Deontológica de la Universitat Jaume I de Castelló de la Plana,

CERTIFICO: Que la Comisión Deontológica de la Universitat Jaume I ha emitido informe favorable sobre el proyecto de tesis con número de expediente 13/2017 "Necesidades formativas de las enfermeras de Cuidados Intensivos en España" del doctorando Yeray Gabriel Santana Padilla, cuya directora es Amparo Bernat Adell, por considerar que cumple las normas deontológicas exigidas.

Castellón de la Plana, 15 de septiembre de 2017 



\section{Anexo 5}

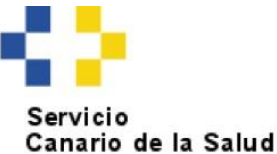

COMITÉ ÉTICO DE INVESTIGACIÓN CON MEDICAMENTOS PROVINCIAL LAS PALMAS. CEI/CEIm

\section{DICTAMEN DEL COMITÉ DE ÉTICA DE LA INVESTIGACIÓN/COMITÉ DE ÉTICA DE} LA INVESTIGACIÓN CON MEDICAMENTOS

Dña Ma DOLORES FIUZA PEREZ, Secretaria Técnica del Comité de Ética de la Investigación/Comité de Ética de la Investigación con Medicamentos (CEI/CEIm) Hospital Universitario de Gran Canaria Dr. Negrín.

\section{E R T I F I C A:}

Que este Comité, según consta en el Acta 3/2018 de fecha 26/04/2018 ha evaluado la propuesta del promotor: SANTANA PADILLA, YERAY GABRIEL, para que se realice el ESTUDIO OBSERVACIONAL - No-EPA. Titulado:

"Necesidades formativas de las enfermeras de Cuidados Intensivos en España".

Promotor: SANTANA PADILLA, YERAY GABRIEL Código CEIm LAS PALMAS: 2018-080-1/1016

Docs. con versiones:

\begin{tabular}{|l|l}
\hline Protocolo & Versión abril 2018 \\
\hline
\end{tabular}

CEIC de Referencia: CEI/CEIm Hospital Universitario de Gran Canaria Dr. Negrín.

Investigador Principal: D. YERAY GABRIEL SANTANA PADILLA del Complejo Hospitalario Universitario Insular Materno Infantil, Servicio Medicina Intensiva.

Y considera que:

Se cumplen los requisitos necesarios de idoneidad del protocolo en relación con los objetivos del estudio y están justificados los riesgos y molestias previsibles para el sujeto.

La capacidad del investigador y los medios disponibles son apropiados para llevar a cabo el ESTUDIO OBSERVACIONAL - NO-EPA

Es adecuado el procedimiento para obtener el consentimiento informado y el modo de reclutamiento.

El investigador y su equipo se comprometen a cumplir las recomendaciones y directrices de Buena Práctica Clínica aplicables a este tipo de estudios y la Declaración de Helsinki actualizada.

El alcance de las compensaciones económicas previstas no interfiere con el respeto a los postulados éticos. 
Servicio

Canario de la Salud

Gobierno
de Canarias

COMITÉ ÉTICO DE INVESTIGACIÓN CON

MEDICAMENTOS PROVINCIAL LAS PALIMAS.

CEI/CEIm

Asimismo, este Comité APRUEBA que dicho ESTUDIO OBSERVACIONAL - No-EPA sea realizado por la D. YERAY GABRIEL SANTANA PADILLA como Investigador Principal.

Que este Comité, tanto en su composición como en los PNTs, cumple con las normas de BPC (CPMP/ICH/135/95).

Con la elevación de este Dictamen a la Dirección Gerencia de este Centro para valoración de su Conformidad, terminan las acciones competencia de este CEI/CEIm sobre su estudio.

Que en dicha reunión se cumplió el quórum preceptivo legalmente.

Que, en el caso de que se evalúe algún proyecto del que un miembro sea investigador/colaborador, dicho miembro no participa en la evaluación ni el dictamen del propio protocolo.

Lo que firmo en Las Palmas de Gran Canaria, a 09 de mayo de 2018

La Secretaria Técnica

Fdo.: DÑA, Ma DOLORES FIUZA PEREZ

\section{Este documento ha sido firmado electrónicamente par:}

MARIA DOLORES FIUZA PEREZ

En la dirección https://sede.gobcan.es/sede/verifica_doc puede ser comprobada la 0qV2MO_7i3OwVf1JHFLGeSq14XNPam1wP

El presente documento ha sido descargado el 14/05/2018 - 13:06:35 
Servicio

Canario de la Salud

Gobierno
de Canarias

COMITÉ ÉTICO DE INVESTIGACIÓN CON

MEDICAMENTOS PROVINCIAL LAS PALMAS.

CEI/CEIm

\section{ANEXO I:}

La Composición actual del Comité es la siguiente:

\section{PRESIDENTE}

Dr. D. Vicente Olmo Quintana Resp. Servicio Farmacia de Atención Primaria

\section{VICEPRESIDENTE:}

Dr. D. Antonio García Quintana Jefe Servicio Cardiología. F.E.A. Servicio de Cardiologia HUGCDN

\section{SECRETARIA TECNICA:}

Dra. Da. Ma Dolores Fiuza Pérez. F.E.A. Epidemiología Clínica HUGCDN. Conocimientos acreditados

en Bioética

\section{VOCALES:}

Dr. D. Daniel López Fernández . Fisioterapéuta del Servicio de Rehabilitación HUGCDN

Dr. D. Antonio Tugores Cester. Responsable Unidad de Investigación CHUIMI

Dra. Da. Attenya Álamo Medina. F.E.A. Servicio de Farmacia Hospitalaria CHUIMI

Dr. D. José L. Alonso Bilbao. F.E.A. Técnico Salud Pública AP

Dr. D. Mauro Boronat Cortés. F.E.A. Servicio Endocrinología CHUIMI

Dr. D. David Aguiar Bujanda. F.E.A. Servicio Oncología Médica HUGCDN

Dra. Da. Elisabet Guerra Hernández F.E.A. Anestesiología y Reanimación HUGCDN

Da. Elisabeth Cheneau. D.U.E. Docencia, Salud Mental CHUIMI

Dr. D. Félix Isidro López Blanco. Farmacólogo Clínico, Dpto. Farmacología ULPGC - CHUIMI

Dr. D. Francisco J. Navarro Vázquez. F.E.A. Técnico salud Pública AP

Dr. D. Jordi López García. F.E.A. Servicio de Neumología CHUIMI

Dña. Fuensanta León Amador. Presidenta de la Asociación de Enfermos de Crohn y colitis ulcerosa de Canarias- Personal ajeno a las Instituciones Sanitarias

Dr. D. Jesús María González Martín. Estadístico Unidad de Investigación HUGCDN

D. José Juan Morales Castro. D.U.E. Área de Quirófano CHUIMI

Dr. D. Octavio Ramírez García. Presidente Comité Ética Asistencial CHUIMI. Conocimientos demostrados en Bioética

Dr. D. Jorge Arencibia Borrego. F.E.A. Servicio de Medicina Interna HUGCDN

Dra. Da. Beatriz Sánchez Lerma. F.E.A. Servicio Farmacia Hospitalaria CHUIMI

Dr. D. Jorge Solé Violán. F.E.A. Servicio de Medicina Interna HUGCDN

D. Julio Ángel de Santiago Angulo. Lcdo. en Derecho, Asesor Jurídico CHUIMI

Dra. Da. Ma. Asunción Acosta Mérida. F.E.A. Servicio de Cirugia General y Digestiva HUGCDN

Dra. Da. Blanca Valenciano Fuente. F.E.A. Pediatra, Servicio de Pediatría CHUIMI

Dña. Rita del Carmen Gutiérrez Gil. Lcda. en Derecho, Asesora Jurídica HUGCDN

Dra. Da. Silvia de la Iglesia Iñigo F.E.A. Servicio de Hematología HUGCDN

Dra. Da. Juana Teresa Rodríguez Sosa. F.E.A. Servicio de Psiquiatría HUGCDN

Da. Ma. Dolores Jarillo López-Mora. D.U.E. Enfermería HUGCDN

Dra. Da. Mireya Amat López. F.E.A. Servicio de Farmacia Hospitalaria HUGCDN

Dra. Da. Ana Aldea Perona. Farmacólogo Clínica HUC

Da. Ma. Del Pino Fierro Ferreyra. Periodista personal ajeno a las Instituciones Sanitarias

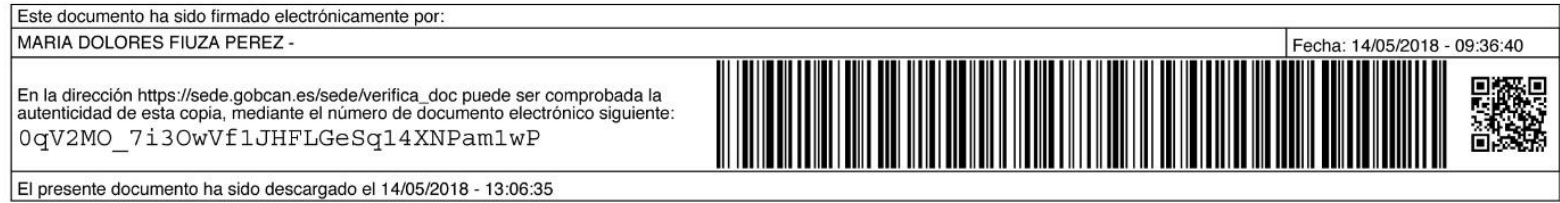




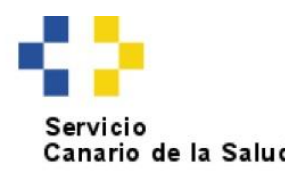

COMITÉ ÉTICO DE INVESTIGACIÓN CON

MEDICAMENTOS PROVINCIAL LAS PALMAS.

CEI/CEIm

\section{ANEXO II:}

Centros colaboradores:

Hospital Universitario de Gran Canaria Dr. Negrín.

Hospital Dr. José Molina Orosa. Lanzarote.

Hospital General de Fuerteventura.

En la dirección https://sede.gobcan.es/sede/verifica_doc puede ser comprobada la 


\section{CONFORMIDAD DE LA DIRECCIÓN DEL CENTRO}

Don Victor Naranjo Sintes Director Gerente del COMPLEJO HOSPITALARIO UNIVERSITARIO INSULAR-MATERNO INFANTIL, al amparo de la Orden SAS/3470/2009 y vista la autorización del Comité de Ética de la Investigación/Comité de Ética de la Investigación con Medicamentos (CEI/CEIm) de este Hospital (Acta 3/2018).

\section{E R T I F I C A:}

Que conoce la propuesta realizada por el promotor SANTANA PADILLA, YERAY GABRIEL para que sea realizado en este Centro el ESTUDIO OBSERVACIONAL - No-EPA Titulado:

\section{"Necesidades formativas de las enfermeras de Cuidados Intensivos en España"}

Promotor: SANTANA PADILLA, YERAY GABRIEL

Código CEIm H.U.G.C. Dr. NEGRIN: 2018-080-1/1016

CEIC de Referencia: CEI/CEIm H.U.G.C. Dr. Negrín

Y que será realizado por el Dr. YERAY GABRIEL SANTANA PADILLA del Servicio de Medicina Intensiva como Investigador Principal.

Que se está de acuerdo con las condiciones establecidas entre el Centro y el Promotor en el que se especifican todos los aspectos relativos a este ESTUDIO OBSERVACIONAL No-EPA.

Que acepta la realización de dicho ESTUDIO OBSERVACIONAL - No-EPA en este Centro.

Lo que firma en Las Palmas de Gran Canaria, a 09 de mayo de 2018

El Director Gerente

Fdo: D. Victor Naranjo Sintes

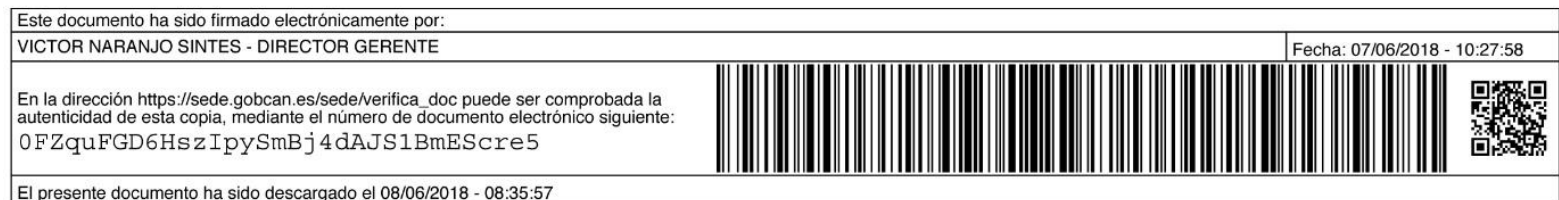




\begin{tabular}{|c|c|c|}
\hline 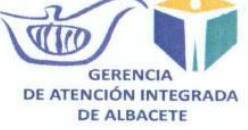 & $\begin{array}{l}\text { COMITÉ DE ÉTICA DE LA } \\
\text { INVETIGACIÓN CON } \\
\text { MEDICAMENTOS }\end{array}$ & $\begin{array}{c}\text { Informe } \\
\text { Conformidad del CEIm }\end{array}$ \\
\hline
\end{tabular}

D. Pedro Abizanda Soler, Presidente del Comité de Ética de la Investigación con Medicamentos de la Gerencia de Atención Integrada de Albacete

\section{INFORMA}

Que este Comité en su reunión de fecha 24 de julio de 2018, Acta 07/2018, ha evaluado el proyecto con código interno No 2018/05/069.

\section{TITULADO: NECESIDADES FORMATIVAS DE LAS ENFERMERAS EN CUIDADOS INTENSIVOS EN} ESPAÑA. Tesis Doctoral.

Investigadora Principal: Da. Yeray Gabriel Santana Padilla. Directora de la Tesis $D^{a}$. Ma. Desamparados Bernat Adell, Directora Unidad Predepartamental de Enfermería, Universitat Jaume I, Castelló de la Plana.

Investigador Principal en el hospital de Hellín: D. RAMÓN JESÚS AZOR GARCIA.

Considera que: Se cumplen los requisitos necesarios de idoneidad del proyecto en relación con los objetivos del estudio.

La capacidad del investigador y los medios disponibles son apropiados para llevar acabo el estudio.

Es adecuado el procedimiento para obtener el consentimiento informado.

Por tanto emite: INFORME FAVORABLE.

Este Comité en sus funciones, composición y en los PNT's cumple con las normas de BPC-CPMP/ICH/135/95 y el Real Decreto 1090/2015 y que su composición actual es la siguiente:

D. Pedro Abizanda Soler

Da. Ma Angeles Lloret Callejo

Da. Eva García Martínez

Da Carmen Díaz Delgado

D. José Gerardo Espinosa Martínez

Da. Beatriz Navarro Bravo

Da. Dolores Jativa Gascó

D. Jesús López-Torres Hidalgo

Da Syonghyun Nam Cha

Da María Pilar Marcos Rabal

D. José Luis Cortes Monedero

D. Alberto Sánchez Romero

D. Ignacio Párraga Martínez

$D^{a}$. Ma. del Carmen Carrascosa Romero

D. Manuel Gerónimo Pardo

Da. Pilar Córcoles Jiménez

Da. Encarna Adrover Cebrián

D. Antonio Honguero Martínez

D. Francisco Javier Callejas González

D. Antonio Gutiérrez Díez

Da. Karen Nieto Rodríguez

Da. Carmen María Bernal Mañas

D. Julián Eloy Solís García del Pozo
PRESIDENTE. Dr. en Medicina. S. Geriatría

VICEPRESIDENTA. Licenciada en Farmacia. S Farmacia AP

SECRETRIA TECNICA. Dra. en Farmacia. S. Farmacia Hospitalaria.

Dra. en Medicina. Profesora Titular de Histología UCLM.

Licenciado en Derecho.

Ajeno a la profesión sanitaria

Ajeno a la profesión sanitaria

Dr. en Medicina. Centro Salud Zona VIII

Licenciada en Medicina. Anatomía Patológica.

Dra. Biología. Prof. Titular de Ciencias Morfológicas UCLM.

Licenciado Medicina. Unidad de Cuidados Intensivos.

Licenciado en Medicina. S. Farmacología Clínica

Dr. en Medicina. Centro Salud La Roda

Licenciada en Medicina. S. Pediatría

Dr. en Medicina. S Anestesiología

Enfermera. Supervisora de Investigación y Docencia

Licenciada en Medicina. S. Oncología

Licenciado en Medicina. S. Cirugía Torácica

Licenciado en Medicina. S Neumología

Licenciado en Medicina. S. Cardiología

Licenciada en Medicina. S. Psiquiatría

Licenciada en Medicina. Anatomía Patológica. Hospital de Hellín.

Licenciado en Medicina. S Medicina Interna. Hospital de Villarrobledo.

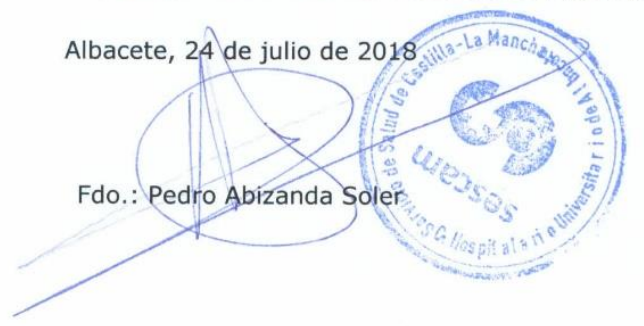




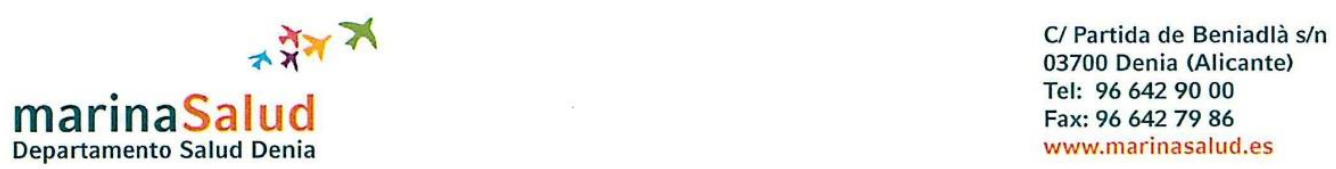

Denia, 28 de marzo del 2018

D. Enrique España Álvarez, secretario de la Comisión de Investigación del Departamento de Salud Dénia.

\section{CERTIFICA:}

Que esta Comisión ha evaluado y ha aprobado la Tesis Doctoral titulada: Necesidades Formativas de las Enfermeras en Cuidados Intensivos en España, cuyo investigador es Yeray Santana Padilla, doctorando de la Universidad Jaume I de Castellón.

Autorizando:

Realizar el citado estudio en el Departamento de Salud Dénia.

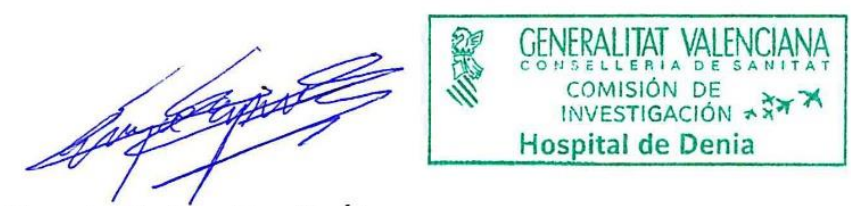

Firmado: Enrique España Álvarez

Secretario de la Comisión de Investigación 
GENERALITAT

VALENCIANA

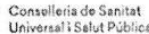

COMITÉ DE ÉTICA DE LA INVESTIGACIÓN (CEI) DEL HOSPITAL GENERAL UNIVERSITARIO DE ELDA Ctra. Elda-Sax, s/n. 03600-Elda. http://www.elda.san.gva.es

Departamento de Elda

\section{Comité de Valoración Institucional del Hospital General Universitario de Elda} Institutional Review Board of Elda General University Hospital

Fecha $23 / 04 / 2018$

Número Protocolo Estudio Clínico

Clinical Study Protocol Number

$\mathrm{PI} 2018 / 05$

Investigador Principa

Principal Investigator

D. Yeray G. Santana Padilla

Departamento

Doctorando de la Universidad

Department Jaime I de Castellón

\begin{tabular}{|l|llll}
\hline Título del Proyecto & $\begin{array}{l}\text { NECESIDADES FORMATIVAS DE LAS ENFERMERAS DE CUIDADOS } \\
\text { INTENSIVOS. } \\
\text { TRAINING REQUIREMENTS OF INTENSIVE CARE NURSES IN SPAIN. }\end{array}$ \\
Project Title & TRAIN R
\end{tabular}

\section{CERTIFICA /CERTIFIES}

Que el estudio arriba indicado, habiendo completado satisfactoriamente todos los requerimientos impuestos por las autoridades de este País, incluyendo los de la Declaración de Helsinki (AMM, 2008) y las Normas de Buena Práctica Clínica de la Unión Europea,

That the above study, having successfully completed all the requirements imposed by the authorities of this Country, including those of the Declaration of Helsinki (WMA, 2008) and Norms of Good Clinical Practice of the European Union,

fue APROBADO por este CEIm

was APPROVED by this IRB

\begin{tabular}{|l|l|}
\hline $\begin{array}{l}\text { en (fecha) } \\
\text { on (date) }\end{array}$ & $23 / 04 / 2018$ \\
\hline
\end{tabular}

\begin{tabular}{|l|l|}
\hline $\begin{array}{l}\text { y efectivo hasta (fecha) } \\
\text { and effective until (date) }\end{array}$ & $30 / 04 / 2020$ \\
\hline
\end{tabular}

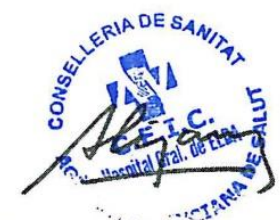

Dr. Alejandro Lizaur Utrilla.

Secretario [Secretary]

CEI Hospital G. U. Elda [IRB Elda G. U. Hospital] 


\section{COMITÉ DE ÉTICA DE LA INVESTIGACIÓN DE ALMERÍA}

JOSE JAVIER VAQUERO MARTÍNEZ, Secretario del Comité de Ética de la Investigación de Almería

\section{CERTIFICA}

Que, este Comité ha evaluado la Tesis Doctoral, del estudio de investigación titulado "Necesidades formativas de las enfermeras de cuidados intensivos en España ". Código interno: 14/2018. Acta ( 6/2018) y considera que:

El estudio no presenta problemas de aspecto ético, tratándose de una investigación que no realiza ninguna intervención a pacientes ni voluntarios sanos, ni incluye el uso de muestras biológicas.

El tratamiento de los datos de carácter personal de los participantes se ajusta a lo dispuesto en el Reglamento Europeo 679/2016 del Parlamento Europeo y del Consejo de 27 de abril de 2016 de Protección de Datos.

Por ello, el Comité de Ética de la Investigación de Almería, tras la valoración del citado estudio, APRUEBA la realización del mismo en la Unidad de Cuidados Intensivos del Complejo Hospitalario Torrecárdenas por D. Yeray Santana Padilla como Investigador principal y D.Francisco Javier Lao Barón como Colaborador.

Lo quei firmo en Almeria, a veintisiete de junio de ags mil dieciocho.

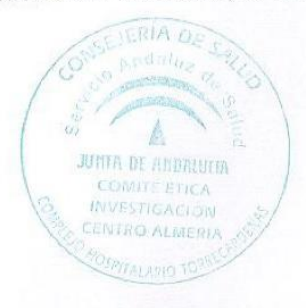

Fdo. José Javier Vaquero Martínez

Complejo Hospitalario Torrecárdenas

Hermandad de Donantes de Sangre, sin. 04009 Ammería. Tifno. 950016000

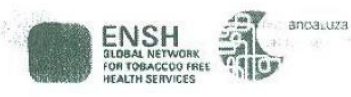


Hospital Infanta Cristina

Complejo Hospitalario

SES Universicario de Bariator

\section{Da. M.TERESA GARLITOS ZORRO, DIRECTORA DE ENFERMERIA DE A.E. DEL ÁREA DE SALUD DE BADAJOZ.}

\section{AUTORIZO:}

A D. Yeray Santana Padilla , para poder realizar la encuesta Google sobre las necesidades formativas de las enfermeras de U.C.I. encuadrada en su proyecto de Doctorado que nos ha solicitado.

Su contacto para poder llevar a cabo esta encuestas será la Responsable de Formación en el Hospital "Infanta Cristina", Da Teresa Fernández Alonso, que se encargará de facilitar dicha encuesta a los profesionales de la Unidad de U.C.I.

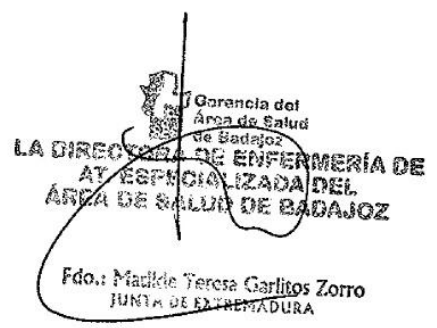




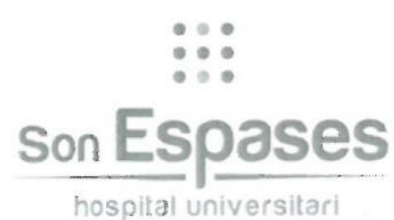

Prasident :

Antorio Cliver

Microbiclog:a 75252

antonio.oilver@ssib.es

Vocals :

Manue: del Rio

Subcirector Sericios Méricos

manueldelo@s b.es

Joana M. Ferrer

juanam.fererioss ij.es

Borja Cosio

Neira Cosio 64513

borja.cosio@ssib.es

Meich.or Riera

M.Interna 76148

melchor.riera@ssib.es

Damian Heire

dam $3 n$.heine âss.j.es

Artoria Barceio

Ana'te's el'nicos 65489

antoria.barcolo@ssib.es

Francesca Cañe las

Psiquiatria 76081

francesca.carellas@ssib.es

Miguel Fo

D. Cientric ic spa 7523

miguel. fol@ssib.es

Antorio Gulérrez

Hemalologia 55118

an:onicm. guterrez Qssib.es.

Cristòfol Vives-Bauzá

UNI-Neurociències 66309

cristofol.vives@ss b.es

Givendoyn Barcs.o Cob

UN-Lipids 26300

gwendoiyn. barce'oCssib.es

P.lar Andreu Rocir go

Aica formacio docenc a

invos gacio: domena ili!

G CONSELLERIA

O SALUT

I

La COMISIÓN DE INVESTIGACIÓN del Hospital Universitario Son Espases de Palma de Mallorca, ha evaluado la solicitud de PROYECTO de YERAY GABRIEL SANTANA PADILLA (UJI) y CELIA SÁNCHEZ CALVIN (HUSE), del Hospital Universitario Son Espases, titulado: "Necesidades formativas de las enfermeras de Cuidados Intensivos en España”.

Revisada la documentación, informa favorablemente dicha petición por considerarla de interés para el HOSPITAL.

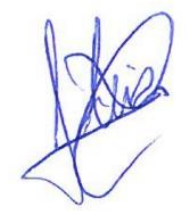

Dr. A. Oliver Palomo

Pres. Comisión Investigación

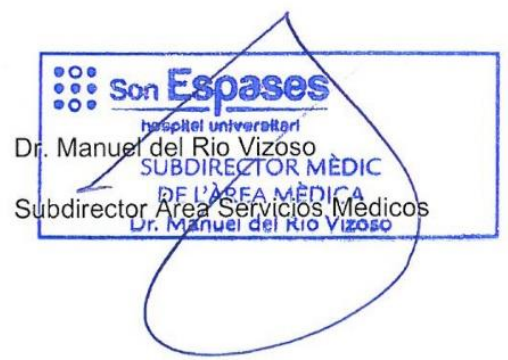

Ctra. de Valldemossa, 79

Tel. $(+34), 87: 205000$

Fax $(+34) 871205500$

sonespases infoessib.es

www.hospitalsonespases.es

.

. 
训

G CONSELLERIA

O SALUT

I HOSPITA

B COMARCAI. INCA

Apreciado/a investigador/a

Por la presente le comunico que el proyecto "Necesidades Formativas de las

Enfermeras de Cuidados intensivos en España", valorado el día 12 de junio de 2018, ha obtenido el visto bueno de la Comisión de Investigación del Hospital Comarcal de Inca (Cl$\mathrm{HCIN}$ ).

Muy cordialmente,

Inca a 12 de junio de 2018

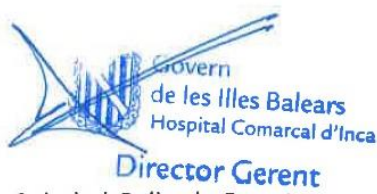

Soledad Gallardo Bonet

Directora Gerente del HCIN

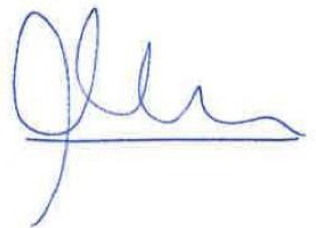

Concha Zaforteza Lallemand

Presidenta de la CI-HCIN 


\section{$\|$ II Bospital Universitari}

\section{AUTORIZACIÓN DE LA DIRECCIÓN ENFERMERA}

El Dr. Jordi Adamuz Tomás como Enfermero de soporte a la investigación del Hospital Universitario de Bellvitge, y en representación de la Dirección Enfermera

Declaro:

Que conozco la documentación relativa al proyecto de investigación biomédica que lleva por título "Necesidades formativas de las enfermeras de Cuidados Intensivos en España"

Y cuyo investigador principal será el Sr. Yeray Gabriel Santana Padilla

Que el investigador principal, así como el resto del equipo, reúne las características de competencia necesarias para llevar a cabo este proyecto así como la metodología específica del proyecto en cuestión.

Que autorizo la realización de este proyecto de investigación biomédica en el Servicio/Unidad descrita.

En L'Hospitalet de Llobregat a 15 de mayo de 2018

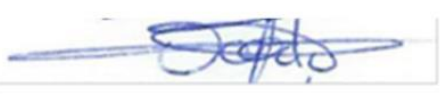

Fdo. Dr. Jordi Adamuz Tomás

Enfermero de soporte a la investigación del Hospital Universitario de Bellvitge 


\section{I|l| Bellvitge Hospital Universitari SOBRE PROYECTOS DE INVESTIGACIÓN}

El Dr. Enric Sospedra Martínez, Secretario del Comité Ético de Investigación Clínica del Hospital Universitari de Bellvitge,

\section{CERTIFICA}

Que el Comité de Ética de Investigación Clínica del Hospital Universitari de Bellvitge, en su reunión de fecha 7 de Junio de 2018 (Acta 11/18), tras examinar toda la documentación presentada sobre el proyecto de investigación con nuestra ref. PR259/18, titulado:

"NECESIDADES FORMATIVAS DE LAS ENFERMERAS DE CUIDADOS INTENSIVOS EN ESPAÑA".

Presentado por el Dr. Rafael Franc Justel García del Servicio de Medicina Intensiva del Hospital Universitari de Bellvitge, como investigador principal y promovido por Yeray Santana Padilla del Servicio de Medicina Intensiva del Hospital Universitario Insular de Gran Canaria, ha acordado emitir INFORME FAVORABLE al mencionado proyecto.

Que la composición actual del Comité de Ética de Investigación Clínica es la siguiente:

$\begin{array}{ll}\text { Presidente } & \text { Dr. Francesc Esteve Urbano } \\ \text { Vicepresidente } & \text { Dra. Pilar Hereu Boher } \\ \text { Secretario } & \text { Dr. Enric Sospedra Martínez } \\ \text { Vocales: } & \text { Dr. Jordi Adamuz Tomás } \\ & \text { Dra. Maria Berdasco Menéndez } \\ & \text { Dra. Concepción Cañete Ramos } \\ & \text { Dr. Enric Condom Mundo } \\ & \text { Dr. Xavier Corbella Virós } \\ & \text { Sra. Consol Felip Farrás } \\ & \text { Dr. José Luis Ferreiro Gutiérrez } \\ & \text { Dra. Ana María Ferrer Artola } \\ & \text { Dr. Josep Ricard Frago Montanuy } \\ & \text { Dr. Xavier Fulladosa Oliveras } \\ \text { Dra. Margarita García Martín } \\ \text { Dr. Carles Lladó i Carbonell } \\ \text { Dr. Josep Manel Llop Talaveron } \\ \text { Sra. Sonia López Ortega } \\ \text { Dr. Sergio Morchón Ramos } \\ \text { Dr. Joan Josep Queralt Jiménez } \\ \text { Dr. Ricard Ramos Izquierdo }\end{array}$

Presidente Secretario

Dr. Ricard Ramos Izquierdo
Médico - Medicina Intensiva

Médico - Farmacología Clínica

Farmacéutico - Farmacia Hospitalaria

Enfermero - Enfermería

Bióloga - miembro no sanitario

Médico - Neumología

Médico - Anatomía Patológica

Médico - Medicina Interna

Miembro Laico - Docencia

Médico - Cardiología

Farmacéutica - miembro sanitario

Médico - Cirugía General y Digestiva

Médico - Nefrología

Médico - Oncología Médica

Médico- Urología

Farmacéutico - Farmacia Hospitalaria

Graduado Social - Atención a la Ciudadanía

Médico - Medicina Preventiva

Jurista

Médico - Cirugía Torácica 


\section{I|||__ Bellvitge}

Generalitat de Catalunya

Departament de Salut

Institut Català
de la Salut
Dra. Gemma Rodríguez Palomar
Dra. Nuria Sala Serra
Farmacéutica - Atención Primaria
Dr. Petru Cristian Simon
Bióloga - miembro no sanitario
Médico - Farmacología Clínica

Que este Comité cumple la legislación española vigente para este tipo de proyectos, así como las normas $\mathrm{ICH}$ y las Normas de Buena Práctica Clínica.

Que en dicha reunión del Comité de Ética de Investigación Clínica se cumplió el quórum preceptivo legalmente.

Lo que firmo en L'Hospitalet de Llobregat, a 7 de Junio de 2018

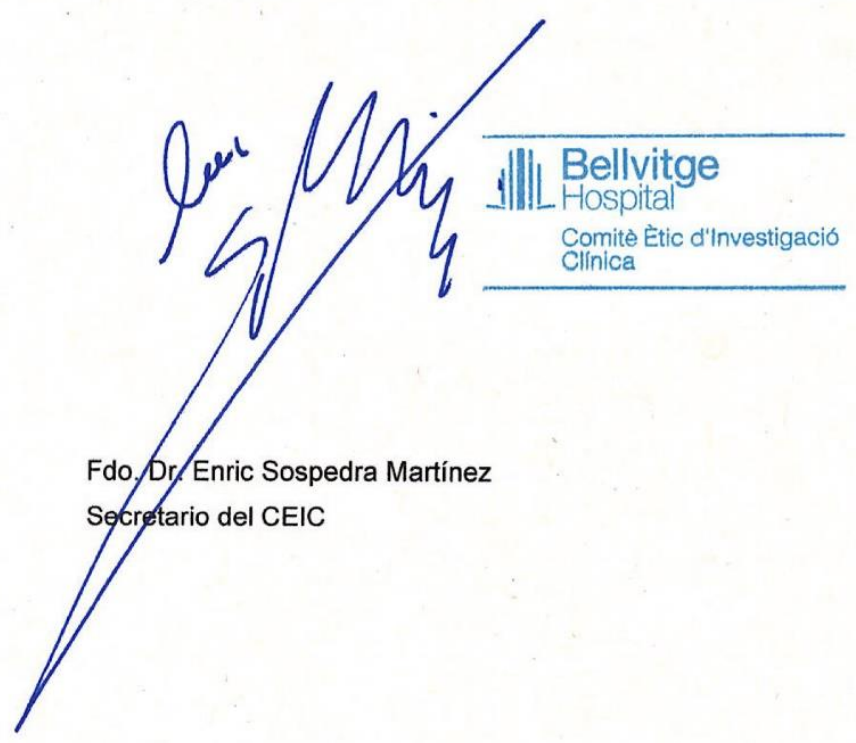




\section{Ill Bellvitge $_{\text {Hospital Universitari }}$}

Institut Català
de la Salut

Observaciones a la aprobación para uso exclusivo del investigador*:

A pesar del informe favorable, se trasladan los siguientes aspectos al investigador, considerados relevantes por el CEIC, en relación a la versión online del consentimiento informado:

1. En relación al formato, debería revisarse el documento con un corrector.

2. Además se debe de mencionar que el estudio ha sido aprobado por el CEI correspondiente $y$ referenciar la Ley de Investigación Biomédica 14/2007 y el reglamento UE 2016/679 de confidencialidad, permitiendo los derechos de acceso, rectificación, cancelación, oposición, limitación del tratamiento de datos que sean incorrectos, solicitar una copia o que se trasladen a un tercero, y especificar cómo a quién debe recurrir para ejercerlos.

Se debería otorgar versión y fecha del documento, añadir el título del estudio y teléfono de contacto.

* Una vez implementados los cambios, puede remitirse las respuestas a presidenciaceic@bellvitgehospital.cat 


\section{I|l| Bellvitge \\ Hospital Universitari \\ Institut Català
de la Salut}

\section{CONFORMIDAD DE LA DIRECCIÓN DEL CENTRO}

La Dra. Cristina Capdevila Aguilera, Directora del Centro del Hospital Universitari de Bellvitge, vista la aprobación del Comité Ético de Investigación Clínica,

\section{CERTIFICA:}

Que conoce la propuesta realizada por el promotor Yeray Santana Padilla del Servicio de Medicina Intensiva del Hospital Universitario Insular de Gran Canaria para que sea realizado en este Centro el proyecto de Investigación Biomédica con nuestra referencia PR259/18 titulado: “NECESIDADES FORMATIVAS DE LAS ENFERMERAS DE CUIDADOS INTENSIVOS EN ESPAÑA", que será realizado por el Dr. Rafael Franc Justel García del Servicio de Medicina Intensiva como investigador principal, aprobado por el Comité de Ética de Investigación Clínica (CEIC) del Hospital Universitari de Bellvitge en su reunión de fecha 7 de Junio de 2018 (Acta 11/18)

Que acepta la realización de dicho estudio en este Centro, una vez sea firmado el correspondiente contrato entre el Centro y el Promotor, si procede, en el que se especifican todos los aspectos económicos.

Lo que firmo en L'Hospitalet de Llobregat, a 7 de Junio de 2018

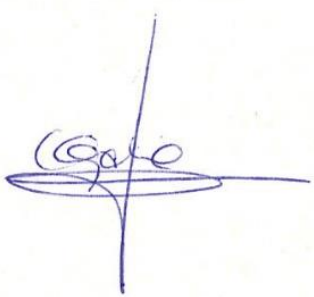

Dra. Cristina Capdevila Aguilera

Directora de Centro 


\title{
COMITÉ ÉTICO DE INVESTIGACIÓN CLÍNICA DE CANTABRIA IDIVAL
}

T. CONCEPCION SOLANAS GUERRERO, Secretario/a del COMITÉ ÉTICO DE INVESTIGACIÓN CLÍNICA DE CANTABRIA

\author{
CERTIFICA
}

Que este Comité ha evaluado la propuesta del Investigador Principal del estudio:

TÍTULO: Necesidades formativas de las enfermeras de Cuidados Intensivos en España.

TIPO DE ESTUDIO: Proyecto de Investigación (Código interno: 2018.103)

y considera que:

- Se cumplen los requisitos necesarios de idoneidad del protocolo en relación con los objetivos del estudio y están justificados los riesgos y molestias previsibles para el sujeto, teniendo en cuenta los beneficios esperados.

- Es adecuado el procedimiento para obtener el consentimiento informado.

- La capacidad del investigador y sus colaboradores, y las instalaciones y medios disponibles, tal y como ha sido informado, son apropiados para llevar a cabo el estudio.

Este CEIC, emite un informe FAVORABLE para que dicho Estudio sea realizado en el HOSPITAL UNIVERSITARIO MARQUÉS DE VALDECILLA, actuando como investigador principal Dña. Ma GEMA GARCÍA LóPEZ.

Como queda reflejado en el Acta: 09/2018.

Lo que firmo en Santander, a 11 de mayo de 2018

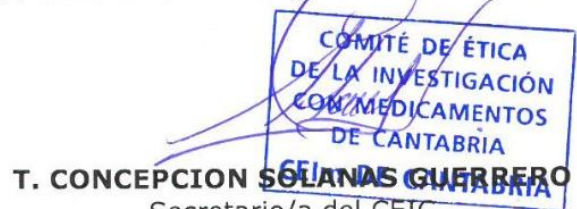

Secretario/a del CEIC 


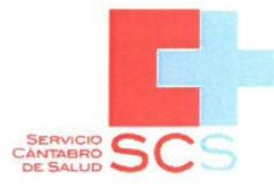

(2) Valdecilla

Dirección Gerencia

\section{CONFORMIDAD DE LA DIRECCIÓN DEL CENTRO}

Don JULIo PASCUAL Gómez Director Gerente del Hospital Universitario Marqués de Valdecilla, visto el informe científico-técnico del Área de Calidad, Formación, I+D+i de Enfermería.

\section{CERTIFICA QUE}

Conoce la propuesta realizada por Yeray Gabriel Santana Padilla, como investigador principal, para que sea desarrollado en este Centro el estudio, titulado "Necesidades formativas de las enfermeras de Cuidados Intensivos en España", así como el compromiso del Equipo Investigador al cumplimiento de la normativa aplicable al mismo, incluyendo la LO 15/1999 de protección de datos de carácter personal, y el RD $1720 / 2007$, de 21 de diciembre, por el que se aprueba el reglamento de desarrollo de la Ley Orgánica 15/1999.

En virtud de las autorizaciones obtenidas para este estudio:

- Se cumplen los requisitos necesarios de idoneidad del Proyecto de Investigación, en relación con los objetivos propuestos y están justificados los riesgos y molestias previsibles para el sujeto.

- Son adecuados tanto el procedimiento para obtener el Consentimiento Informado, como el modo de reclutamiento previsto.

ACEPTA la realización de dicho Proyecto en este Centro.

Lo que firma en Santander a 05 de junio de 2018

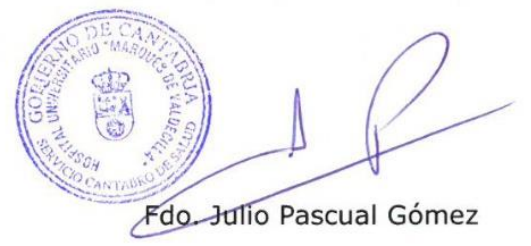

Correo electrónico:

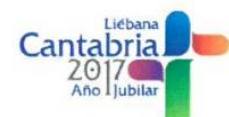

Avda. de Valdecilla, $s / n$ 39008 Santander Teléfono: 942202560 

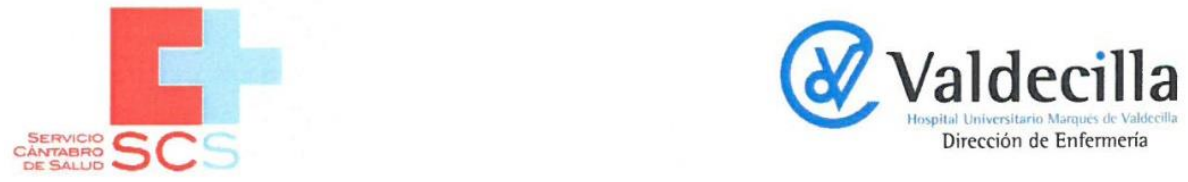

\section{CONFORMIDAD DE LA DIRECCIÓN DEL CENTRO}

Doña NURIA Ma MARTÍnez RUEDA Directora de Enfermería del Hospital Universitario Marqués de Valdecilla, visto el informe científico-técnico del Área de Calidad, Formación, I+D+i de Enfermería.

\section{CERTIFICA QUE}

Conoce la propuesta realizada por Yeray Gabriel Santana Padilla, como investigador principal, para que sea desarrollado en este Centro el estudio, titulado "Necesidades formativas de las enfermeras de Cuidados Intensivos en España", así como el compromiso del Equipo Investigador al cumplimiento de la normativa aplicable al mismo, incluyendo la LO 15/1999 de protección de datos de carácter personal, y el RD $1720 / 2007$, de 21 de diciembre, por el que se aprueba el reglamento de desarrollo de la Ley Orgánica 15/1999.

En virtud de las autorizaciones obtenidas para este estudio:

- Se cumplen los requisitos necesarios de idoneidad del Proyecto de Investigación, en relación con los objetivos propuestos y están justificados los riesgos y molestias previsibles para el sujeto.

- Son adecuados tanto el procedimiento para obtener el Consentimiento Informado, como el modo de reclutamiento previsto.

ACEPTA la realización de dicho Proyecto en este Centro.

Lo que firma en Santander a 05 de junio de 2018

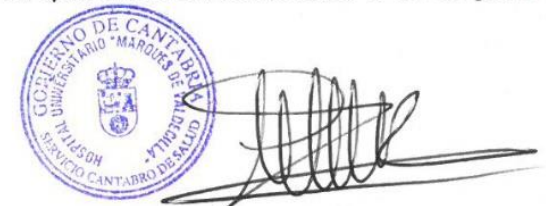

Fdo. Nuria Ma Martínez Rueda

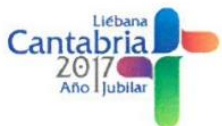


Dervicio Andaluz de Salud

CONSEIERIA DE IGUALIDAD
SAIUDY Y POITISAS SOCIALSS

\section{COMITÉ DE ÉTICA DE LA INVESTIGACIÓN DE LA PROVINCIA DE JAEN}

Da. Elisa Nieves Godoy, Secretaria del Comité de Ética de la Investigación de la Provincia de Jaén,

\section{CERTIFICA}

Que ha valorado la propuesta del promotor D. Yeray Santana Padilla, Enfermero y Doctorando de la Universidad Jaume I, de Castellón de la Plana, del estudio de investigación titulado: Tésis Doctoral . "Necesidades formativas de las Enfermeras en Cuidados Intensivos en España", por el procedimiento establecido por el Comité Coordinador de Ética de la Investigación Biomédica de Andalucia, en su reunión de 21 de junio de 2016, para los estudios de Baja Carga Ética,

\section{$Y$ considera que,}

El estudio no presenta problemas de aspecto ético, tratándose de una investigación que no realiza ninguna intervención a pacientes, ni voluntarios sanos, ni incluye el uso de muestras biológicas, ni el uso de ningún tipo de datos de pacientes.

El tratamiento de los datos de carácter personal de los participantes se ajusta a lo dispuesto en la Ley Orgánica 15/1999 de 13 de diciembre de protección de datos de carácter personal.

Por ello, el Comité de Ética de la Investigación de Jaén, tras la valoración del citado estudio, APRUEBA la realización del mismo.

Lo que firmo en Jaén,

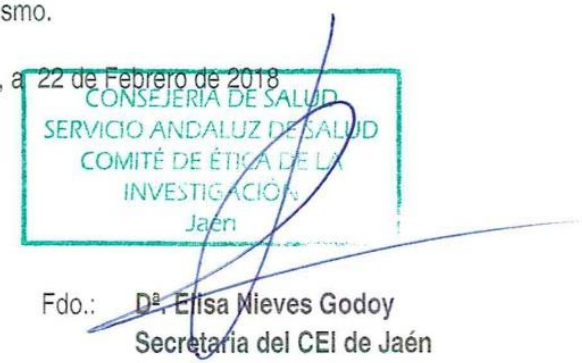


sudularaxid Severo Ochoa

D. Ricardo Díaz Abad, Secretario del Comité de Ética de la Investigación con medicamentos del Hospital Universitario Severo Ochoa,

\section{CERTIFICA}

Que el Proyecto de Tesis con título:

"Necesidades formativas de las enfermeras de Cuidados Intensivos en España"

Ha sido valorado por este CEIm en su reunión de fecha 27 de junio de 2018 y considerando que:

No es un estudio que se realice con pacientes, ni precisa de consentimiento informado de ningún tipo, no plantea problemas éticos derivados de los estudios o ensayos con pacientes habituales, por lo que este CEIm

ACEPTA que sea llevado a cabo por D. Yeray Gabriel Santana Padilla de la Universidad Jaume I de Castellón de la Plana (Castellón) y dirigido por $\mathbf{D}^{\mathbf{a}}$. Amparo Bernat Adell, al considerar que no presenta problemas éticos para su realización.

$1^{\circ}$. El CEIm, tanto en su composición, como en los PNTs cumple las normas de BPC (CPMP/ICH/135/95) y con la Orden SAS 3470/2009, de 16 de diciembre.

$2^{\circ}$. La composición actual del CEIm es la siguiente:

D. Adolfo Ramos Luengo

D. Carlos González Juárez

D. Ricardo Díaz Abad

$D^{a}$. Ana López Martín

$D^{a}$ Amparo Lucena Campillo

$D^{a}$ Beatriz Medina Bustillo

D. Miguel Cervero Jiménez

D. Sergio Quevedo Teruel

D. Daniel Ordorica Rubiano

$\mathrm{D}^{\mathrm{a}}$. Lucía Llanos Jiménez

$\mathrm{D}^{\mathrm{a}}$. $\mathrm{M}^{\mathrm{a}}$ Teresa Rodríguez Monje

$D^{a}$ Isabel Herranz Lama Noriega

$D^{a}$ Ana Isabel Martín Cuesta

D. Manuel Martínez Domínguez
Presidente, adjunto del Servicio de Anestesiología

Vicepresidente, adjunto de Psiquiatría

Secretario Técnico, adjunto de Medicina Intensiva

Vocal, adjunta del servicio de Oncología.

Vocal, adjunta del servicio de Farmacia

Vocal, Farmacéutica Atención Primaria Dirección Asistencial Sur

Vocal, Presidente de la Comisión de Investigación

Vocal, adjunto de Pediatría y Áreas Específicas.

Vocal, enfermero, Especialista en Geriatría.

Vocal, Farmacóloga Clínica

Vocal, médico de Atención Primaria.

Vocal lego, Lda. en Derecho, Especialista en Derecho sanitario.

Vocal, miembro lego, administrativa del CEIm

Vocal, miembro lego representante de los pacientes

Leganés, 27 de junio de 2018

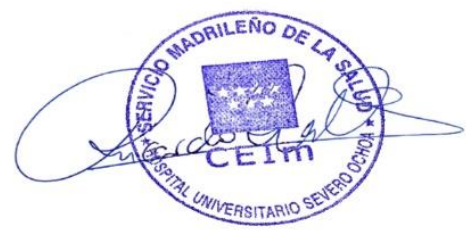

Fdo.: Ricardo Díaz Abad 


\section{Hospital Universitario saludmadrid de Móstoles}

Dña. Manuela Mateos Romero Directora de Enfermeria del Hospital Universitario de Móstoles.

\section{Autorizo:}

A D $D^{a}$. Yeray Santana Padilla, para poder realizar la encuesta Google sobre las necesidades formativas de las enfermeras de U.C.I. encuadrada en su proyecto de Doctorado que nos ha solicitado.

Su contacto para poder llevar a cabo estas encuestas será la Enfermera de Cuidados Intensivos del Hospital Universitario de Mostoles Dña. Saray Blanco Abril, que se encargará de facilitar dicha encuesta a los profesionales de la Unidad de U.C.I.

Móstoles 14 de mayo de 2018,

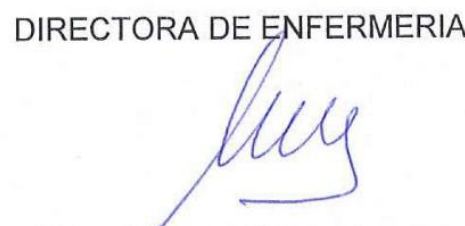

Dña. Manuela Mateos Romero

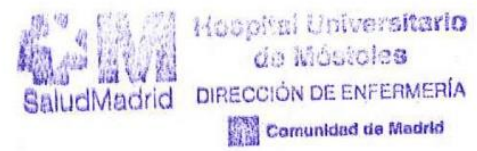

C/ Río Júcar $s / n$

28935 Móstoles-Madrid

TI. 916648641

e-mail: direnf.hmtl.@salud.madrid.org

www.madrid.org/hospitalmostoles

Red

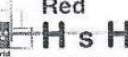

Fumar perjudica su salud y la de los que le rodean Está prohibido fumar en los centros sanitarios (Ley 42/2010) 

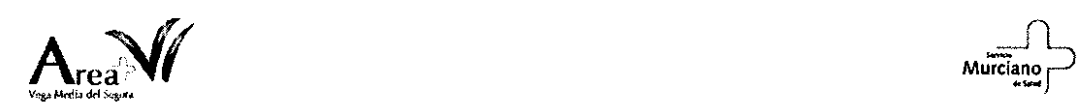

AUTORIZACIÓN PARA LA REALIZACIÓN DE UN ESTUDIO DE INVESTIGACIÓN

COMISIÓN DE EVALUACIÓN DE TRABAJOS DE INVESTIGACIÓN (CETI)

ÁREA VI-VEGA MEDIA DEL SEGURA DEL SERVICIO MURCIANO DE SALUD

I N F O R M A: Que se ha solicitado la autorización para realizar un estudio de investigación en el Hospital General Universitario J.M. Morales Meseguer.

- Solicitante: Yeray Gabriel Santana Padilla

- Título del estudio: Necesidades Formativas de las Enfermeras de Cuidados Intensivos

- Período de estudio: 2018

- Supervisión y Dirección del estudio:

$>$ Luciano Santana Cabrera

FEA Medicina Intensiva Hospital Universitario Insular de Gran Canaria

$>$ Susana Garnes Gonzalez. Supervisora de UCI-HMM

Una vez revisada la documentación enviada, se comprueba que se cumplen los siguientes requisitos:

- El protocolo de estudio cuenta con el rigor metodológico adecuado a los objetivos de la investigación.

- Se garantiza la confidencialidad de los datos y custodia de la información.Firma cláusula de confidencialidad.

- Se garantiza la idoneidad de la información al paciente, verificando la hoja de información al paciente y su autorización para participar en el estudio.

Por todo lo anteriormente expuesto informo que el estudio es viable en todos sus términos. Se adjunta anexo con recomendaciones menores de los evaludores.

Y para que conste, a los efectos oportunos, se expide este informe en Murcia, a ...... de 02 de Marzo 2018

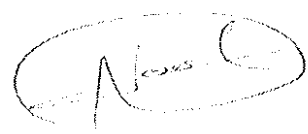

Fdo. : Jesus Leal Llopis Vice-Presidente

Comisión de Evaluación de Trabajos de Investigación (CETI)

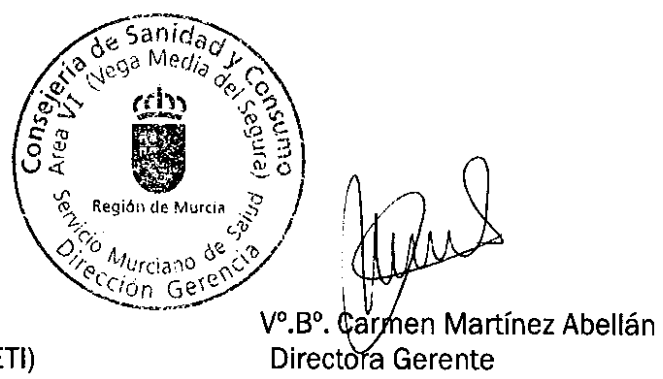




\section{A/A.: Yeray Gabriel Santana \\ Enfermería}

Dña. Pilar Codoñer Franch, Presidenta del Comité Ético de Investigación Clínica del Hospital Universitario Dr. Peset.

\section{CERTIFICA:}

Que este comité en su reunión celebrada el día 25 de abril de 2018 ha evaluado y ha aprobado el estudio titulado: Necesidades formativas de las enfermeras de Cuidados Intensivos en España

Se cumplen los requisitos necesarios de idoneidad del protocolo en relación con los objetivos del estudio y están justificados los riesgos y molestias previsibles para el sujeto.

La capacidad del investigador y los medios disponibles son apropiados para llevar a cabo el estudio.

Son adecuados la Hoja de información al paciente, el procedimiento para obtener el consentimiento informado, y el modo de reclutamiento previsto.

Se cumplen los preceptos éticos formulados en la Declaración de Helsinki de la Asociación Médica Mundial sobre principios éticos para las investigaciones médicas en seres humanos y en sus posteriores revisiones, así como aquellos exigidos por la normativa aplicable en función de las características del estudio 


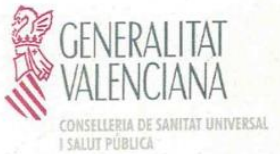

Proyecto de investigación. Tesis doctoral Código Ceim: 37/18

Valencia 2 de mayo de 2018

Fdo.: Dra. Pilar Codoñer Franch 


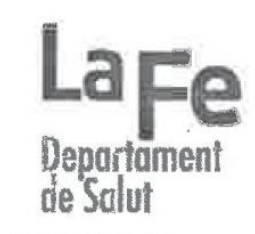

FPNT-CEIB-07 (A)

\section{DICTAMEN DEL COMITÉ DE ÉTICA DE LA INVESTIGACIÓN CON MEDICAMENTOS}

Dña. María Tordera Baviera, titular de la Secretaría Técnica del Comité de Ética de la Investigación con medicamentos del Hospital Universitario y Politécnico La Fe,

\section{CERTIFICA}

Que este Comité ha evaluado en su sesión de fecha 19 de septiembre de 2018, el Proyecto de Tesis:

Título: "NECESIDADES FORMATIVAS DE LAS ENFERMERAS DE UCI EN ESPAÑA."

$\mathrm{N}^{\circ}$ de registro: 2018/0235

Versión/fecha de la memoria del proyecto: TESIS

Versión/fecha de la Hoja de Información al Paciente y Consentimiento Informado: 02/ 11 de julio de 2018

Que dicho proyecto se ajusta a las normativas éticas sobre investigación biomédica con sujetos humanos y es viable en cuanto al planteamiento científico, objetivos, material y métodos, etc, descritos en la solicitud, así como la Hoja de Información al Paciente y el Consentimiento Informado.

En consecuencia, este Comité acuerda emitir INFORME FAVORABLE de dicho Proyecto de Tesis que será realizado en el Hospital Universitario y Politécnico La Fe, siendo el Tutor del Hospital la Dra. Josefa $M^{\mathbf{a}}$ Monzón Soriano del servicio de ENFERMERÍA, y el DOCTORANDO D./ Dña. Yeray Gabriel Santana Padilla.

Que el CEIm del Hospital Universitario y Politécnico La Fe, tanto en su composición como en sus procedimientos, cumple con las normas de BPC (CPMP/lCH/135/95) y con la legislación vigente que regula su funcionamiento, y que la composición del CEIm del Hospital Universitario y Politécnico La Fe es la indicada en el anexo I, teniendo en cuenta que, en el caso de que algún miembro participe en el estudio o declare algún conflicto de interés, no habrá participado en la evaluación ni en el dictamen de la solicitud de autorización del estudio clínico.

Lo que firmo en Valencia, a 19 de' deptrambre de 2018

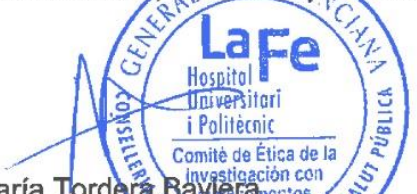

Fdo.: Dra. María Torderáa Bavivesticacion con

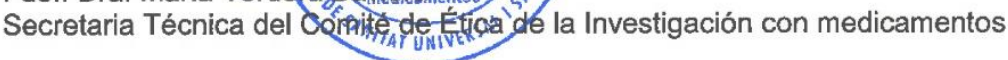




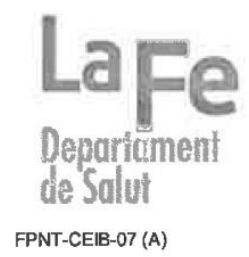

ANEXO I

COMPOSICIÓN CEIm

\section{Presidente:}

Dra. Adela Cañete Nieto (Oncología Pediátrica)

Vicepresidente:

Dr. Salvador Aliño Pellicer (Catedrático Farmacólogo Clínico)

Secretaria Técnica:

Dra. María Tordera Baviera (Farmacéutica del Hospital)

\section{Miembros:}

Dr. Bonaventura Casanova Estruch (Neurología)

Dra. M ${ }^{\mathrm{a}}$ Isabel Izquierdo Macián (Neonatología)

Dr. Luis Vicente Martínez Dolz (Cardiología)

Dra. Paula Ramírez Galleymore (Medicina Intensiva - Miembro de la Comisión de Investigación)

Dra. Sara Brugger Frigols (Radiodiagnóstico)

D. Serafín Rodríguez Capellán (Licenciado en derecho - Ajeno a las profesiones sanitarias)

Dña. María Victoria Paricio Gómez (Enfermería)

Dr. José Maria Canelles Gamir (Farmacéutico de Atención Primaria)

Dr. Matteo Frasson (Cirugia General y Aparato Digestivo)

Dr. José Vicente Solanas Prats (Atención Primaria)

Dña. Pilar Robles Villalba (Vicepresidenta de la asociación de Miastenia - Miembro ajeno a las profesiones sanitarias)

Dr. Javier Lluna González (Cirugía Pediátrica - Miembro del Comité de Ética Asistencial Formación acreditada en Bioética)

D. Miguel Ángel Cano Torres (Secretario de ASLEUVAL - Miembro Lego - Ajeno a las profesiones sanitarias) 


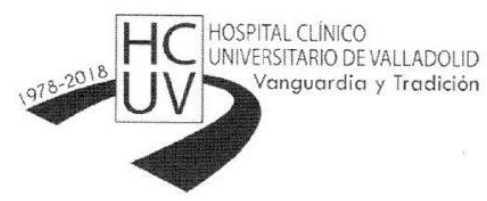

Sacyl

\section{CONFORMIDAD DEL DIRECTOR DE ENFERMERÍA}

D. Natán Redondo Pérez, como Director de Enfermería del Hospital Clínico Universitario de Valladolid

Hago constar:

Que conozco la documentación relativa al proyecto de investigación que lleva por título “.......Necesidades Formativas de las Enfermeras de Cuidados Intensivos en España......."

Y cuyo investigador principal será D. Yeray Gabriel Santana Padilla....

Declaro tener conocimiento y apruebo la realización del proyecto de investigación en este Servicio.

En Valladolid a 9 de Mayo.de 2018

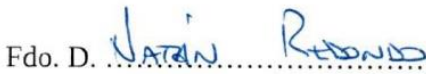

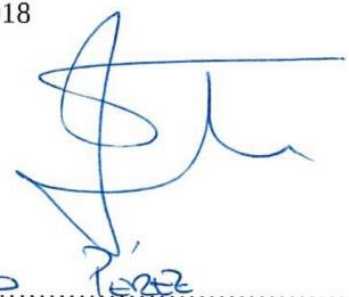

Director de Enfermería del Hospital Clínico Universitario de Valladolid 


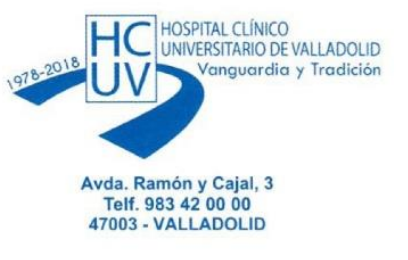

\section{CONFORMIDAD DE LA DIRECCIÓN DEL CENTRO}

Don Francisco Javier Vadillo OImo,

Director Gerente del

Hospital Clínico Universitario de Valladolid,

\begin{tabular}{|c|c|c|}
\hline $\begin{array}{l}\text { CODIGO } \\
\text { HOSPITAL }\end{array}$ & TITULO & $\begin{array}{l}\text { INVESTIGADOR PRINCIPAL } \\
\text { SERVICIO } \\
\text { PROMOTOR }\end{array}$ \\
\hline $\begin{array}{l}\text { PI } 18-1029 \\
\text { TFM }\end{array}$ & $\begin{array}{l}\text { NECESIDADES FORMATIVAS DE LAS } \\
\text { ENFERMERAS DE CUIDADOS } \\
\text { INTENSIVOS EN ESPAÑA }\end{array}$ & $\begin{array}{l}\text { I.P.: YERAY GABRIEL SANTANA } \\
\text { PADILLA } \\
\text { EQUIPO: MERCEDES FERNÁNDEZ } \\
\text { CASTRO, M. }{ }^{a} \text { DESAMPARADOS } \\
\text { BERNAT, LUCIANO SANTANA } \\
\text { CABRERA } \\
\text { ENFERMERIA } \\
\text { RECIBIDO: } 15-05-2018 \\
\end{array}$ \\
\hline
\end{tabular}

En relación con el citado Proyecto de Investigación, de acuerdo a la evaluación favorable a su realización en este Hospital por parte del CEIm Área de Salud Valladolid Este en su sesión del 2405-2018.

Se Informa favorablemente la realización del dicho estudio en el Hospital Clínico Universitario de Valladolid,

Lo que firma en Valladolid, a 24 de mayo de 2018

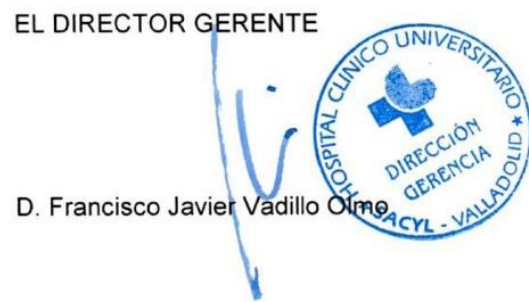



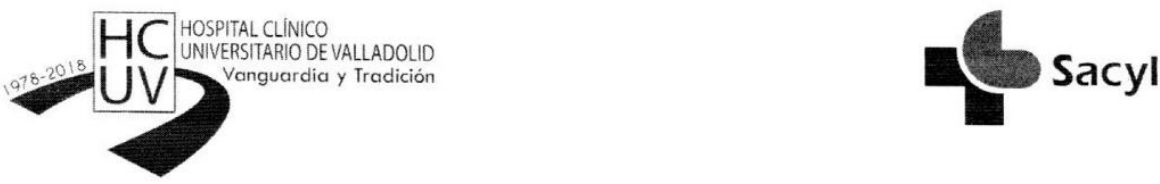

\section{COMITÉ DE ÉTICA DE LA INVESTIGACIÓN CON MEDICAMENTOS ÁREA DE SALUD VALLADOLID}

En la reunión del CEIm ÁREA DE SALUD VALLADOLID ESTE del 24 de mayo de 2018, se procedió a la evaluación de los aspectos éticos del siguiente proyecto de investigación.

\begin{tabular}{|c|c|c|}
\hline $\begin{array}{l}\text { PI } 18-1029 \\
\text { TFM }\end{array}$ & $\begin{array}{l}\text { NECESIDADES FORMATIVAS DE } \\
\text { LAS ENFERMERAS DE } \\
\text { CUIDADOS INTENSIVOS EN } \\
\text { ESPAÑA }\end{array}$ & $\begin{array}{l}\text { I.P.: YERAY GABRIEL SANTANA } \\
\text { EQUIPO: MERCEDES } \\
\text { FERNÁNDEZ CASTRO, M.a } \\
\text { DESAMPARADOS BERNAT, } \\
\text { LUCIANO SANTANA CABRERA } \\
\text { ENFERMERÍA } \\
\text { RECIBIDO: } 15-05-2018\end{array}$ \\
\hline
\end{tabular}

A continuación les señalo los acuerdos tomados por el CEIm ÁREA DE SALUD VALLADOLID ESTE en relación a dicho Proyecto de Investigación:

Considerando que el Proyecto contempla los Convenios y Normas establecidos en la legislación española en el ámbito de la investigación biomédica, la protección de datos de carácter personal y la bioética, se hace constar el informe favorable y la aceptación del Comité de Ética de la Investigación con Medicamentos Área de Salud Valladolid Este para que sea llevado a efecto dicho Proyecto de Investigación.

Un cordial saludo.

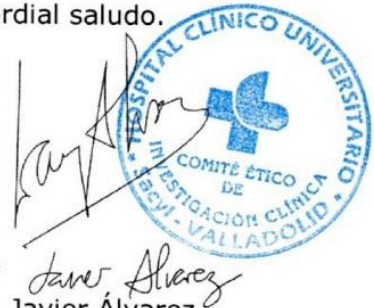

Dr. F. Javier Álvarez.

CEIm Área de Salud Valladolid Este

Hospital Clínico Universitario de Valladolid

Farmacología,

Facultad de Medicina,

Universidad de Valladolid,

c/ Ramón y Cajal 7,

47005 Valladolid

alvarez@med.uva.es,

jalvarezgo@saludcastillayleon.es

tel.: 983423077 


\section{FRANCISCO JAVIER MONTES VILLAMERIEL, Gerente de Asistencia Sanitaria del Complejo Asistencial de Zamora}

Da Yeray Gabriel Santana Padilla con D.N.I. 44.318.555-Q, Graduado en Enfermeria, ha solicitado autorización para la realización de un proyecto de investigación (tesis doctoral) denominado NECESIDADES FORMATIVAS DE LAS ENFERMERAS DE CUIDADOS INTENSIVOS EN ESPAÑA, en el Servicio de UCl del Complejo Asistencial de Zamora.

Se ha solicitado dictamen al Comité de Ética de Investigación con Medicamentos del Área de Salud de Zamora.

Con fecha 17 de mayo de 2018 se emite Dictamen en el que consta que una vez evaluado el proyecto resulta que se cumplen los requisitos de idoneidad en relación con los objetivos del estudio, en el procedimiento para obtener el consentimiento informado y en el plan de reclutamiento de sujetos.

A la vista de lo cual D. Francisco J. Montes Villameriel, en calidad de Gerente de Asistencia Sanitaria de Zamora autoriza la realización del estudio en el Servicio de UCl del Complejo Asistencial de Zamora, cumpliendo con todos los requerimientos establecidos en el nuevo Reglamento General de Protección de Datos de fecha 25 de mayo de 2018.

Lo que firmo en Zamora a 30 de Julio de 2018

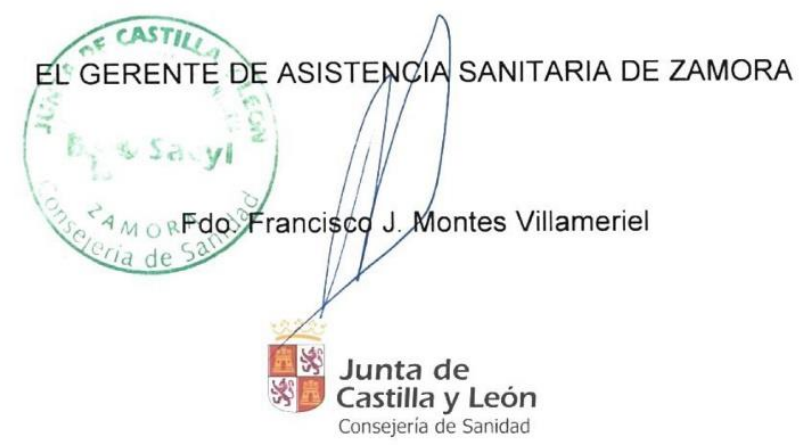




\section{Comité de Ética de la Investigación con Medicamentos}

Área de Salud de Zamora

COMPLEJO ASISTENCIAL DE ZAMORA

DICTAMEN DE TESIS DOCTORALES/PROYECTOS DE INVESTIGACIÓN

D. Manuel A. Franco Martin, Secretario Técnico del Comité de Ética de Investigación con Medicamentos del Área de Salud de Zamora

\section{CERTIFICA}

Que este Comité ha evaluado la Tesis Doctoral de Dña. YERAY GABRIEL SANTANA PADILLA, Titulado:

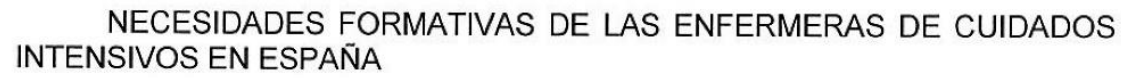

y considera que:

Se cumplen los requisitos necesarios de idoneidad del proyecto en relación con los objetivos del estudio.

El procedimiento para obtener el consentimiento informado, y el plan de reclutamiento de sujetos previstos son adecuados.

Por tanto, este Comité acepta que dicho proyecto sea realizado Dña. YERAY GABRIEL SANTANA PADILLA, en el Servicio de U.C.I. del Hospital Virgen de la Concha.

Lo que firmo en Zamora a 17 de mayo de 2018

Fdo: Manue/A. Franco Martin
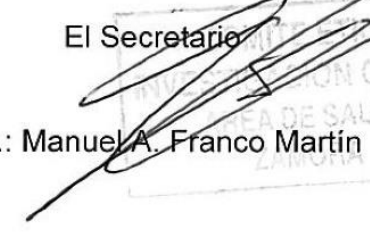

Secretaria Técnica CEIm

Hospital Provincial

C/ Hernán Cortés, n 40 - 49021- Zamora

Teléfono: 980 548572- Fax: 980517305

E-mail: psq.hvcn@saludcastillayleon.es 


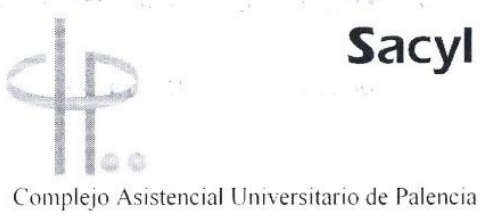

\section{DICTAMEN DE LA COMISIÓN DE INVESTIGACIÓN}

Reunidos el día 31 de Mayo de 2018, los miembros de la Comisión de Investigación y Biblioteca han evaluado el proyecto abajo mencionado y han considerado emitir el siguiente informe:

\begin{tabular}{|l|l|l|}
\hline TITULO & \multicolumn{2}{|l|}{$\begin{array}{l}\text { Necesidades formativas de las enfermeras de } \\
\text { Cuidados Intensivos en España }\end{array}$} \\
\hline INVESTIGADOR PRINCIPAL & Yeray Gabriel Santana Padilla \\
\hline FAVORABLE & SI $\square \mathrm{x}$ & NO $\square$ \\
\hline CONSIDERACIONES & SI $\square$ x(Ver anexo) & NO $\square$ \\
\hline
\end{tabular}

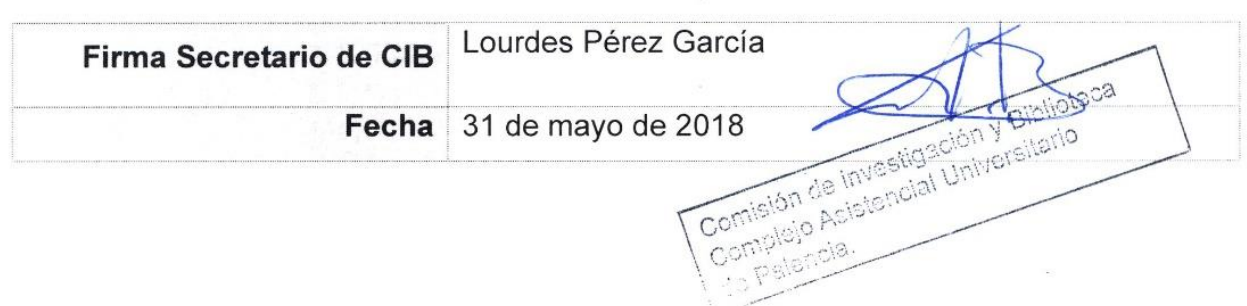

